
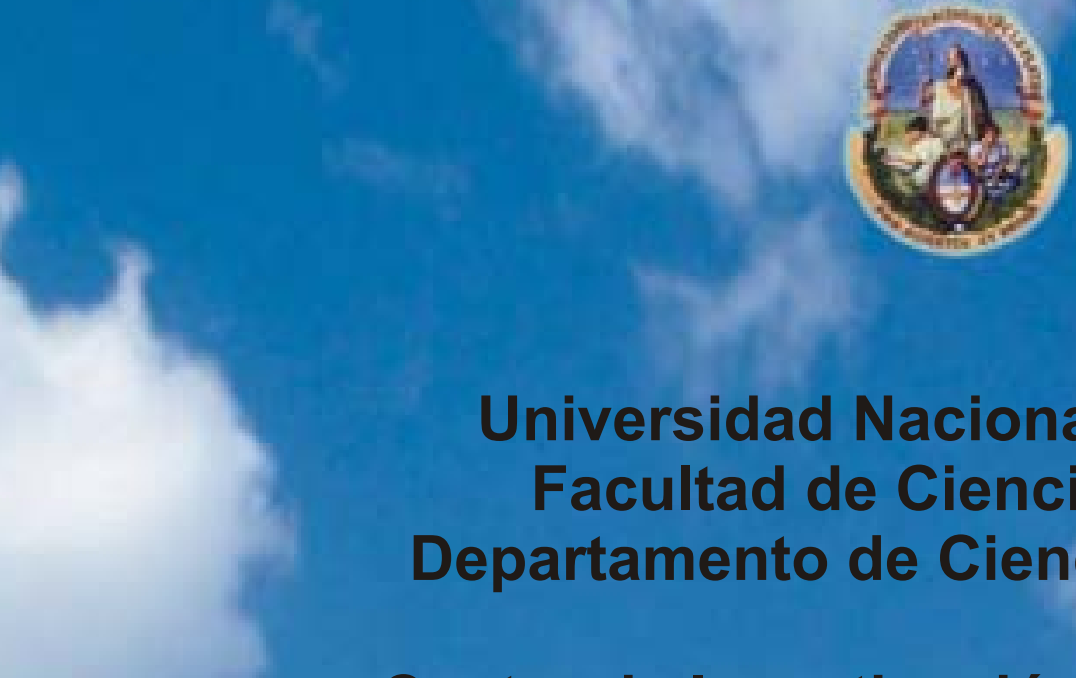

Universidad Nacional de La Plata

Facultad de Ciencias Exactas Departamento de Ciencias Biológicas

Centro de Investigación y Desarrollo en

Criotecnología de Alimentos

(CIDCA-UNLP-CONICET)

\title{
EFECTO DE CELULOSAS MODIFICADAS Y PECTINAS SOBRE LA MICROESTRUCTURA Y ATRIBUTOS DE CALIDAD DE LA MASA PANARIA
}

\section{Tesis Doctoral}

Bioq. María Jimena Correa 
El presente trabajo de Tesis para optar al título de Doctor de la Facultad de Ciencias Exactas de la Universidad Nacional de La Plata fue realizado en el Centro de Investigación y Desarrollo en Criotecnología de Alimentos (CIDCA-UNLP-CONICET) bajo la dirección de la Dra. Cristina Ferrero y la codirección de la Dra. Gabriela Teresa Pérez. 
Parte de los resultados obtenidos en esta tesis fueron difundidos a través de su publicación en revistas internacionales, nacionales y en actas de congresos.

- Correa, M.J., Añón, M.C; Pérez, G.T.; Ferrero, C. Effect of modified celluloses on dough rheology and microstructure. Food research International 43 (3) 780 787 (2010).

- Correa, M.J., Pérez, G.T., Ferrero, C. Pectins as Breadmaking Additives: Effect on Dough Rheology and Bread Quality. Food and Bioprocess Technology. DOI: 10.1007/s11947-011-0631-6 (2011).

- Celulosas modificadas: Una alternativa en aditivos para panificación. Correa, M.J, Pérez, G.T., Añon, M.C, Ferrero, C. Revista Heladería - Panadería Latinoamericana №203, pp 68-73 (2010).

- "Caracterización reológica de masas aditivadas con celulosas modificadas y pectinas“. Correa, M.J, Pérez, G.T., Añon, M.C, Ferrero, C. Actas del III Congreso Internacional de Ciencia y Tecnología de los alimentos. Córdoba, 2009.

- "Celulosas modificadas: Una alternativa en aditivos para panificación". Correa, M.J, Pérez, G.T., Añon, M.C, Ferrero, C. Actas del XII Congreso Cytal. Entre Ríos, 2009.

- "Celulosas modificadas y pectinas como aditivos en panificación". Correa, M.J, Pérez, G.T., Ferrero, C. Actas del XIII Congreso Cytal. Buenos Aires, 2011. 
Dedico mi tesis a quienes siempre me han acompañado y me han brindado todo sin haberlo pedido: mi mamá, mi papá, mis hermanas y mi querida abuela Rita. 


\section{Resumen}

Los hidrocoloides son polisacáridos de alto peso molecular, altamente hidrofilicos, que modifican la reología y textura de los sistemas en los cuales se incorporan. En este trabajo de tesis se estudió el efecto del agregado de hidrocoloides de diferente estructura química en la masa panaria de harina de trigo y se analizaron los atributos de calidad del pan obtenido. Se estudiaron los cambios microestructurales producidos por el agregado de estos aditivos y se vincularon con los cambios observados en las características de masa y pan. Los hidrocoloides utilizados fueron: dos tipos de hidroxipropilmetilcelulosa de distinto grado de sustitución (HPMC F 4M y HPMC F50), celulosa microcristalina (MCC), carboximetilcelulosa (CMC), y dos tipos de pectinas, una amidada de bajo grado de esterificación (PBM) y otra de alto grado de esterificación (PAM). La formulación básica empleada para la panificación en base a $100 \mathrm{~g}$ de harina fue: hidrocoloides, entre 0,25 y $2 \%$, levadura $3 \%, \mathrm{NaCl} 2 \%$, y cantidad de agua farinográfica. Se realizaron ensayos sin y con $\mathrm{NaCl}$.

La reología de la masa se caracterizó a través de ensayos farinográficos, análisis de perfil de textura, de punción, de relajación ante una compresión y ensayos dinámicos oscilatorios. Sobre los panes se determinó el volumen específico, el color de la corteza, textura de la miga, características del alveolado. Se evaluó el cambio en los atributos texturales después de 1 y 3 días de almacenamiento a temperatura ambiente. La microestructura de la masa se analizó por microscopía electrónica de barrido (SEM), microscopía láser confocal de barrido (CSLM), espectroscopía ${ }^{1} \mathrm{H}-\mathrm{RMN}$ y análisis mecánico dinámico (DMA) para analizar la movilidad molecular. Se estudiaron las interacciones almidón-hidrocoloide a través de calorimetría diferencial de barrido DSC (gelatinización de almidón y retrogradación de amilopectina en sistemas modelo y masas). Las interacciones proteína-hidrocoloide se analizaron por electroforesis (SDS-PAGE) y espectroscopía FT-Raman. Los resultados fueron analizados mediante ANOVA y análisis de componentes principales (PCA).

En general, los hidrocoloides condujeron a mayores absorciones de agua farinográfica, masas más blandas, menos consistentes, más cohesivas, menos resilientes y menos adhesivas. Este efecto general varió de acuerdo al tipo, concentración de hidrocoloide y la presencia o ausencia de sal. Estos resultados concuerdan en general con un aumento de la tangente del ángulo de desfasaje obtenida en los ensayos reológicos dinámicos. La sal reforzó la red de gluten. Este efecto del $\mathrm{NaCl}$ y la interacción con los hidrocoloides afectó los parámetros farinográficos. La estabilidad de la masa en presencia de sal no se vió afectada por el agregado de CMC mientras que las HPMC provocaron una disminución de la estabilidad. Un comportamiento inverso se apreció en ausencia de sal: las HPMC no modificaron la estabilidad farinográfica mientras que CMC provocó una disminución de la misma. Las pectinas no modificaron sustancialmente la estabilidad de la masa.

Los panes con agregado de CMC, HPMCs y PAM presentaron los mayores incrementos en el volumen específico respecto al control. Las migas de los panes con hidrocoloide resultaron más blandas, particularmente con el agregado de HPMCs, PAM y CMC. Se vieron incrementadas también la elasticidad y cohesividad de la miga. No se observaron diferencias 
sustanciales en el color de la corteza ni en las características del alveolado por lo que los panes tuvieron buena aceptabilidad y no fueron distinguidos por el panel de análisis sensorial de los panes sin agregado.

Respecto al efecto sobre el envejecimiento del pan, luego del almacenamiento se verificó que si bien la miga aumentó su dureza y perdió elasticidad y cohesividad, estos efectos no deseados fueron menores que en el pan control, indicando una atenuación del deterioro en presencia de los hidrocoloides. La pérdida de humedad también resultó menor. Los resultados de este trabajo indican que la utilización de CMC, PAM y HPMC F 4M en alguna de las concentraciones estudiadas llevó a la obtención de un pan de mejor calidad y con mayor estabilidad dentro de las 72 hs de almacenamiento.

Desde un punto de vista microestructural, se observó que existe interacción de los hidrocoloides con las proteínas de gluten, dependiendo de su estructura química. La interacción con las proteínas es la que determina finalmente las diferentes características de la masa encontradas. La presencia o ausencia de $\mathrm{NaCl}$ es un factor importante ya que favorece las interacciones hidrofóbicas tanto entre cadenas polipeptídicas como entre proteínahidrocoloide. Así, en presencia de sal las HPMCs al ser relativamente más hidrofóbicas pueden interactuar con las proteínas del gluten dando lugar a una red menos estable. En ausencia de sal se favorece la interacción del gluten con moléculas cargadas como CMC. A través de los ensayos microscópicos se observó que los hidrocoloides conducen en general a matrices más filamentosas y abiertas, con disrupciones. En presencia de $\mathrm{NaCl}$ este efecto se ve atenuado observándose redes más orientadas y entrecruzadas. Los sistemas con hidrocoloide presentaron mayor movilidad molecular tanto en ausencia como en presencia de $\mathrm{NaCl}$, indicando redes más flexibles, salvo en el caso de masas con PAM. Los resultados obtenidos por FT-Raman confirmaron esta hipótesis, ya que revelaron el incremento en masa con hidrocoloide de estructuras más desordenadas como la hoja $\beta$-plegada, estructura al azar y giro $\beta$ en detrimento de la conformación más ordenada de $\alpha$-hélice que predomina en las masas sin hidrocoloide. Se vio que particularmente la presencia de $C M C$ en masas $\sin$ y con $\mathrm{NaCl}$ disminuía marcadamente la proporción de $\alpha$-hélice. Este desplegamiento de las proteínas explicaría los diferentes perfiles electroforéticos que revelaron una menor capacidad de extracción de algunas subunidades que estarían, por lo tanto, más retenidas en la red. Respecto a la interacción con el almidón, se observó que el tipo de hidrocoloide no afectaba mayormente la gelatinización ni la retrogradación de amilopectina. 


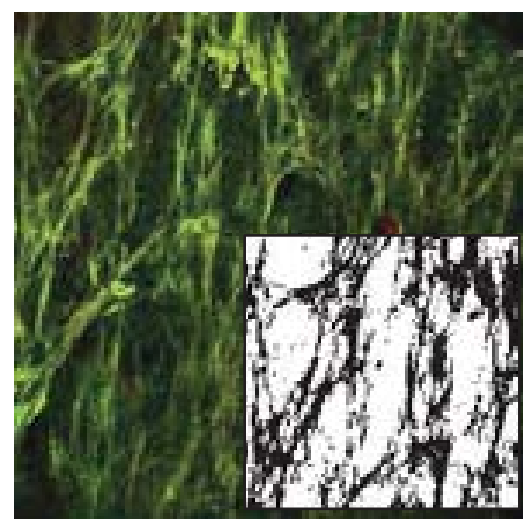

Control: red con poca orientación, entrecruzada y abierta
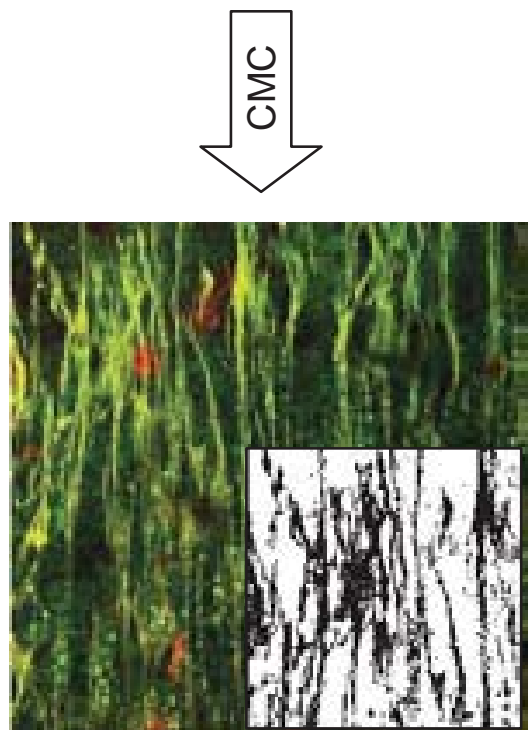

Masa con CMC: red poco entrecruzada, abierta, orientada
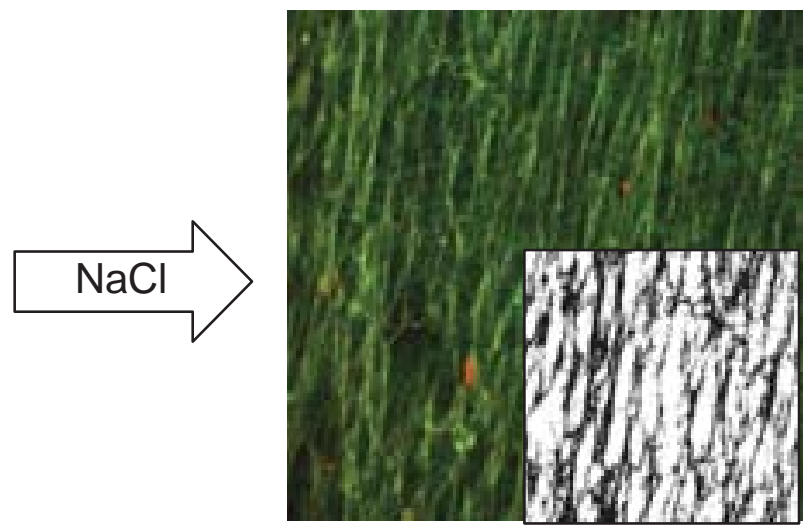

Con $\mathrm{NaCl}$ : más orientación $\mathrm{y}$ entrecruzamiento $=$ red más cerrada
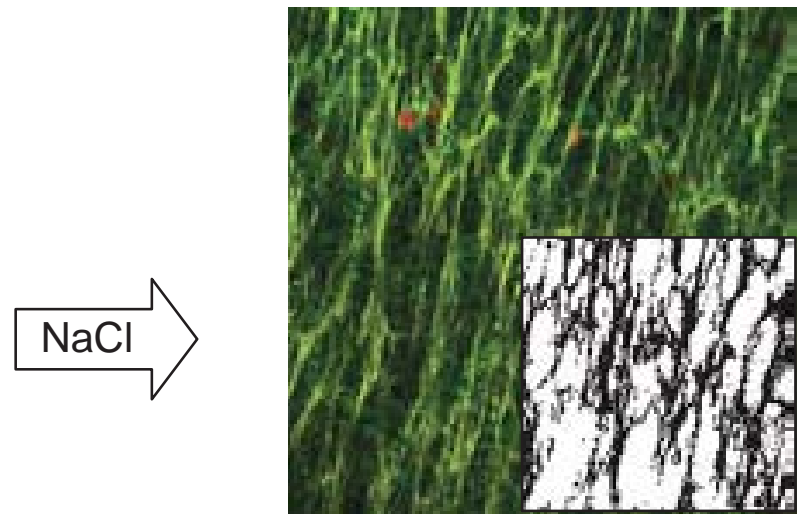

Masa con $\mathrm{CMC}+\mathrm{NaCl}$ : red entrecruzada y

orientada

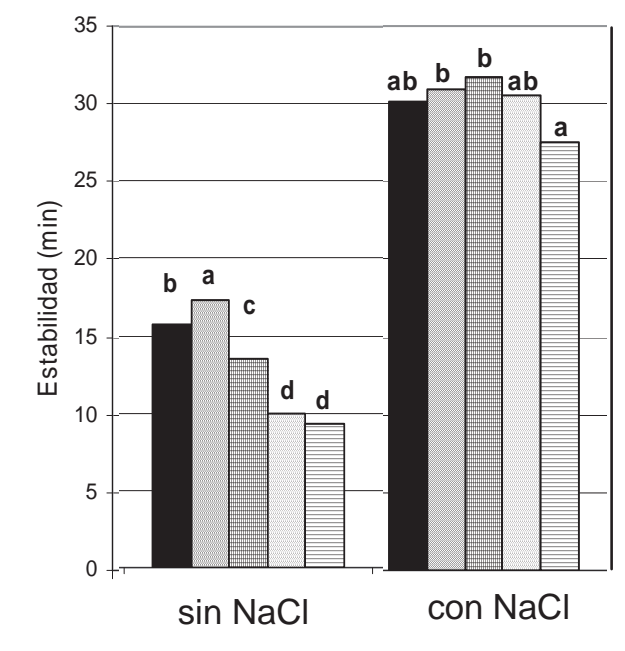

La carboximetilcelulosa fue el hidrocoloide que más afectó la red de gluten y en

consecuencia a la estabilidad farinográfica(en forma diferencial en ausencia o presencia de $\mathrm{NaCl}$ ) 


\section{Agradecimientos}

- A Cristina Ferrero, mi Directora por su apoyo durante estos 5 años, por haberme guiado, aconsejado y ayudado a crecer profesionalmente. Pero también le agradezco por su calidez y por haberme acompañado y comprendido en los momentos difíciles.

- A Gabriela Pérez gracias por tu asistencia y orientación durante mi estadía en Córdoba y por haber colaborado a pesar de la distancia.

- A Cristina Añon por su accesibilidad, buena predisposición y valiosa colaboración en el análisis e interpretación de resultados, en particular, de las electroforesis y FT-Raman.

- A Evelina Ferrer por su colaboración en la realización y análisis de los ensayos de FT-Raman. Además, gracias porque junto con Patricia Williams me introdujeron en la investigación cuando era alumna.

- A la Universidad Nacional de La Plata, la Facultad de Ciencias Exactas y al CIDCA por haberme dado la posibilidad brindándome sus instalaciones para realizar el doctorado.

- Al CONICET por haberme financiado con la beca tipo I y la beca tipo II la realización del doctorado.

- A Alicia Chávez por la amabilidad con que nos asesoró sobre el análisis estadístico.

- Al Molino Campodónico y su personal, Miguel Cardós, Leda Campaña y Rodolfo Camillón, por el asesoramiento y por haberme permitido realizar los farinogramas en sus instalaciones.

- A Latinoquímica S.A. por la donación de la CMC y a Dow Chemical Company por la donación de las dos HPMCs.

- A Javier y Daniel por su gran ayuda en la realización de los ensayos de DMA y DSC. Gracias por la paciencia y las horas compartidas junto al DSC.

- A Aldo, Laura Villata y Vanina por su colaboración en la realización de las medidas de determinación de peso molecular por HPLC, viscosimetría capilar y microscopía confocal.

- A Diana por su buena predisposicón y la gran ayuda con la búsqueda bibliográfica.

- A Emanuel y Sandro por la colaboración en la puesta a punto de las condiciones de horneado. 
- A Bruna por su colaboración en la realización de las medidas en el RVA y su compañía durante mi estadía en Lisboa.

- Al personal del CIDCA por haber participado en los ensayos de evaluación sensorial

- A mi familia por el amor, la comprensión, la paciencia y el apoyo incondicional.

- A Dario por el amor, la comprensión, la tolerancia y las horas compartidas frente a la computadora. También gracias por la realización de la tapa y de las carátulas.

- A mis amigas Vicky, Anita, Vane, San, Ruthi, Lu, Vero y Mily por la compañía, la amistad y por el apoyo.

- A mis compañeritos del box, Vane, Martín, Dario, Ana y Silvana por haberme comprendido y haberme dado aliento.

- A todos mis compañeros de grupo: Ana, Vicky, Facu, Leo, Felipe, Cecilia, Pau, Karim por la buena compañía y el buen ambiente de trabajo.

- A los chicos de vegetales: Lau, Ana, Joaquín, Facu, Luis, Majo por los lindos momentos compartidos. 


\section{Índice}

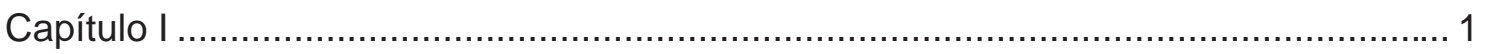

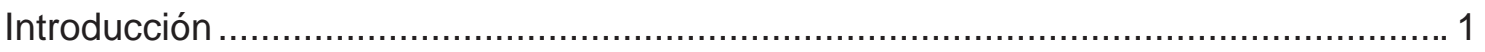

1.1. Producción de trigo en la Argentina .............................................................. 2

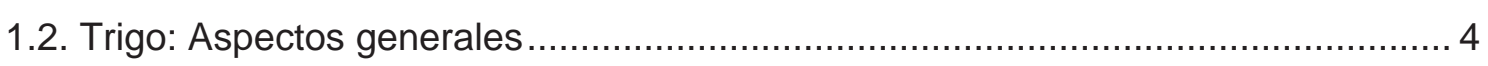

1.3. Estructura y composición del grano de trigo .................................................. 5

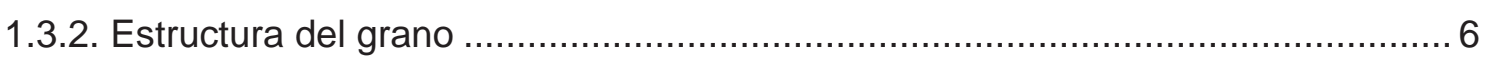

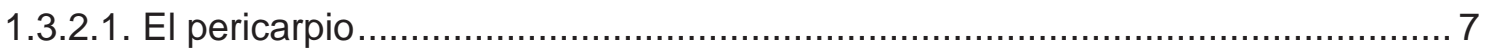

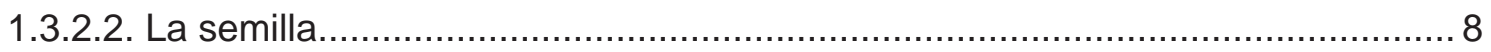

1.3.2.2.1. Cubierta de la semilla y epidermis nucelar ................................................... 8

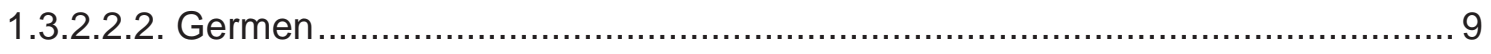

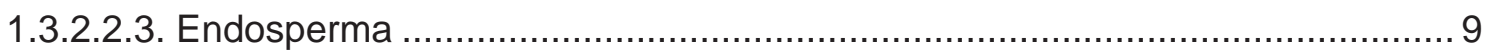

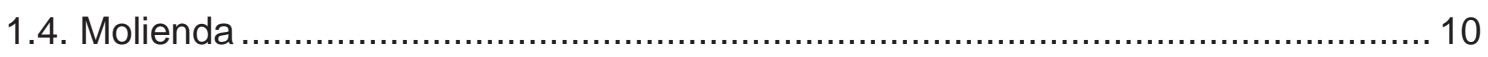

1.4.1. Limpieza de los granos y acondicionamiento ............................................. 10

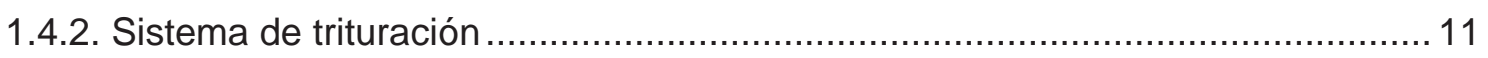

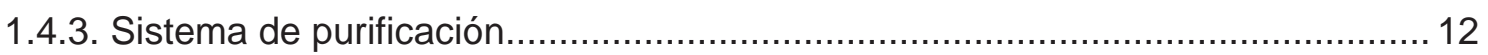

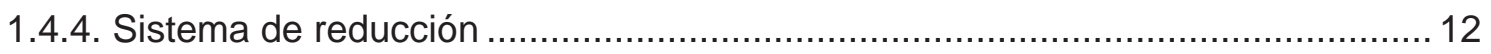

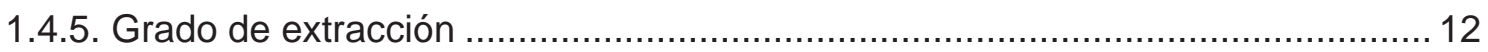

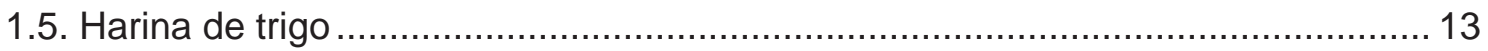

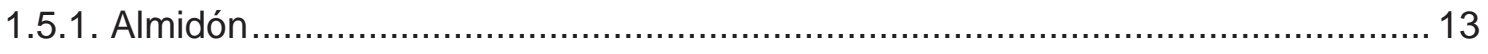

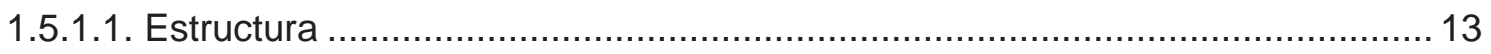

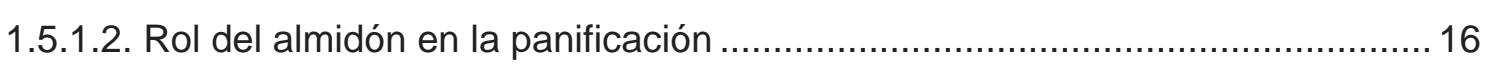

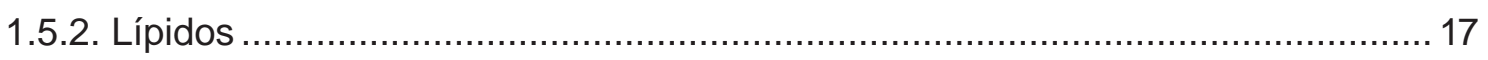

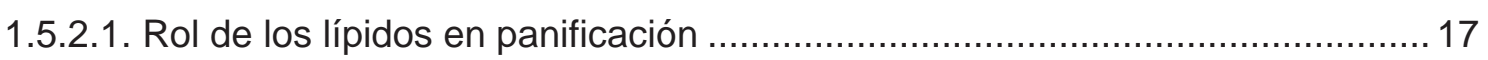

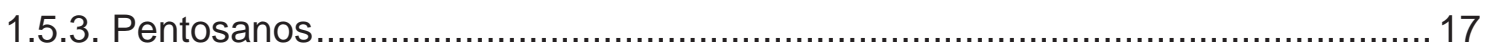

1.5.3.1. Rol de los pentosanos en la panificación ..................................................... 18

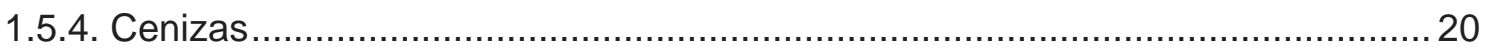

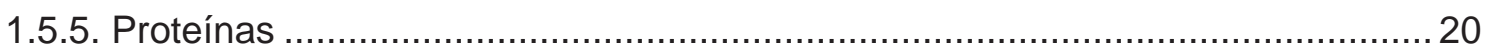

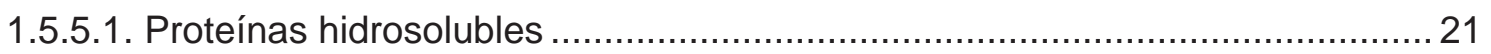

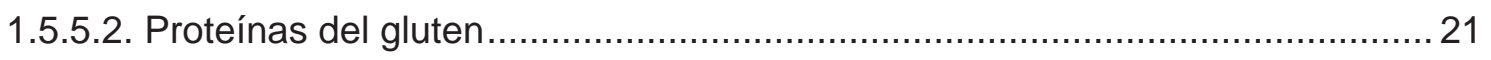

1.5.5.2.1. Estructura de gliadinas y gluteninas .................................................. 22

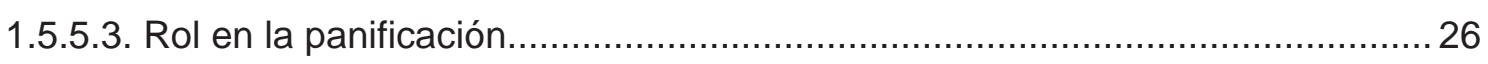

1.5.5.3.1. Factores que determinan la calidad del gluten ........................................ 27

1.6. Tipificación comercial de las harinas en la República Argentina...........................28

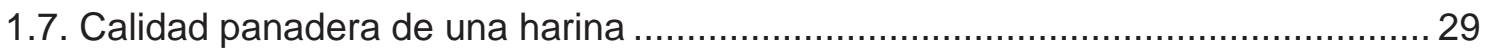




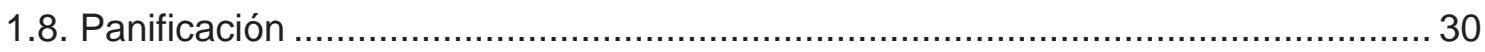

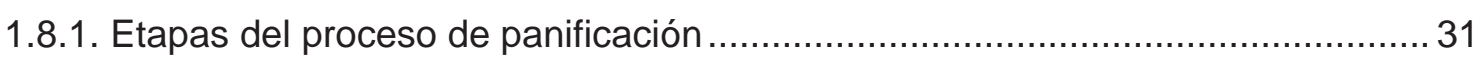

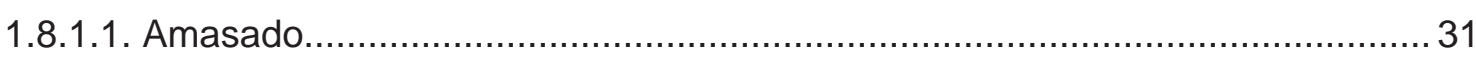

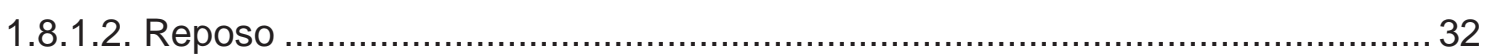

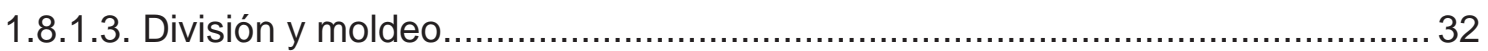

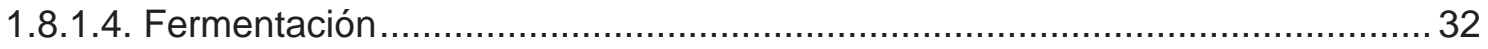

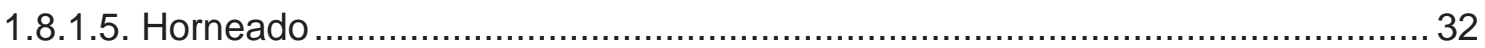

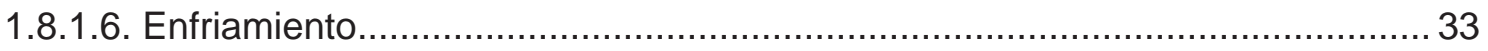

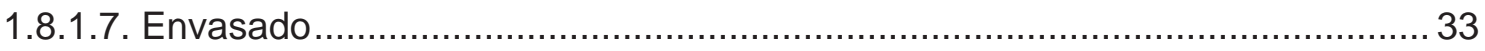

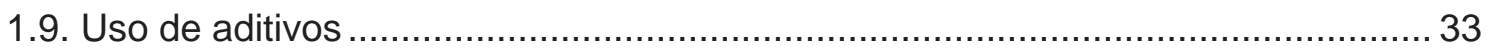

1.10. Hidrocoloides: estructura química y funcionalidad .......................................... 35

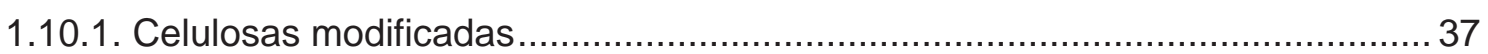

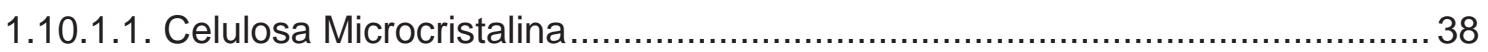

1.10.1.2. Carboximetilcelulosa sódica (CMC) …....................................................... 40

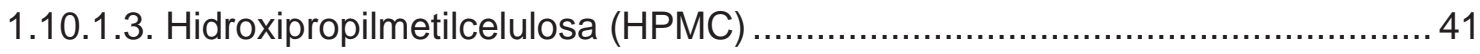

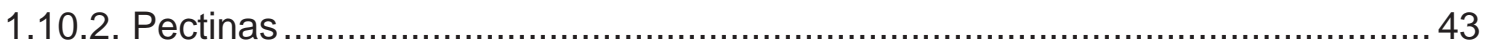

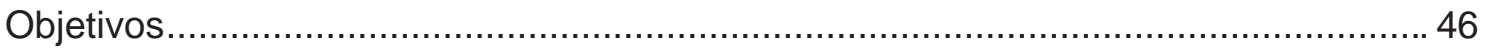

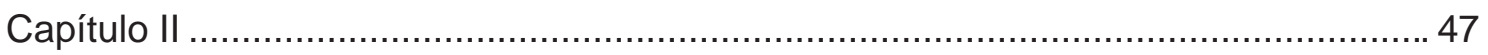

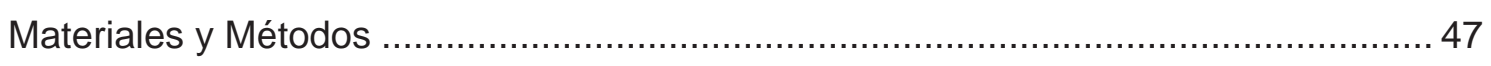

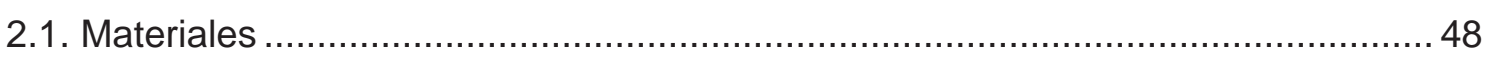

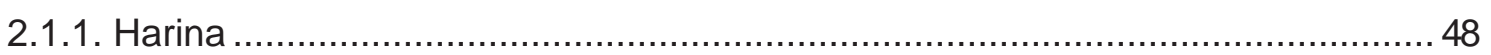

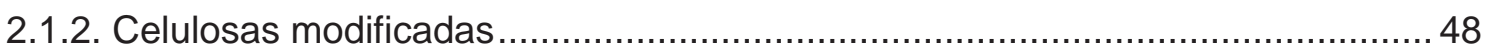

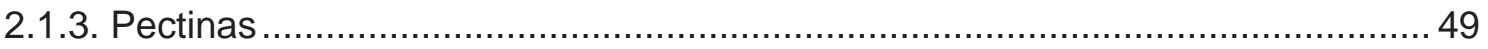

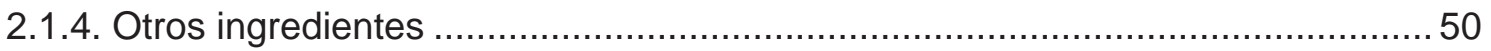

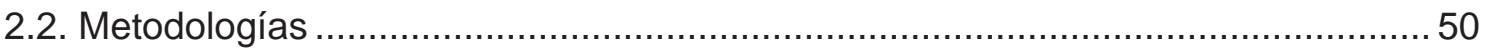

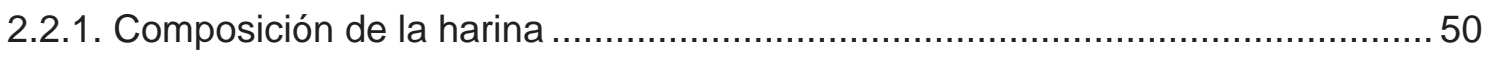

2.2.1.1. Determinación de proteínas................................................................... 50

2.2.1.2. Determinación del contenido de lípidos..................................................... 51

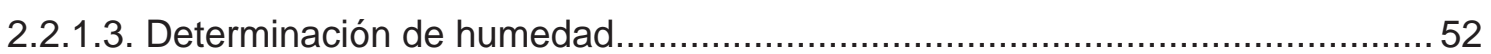

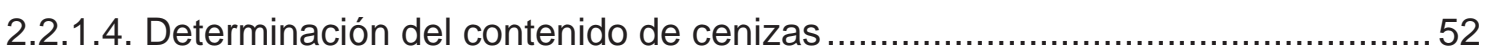

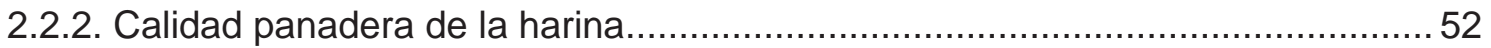

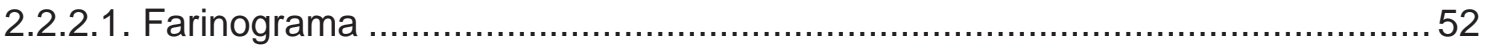

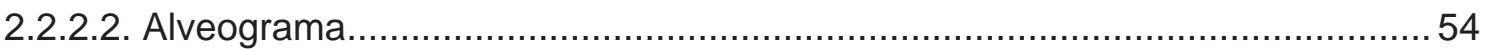

2.2.2.3. Determinación del contenido de gluten ................................................. 55

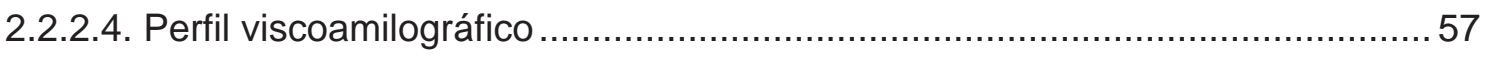




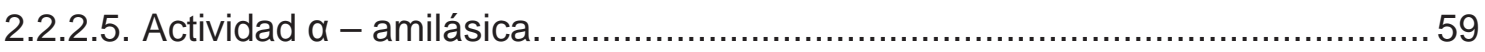

2.2.2.5.1. Índice de caída de Hagberg (Falling Number) ............................................ 59

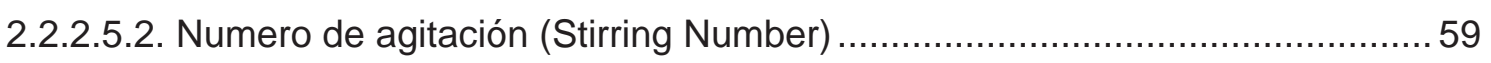

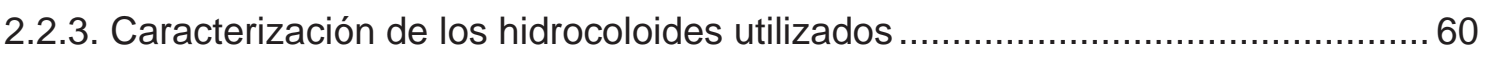

2.2.3.1. Determinación de la pureza y grado de esterificación de las pectinas y del grado de amidación de la pectina de bajo metoxilo................................................... 60

2.2.3.2. Determinación del peso molecular promedio de las pectinas por viscosimetría

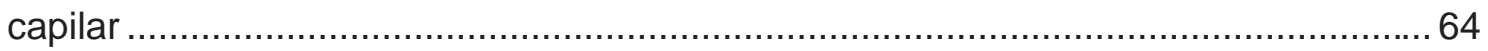

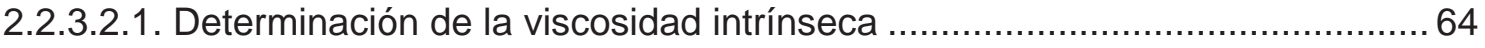

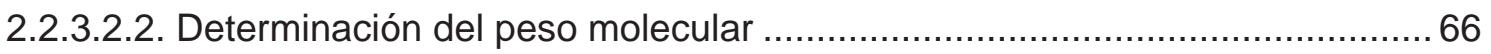

2.2.3.3. Determinación del peso molecular promedio de las celulosas por HPLC ........66

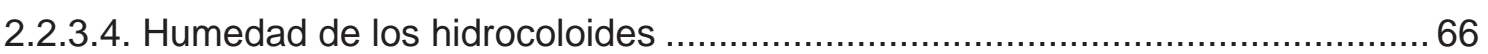

2.2.4. Caracterización reológica de las masas con hidrocoloide ................................... 67

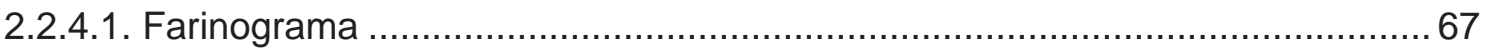

2.2.4.2. Ensayos con el texturómetro: perfil de textura (TPA), punción y relajación ....67

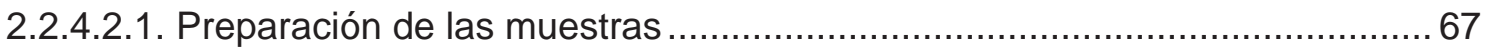

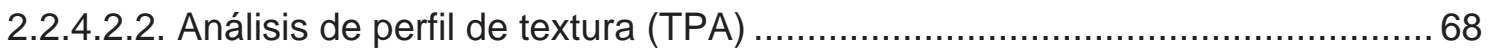

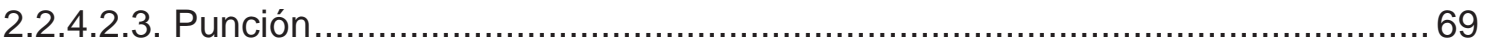

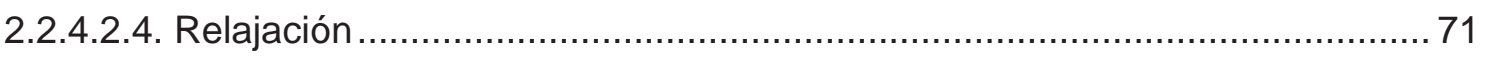

2.2.4.3. Ensayos dinámicos en reómetro oscilatorio ............................................... 73

2.2.5. Caracterización fisicoquímica y microestructural de las masas .........................77

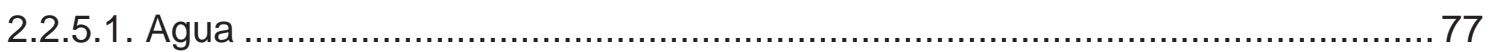

2.2.5.1.1. Ensayo de absorción de agua (WIC) ..................................................... 77

2.2.5.1.2. Contenido y disponibilidad de agua......................................................... 78

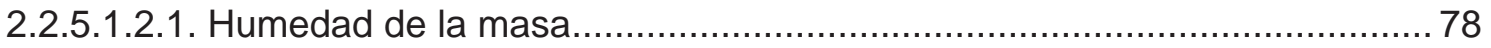

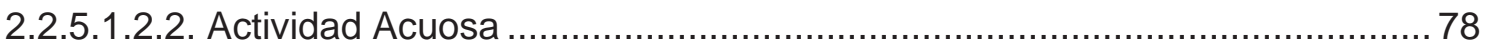

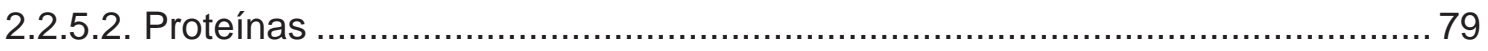

2.2.5.2.1. Gluten húmedo, gluten seco, agua ligada al gluten y relación gluten

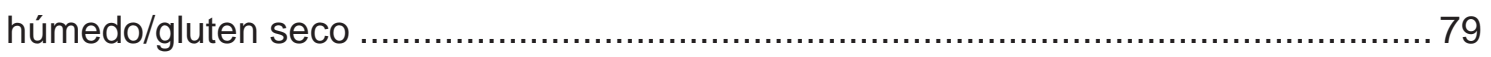

2.2.5.2.2. Electroforesis desnaturalizante - disociante (SDS-PAGE) .......................... 79

2.2.5.2.2.1. Extracción secuencial de las fracciones proteicas. .................................. 80

2.2.5.2.2.2. Extracción en condiciones reductoras ................................................... 81

2.2.5.2.2.3. Reactivos utilizados en la electroforesis SDS-PAGE .............................. 81

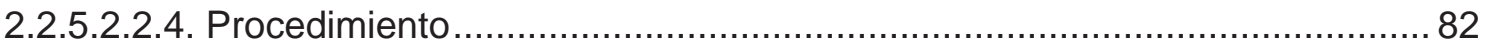

2.2.5.2.3. Espectroscopía Raman con transformada de Fourier ............................... 82 


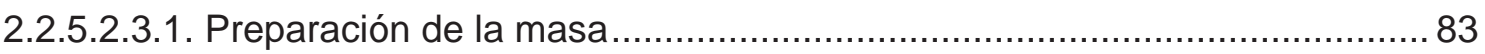

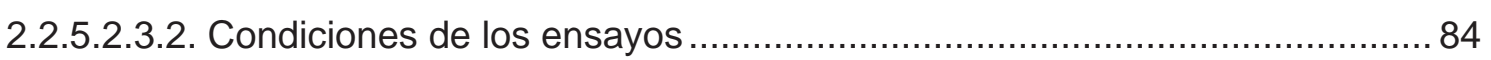

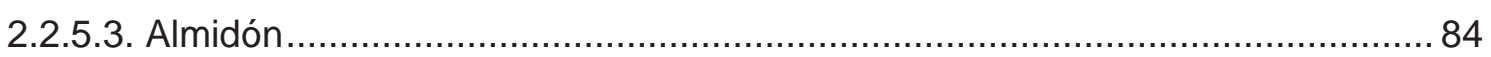

2.2.5.3.1. Gelatinización por calorimetría diferencial de barrido (DSC) ....................... 84

2.2.5.3.1.1. Sistemas modelo almidón-hidrocoloide .................................................... 85

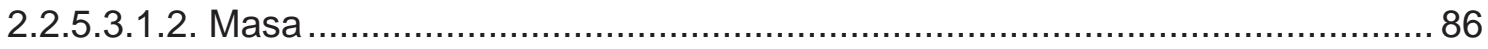

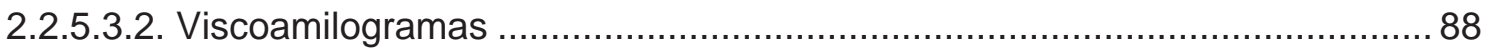

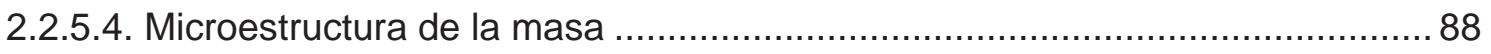

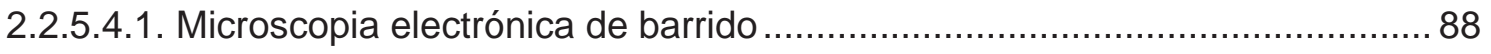

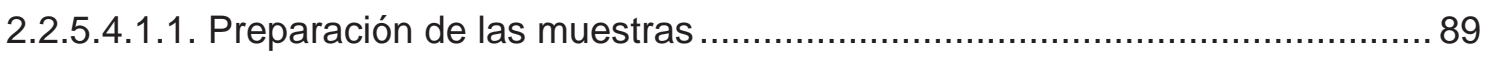

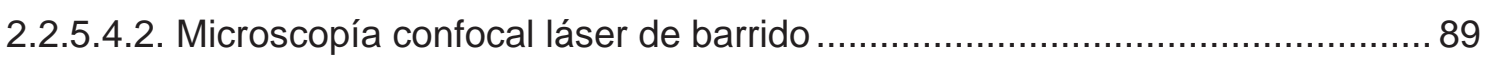

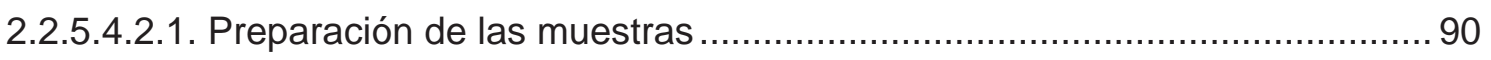

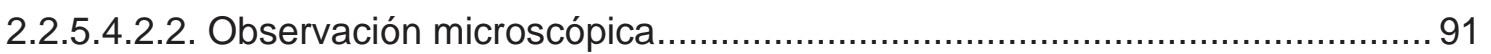

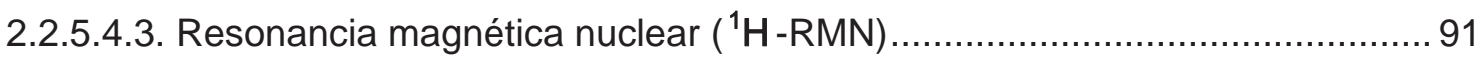

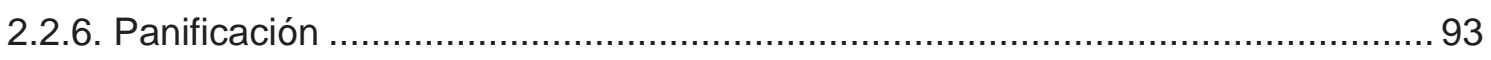

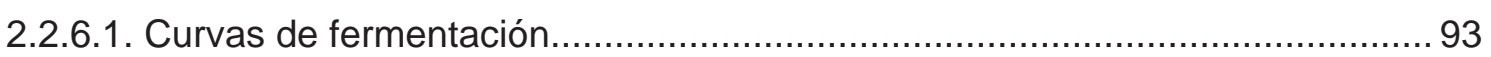

2.2.6.1.1. Formulación empleada en las curvas de fermentación ................................93

2.2.6.1.2. Elaboración de la masa y fermentación...................................................... 93

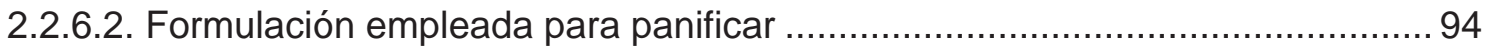

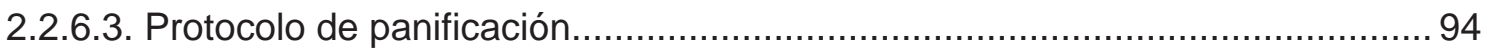

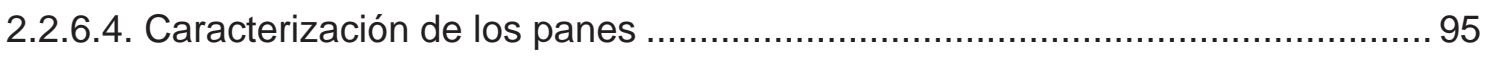

2.2.6.4.1. Determinación del volumen específico de pan ...........................................95

2.2.6.4.2. Determinación del color de la corteza de los panes ....................................95

2.2.6.4.3 Determinación de la humedad de la miga .................................................96

2.2.6.4.4. Análisis de perfil de textura (TPA) de la miga del pan fresco .......................96

2.2.6.4.5. Análisis dinámico-mecánico de la miga de los panes frescos ......................97

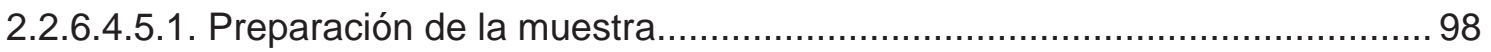

2.2.6.4.5.2. Caracterización del comportamiento dinámico mecánico (DMA) ...............98

2.2.6.4.6. Análisis del alveolado de la miga.............................................................. 99

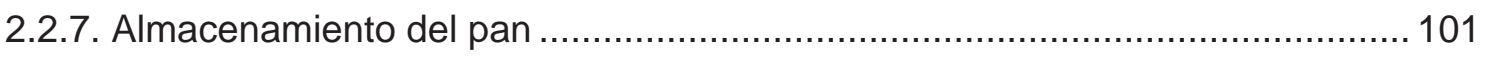

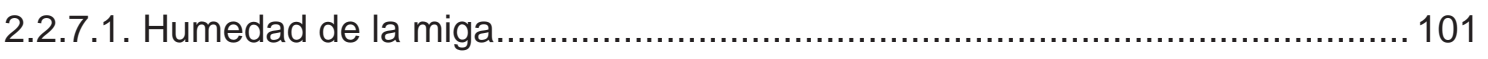

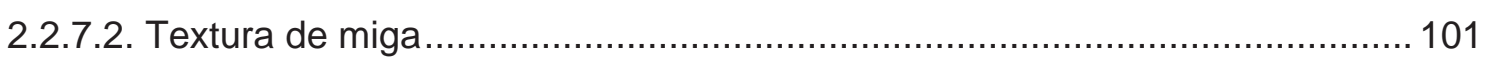

2.2.7.3. Evaluación de la retrogradación del almidón.............................................. 101

2.2.7.3.1. Preparación de la masa............................................................................ 101

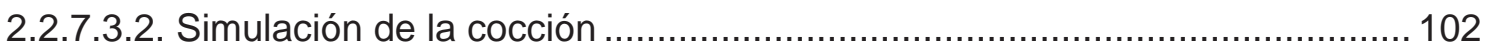


2.2.7.3.3. Almacenamiento y evaluación de la retrogradación .................................... 102

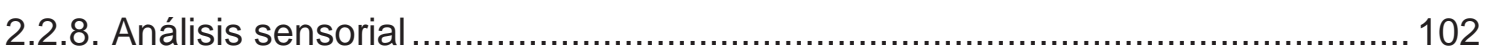

2.2.8.1. Ensayo de discriminación: prueba del triángulo ......................................... 102

2.2.8.1.1. Diseño de la prueba del triángulo ...................................................... 103

2.2.8.1.2. Preparación de las muestras ................................................................ 103

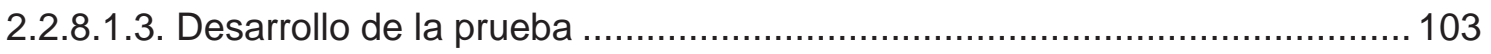

2.2.8.2. Ensayo de aceptabilidad: escala hedónica................................................... 104

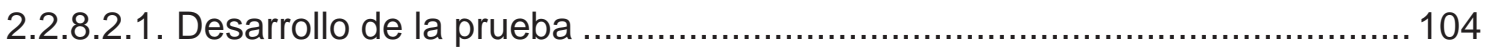

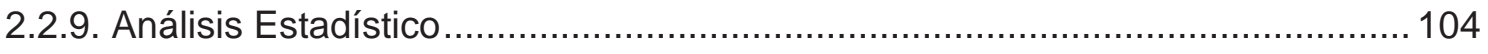

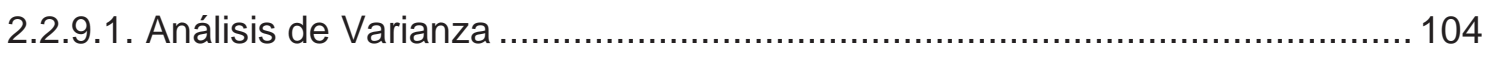

2.2.9.2. Análisis de componentes principales.................................................. 105

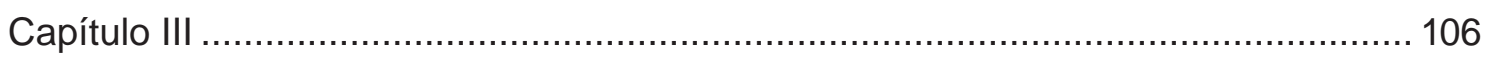

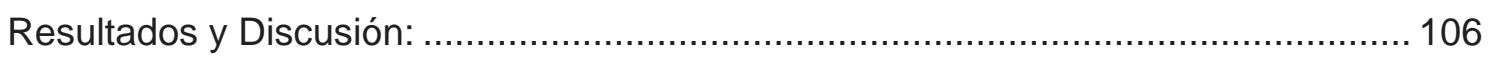

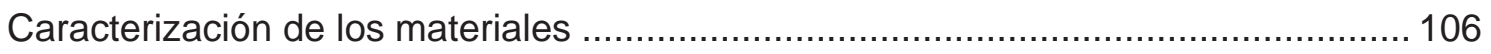

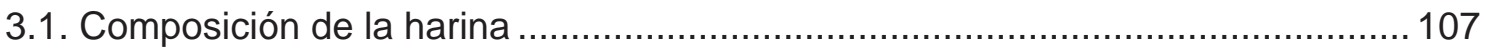

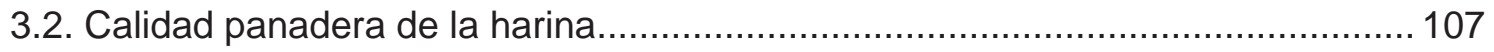

3.2.1. Evaluación de la cantidad y calidad del gluten ........................................... 108

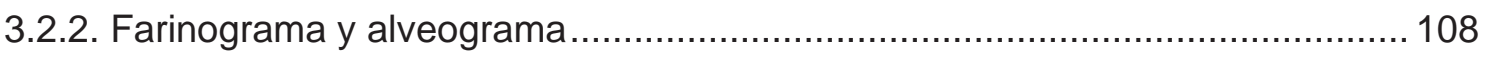

3.2.3. Determinación de la actividad $\alpha$-amilásica de la harina ................................... 109

3.2.4. Perfil viscoamilográfico de la harina ....................................................... 110

3.2.5. Electroforesis de fracciones proteicas de la harina ..................................... 112

3.3. Caracterización de los hidrocoloides utilizados ............................................... 113

3.3.1 Determinación de la pureza y grado de esterificación de las pectinas y del grado de amidación de la pectina de bajo metoxilo............................................................ 113

3.3.3. Determinación del PM de las pectinas por viscosimetría capilar....................... 114

3.3.4. Determinación del peso molecular promedio de las celulosas por HPLC ......... 115

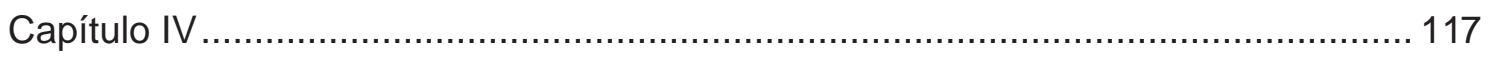

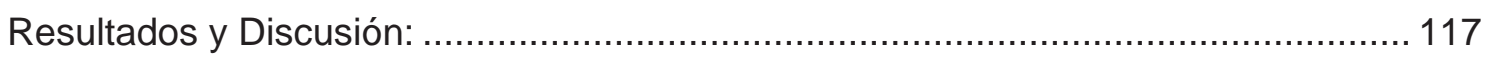

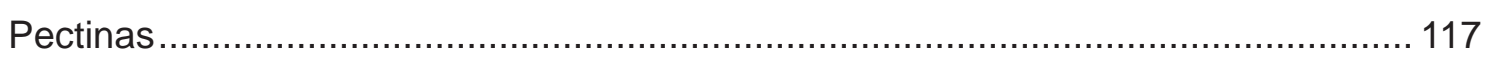

4.1. Caracterización fisicoquímica y reológica de las masas ..................................... 118

4.1.1. Absorción de agua de las mezclas harina - pectina ...................................... 118

4.1.2. Humedad y actividad acuosa................................................................ 121

4.1.3 Capacidad de hidratación de las proteínas de gluten....................................... 122

4.1.4. Ensayos reológicos empíricos y fundamentales............................................... 123

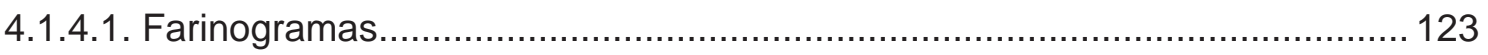




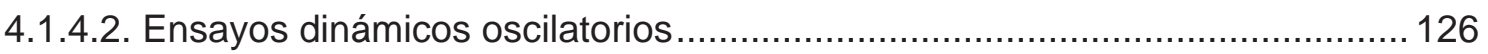

4.1.4.3. Análisis de perfil de textura de las masas ................................................. 130

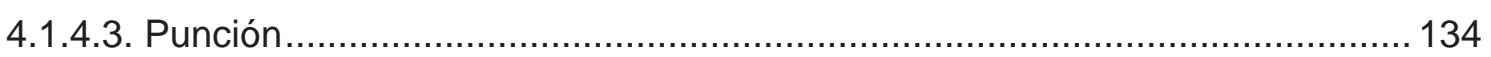

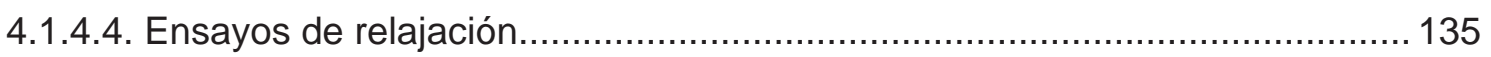

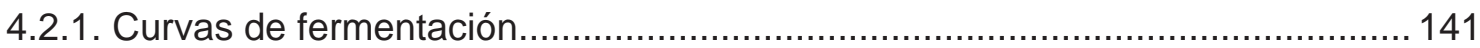

4.2.2. Evaluación de la calidad de los panes........................................................... 143

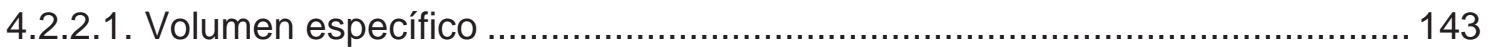

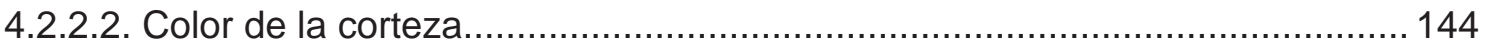

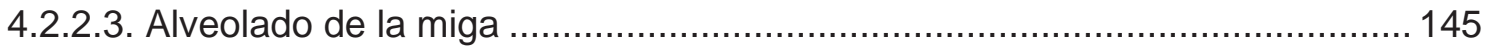

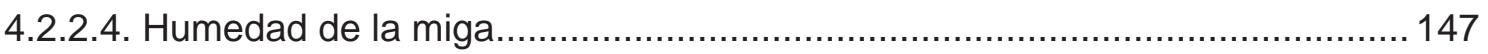

4.2.2.5. Análisis de perfil de textura de panes frescos y almacenados ...................... 147

4.2.3. Evaluación sensorial : Ensayo de discriminación .......................................... 153

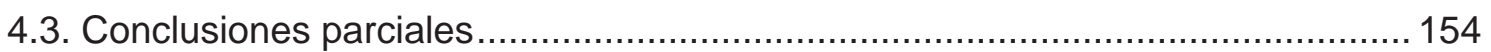

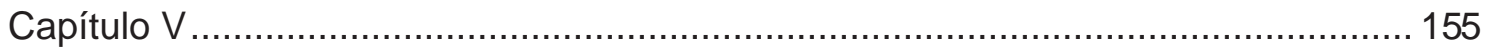

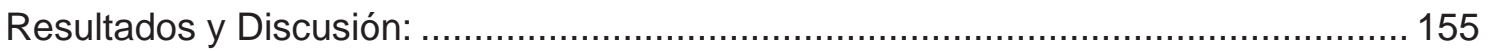

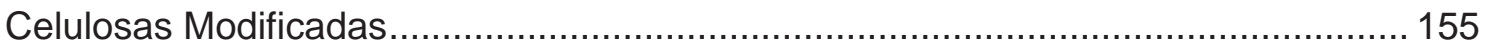

5.1. Caracterización fisicoquímica y reológica de las masas ..................................... 156

5.1.1. Absorción de agua de las mezclas harina - celulosas modificadas.................. 156

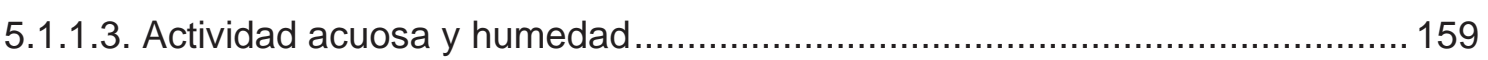

5.1.1.4. Capacidad de hidratación de las proteínas de gluten.................................... 160

5.1.2. Ensayos reológicos empíricos y fundamentales............................................ 162

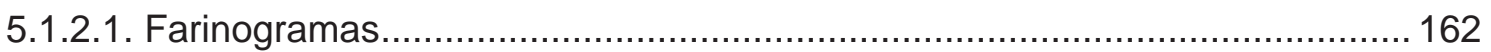

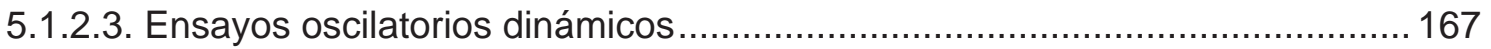

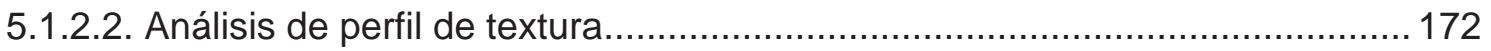

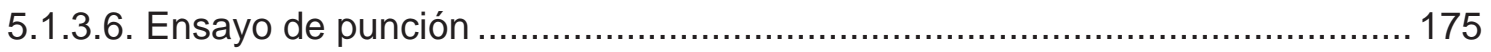

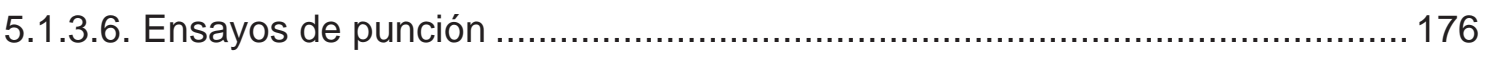

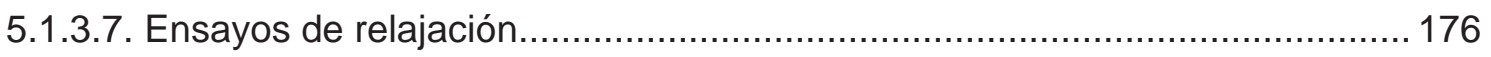

5.1.3.5. Análisis de componentes principales de los parámetros reométricos y

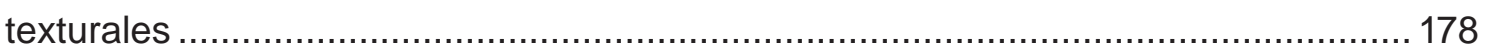

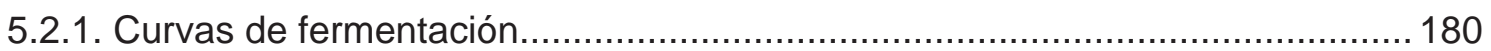

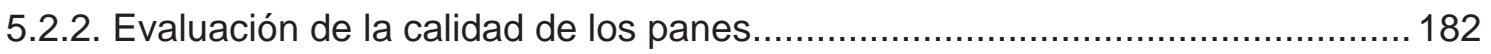

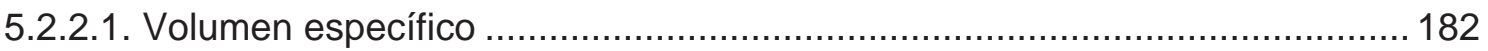

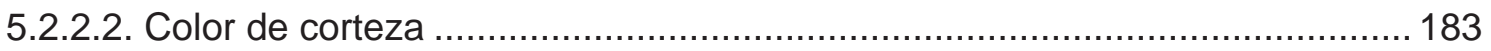

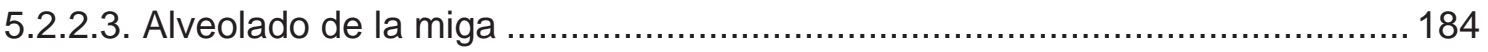

5.2.2.4. Humedad de panes frescos y almacenados............................................ 185 
5.2.2.5. Análisis de perfil de textura de panes frescos y almacenados ........................ 186

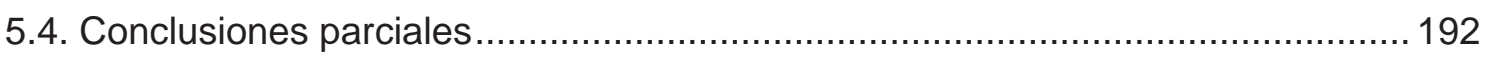

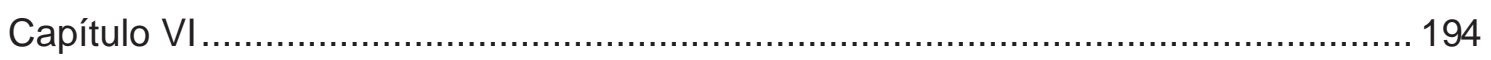

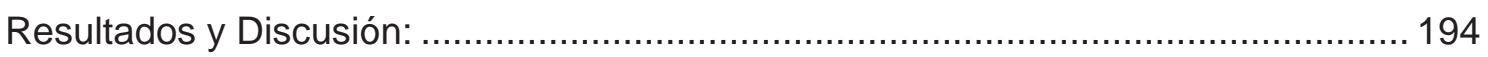

Microestructura e interacción entre los componentes ............................................. 194

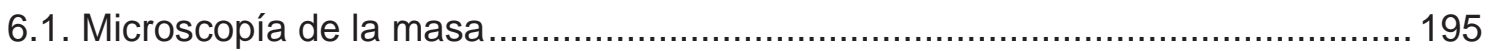

6.1.1. Microscopía electrónica de barrido (SEM) .................................................. 195

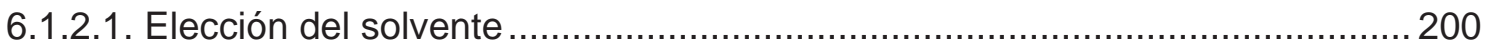

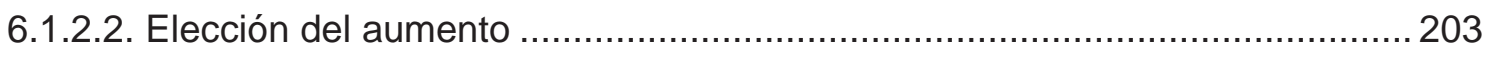

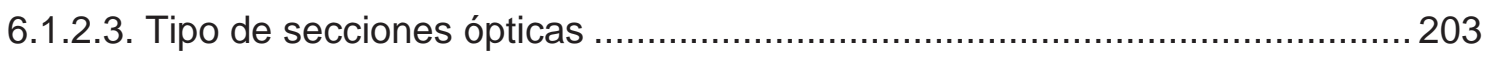

6.1.2.4. Efecto de los hidrocoloides sobre la microestructura de la masa...................205

6.2. Movilidad molecular en la matriz panaria ..................................................... 210

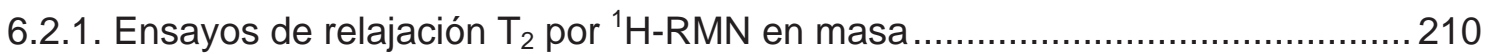

6.2.2. Ensayos de análisis mecánico diferencial (DMA) en miga ..............................2 213

6.3. Interacción entre los principales componentes de la masa y los aditivos ...........219

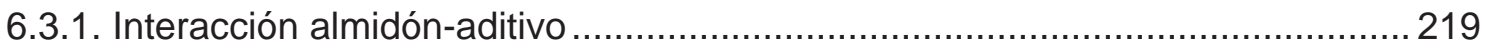

6.3.1.1. Interacción almidón-aditivo en sistemas modelo .......................................219

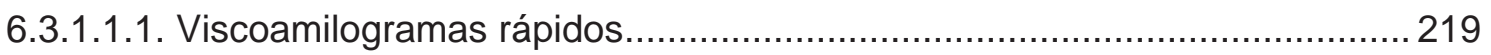

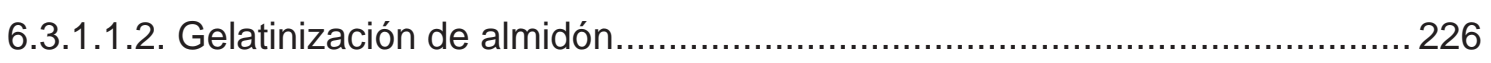

6.3.1.2. Interacción almidón-aditivo en masa ..................................................... 231

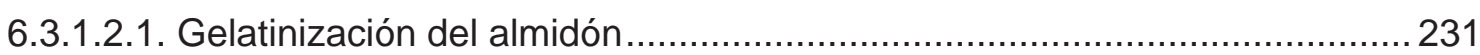

6.3.1.2.2 Retrogradación del almidón en presencia de hidrocoloides ........................ 233

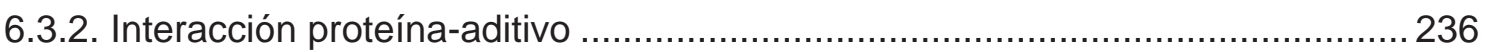

6.3.2.1. Electroforesis de los extractos proteicos de las masas ..................................236

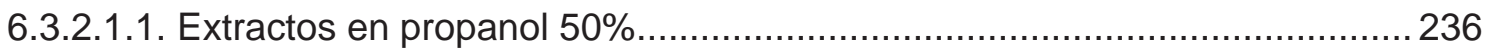

6.3.2.1.2. Extractos en ácido acético en condiciones no reductoras .......................... 239

6.3.2.1.3. Extractos con propanol 50\% en condiciones reductoras............................. 241

6.3.2.2. Espectroscopía FT-Raman ............................................................... 243

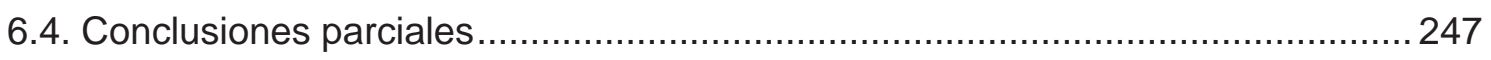

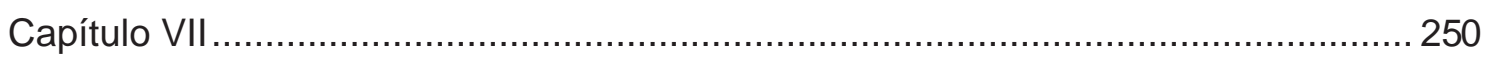

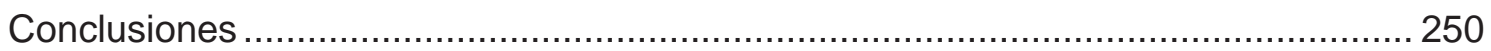

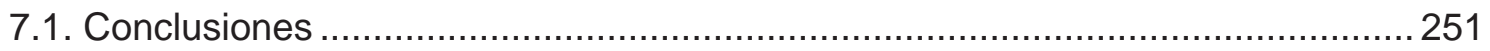

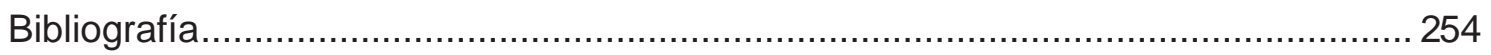

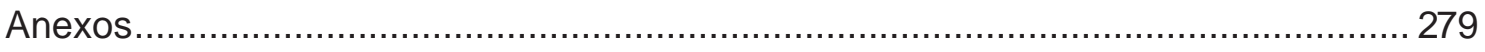

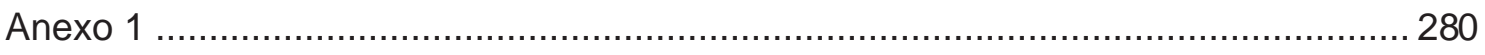


Índice

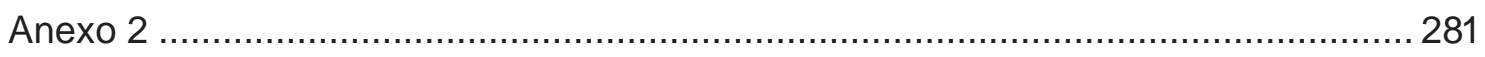

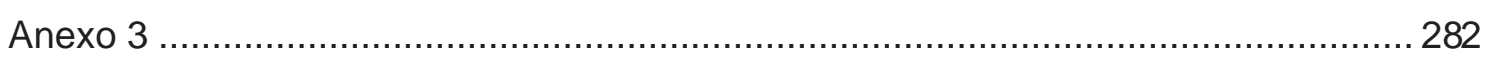

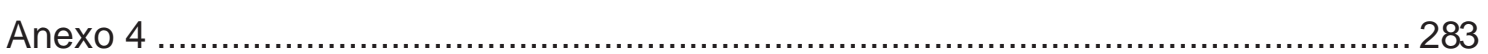

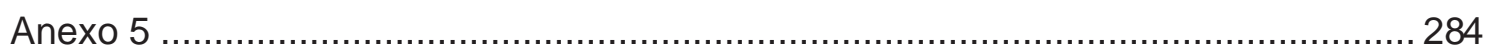

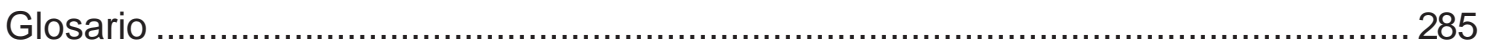




\section{Capítulo I}

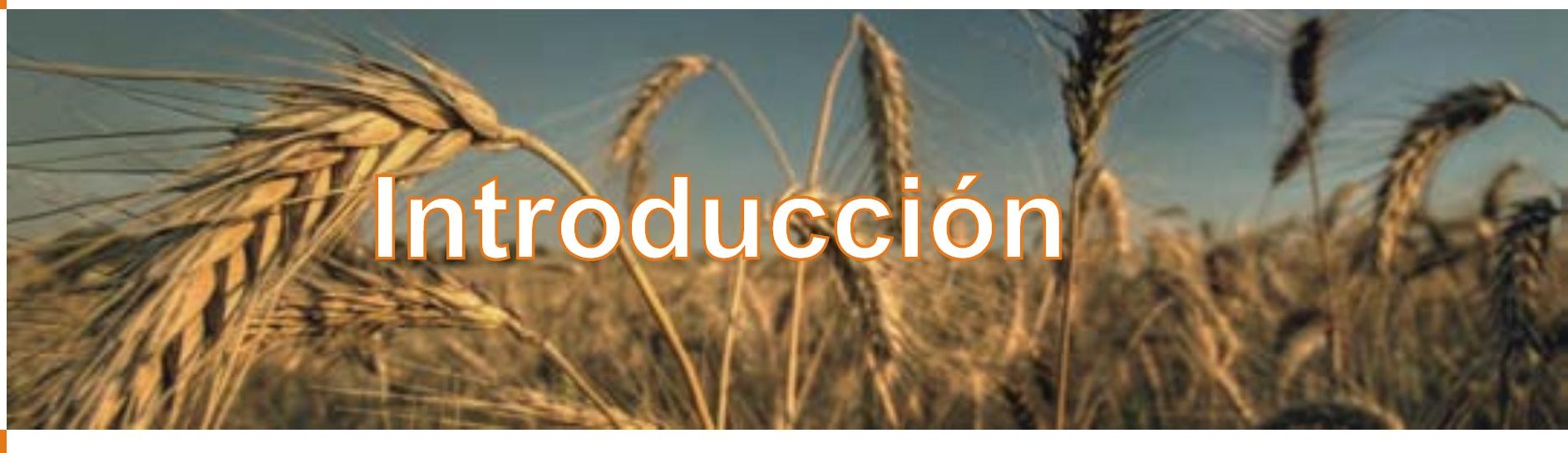




\subsection{Producción de trigo en la Argentina}

Nuestro país se encuentra entre los 20 principales productores de trigo a nivel mundial, habiendo ocupado en el año 2008 el puesto número 16 con 8.508.160 de toneladas producidas, lo cual sitúa al trigo como el $5^{\circ}$ producto en el país durante ese año (Fuente: Faostat, 2010). En el mercado interno su destino fundamental es la obtención de harina, habiéndose molturado en el año 2008 6,1 millones de toneladas de trigo destinadas a la panificación.

La región triguera argentina se extiende desde los $25^{\circ}$ de latitud sur, incluyendo la zona de Chaco y Formosa, hasta los $40^{\circ}$, con los cultivos de Patagones y Villarino, de este a oeste abarca de los $58^{\circ}$ a los $66^{\circ}$ de longitud oeste (Chidichimo y col.,2008), por lo que ocupa las provincias de Santa Fe, Entre Ríos, Buenos Aires, Córdoba y La Pampa. Sin embargo, sobre la base de condiciones agroecológicas homogéneas para los requerimientos del cultivo, la región triguera se ha subdividido en 9 subregiones productivas (Fig.1.1): subregión I, subregión II norte y sur, subregión III, subregión IV, subregión $V$ norte y sur y subregión NOA/ NEA (Fuente: Sistema Nacional de Vigilancia y Monitoreo de Plagas - SENASA).

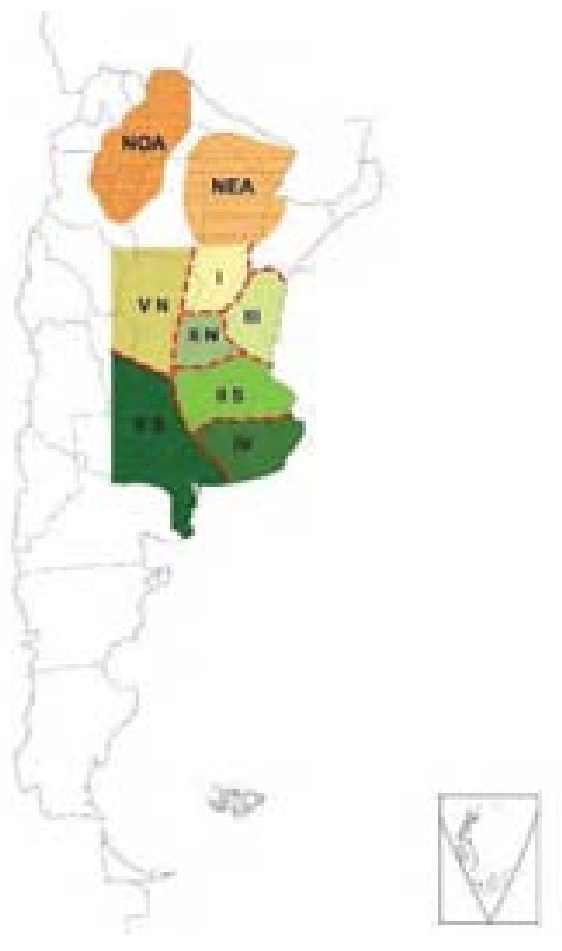

Figura 1.1. Subregiones trigueras de la República Argentina (Fuente: www trigoargentino.com.ar) 
En la Figura 1.2 se muestran la superficie sembrada en hectáreas (ha), la superficie cosechada (ha) y la producción, expresada en toneladas (tn), de trigo a nivel nacional de los últimos 40 años (1969-2011)(MAGyP: Ministerio de Agrícultura, Ganadería y Pesca). Las variaciones observadas en la producción a lo largo del tiempo se deben a variaciones en la situación económica nacional e internacional y a las condiciones climáticas del período.

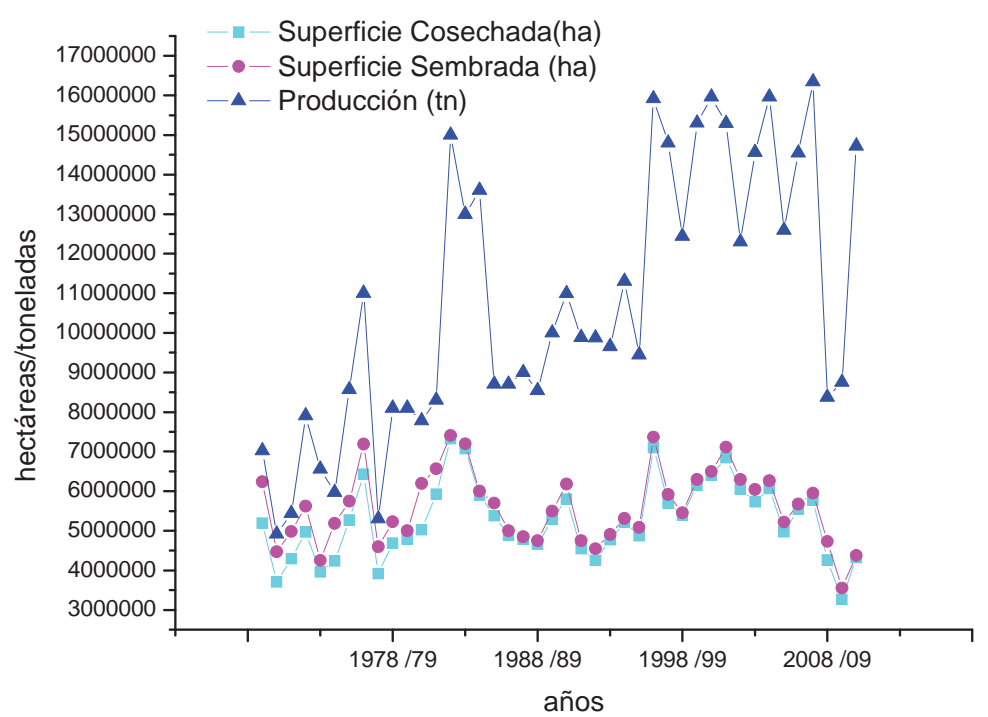

Figura 1.2. Producción (tn), superficie sembrada y cosechada (ha) de trigo en la República Argentina entre los años 1969 y 2011.(Adaptado de: MAGyP).

En la Figura 1.3 se muestra un promedio de la producción total de trigo por provincia del último quinquenio. De la misma surge que entre Buenos Aires, Córdoba y Santa Fe se obtiene el $87 \%$ de la producción total del país. 


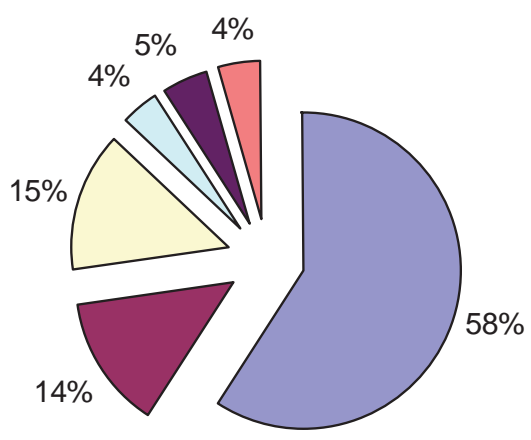

$\square$ Buenos Aires $\square$ Córdoba $\square$ Santa Fe $\square$ Enre Ríos $\square$ La Pampa $\square$ Resto del país

Figura 1.3. Producción total de trigo por provincia, años 2005-2010.(Adaptado de la Dirección de Coordinación de delegaciones - Estimaciones Agrícolas- SAGPYA- CNA 2002).

\subsection{Trigo: Aspectos generales}

El trigo pertenece a la familia de las gramíneas y al género Triticum, plantas caracterizadas por presentar inflorescencias (conjunto de flores que forman el aparato reproductor) llamadas espigas, las que se encuentran formadas por un tallo central o raquis en el que se hallan dispuestas 20 - 30 espiguillas (Gómez y col., 2007a). La espiguilla está formada por nueve flores, las que se encuentran protegidas en su base por dos brácteas denominadas glumas (Figura 1.4). Las brácteas que protegen los órganos reproductores de cada flor de la espiguilla se denominan glumillas: palea y lemma. Por su situación en la espiguilla, la palea es la glumilla superior y la lemma la inferior. En el grano, la palea recubre la parte ventral y la lemma la dorsal.

Desde el punto de vista botánico, el grano del trigo es una cariopsis, es decir, un fruto seco indehiscente en el que la pared del ovario, el pericarpio, se encuentra unido con el tegumento exterior de la semilla, testa, por lo que no es posible separarlos (Šramková y col., 2009). En la trilla los granos de trigo pierden las glumillas por lo que se los llama granos desnudos. 


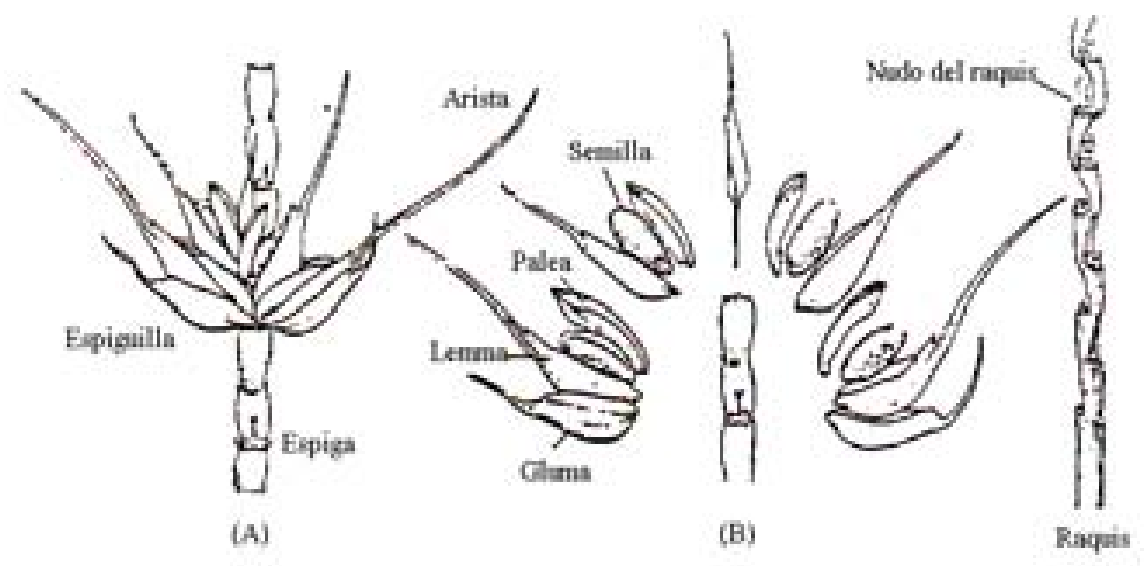

Figura 1.4. A) Espiguilla de trigo, B) Detalle de sus componentes.

Las especies cultivadas más importantes desde el punto de vista comercial se pueden clasificar en dos grandes grupos: las destinadas a panificación o trigo pan (T.aestivum) y aquellas utilizadas en pastas o trigo fideo (T.durum). A su vez, el trigo pan se clasifica como duro o blando de acuerdo a la dureza de sus granos. El producto de la molienda de los granos de un cereal se conoce como harina. Dado que la harina proveniente de trigos duros suele tener un mayor contenido proteico ( $\mathrm{y}$ un menor contenido de almidón) que la obtenida por molienda de trigo blando, se utiliza para panificación mientras que la harina proveniente de trigo blando se emplea para la producción de galletitas (Hoseney y Rogers., 1990).

\subsection{Estructura y composición del grano de trigo}

La estructura y composición del grano han contribuido al uso del trigo en alimentos, ya que facilitan su almacenamiento el bajo contenido de humedad (composición) y la presencia de una capa de salvado protectora (estructura). La estructura ha sido también la base de los métodos de separación y refinamiento del endosperma almidonoso para uso en alimentos, dado que el salvado es más duro y liviano que el endosperma almidonoso y esto facilita su separación. 


\subsubsection{Estructura del grano}

El grano de trigo (cariopsis) presenta forma ovalada, una longitud de 5-9 $\mathrm{mm}$ y se encuentra formado por el pericarpio (envoltura del fruto) y la semilla (Fig.1.5 y Fig. 1.6).

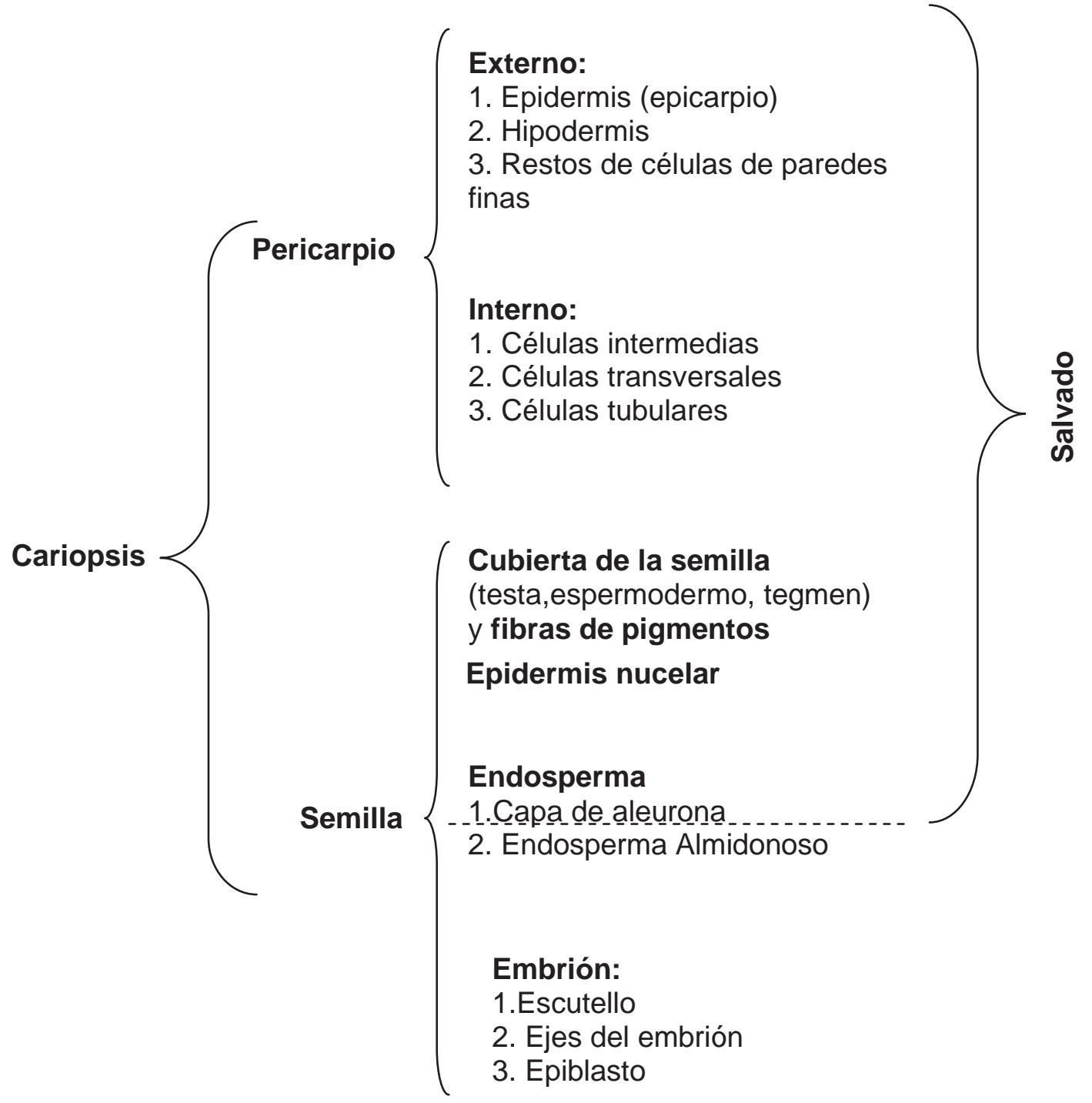

Figura 1.5. Estructura del grano de trigo (Adaptado de McMasters, 1978) 


\subsubsection{El pericarpio}

El pericarpio presenta un espesor de 45 a $50 \mu \mathrm{m}$ y actúa como una cubierta protectora. Se encuentra conformado por diversas capas: en el exterior, por la epidermis (epicarpio), la hipodermis y restos de células de paredes finas mientras que en el interior, por las células intermedias, las células transversales y las células tubulares.

La epidermis consiste en una capa simple de células que forman la superficie externa del grano excepto en el lugar en que el grano se une a la planta. En su pared externa presentan una capa fina y relativamente impermeable al agua, llamada cutícula, que es especialmente delgada en el germen. Debido al daño mecánico que ocurre durante la cosecha y al manipuleo posterior generalmente ocurre la ruptura de la cutícula y el daño de las células que se encuentran debajo. La hipodermis esta constituida por una o dos capas de células; tanto en la epidermis como en la hipodermis, las células tienen paredes gruesas, se encuentran muy juntas, sin espacios intracelulares y con sus ejes longitudinales paralelos al largo del grano. Los restos celulares de paredes delgadas representan un plano natural de separación entre el pericarpio interno y externo. Aquí, la difusión de agua es facilitada por la pérdida de estructura celular continua en el área.

El pericarpio interno se encuentra formado por las células intermedias, las células transversales y las células tubulares. Las células intermedias tienen forma irregular y se encuentran ausentes en algunas partes del grano, en las cercanías del germen se encuentran algo achatadas y sus proyecciones sirven para unirlas unas a otras y a las células transversales, por lo que se encuentran numerosos espacios intercelulares en esta región.

Por debajo de los restos celulares de paredes finas se encuentran las células transversales, llamadas así porque sus ejes longitudinales, se encuentran perpendiculares a los ejes longitudinales del grano. Las células de esta capa se encuentran muy juntas, con poco o sin espacio intercelular, excepto por encima de la parte más baja del germen donde las células tienen forma irregular y hay numerosos espacios intercelulares. Normalmente las células transversales están sometidas a tanta presión que en un corte transversal parecen rectangulares. Las células tubulares sólo las encontramos en ciertas zonas del grano y se unen entre ellas a través de proyecciones por lo tanto la capa presenta muchos espacios intracelulares (MacMasters, 1978). 
El pericarpio comprende aproximadamente el 5\% del grano, y está compuesto aproximadamente por un $6 \%$ de proteínas, un $2 \%$ de cenizas, un $25 \%$ de celulosa, $0,5 \%$ de lípidos, y $30 \%$ de pentosanos.

\subsubsection{La semilla}

En la semilla distinguimos tres zonas: el germen o embrión, el endosperma encerrado por la epidermis nucelar y la cubierta de la semilla (Fig.1.5 y 1.6).

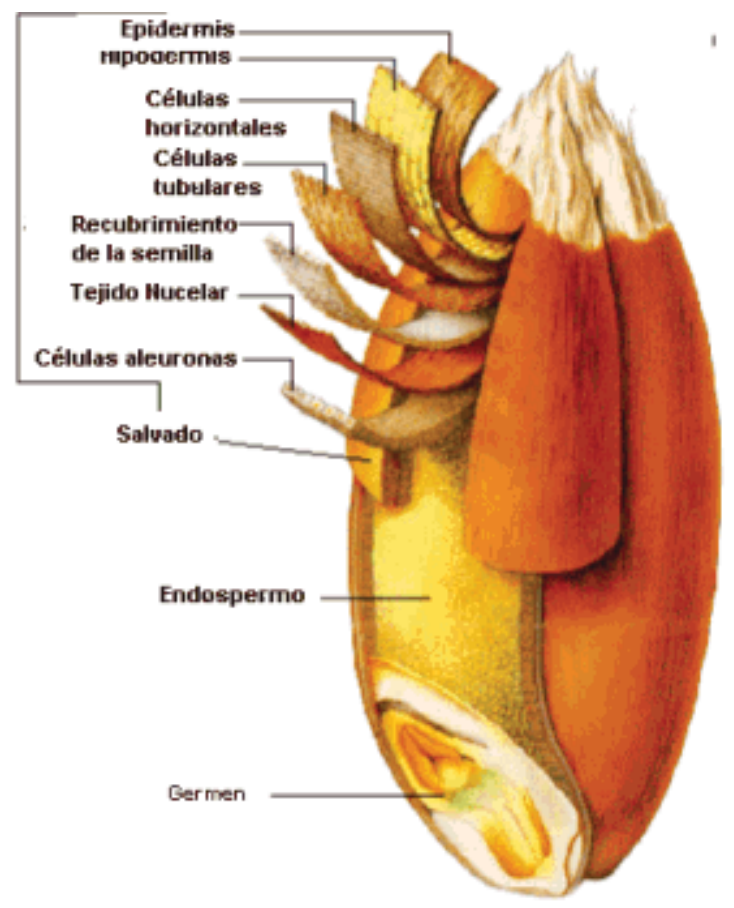

Figura 1.6. Grano de trigo y sus partes (Fuente: Red interinstitucional de tecnologías limpias www.tecnologiaslimpias.org).

\subsection{Cubierta de la semilla y epidermis nucelar}

La cubierta de la semilla se encuentra firmemente adherida al pericarpio y a la epidermis nucelar y se encuentra formada por tres capas: una cutícula exterior gruesa, una capa pigmentada y una cutícula interior fina. La capa pigmentada sólo contiene pigmentos en los trigos rojos. 
La epidermis nucelar o capa hialina presenta un espesor de aproximadamente $7 \mu \mathrm{m}$ y se encuentra fuertemente unida a la cubierta de la semilla y a la capa de aleurona.

La cubierta de la semilla y la epidermis nucelar representan el 2,5\% de la semilla de trigo y contienen principalmente proteínas (15\%), cenizas (13\%) y pentosanos (15\%).

\subsection{Germen}

El germen está formado por dos partes principales: el eje embrionario y el escutelo (cotiledón). El eje embrionario esta formado por una raíz y tallo rudimentarios y el escutelo funciona como un órgano de digestión, absorción y almacenamiento de nutrientes.

El germen representa aproximadamente el $3 \%$ del grano de trigo y contiene un $30 \%$ de proteínas, $4 \%$ de cenizas, $17 \%$ de azúcares (siendo los mayoritarios sacarosa y rafinosa), $10 \%$ lípidos y contiene gran variedad de enzimas (lipasas, lipooxigenasa, amilasas, proteinasas, dipeptidasas, etc) y vitaminas de los grupos B (niacina, riboflavina, tiamina) y $\mathrm{E}$ (tocoferol).

\subsection{Endosperma}

El endosperma esta formado por la capa de aleurona y el endosperma almidonoso. La capa de aleurona es la capa más externa del endosperma, se encuentra formada por una sola capa de células y rodea al endosperma y al germen por completo presentando un espesor de 65-70 $\mu \mathrm{m}$. Sus células tienen un núcleo grande, poseen gránulos que consisten principalmente en proteína y presentan paredes celulares gruesas y ricas en celulosa. La capa de aleurona contiene aproximadamente el $61 \%$ de los minerales del grano de trigo, el $80 \%$ de la niacina y $60 \%$ de la piridoxina (vitamina B6). En la molienda la capa de aleurona se desprende junto con el pericarpio, las envolturas de la semilla y la epidermis nuclear constituyendo parte del salvado.

El endosperma almidonoso está formado por tres tipos de células: periféricas, prismáticas y centrales, las cuales se diferencian en su ubicación, forma y tamaño. El endosperma es la fuente de la harina ya que sus células contienen gránulos de almidón embebidos en una matriz proteica. Además, sus células contienen dos tipos de proteínas, unas con función citoplasmática, albúminas y globulinas, y otras de reserva, las gliadinas y gluteninas, las que se encuentran formando partículas discretas. La composición del endosperma almidonoso presenta una disminución del 
contenido proteico y de cenizas desde el exterior hacia el centro, siendo posible encontrar una relación 6:1 en el contenido proteico entre diferentes zonas del endosperma. El endosperma almidonoso contiene el 72\% de las proteínas del grano de trigo y contiene una proporción importante de las vitaminas riboflavina y ácido pantoténico.

\subsection{Molienda}

En el proceso de molienda del grano de trigo se separa el endosperma del germen y del salvado obteniéndose harina. Un esquema simplificado del proceso de molienda se muestra en la Figura 1.7.

\subsubsection{Limpieza de los granos y acondicionamiento}

En la sala de limpieza del molino se reciben los granos de trigo provenientes de los silos y se eliminan impurezas que suelen acompañar al trigo: paja, arena, polvo, metales, otras semillas, etc. A través de la utilización de un sistema de tamices de doble malla se eliminan algunas impurezas, un tamiz grueso elimina las impurezas de mayor tamaño y permite que el grano de trigo pase a la segunda malla junto a las impurezas más pequeñas, el grano de trigo queda retenido mientras que las impurezas de menor tamaño, como arena y polvo pasan a través del tamiz. La separación también puede realizarse empleando tamices inclinados oscilantes donde el trigo es fluidizado por la aplicación de un flujo de aire transversal, de este modo se separan partículas más densas como piedras. Se emplean imanes para eliminar material ferroso, y por aspiración es posible eliminar impurezas ligeras como polvo (Caterall, 1998).

En el proceso de acondicionamiento se adiciona agua al grano de trigo y se deja reposar durante 20 horas para de este modo uniformizar la humedad en el grano. Con el acondicionamiento se incrementa la humedad del grano de $14 \%$ a $16 \%$, el pericarpio se vuelve más flexible y laminable, lo cual facilita la separación de las capas de salvado del endosperma y permite obtener fragmentos de mayor tamaño. La eliminación del salvado y el calor generado en el proceso de molienda hacen que la humedad final de la harina obtenida se encuentre cercana al $14 \%$. 


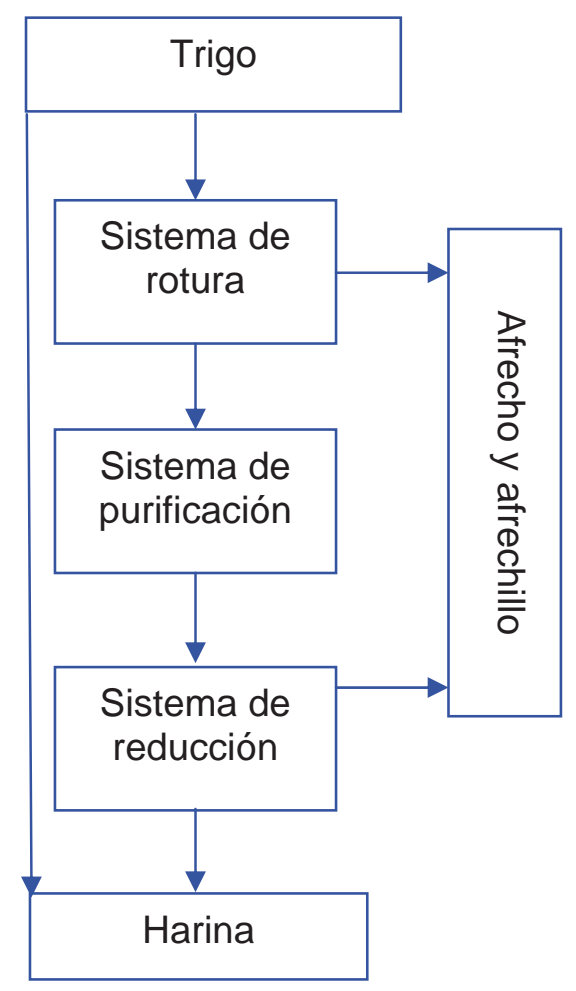

Figura 1.7. Esquema simplificado del proceso de molienda (Adaptado de Webb, 2003)

\subsubsection{Sistema de trituración}

El objetivo del sistema de trituración es alcanzar la máxima liberación de partículas del endosperma con la mínima desintegración posible del salvado (Webb, 2003). Se emplea un sistema de 4 a 6 pares de rodillos estriados, presentando en cada par uno de los rodillos una velocidad de giro que duplica a la del otro, por su acción se rompe y abre el grano y se extrae el endosperma. Las partículas grandes obtenidas de endosperma en esta etapa se denominan sémola. Después de pasar por cada par de rodillos los productos pasan a un cernedor oscilatorio que los separa en subfracciones y las envía al par siguiente de rodillos, al sistema de purificación o hacia los rodillos de reducción. También es posible obtener algo de harina en esta etapa, la cual se tamiza y separa, no pasando por el resto del proceso.

Algunos molinos poseen un sistema de raspado para eliminar los últimos fragmentos de endosperma que quedan adheridos al salvado, este sistema consiste en rodillos con acanaladuras más finas (Caterall, 1998). 


\subsubsection{Sistema de purificación}

El sistema de purificación presenta tres tipos de equipos: los purificadores, los rodillos de molienda y los tamices. Los purificadores separan las partículas en base a diferencias de tamaño y peso específico. Un purificador es un tamiz oscilante colocado en pendiente sobre tolvas receptoras cuyo tamaño de poro se incrementa en forma gradual y a través del cual pasa una corriente de aire. Las partículas de endosperma al ser más pesadas permanecen en el tamiz hasta que encuentran un tamaño de poro tal que les permite atravesarlo y caer a la tolva que se encuentra debajo, mientras que las partículas de salvado al ser más livianas son arrastradas por el flujo de aire. La corriente de alimentación del sistema de purificación proviene del sistema de trituración. Las partículas de clasifican en base al tamaño previamente a su entrada al sistema de purificación y contiene mezclas de endosperma puro y partículas de pureza intermedia. La mayor parte del material obtenido en esta etapa va a tener la pureza requerida y pasa hacia el sistema de reducción, mientras que el remanente vuelve al sistema de trituración. Generalmente la purificación del material proveniente de la primera y segunda rotura da lugar a endosperma puro, mientras que la purificación de roturas posteriores da lugar a material con mayor contenido de salvado (Webb, 2003).

\subsubsection{Sistema de reducción}

El sistema de reducción es la etapa final de la molienda, en ella se obtiene la harina con las características buscadas. Se emplean hasta 12 pares de cilindros de compresión, lisos y que giran con diferente velocidad, para reducir el tamaño de las partículas de harina. A partir de los diferentes cilindros se obtiene harina de diferente calidad, obteniéndose la harina de mejor funcionalidad para la panificación a partir de los primeros cilindros. El material obtenido en cada par de cilindros de reducción pasa a través de un cernedor oscilatorio que lo clasifica, la harina se elimina y las fracciones restantes, con mayor tamaño de partícula, pasan al cilindro siguiente.

La compresión realizada por los cilindros en esta etapa produce la rotura de los gránulos de almidón, lo cual afecta a la absorción de agua de la harina resultante.

\subsubsection{Grado de extracción}

El grado de extracción de la harina indica la eficiencia de la molienda y se calcula como la cantidad de harina obtenida cada $100 \mathrm{~g}$ de trigo (Ecuación 1.1.). 


$$
\text { Eficiencia de la molienda }=\frac{\mathrm{g} \text { harina }}{\mathrm{g} \text { trigo }} * 100 \quad \text { Ec. } 1.1
$$

Así, una harina de calidad media presenta un grado de extracción de 76 - 78\% mientras que una harina de buena calidad o harina flor tiene un grado de extracción del $60 \%$ por lo cual es más costosa. Una harina de buena calidad presenta el color más blanco debido a que tiene mayor contenido de endosperma almidonoso. Además, presenta el menor contenido proteico debido al gradiente proteico que existe en el grano de trigo.

\subsection{Harina de trigo}

La composición promedio de la harina es 70-75\% de almidón, $2 \%$ de lípidos, 2-3\% de pentosanos (arabinoxilanos y arabinogalactanos), $0,5 \%$ de sales, $14 \%$ de agua y 10 $12 \%$ de proteínas, de las cuales $85 \%$ son gliadinas y gluteninas y $15 \%$ albúminas y globulinas. El $73 \%$ de la harina obtenida se utiliza en la fabricación de pan, siendo las harinas de trigo y en menor grado la de centeno las únicas que resultan panificables. Esta particularidad de la harina de trigo se debe a las características de las proteínas: gliadinas y gluteninas presentes en el grano (Lindsay y Skerritt, 1999; Shewry y col., 2001).

\subsubsection{Almidón}

\subsubsection{Estructura}

El almidón es el polisacárido de reserva del grano de trigo y se encuentra en las células del endosperma empaquetado en forma de gránulos. Esta compuesto por dos polímeros de glucosa: amilosa en un $25 \%$ y amilopectina en un $75 \%$, por lo que estos representan aproximadamente el 15 y el $50 \%$ de la harina, respectivamente. La amilosa esta formada por residuos de glucosa unidos a través de enlaces $\alpha(1 \rightarrow 4)$ (Figura 1.8.A), aunque en los últimos años se han encontrado moléculas de amilosa levemente ramificadas a través de enlaces $\alpha(1 \rightarrow 6)$, éstas se encuentran en muy baja proporción (Hizukuri y col., 1981; Shibanuma y col., 1994). El grado de polimerización 
de la amilosa se encuentra entre 500 y 6000 residuos de glucosa y sus cadenas presentan una estructura helicoidal, en la cual los grupos hidroxilo están orientados hacia el exterior, estableciéndose en el interior un ambiente no polar en el cual pueden incluirse moléculas tales como los ácidos grasos. La amilopectina es un polímero altamente ramificado formado por cadenas de residuos de glucosa unidos a través de enlaces $\alpha(1 \rightarrow 4)$ las cuales se unen a través de enlaces $\alpha(1 \rightarrow 6)$, estableciéndose de este modo las ramificaciones (Figura 1.8.B). El grado de polimerización de la amilopectina se encuentra entre $3 \times 10^{5}$ y $3 \times 10^{6}$ residuos de glucosa, sus cadenas se clasifican en $A, B, C$, en base a la presencia de ramificaciones y extremos reductores y presentan una estructura en clusters.

En la harina de trigo encontramos una distribución bimodal en el tamaño de los gránulos de almidón, los gránulos de menor tamaño son esféricos y con diámetros de hasta $10 \mu \mathrm{m}$ mientras que la población de gránulos de mayor tamaño presenta un tamaño de hasta $20 \mu \mathrm{m}$ y un aspecto lenticular (Karlsson y col., 1983; Moon y col., 1993). Al observarlos con un microscopio de luz polarizada presentan birrefringencia con forma de cruz de Malta, la cual refleja el arreglo radial de las moléculas de almidón en el gránulo alrededor del centro biosintético, el hilium (Jane, 2004).

A

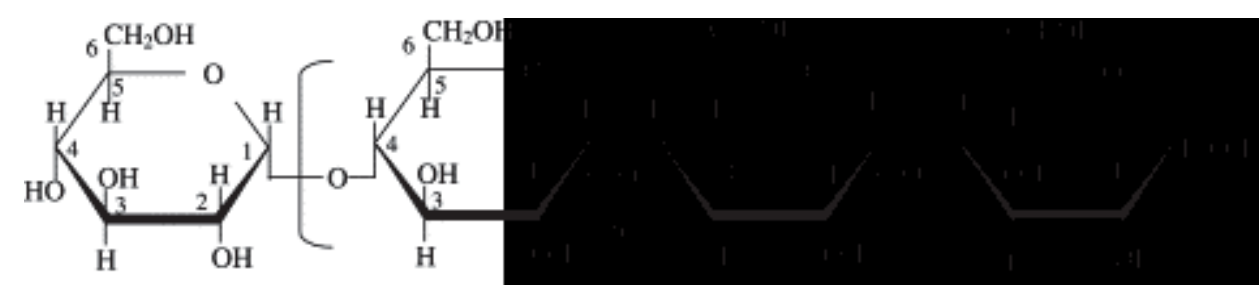

B

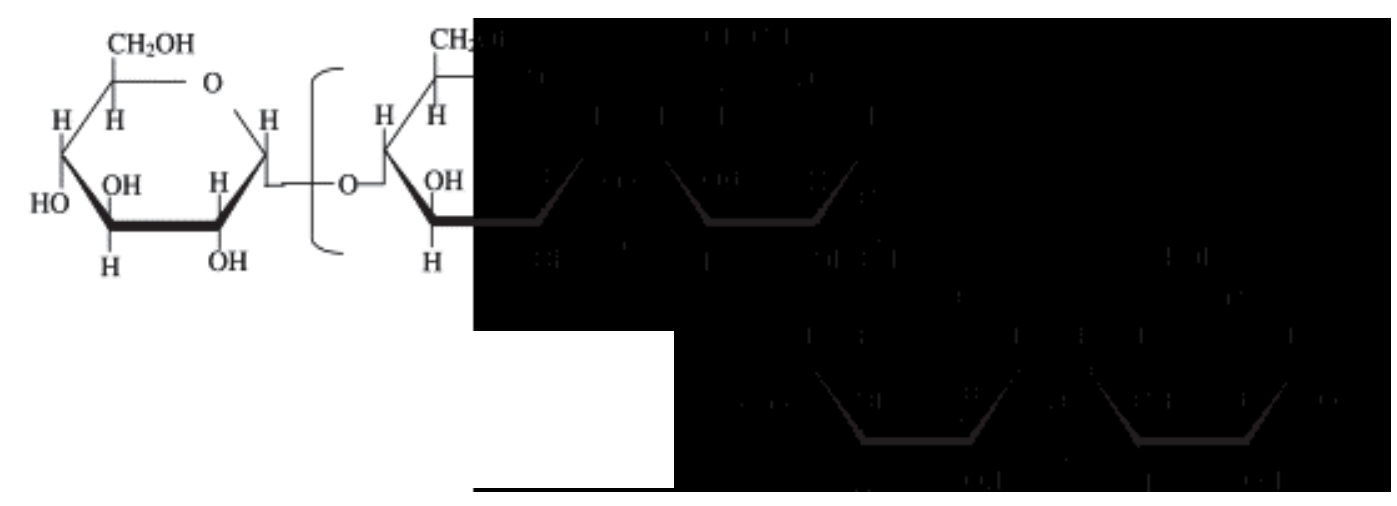

Figura 1.8. Estructuras de A) amilosa y B) amilopectina. 
El gránulo de almidón presenta una estructura semicristalina dado que es posible distinguir zonas amorfas y cristalinas (20-40\%) alternadas. Las zonas amorfas son menos densas y están conformadas principalmente por la amilosa mientras que las zonas cristalinas están formadas principalmente por doble hélices de amilopectina.

Si se prepara una suspensión de almidón en exceso agua a temperatura ambiente los gránulos de almidón pueden absorber parte del agua incrementando su tamaño un 1030\% (Dengate, 1984). Si esta suspensión se calienta, ocurre un fenómeno irreversible conocido como gelatinización (Figura 1.9), en el cual se pierde el orden molecular y el gránulo de almidón pierde la birrefringencia. La gelatinización comienza en las zonas amorfas ya que los enlaces de hidrógenos son más lábiles en estas zonas y permiten la entrada de agua al gránulo por lo que comienza a hidratarse y se hincha. Además, ocurre la disociación de la doble hélice de moléculas de amilopectina, la fusión de las zonas cristalinas y la salida de moléculas de amilosa lo que ocasiona un incremento de la viscosidad de la suspensión. Para el almidón de trigo la gelatinización determinada por calorimetría diferencial de barrido (DSC), cuando se encuentra en exceso de agua, se presenta como una única endoterma y suele comenzar aproximadamente a los $50^{\circ} \mathrm{C}$ y finalizar cerca de los $80^{\circ} \mathrm{C}$. Mientras que en los sistemas en donde el agua es limitante se observa un aumento del rango de temperatura de gelatinización y un desdoblamiento de la endoterma. (Ghiasi, 1982) Si se continua incrementando la temperatura o se realiza un esfuerzo de cizalla la estructura remanente del gránulo sigue dañándose y también continua la salida de amilosa. Al enfriar la pasta así obtenida ocurre la gelación de la amilosa (Figura 1.9, IIla) debido a la formación de una estructura de doble hélice entre las moléculas, obteniéndose una matriz de amilosa continua en la cual se encuentran embebidos gránulos de almidón gelatinizados enriquecidos en amilopectina o sus remanentes. La recristalización de la amilosa y la amilopectina se conoce como retrogradación (Figura $1.9, \mathrm{Illb})$. El proceso ocurre en el término de horas en el caso de la amilosa y es más lento -días a semanas- para la amilopectina. La retrogradación de la amilopectina ocurre en los gránulos gelatinizados o en los remanentes. 


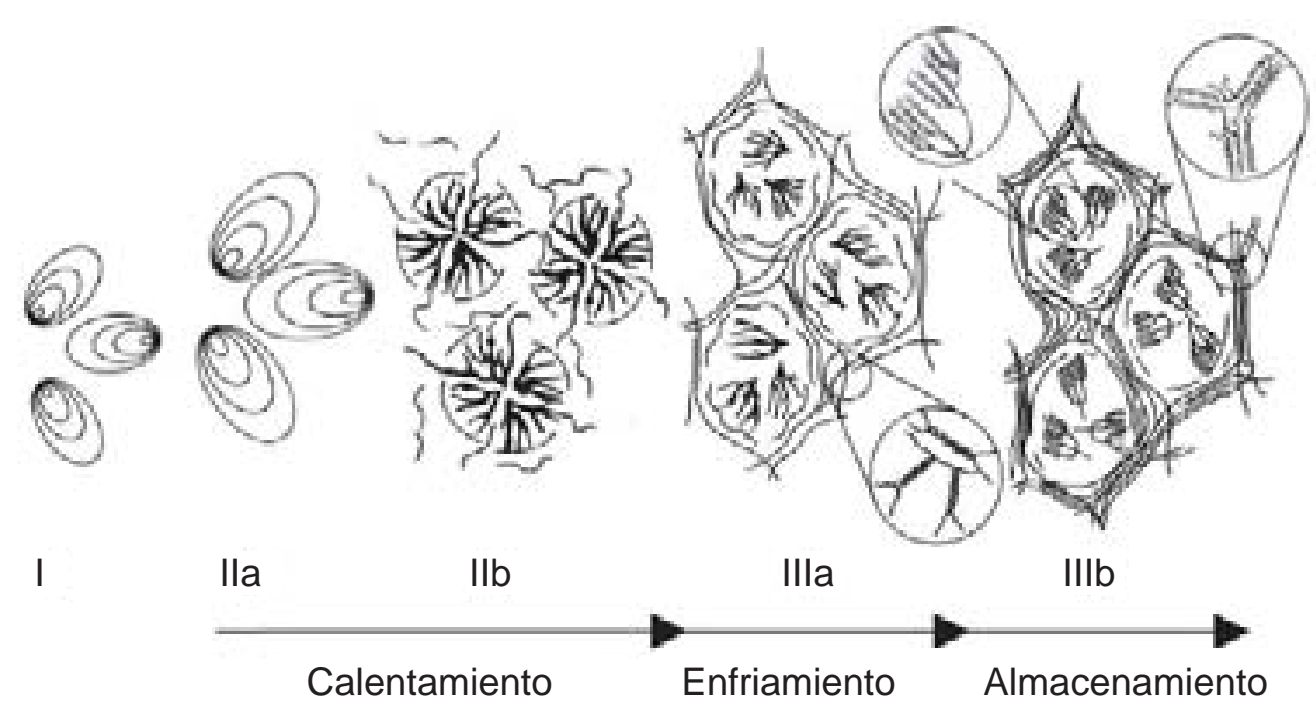

Figura 1.9. Cambios que experimenta el gránulo de almidón en una mezcla almidón agua durante un calentamiento, enfriamiento y almacenamiento. I) Almidón nativo, II) Gelatinización, IIla) Gelación, Illb) Retrogradación (Adaptada de Goesaert, 2005).

\subsubsection{Rol del almidón en la panificación}

Durante el amasado el almidón absorbe cerca del 40\% del agua (Stauffer, 1998) y actuaría como relleno en la matriz de la masa contribuyendo a aumentar su viscoelasticidad. Se ha propuesto que en la masa el almidón y las proteínas del gluten se encontrarían formando fases diferentes (Tolstoguzov, 1997).

En la harina de trigo podemos encontrar hasta un 15\% de gránulos de almidón dañados, los cuales presentan grietas y fisuras producidas durante la molienda. Los gránulos dañados absorben hasta 4 veces más agua que los gránulos intactos y en la etapa de fermentación son más susceptibles a la acción de la enzima $\alpha$-amilasa por lo que modifican las características de la masa en la fermentación (Howitt y col., 2003; Hajsělová, 2003; Stauffer, 1998) ya que a partir de su hidrólisis se forma glucosa que servirá de sustrato para las levaduras.

Durante el horneado ocurre la gelatinización del almidón determinando de este modo el volumen alcanzado por el pan y contribuyendo a fijar la estructura alveolar de la miga (Eliasson, 2003). En el almacenamiento, el almidón es el mayor responsable del endurecimiento del pan debido al fenómeno de retrogradación (Pateras, 1998). 


\subsubsection{Lípidos}

Los lípidos representan aproximadamente el 2,5\% de la harina; de los cuales el 1\% son apolares y están formados por triglicéridos, diacilglicéridos, ácidos grasos libres y ésteres de colesterol; el 1,5\% restante son lípidos polares y están formados por glicéridos de galactosa $(0,6 \%)$ y fosfolípidos $(0,9 \%)$, los cuales forman complejos de inclusión con la amilosa.

\subsubsection{Rol de los lípidos en panificación}

Los lípidos que se encuentran complejados con la amilosa no están disponibles para afectar el procesamiento durante el amasado. Mientras que los que se encuentran libres pueden interaccionar uniéndose al gluten o a la superficie de los gránulos de almidón. Los lípidos polares influyen en el comportamiento del pan en el horneado y en el volumen de pan obtenido ya que aumentan la retención de gas estabilizando los alvéolos de la miga. La mayor estabilidad se debe a la formación de una monocapa lipídica en la interfase gas/líquido de la masa (Sroan y col., 2009).

Los ácidos grasos poliinsaturados pueden ser oxidados por la lipooxigenasa dando lugar a radicales libres e hidroperóxidos que pueden oxidar a carotenoides y proteínas afectando al color de la miga y a las propiedades reológicas (Chung y col., 1978).

\subsubsection{Pentosanos}

A todos los polisacáridos no almidonosos presentes en la harina se los denomina en forma genérica como pentosanos ya que el $80 \%$ de los azúcares que los componen son pentosas: D-xilosa y D-arabinosa. También se los denomina hemicelulosas porque son los polisacáridos predominantes de las paredes celulares. Son sustancias complejas, cuyo esqueleto está formado por residuos de D-xilosa unidos por enlaces $\beta$ $(1 \rightarrow 4)$ al que se denomina xilano. El xilano puede estar sustituido en el carbono 2 ó en el carbono 3 por residuos de D-arabinofuranosa principalmente y en menor medida de glucosa, fructosa y manosa. Los residuos de arabinosa pueden estar a su vez, sustituidos en su C5 por ácido ferúlico (Fig.1.10). Un parámetro de caracterización es la relación arabinosa/xilosa cuyo valor típico es 0,5-0,6 (Cleemput, 1993). 


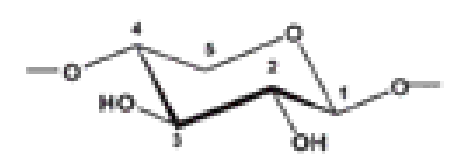

A

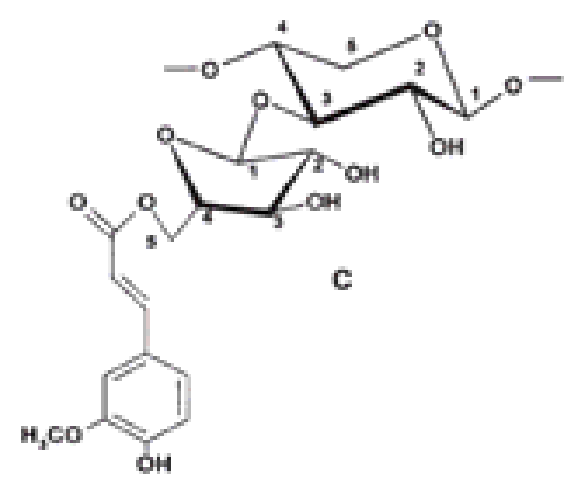

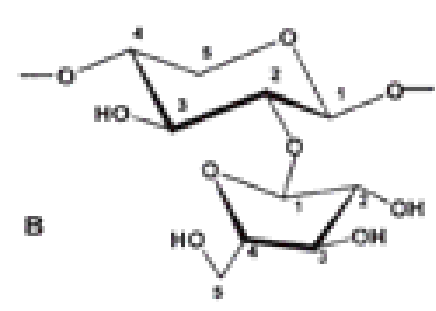

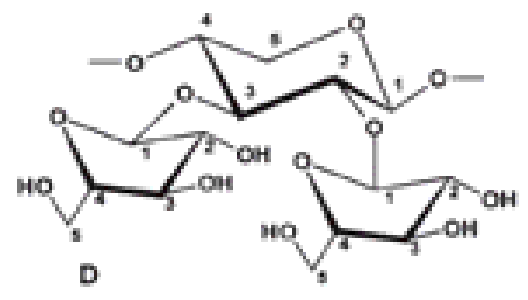

Figura 1.10. A) residuo de xilosa, B) residuo de xilosa sustituido en el C2 con Darabinosa, C) residuo de xilosa sustituido en el C3 con D-arabinosa, la cual esta sustituida en el C5 por ácido ferúlico, D) residuo de xilosa sustituido en los carbonos 2 y 3 con un residuo de D-arabinofuranosa. (Courtin, 2002).

Se los clasifica en base a su solubilidad en agua como pentosanos solubles e insolubles en agua como se muestra en la Figura 1.11.

Absorben muchas veces (10-15 veces) su peso en agua y forman soluciones muy viscosas motivo por el cual, aunque representan sólo el 2-2,5 \% de la harina tienen gran influencia en las propiedades de la masa.

\subsubsection{Rol de los pentosanos en la panificación}

Existen resultados contradictorios en relación al efecto positivo o no de los arabinoxilanos en panificación. A pesar de que constituyen aproximadamente sólo el $2 \%$ de la harina retienen más de un cuarto del agua de la masa (Tabla 1.1). Los pentosanos solubles en agua influyen en la viscoelasticidad de la masa y los insolubles aumentan la consistencia y dureza de la misma. Los arabinoxilanos insolubles disminuyen el tiempo de desarrollo y aumentan la resistencia a la extensión lo que apoyaría la hipótesis de que interfieren con la formación de la masa. 


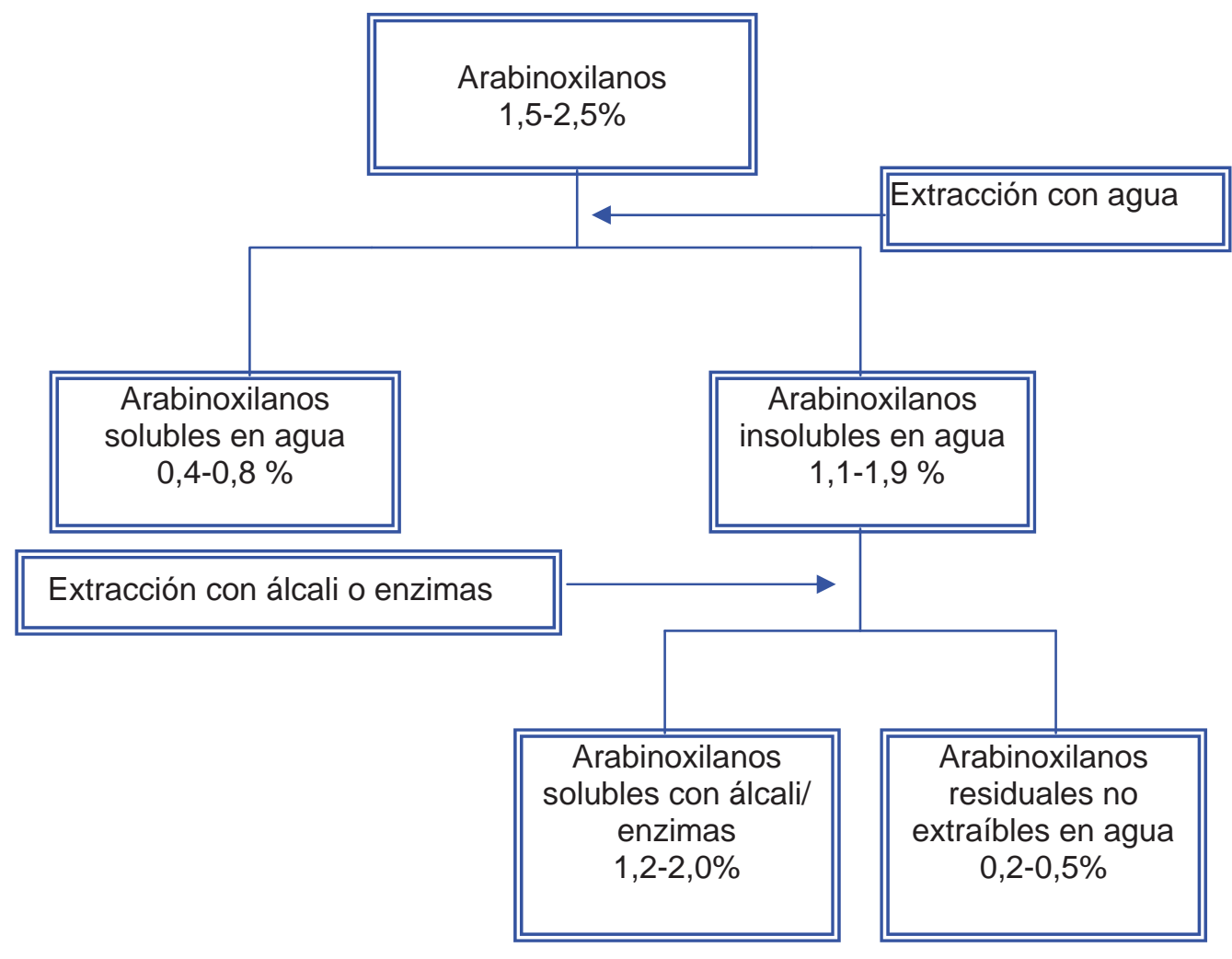

Figura 1.11. Clasificación de los arabinoxilanos en base a su solubilidad (Adaptado de Courtin, 2002).

En el amasado, los residuos de ácido ferúlico se unen a las proteínas del gluten, generando entrecruzamientos y aumentando la elasticidad de la masa.

En la fermentación, los pentosanos colaborarían disminuyendo la velocidad de difusión de $\mathrm{CO}_{2}$. Además, aumentarían la estabilidad de los alvéolos gaseosos debido a que incrementan la viscosidad de la fase acuosa estabilizando de este modo a los alvéolos de gas (Hoseney y Rogers, 1990). Durante el horneado, los arabinoxilanos solubles en agua estabilizarían los alvéolos por lo que se obtendrían mayores volúmenes de pan mientras que los insolubles disminuirían la calidad del mismo.

Algunos autores postulan que durante el envejecimiento del pan los pentosanos tendrían un efecto positivo ya que debido a un efecto estérico interferirían con la asociación intermolecular de la amilosa y la amilopectina (Kim y col., 1977, a y b). 
Tabla 1.1.Absorción de agua por los componentes de la harina

\begin{tabular}{cccc}
\hline Componente & $\begin{array}{c}\text { Agua / g de } \\
\text { componente }\end{array}$ & $\begin{array}{c}\text { Cantidad de } \\
\text { componente en } 100 \\
\text { g de harina }\end{array}$ & $\begin{array}{c}\text { Absorción por } \\
100 \mathrm{~g} \text { de harina }\end{array}$ \\
\hline Proteína & 1,3 & 12 & 15,6 \\
\hline Almidón intacto & 0,4 & 57 & 22,8 \\
\hline Almidón dañado & 2,0 & 8 & 16,0 \\
\hline Pentosanos & 7,0 & 2 & 14,0 \\
\hline
\end{tabular}

(Adaptado de Stauffer, 1998)

\subsubsection{Cenizas}

Las cenizas representan el contenido mineral de la harina. En el grano de trigo se hallan principalmente en las cubiertas externas y en el germen por lo que durante la molienda se reduce considerablemente su contenido en relación a las presentes en el grano. El contenido medio de cenizas de una harina es aproximadamente 0,5\% y esta conformado principalmente por K, P, Mg, Ca, Na, Zn, Fe, Mn, Cu, Mo y Co (Czerniejewski y col., 1964).

Altos contenidos de cenizas pueden impartir un color oscuro al producto terminado por lo que se debe tener en cuenta al elegir la harina (Wheat Marketing Center, 2008).

\subsubsection{Proteínas}

Las proteínas de la harina de trigo se clasifican, al igual que para otros cereales, en base a su solubilidad según la secuencia de Osborne (Tabla 1.2). En el caso del trigo, a las prolaminas se las denominan gliadinas y a las glutelinas, gluteninas. 
Tabla 1.2. Clasificación de las proteínas de trigo

\begin{tabular}{|c|c|c|}
\hline $\begin{array}{c}\text { Fracción de } \\
\text { Osborne }\end{array}$ & $\begin{array}{l}\text { Solvente de } \\
\text { extracción }\end{array}$ & Función en la célula \\
\hline Albúminas & Agua & $\begin{array}{c}\text { Metabólica y } \\
\text { estructural }\end{array}$ \\
\hline Globulinas & $\begin{array}{l}\text { Solución salina } \\
\text { diluida }\end{array}$ & $\begin{array}{l}\text { Metabólica y } \\
\text { estructural }\end{array}$ \\
\hline $\begin{array}{c}\text { Gliadinas } \\
\text { (Prolaminas) }\end{array}$ & Solución alcohólica & Almacenamiento \\
\hline $\begin{array}{l}\text { Gluteninas } \\
\text { (glutelinas) }\end{array}$ & $\begin{array}{c}\text { Extraíbles en medio } \\
\text { ácido o básico }\end{array}$ & Almacenamiento \\
\hline Residuo insoluble & No extraíble & Almacenamiento \\
\hline
\end{tabular}

\subsubsection{Proteínas hidrosolubles}

Las proteínas hidrosolubles representan entre el 15 y el $20 \%$ de las proteínas totales y corresponderían a las albúminas y globulinas de la secuencia de Osborne. En estas fracciones se encuentran proteínas estructurales, enzimas, inhibidores enzimáticos, etc., pero con excepción de la $\alpha$ - amilasa no presentan gran relevancia en el proceso de panificación. La $\alpha$ - amilasa corta los enlaces glucosídicos $\alpha(1 \rightarrow 4)$ generando azúcares de bajo peso molecular que sirven de sustrato a las levaduras (Hajsělová, 2003).

\subsubsection{Proteínas del gluten}

Con el término de gluten se designa a la red que forman gluteninas y gliadinas hidratadas durante el amasado. Son las proteínas de reserva del grano de trigo y constituyen entre el 80 y el $85 \%$ de las proteínas totales. Un tercio de su composición aminoacídica se encuentra formado por residuos de glutamina, la cual puede establecer puentes de hidrógeno, un $14 \%$ por residuos de prolina la cual favorece la formación de hojas $\beta$ plegadas y presentan muy pocos residuos básicos y ácidos por lo que la densidad de carga superficial es baja.

Estas proteínas son capaces de absorber gran cantidad de agua y de constituir una red deformable, elástica y extensible que puede retener los gases durante la 
fermentación y posterior cocción. Durante el amasado se producen interacciones no sólo entre las proteínas y el agua para formar la red de gluten, sino también entre otros componentes de la harina como almidón, polisacáridos no almidonosos (arabinoxilanos, arabinogalactanos) y lípidos (fosfo y glicolípidos) (Carr y col., 1992; Bettge y Morris, 2000; Lee y col., 2001). Estas interacciones permiten obtener una matriz viscoelástica capaz de formar, tras la cocción, el producto con características únicas que conocemos como pan.

\subsubsection{Estructura de gliadinas y gluteninas}

Las gliadinas son proteínas monoméricas altamente polimórficas (se han separado más de 100 componentes) con masas entre 30-50 KDa que presentan solubilidad en soluciones alcohólicas y constituyen aproximadamente el $50 \%$ del gluten. En base a su estructura y composición interaccionan a través de la formación de puentes de hidrógeno y el establecimiento de interacciones hidrofóbicas (Tatham y Shewry, 1995). Se clasifican en base a su movilidad electroforética en geles de poliacrilamida en medio ácido (lactato PAGE) en 3 grupos denominados $\alpha / \beta$-gliadinas, $\gamma$-gliadinas y $\omega$ gliadinas, siendo las proteínas de la fracción $\alpha / \beta$ las más rápidas y las $\omega$-gliadinas las de menor movilidad. Las $\alpha / \beta$ y $\gamma$-gliadinas son ricas en azufre mientras que las $\omega$ gliadinas son deficientes en azufre (Fig.1.12). Se conoce la secuencia completa de aminoácidos de las $\alpha$ y $\gamma$-gliadinas y se puede dividir su estructura en un dominio $\mathrm{N}$ terminal pequeño, un dominio central repetitivo y un dominio C-terminal no repetitivo de aproximadamente 300 residuos (Figura 1.13). Las $\alpha / \beta$ y $\gamma$-gliadinas presentan puentes disulfuro intracatenarios y una estructura más compacta. Las $\alpha$-gliadinas contienen 6 residuos de cisteína, los cuales forman tres puentes disulfuro intracatenarios mientras que las $\gamma$-gliadinas tienen 8 residuos de cisteína y forman 4 enlaces disulfuro intracatenarios. Todos los residuos de cisteína se encuentran localizados en el extremo C-terminal (Lindsay y Skerritt, 1999). Las $\alpha / \beta$ y $\gamma$-gliadinas presentan masas moleculares entre 28 y $35 \mathrm{kDa}$.

Las $\omega$-gliadinas consisten en secuencias repetitivas ricas en glutamina, que pueden formar puentes de hidrógeno con el agua, proteínas, almidón y otros componentes de la masa. A diferencia de las $\alpha / \beta$ y $\gamma$-gliadinas no tienen puentes disulfuro y no presentan una estructura compacta. Su estructura secundaria y sus interacciones (proteína-proteína o proteína- agua) se encuentran influenciadas por el grado de hidratación. 


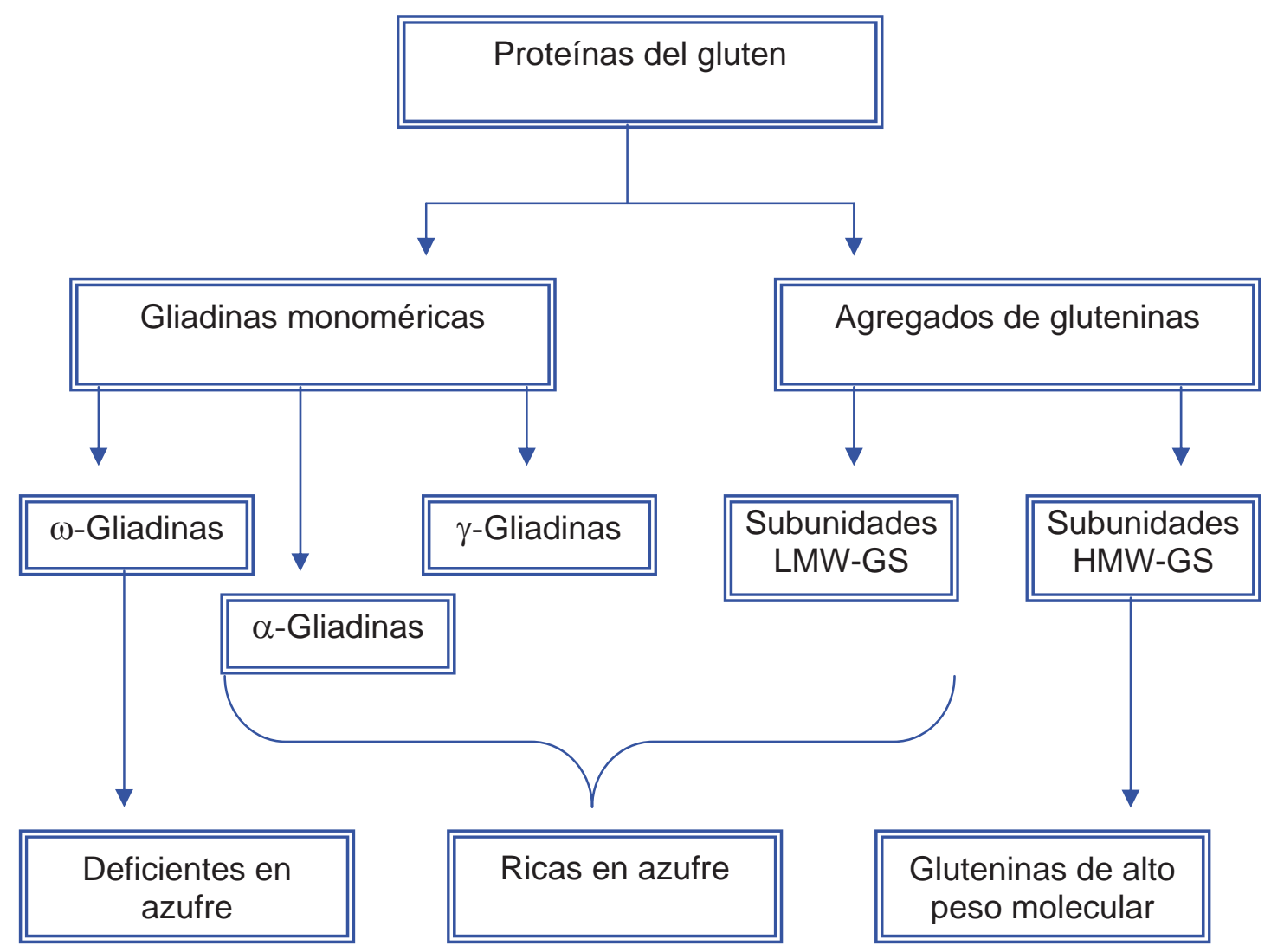

Figura 1.12. Clasificación de las gliadinas y subunidades de gluteninas (Adaptado de Lindsay y Skerritt, 1999).

A

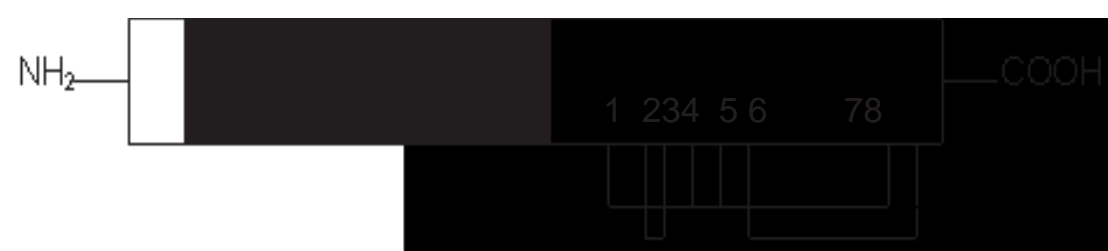

B

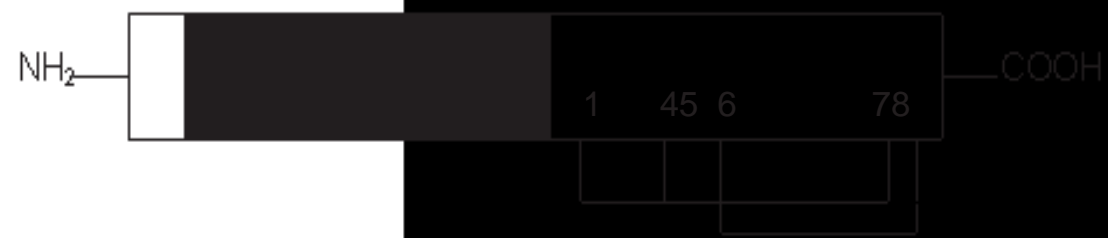

Figura 1.13. Localización de los residuos de cisteína en las A) $\gamma$-gliadinas y B) $\alpha$ gliadinas (Adaptado de Lindsay y Skerritt, 1999). 
En las $\alpha / \beta$ y $\gamma$-gliadinas el contenido de glutamina es menor que el de las $\omega$-gliadinas y la mayor parte se encuentran en la zona repetitiva por lo que queda muy restringida la cantidad de puentes de hidrógeno que pueden establecer en comparación con las $\omega$ gliadinas. Por otro lado, las gliadinas del tipo $\alpha(\alpha+\beta)$ tienen más glutamina que las $\gamma$ (Fido y col.,1997).

Las gluteninas son una mezcla heterogénea de polímeros con pesos moleculares superiores a $1 \times 10^{6}$. Se encuentran formadas por subunidades de alto (high molecular weight: HMW-GS) y bajo peso molecular (low molecular weight: LMW-GS) enlazadas por uniones disulfuro. La relación molar LMW-GS/HMW-GS es 2: 1. Si se reducen los puentes disulfuro, las subunidades de glutenina obtenidas presentan solubilidad en soluciones alcohólicas similar a la de las gliadinas.

Las HMW-GS (o subunidades $A$ ) se dividen en dos tipos $X$ e $Y$, presentando las subunidades $X$ masas entre 83 y $88 \mathrm{kDa}$ y las subunidades $Y$ entre 67 y $74 \mathrm{kDa}$. Presentan dominios no repetitivos en sus extremos $\mathrm{N}$ y C-terminales, encontrándose en estos la mayor parte de los residuos de cisteína. Ambos tipos de subunidades HMW-GS presentan un residuo de cisteína en el extremo C-terminal, en el extremo Nterminal las $X$ tienen 3 mientras que las $Y$ presentan 5 residuos de cisteína. El dominio central es repetitivo por lo cual forma giros $\beta$ los cuales se pliegan en una estructura espiral o helicoidal mientras que los dominios no repetitivos $\mathrm{N}$ y C-terminales presentan estructura globular (Figura 1.14).

Las subunidades de bajo peso molecular se dividen según su movilidad molecular es SDS-PAGE en 3 tipos: B, C y D. Hay dos tipos principales de subunidades de LMW: m-LMW, que contienen metionina como primer aminoácido de la secuencia, y s-LMW, que tienen serina como primer aminoácido de la secuencia, ambas dentro de las subunidades del tipo B. Algunas de las secuencias N-terminales de C-LMW corresponden al tipo m-LMW mientras que otras presentan secuencias similares a las de las gliadinas por lo que se denominan $\alpha / \gamma$-LMW. Las $\alpha / \gamma$-LMW contienen un residuo de cisteína extra por el cual se unen covalentemente al polímero y como tienen un numero impar de residuos de cisteína se denominan terminadores de cadena. Por otro lado, las B-LMW presentan un número par de residuos de cisteína por lo que se las denomina extendedores de cadena. Las D-LMW se piensa que se formaron por mutación en uno o más genes que codifican para las $\omega$-gliadinas. Las secuencias repetitivas de las LMW representan aproximadamente el $30 \%$ de la estructura de la proteína, por lo que se diferencian dos dominios estructurales. Los giros $\beta$ en el extremo N-terminal y un dominio central rico en prolina mientras que el extremo Cterminal contiene estructura $\alpha$ hélice, la cual representa aproximadamente el 35\% de 


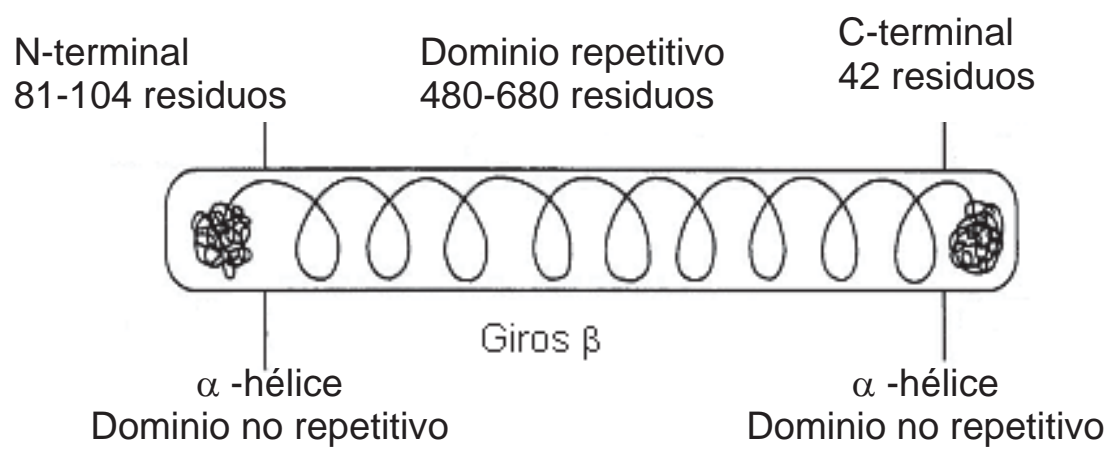

Figura 1.14. Subunidad de gluteninas de alto peso molecular (Adaptado de Shewry y col., 2001).

la estructura de la proteína (Lindsay y Skerritt, 1999).

Aunque tanto en las gliadinas como en las gluteninas existen puentes disulfuro intracatenarios estabilizando su conformación, la capacidad de formación de puentes intercatenarios es exclusiva de las gluteninas por lo que se ha propuesto que en la masa las HMW-GS forman el esqueleto del macropolímero a través de la formación de puentes disulfuro. La habilidad de las subunidades de glutenina para establecer enlaces disulfuro se deben a sus estructuras primaria y secundaria, ya que éstas determinan la existencia de residuos de cisteína, su disponibilidad para formar enlaces disulfuro y la capacidad de la subunidad para plegarse de la manera requerida y formar el enlace. Las HMW-GS son capaces de establecer enlaces disulfuro entre ellas y con las LMW-GS. En la Figura 1.15 se muestra el modelo estructural propuesto para el gluten, en el cual las HMW forman el esqueleto, un polímero formado a través de uniones disulfuro "cabeza-cola" entre HMW-GS que otorga las propiedades elásticas a la masa, y al cual las LMW-GS se unen a través de enlaces disulfuro formando las ramificaciones. En este esquema las gliadinas interaccionan a través de fuerzas no covalentes, las cuales contribuyen a la viscosidad del gluten. 


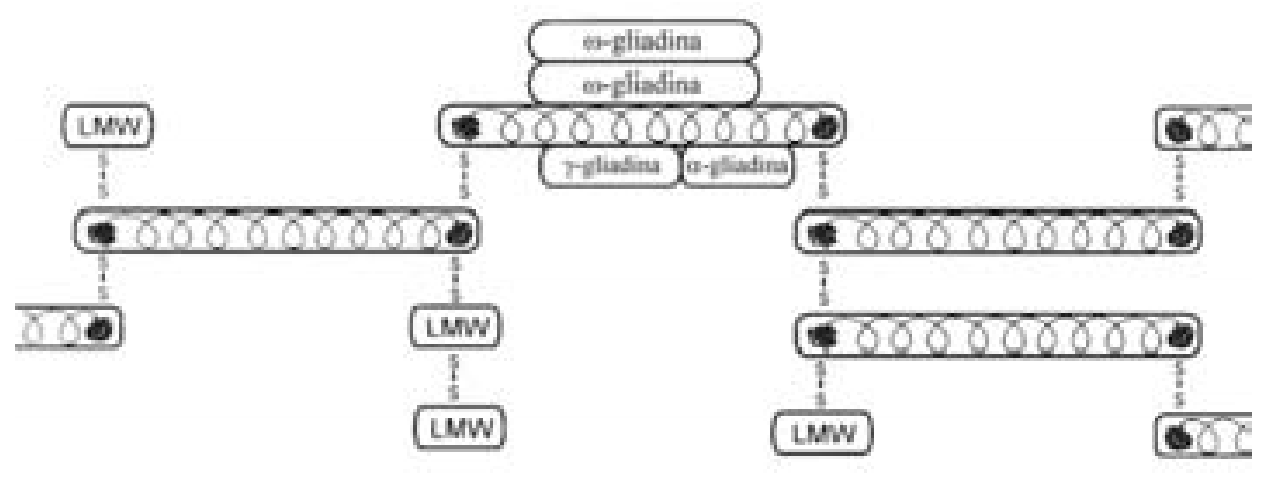

00000008000 HMW-GS

LMW LMW-GS

Figura 1.15. Modelo estructural propuesto para el gluten (Shewry y col., 2001).

Diversos autores han establecido diferentes rangos de masas moleculares para cada una de las fracciones proteicas, los que en muchos casos se superponen (Kruger y col., 1988; Singh, 1990; Lindsay y Skerrit, 1999; Wieser y col., 2006; Wieser, 2007). Esta situación puede atribuirse a que han empleado diferentes tipos de harina, distintos métodos de extracción, purificación y determinación de las masas moleculares (HPLC, electroforesis, etc).

\subsubsection{Rol en la panificación}

Durante el amasado la presencia de agua y la realización de un trabajo mecánico permiten la hidratación de gliadinas y gluteninas y se produce el desarrollo de una red viscoelástica, el gluten. La cantidad y calidad del gluten determinan el tiempo necesario de amasado y las propiedades reológicas de la masa.

Durante la fermentación la red de gluten sigue experimentando cambios (disminuye su adhesividad, se hace menos extensible y más elástica), y es determinante para la retención del gas formado durante la misma (Hoseney y Rogers,1990) y en la etapa inicial del horneado, lo cual determina el volumen del pan y la estructura de la miga.

Durante el horneado ocurren varios cambios a la vez, cambia la hidrofobicidad superficial de las proteínas, se produce un intercambio de puentes disulfuro y formación de nuevos enlaces disulfuro (Weegels y col., 1994). Debido a estos cambios, junto con los experimentados por el almidón, se forma la estructura del pan. 
El rol del gluten en el envejecimiento del pan no es claro aunque se ha encontrado que forma enlaces de hidrógeno con el almidón gelatinizado (Martin y col., 1991).

\subsection{Factores que determinan la calidad del gluten}

Hay dos factores determinantes de la calidad del gluten para panificación (Figura 1.16): la relación gliadinas/gluteninas y la calidad de las gluteninas.

1) Relación gliadina/glutenina

La relación gliadinas/gluteninas es importante debido a que cumplen diferentes roles en la masa, mientras que las gluteninas otorgan resistencia a la deformación y elasticidad, las gliadinas actúan como plastificantes otorgando plasticidad y viscosidad (Belton, 1999 y 2003). Para obtener un pan de buena calidad se necesita un balance adecuado entre viscosidad y tenacidad.

2) Calidad de las gluteninas

Se ha visto que es la fracción correspondiente a las gluteninas la que presenta mayor influencia en la calidad panadera ya que variaciones cualitativas y/o cuantitativas en sus subunidades ocasionan cambios en la misma (NG y Bushuk, 1988; Khan y col., 2002;). Las variaciones en la composición de las subunidades pueden dar lugar a diferentes interacciones covalentes que son las que determinan la elasticidad de las mismas y, a su vez, a diferentes estructuras poliméricas lo cual puede afectar su funcionalidad en el proceso de panificación. El grado de polimerización también es importante dado que según la teoría de polímeros sólo los que superan un determinado tamaño podrían contribuir a la elasticidad (Singh y MacRitchie, 2001). 


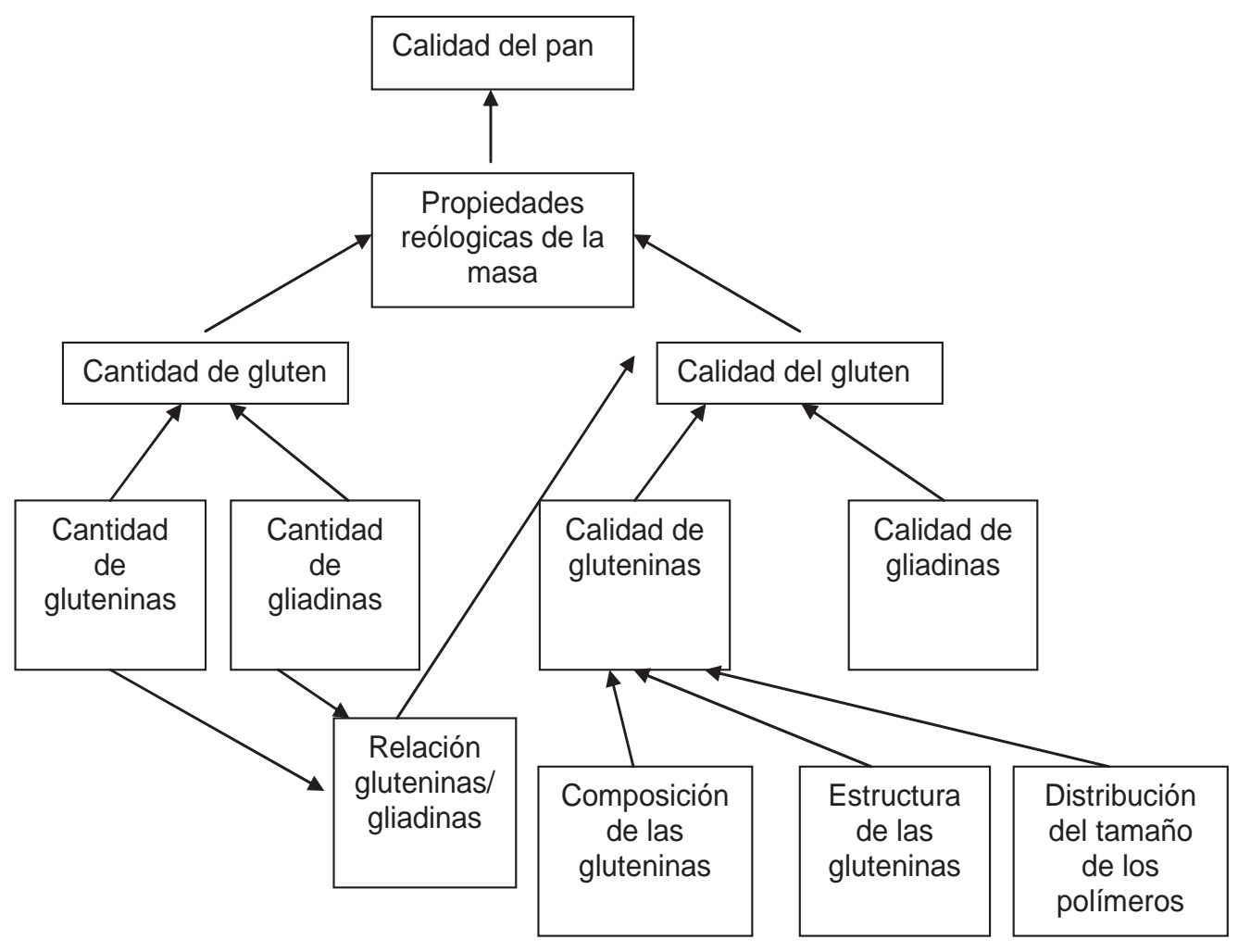

Figura 1.16. Factores que determinan la calidad del gluten (Adaptado de Goesaert, 2005).

\subsection{Tipificación comercial de las harinas en la República Argentina.}

El Código Alimentario Argentino (CAA) en su Capítulo IX, artículo 661 (Res 167, 26.1.82) define como Harina al producto obtenido de la molienda del endosperma del grano de trigo y tipifica comercialmente a las harinas del siguiente modo: cuatro ceros (0000), tres ceros (000), dos ceros (00), cero (0), medio cero (medio 0), Harinilla de primera y Harinilla segunda, las cuales se obtienen de la molienda gradual y metódica del endosperma en cantidad de $70-80 \%$ del grano limpio. En las Tablas 1.3 y 1.4 se muestran las características requeridas para los diferentes tipos de harinas y harinillas. La tipificación de las harinas se basa en 1) el contenido de cenizas determinado a 900$920{ }^{\circ} \mathrm{C}$ (calculadas sobre residuo seco), 2) la humedad determinada a $130{ }^{\circ} \mathrm{C}$ durante una hora, 3) la absorción farinográfica de agua (cantidad de agua que absorben $100 \mathrm{~g}$ de harina) y 4) el volumen de pan que puede obtenerse a partir de $100 \mathrm{~g}$ de harina. En 
la determinación de cenizas se admite una tolerancia de hasta un 3\% sobre los valores establecidos para las harinas 000 . Se debe rotular como harina o harina de trigo con la tipificación correspondiente.

Tabla 1.3. Tipificación comercial de las harinas según el CAA.

\begin{tabular}{ccccc}
\hline Harina tipo & Humedad g/100 g & $\begin{array}{c}\text { Cenizas } \\
\mathrm{g} / 100 \mathrm{~g}{ }^{*}\end{array}$ & $\begin{array}{c}\text { Absorción } \\
\mathrm{g} / 100 \mathrm{~g}\end{array}$ & $\begin{array}{c}\text { Volumen pan } \\
\left(\mathrm{cm}^{3}\right)\end{array}$ \\
\hline 0000 & 15,0 max & $0,492 \max$ & $56-62$ & 550 mín \\
\hline 000 & $15,0 \max$ & $0,65 \max$ & $57-63$ & 520 mín \\
\hline 00 & 14,7 max & 0,678 max & $58-65$ & 500 mín \\
\hline 0 & 14,7 max & 0,873 max & $60-67$ & 475 mín \\
\hline $1 / 20$ & 14,5 max & 1,350 max & - & - \\
\hline
\end{tabular}

* en base seca

Tabla 1.4. Tipificación comercial de las harinillas según el CAA.

\begin{tabular}{llll}
\hline Harinillas tipo & Humedad $\mathrm{g} / 100 \mathrm{~g}$ & Cenizas $\mathrm{g} / 100 \mathrm{~g}$ & Tamizado \\
\hline Primera & $14,5 \max$ & $1,35-2,00$ max & $\begin{array}{l}50,60 \text { y } 80 \text { XX sin } \\
\text { residuo }\end{array}$ \\
\hline Segunda & $14,5 \max$ & $2,00-3,00$ max & $\begin{array}{l}50 \text { y } 60 \text { XX } \\
8 \text { XX hasta } 10 \%\end{array}$ \\
\hline
\end{tabular}

El CAA en el art. 662 (Dec 2370, 28.3.73) define como harina integral o de Graham al producto que se obtiene por la molienda del grano de trigo y las tipifica según el grado de molienda en: Gruesa, mediana y fina. Su humedad no debe ser mayor de 15,5 $\mathrm{g} / 100 \mathrm{~g}$ y el contenido de cenizas no mayor de $2,30 \mathrm{~g} / 100 \mathrm{~g}$.

\subsection{Calidad panadera de una harina}

La calidad panadera de una harina se determina por el volumen y calidad del pan obtenido. Si bien los ensayos de panificación en condiciones estandarizadas son los que mejor permiten evaluar cómo se comportará una harina durante la panificación posterior, existen además ensayos predictivos (relación gluten húmedo/gluten seco, 
cantidad de proteína, alveograma, farinograma, extensograma entre otros) que, en conjunto, logran una buena aproximación al comportamiento que se observará durante la panificación.

Las harinas obtenidas de los trigos cultivados en Argentina difieren notablemente en calidad industrial, según la zona de procedencia del cereal ya que las variedades sembradas en mayor proporción cambian según la región. En base a su uso final se clasifican las variedades de trigo en tres grupos. En el grupo 1 se incluyen las variedades genéticamente fuertes con las que se obtienen masas de alta tenacidad por lo que suelen utilizarse como correctores de trigos de inferior calidad por panificadoras industriales. En el grupo 2 se incluyen variedades también de alta calidad panadera que son aptas para el sistema de panificación manual tradicional de nuestro país ya que toleran fermentaciones largas de más de 8 horas y hasta 16 hs; mientras que las variedades del grupo 3 son trigos de alto potencial de producción, pero de baja calidad panadera, adecuadas para métodos de panificación directos en los que se empelan tiempos de fermentación cortos de no más de 6-8 horas. Esta clasificación es revisada anualmente debido a que la interacción genotipo-ambiente afecta la calidad panadera (Juan, 2003). Dado que las variedades del grupo I se siembran en mayor proporción (más del 40\%) en Buenos Aires y Córdoba, las variedades del grupo II en Santa Fe, Entre Ríos y Santiago del Estero en donde representan más del $60 \%$ y las variedades del grupo III en Chaco, La Pampa, Córdoba y Buenos Aires donde presentan una superficie sembrada mayor al 15\%, los granos de trigo procedentes de estas diferentes regiones diferirán en calidad industrial (Yalungo, 2007).

\subsection{Panificación}

A través del proceso de panificación se busca obtener un producto esponjoso y apetitoso a partir de la harina de trigo: el pan, el cual es uno de los alimentos procesados más antiguos y más ampliamente consumidos por la humanidad (Dewettinck y col., 2008).

La capacidad de la harina de trigo para formar una masa viscoelástica, lo cual está determinado por las características de las proteínas de reserva del grano de trigo, es la que permite la obtención del pan.

Las diferencias principales entre las distintas formas de panificación se encuentran en la mezcla, amasado, incorporación de aire, formación y desarrollo del gluten. La 
subdivisión de la masa y las etapas del proceso que afectan a las piezas individuales modifican la calidad del producto, aunque dicha calidad se genere durante el desarrollo de la masa. Los cambios deseables resultantes de un desarrollo óptimo de la masa están asociados a la capacidad de la masa de retener burbujas de gas $\left(\mathrm{CO}_{2}\right)$ y permitir, durante las fases de fermentación y horneado la expansión uniforme de la pieza. Para mejorar la retención de gas es deseable obtener masas extensibles además la reducción de la resistencia y elasticidad son importantes en la modificación de la estructura de las burbujas durante el proceso (Cauvain, 2002).

\subsubsection{Etapas del proceso de panificación}

\subsubsection{Amasado}

Durante la etapa de amasado la harina de trigo es hidratada y como resultado de la entrega de energía mecánica se produce el desarrollo de la red de gluten, ocurriendo la disrupción de los aglomerados de las proteínas de gluten y transformándose en una red cohesiva y viscoelástica. Además durante esta etapa se incorporan burbujas de aire. Al final del amasado la masa panaria tiene las características viscoelásticas óptimas para el procesado posterior (Belton, 2003).

La producción de una estructura alveolar definida en el pan depende de la formación y

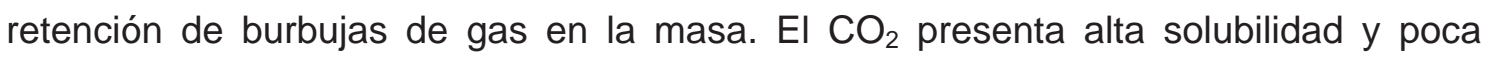
capacidad de formar burbujas de gas, por lo que queda retenido en la fase acuosa y cuando ésta se satura pasa a los alvéolos (Maloney y Foy, 2003).

Además, en la masa quedan atrapados durante el amasado $\mathrm{O}_{2}$ y $\mathrm{N}_{2}$. $\mathrm{El} \mathrm{O}_{2}$ se agota rápidamente porque es consumido por las levaduras y el $\mathrm{N}_{2}$ es importante ya que proporciona el núcleo de la burbuja a cuyo interior puede difundir el $\mathrm{CO}_{2}$ cuando abandona la solución. El número y tamaño de las burbujas de gas disponibles en la masa al final del amasado se encuentra influenciado por el método de formación de masa que se emplee y por las condiciones del amasado (Campbell, 2003)

La obtención de un pan de buena calidad está determinada por las características de la masa, siendo de importancia la capacidad de retención del gas generado durante la fermentación (Gan y col., 1995)y un adecuado balance entre el flujo viscoso y la fuerza elástica, lo cual depende de las características del gluten. 


\subsubsection{Reposo}

La etapa de reposo permite que la masa se relaje antes del moldeado, se busca la obtención de una masa a la vez, elástica y moldeable. Además, durante esta etapa se generan sustancias que contribuyen al aroma y sabor de la masa.

\subsubsection{División y moldeo}

La masa se divide en piezas, las que en la etapa de moldeo, adquieren la forma correcta para poder originar una estructura que dará lugar a un producto de buena calidad. El uso de moldes admite que las masas sean más blandas y fluyan más que cuando las piezas de masa deben mantener la forma por sí solas. En estas etapas la masa se hace menos relajada y más elástica.

A estas etapas suele seguirlas un tiempo de reposo, durante el cual se continúan modificando las propiedades físicas y químicas de la masa.

\subsubsection{Fermentación}

El fin es permitir que la pieza ya moldeada se relaje y expanda para que se forme una pieza aireada de masa que, cuando se hornee, tenga la forma y el volumen requeridos.

En la fermentación también se producen cambios debido en la composición de la matriz por los productos formados durante la misma como, etanol y $\mathrm{CO}_{2}$, por la acción de los aditivos y proteasas de la harina.

\subsubsection{Horneado}

Es la fase final de la fabricación de pan durante la cual se aplica calor, el que ocasiona una rápida expansión del gas en la masa, la eliminación de agua, la gelatinización del almidón y la coagulación de las proteínas. Estas reacciones, junto a la formación de corteza transforman un trozo de masa en una pieza de pan. La transferencia de calor en una masa menos densa implica que el centro de la pieza puede alcanzar la temperatura requerida $\left(96^{\circ} \mathrm{C}\right)$ en menos tiempo.

Cuando se introducen las piezas en el horno, durante los primeros minutos, antes que mueran las levaduras, se genera la mayor cantidad de $\mathrm{CO}_{2}$ por lo que la masa continua expandiéndose y debe tener la capacidad de retener el gas que se está 
formando, lo cual sólo puede lograrse si se ha formado una adecuada estructura del gluten durante el amasado (Maloney y Foy, 2003).

\subsubsection{Enfriamiento}

Esta etapa es particularmente importante cuando el pan se envasa en rebanadas, para que no se rompa al cortarse y evitar el crecimiento de mohos que ocurriría de envasarse cuando aún se encuentra la pieza caliente (Pateras, 1998). La pérdida de humedad excesiva debe evitarse porque constituye una pérdida económica y porque acelerará el envejecimiento del pan.

\subsubsection{Envasado}

El material más común para realizar el envasado es el polietileno de baja densidad en forma de bolsa. Constituye una buena barrera frente al vapor de agua por lo que se previene la deshidratación, a la vez permite al consumidor ver el producto que está comprando.

\subsection{Uso de aditivos}

Una harina de trigo de buena calidad panadera no debería necesitar de aditivos para lograr un producto de buen volumen, textura y aspecto. Sin embargo, el agregado de oxidantes, emulsificantes y enzimas es una práctica común en panificación para mejorar el rendimiento de harinas de calidades inferiores. Los factores ambientales como la temperatura, la disponibilidad de agua, la presencia de malezas y plagas y el uso de fertilizantes influyen sobre la velocidad y la duración del desarrollo del grano, la acumulación de proteínas y la deposición de almidón por lo que modifican el rendimiento del cultivo y la calidad de la harina. Para el trigo, los máximos rendimientos se obtienen con temperaturas entre 15 y $20^{\circ} \mathrm{C}$. Además en este rango se obtiene la máxima duración de llenado del grano y la mayor acumulación de almidón por grano. Por otro lado, la temperatura junto con la utilización de fertilizantes afectan la cantidad, composición y/o polimerización de las proteínas del gluten (Dupont y col., 2003). Una variación en la composición proteica también puede ser ocasionada por una deficiencia de azufre observándose en este caso un incremento en el contenido de gliadinas y una disminución de las HMW-GS (Wrigley y col., 1984). Zhao y col. 
(1999) estudiaron el efecto de la aplicación de azufre sobre la calidad panadera de la harina, para lo cual emplearon combinaciones de azufre y nitrógeno, observando que la deficiencia de azufre ocasiona modificaciones reológicas en la masa que pueden ser más importantes que las ocasionadas por una deficiencia de nitrógeno.

Estas variaciones ocasionadas por las condiciones ambientales afectan la calidad de la harina y pueden variar en cada cosecha por lo que se recurre a la utilización de aditivos para compensar la pérdida de calidad y obtener una harina de comportamiento uniforme a lo largo del tiempo que permita mantener constancia en la calidad del producto obtenido.

Además, la necesidad de reemplazar al bromato de potasio como aditivo en panificación ya que a causa de sus efectos carcinogénicos se encuentra prohibido en nuestro país desde el año 1997 (Resolución 190/98d del Ministerio de Salud y Acción Social) ha conducido a la búsqueda de aditivos o mezclas de los mismos que puedan sustituirlo eficientemente y a un costo accesible.

Entre los aditivos más utilizados actualmente se encuentran: 1) agentes oxidantes como el ácido ascórbico y la azodicarbonamida, los que refuerzan la red de gluten aumentando su grado de entrecruzamiento; 2) emulsificantes como los ésteres de mono y diglicéridos del ácido diacetil tartárico (DATEM) y el estearoil lactilato de sodio (SSL) que interaccionan con las proteínas del gluten facilitando la agregación proteica debido a neutralización de cargas superficiales y 3) distintas enzimas como por ejemplo: proteasas, que hidrolizan el enlace peptídico por lo que disminuyen la tenacidad de la masa; y amilasas, que por un lado generan glucosa y maltosa que sirven como sustrato para las levaduras durante la fermentación y por otro, generan dextrinas que interfieren en la retrogradación del almidón (Stauffer, 1990).

Otro tipo de aditivos que potencialmente podrían ser útiles para mejorar la calidad panadera son polisacáridos de alto peso molecular, de diverso origen, denominados hidrocoloides o gomas. Entre los polisacáridos no almidonosos usados como aditivos para mejorar la calidad de productos panificados, y prolongar su conservación se encuentran: goma xántica, goma guar, garrofín, celulosas modificadas, carragenanos, alginatos, pectinas, entre otros (Stauffer, 1990). Estos aditivos han sido objeto de numerosos estudios, encontrándose efectos diversos sobre la masa y la calidad del pan obtenido (volumen, textura) dependiendo del tipo de hidrocoloide (Rojas y col., 1999; León y col., 2000; Rosell y col., 2001; Guarda y col., 2004; Gómez y col., 2007b; Bárcenas y col., 2006). A la vez, estos aditivos, por su estructura y comportamiento en el aparato digestivo, se pueden clasificar como componentes de la fibra dietaria (Prosky, 1999) por lo que su incorporación a la masa es positiva desde el punto de 
vista nutricional. Además de los efectos conocidos de la fibra dietaria (prevención de constipación y reducción del riesgo de cáncer de colon, entre otros) (Faivre y Bonithon-Kopp, 1999; Feldheim y Wisker, 2000) se ha encontrado que la incorporación de fibra puede ser útil para la formulación de alimentos de bajo índice glucémico. La incorporación de hidrocoloides como goma guar en cantidades de 3 a $7 \%$ en pastas disminuye la liberación de glucosa en ensayos de digestibilidad in vitro, probablemente debido a que los gránulos de almidón quedarían atrapados en una red viscosa formada por la interacción de proteínas - hidrocoloide - almidón (Tudorica y col., 2002). No obstante, los niveles en que se suelen agregar en las formulaciones para obtener un efecto positivo sobre la calidad panadera -entre 0,1 y $1 \mathrm{~g}$ cada $100 \mathrm{~g}$ de harina- (Rojas y col., 1999, Guarda y col., 2004, Bárcenas y col., 2004) conducen a valores bajos del hidrocoloide en el producto terminado por lo cual su incidencia efectiva desde el punto de vista nutricional es escasa en el caso del pan de harina refinada.

\subsection{Hidrocoloides: estructura química y funcionalidad}

Los hidrocoloides son polisacáridos de alto peso molecular o proteínas que presentan tamaños entre 10 y $1000 \AA$ y se disuelven o dispersan en agua causando un aumento de la viscosidad (Glicksman, 1982). Pueden obtenerse a partir de diversas fuentes: semillas, algas, exudados de plantas, bacterias, animales, etc. En la Tabla 1.5 se muestra su clasificación de acuerdo a su origen (BeMiller, 2001).

Los hidrocoloides son ampliamente utilizados en la industria alimentaria como espesantes y gelificantes, estabilizantes de espumas, emulsiones y dispersiones, inhibidores de la cristalización de hielo y azúcar, agentes encapsulantes, precipitantes, inhibidores de sinéresis y formadores de películas, entre otros, pero su uso en masa panaria se encuentra menos extendido. A pesar de que generalmente se emplean en bajas concentraciones tienen una gran influencia en las propiedades organolépticas y texturales de los productos en los cuales se agregan. En la industria, la elección del hidrocoloide a emplear se realiza de acuerdo a sus propiedades funcionales, precio y aseguramiento de abastecimiento. Por este motivo los almidones son los hidrocoloides más ampliamente usados como agentes espesantes (Williams y Phillips, 2000).

Muchas de las propiedades funcionales de los hidrocoloides son atribuibles a su comportamiento en soluciones acuosas. En general, la viscosidad de las soluciones de polímeros presentan una concentración crítica $\mathrm{C}^{*}$ a partir de la cual se pasa de tener 
una solución "diluida", donde las moléculas de polímero se encuentran libres y se pueden mover en forma independiente a una región semi diluida donde la aglomeración molecular da lugar al solapamiento de los ovillos de polímero y la interpenetración.

Tabla 1.5 Clasificación de los hidrocoloides de acuerdo a la fuente

\begin{tabular}{lll}
\hline Origen & & Ejemplos \\
\hline \multirow{2}{*}{$\begin{array}{ll}\text { Plantas } \\
\text { superiores }\end{array}$} & $\begin{array}{l}\text { goma arábiga, goma } \\
\text { tragacanto, goma karaya, } \\
\text { goma Gatti }\end{array}$ \\
\cline { 2 - 3 } & Estructurales & almidón, pectinas, celulosa \\
\cline { 2 - 3 } & De reserva (semillas, & goma guar, goma garrofin, \\
& tubérculos) & goma tara, goma del \\
Extractos de & Algas rojas & agar- agar, carragenanos \\
\cline { 2 - 3 } algas & Algas marrones & Alginatos \\
\hline Microbiano & goma xántica, goma curdlan, dextrano, goma gellano, \\
& celulosa & \\
\hline Animal & gelatina, caseinato, quitosano, proteínas del suero \\
\hline
\end{tabular}

Basada en BeMiller, 2001

Las soluciones de polisacáridos presentan un comportamiento Newtoniano a concentraciones menores que $\mathrm{C}^{*}$, en este caso el esfuerzo de corte es directamente proporcional al gradiente de velocidad de cizallamiento, por lo cual la viscosidad es independiente del esfuerzo de corte. A concentraciones mayores de $C^{*}$ no se presenta un comportamiento Newtoniano. Un perfil de viscosidad típico de una solución por encima de $C^{*}$ se muestra en la Figura 1.17, donde se distinguen 3 regiones: 1 ) un plateau a valores bajos de la velocidad de cizalla; 2) una región de fluidificación por cizalla (comportamiento pseudoplástico) y 3 ) un plateau a valores altos de la velocidad de cizalla. En la región 1, la velocidad de ruptura de los aglomerados de polímero es menor que la velocidad de entrecruzamiento y la viscosidad es independiente de la velocidad de corte. Por encima de un gradiente de velocidad de corte crítico el 
desentrecruzamiento predomina y la viscosidad cae hacia un plateau mínimo (Williams y Phillips, 2000).

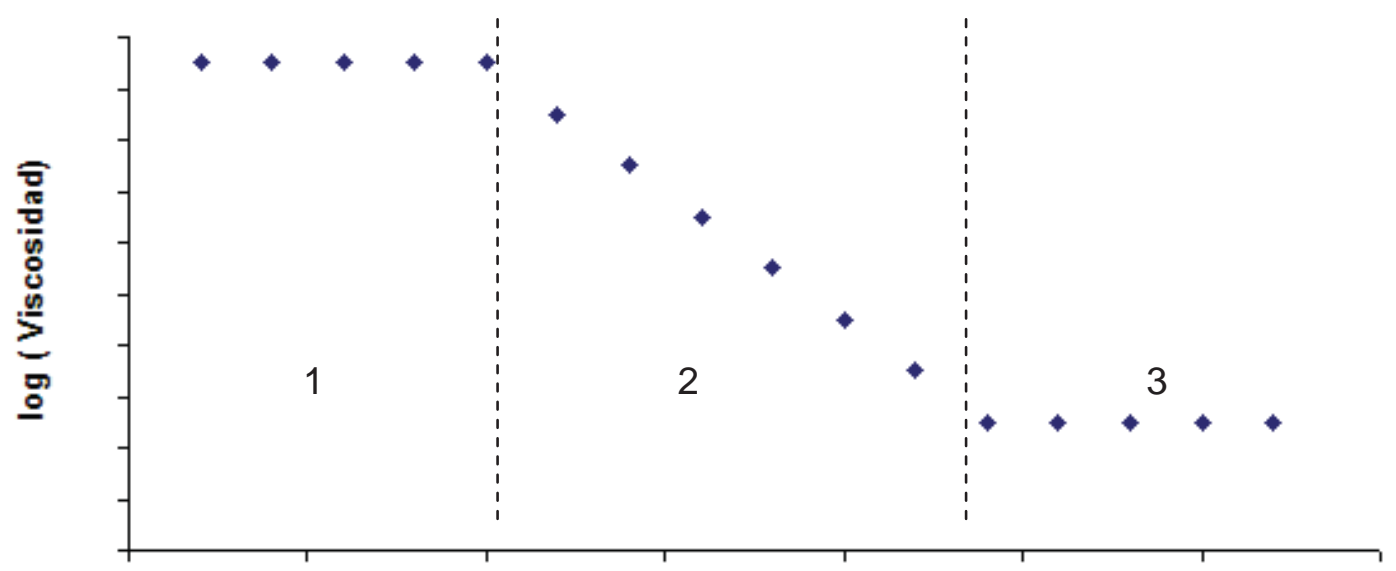

$\log$ ( gradiente de velocidad)

Figura 1.17. Perfil de viscosidad para una suspensión de un hidrocoloide por encima de $C^{*}$ ( Fuente: Williams y Phillips, 2000)

Entre los hidrocoloides que se pueden utilizar como aditivos se encuentran las pectinas y celulosas, polisacáridos de la pared celular de plantas, que presentan la ventaja, frente a otros, de provenir de recursos abundantes en la naturaleza y de bajo costo y de ofrecer una amplia gama de posibilidades desde el punto de vista funcional.

\subsubsection{Celulosas modificadas}

Las celulosas modificadas se obtienen por modificaciones químicas de la celulosa nativa, las cuales le otorgan propiedades distintas a las de la celulosa sin modificar. La celulosa es un polímero de unidades de anhidroglucosa unidas por enlaces $\beta(1 \rightarrow 4)$ glicosídicos (Fig.1.18), su grado de polimerización puede variar entre 100 y 3500 unidades de anhidroglucosa. La celulosa es una fibra insoluble en agua lo que se atribuye al alineamiento de sus moléculas en fibras formando regiones cristalinas altamente ordenadas y estabilizadas por puentes de hidrógeno intercatenarios. Estas características limitan su uso como aditivo alimentario, por ese motivo se la modifica químicamente para hacerla soluble y conferirle diversas propiedades de acuerdo al tipo de derivatización realizada. Existen gran diversidad de celulosas modificadas 
dependiendo del tipo de reacción química, tipo de sustituyente, porcentaje de sustitución y grado de polimerización, estos modifican la capacidad de retención de agua, la sensibilidad a los electrolitos, la solubilidad, propiedades de gelación, etc. Entre las celulosas modificadas se hallan la celulosa microcristalina (MCC), la carboximetilcelulosa (CMC), y la hidroxipropilmetilcelulosa (HPMC), las que se encuentran dentro de los aditivos permitidos en alimentos en general según el Programa Conjunto FAO/OMS sobre Normas Alimentarias para el Codex Alimentarius. Cada una de estas celulosas tiene, debido a su diferente estructura química un comportamiento particular por lo que su incorporación en la masa panaria haría esperable un efecto distinto sobre la aptitud panadera, y en particular sobre las propiedades reológicas de la masa.

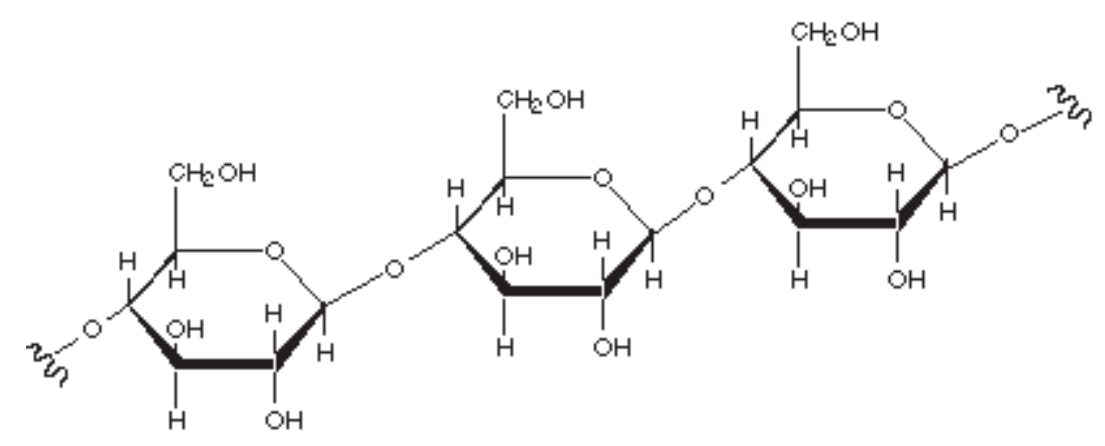

Figura.1.18. Estructura de la celulosa

\subsubsection{Celulosa Microcristalina}

La celulosa microcristalina (MCC) se obtiene por concentración de las regiones cristalinas de las fibras de celulosa luego de una hidrólisis ácida. Por este motivo, no es estrictamente un derivado químico sino que se trata de celulosa nativa concentrada. En el proceso de hidrólisis, el ácido actúa sobre las regiones amorfas de las fibras de celulosa debilitándolas y luego por la aplicación de un esfuerzo de corte se separan los agregados de celulosa. Las técnicas de producción tienen un rendimiento del $90 \%$ y se obtiene un 60-70\% de agregados cristalinos con un tamaño inferior a los 0,2 $\mu \mathrm{m}$. Si la celulosa coloidal se secara inmediatamente luego del tratamiento ácido se produciría el endurecimiento de las fibras, es por este motivo que se incorpora CMC durante el secado la cual actúa como barrera entre los agregados de celulosa. Además CMC 
ayuda en la dispersión de los microcristales insolubles en sistemas acuosos. Las dispersiones, al superar una cierta concentración forman geles tixotrópicos, los cuales aumentan su estabilidad gracias a la presencia de CMC. Estos geles al someterse a un esfuerzo de corte se rompen debido a que las partículas que lo forman (CMC + agregados de celulosa) actúan en forma independiente, cuando se le permite reposar las partículas vuelven a formar la red (Thomas ,1982).

En una dispersión MCC no se hincha como el almidón ni se hidrata como una goma por lo que una dispersión de MCC liga mucha menor cantidad de agua que la de otros hidrocoloides, aunque parcialmente es ligada debido a la presencia de CMC (Fig.1.19). La formación de una matriz tridimensional crea una red que afecta a la movilidad del agua y da lugar a las propiedades funcionales de la MCC (Thomas ,1982).

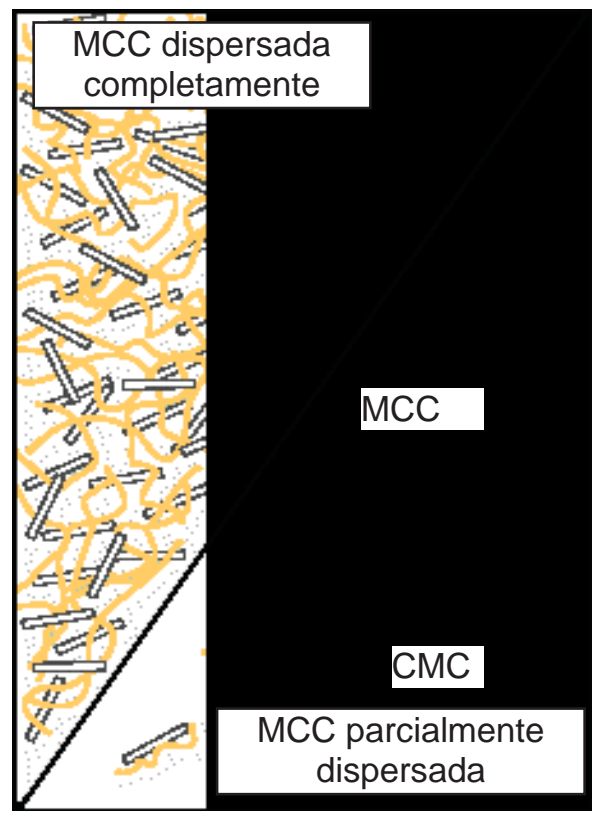

Figura 1.19. Dispersión completa y parcial de MCC en agua (Fuente: www.fmcbiopolymer.com)

A pesar de que la MCC se ha usado ampliamente en alimentos como espesante, agente para el control de la formación de hielo en helados, estabilizante de espumas y emulsiones y en productos dietéticos como fibra, su uso en productos panificados no se ha estudiado ampliamente. 


\subsubsection{Carboximetilcelulosa sódica (CMC)}

La carboximetilcelulosa es un polisacárido lineal, de cadena larga, que se obtiene por sustitución de la celulosa con grupos carboximetilo (Fig.1.20), aumentando de este modo su solubilidad en agua (Keller,1982). En el proceso de obtención se trata a la celulosa purificada con hidróxido de sodio y luego se la hace reaccionar con monocloroacetato de sodio.

En solución, la carga negativa de la molécula la mantiene en suspensión debido a efectos de repulsión. Cuanto mayor sea el grado de sustitución mayor hidrofilicidad presentará la goma y mayor será su solubilidad. En presencia de sales disminuye su hidratación y por ende la viscosidad de sus soluciones, esto es debido a que las sales apantallan las cargas de los carboxilatos disminuyendo la repulsión y desfavoreciéndose de este modo la disolución. Al preparar disoluciones con CMC es importante considerar el orden de agregado de los solutos ya que de este modo se están regulando las interacciones que pueden establecerse. Si la CMC se agrega a una solución salina, no tiene la posibilidad de separase por repulsión por lo cual no se disuelve, mientras que si se tiene una disolución de CMC y se agrega una sal se observa una pequeña disminución de la viscosidad.

Para uso en alimentos, productos farmacéuticos y cosméticos se necesita un elevado nivel de pureza (superior al 99,5\%) designándose a CMC de esta calidad como goma de celulosa, la cual es un polvo de color blanco- crema, que no presenta sabor, es inodoro y volátil (Keller,1982).

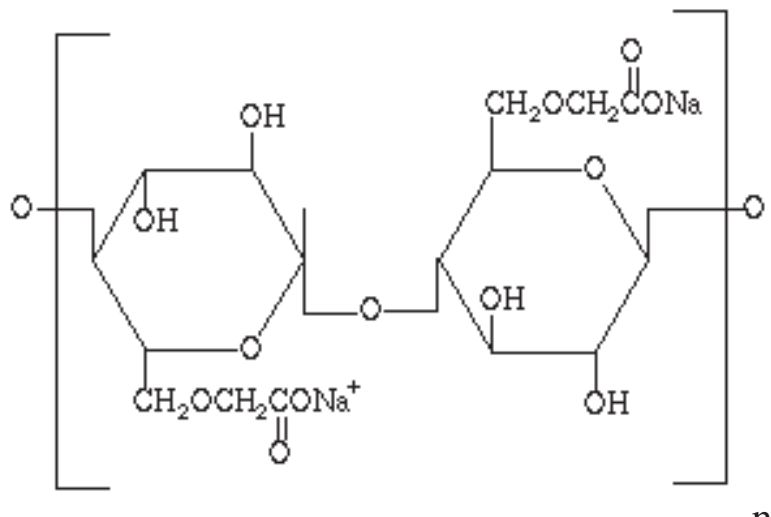

Figura 1.20. Estructura de CMC

La CMC se ha empleado como estabilizante de helados y bebidas lácteas (Janhøj y col., 2008), como agente espesante, agente para la suspensión de sólidos en batidos y 
coberturas y como espesante en rellenos de tartas. La utilización de CMC en productos de panificación ha sido estudiada por diversos autores habiéndose encontrado que mejora la calidad de panes frescos y congelados y de panes enriquecidos en fibra (Armero y Collar., 1996; Dodić y col., 2007; Angioloni y Collar., 2009).

\subsubsection{Hidroxipropilmetilcelulosa (HPMC)}

Las hidroxipropilmetilcelulosas son celulosas sustituidas con gupos hidroxipropilo y metilo (Fig.1.21), los cuales les confieren un cierto grado de hidrofobicidad respecto a otros hidrocoloides. Las HPMC se obtienen por tratamiento de la celulosa en medio alcalino con cloruro de metilo y óxido de propileno (Murray, 2000). Se define el grado de sustitución (Gs) de las HPMC como el número promedio de grupos hidroxilo por residuo de anhidroglucosa que fueron sustituidos, mientras que el grado de sustitución molar (Sm) se define como el número promedio de moléculas de sustituyente que se han incorporado por unidad de anhidroglucosa. Se realiza esta distinción dado que el grupo hidroxipropilo tiene un grupo hidroxilo que puede ser a su vez sustituido por lo cual es posible obtener cadenas de polihidroxipropilo. Es posible tener una HPMC con $\mathrm{Gs}=1$ (un grupo hidroxilo sustituido) pero $\mathrm{Sm}=2$ (2 moles de hidroxipropilo por molécula de glucosa). En cambio en el caso de los grupos metilo, el grado de sustitución y la sustitución molar son iguales. Variaciones en el nivel absoluto de grupos metilo e hidroxipropilo afectan a las propiedades físicas y químicas como la capacidad de retención de agua, la sensibilidad a electrolitos, la temperatura de disolución, las propiedades de gelación y la solubilidad en sistemas no acuosos.

La celulosa es insoluble en gran cantidad de solventes debido a su alto nivel de puentes de hidrógeno intercatenarios lo que da lugar a un alto nivel de cristalinidad, en cambio en las HPMCs se reduce la posibilidad de formar puentes de hidrógeno, pero no la capacidad del polímero para hidratarse, además la presencia de los sustituyentes por efecto estérico inhibe el acercamiento de los polímeros y la cristalización. De este modo la sustitución incrementa el rango de solubilidad en agua y solventes orgánicos.

Al tratarse de moléculas no iónicas, son relativamente insensibles a los cambios de $\mathrm{pH}$ y a la presencia de electrolitos.

El comportamiento reológico de sus soluciones depende de la concentración de polímero disuelta, el peso molecular, la temperatura de la solución y la presencia de solutos pero en general presentan un comportamiento pseudoplástico, disminuyendo 
la viscosidad cuando aumenta el esfuerzo de corte. A esfuerzos de corte muy bajos presentan un comportamiento newtoniano.

Las HPMCs presentan la propiedad de formar geles reversibles al calentar sus soluciones. En la Figura 1.22 se muestra el comportamiento que presenta una solución de HPMC al calentarla y posteriormente enfriarla. A bajas temperaturas las moléculas se encuentran hidratadas pero hay baja interacción entre ellas encontrándose valores elevados de la viscosidad. Al comenzar el calentamiento los polímeros van perdiendo el agua de hidratación por lo que la viscosidad disminuye. En el punto de inicio de la gelificación los polímeros se encuentran suficientemente deshidratados como para que pueda ocurrir la interacción entre polímeros y se forme el gel. Al enfriar se revierte el gel por lo que la viscosidad disminuye. Es importante tener en cuenta que tanto la deshidratación como la asociación son procesos tiempo dependientes por lo que la velocidad de calentamiento puede afectar la temperatura de gelificación. El efecto del tiempo de equilibrio entre las formas asociadas y deshidratadas da lugar a histéresis al enfriar el gel (Grover, 1982).

Las HPMC se utilizan en la formación de películas, como estabilizantes en aderezos para ensaladas, como agentes barrera al aceite en alimentos fritos y en alimentos congelados inhiben la pérdida de humedad y la formación de cristales de hielo. Con respecto a su utilización en productos panificados se han informado diversos beneficios sobre el volumen específico de pan y la textura de la miga de pan (Rosell y col., 2001) así como también en la vida útil de pan parcialmente cocido (Bárcenas y col., 2004).

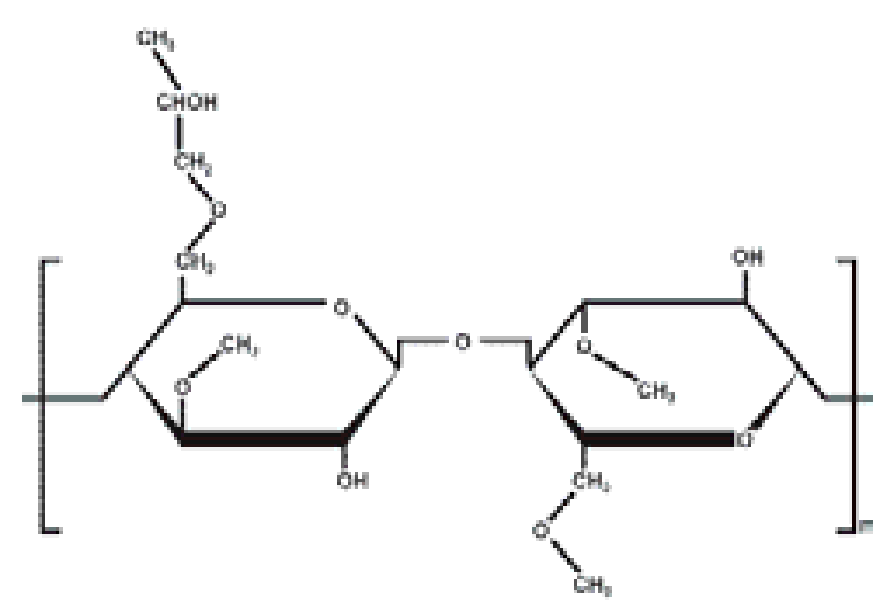

Figura 1.21. Estructura de una HPMC. 


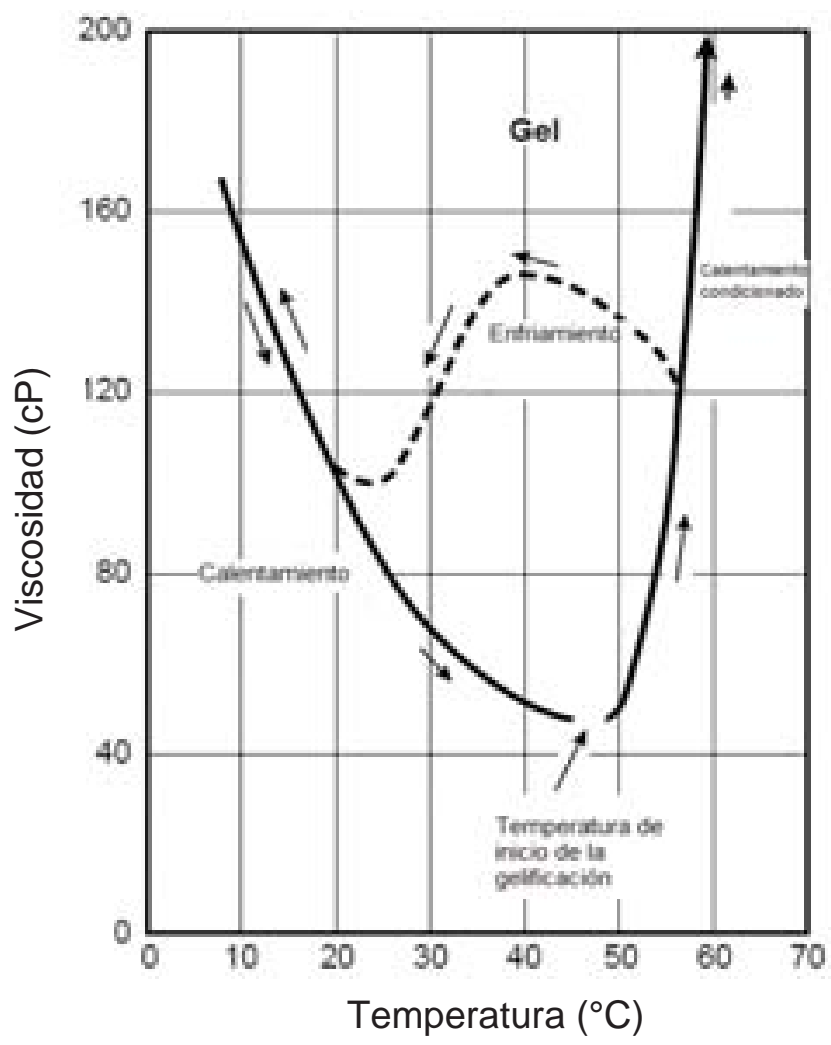

Figura 1.22. Termogelación de las HPMC (Fuente: Dow Chemical Company, 1997)

\subsubsection{Pectinas}

Las pectinas son carbohidratos estructurales presentes en la lamela media de las paredes primarias de las plantas. Desde un punto de vista químico, las pectinas son heteropolisacáridos solubles en agua conformados por una cadena lineal de residuos de ácido galacturónico y residuos de metilesteres del ácido galacturónico, los cuales se encuentran unidos por enlaces $\alpha(1 \rightarrow 4)$. El número de residuos por cadena se encuentra entre 200 y 1000 (Christensen, 1982). El grado de esterificación (GE) se define como el porcentaje de grupos carboxilo esterificados, las pectinas de alto metoxilo o alto grado de esterificación (PAM) presentan un grado de esterificación mayor al 50\% mientras que las pectinas de bajo metoxilo o bajo grado de esterificación (PBM) son aquellas que poseen un grado de esterificación inferior al 50\% (Figura 1.23). La deesterificación de PAM en medio ácido o alcalino da lugar a PBM. Si la hidrólisis se realiza en medio amoniacal, la PBM obtenida contendrá residuos de galacturonamida en su cadena. Con el propósito de estandarizarlas, las pectinas comerciales se encuentran adicionadas con buffers de grado alimenticio y sales para 
controlar el $\mathrm{pH}$ y obtener las características deseadas cuando son utilizadas por su capacidad gelificante.

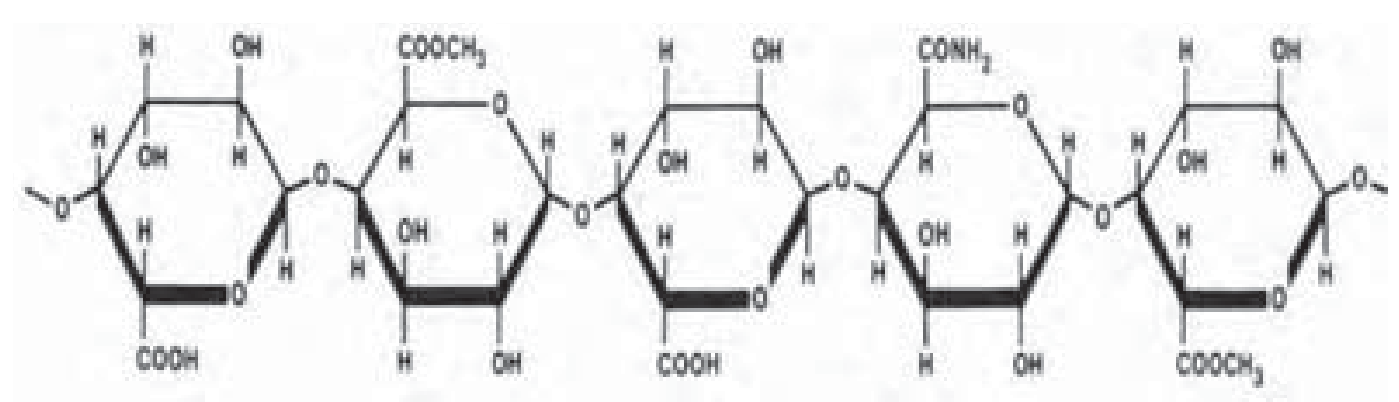

Figura 1.23. Pectina de bajo grado de esterificación y amidada.

Las pectinas se clasifican como fibra dietaria, ya que no sufren hidrólisis, digestión ni absorción en el intestino delgado (Prosky, 1999). Aunque en el intestino delgado las pectinas pueden ser utilizadas por las bacterias, tienen una carga calórica insignificante. Se ha informado que su ingesta produce una reducción plasmática del nivel de colesterol LDL en animales y también de la ateroesclerosis. Su acción parece estar relacionada a sus propiedades fisicoquímicas como son la capacidad de retención de agua y sus propiedades espesantes, lo que retardaría el vaciado estomacal y disminuiría la movilización hacia el íleon que es donde ocurre la absorción de las grasas (Fernández, 2001).

Además, las pectinas son reconocidas como seguras (GRAS) por la legislación de los Estados Unidos y la ingesta diaria aceptable (ADI) no es especificada por el comité de expertos en alimentos de la FAO/OMS (JECFA) para el Codex Alimentarius y ni por el Comité Científico para la Alimentación Humana (SCF) de la Unión Europea (May, 2000).

En la industria alimentaria las pectinas tienen una amplio rango de aplicación. Su uso principal es en mermeladas, con 60-70 \% de sólidos solubles totales y pH 3,0-3,3, en los cuales las pectinas de alto metoxilo pueden gelificar, mientras que las pectinas de bajo metoxilo se emplean en mermeladas y jaleas bajas calorías. En productos lácteos las pectinas pueden tener dos funciones diferentes, las PAM pueden estabilizar dispersiones proteicas a $\mathrm{pH}$ bajos como los de un yogur mientras que PBM se comporta como un agente gelificante en presencia de calcio en leche o en otros 
productos más ácidos. Las pectinas también pueden ser utilizadas como una alternativa a la gelatina en postres con frutas, trifles y rellenos de pastelería. En todos los casos, el efecto de las pectinas depende del pH, la fuerza iónica, la composición del medio y la proporción y tipo de edulcorantes presentes en el sistema (May, 2000). Diversos autores han encontrado efectos favorables del agregado de pectinas en productos panarios (Ribotta y col., 2005; Gómez y col., 2007b). 


\section{Objetivos}

\section{Objetivo general:}

Contribuir a la optimización y al adecuado uso de hidrocoloides en productos panificados a través de un mejor conocimiento de su efecto sobre la calidad panadera y de su mecanismo de acción a nivel molecular.

\section{Objetivos específicos:}

- Evaluar el efecto de diferentes celulosas modificadas y pectinas sobre las características de la masa a nivel reológico y microestructural

- Optimizar variables del proceso de panificación con el empleo de celulosas modificadas y pectinas, particularmente, cantidad de agua, tiempo de amasado y de fermentación

- Caracterizar los atributos del producto obtenido que afecten la aceptabilidad por parte del consumidor: volumen de pan, calidad de miga, color

- Evaluar el efecto de celulosas modificadas y pectinas sobre el deterioro producido durante el almacenamiento del pan

- Analizar el tipo de interacciones que establecen los diferentes polisacáridos con los principales componentes de la harina y postular mecanismos que expliquen los efectos encontrados 


\section{Capítulo II}

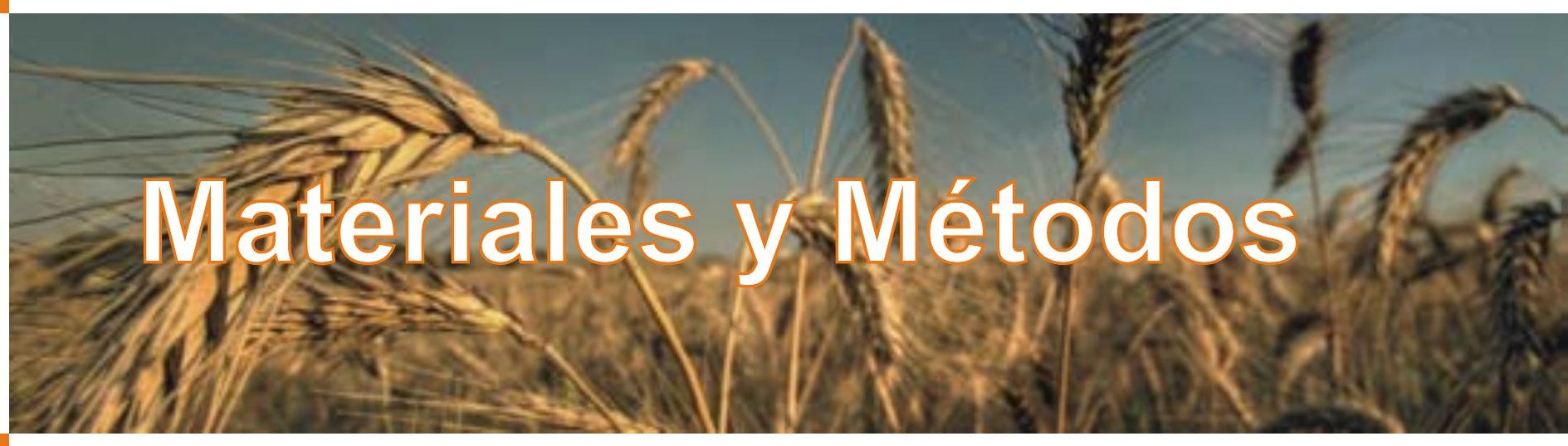




\section{Materiales y métodos}

\subsection{Materiales}

\subsubsection{Harina}

Para la preparación de las masas se utilizó harina de trigo comercial 000 (Código Alimentario Argentino) de la cosecha del año 2007, la cual fue provista por el Molino Campodónico S.A. (La Plata, Argentina). Los parámetros alveográficos, suministrados por el molino fueron: $\mathrm{P}=96 \mathrm{~mm} \mathrm{H} \mathrm{H}_{2} \mathrm{O}, \mathrm{L}=93 \mathrm{~mm}, \mathrm{~W}=326.10^{-4} \mathrm{~J}$.

A lo largo del período que insumió el trabajo de tesis la harina fue conservada en envases de plástico herméticos a $-20^{\circ} \mathrm{C}$. Previo a ser utilizada se la acondicionó en cámara de $4^{\circ} \mathrm{C}$.

\subsubsection{Celulosas modificadas}

Se emplearon 4 tipos de celulosas modificadas de grado alimentario, cuyas características brindadas por el proveedor son:

a) Celulosa microcristalina (MCC, FMC Biopolymer, Filadelfia)

La celulosa microcristalina se comercializa co-polimerizada con carboximetilcelulosa (12\%) para facilitar su dispersión en soluciones acuosas.

Características de la MCC utilizada:

- Viscosidad de una dispersión al $1,2 \%=61 \mathrm{cps}$

- $\mathrm{pH}$ en solución acuosa: 6

- Retención en malla de 60 mesh $(250 \mu \mathrm{m})=0 \%$ mientras que en una de 325 mesh $(44 \mu \mathrm{m})=57 \%$

b) Carboximetilcelulosa (CMC, Latinoquímica Amtex S.A, Argentina)

La información suministrada por el fabricante sobre la CMC utilizada fue:

- grado sustitución de grupos carboximetilo de 0,9\%

- pureza: 99,69\%

- Viscosidad de una solución al $1 \%$ a $25^{\circ} \mathrm{C}$ determinada empleando un viscosímetro Brookfield LVF según el método ASTM - D 1439/03: 3640 cps

- $\mathrm{pH}$ en solución acuosa=6,87 
- Retención en malla de 60 mesh $(250 \mu \mathrm{m})=22,48 \%$ mientras que en una malla de 200 mesh $(74 \mu \mathrm{m})=49,86 \%$

c) Hidroxipropilmetilceluosa: HPMC F 4M (HPMC, Dow Chemical Company, Estados Unidos)

- $\quad 29,3 \%$ de sustitución de grupos metoxilo

- $6,0 \%$ de grupos hidroxipropilo

- La viscosidad a $20^{\circ} \mathrm{C}$ de una solución acuosa al $2 \%$ fue de 4477 cps (USP)

d) Hidroxipropilmetilceluosa: HPMC F 50 (HPMC, Dow Chemical Company, Estados Unidos)

- $28,6 \%$ de sustitución de grupos metoxilo

- $5,4 \%$ de grupos hidroxipropilo

- La viscosidad a $20^{\circ} \mathrm{C}$ de una solución acuosa al $2 \%$ fue de 46 cps (USP)

En base a las características anteriores y a otras declaradas por el fabricante, los hidrocoloides empleados cumplen con las exigencias de designación, composición, identificación y pureza que establece el Código Alimentario Argentino (Capítulo XVIII Art. 1398, 2011)

\subsubsection{Pectinas}

Se emplearon dos tipos de pectinas cítricas de grado alimentario las cuales se comercializan estandarizadas con sacarosa y cumplen con los criterios de pureza establecidos por el Código de Sustancias Químicas Alimenticias (Food Chemicals Codex), el Comité Mixto FAO/OMS de Expertos en Aditivos Alimentarios (JECFA) y las directivas de la Unión Europea.

a) Pectina de bajo grado de esterificación y amidada (PBM): Genu Pectin 8001 (CP Kelco, Estados Unidos) con las siguientes características (brindadas por el proveedor):

- $\mathrm{pH}$ de una solución $1 \%=4,6$

- La reactividad al calcio se evalúa mediante ensayos en los cuales se preparan geles con diferente contenido de calcio, para esta pectina se ensayaron 2 niveles: 80 ppm y 160 ppm. El gel formado con 80 ppm de calcio ante una 
compresión de un 25\% presentó una firmeza de $21 \mathrm{~g}$, mientras que para el formado con $160 \mathrm{ppm}$ de calcio la firmeza fue de $32 \mathrm{~g}$

- Tamaño de partícula: retención en tamiz de $250 \mu \mathrm{m}$ menor al 1\%

b) Pectina de alto grado de esterificación (PAM): Genu Pectin 105 rapid set (CP Kelco, Estados Unidos). Se designan como "rapid set" a las pectinas que presentan temperatura y velocidad de gelificación elevadas.

- Grado de esterificación: 69\%

- $\quad \mathrm{pH}$ de una solución $1 \%=3,5$

- grado USA SAG: 150, lo cual equivale a decir que $1 \mathrm{~kg}$ de pectina estandarizada puede formar un gel de composición y fuerza estándar (sólidos solubles $65 \%$, $\mathrm{pH} \mathrm{2,2} \mathrm{-2,4,} \mathrm{fuerza} \mathrm{del} \mathrm{gel} \mathrm{23,5 \%} \mathrm{SAG)} \mathrm{que} \mathrm{contenga} 150 \mathrm{~kg}$ de azúcar

- Tamaño de partícula: retención en tamiz de $250 \mu \mathrm{m}$ menor al $1 \%$

\subsubsection{Otros ingredientes}

Para la preparación de todas las muestras se utilizaron agua destilada, $\mathrm{NaCl}$ comercial (Celusal), y levadura fresca comercial (Calsa S.A.).

\subsection{Metodologías}

\subsubsection{Composición de la harina}

Se determinaron el contenido de proteínas, lípidos, cenizas y humedad de la harina según se describe a continuación. El contenido de hidratos de carbono se calculó por diferencia.

\subsubsection{Determinación de proteínas}

La determinación del contenido de proteínas es muy importante en harinas debido a que la mayor parte de las propiedades de la masa presentan alta correlación con el contenido proteico (Pomeranz, 1987). La técnica empleada fue una modificación de la técnica ISO 20483:2006 (E). Con esta técnica se determina el contenido total de nitrógeno por lo que se están determinando también ácidos nucleicos, sales de 
amonio, compuestos de aromáticos nitrogenados y vitaminas, entre otros, pero dado que por lo general los alimentos sólo contienen trazas de estos compuestos el error cometido se considera despreciable (Mattisek, 1998). Se utilizó el método de Kjeldhal, en el cual el contenido de nitrógeno total se determina por digestión de la muestra en $\mathrm{H}_{2} \mathrm{SO}_{4}$ concentrado en presencia de una mezcla catalizadora, en nuestro caso formada por $\mathrm{K}_{2} \mathrm{SO}_{4}$ y $\mathrm{CuSO}_{4} \cdot 5 \mathrm{H}_{2} \mathrm{O}$ en una relación 10:1. Posteriormente el amonio se transforma en $\mathrm{NH}_{3}$ por alcalinización con $\mathrm{NaOH} 32 \%$ y el $\mathrm{NH}_{3}$ liberado se destila y recibe en una solución de $\mathrm{H}_{3} \mathrm{BO}_{3} 4 \%$ que contiene el indicador de $\mathrm{pH}$ Mortimer. Se tituló con $\mathrm{HCl} 0,1 \mathrm{~N}$ hasta viraje del indicador al color rojo inicial. Para determinar el contenido proteico es necesario emplear un factor que permite convertir gramos de nitrógeno en gramos de proteína. El factor empleado depende del tipo de proteína, en el caso de la harina de trigo el factor utilizado es 5,7. La determinación se realizó por triplicado.

El contenido de nitrógeno se calculó empleando la ecuación 2.1:

$$
\% \mathrm{~N}=\frac{\left(\mathrm{V}_{\mathrm{m}}-\mathrm{V}_{0}\right) \mathrm{N}\left(\mathrm{P}_{\text {meq }}\right)}{\mathrm{m}\left(\frac{100-\mathrm{H}}{100}\right)} 100
$$

donde:

$\% \mathrm{~N}$ : cantidad de nitrógeno cada $100 \mathrm{~g}$ de harina, en base seca

$\mathrm{V}_{\mathrm{m}}$ : Volumen de $\mathrm{HCl}$, en $\mathrm{ml}$, requeridos para titular la muestra

$\mathrm{V}_{0}$ : Volumen de $\mathrm{HCl}$, en $\mathrm{ml}$, requeridos para titular el blanco

$\mathrm{N}$ : Normalidad del $\mathrm{HCl}$ utilizado

$P_{\text {meq: }}$ : Peso del miliequivalente de nitrógeno

$\mathrm{m}$ : masa de harina pesada $(\mathrm{g})$

$\mathrm{H}$ : Humedad de la harina

\subsubsection{Determinación del contenido de lípidos}

Se realizó por extracción directa utilizando una modificación de la técnica AACC 3025.01 (2000) en la cual se emplea el equipo de Soxhlet. La harina se extrajo con una mezcla de éter dietílico: éter de petróleo (1:1) llevándose a cabo 6 sifonadas para lograr una extracción completa. Luego se determinó gravimétricamente el extracto 
seco, del cual se habían eliminado previamente los solventes. El ensayo se realizó por triplicado.

El porcentaje de grasa se calculó utilizando la ecuación 2.2 :

$$
\% \text { grasa }=\frac{m_{2}-m_{1}}{m} 100
$$

donde:

$\mathrm{m}_{2}$ : masa en gramos del balón con grasa después del secado $(\mathrm{g})$

$\mathrm{m}_{1}$ :masa del balón vacío $(\mathrm{g})$

$\mathrm{m}$ : masa de harina $(\mathrm{g})$

\subsubsection{Determinación de humedad}

Se realizó de acuerdo al método AACC 44-19 (2000), en el cual la muestra (2 g \pm $0,001 \mathrm{~g})$ se seca en estufa durante dos horas a $135^{\circ} \mathrm{C}$. Se empleó una estufa de convección forzada (velocidad del aire $0,25 \mathrm{~m} / \mathrm{seg}$ ) (Estigia, Argentina). El ensayo se realizó por triplicado.

\subsubsection{Determinación del contenido de cenizas}

El contenido de cenizas es el residuo que queda luego de la combustión completa de la harina y se relaciona con el grado de extracción de la misma. Se realizó de acuerdo al método AACC 08-01, para lo cual se pesaron $4 \mathrm{~g}$ de harina (pesados a la décima de miligramo), se carbonizaron sobre mechero y triángulo de pipas y luego se calcinaron en mufla a $550{ }^{\circ} \mathrm{C}$ hasta obtención de peso constante. Las cenizas se enfriaron en desecador y se pesaron al alcanzar temperatura ambiente. El ensayo se realizó por duplicado.

\subsubsection{Calidad panadera de la harina}

\subsubsection{Farinograma}

El farinograma registra la consistencia de una masa durante el amasado y permite predecir la aptitud panadera de una harina. Se realizó de acuerdo al método IRAM 15855:2000, empleando un equipo Brabender de $300 \mathrm{~g}$ de capacidad (Duisburg, Alemania). La harina, con un contenido de humedad del 14\%, se mezcló durante 1 min 
en la amasadora y se agregó con una bureta un volumen de agua cercano al esperado para obtener una consistencia de 500 UF. Se repitió este procedimiento hasta lograr la adición de agua en 25 s y consistencias máximas entre 480 y 520 UF. Los parámetros determinados fueron:

- Absorción de agua (A): volumen de agua necesario para obtener una masa con una consistencia máxima de 500 UF. Se expresa como mililitros cada 100 gramos de harina ( $14 \%$ de humedad).

- Tiempo de desarrollo (td): es el tiempo que transcurre desde que comienza a agregarse agua y el momento en que se alcanza la máxima consistencia. Se expresa en minutos.

- Estabilidad: se calcula como la diferencia de tiempo entre el punto en que la parte superior de la curva alcanza por primera vez la línea de 500 Unidades Farinográficas (UF) y el punto en que la deja. Se expresa en minutos.

- Aflojamiento: diferencia en UF entre el centro de la curva en el punto en que comienza la declinación (tiempo de desarrollo) y el centro de la curva 12 minutos después. Una UF corresponde a un momento de torsión de $100 \mathrm{~g} . \mathrm{cm}$, medido en el eje de la amasadora.

En la Figura 2.1 se señala como fueron determinados los parámetros. El ensayo se realizo por duplicado.

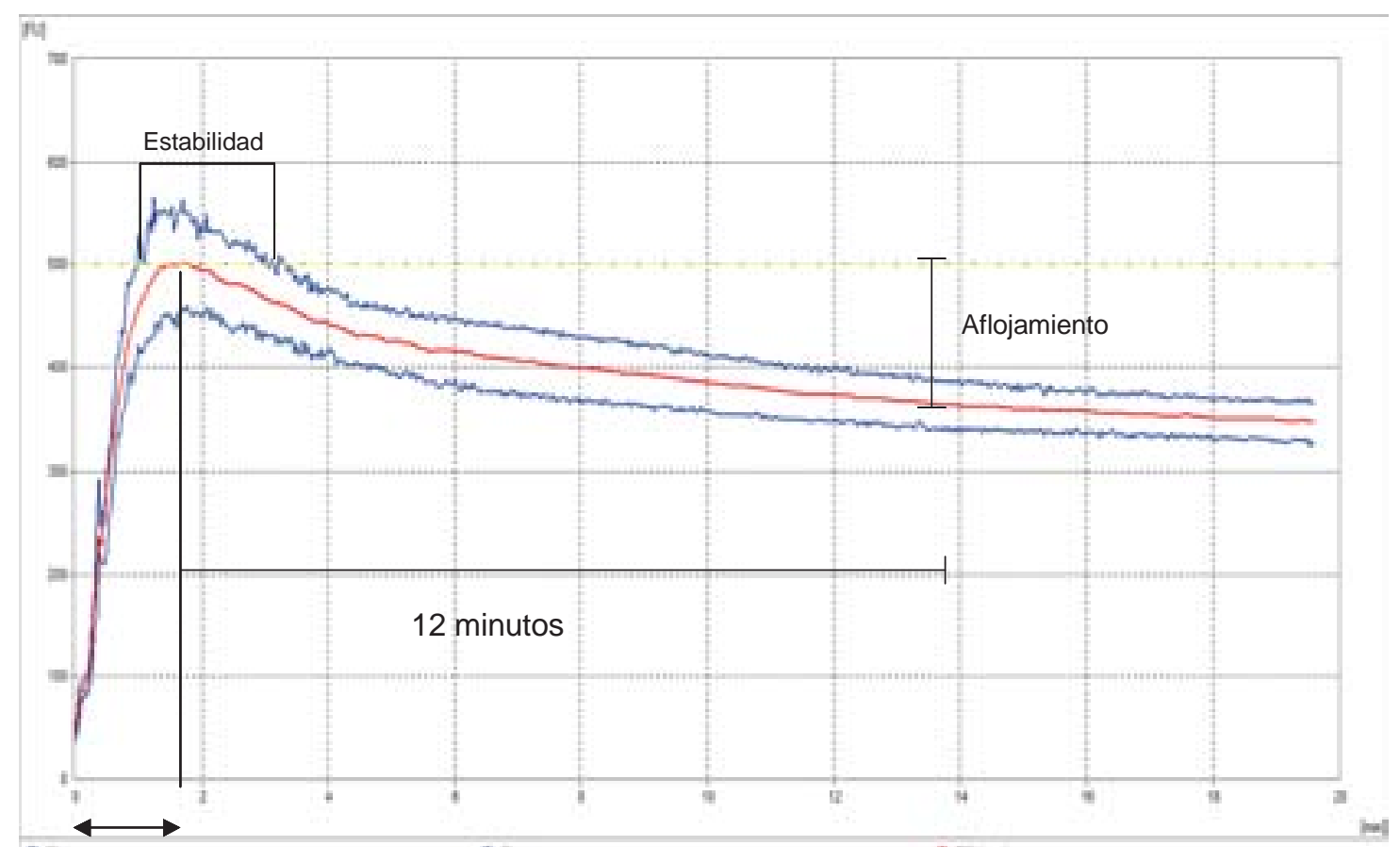

Tiempo de desarrollo

Figura 2.1. Farinograma. Se señalan los parámetros obtenidos del mismo. 


\subsubsection{Alveograma}

El alveógrafo evalúa la resistencia de una masa ante una extensión biaxial por lo que permite simular el comportamiento de la masa durante la fermentación. Según la norma AACC 54.30 .02 (2000) se prepara una masa de humedad constante a partir de $250 \mathrm{~g}$ de harina y de una solución de $\mathrm{NaCl} 2,5 \%$. Se cortan discos de masa de un espesor definido los cuales se inflan por una presión de aire. Se forma una burbuja que se expande a medida que se insufla más aire; el ensayo finaliza cuando la burbuja formada se rompe. Se registra gráficamente la presión interna de la burbuja en función del tiempo. El ensayo se realiza por quintuplicado y el software calcula una curva media de la que se obtienen los parámetros. En la Figura 2.2 se muestra un alveograma en el cual se indican: la tenacidad $(P)$, la extensibilidad $(L)$ y el trabajo de deformación (W).

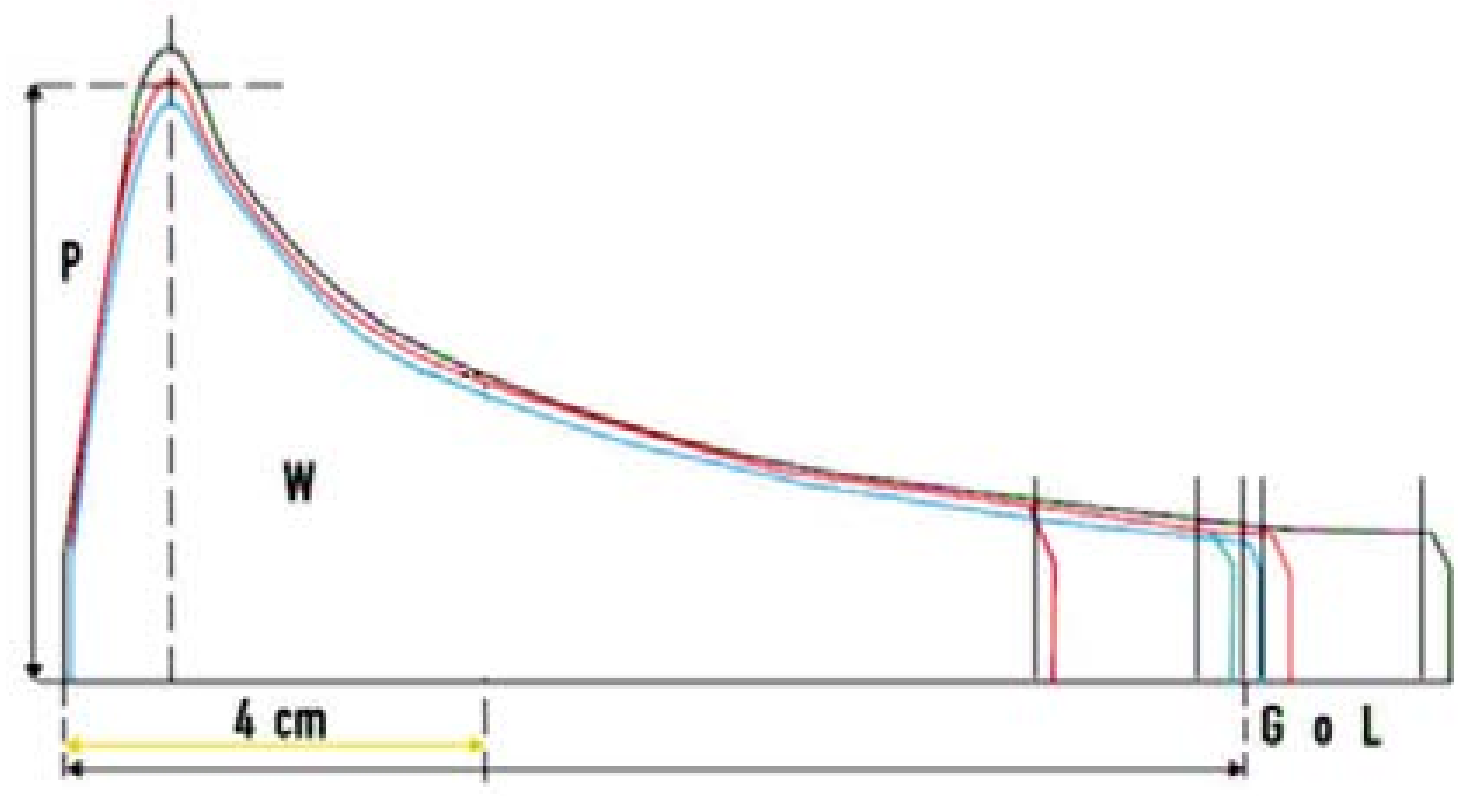

Figura 2.2. Alveograma donde se indican los parámetros: $P$ (tenacidad), L (extensibilidad) y W (trabajo de deformación).

La máxima sobrepresión o tenacidad $(\mathrm{P})$ se relaciona con la resistencia de la masa a ser deformada y se calcula como la media de las ordenadas máximas ( $\mathrm{mm}$ ) multiplicada por 1,1. La extensibilidad (L) se relaciona con la capacidad de 
estiramiento de la masa y se calcula midiendo la abscisa a partir del origen de las curvas hasta la caída de la presión, la cual corresponde al momento en que se produce la ruptura de la masa. Un parámetro que suele calcularse es la relación de equilibrio o configuración de la curva (P/L). El trabajo de deformación (W) indica la energía que fue necesaria entregar a la masa para inflar la burbuja hasta su ruptura. El valor de $\mathrm{W}$ nos indica la fuerza panadera de la harina y se relaciona con el potencial panadero de la misma. Se calcula a partir del área bajo la curva y se expresa en décimas de milijoules $\left(10^{-4} \mathrm{~J}\right)$.

\subsubsection{Determinación del contenido de gluten}

La determinación del contenido del gluten de la harina se realizó de acuerdo a la norma IRAM 15864:1995. A 10,00 g de harina se agregaron $5 \mathrm{ml}$ de agua destilada y se amasó en el Glutomatic (Perten Instruments, Suecia) durante 1 min luego se lavó la masa obtenida durante $5 \mathrm{~min}$, empleandose mallas metálicas de $80 \mu \mathrm{m}$ de poro. El gluten obtenido se centrifugó en una centrífuga 2015 (Perten Instruments, Suecia) (Figura 2.3) a 6000 rpm durante 1 min. Se registró el peso del gluten que atravesó el tamiz metálico de $500 \mu \mathrm{m}$ para la determinación del gluten index y el del gluten húmedo total $\left(\mathrm{m}_{1}\right)$. El gluten húmedo $(\mathrm{GH})$, cada $100 \mathrm{~g}$ de harina, referido a harina de $14 \%$ de humedad se calculó de acuerdo a la ecuación 2.3.

$$
\text { Gluten Húmedo }=\frac{\mathrm{m}_{1}}{\mathrm{~m}} 100\left(\frac{86}{100-\mathrm{H}}\right)
$$

donde:

$\mathrm{m}_{1}$ : masa de gluten húmedo pesada $(\mathrm{g})$

$\mathrm{m}$ : masa de harina pesada $(\mathrm{g})$

$\mathrm{H}$ : humedad de la harina 


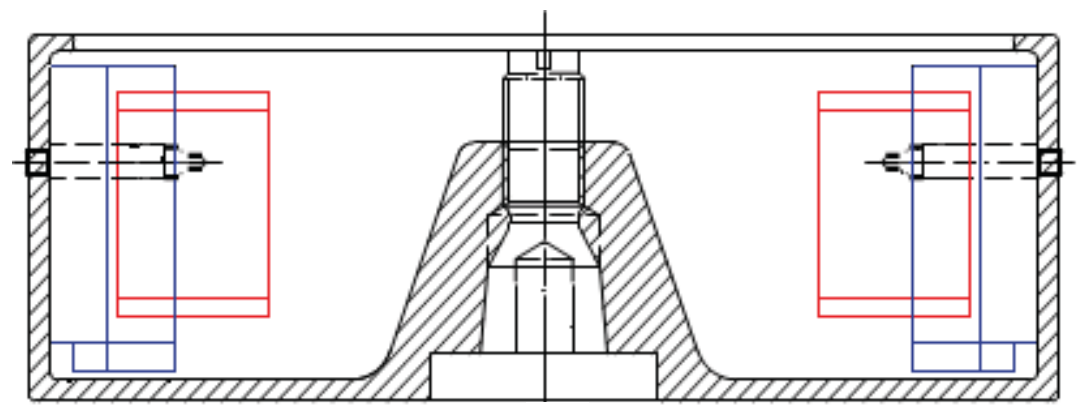

Figura 2.3. Esquema de la centrífuga 2015 (Perten Instruments, Suecia) para la determinación del gluten index, en azul se indican los tamices metálicos y en rojo donde se ubicaría el gluten (Adaptado de ISO/ FDIS 21415-2).

El gluten se secó en condiciones estandarizadas durante 5 min a $150{ }^{\circ} \mathrm{C}$ en el aparato Glutork (Perten Instruments, Suecia) y se pesó una vez enfriado. El cálculo del gluten seco se realizó de acuerdo a la ecuación 2.4:

$$
\text { Gluten } \operatorname{Seco}=\frac{\mathrm{m}_{2}}{\mathrm{~m}} 100\left(\frac{86}{100-\mathrm{H}}\right)
$$

La diferencia entre el gluten húmedo y el seco nos proporciona el agua unida al gluten húmedo según la ecuación 2.5:

$$
\text { Agua unida al gluten }=\% \mathrm{GH}-\% \text { GS }
$$

El gluten Index (GI) se calcula a través del cociente entre el gluten que permanece en el tamiz luego de la centrifugación sobre el gluten húmedo total (Ec. 2.6) y se relaciona con la calidad del gluten:

$$
\text { Gluten Index }=\frac{\text { Gluten que no atraviesa el tamiz * } 100}{\text { Gluten Húmedo total }}
$$




\subsubsection{Perfil viscoamilográfico}

Se empleó un viscoamilografo rápido (RVA-4, Newport Scientific Pty.LTD., Warriewood, Australia) para caracterizar el comportamiento de una suspensión de harina en agua ante un ciclo de calentamiento / enfriamiento. El ensayo se realizó por triplicado y de acuerdo al método AACC 76-21 (1999), en el cual a 25,0 \pm 0,1 ml de agua destilada se agregan $3,50 \mathrm{~g}$ de harina (14\% de humedad); ésta suspensión se agita en forma vigorosa y se coloca en el RVA. En la Tabla 2.1 se muestra el perfil de calentamiento / enfriamiento utilizado.

Tabla 2.1. Perfil empleado en el RVA.

\begin{tabular}{ccc}
\hline Etapa & Temperatura /Velocidad & Tiempo \\
\hline 1 & $50^{\circ} \mathrm{C}$ & $0 \mathrm{~min}, 0 \mathrm{~s}$ \\
\hline 2 & $960 \mathrm{rpm}$ & $0 \mathrm{~min}, 0 \mathrm{~s}$ \\
\hline 3 & $160 \mathrm{rpm}$ & $0 \mathrm{~min}, 10 \mathrm{~s}$ \\
\hline 4 & $50^{\circ} \mathrm{C}$ & $1 \mathrm{~min}, 0 \mathrm{~s}$ \\
\hline 5 & $95^{\circ} \mathrm{C}$ & $4 \mathrm{~min}, 42 \mathrm{~s}$ \\
\hline 6 & $95^{\circ} \mathrm{C}$ & $7 \mathrm{~min}, 12 \mathrm{~s}$ \\
\hline 7 & $50^{\circ} \mathrm{C}$ & $11 \mathrm{~min}, 0 \mathrm{~s}$ \\
\hline Fin del ensayo & $50^{\circ} \mathrm{C}$ & $13 \mathrm{~min}, 0 \mathrm{~s}$ \\
\hline
\end{tabular}

Durante los primeros 10 segundos se realiza una agitación vigorosa para homogenizar la muestra.

En la Figura 2.4 se muestra un viscoamilograma típico y los parámetros obtenidos a partir del mismo. Se empleó el programa Thermocicline para Windows (ver 2.4 b 31) para el cálculo de:

- Temperatura de empaste $\left(T_{e}\right)$ : temperatura en la cual comienza el aumento de viscosidad

- Tiempo en el cual comienza el aumento de la viscosidad ( $\left.t_{p}\right)$

- Viscosidad de pico $\left(\eta_{\mathrm{p}}\right)$ : máxima viscosidad obtenida durante el calentamiento hasta $95^{\circ} \mathrm{C}$, relacionada con la capacidad de la muestra para ligar agua 
- Viscosidad mínima $\left(\eta_{\min }\right)$ durante el mantenimiento de la temperatura en $95^{\circ} \mathrm{C}$ o viscosidad de la pasta caliente cuyo valor depende de la habilidad de la muestra para resistir el calentamiento y el esfuerzo de cizalla

- Viscosidad final $\left(\eta_{\mathrm{f}}\right)$ o temperatura de la pasta fría: relacionada con la habilidad de la muestra para formar una pasta viscosa o gel después de la cocción y el enfriamiento

- Inestabilidad: definida como $\left(\eta_{\mathrm{p}}-\eta_{\min }\right)$, relacionada con la habilidad de la muestra para resistir el calentamiento y el esfuerzo de cizalla

- Asentamiento $1\left(\eta_{f}-\eta_{\min }\right)$ : definido como la diferencia entre la viscosidad final y la viscosidad mínima. Al enfriar la muestra ocurre una asociación de las moleculas de almidón formándose un gel por lo que esta zona de la curva se relaciona con la tendencia a retrogradar de la pasta.

- Asentamiento $2\left(\eta_{\mathrm{f}}-\eta_{\mathrm{p}}\right)$ : definido como la diferencia entre la viscosidad final y la viscosidad de pico

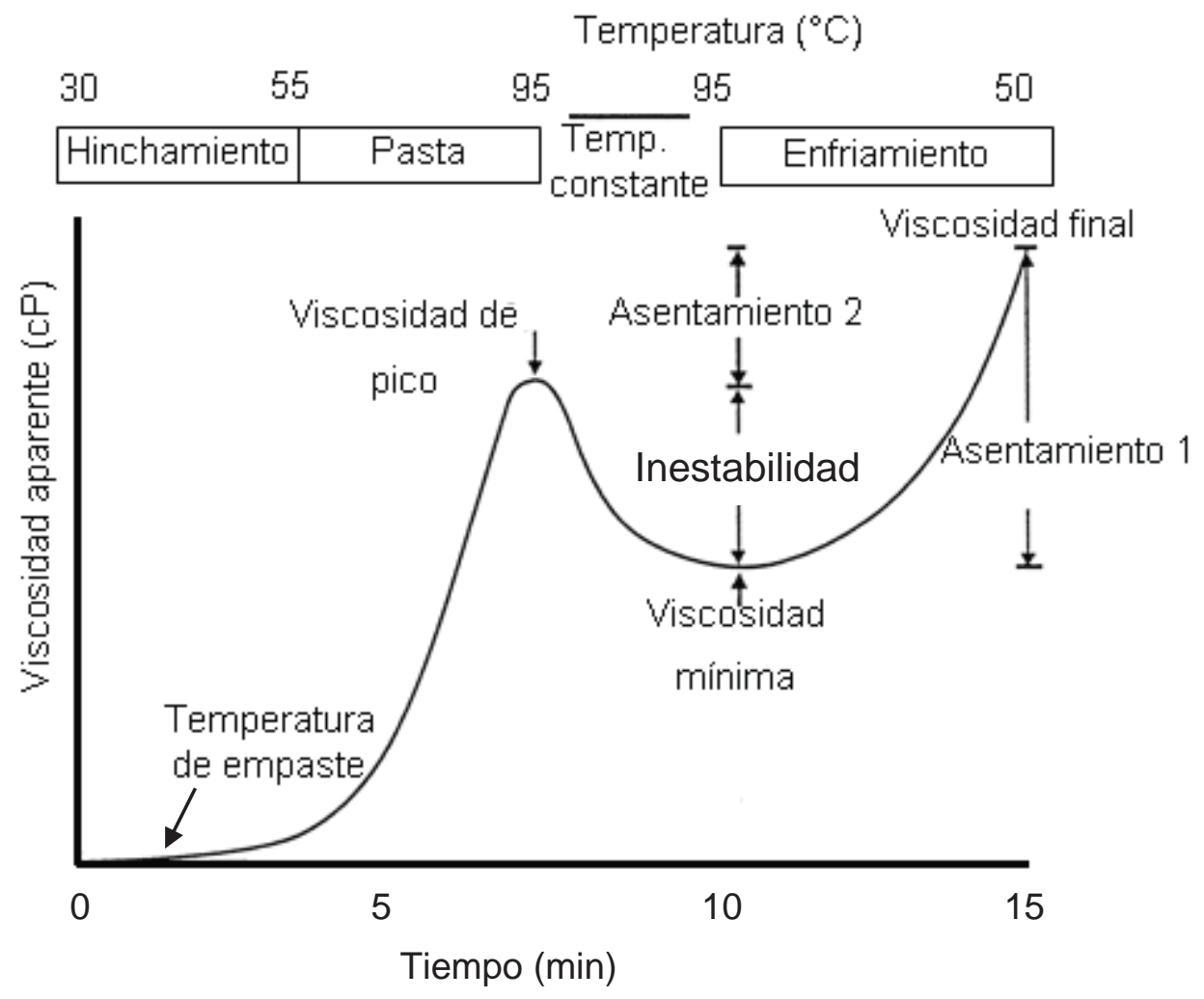

Figura 2.4. Perfil viscoamilográfico típico de almidón de trigo y parámetros calculados a partir del mismo. (Adaptado de Dengate, 1984). 


\subsubsection{Actividad $\alpha$ - amilásica.}

\subsubsection{1. Índice de caída de Hagberg (Falling Number)}

A través de este ensayo se mide indirectamente la actividad de la enzima $\alpha$-amilasa presente en la harina. Esta enzima se encuentra en mayores cantidades cuando ha habido una germinación prematura del grano (por ejemplo por factores climáticos) ocasionando un deterioro de la calidad panadera. La determinación fue realizada de acuerdo al método AACC 56.81 (2000). Se coloca una suspensión de harina en agua y se calienta en un baño de agua hirviendo, mientras se agita durante un minuto. Luego se libera el agitador desde la parte superior del tubo y se mide el tiempo en segundos que tarda el agitador en caer una determinada distancia. En este tiempo se incluyen los 60 segundos de agitación. Dado que este ensayo se basa en la habilidad de la enzima para hidrolizar el almidón a dextrinas, lo que provoca la licuefacción del gel de almidón, valores bajos (menores de 200 segundos) se relacionan con una alta actividad de la enzima y valores elevados (mayores de 300 segundos) con baja actividad enzimática.

\subsubsection{Numero de agitación (Stirring Number)}

El método del número de agitación (SN) también permite determinar indirectamente la actividad de la enzima a-amilasa. EI SN se define como la viscosidad aparente, medida en el RVA, de una suspensión caliente de harina en agua que está sufriendo licuefacción. El equipo registra la variación de la energía requerida para agitar la muestra durante el ensayo (Wrigley y Batey, 1996). Debido a la actividad hidrolítica de la enzima la viscosidad disminuye por lo que valores elevados del SN se relacionan con una alta actividad enzimática. La determinación se realizó por triplicado y siguiendo lo estipulado en la norma AACC 22-08.01 (2000). Se preparó una suspensión de harina en agua, para lo cual se pesaron $3,50 \mathrm{~g}$ de harina $(14 \%$ humedad) y se colocaron en un recipiente que contenía $25,0 \mathrm{ml}$ de agua destilada. La muestra así preparada se sometió en el viscoamilógrafo rápido (RVA- 4 Newport) al programa que se indica en la Tabla 2.2.

La viscosidad final en unidades RVU (Unidades del viscoamilógrafo rápido) se conoce como SN; 1 RVU equivale a $12 \mathrm{cP}$. Valores de SN cercanos a $160 \mathrm{RVU}$ indican baja actividad a-amilásica. 
Tabla 2.2. Protocolo utilizado en el RVA.

\begin{tabular}{c|c}
\hline Velocidad/ temperatura & Tiempo \\
\hline $960 \mathrm{rpm}$ & $0 \mathrm{~min}, 0 \mathrm{~s}$ \\
\hline $160 \mathrm{rpm}$ & $0 \mathrm{~min}, 10 \mathrm{~s}$ \\
\hline $95^{\circ} \mathrm{C}$ & $3 \mathrm{~min}, 0 \mathrm{~s}$ \\
\hline Fin del ensayo & $3 \mathrm{~min}, 0 \mathrm{~s}$ \\
\hline
\end{tabular}

\subsubsection{Caracterización de los hidrocoloides utilizados}

\subsubsection{Determinación de la pureza y grado de esterificación de las pectinas y del grado de amidación de la pectina de bajo metoxilo}

Las determinaciones se realizaron de acuerdo a la técnica descripta en FAO- FNP 52 add 9 (2001). En la Figura 2.5 se muestra el protocolo seguido para realizar la purificación de las pectinas, en el cual estas se separan de los azúcares de bajo peso molecular y sales que las acompañan en la presentación comercial por medio de una serie de lavados con una mezcla de etanol $60 \%$ y HCl concentrado $(10: 0,5)$.

El grado de esterificación de las pectinas se define como el porcentaje de grupos carboxilo de los residuos de ácido galacturónico que se encuentran esterificados con metanol. Para su determinación se partió de la pectina purificada y a través de la serie de pasos indicados en la Figura 2.6.A (parte superior) se determinó el grado de esterificación empleando la ecuación 2.7:

$$
\text { Grado de esterificación }=\frac{V_{2}}{V_{1}+V_{2}} 100
$$

donde :

$\mathrm{V}_{1}$ : $\mathrm{ml}$ de $\mathrm{NaOH}$ 0,1M utilizados en la primera titulación (titulación de los grupos carboxilo)

$\mathrm{V}_{2}$ : $\mathrm{ml}$ de $\mathrm{NaOH}$ 0,1M utilizados en la segunda titulación (título de la saponificación)

La determinación del grado de amidación de la pectina de bajo metoxilo se realizó según se indica en la Figura 2.6 B y se empleó para su cálculo la ecuación 2.8: 


$$
\text { Grado de amidación }=\frac{V_{B}-V_{S}}{V_{1}+V_{2}+\left(V_{B}-V_{s}\right)} 100
$$

donde :

$\mathrm{V}_{1}$ : $\mathrm{ml}$ de $\mathrm{NaOH} 0,1 \mathrm{M}$ utilizados en la primera titulación (titulación de los grupos carboxilo)

$\mathrm{V}_{2}$ : $\mathrm{ml}$ de $\mathrm{NaOH} 0,1 \mathrm{M}$ utilizados en la segunda titulación (título de la saponificación)

$\mathrm{V}_{\mathrm{B}}: \mathrm{ml}$ de $\mathrm{NaOH} 0,1 \mathrm{M}$ utilizados en el blanco de $20 \mathrm{ml}$ de $\mathrm{HCl} 0,1 \mathrm{M}$

$V_{\mathrm{S}}: \mathrm{ml}$ de $\mathrm{NaOH} 0,1 \mathrm{M}$ utilizados al titular el $\mathrm{HCl}$ en exceso.

El contenido de ácido galacturónico de las pectinas se calculó empleando la ecuación 2.9:

$$
\text { mg de ácido galacturónico }=19,4\left(\mathrm{~V}_{1}+\mathrm{V}_{2}+\left(\mathrm{V}_{\mathrm{B}}-\mathrm{V}_{\mathrm{s}}\right)\right) \quad \text { Ec. } 2.9
$$

En el caso de la pectina de alto metoxilo, al ser no amidada, sólo se determinan $V_{1}$ y $\mathrm{V}_{2}$ y $\left(\mathrm{V}_{\mathrm{B}}-\mathrm{B}_{\mathrm{S}}\right)$ se considera como cero.

La pureza de las pectinas se calculó como los gramos de ácido galacturónico presentes cada $100 \mathrm{~g}$ de pectina comercial (Ec. 2.10):

$$
\text { Pureza }=100 \frac{\mathrm{g} \text { de ácido galacturónico }}{\mathrm{g} \text { de pectina comercial }}
$$

Se determinó el contenido de cenizas de las dos pectinas comerciales empleadas según se describe en el ítem 2.2.1.4. El ensayo se realizó por duplicado. 


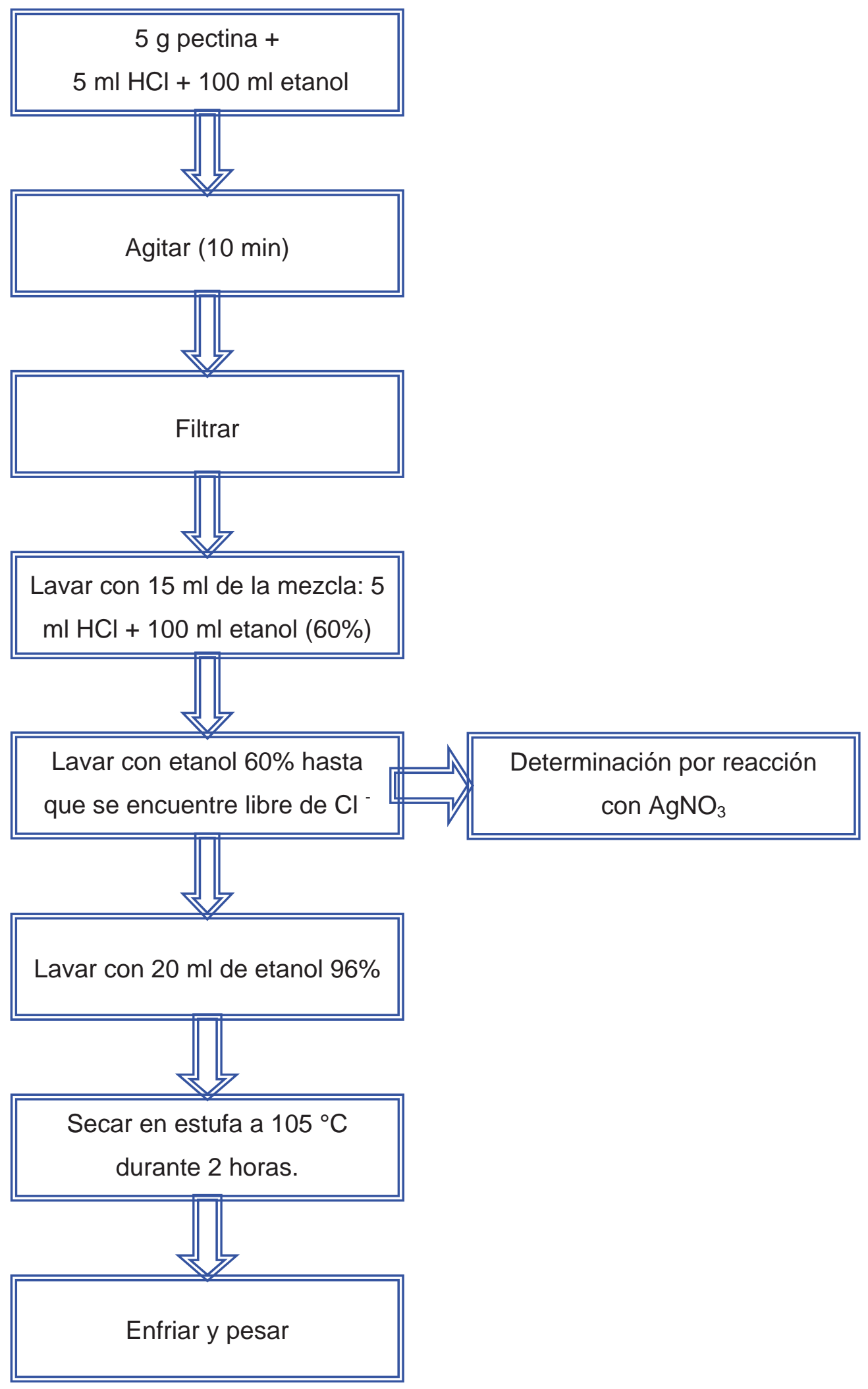

Figura 2.5. Purificación de las pectinas 


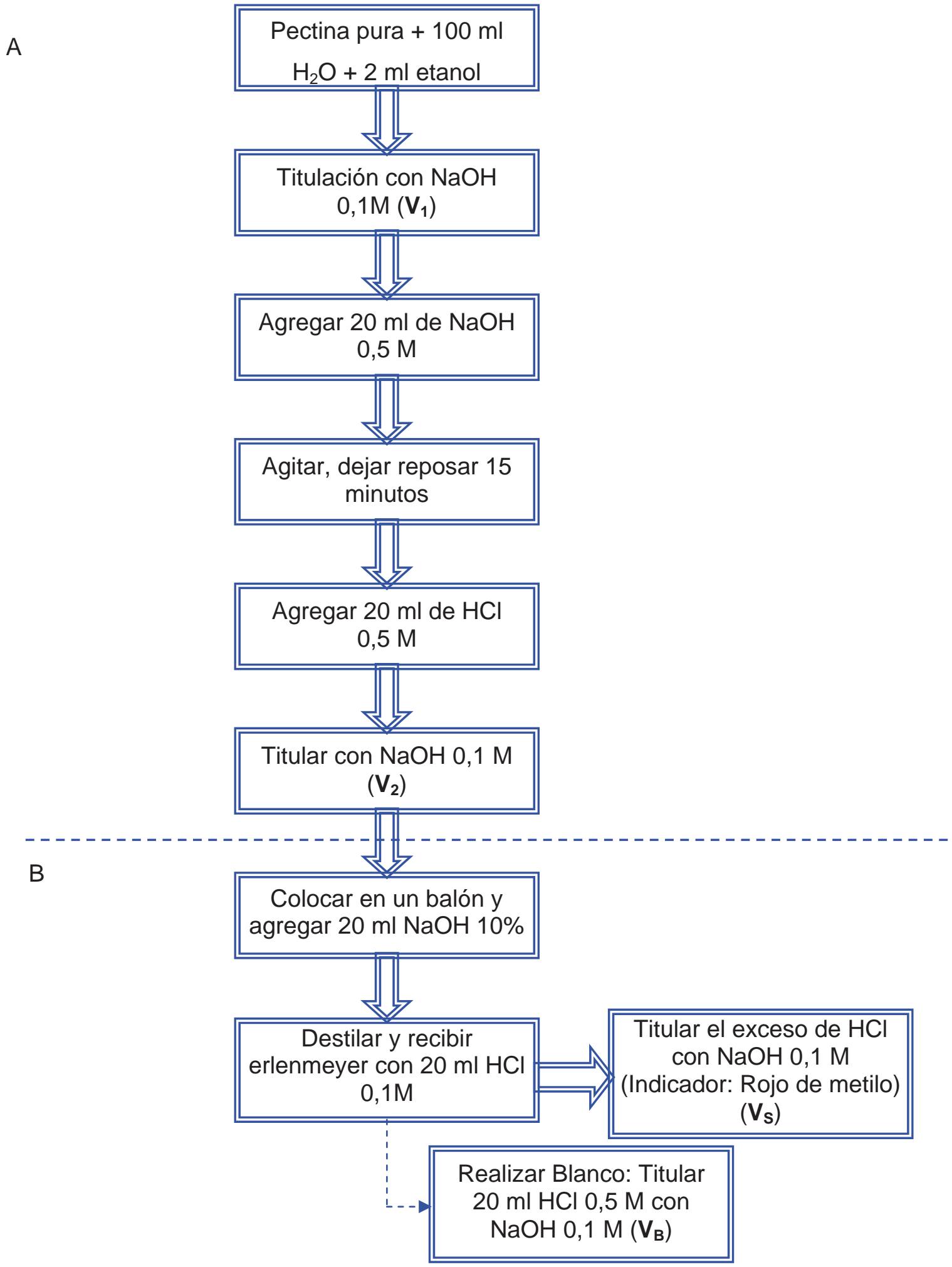

Figura 2.6. A) Determinación del grado de esterificación. B) Determinación del grado de amidación en pectinas de bajo metoxilo. 


\subsubsection{Determinación del peso molecular promedio de las pectinas por}

\section{viscosimetría capilar}

\subsubsection{Determinación de la viscosidad intrínseca}

La determinación de la viscosidad intrínseca se realizó con un viscosímetro capilar de Ostwald (Fig. 2.7), el que se colocó en un baño de agua termostizado a $25^{\circ} \mathrm{C}$ (Termostato Lauda E100). Para este ensayo se emplearon las pectinas puras obtenidas según se indicó en el ítem 2.2.3.1. Se midió el tiempo que empleó un volumen de $3 \mathrm{ml}$ de muestra en fluir a través de un capilar. Para ambas pectinas se prepararon soluciones en $\mathrm{NaCl} 0,15 \mathrm{M}$, las concentraciones empleadas fueron: $1 \times 10^{-4}$ $\mathrm{g} / \mathrm{ml}, 6,25 \times 10^{-4} \mathrm{~g} / \mathrm{ml}, 1,25 \times 10^{-3} \mathrm{~g} / \mathrm{ml}, 2,5 \times 10^{-3} \mathrm{~g} / \mathrm{ml}$. Se realizaron diez mediciones para cada concentración. A partir del tiempo de escurrimiento de las soluciones y del solvente se determinó la viscosidad relativa $\left(\eta_{\text {rel }}\right)$ (Ec. 2.11 y Ec. 2.12).

$$
\eta_{\text {rel }}=\frac{t}{t_{0}} \frac{\rho}{\rho_{0}}
$$

donde t es el tiempo de elusión de la muestra, $t_{0}$ el tiempo de elusión del solvente, $\rho$ la densidad de la muestra y $\rho_{0}$ la densidad del solvente. Para soluciones diluidas $\rho \sim \rho_{0}$, por lo que la ecuación 2.11 se reduce a la Ec. 2.12 .

$$
\eta_{\text {rel }}=\frac{t}{t_{0}}
$$

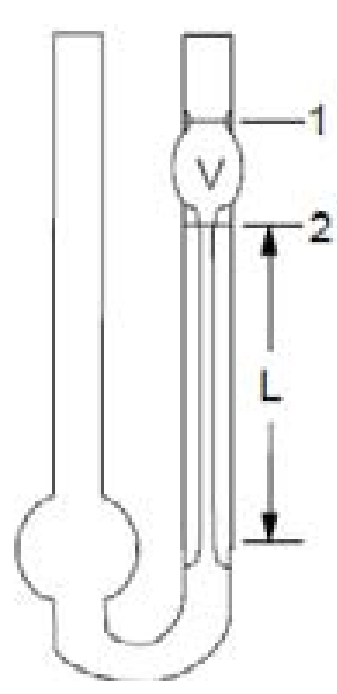

Figura.2.7. Viscosímetro de Ostwald (Fuente: Steffe, 1996) 
A partir de la $\eta_{\text {rel }}$ se calculó la viscosidad específica (Ec. 2.13) y con ésta la viscosidad reducida (Ec. 2.14). Debido a que los sistemas reales no cumplen con las condiciones de idealidad y a la existencia de fenómenos de asociación, la viscosidad reducida depende de la concentración (Harding, 1997), definiéndose como la viscosidad específica por unidad de concentración (C) $(\mathrm{mg} / \mathrm{g})$.

$$
\begin{aligned}
& \eta_{\text {sp }}=\eta_{\text {rel }}-1 \\
& \eta_{\text {red }}=\frac{\eta_{\text {sp }}}{C}
\end{aligned}
$$

El límite de la viscosidad reducida cuando la concentración tiende a cero se define como la viscosidad intrínseca [ $\eta$ ] (Ec. 2.15). La viscosidad intrínseca se obtuvo por extrapolación, empleando los criterios de Huggins y Kraemer (Harding, 1997).

$$
[\eta]=\lim _{c \rightarrow 0}\left(\eta_{\text {red }}\right)=\lim _{c \rightarrow 0} \frac{\eta_{\text {sp }}}{C}
$$

El criterio de Huggins se basa en que en soluciones diluidas la viscosidad reducida es función lineal de la concentración, así graficando $\eta_{\mathrm{sp}} / \mathrm{C}$ en función de la concentración se obtiene una recta de cuya ordenada al origen es posible determinar la viscosidad intrínseca según (Ec. 2.16):

$$
\eta_{\text {red }}=[\eta]\left(1+K_{H}[\eta] C\right)
$$

donde $\mathrm{K}_{\mathrm{H}}$ es una constante adimensional.

En el criterio de Kraemer se grafica $\ln \left(\eta_{\text {red }}\right) / C$ en función de $C$ obteniéndose una recta de cuya ordenada al origen podemos obtener la viscosidad intrínseca (Ec.2.17).

$$
\frac{\ln \eta_{\text {red }}}{C}=[\eta]\left(1-K_{K}[\eta] C\right)
$$

donde $\mathrm{K}_{\mathrm{k}}$ es una constante. 


\subsection{Determinación del peso molecular}

El peso molecular se determinó empleando la ecuación de Mark - Houwink (Ec.2.18) y los coeficientes ( $\mathrm{K}$ y a) determinados por Anger y Berth (1986) para pectinas.

$$
[\eta]=\mathrm{KPM}^{\mathrm{a}}
$$

donde $[\eta]$ es la viscosidad intrínseca y $\mathrm{K}$ y a son constantes que dependen del tipo de polímero, solvente y temperatura. El coeficiente a es función de la geometría del polímero.

\subsubsection{Determinación del peso molecular promedio de las celulosas por HPLC}

Para la determinación del peso molecular de las celulosas solubles (CMC, HPMC F 4M y HPMC F 50) se realizó una cromatografía de exclusión molecular de acuerdo a la metodología descripta por Piermaría (2008). Se empleó un equipo de cromatografía líquida de alta resolución (HPLC) (Waters, Milford, Estados Unidos) equipado con una columna OH-PAK SB - 805HQ (SHODEX, Kawasaki, Japón), al cual se acopló un refractómetro diferencial (R 410, Waters, Milford, Estados Unidos) como detector. Las muestras se prepararon en agua bidestilada $(0,5 \mathrm{~g} / \mathrm{l})$ y se filtraron antes de ser inyectadas empleando un filtro de nylon de 0,45 $\mu \mathrm{m}$ de diámetro de poro (PK150, Millipore, San Pablo, Brasil). El volumen de muestra inyectado fue de $50 \mu \mathrm{l}$ y la corrida se realizó a temperatura ambiente empleando $\mathrm{NaNO}_{3} \quad 0,1 \mathrm{M}$ como fase móvil. La velocidad de flujo fue de 0,95 ml/min (presión 120-130 psi) y se mantuvo constante a lo largo de toda la corrida. Se emplearon como patrones polímeros de dextrano con pesos moleculares entre 97000 y 3800000 (ALO-2770, Phenomenex, Torrance, CA). Se determinó para cada patrón el tiempo de retención y se graficó la curva de calibración como el logaritmo del peso molecular en función del tiempo de retención, obteniéndose una recta a partir de la cual se pueden calcular los pesos moleculares.

\subsubsection{Humedad de los hidrocoloides}

Se determinó la humedad de todos los hidrocoloides en estufa a105ํㅡ hasta peso constante. 


\subsubsection{Caracterización reológica de las masas con hidrocoloide}

Se realizaron sobre las mezclas de harina- hidrocoloide, $\sin$ y con $\mathrm{NaCl}$, y sobre las masas ya preparadas ensayos empíricos (ítems 2.2.4.1 y 2.2.4.2) y fundamentales (ítem 2.2.4.3.). Los ensayos empíricos son ensayos descriptivos, que dependen del tipo de instrumento utilizado, el tamaño y geometría de la muestra y de las condiciones específicas en las cuales se realizan. Son útiles para la evaluación del comportamiento de una muestra durante el procesamiento de la misma y para el control de calidad durante el proceso de fabricación (Dobraszczyk, 2003a). Así mismo, permiten la determinación de parámetros que se relacionan con la calidad textural (Bourne, 2002). En los ensayos fundamentales se miden propiedades reológicas bien definidas las cuales son independientes de la forma y tamaño de la muestra y de cómo se midieron, se pueden emplear para realizar cálculos al diseñar un proceso y para realizar el modelado de sistemas complejos (Dobraszczyk, 2003a).

\subsubsection{Farinograma}

Los farinogramas de las mezclas harina - hidrocoloide en ausencia y presencia de $\mathrm{NaCl}(2 \%)$ se realizaron como se indicó en el ítem 2.2.2.1, siguiendo la norma IRAM 15855:2000. Los niveles empleados para las celulosas modificadas fueron $0,25 \%$, $0,5 \%, 1,0 \%$ y $1,5 \%$, las pectinas se utilizaron en los mismos niveles y además al $2 \%$. A partir de los farinogramas se determinaron la absorción de agua (A), el tiempo de desarrollo (td), la estabilidad y el aflojamiento. Además, se calculó el incremento porcentual de la absorción de agua respecto al control empleando la siguiente ecuación:

$$
\% \text { variación }=\frac{A-A_{0}}{A_{0}} 100
$$

Se graficó el \% de variación en función de la concentración de hidrocoloide y se compararon las pendientes.

\subsubsection{Ensayos con el texturómetro: perfil de textura (TPA), punción y relajación}

\subsection{Preparación de las muestras}

La formulación empleada para la preparación de las masas fue: harina $100 \mathrm{~g}$, agua destilada según absorción farinográfica, hidrocoloides en dos niveles: 0,5 \% y 1,5\% 
para las celulosas modificadas y $1 \%$ y $2 \%$ para las pectinas. Las masas se prepararon sin y con $\mathrm{NaCl}(2 \%)$ y sin el agregado de levadura para evitar la fermentación durante la medición. Se utilizaron como controles las masas sin agregado de hidrocoloide. Para la preparación de las masas los ingredientes fueron mezclados en seco durante un minuto en una amasadora planetaria (Kenwood, Italia), luego se agregó el agua y se amasó cada mezcla su tiempo de desarrollo farinográfico. Con la finalidad de favorecer el desarrollo de la red de gluten la masa se laminó 4 veces en una laminadora manual (luego de cada pasaje por la laminadora la masa se giró $90^{\circ}$ ), posteriormente se dejó reposar durante 15 minutos a temperatura ambiente cubierta con un film para evitar su desecación. A partir de esta masa se cortaron piezas cilíndricas de $3 \mathrm{~cm}$ de diámetro y $1 \mathrm{~cm}$ de espesor para los ensayos de textura. Las masas se prepararon por duplicado.

\subsubsection{Análisis de perfil de textura (TPA)}

En el ensayo de perfil de textura la muestra es sometida a dos compresiones sucesivas con un período de reposo entre ambas (Bourne, 2002).

En la Figura 2.8 se muestra una curva obtenida en este tipo de ensayo y se indican los parámetros calculados, según se detalla.

- Dureza: máxima fuerza registrada durante el primer ciclo de compresión; en este punto se realiza la máxima deformación del producto.

- Cohesividad: cociente entre el área positiva del segundo ciclo (Área 4 + Área 5) y el área positiva del primer ciclo (Área 1+Área 2); se relaciona con la fuerza de los enlaces entre los componentes que forman el producto (Szczesniak, 1962; Bourne, 2002)

- Elasticidad: cociente entre la distancia necesaria para alcanzar el máximo del segundo pico (L3) y la distancia para alcanzar el máximo del primer pico (L1); se relaciona con la recuperación del material luego de la primer compresión.

- Adhesividad: área del pico negativo (Área 3); se relaciona con el trabajo necesario para vencer las fuerzas de atracción entre la superficie del alimento y los materiales con los cuales tome contacto (Szczesniak, 1962; Bourne, 2002)

- Resiliencia: cociente entre el área del primer ciclo luego del máximo (Área 2) y el área del primer ciclo hasta alcanzar el máximo (Área 1); se relaciona con la recuperación instantánea del material.

- Consistencia: suma de las áreas del primer (Área 1+Área 2) y del segundo pico (Área 4 + Área 5). 
Dado que la masa no presenta fracturabilidad (fuerza con la cual el material se fractura), aunque se señala en Fig. 2.8, no fue calculada.

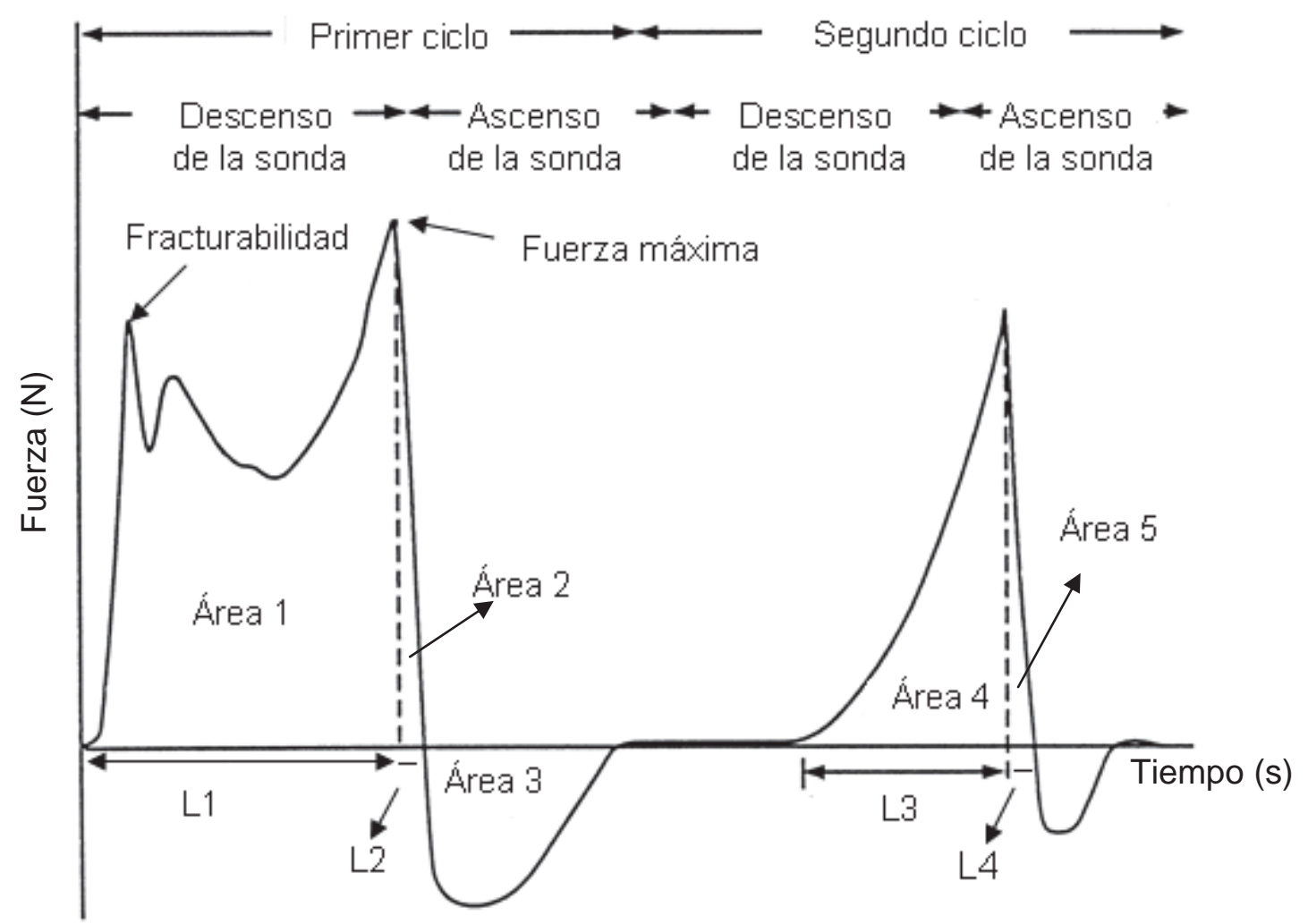

Figura 2.8. Curva general del perfil de textura (Fuente: Bourne, 2002)

La masa fue sometida a un ensayo de compresión de dos ciclos utilizando un texturómetro TA-XT2i (Stable Micro Systems, Surrey, Reino Unido.). Se comprimió hasta un $40 \%$ de la altura original con una sonda cilíndrica de $7,5 \mathrm{~cm}$ de diámetro y se registró la fuerza en función del tiempo a una velocidad de 0,5 mm/s. Los parámetros determinados fueron: dureza, cohesividad, elasticidad, adhesividad, resiliencia y consistencia de la masa. Para el cálculo de los mismos se empleó el software Texture Expert para Windows, versión 1.2.

\subsection{Punción}

En los ensayos de punción se determina la fuerza máxima requerida para introducir una sonda de metal en un alimento, que es una medida de la firmeza y cohesión del 
mismo. En la Figura 2.9 se muestran curvas típicas de alimentos, en las cuales pueden distinguirse diferentes regiones: al comienzo de las curvas ocurre un aumento rápido de la fuerza debido a la deformación del material por la sonda (1). El momento en el cual la sonda lo penetra se evidencia por un cambio de pendiente (2), aquí ocurre una rotura irreversible del mismo y a este punto se lo llama punto de fluencia (no observable en la curva E). En el punto de fluencia la fuerza es proporcional al área y perímetro de la sonda y a las características texturales de la muestra. La tercera zona (3) de la curva indica el cambio en la tasa de crecimiento del módulo de la fuerza que es necesaria realizar para que la sonda continúe penetrando en la muestra (Bourne, 2002). En esta zona se determinó la firmeza de la masa como la máxima fuerza registrada durante la penetración (4). Luego de este punto, la sonda se retira.

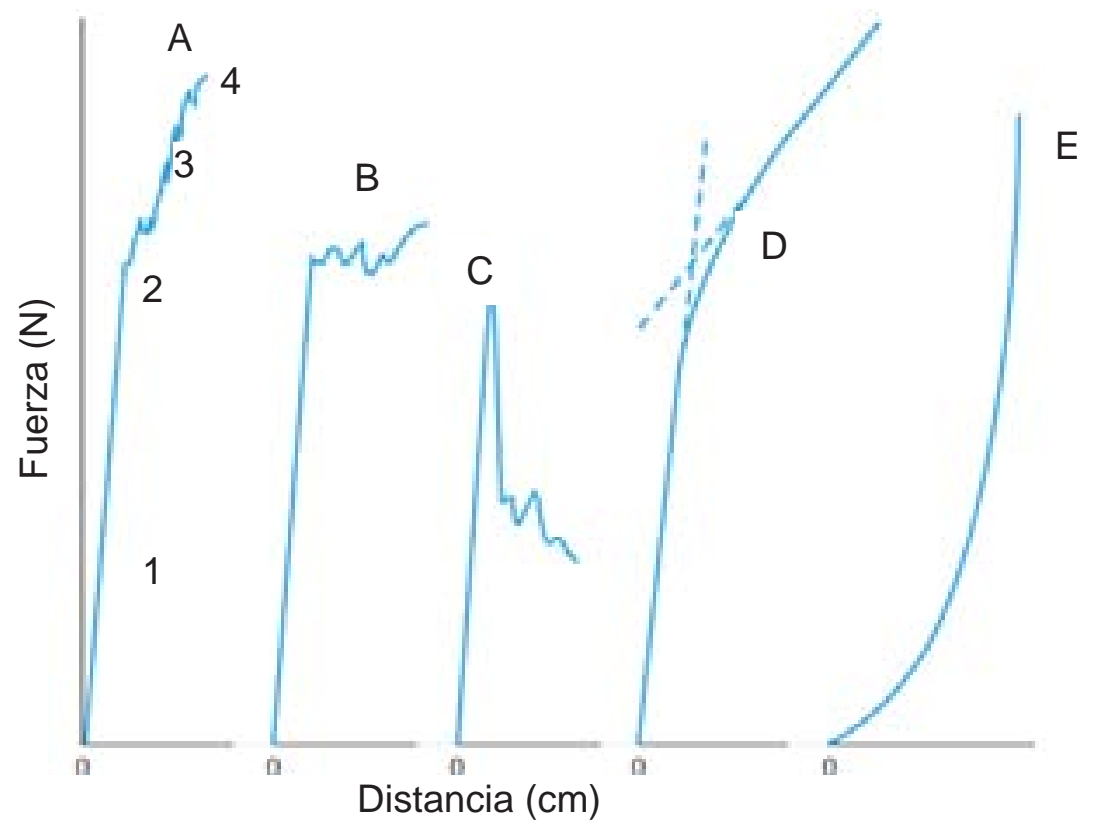

Figura 2.9. Representación esquemática de curvas típicas obtenidas en ensayos de punción para distintos materiales (Adaptada de Bourne, 2002).

Piezas de masa cilíndricas preparadas de igual modo que en el ítem 2.2.4.2.1. se sometieron a un ensayo de punción hasta una profundidad de un $40 \%$ de su altura original con el empleo de un texturómetro TA-XT2i (Stable Micro Systems, Surrey, Reino Unido) y una sonda cilíndrica SMS P/3 (diámetro $3 \mathrm{~mm}$ ). Se realizó un registro de la fuerza en función del tiempo del ensayo. 


\subsection{Relajación}

En los ensayos de relajación la muestra es sometida a una deformación de compresión constante y se registra la variación del esfuerzo necesario para mantener la deformación en función del tiempo. En la Figura 2.10 se muestra el comportamiento presentado por diferentes tipos de materiales en esta clase de ensayo. Mientras, los sólidos elásticos ideales no presentan relajación, los líquidos viscosos ideales relajan inmediatamente. Un comportamiento intermedio entre ambos es el que presentan los materiales viscoelásticos, los cuales relajan en forma gradual y cuyo valor de esfuerzo final dependerá de la estructura del material, si se trata de un sólido viscoelástico alcanzará un valor de equilibrio $\left(\sigma_{e}>0\right)$ mientras que en los materiales viscoelásticos líquidos el esfuerzo final será cero (Steffe, 1996).

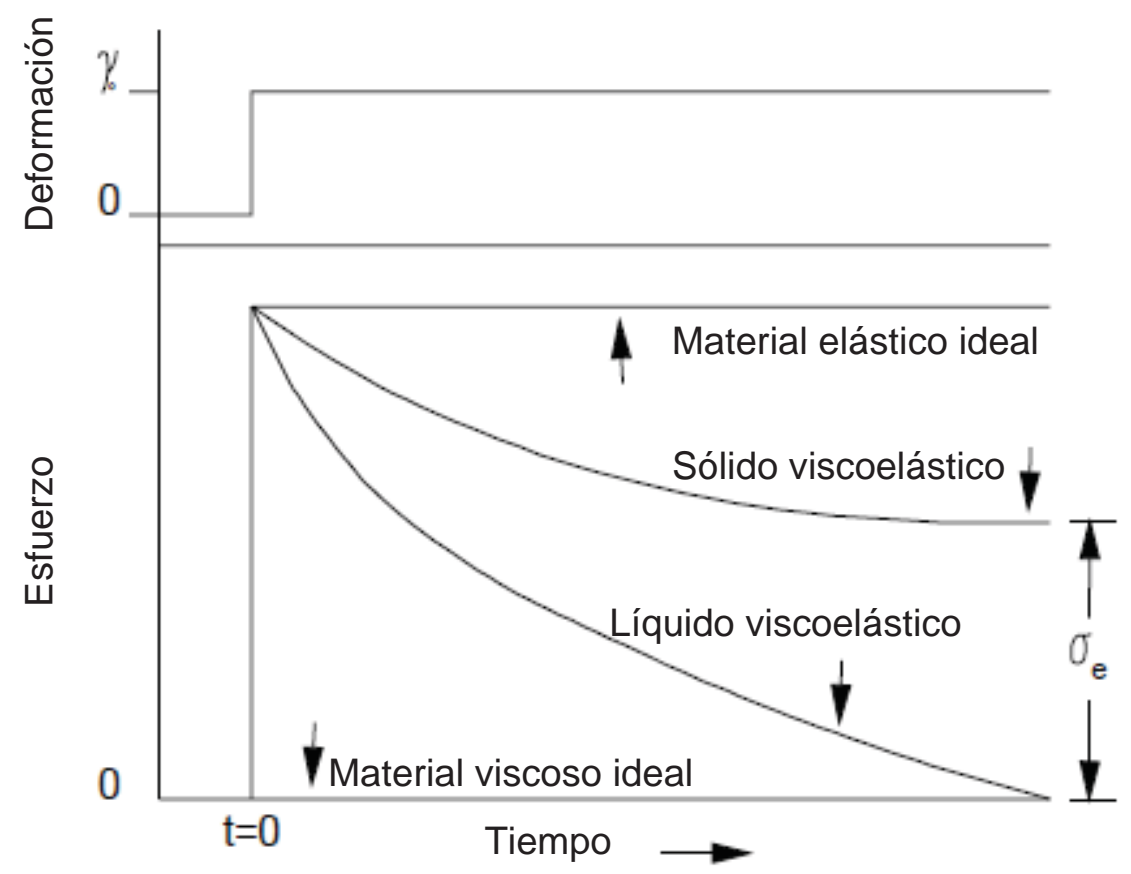

Figura 2.10. Arriba: deformación aplicada. Abajo: Comportamiento presentado por distintos materiales en ensayos de relajación ( $\sigma_{\mathrm{e}}$ : valor del esfuerzo una vez alcanzado el equilibrio) (Adaptado de Steffe, 1996).

Para el estudio del comportamiento reológico se utilizan modelos mecánicos compuestos por resortes y amortiguadores. El resorte es el modelo mecánico para el sólido ideal por lo que obedece la ley de Hooke (Ec. 2.20). 


$$
\sigma=\mathrm{G} \gamma
$$

donde $\sigma$ es el esfuerzo o el esfuerzo cortante $\left(\mathrm{N} / \mathrm{m}^{2}\right)$, G es el módulo elástico y $\gamma$ es la deformación relativa.

El modelo del líquido ideal es el amortiguador, en el cual puede subir y bajar libremente un pistón siendo la viscosidad del líquido la única resistencia que se opone a su movimiento. El amortiguador cumple con la ley de Newton (Ec. 2.21):

$$
\sigma=\mu \dot{\gamma}
$$

donde $\sigma$ es el esfuerzo de corte, $\mu$ es el coeficiente de viscosidad y $\gamma$ el gradiente de velocidad.

Los resortes y amortiguadores se pueden acomodar de diferentes modos para describir el comportamiento viscoelástico de los materiales. Entre los modelos viscoelásticos más comunes se tienen el modelo de Maxwell en el cual se asocian en serie un resorte y un amortiguador con líquido y el de Kelvin en el cual se asocian en paralelo en resorte y un amortiguador (Figura 2.11).
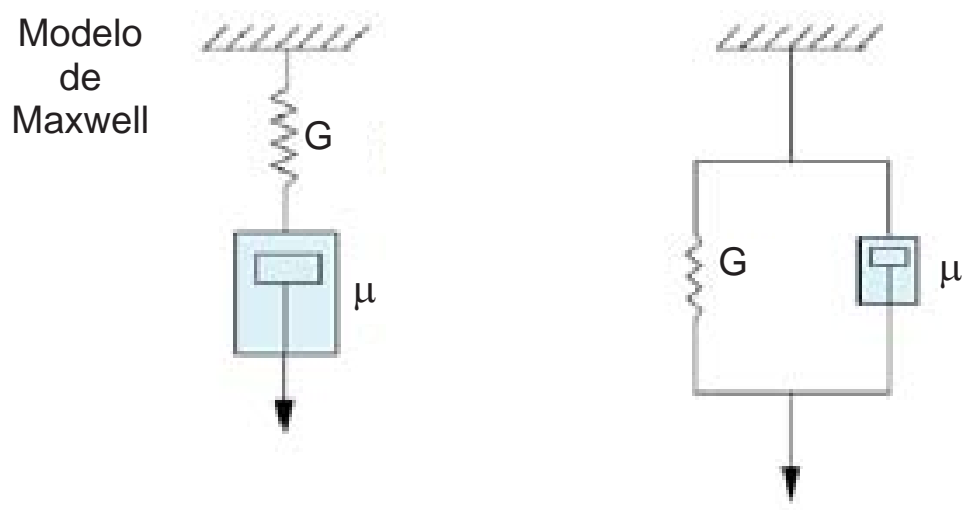

Modelo

de

Kelvin

Figura 2.11. Modelos de Maxwell y Kelvin (Adaptado de Steffe, 1996).

Para el estudio de los ensayos de relajación resulta útil el modelo de Maxwell generalizado (Ec. 2.22), el cual consiste en varios elementos de Maxwell conectados en paralelo con un resorte; éste último contempla el esfuerzo de equilibrio presentado por los sólidos viscoelásticos. 


$$
\sigma=\gamma_{0} G_{0}+\sum_{i=1}^{n} A_{i} \exp \left(\frac{-t G_{i}}{\mu_{i}}\right)
$$

La ecuación 2.22 también puede escribirse como (Ec. 2.23):

$$
\sigma=\sigma_{e}+\sum_{i=1}^{n} A_{i} \exp \left(\frac{-t}{\lambda_{i}}\right)
$$

donde $\sigma_{e}$ es el esfuerzo de equilibrio y $\lambda_{i}$ es el tiempo de relajación de cada elemento de Maxwell.

En este ensayo se empleó un texturómetro TA-XT2i (Stable Micro Systems, Surrey, Reino Unido) y una sonda cilíndrica de $7,5 \mathrm{~cm}$ de diámetro para la compresión piezas de masa cilíndricas durante 20 minutos hasta un $40 \%$ de su altura original a una velocidad de $0,5 \mathrm{~mm} / \mathrm{s}$. El borde de las muestras se cubrió con vaselina sólida para evitar la deshidratación durante el ensayo. Los ensayos se realizaron por triplicado a temperatura ambiente.

Se registró la fuerza en función del tiempo y las curvas de relajación se ajustaron a una ecuación exponencial como la dada por la Ec. 2.23.

\subsubsection{Ensayos dinámicos en reómetro oscilatorio}

Los ensayos oscilatorios son muy sensibles a la composición química y a la estructura de los alimentos por lo que son los métodos dinámicos más ampliamente utilizados para estudiar el comportamiento viscoelástico de los mismos (Steffe, 1996). La muestra se somete a un esfuerzo (en un reómetro de esfuerzo controlado) o una deformación (en un reómetro de velocidad controlada) que varía armónicamente con el tiempo y se registran el desfasaje entre las oscilaciones del esfuerzo y la deformación y los cambios en la amplitud de la oscilación. En los reómetros de esfuerzo controlado se fija la amplitud del esfuerzo y se mide la deformación mientras que en los de velocidad controlada se fija la deformación y se mide el esfuerzo. Se define como rango de viscoelasticidad lineal de un material a aquel en el cual las propiedades del mismo no dependen de la magnitud del esfuerzo aplicado, de la deformación realizada o de la velocidad de aplicación de la deformación (Figura 2.12). 


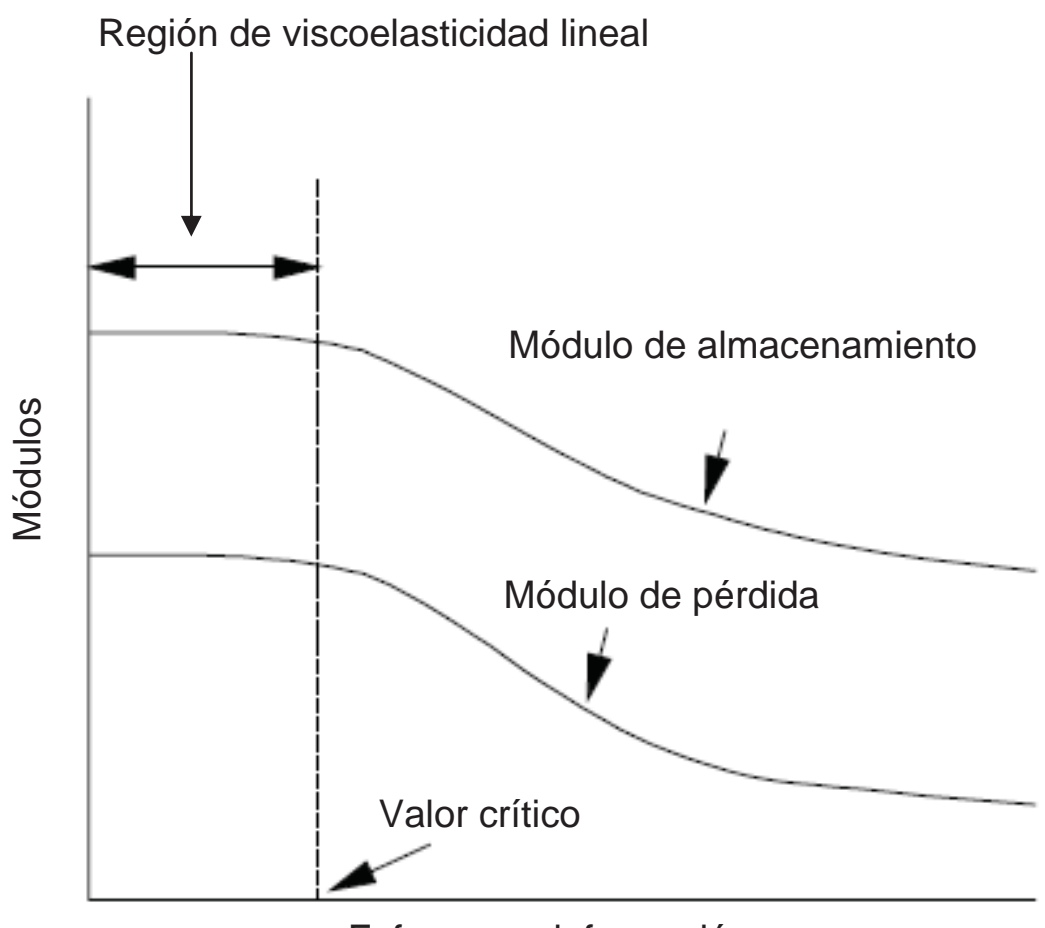

Esfuerzo o deformación

Figura 2.12. Rango de viscoelasticidad lineal (Adaptado de Steffe, 1996).

Si tenemos una muestra a la cual se aplica un esfuerzo de cizalla entre dos platos paralelos (Fig. 2.13), de forma tal que el plato inferior se encuentra fijo mientras que el superior se mueve describiendo un movimiento sinusoidal de frecuencia $\omega$ entonces la deformación del material está dada por la ecuación 2.24.

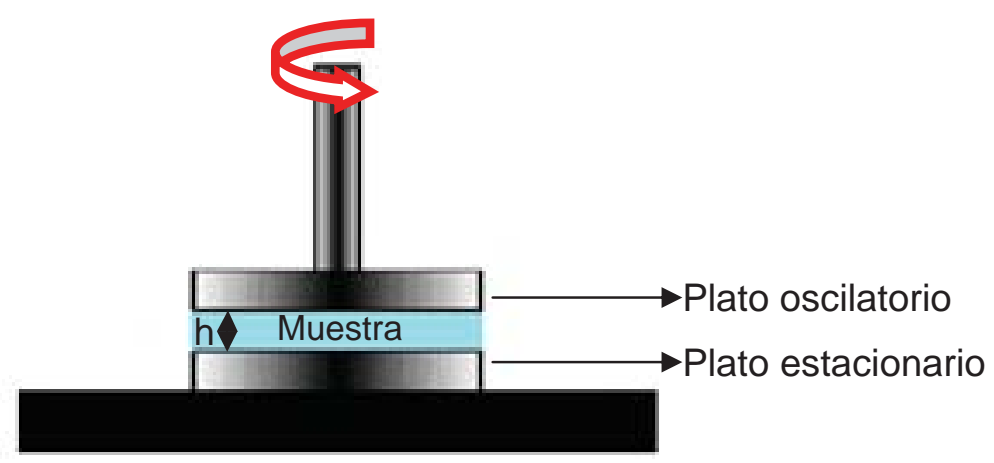

Figura 2.13. Ensayo oscilatorio dinámico: Esquema de un sistema de platos paralelos (Fuente: Adaptado de Steffe, 1996). 


$$
\gamma=\gamma_{0} \operatorname{sen}(\omega t)
$$

donde $\gamma$ es la deformación del material, $\gamma_{0}$ es la amplitud de la deformación, $\omega$ es la frecuencia angular ( $\mathrm{rad} / \mathrm{s})$ y t el tiempo (s).

Si la amplitud de la deformación que se aplica es pequeña, de forma tal de encontrarnos dentro del rango de viscoelasticidad lineal el esfuerzo producido esta dado por la ecuación 2.25.

$$
\sigma=\sigma_{0} \operatorname{sen}(\omega t-\delta)
$$

donde $\sigma_{0}$ es la amplitud del esfuerzo y $\delta$ es el ángulo de desfasaje, que separa al esfuerzo realizado de la deformación. En los objetos sólidos ideales, que presentan un comportamiento elástico, el esfuerzo y la deformación se encuentran en fase $(\delta=0)$. Mientras que en un líquido viscoso ideal se presenta una diferencia de fase de $90^{\circ}$ entre el esfuerzo y la deformación (Figura 2.14). Aquellos elementos que presentan ángulos de desfasaje entre $0^{\circ}$ y $90^{\circ}$ se denominan viscoelásticos pues presentan un comportamiento intermedio entre el sólido ideal y el líquido viscoso ideal.

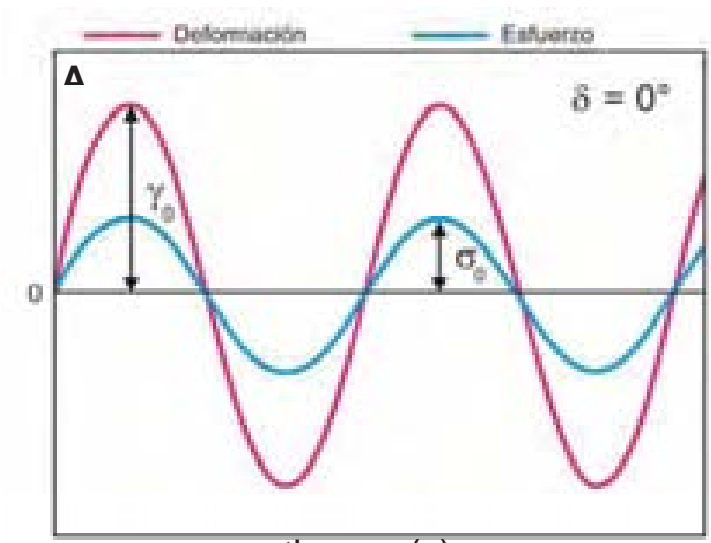

tiempo (s)

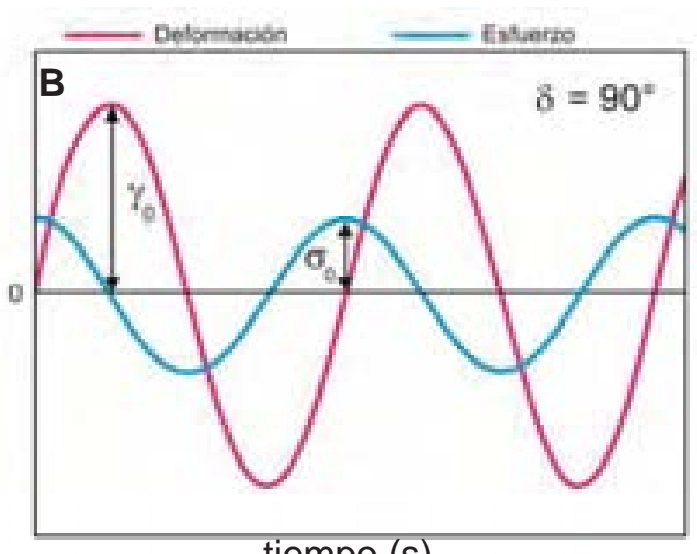

tiempo (s)

Figura 2.14. Comportamiento mostrado por: A) un sólido ideal; B) un líquido viscoso ideal. 
La ecuación 2.25 también puede escribirse como:

$$
\sigma=G^{\prime} \gamma+\left(\frac{G^{\prime \prime}}{\omega}\right) \gamma
$$

donde G'es el módulo de almacenamiento o módulo elástico (Ec. 2.27) y G" es el módulo de pérdida o viscoso (Ec. 2.28). El módulo elástico se encuentra relacionado con la respuesta del material como un sólido mientras que el módulo viscoso se relaciona con la respuesta del material como un fluido. Ambos módulos son función de la frecuencia y se pueden expresar en función de la amplitud y el ángulo de desfasaje:

$$
\begin{aligned}
& G^{\prime}=\frac{\sigma_{0}}{\gamma_{0}} \cos (\delta) \\
& G^{\prime \prime}=\frac{\sigma_{0}}{\gamma_{0}} \operatorname{sen}(\delta)
\end{aligned}
$$

$G^{\prime} \gamma_{0}$ puede interpretarse como la componente del esfuerzo que se encuentra en fase con la deformación y G" $\gamma_{0}$ puede interpretarse como la componente del esfuerzo que se encuentra desfasada en $90^{\circ}$ de la deformación.

Otras funciones que describen el comportamiento viscoelástico de la muestra y su dependencia con la frecuencia son el módulo complejo (Ec. 2.29), la viscosidad compleja (Ec. 2.30) y la tangente del ángulo de desfasaje (Ec. 2.31).

$$
\begin{gathered}
G^{*}=\frac{\sigma_{0}}{\gamma_{0}}=\sqrt{\left(G^{\prime}\right)^{2}+\left(G^{\prime \prime}\right)^{2}} \\
\eta^{*}=\frac{G^{*}}{\omega} \\
\tan (\delta)=\frac{G^{\prime \prime}}{G^{\prime}}
\end{gathered}
$$

La $\tan (\delta)$ se vincula con la relación entre la energía perdida por la muestra por ciclo respecto a la energía almacenada por ciclo (Steffe, 1992). 
Para la realización de los ensayos en reómetro oscilatorio la masa se preparó como se describe en el ítem 2.2.4.2.1., se cortaron piezas cilíndricas de $3 \mathrm{~cm}$ de diámetro y 2 $\mathrm{mm}$ de espesor, las que se cubrieron con un film para evitar su deshidratación y se mantuvieron refrigeradas hasta 10 minutos antes de realizar la medida. Para la realización de los ensayos se empleó un reómetro oscilatorio de esfuerzo controlado Haake RS 600 (Haake, Alemania). Las medidas se realizaron a $25 \pm 0,1^{\circ} \mathrm{C}$ utilizando como sensor un sistema plato - plato de superficie rugosa con una separación entre los mismos de $1,5 \mathrm{~mm}$. Se cubrieron los bordes de las muestras con vaselina sólida para evitar la pérdida de humedad durante el ensayo. Se realizaron barridos de esfuerzo entre 0,5 y $200 \mathrm{~Pa}$ a una frecuencia de $1 \mathrm{~Hz}$ para determinar el rango de viscoelasticidad lineal de las muestras. Se fijó un esfuerzo de $5 \mathrm{~Pa}$, comprendido dentro del intervalo de viscoelasticidad lineal, para realizar los barridos de frecuencia, los cuales fueron realizados entre 0,005 y $100 \mathrm{~Hz}$. En ambos ensayos las muestras se dejaron relajar durante 15 minutos, entre los platos, antes de comenzar la medida. Se determinaron el módulo elástico (G'), el módulo viscoso (G'), el módulo complejo, la tangente del ángulo de desfasaje $(\delta)$ y la viscosidad compleja $\left(\eta^{*}\right)$.Se prepararon 2 masas y cada una se midió por triplicado.

\subsubsection{Caracterización fisicoquímica y microestructural de las masas}

\subsubsection{Agua}

\subsection{Ensayo de absorción de agua (WIC)}

Se determinó la capacidad de imbibición de agua de la harina y de las mezclas harinahidrocoloide, las celulosas modificadas se emplearon al $1,5 \%$ y las pectinas al $2 \%$. Se empleó un equipo de Baumann, el cual consiste en una base perforada sobre la cual se coloca papel de filtro y que se conecta a una pipeta graduada a través de un tubo flexible, la base y la pipeta se encuentran en posición horizontal y al mismo nivel (Figura 2.15). El sistema se llena de agua, se enrasa la pipeta y se coloca una capa uniforme de muestra $(50 \mathrm{mg})$ sobre el papel de filtro. Se mide la variación del volumen de agua de la pipeta en función del tiempo hasta que se obtiene un volumen constante. La capacidad de imbibición (water imbibing capacity: WIC) de agua se determina como: 


$$
\text { WIC }=\frac{\text { ml de agua absorbida }}{\text { mg de mezcla }}
$$

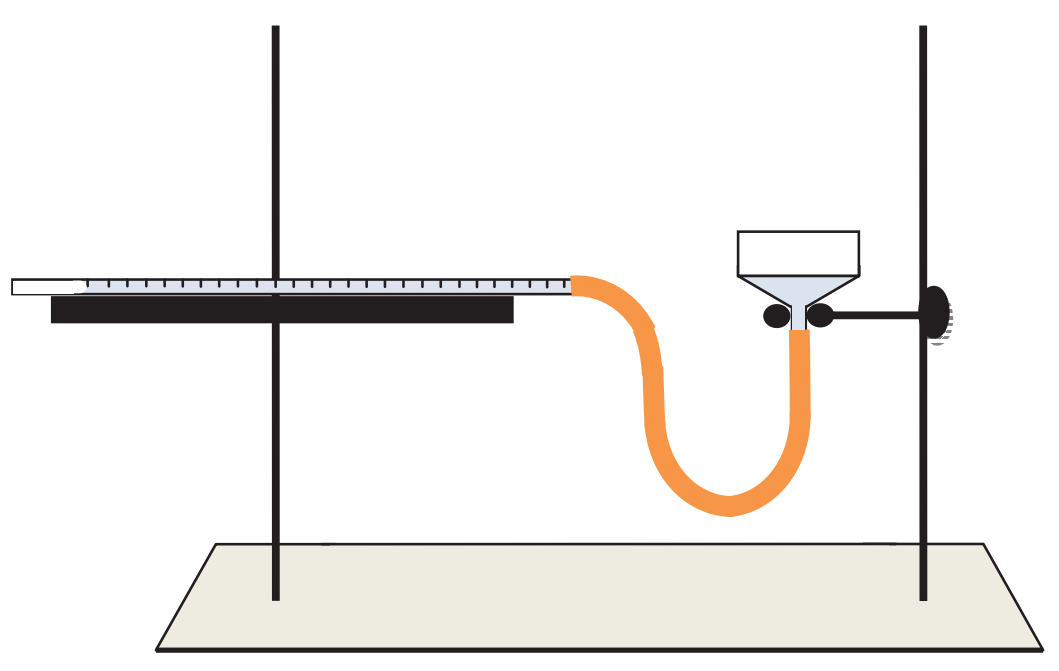

Figura 2.15. Esquema del equipo de Baumann (Dibujo: Ferrero, C.)

\subsection{Contenido y disponibilidad de agua}

\subsection{Humedad de la masa}

Se realizó de acuerdo al método AACC 44-19 (2000), en el cual la muestra se seca en estufa durante dos horas a $135^{\circ} \mathrm{C}$. Se empleó una estufa de convección forzada (velocidad del aire $25 \mathrm{~cm} / \mathrm{seg}$ ) (Estigia, Argentina).

\subsection{Actividad Acuosa}

Se define como actividad acuosa al cociente entre la presión parcial de vapor de agua en equilibrio con el alimento y la presión de vapor de agua pura a la misma temperatura. La actividad acuosa se relaciona con la disponibilidad del agua; cuanto mayor sea la interacción del agua con los constituyentes del alimento, más ligada se encontrará y menor será el valor de la actividad del agua.

Se determinó la actividad acuosa de las masas a $25^{\circ} \mathrm{C}$ con el empleo de un equipo AQUALAB (Decagon Devices, Inc, Pullman, and EUA) que utiliza la técnica del punto 
de rocío. La muestra se coloca en una cámara sellada que contiene un espejo, se espera a que se equilibre y condense el vapor de agua sobre el espejo. La temperatura del espejo es controlada por un circuito Peltier y una célula fotoeléctrica detecta la condensación sobre el espejo. Un haz de luz es dirigido hacia el espejo y se refleja en un fotodetector, el cual censa el cambio en la reflectancia cuando ocurre la condensación en el espejo. Una termocupla detecta la temperatura a la cual ocurre la condensación. En el equilibrio, la humedad relativa del aire en la cámara es igual a la actividad de agua de la muestra.

Se utilizó como patrón para calibrar el equipo una solución saturada de $\mathrm{K}_{2} \mathrm{SO}_{4}$. El ensayo se realizó por duplicado.

\subsubsection{Proteínas}

\subsection{Gluten húmedo, gluten seco, agua ligada al gluten y relación gluten húmedo/gluten seco}

La determinación de los valores de gluten húmedo (GH) y seco (GS) y los parámetros calculados a partir de ellos (agua ligada al gluten y relación $\mathrm{GH} / \mathrm{GS}$ ) requirió una modificación del método AACC 38-12 (2000) debido a que no fue posible la formación de una masa en presencia de los hidrocoloides con los tiempos de amasado factibles de realizar con el Glutomatic (Perten Instruments, Suecia). Por lo tanto, las masas se prepararon de igual modo que para los ensayos reológicos tal como se describió en el ítem 2.2.4.2.1. y luego se realizó solamente la etapa de lavado en el Glutomatic. Se pesaron aproximadamente $15 \mathrm{~g}$ masa y se lavaron durante $5 \mathrm{~min}$. El gluten obtenido se centrifugo a 6000 rpm en una centrífuga 2015 (Perten Instruments, Suecia) durante $1 \mathrm{~min}$, se pesó el gluten total y este luego se secó a $150^{\circ} \mathrm{C}$ durante $4 \mathrm{~min}$. El ensayo se realizó al menos por duplicado.

Los parámetros determinados fueron GH, GS, GH-GS y GH/GS. Para el cálculo de los mismos se refirió la cantidad de masa pesada a la cantidad de harina a partir de la cual se había formado.

\subsection{Electroforesis desnaturalizante - disociante (SDS-PAGE)}

En la electroforesis de proteínas se realiza una separación de las mismas por la aplicación de un campo eléctrico y éstas se separan en función de su relación carga/masa. Se suelen realizar en geles de poliacrilamida, los cuales forman una 
matriz porosa que permite separar a las proteínas en función de su carga y/o tamaño. El tamaño del poro de los geles es inversamente proporcional a la concentración de acrilamida y depende de la relación acrilamida/bis-acrilamida, así como también de las condiciones de polimerización (Shewry, 2003). El detergente dodecil sulfato de sodio (SDS) es un compuesto aniónico que rompe los puentes de hidrógeno y bloquea la interacción hidrofóbica, por lo tanto despliega a las proteínas. Además forma complejos con ellas otorgándoles una carga negativa que enmascara la carga nativa de la proteína. Debido a que la cantidad de SDS que se une a una proteína es proporcional a su número de aminoácidos, los complejos proteína-SDS tienen un valor carga/masa constante. En las electroforesis con geles de poliacrilamida realizadas en presencia de SDS (SDS-PAGE) las moléculas se separaran en condiciones desnaturalizantes y en función de su masa molecular. La electroforesis SDS- PAGE se basa en el método de Laemmli (1970), quien empleó un sistema de buffers y geles discontinuos. Un gel discontinuo está formado por un gel separador y uno de apilamiento que presentan diferentes valores de $\mathrm{pH}$ y concentración de acrilamida. Esto permite concentrar las proteínas en una banda estrecha en la interfase entre ambos geles y por lo tanto las proteínas migran como una banda más definida a lo largo del gel separador lo cual mejora la resolución de las bandas.

Se realizaron electroforesis SDS-PAGE de las fracciones proteicas obtenidas por extracción: con propanol 50\%, ácido acético 0,1M (secuencia de Osborne modificada) y de las proteínas obtenidas en condiciones desnaturalizantes, según se detalla a continuación. Las extracciones se realizaron a partir de harina y masa liofilizada (preparada según el ítem 2.2.4.2.1) con el máximo nivel de hidrocoloide, sin y con $\mathrm{NaCl}$.

\subsection{Extracción secuencial de las fracciones proteicas.}

Las fracciones proteicas fueron extraídas en forma secuencial a partir de masa liofilizada utilizando una modificación de la secuencia de Osborne. Los solventes empleados fueron agua destilada para extraer las albúminas, Tris- $\mathrm{HCl} 50 \mathrm{mM}(\mathrm{pH} 7,8)$ conteniendo $\mathrm{KCl} 100$ mM y EDTA 5 mM para la extracción de las globulinas, 1propanol al 50\% para extraer las gliadinas y una solución de ácido acético 0,1M para extraer las gluteninas. Se pesaron $3 \mathrm{~g}$ de masa liofilizada por tubo de centrífuga y se agregaron $15 \mathrm{ml}$ del solvente de extracción, se mantuvo con agitación constante durante 30 min a temperatura ambiente. Luego las suspensiones fueron centrifugadas (centrífuga Avanti J-25- Beckman Coulter, California, Estados Unidos) a $12096 \mathrm{~g}$ 
durante 15 min a $4 \stackrel{\circ}{\circ}$. Este procedimiento se realizó dos veces con cada solvente. Sólo las proteínas provenientes de la primera extracción con ácido acético se liofilizaron para realizar la electroforesis.

\subsection{Extracción en condiciones reductoras}

Se realizó una extracción secuencial de las gliadinas y gluteninas a partir de masa liofilizada y harina según la técnica de Sing y col. (1991) modificada por Nieto y col. (1997). La extracción se realizó en tubos eppendorf a partir de 200 mg de masa liofilizada en baño termostático a $65^{\circ} \mathrm{C}$. Para la extracción de las gliadinas se utilizó propanol 50\% se incubó 30 min y se centrifugó durante 2 min a $9300 \mathrm{~g}$ en una microcentrífuga eppendorf $5415 \mathrm{R}$ (Hamburgo, Alemania) separándose el sobrenadante con las gliadinas. Se realizaron sobre el pellet dos extracciones más para minimizar la posibilidad de gliadinas remanentes en el mismo. Para extraer las gluteninas, el pellet se incubó con propanol 50\% + Tris- $\mathrm{HCl} 0,08 \mathrm{M}(\mathrm{pH}=8,0)$ con ditiotreitol (DTT) $1 \% \mathrm{p} / \mathrm{v}$ en baño termostático a $65^{\circ} \mathrm{C}$ durante $30 \mathrm{~min}$ y luego se centrifugó durante $5 \mathrm{~min}$ a $9300 \mathrm{~g}$ en una microcentrífuga eppendorf $5415 \mathrm{R}$, posteriormente se agregó propanol $50 \%+$ Tris- $\mathrm{HCl} 0,08 \mathrm{M}(\mathrm{pH}=8,0)+4$-vinilpiridina $1,4 \% \mathrm{v} / \mathrm{v}$. Se incubó durante $15 \mathrm{~min}$ y se centrifugó durante 2 min a $15700 \mathrm{~g}$. En el sobrenadante se encontraron las gluteninas.

Para realizar las electroforesis a ambas fracciones proteicas se les agregó igual volumen de buffer de muestra $2 \mathrm{X}$ (2X significa que fue preparado de forma tal que presenta una concentración que duplica al valor de concentración con el cual se empleara en la muestra).

\subsection{Reactivos utilizados en la electroforesis SDS-PAGE}

- Buffer de electrodo o de corrida 5X: Tris base 0,125 M con glicina 0,96 M y SDS $0,5 \%, \mathrm{pH}=8,3$.

- Buffer separador 4X: Tris base 1,5 M, SDS 0,4\%, pH 8,8.

- Solución de Acrilamida/Bis acrilamida 30,8\%

- Temed ( $N, N_{,}, N^{\prime}, N^{\prime}$, -tetrametiletilendiamina) $0,4 \%$

- Persulfato de amonio $10 \%$

- Buffer de muestra 2X: Tris 0,37 M, glicerol 25\% p/v, SDS 4,0\% p/v y azul de bromofenol $0,1 \% \mathrm{p} / \mathrm{v}$

- $\quad$ Buffer stacking $4 \mathrm{X}$ : tris base $0,5 \mathrm{M}$, SDS 0,4\%, pH 6,8 
- El colorante fue preparado disolviendo 1,92 g de Coomasie blue R- 250 en 400 $\mathrm{ml}$ de alcohol metílico, $440 \mathrm{ml}$ de agua destilada y $160 \mathrm{ml}$ de ácido acético.

- El decolorante utilizado tuvo la siguiente composición: $650 \mathrm{ml}$ de agua, $100 \mathrm{ml}$ de ácido acético y $250 \mathrm{ml}$ de etanol.

- Patrones de masa molecular: se utilizaron en las corridas como patrones A) proteínas baja masa molecular para los extractos obtenidos con propanol 50\% y con ácido acético $0,1 \mathrm{M}$ (condiciones no reductoras) y B) proteínas de alta masa molecular para los extractos obtenidos en condiciones reductoras. Los patrones de baja masa molecular fueron: fosforilasa b (97 kDa), albúmina (66 kDa), ovoalbúmina (45 kDa), anhidrasa carbónica (30 kDa), inhibidor de tripsina (20,1 kDa) y $\alpha$ - lactoálbumina (14,4 kDa) (GE Healthcare, Inglaterra), los que se prepararon disolviéndolos en $200 \mu$ de buffer de muestra con $\beta$ mercaptoetanol. Los patrones de alta masa molecular utilizados fueron: miosina (212 kDa), $\alpha_{2}$-macroglobulina (170), $\beta$-galactosidasa (116 kDa), transferrina (76 kDa) y deshidrogenasa glutámica (53 kDa) (Pharmacia, Biotech, Estados Unidos).

\subsection{Procedimiento}

Para la realización de las electroforesis se emplearon miniplacas en un equipo MiniProtean III (BIO-RAD, Inglaterra). Se utilizaron geles de $1 \mathrm{~mm}$ de espesor con 10 calles cada uno, en los cuales el gel separador tuvo una concentración de acrilamida/bisacrialmida de del $12 \%$ y el gel apilador o concentrador del $4 \%$. Las fracciones proteicas liofilizadas fueron resuspendidas en el buffer de muestra. El volumen de muestra sembrado por calle fue de 15 - $20 \mu$ l mientras que el volumen sembrado para los patrones de baja masa molecular fue de $4 \mu \mathrm{l}$ y de $10 \mu \mathrm{l}$ para los patrones de alta masa molecular. Las corridas se realizaron a voltaje constante (200V) durante el tiempo necesario (aproximadamente 2 horas). Luego los geles se fijaron y tiñeron con Coomassie blue R-250 y posteriormente se decoloraron.

Los geles fueron escaneados empleando un escáner HP 4070 y se realizó el análisis de las masas moleculares de las bandas con el empleo del programa Sigma Gel versión 1.0 (Jandel Scientific, Estados Unidos).

\subsubsection{Espectroscopía Raman con transformada de Fourier}

La espectroscopía Raman con transformada de Fourier permite estudiar la estructura secundaria de las proteínas. 
La espectroscopía Raman se basa en el análisis de la luz dispersada por un material cuando incide sobre él un haz de luz monocromático, láser. La luz dispersada que presenta igual frecuencia que la luz incidente no aporta información acerca de la estructura molecular (radiación de Rayleigh) mientras que la que presenta una frecuencia diferente de la incidente, debida a la interacción con la materia, nos aporta información acerca de la estructura molecular de la misma y se denomina dispersión Raman (Fig. 2.17). En el espectro Raman se registra la intensidad de la luz dispersada en función del desplazamiento del número de onda $\Delta v\left(\mathrm{~cm}^{-1}\right)$, que se calcula como la diferencia entre el número de onda de la radiación incidente y la dispersada. Las bandas observadas ofrecen información acerca del movimiento vibracional de las moléculas y la intensidad de las mismas depende linealmente de la cantidad de sustancia presente (Long, 1977). Una desventaja de los espectrómetros Raman que utilizaban luz láser correspondiente a la zona del visible y ultravioleta para excitar era la aparición de fluorescencia ya que en algunos casos se podía ocultar la señal buscada pero el desarrollo de espectrómetros Raman con transformada de Fourier que emplean luz láser de 1,064 nm correspondiente al infrarrojo cercano como radiación de excitación minimizó los problemas de fluorescencia debido a que esta radiación no posee la energía suficiente para excitar a la mayor parte de los estados electrónicos (Ma, 2002).

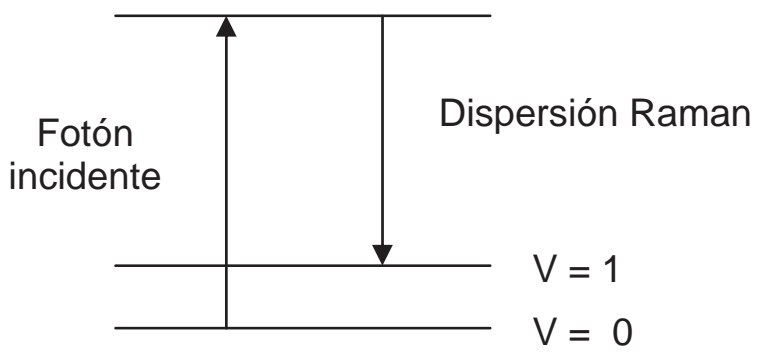

Figura 2.17. Diagrama energético, las líneas corresponden a diferentes niveles vibracionales (Dibujo del autor).

\subsection{Preparación de la masa}

Las masas fueron preparadas de igual modo que en el ítem 2.2.4.2.1. en ausencia y presencia de $\mathrm{NaCl}$. Se ensayó sólo el mayor nivel de hidrocoloide (1,5\% para las celulosas modificadas y $2 \%$ para las pectinas). La masa recién preparada fue 
congelada a $-80^{\circ} \mathrm{C}$ y posteriormente liofilizada. Los ensayos fueron realizados sobre la masa liofilizada. Para cada formulación se preparó un control en el cual se mezclaron almidón con $\mathrm{KBr}$, de forma tal que el contenido de almidón fuera igual al presente en la masa.

\subsection{Condiciones de los ensayos}

Los espectros FT-Raman fueron obtenidos en un espectrómetro Bruker IFS 113 FT-IR (Ettlingen, Alemania) equipado con un láser Nd: YAG de $1064 \mathrm{~nm}$ con una potencia de $500 \mathrm{~mW}$ (76 mW en la muestra). Los espectros fueron registrados a temperatura ambiente, con una resolución de $6 \mathrm{~cm}^{-1}$ y resultaron del promedio de 1000 escaneos. El procedimiento de ajuste de las curvas se realiza en varias etapas de ajuste iterativo. Para determinar la forma y posición de las bandas se utiliza el método de la segunda derivada mediante el cual se localiza a priori la posición y número de bandas a ajustar en el espectro Raman. Este procedimiento se llevó a cabo asumiendo una mezcla inicial de curvas Lorentzianas y Gaussianas, con una anchura de banda $(F W H H)$ entre $6-8 \mathrm{~cm}^{-1}$. Las correcciones de la línea de base, normalización, la derivación, ajuste de la curva y el cálculo del área para las mismas se llevaron a cabo por medio de los programas Grams/32 (Galáctica Industries Corporation, EE.UU.) y OPUS 4.0 (Bruker Optics, Alemania). Las curvas resultantes se analizaron teniendo en cuenta las asignaciones para la región de la banda de Amida I informadas en la literatura (Tu, 1982; Herrero, 2008; Ngarize, 2004). Con el fin de calcular el porcentaje de la contribución de los diferentes tipos de conformaciones al área total de la curva, las bandas asignadas a una conformación determinada se sumaron y dividieron por el área total. Los resultados informados corresponden al promedio de tres muestras de masas preparadas de manera independiente.

\subsubsection{Almidón}

\subsection{Gelatinización por calorimetría diferencial de barrido (DSC)}

Esta técnica permite el estudio de diferentes transiciones térmicas que involucran al almidón y que se hallan vinculadas al proceso de panificación y almacenamiento del pan (gelatinización y retrogradación).

En la calorimetría diferencial de barrido se mide la diferencia de temperatura entre la muestra y un material de referencia durante un calentamiento o enfriamiento 
programados y se compara el flujo de calor (energía/tiempo) de la muestra con el de la referencia (Choi y col., 2010). La referencia debe ser un material inerte que no sufra ningún cambio físico ni químico en el rango de temperatura ensayado (Añon, 2000). Cuando la muestra sufre algún cambio de fase o alguna transición, la energía absorbida o liberada se refleja en un cambio de temperatura entre la muestra y el material de referencia, el cual es proporcional al flujo de calor. Las transiciones térmicas pueden obtenerse al graficar el flujo de calor como función de la temperatura o el tiempo, obteniéndose picos cuya área es proporcional al cambio de entalpía y la dirección (hacia arriba o hacia abajo) indica si se trata de un proceso endotérmico o exotérmico.

Se estudió el efecto de los hidrocoloides en la gelatinización del almidón de trigo tanto en masa como en sistemas modelo. En este último caso, se extrajo previamente el almidón y con éste y los hidrocoloides se formularon los distintos sistemas. Las mediciones se realizaron con un calorímetro Q100 de TA Instruments, Estados Unidos.

\subsection{Sistemas modelo almidón-hidrocoloide}

\section{A) Extracción de almidón}

Se realizó una extracción de almidón a partir de masa preparada según se describe en el ítem 2.2.4.2.1. Se formó una masa a partir de $200 \mathrm{~g}$ de harina y la cantidad adecuada de agua, la que luego se lavó bajo canilla en forma manual, recogiéndose el agua de lavado ya que en ella se encuentra el almidón. Luego se centrifugó el agua de lavado en una centrífuga Avanti J-25 (Beckman Coulter, California, Estados Unidos) a $12096 \mathrm{~g}$ durante $10 \mathrm{~min}$ a $10^{\circ} \mathrm{C}$. Se realizó un lavado del pellet con propanol $50 \%$ y se realizó otra centrifugación a $12096 \mathrm{~g}$ a $10^{\circ} \mathrm{C}$ durante $10 \mathrm{~min}$, por último se secó en estufa a $30^{\circ} \mathrm{C}$ (Figura 2.18).

\section{B) Ensayos de gelatinización con sistemas modelo}

Se prepararon mezclas almidón - hidrocoloide en presencia y ausencia de $\mathrm{NaCl}$, las cuales se mezclaron en seco y a las que luego se les agregó agua y se mezclo hasta formar una pasta homogénea. La cantidad de agua agregada para cada mezcla se calculó a partir del agua empleada en la preparación de las respectivas masas. En base a la cantidad de almidón que posee la harina se calculó la cantidad de agua que debía agregarse en forma proporcional. Se evaluaron los picos correspondientes a la gelatinización del almidón y a la disociación del complejo amilosa - lípido. Para cada 
uno se determinaron: la temperatura de inicio, la temperatura del pico y la temperatura de finalización y el cambio entálpico asociado a la transición térmica. El ensayo se realizó por duplicado.

Se pesaron entre 6 y $15 \mathrm{mg}$ de muestra en cápsulas de aluminio que se sellaron herméticamente y se sometieron a una rampa de calentamiento desde $10^{\circ} \mathrm{C}$ hasta $130^{\circ} \mathrm{C}$ a una velocidad de $10^{\circ} \mathrm{C} / \mathrm{min}$ en un calorímetro diferencial de barrido (Q100 TA Instruments, Estados Unidos).

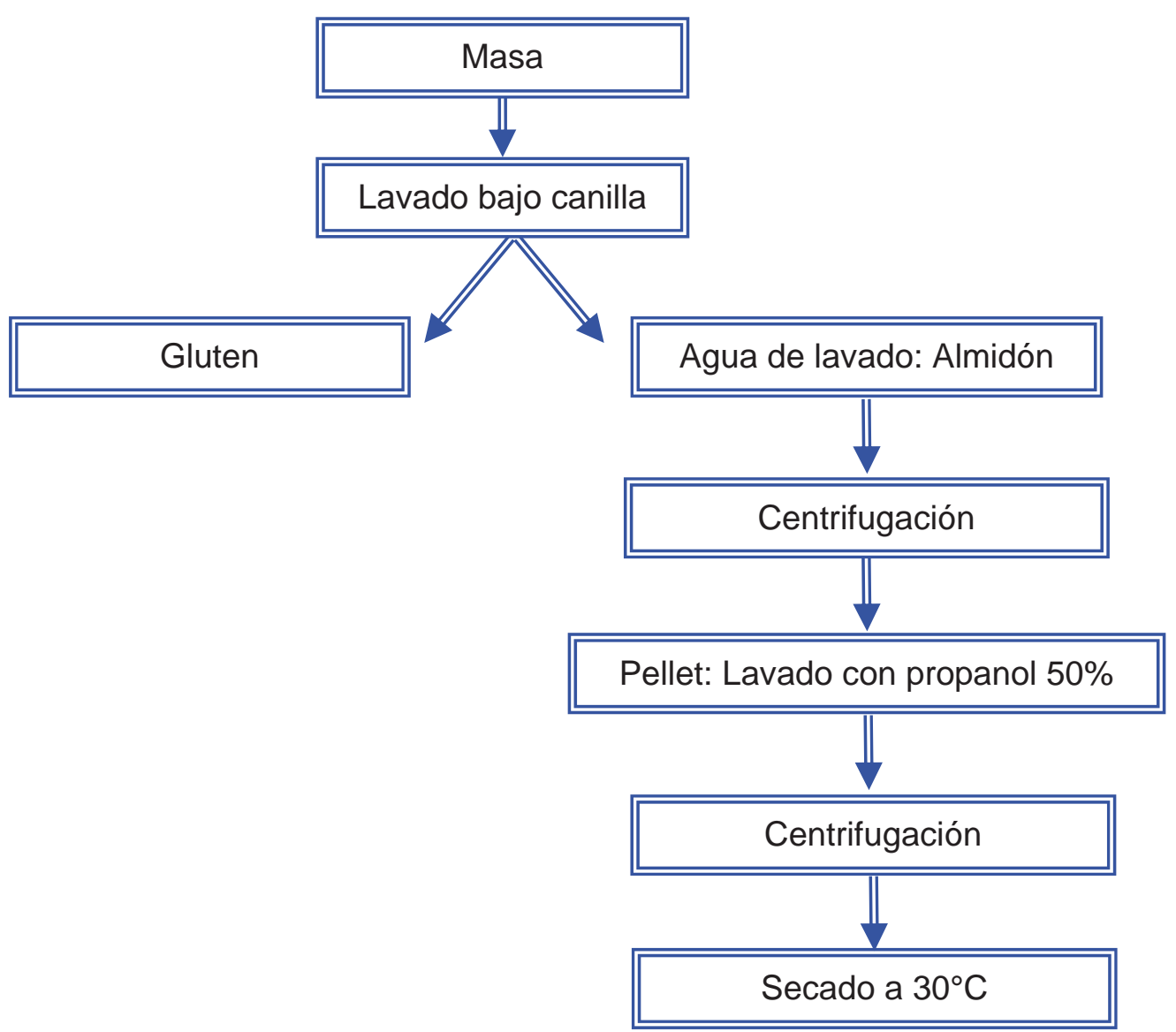

Figura 2.18. Obtención de almidón a partir de masa

\subsection{Masa}

\section{A) Preparación de las masas}

La formulación empleada fue: $100 \mathrm{~g}$ de harina, agua según la absorción farinográfica, celulosas modificadas $1,5 \%$ y pectinas $2,0 \%$. Las masas se prepararon sin levadura y 
sin y con $\mathrm{NaCl}(2 \%)$ en un microfarinógrafo (Brabender, Duisburg, Alemania). Se realizó una premezcla de los ingredientes durante un minuto, luego se agregó el agua y se amasó cada mezcla durante un tiempo igual a su tiempo de desarrollo farinográfico.

\section{B) Gelatinización del almidón en masa}

Se pesaron entre 7 - $15 \mathrm{mg}$ de masa en una cápsula de aluminio y se la sometió a un calentamiento desde $10^{\circ} \mathrm{C}$ a $130^{\circ} \mathrm{C}$ a una velocidad de $10^{\circ} \mathrm{C} / \mathrm{min}$ en un calorímetro diferencial de barrido (Q100 TA Instruments, Estados Unidos). Se utilizó como referencia una cápsula vacía.

Se evaluaron la gelatinización del almidón y la disociación del complejo amilosa-lípido (Figura 2.19). Para ambos procesos se determinaron la temperatura de inicio, la temperatura de pico y la temperatura de finalización, así como también el cambio entálpico asociado. El ensayo se realizó por duplicado.

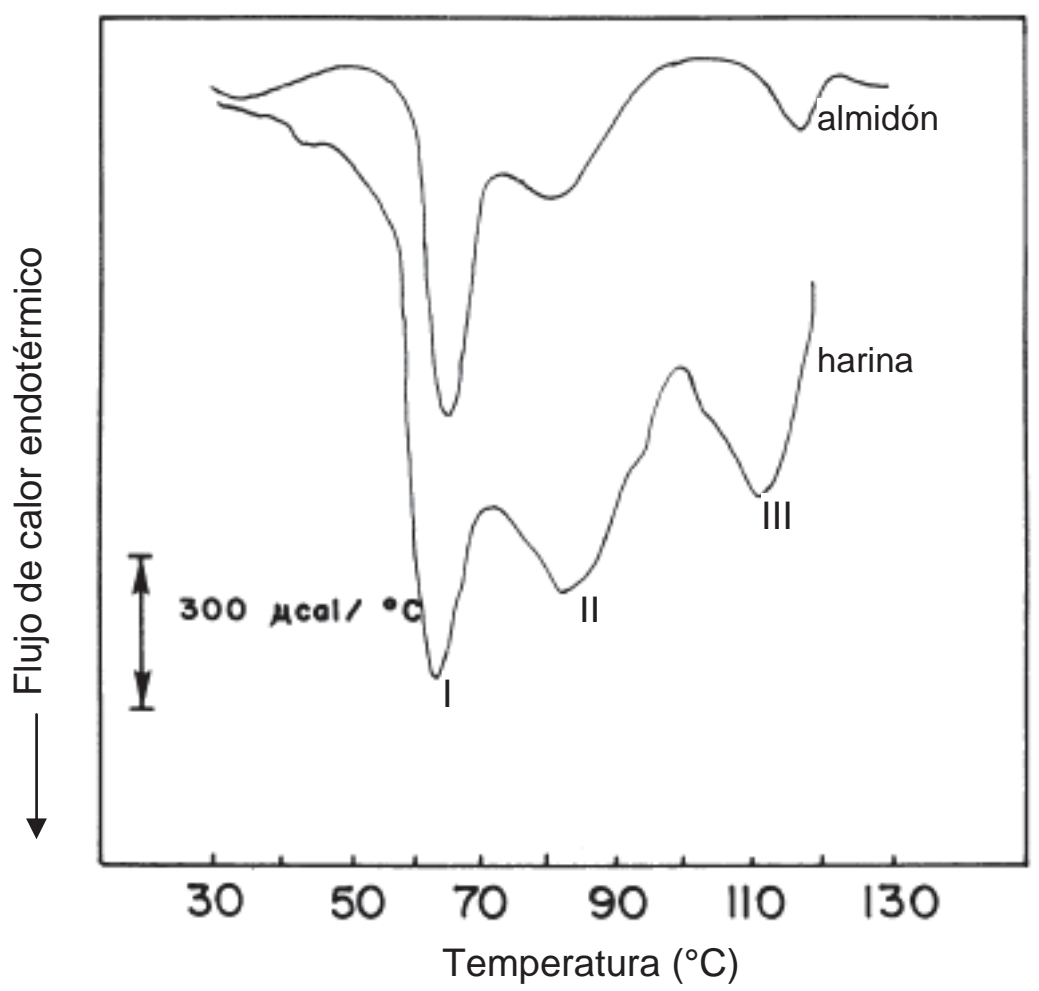

Figura 2.19. Termogramas típicos de almidón de trigo y harina. I y II endotermas correspondientes a la gelatinización del almidón, III: endoterma correspondiente a la disociación del complejo amilosa-lípido (Adaptada de Ghiasi y col., 1982). 


\subsection{Viscoamilogramas}

Se realizaron los viscoamilogramas de las mezclas harina- hidrocoloide en ausencia y presencia de $\mathrm{NaCl}(2 \%)$ de igual modo que se describe en el ítem 2.2.2.4.

\subsubsection{Microestructura de la masa}

\subsection{Microscopia electrónica de barrido}

La microscopía electrónica de barrido (SEM: scanning electron microscopy) permite conocer la morfología de la superficie de las muestras a estudiar. La diferencia principal con la microscopía óptica radica en que emplea un haz de electrones en lugar de un haz de luz visible, obteniéndose una resolución mucho mayor que la alcanzada con microscopía óptica. En un microscopio electrónico de barrido los electrones son emitidos desde un filamento de tungsteno (cátodo) y acelerados en un campo eléctrico (Figura 2.20). Los electrones son enfocados por un condensador y una lente objetivo electromagnética sobre la muestra cubierta por un metal pesado (oro, osmio). Bobinas de barrido mueven el haz de electrones a través de la muestra y los electrones secundarios liberados del metal son recogidos por un tubo detector fotomultiplicador. El número de electrones secundarios liberados depende del ángulo del haz de electrones respecto de la superficie por lo que la imagen obtenida tiene aspecto tridimensional (Lodish, 2005).

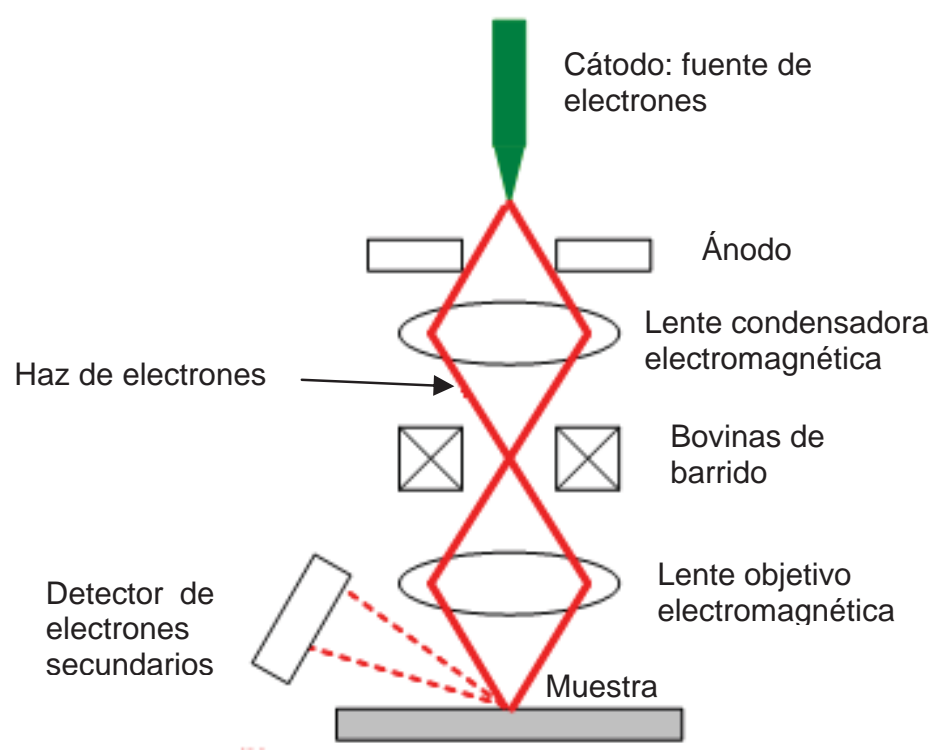

Figura 2.20. Camino óptico seguido por el haz de electrones en un microscopio electrónico de barrido (Fuente: www. substech.com) 
Todo el sistema entre la fuente de electrones y el detector se mantiene bajo vacío debido a que los electrones pueden ser absorbidos por los átomos del aire. La resolución alcanzada por SEM depende del espesor del recubrimiento metálico y es de aproximadamente $10 \mu \mathrm{m}$.

\subsection{Preparación de las muestras}

Se realizaron micrografías de masa a 500X, 3000X y 5000X empleando un microscopio electrónico (JEOL $35 \mathrm{CF}$, Japón). Las masas se prepararon sin y con $\mathrm{NaCl}(2 \%)$, las celulosas modificadas se adicionaron al $1,5 \%$ y las pectinas al $2 \%$, se siguió el procedimiento descripto en el ítem 2.2.4.2.1. para los ensayos reológicos. La preparación de la muestra consistió en colocar pequeñas porciones de masa en glutaraldehído al 10\% y embeberlas secuencialmente en soluciones de acetona de concentración creciente para asegurar la deshidratación completa, luego se realizó un secado por la técnica del punto crítico y se cubrieron con partículas de oro.

Los ensayos fueron realizados en el laboratorio de microscopía electrónica de CRIBABB (Centro regional de Investigaciones Básicas y Aplicadas de Bahía Blanca).

\subsection{Microscopía confocal láser de barrido}

La microscopía confocal láser de barrido (CSLM) es una técnica de observación que ofrece múltiples ventajas frente a la microscopía óptica tradicional ya que permite obtener imágenes de mayor nitidez y contraste, mayor resolución vertical y horizontal y además permite obtener secciones ópticas de la muestra a partir de las cuales se logra obtener una reconstrucción tridimensional de la misma. Esto básicamente se logra a través de 1) la eliminación de la luz fluorescente procedente de los planos fuera de foco, 2) la utilización de un láser como fuente de luz lográndose de este modo que una pequeña región de la muestra sea iluminada con gran intensidad y 3) la presencia de dos diafragmas (pinhole), uno entre la fuente de luz y el objetivo y otro entre el objetivo y el detector. En la Figura 2.21 se muestra un esquema del microscopio. 


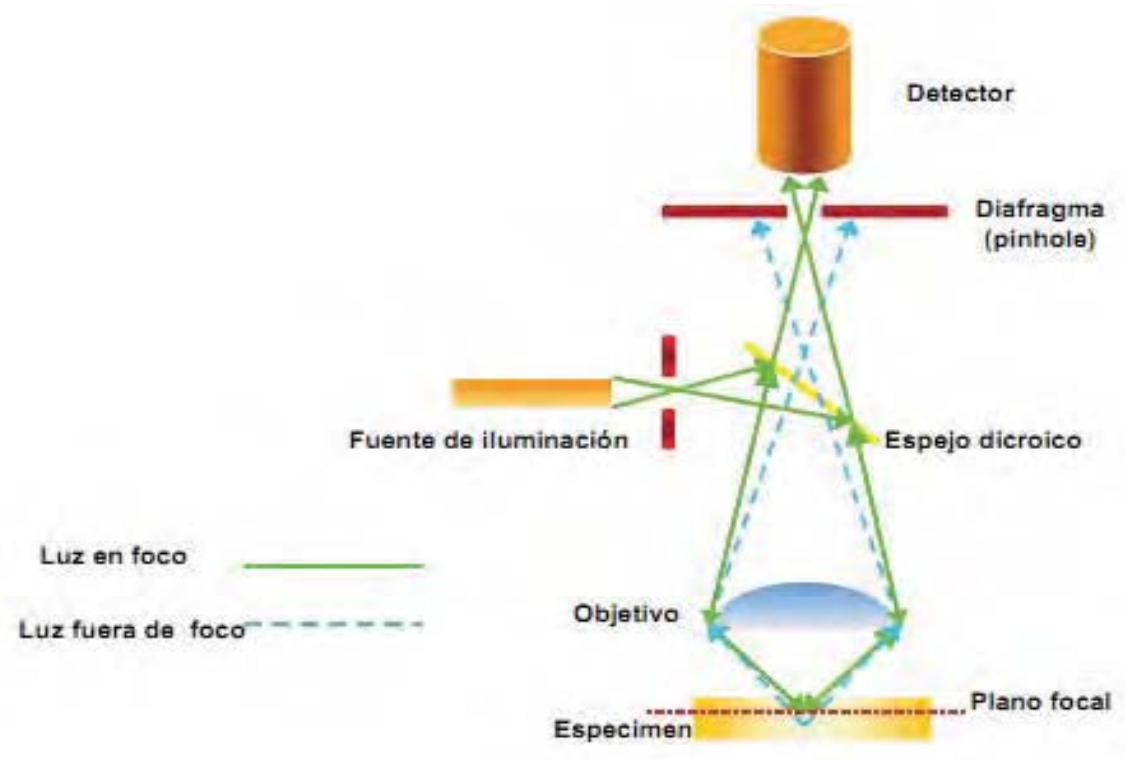

Figura 2.21: Camino óptico en un microscopio confocal (Fuente: Martínez, Servicio de Procesamiento de imágenes, Universidad de Oviedo, España).

\subsection{Preparación de las muestras}

Se estudiaron las masas control y con hidrocoloide en los niveles más altos (1,5\% para las celulosas modificadas y $2 \%$ para las pectinas) en presencia y ausencia de $\mathrm{NaCl}$. Se realizó un marcado no covalente con rodamina B (Biopack) e isotiocianato de fluoresceína (Sigma). El contraste obtenido a través de la tinción depende del balance entre la afinidad de los fluoróforos por las fases a ser teñidas. Se ensayaron agua y $\mathrm{N}, \mathrm{N}$-dimetilformamida (DMF) como solventes para preparar la solución colorante. En la solución acuosa las concentraciones empleadas fueron FITC $0,01 \%$ y rodamina B $0,001 \%$ mientras que en DMF se usaron: FITC $1 \%$ y rodamina $\mathrm{B} 0,1 \%$.

Las masas se prepararon como se describe en el ítem 2.2.5.3.1.2.A. Se tomó una porción de masa y se extendió sobre un portaobjetos con la ayuda de una varilla de acrílico, inmediatamente se cubrió con la solución que contenía los fluoróforos. Se dejó una hora en reposo en un recipiente cerrado y en la oscuridad, luego se lavó con el solvente correspondiente y se cubrió con un portaobjetos. Se utilizaron como controles las masas sin fluoróforos y las masas con FITC y rodamina B por separado. Las masas se prepararon por duplicado. 


\subsection{Observación microscópica}

Se empleó un microscopio confocal invertido LEICA TCS SP5 (Mannheim, Alemania) equipado con láseres de Argón y HeNe. Los parámetros de captura utilizados fueron:

- Resolución: 1024 X 1024 pixeles

- Modo de adquisición: xyz

- Formato: lif

- Objetivos utilizados: HCX PL APO CS 20,0X (inmersión con agua) y HCX PL APO CS 63,0X (inmersión con aceite)

- Apertura numérica: 0,70 para el objetivo de 20 X y 1,40 para el objetivo de $63 \times$

- Velocidad de escaneo: $200 \mathrm{~Hz}$

- Láser de Argon: $20 \%$

Se utilizaron como longitudes de onda de excitación $488 \mathrm{~nm}$ (para FITC) y $568 \mathrm{~nm}$ (para rodamina B) y como longitudes de onda de emisión 518 nm y $625 \mathrm{~nm}$ para FITC y rodamina B respectivamente.

Se realizaron observaciones de varios campos con diferentes aumentos: $20 \mathrm{X}, 63 \mathrm{X}$, $63 \mathrm{X}+$ zoom óptico de 3,3 y escaneos en z con un aumento de $63 \mathrm{X}+$ zoom óptico de 3,3 con la finalidad de buscar las mejores condiciones para el estudio de las masas. A partir de los escaneos en z se logró obtener imágenes tridimensionales de la masa. El análisis de las imágenes se realizó con el empleo del programa provisto por el fabricante del microscopio: LAS AF versión 2.2.1. build 4842 y con el programa Image J $1.43 \mathrm{u}$.

\subsection{Resonancia magnética nuclear ( $\left.{ }^{1} \mathrm{H}-\mathrm{RMN}\right)$}

La espectroscopia de resonancia magnética nuclear es una técnica no invasiva que permite determinar la movilidad molecular de los protones en sistemas complejos a través de ensayos de relajación (Chinachoti y col., 2008). Los núcleos de los átomos de hidrógeno poseen un momento angular de spin no nulo por lo cual cuando son sometidos a un campo magnético se alinean paralelos al mismo, ocasionando la magnetización masiva de la muestra.

Se puede cambiar la orientación de los núcleos aplicando radiación de radiofrecuencia que es absorbida por la muestra; cuando cesa la aplicación los núcleos vuelven a su estado inicial emitiendo una señal. El tipo de onda utilizada habitualmente es la onda pulsada (con pulsos de pocos microsegundos). Se logra así rotar los núcleos en 90 
respecto a la dirección del campo magnético estático, obteniéndose así la máxima intensidad de señal. El retorno al estado de equilibrio involucra dos procesos de relajación: la longitudinal o spin-red $\left(T_{1}\right)$ y la transversal o spin-spin $\left(T_{2}\right)$. La relajación longitudinal $T_{1}$ se define como la constante de tiempo que caracteriza la velocidad a la cual la componente $z$ del vector de magnetización vuelve a su valor de equilibrio. La relajación transversal se define como la constante de tiempo que caracteriza a la velocidad de decaimiento de la magnetización en el plano xy.

La medición de la señal en función del tiempo después de aplicado el pulso (curva de relajación) permite obtener una gran cantidad de información respecto al sistema (Choi y col. 2010):

- La amplitud inicial de la señal es proporcional al número total de núcleos de hidrógeno en la muestra.

- Las señales de núcleos correspondientes a diferentes entornos físicos o químicos decaen a diferentes velocidades constituyendo diferentes componentes (superpuestas) de la señal observada

-Cada componente de la señal decae con una constante de tiempo característica denominada "tiempo de relajación". Los núcleos de fases sólidas decaen más rápidamente que los de fases líquidas.

Es posible modelar los registros de decaimiento obtenidos con ecuaciones de tipo exponencial, de uno o más términos:

$$
I=\sum_{i=1}^{n} y_{i} \exp \left(\frac{-x}{T_{2 i}}\right)
$$

donde I es la intensidad de la señal de los protones, la cual es proporcional a la cantidad de protones en la muestra, $\mathrm{T}_{2 i}$ el tiempo de relajación de la población i de protones y $y_{i}$ es la intensidad de la señal de los protones en el estado $T_{2 i}$.

Con un equipo de RMN de baja resolución (Minispec, Bruker, Alemania) se determinaron los tiempos de relajación spin-spin $\left(T_{2}\right)$ de los núcleos de hidrógeno presentes en la masa. Las masas se prepararon con y $\sin \mathrm{NaCl}$ de igual modo que en 2.2.4.2.1. y los hidrocoloides se utilizaron en dos niveles: las celulosas al 0,5 y $1,5 \%$ mientras que las pectinas al 1 y $2 \%$. El ensayo se realizó a temperatura ambiente y por duplicado. Se aplicó la secuencia de pulsos Carr-Purcell-Meiboom-Gill (CPMG) con un tiempo entre pulsos de $200 \mu \mathrm{s}$. La secuencia de pulsos de eco de spin de CPMG se utiliza para promediar las inhomogeneidades macroscópicas que podrían causar un 
ensanchamiento significativo de la señal. El empleo de secuencia de pulsos es necesario cuando se miden tiempos de relajación del orden de los milisegundos. El decaimiento observado se modeló con una ecuación exponencial (Ec. 2.33) utilizando el programa Origin.

\subsubsection{Panificación}

\subsubsection{Curvas de fermentación}

Las curvas de fermentación se realizaron con la finalidad de evaluar el efecto del hidrocoloide en esta etapa del proceso de panificación y determinar el tiempo óptimo de fermentación para cada mezcla harina - hidrocoloide.

\subsection{Formulación empleada en las curvas de fermentación}

La formulación empleada para la realización de las curvas de fermentación, en base harina fue: $\mathrm{NaCl} 2,0 \%$, levadura $3,0 \%$ y cantidad de agua según la absorción farinográfica. Las celulosas modificadas se utilizaron en cuatro niveles: $0,25 \%, 0,5 \%$, $1,0 \%$ y $1,5 \%$, mientras que las pectinas además se emplearon al 2,0\%.

\subsection{Elaboración de la masa y fermentación}

Las masas se prepararon con el empleo de una amasadora planetaria (Kenwood, Italia). Los ingredientes secos se premezclaron durante un minuto, la levadura se disolvió en el agua y se agregó a la mezcla durante el primer minuto de amasado. Los tiempos de amasado se fijaron de acuerdo al tiempo de desarrollo farinográfico de cada mezcla. La amasadora planetaria no tiene la misma geometría que la del farinógrafo y tampoco es posible lograr exactamente la misma velocidad de amasado. Por ello, para corroborar que el tiempo de desarrollo farinográfico era adecuado se probaron para diversas muestras tiempos menores y mayores. Se verificó así que la masa adquiría la consistencia y extensibilidad adecuadas con los tiempos aplicados.

Después del amasado, la masa se dejó reposar durante 15 minutos, se laminó y se dejó reposar durante otros 15 minutos. Luego, se dividió en piezas de $50 \mathrm{~g}$, se colocó en la base de una probeta graduada y sobre ella se ubicó un émbolo móvil muy ligero que se elevó junto con la masa facilitando la lectura del volumen. La probeta se colocó en una estufa a $30^{\circ} \mathrm{C}$ y se registró la variación del volumen $(\Delta \mathrm{V})$ a lo largo del tiempo, las lecturas se realizaron cada 10 min. Se graficó $\Delta \mathrm{V}\left(\mathrm{cm}^{3}\right)$ en función del tiempo (min) 
y se ajustó la curva obtenida mediante distintas ecuaciones para seleccionar la más adecuada.

Dado que la masa cuando se coloca en el horno continúa dilatándose hasta que se fija la estructura de la miga, es necesario darle un tiempo de leudado previo menor al correspondiente al volumen máximo para evitar la excesiva expansión de la masa y el consecuente colapso. Por lo tanto, se estableció el tiempo de fermentación como el tiempo necesario para alcanzar tres cuartos del $\Delta \mathrm{V}_{\max }$. Se calcularon las velocidades iniciales de la fermentación, para lo cual se tomaron los incrementos de volumen alcanzados durante la primera hora de fermentación y se realizó una regresión lineal. La pendiente de la recta obtenida corresponde a la velocidad inicial.

\subsubsection{Formulación empleada para panificar}

La formulación empleada para la elaboración de los panes cada $100 \mathrm{~g}$ de harina fue: $\mathrm{NaCl} 2,0 \%$, levadura 3,0 \% y cantidad de agua según la absorción farinográfica. Las celulosas modificadas se utilizaron en dos niveles 0,5 y $1,5 \%$, mientras que los niveles empleados para las pectinas fueron 1,0 y 2,0\%. Las masas se elaboraron a partir de $400 \mathrm{~g}$ de harina. Al pan elaborado sin el agregado de aditivos se lo tomo como control. La panificación se realizó por duplicado.

\subsubsection{Protocolo de panificación}

El amasado se realizó en una amasadora planetaria (Kenwood, Italia). Los ingredientes secos fueron mezclados durante un minuto y la levadura se disolvió en el agua. El tiempo de amasado para cada mezcla fue el tiempo de desarrollo farinográfico. Durante el primer minuto de amasado a baja velocidad (52 rpm) se agregó el agua con la levadura, el resto del tiempo se amasó a velocidad 2 (89 rpm). La masa se dejó reposar durante 15 minutos a temperatura ambiente y se cubrió con film para evitar su desecación. Luego se laminó en forma manual, se realizaron cuatro pasadas por la laminadora (Pastafacil, Argentina) con una luz de 0,5 cm entre los rodillos, y se dejó reposar durante otros 15 minutos. Pasado el tiempo de reposo, la masa se dividió en porciones de $90 \mathrm{~g}$. Cada una fue sometida a un bollado manual y se dejó reposar durante 10 minutos. Por último se formaron las piezas de pan francés con el empleo de una armadora MPZ (Buenos Aires, Argentina). Las piezas se colocaron en bandejas y se dejaron leudar durante su tiempo de fermentación óptimo, en una cámara de fermentación a $30^{\circ} \mathrm{C}$ (Brito Hnos., Argentina). La cocción se realizó 
en un horno a convección Aristón XF 995.3 a $210^{\circ} \mathrm{C}$ durante 26 minutos. Los panes se dejaron enfriar a temperatura ambiente al menos durante una hora y se colocaron en bolsas de polietileno para su almacenamiento a $20^{\circ} \mathrm{C}$ por 1 y 3 días.

\subsubsection{Caracterización de los panes}

\subsection{Determinación del volumen específico de pan}

La determinación del volumen de pan se realizó por desplazamiento de semillas de colza empleando un volumenómetro, previa medición del peso de cada pan mediante la utilización de una balanza granataria. El peso específico se calculó como el cociente entre el volumen y el peso del pan. Para cada formulación se determinó el volumen específico de 8 panes, 4 provenientes de cada panificación y cada pan fue medido 15 veces.

\subsection{Determinación del color de la corteza de los panes}

Se determino el color de la corteza utilizando como medida objetiva de color el espacio rectangular Hunter $\boldsymbol{L}, \boldsymbol{a}, \boldsymbol{b}$ donde el eje $\boldsymbol{L}$ indica la luminosidad y toma valores entre 0 (negro) y 100 (blanco), en el eje a los valores positivos indican la dirección del rojo y los negativos la dirección del verde y en el eje $\boldsymbol{b}$ los valores positivos indican la dirección del amarillo mientras que los negativos la dirección del azul (Fig. 2.22). Se realizaron 20 medidas del color por panificación con un colorímetro triestímulo Chroma Meter CR-400 Konica Minolta (Osaka, Japón), previa calibración del mismo con un patrón provisto por el fabricante $(\mathrm{Y}=93,2 ; \mathrm{x}=0,3133, \mathrm{y}=0,3192)$.

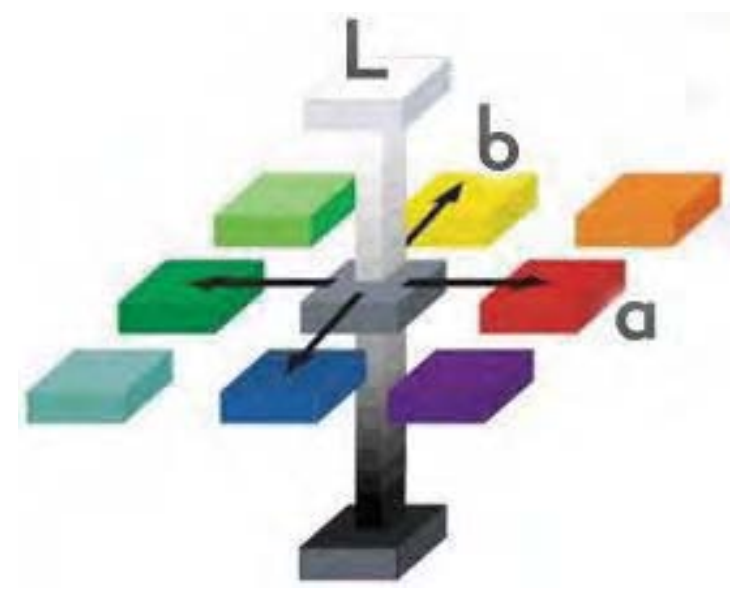

Figura 2.22. Espacio de color Hunter L, a, b. 
Además, se calculó el índice de pardeamiento o browning index (BI) (Ecuación 2.34) que es una medida de la pureza del color marrón (Buera y col., 1985). Este parámetro ha demostrado presentar una correlación lineal con la concentración de pigmento marrón por lo que ha resultado de utilidad para la evaluación de los cambios de color en alimentos que experimentan reacciones de pardeamiento enzimático y no enzimático. En particular, en panificación ha permitido observar variaciones en el color del pan debido a modificaciones en la formulaciones empleadas (Shittu y col. 2007 y 2008; Komlenic y col., 2010).

$$
\mathrm{BI}=\frac{100(\mathrm{X}-0,31)}{0,172}
$$

donde X esta definido por la ecuación 2.35

$$
X=\frac{a+1,75 L}{5,645 L+a-3,012 b}
$$

\subsection{Determinación de la humedad de la miga}

Se determinó la humedad de la miga de los panes frescos de acuerdo a la técnica AACC 44-19 (2000), por secado en estufa de convección forzada (velocidad del aire $25 \mathrm{~cm} / \mathrm{s}$ ) (Estigia, Argentina) durante dos horas a $135^{\circ} \mathrm{C}$. El ensayo se realizó por triplicado.

\subsection{Análisis de perfil de textura (TPA) de la miga del pan fresco}

Entre las características que se buscan en un pan fresco se encuentran la blandura y la elasticidad de la miga. Estos atributos pueden ser rápidamente evaluados por el consumidor al presionar con su dedo la miga del pan. Esta práctica lo lleva a rechazar aquel producto en el cual la miga es demasiado dura o en la cual la misma permanece aplastada una vez finalizada la compresión. Es por este motivo que se utilizan ensayos de compresión entre los ensayos objetivos para evaluar la calidad del pan (Cauvain, 2004a).

Se evaluó la textura de la miga de los panes frescos a través del análisis de perfil de textura, en el cual la muestra se somete a dos compresiones sucesivas, con un período de descanso entre ambas. De este modo, se intenta simular el proceso de 
masticación que experimenta el alimento en la boca. Se ha encontrado buena correlación entre los valores instrumentales y los obtenidos a través de la evaluación sensorial (Friedman y col., 1962).

Se utilizó un analizador de textura TA.XT2i (Stable Micro Systems, Surrey, Reino Unido) equipado con una celda de carga de $25 \mathrm{~kg}$. En este ensayo para cada formulación se evaluó la textura de 8 panes, 4 panes procedentes de cada panificación. A partir de cada pan se obtuvieron 2 rodajas de $2 \mathrm{~cm}$ de espesor provenientes de la parte central del mismo. Las rodajas fueron sometidas a dos ciclos de compresión hasta un $40 \%$ de su altura original usando una sonda de 2,5 cm de diámetro (SMS P/25) y una velocidad de ensayo de $0,5 \mathrm{~mm} / \mathrm{seg}$. Los parámetros determinados fueron:

- Dureza de la miga, que se relaciona con la fuerza necesaria para realizar la primera mordida

- Cohesividad: se compara el trabajo que es necesario realizar en la segunda mordida con respecto al que fue necesario realizar en la primera

- Consistencia: relacionada con el trabajo que es necesario realizar al masticar en dos oportunidades

- Elasticidad: relacionada con la recuperación de la forma original por la muestra luego de la deformación

- Resiliencia: relacionada con la recuperación instantánea del material luego de la primera compresión

- Masticabilidad: se obtuvo como el producto de la cohesividad, la dureza y la elasticidad y se relaciona con el esfuerzo que es necesario realizar al masticar.

Los cinco primeros parámetros se calcularon de igual modo que en 2.2.4.2.2.

\subsection{Análisis dinámico-mecánico de la miga de los panes frescos}

En un ensayo dinámico mecánico (DMA) la muestra se somete a un esfuerzo sinusoidal (Ec. 2.26) perpendicular a la misma, el cual le produce una deformación sinusoidal dada por la Ec. 2.36.

$$
\varepsilon(\mathrm{t})=\varepsilon_{0} \operatorname{sen}(\omega \mathrm{t})
$$

donde $\varepsilon_{0}$ es la máxima deformación alcanzada y $\omega$ la frecuencia. La ecuación 2.37 nos muestra la relación existente entre el esfuerzo y la deformación. 


$$
\sigma(t)=E^{*}(\omega) \varepsilon(t)
$$

donde $\mathrm{E}^{\star}$ es el módulo dinámico y está representado por:

$$
E^{*}=E^{\prime}(\omega)+i E^{\prime \prime}(\omega)
$$

donde $E^{\prime}(\omega), E^{\prime \prime}(\omega)$ son los módulos elástico y viscoso respectivamente. Para un polímero viscoelástico, $E^{\prime}$ caracteriza su habilidad para almacenar energía (comportamiento elástico) mientras que $\mathrm{E}^{\prime \prime}$ se relaciona con la tendencia del material a disipar energía (comportamiento viscoso). La tangente del ángulo de desfasaje se calcula como

$$
\tan (\delta)=\frac{E^{\prime \prime}}{E^{\prime}}
$$

\subsection{Preparación de la muestra}

Para la preparación de la muestra se siguió la técnica descripta por Ribotta y Le Bail (2007a). Los panes fueron cortados en forma transversal y a partir de la zona central de los mismos se obtuvieron rodajas de aproximadamente $1 \mathrm{~cm}$ de espesor, las cuales se comprimieron durante 10 min hasta un $90 \%$ de su altura original en un texturómetro TA.XT2i (Stable Micro Systems, Surrey, Reino Unido) utilizando una sonda cilíndrica de $7,5 \mathrm{~cm}$ de diámetro. A partir de la miga comprimida se cortaron piezas de geometría rectangular de $60 \mathrm{~mm}$ de largo, $15 \mathrm{~mm}$ de ancho y espesor inferior a $5 \mathrm{~mm}$ que se congelaron a $-18^{\circ} \mathrm{C}$ hasta el momento de su utilización.

\subsection{Caracterización del comportamiento dinámico mecánico (DMA)}

Se realizó el análisis dinámico mecánico de la miga proveniente de los panes con el mayor nivel de hidrocoloide (celulosas modificas $1,5 \%$ y pectinas $2,0 \%$ ). Antes de realizar el ensayo se midieron las dimensiones de cada muestra con un calibre debido a que el software las utiliza para el cálculo de los módulos.

Se empleó un analizador dinámico mecánico Q 800 (TA Instrumets, Estados Unidos) equipado con una mordaza dual cantilever, en la cual la muestra se sujeta por tres puntos (los extremos y la región central) y la deformación se aplica en la zona central de la misma (Figura 2.23). 


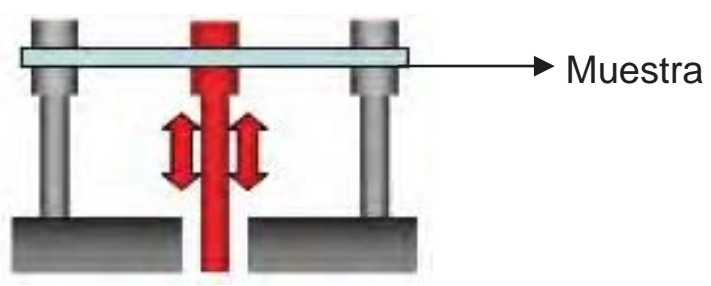

Figura 2.23. Mordaza dual cantilever donde se indica como se coloca la muestra (Fuente: Triton Technology www.http://triton-technology.co.uk)

El equipo se operó en dos modos 1) multi esfuerzo/ deformación y 2) multifrecuencia. Para la determinación del rango de viscoelasticidad lineal de las muestras el equipo se operó en el modo multi esfuerzo/deformación, en el cual se registran las propiedades viscoelásticas a medida que se varía el esfuerzo o la deformación realizada y se mantienen constantes la temperatura y la frecuencia. En el modo de multifrecuencia se determinan las propiedades viscoelásticas de la muestra en función de la frecuencia mientras se realiza una deformación constante (la amplitud de la oscilación se mantiene constante) en forma perpendicular a la superficie de la muestra y una rampa de temperatura. Se utilizó una amplitud de $15 \mu \mathrm{m}$ dentro del rango de viscoelasticidad lineal y una rampa de temperatura desde $-100^{\circ} \mathrm{C}$ a $40^{\circ} \mathrm{C}$ a una velocidad de $5^{\circ} \mathrm{C} / \mathrm{min}$. Los parámetros determinados fueron los módulos elástico y viscoso y la tangente del ángulo de desfasaje, los cuales se evaluaron en tres frecuencias: 1, 5 y $10 \mathrm{~Hz}$.

\subsection{Análisis del alveolado de la miga}

El tipo de alveolado de la miga (cantidad, tamaño, forma y distribución de las burbujas que quedan atrapadas luego de la fermentación y el horneado) es un atributo determinante de la calidad del pan. Una miga bien aireada es característica de un producto de buena calidad en tanto que migas apelmazadas y con un alveolado deficiente generalmente relacionado a bajos volúmenes de pan pueden conducir al rechazo del producto.

En cada panificación se realizó el escaneo de 4 rodajas de pan con un escáner HP 4070, el tamaño de las imágenes adquiridas fue de 10 X10 cm y la resolución de 350 dpi. Mediante la utilización del programa ImageJ versión 143 se procedió al análisis de imagen de la miga. A partir del centro de cada rodaja se obtuvo una imagen de 3,20 $\mathrm{cm} \times 3,20 \mathrm{~cm}$ para todas las muestras. Luego la imagen digital en RGB color se convirtió a imagen de 8 bit en escala de grises y se binarizó con la utilización del 
algoritmo de Huang, el cual se eligió entre otros que ofrece el programa image $\mathrm{J}$ debido a que fue el que mejor reflejó la estructura original de la miga. Para binarizar se eligió un valor umbral (206) dentro de los grises, de forma tal que los niveles de grises inferiores al umbral se convirtieron en negro y los mayores en blanco. De este modo se convirtió la imagen en escala de grises en una imagen binarizada, donde los alvéolos se representan en negro y las paredes de los mismos en color blanco. Los resultados del procedimiento descripto se muestran en la Figura 2.24. Antes de proceder al análisis de las muestras se realizó una calibración utilizando una imagen de una regla, de este modo una distancia de $1 \mathrm{~cm}$ correspondió a 138 pixeles.

Luego se analizó la imagen binarizada determinándose el número de alvéolos, el área alveolar (promedio y moda), la fracción de aire (relación entre el área alveolar y el área total), la circularidad y el perímetro alveolar. Se tomo como umbral alveolar $0,002 \mathrm{~cm}^{2}$, es decir sólo aquellas zonas de la imagen con un área superior al umbral se consideraron como alvéolos. De esta manera se pueden eliminar las interferencias de pequeñas imperfecciones de la imagen debido por ejemplo al escaneo.

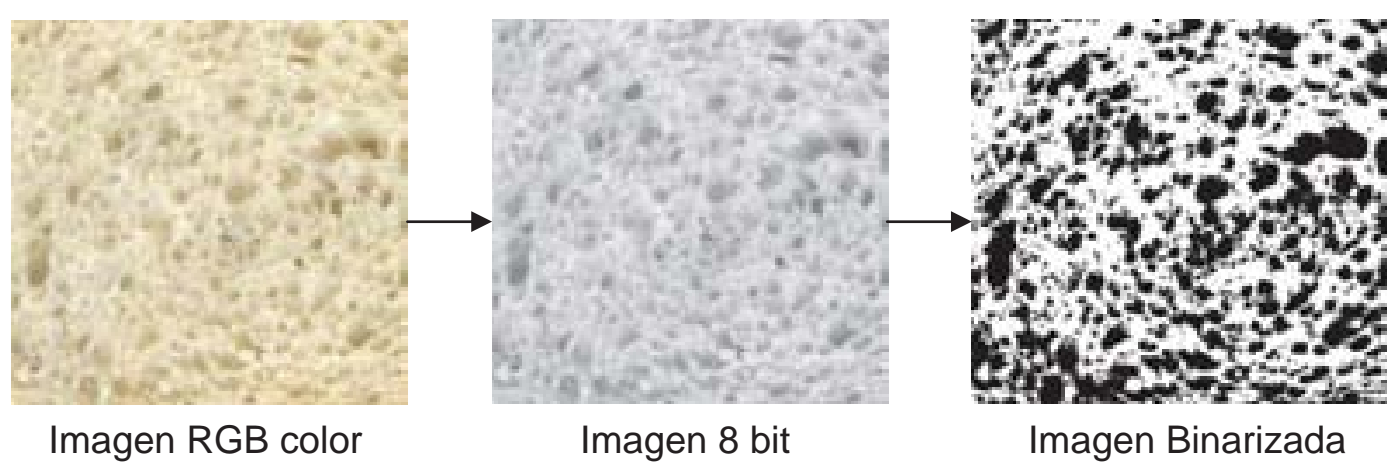

Figura 2.24. Ejemplo de imagen binarizada según el procedimiento descripto.

La circularidad es un descriptor de forma adimensional que se relaciona con el grado de compactación. Se calcula como el cociente entre el área del alvéolo y el área de un círculo con igual perímetro que el mismo. Toma valores entre 0 y 1 , correspondiendo el valor 1 a un círculo perfecto, a medida que el valor se acerca a 0 indica que el alvéolo presenta una forma más alargada. Se calculó según:

$$
\text { Circularidad }=4 \pi \frac{\text { área }}{\text { perímetro }^{2}}
$$




\subsubsection{Almacenamiento del pan}

Los panes se colocaron en bolsas de polietileno cerradas y se almacenaron durante 1 y 3 días a $20^{\circ} \mathrm{C}$. El envejecimiento de los mismos se evaluó mediante la determinación de la humedad y el análisis de perfil de textura de la miga.

\subsubsection{Humedad de la miga}

La determinación de la humedad de la miga de los panes almacenados durante 1 y 3 días se realizó como se describe en el ítem 2.2.6.4.3. Además se calculó la pérdida global de humedad porcentual entre el día 3 y el día 0 (Ec. 2.41). El ensayo se realizó por triplicado.

$$
\% \text { pérdida de humedad }=\frac{\mathrm{H}_{3}-\mathrm{H}_{0}}{\mathrm{H}_{0}} 100
$$

donde $\mathrm{H}_{3}$ es la humedad de la miga en el día 3 y $\mathrm{H}_{0}$ es la humedad de la miga en el día 0 .

\subsubsection{Textura de miga}

Se realizó el análisis de perfil de textura de la miga de los panes almacenados durante 1 y 3 días de igual modo que en 2.2.6.4.4.

\subsubsection{Evaluación de la retrogradación del almidón.}

Se evaluó la retrogradación del almidón por calorimetría diferencial de barrido Q100 (TA Instruments).

\subsection{Preparación de la masa}

La metodología seguida para la preparación de la masa fue la utilizada en 2.2.5.3.1.2. A, se prepararon sólo masas con $\mathrm{NaCl}$. Los hidrocoloides se utilizaron en la mayor concentración: 1,5\% para las celulosas modificadas y 2,0\% para las pectinas. El 
amasado se realizó en un microfarinógrafo Brabender (10 g), con cantidad de agua y tiempo de desarrollo óptimos.

\subsection{Simulación de la cocción}

Se pesaron aproximadamente $15 \mathrm{mg}$ de masa en una cápsula de aluminio para DSC y se sometió a un calentamiento desde $5^{\circ} \mathrm{C}$ hasta $105^{\circ} \mathrm{C}$ a una velocidad de $10^{\circ} \mathrm{C}$ por minuto, con este proceso se simuló la cocción de la masa.

\subsection{Almacenamiento y evaluación de la retrogradación}

Las cápsulas fueron almacenadas a $25^{\circ} \mathrm{C}$ durante 0,3 y 7 días. Pasado este tiempo se evaluó el proceso de retrogradación del almidón por DSC. Las corridas se realizaron en un calorímetro Q100 (TA, Instrumets, USA), con un programa de calentamiento que consistió en una isoterma de 5 minutos a $5^{\circ} \mathrm{C}$ y luego una rampa de calentamiento de $5^{\circ} \mathrm{C} / \mathrm{min}$ desde $5^{\circ} \mathrm{C}$ hasta $140^{\circ} \mathrm{C}$. Se determinaron las temperaturas de inicio, de pico y de finalización de las endotermas del almidón y el cambio de entalpía asociado.

\subsubsection{Análisis sensorial}

Se realizó la evaluación sensorial de las formulaciones con las cuales se obtuvieron panes de mejor calidad panadera. En primer lugar se realizó un ensayo de discriminación (prueba del triángulo) con el que se buscó determinar si existían diferencias sensoriales perceptibles entre el control y el pan con el agregado de aditivo. Luego, se realizó un ensayo de aceptabilidad sensorial empleando el método de la escala hedónica. Para ambos ensayos se utilizó un panel no entrenado.

\subsubsection{Ensayo de discriminación: prueba del triángulo}

La prueba del triángulo es una prueba de discriminación, es decir, se utiliza para determinar si es posible distinguir dos muestras entre sí a través de la evaluación sensorial (Watts, 1992). A cada evaluador se le entregan tres muestras codificadas y se le indica que dos de las muestras son iguales y una es diferente, debiendo luego probar las muestras e identificar la diferente. En esta prueba, el evaluador debe señalar a una de las muestras como diferente aunque no la perciba como tal. 


\subsection{Diseño de la prueba del triángulo}

Las hipótesis planteadas fueron:

- Hipótesis nula $\left(\mathrm{H}_{0}\right)$ : El pan control y el pan elaborado con el agregado de hidrocoloide no presentan diferencias significativas.

- Hipótesis Alternativa $\left(\mathrm{H}_{1}\right)$ : El pan control y el pan elaborado con el agregado de hidrocoloide son diferentes.

Para un nivel de significancia $(\alpha)$ del $0,01 \%, \beta=0,3$ y $p_{d}=40 \%$ el número mínimo de evaluadores se obtuvo de una tabla, hallándose que el número mínimo de respuestas era 30. Por lo cual, se convocaron 30 evaluadores adultos, de ambos sexos y no entrenados, a los cuales se les solicitó que efectuaran la prueba por duplicado.

\subsection{Preparación de las muestras}

Los panes control y con agregado de hidrocoloide se elaboraron siguiendo las condiciones de amasado óptimas según se describe en 2.2.6.3. Los panes se dejaron enfriar a temperatura ambiente y se obtuvieron 4 rodajas a partir de cada uno. Se operó de igual modo con los productos con y sin agregado de hidrocoloide.

\subsection{Desarrollo de la prueba}

Los panelistas recibieron en cada serie dos muestras de pan control $(C)$ y una de pan con agregado de hidrocoloide $(\mathrm{H})$ o dos rodajas de $\mathrm{H}$ y una de $\mathrm{C}$. Así, se prepararon 10 series con las seis combinaciones posibles en el orden de presentación de las muestras: $\mathrm{HHC}, \mathrm{CHH}, \mathrm{HCH}, \mathrm{CCH}, \mathrm{HCC}$ y $\mathrm{CHC}$; de este modo cada muestra se sirvió un número igual de veces. Las muestras fueron asignadas al azar a los evaluadores según se muestra en el anexo 1.

A cada evaluador se le entregó una planilla de evaluación (anexo 2) y una bandeja con un número identificatorio conteniendo 6 rodajas codificadas con números de tres dígitos, los cuales fueron seleccionados de una tabla de números aleatorios. Se proporcionó agua potable comercial, como agente neutralizante para el enjuague de la boca entre muestras. La prueba se efectuó entre las 15 y las 17 horas. A cada evaluador se le indicó que probara las muestras de izquierda a derecha e identificara 
cual era la diferente. Si lo consideraba necesario podía volver a probar cualquiera de las muestras de cada trío. Dado que se trata de un prueba de respuesta forzada, se instruyó a los evaluadores en que "no hay diferencia" no era una respuesta válida, en ese caso debían elegir al azar la muestra diferente.

\subsubsection{Ensayo de aceptabilidad: escala hedónica}

Se comparó la aceptabilidad del pan control (C) y el pan obtenido con el agregado de Hidrocoloide $(\mathrm{H})$ y se evaluó el motivo de la preferencia o rechazo por parte del consumidor. Para lo cual se realizaron preguntas sobre determinados atributos: apariencia, textura, sabor y aceptabilidad general.

\subsubsection{Desarrollo de la prueba}

Se prepararon 60 series con las dos combinaciones posibles $\mathrm{CH}$ y $\mathrm{HC}$ en el orden de presentación de las muestras y fueron asignadas al azar a los evaluadores. Los evaluadores fueron convocados en grupos de 10 personas. A cada evaluador se le entrego una bandeja conteniendo cada uno de los panes junto con la planilla de evaluación. Las muestras fueron codificadas con tres dígitos al azar, fueron servidos a temperatura ambiente y en forma aleatoria. En el anexo 3 se muestra la planilla de evaluación.

Se proporcionó agua potable comercial, a temperatura similar a la de las muestras, como agente neutralizante para el enjuague de la boca entre muestras.

A los evaluadores se les indicó que examinaran primero los atributos de una muestra y luego recién los de la otra.

\subsubsection{Análisis Estadístico}

\subsubsection{Análisis de Varianza}

En el análisis de varianza (ANOVA)se realiza una separación de la variabilidad total de una variable en dos componentes: 1) variabilidad entre muestras, la cual es debida a los efectos del factor en estudio, llamada variación sistemática, 2) variabilidad dentro de las muestras, la cual expresa la variación aleatoria.

Con el fin de determinar si existían diferencias significativas entre las muestras se realizó un análisis de varianza de un factor y se compararon las medias por el test de 
Bonferroni (nivel de confianza del 95\%). También se realizaron en algunos casos ANOVAS bifactoriales. El programa empleado fue Stat Graphics Plus 4.0.

\subsubsection{Análisis de componentes principales}

El análisis de componentes principales es una técnica estadística que permite reducir el número de variables de trabajo y de este modo facilita el análisis de los resultados. Se obtienen nuevos componentes independientes entre sí, los cuales son una combinación lineal de las variables originales. Se realizó el análisis de componentes principales con el empleo del programa Minitab 15 (Minitab Inc.2006, Estados Unidos). 


\title{
Capítulo III
}

Resiultados y Discusión

\author{
Caracterización \\ de los materiales
}




\subsection{Composición de la harina}

En Tabla 3.1 se muestran los resultados del análisis de composición de la harina de trigo 000 (Molino Campodónico S.A. La Plata, Buenos Aires, Argentina) empleada para todos los ensayos realizados en la tesis.

Tabla 3.1 Composición porcentual de la harina

\begin{tabular}{|c|c|}
\hline Componente & Porcentaje $(\mathrm{g} / 100 \mathrm{~g})$ \\
\hline Humedad & 14,2 \\
\hline Proteínas & 11,4 \\
\hline Lípidos & 1,4 \\
\hline Cenizas & 0,678 \\
\hline $\mathrm{HDC}_{\mathrm{t}}{ }^{*}$ & 72,3 \\
\hline
\end{tabular}

La harina empleada presentó la composición porcentual esperada para una harina de trigo y cumplió con las especificaciones del CAA en cuanto al contenido de humedad mientras que el contenido de cenizas superó en 1,5\% al máximo valor admitido por el CAA para este tipo de harina. Esta discrepancia podría atribuirse a que en la técnica utilizada (AACC 08-01, 2000) la muestra se calcina en mufla a una temperatura inferior $\left(550^{\circ} \mathrm{C}\right)$ a la especificada en el CAA $\left(900-920^{\circ} \mathrm{C}\right)$.

El contenido proteico es un parámetro de calidad importante para las harinas ya que se relaciona con el contenido de gluten, la absorción de agua, el tiempo de amasado y la estabilidad de la masa. Además influye sobre los atributos de calidad del producto terminado (Wheat Marketing Center, 2008). En el caso de la harina utilizada, el contenido proteico hallado es el esperable para una harina de este tipo, apta para panificación.

\subsection{Calidad panadera de la harina}

La calidad panadera de la harina se evaluó mediante los ensayos que se describen a continuación. 


\subsubsection{Evaluación de la cantidad y calidad del gluten}

El gluten es responsable de las características viscoelásticas de la masa determinando en gran medida su comportamiento en la panificación. Para evaluar la calidad y el contenido de gluten se determinaron el gluten húmedo $(\mathrm{GH})$, el gluten seco (GS), la relación $\mathrm{GH} / \mathrm{GS}$, el agua unida al gluten (GH-GS) y el gluten index (GI). Los resultados se muestran en la Tabla 3.2.

Tabla 3.2: valores de GH, GS, GH/GS, (GH-GS) y GI de la harina

\begin{tabular}{cc}
\hline Parámetro & $\begin{array}{c}\text { Porcentaje } \\
(\mathrm{g} / 100 \mathrm{~g})\end{array}$ \\
\hline GH & $31,5 \pm 1,3$ \\
\hline GS & $11,0 \pm 0,3$ \\
\hline GH/GS & $2,9 \pm 0,2$ \\
\hline GH-GS & $20,5 \pm 1,4$ \\
\hline GI & $93,4 \pm 3,8$ \\
\hline
\end{tabular}

Los valores hallados por la harina 000 utilizada muestran que se trata de una harina de buena calidad, ya que las proteínas del gluten absorben dos veces su peso en agua. Además el valor de Gl indica que se trata de una harina con gluten fuerte. Se considera que harinas con valores de Gl entre 60 y 90 son buenas para panificación, aquellas con valores superiores a 95 son demasiado fuertes y aquellas con valores inferiores a 60 son demasiado débiles (Curic y col., 2001).

\subsubsection{Farinograma y alveograma}

Los ensayos farinográficos permiten predecir el comportamiento que presentará la harina durante la panificación. Entre los parámetros que se determinan a través de este ensayo se encuentra la absorción farinográfica de agua, la que se relaciona con el contenido proteico de la harina. En general, la absorción de agua se incrementa a medida que lo hacen la cantidad y calidad del gluten (Pomeranz, 1987). Tiempos de desarrollo y estabilidad elevados y valores bajos de decaimiento se relacionan con harinas fuertes y con buena tolerancia al amasado (Catterall, 1998). En la Tabla 3.3 se 
muestran los parámetros farinográficos y alveográficos de la harina. La absorción de agua se encuentra dentro de los valores establecidos por el CAA para una harina 000 y el tiempo de desarrollo y la estabilidad indican que se trata de una harina adecuada para panificación. El grado de aflojamiento, relacionado inversamente con la estabilidad, se encuentra cercano al valor esperado para una harina de buena calidad (30-50 UF) (Pantanelli, 2003). A partir de los resultados obtenidos en el alveógrafo puede decirse que se trata de una harina equilibrada con buena relación entre la tenacidad y la extensibilidad $(P / L \approx 1)$.

Tabla 3.3.Parámetros farinográficos y alveográficos de la harina

\begin{tabular}{|c|c|c|}
\hline Ensayo & Parámetro & Valor hallado \\
\hline \multirow{4}{*}{ 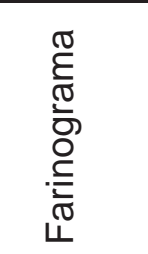 } & Absorción de agua & $58,2 \pm 0,5 \mathrm{ml} \%$ \\
\hline & Tiempo de desarrollo & $8,3 \pm 0,4 \min$ \\
\hline & Estabilidad & $15,8 \pm 0,4 \min$ \\
\hline & Aflojamiento & $55 \pm 0$ UF \\
\hline \multirow{4}{*}{ 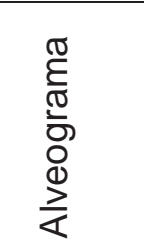 } & P (Tenacidad) & $96 \mathrm{~mm} \mathrm{H}_{2} \mathrm{O}$ \\
\hline & L (Extensibilidad) & $93 \mathrm{~mm}$ \\
\hline & W (Fuerza) & $330 \times 10^{-4} \mathrm{~J}$ \\
\hline & $P / L$ & 1,03 \\
\hline
\end{tabular}

media \pm DE. Coeficiente de variación de parámetros alveográficos:

$P: 8 \%, W: 8 \%, G: 5 \%\left(G=2,22 L^{1 / 2}\right)$

\subsubsection{Determinación de la actividad $\alpha$-amilásica de la harina}

Se evaluó a través de dos ensayos: 1) índice de caída (Falling Number-FN) y 2) número de agitación (Stirring Number-SN). En el ensayo del índice de caída se obtuvo un valor de 486 segundos, mientras que el valor del número de agitación (SN) fue de 168 I 9 RVU, ambos ensayos indican que la actividad enzimática es baja. Según un informe de INTA (Cuniberti, 2008) sobre harinas de la subregión II norte y V norte, valores de FN cercanos a 340 s son ideales para una adecuada panificación. 


\subsubsection{Perfil viscoamilográfico de la harina}

En el viscoamilógrafo rápido (RVA) se estudia el comportamiento de la harina frente a un ciclo de calentamiento/enfriamiento; este comportamiento se encuentra asociado a las características de gelatinización del almidón presente en ella (Beta y col., 2000). Las propiedades de empaste determinadas para la harina se encuentran influenciadas por la presencia de los otros componentes: proteínas, pentosanos, cenizas y lípidos (Chung, 2003). En la Figura 3.1 se muestran el perfil de la harina 000 y la rampa de calentamiento/enfriamiento utilizada y se indica como se realizó el cálculo de los parámetros. En la Tabla 3.4 se presentan los valores hallados para los parámetros determinados, los que se encuentran dentro de los normalmente obtenidos para una harina argentina (Cuniberti, 2012).

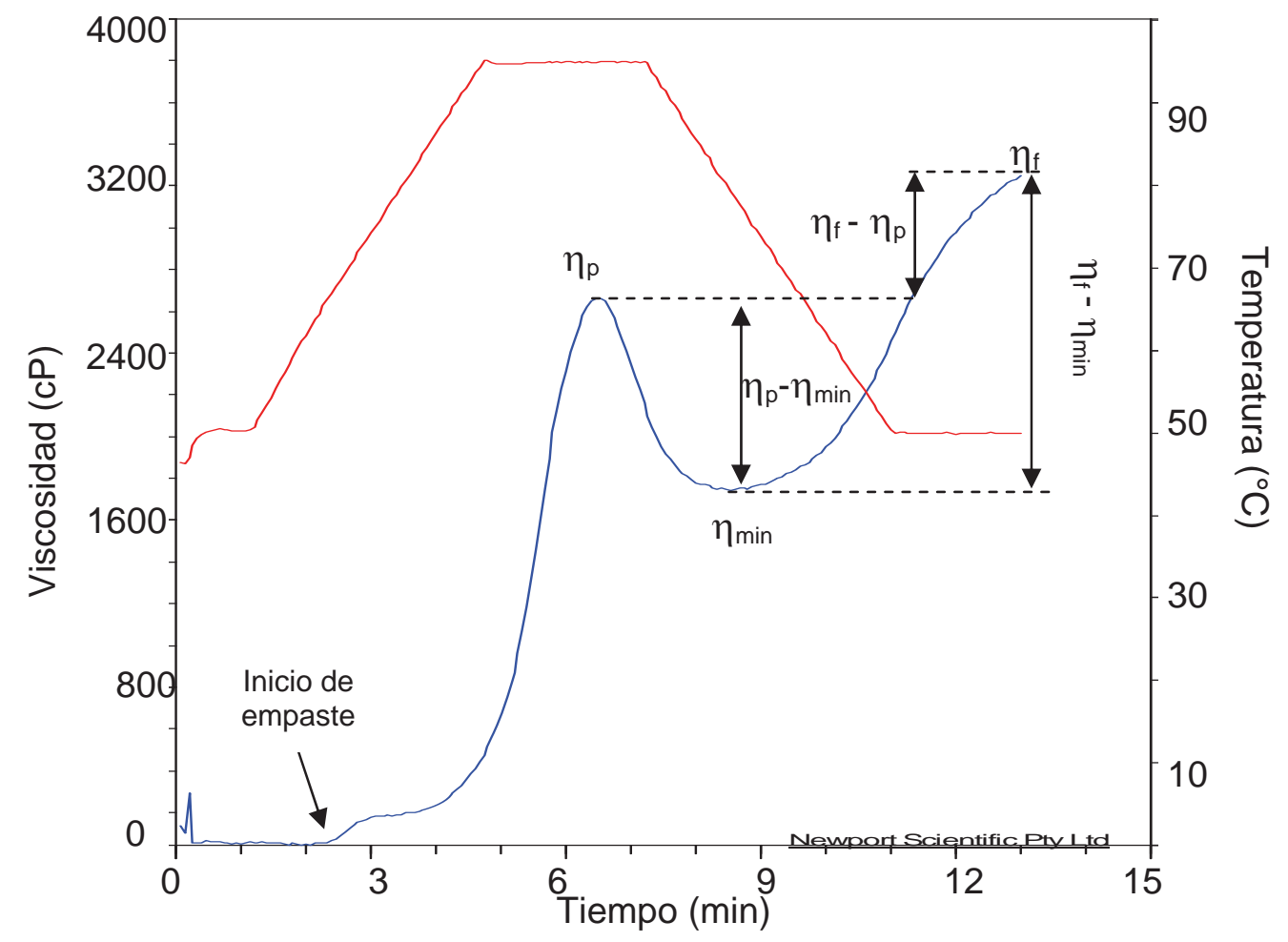

Figura 3.1. Viscoamilograma de la harina 000 (azul) y rampa de temperatura utilizada (rojo). 
Tabla 3.4. Parámetros obtenidos en el perfil del RVA

\begin{tabular}{cc}
\hline Parámetro & Media \pm DE \\
\hline$\eta_{p}(c P)$ & $2623 \pm 44$ \\
\hline$\eta_{\min }(\mathrm{cP})$ & $1703 \pm 49$ \\
\hline$\left(\eta_{\mathrm{p}}-\eta_{\min }\right)(\mathrm{cP})$ & $919 \pm 77$ \\
\hline$\eta_{\mathrm{f}}(\mathrm{cP})$ & $3198 \pm 44$ \\
\hline $\mathrm{t}_{\mathrm{e}}(\mathrm{min})$ & $2,5 \pm 0,4$ \\
\hline $\mathrm{T}_{\mathrm{e}}\left({ }^{\circ} \mathrm{C}\right)$ & $66,6 \pm 0,4$ \\
\hline$\left(\eta_{\mathrm{f}}-\eta_{\mathrm{p}}\right)(\mathrm{cP})$ & $576 \pm 33$ \\
\hline$\left(\eta_{\mathrm{f}}-\eta_{\min }\right)(\mathrm{cP})$ & $1495 \pm 45$
\end{tabular}

La viscosidad de pico, la temperatura de empaste y el asentamiento $\left(\eta_{\mathfrak{f}}-\eta_{\min }\right)$ determinados con el RVA pueden utilizarse como predictores del endurecimiento que presentará el pan durante el almacenamiento (Collar, 2003). Estos parámetros están relacionados con el contenido de amilosa del gránulo de almidón, polisacárido involucrado en la etapa inicial de la retrogradación. Una mayor liberación de amilosa durante la gelatinización conduce a viscosidades de pico mayores. Por otro lado, al enfriarse la pasta de almidón gelatinizado la viscosidad final alcanzada también dependerá de la cantidad y características de la amilosa exudada. Blazek y Copeland (2008) caracterizaron almidones extraídos de diferentes trigos australianos encontrando que para las variedades waxy (ricas en amilopectina), $\eta_{f}<\eta_{p}$, para las variedades de alto contenido de amilosa la diferencia entre viscosidad de pico y la mínima, $\left(\eta_{p}-\eta_{\min }\right)$, conocida como inestabilidad y relacionada con la susceptibilidad a la desintegración del gránulo es muy baja y para los almidones normales el amilograma es similar al obtenido en el presente trabajo, con valores de $\eta_{f}>\eta_{p}$ e inestabilidad $\left(\eta_{p}-\eta_{\min }\right)$ elevada. Ohm y Chung (1999) encontraron una correlación negativa entre la temperatura de empaste y el volumen de pan y una relación óptima de 0,17-0,18 para la relación contenido de proteínas/temperatura de empaste para obtener un buen volumen de pan. 


\subsubsection{Electroforesis de fracciones proteicas de la harina}

Por medio de la electroforesis SDS-PAGE se separaron en base a su masa molecular las proteínas de la harina que conforman las fracciones correspondientes a las gliadinas (solubles en propanol 50\%) y a las gluteninas solubles en propanol $50 \%$ en presencia de DTT (condiciones reductoras).

En la Figura 3.2 se muestran las electroforesis de los extractos proteicos obtenidos con propanol $50 \%$ (condiciones no reductoras) (A) y propanol 50\% con DTT (B), según se describe en el ítem 2.2.5.2.2 del Capítulo II.

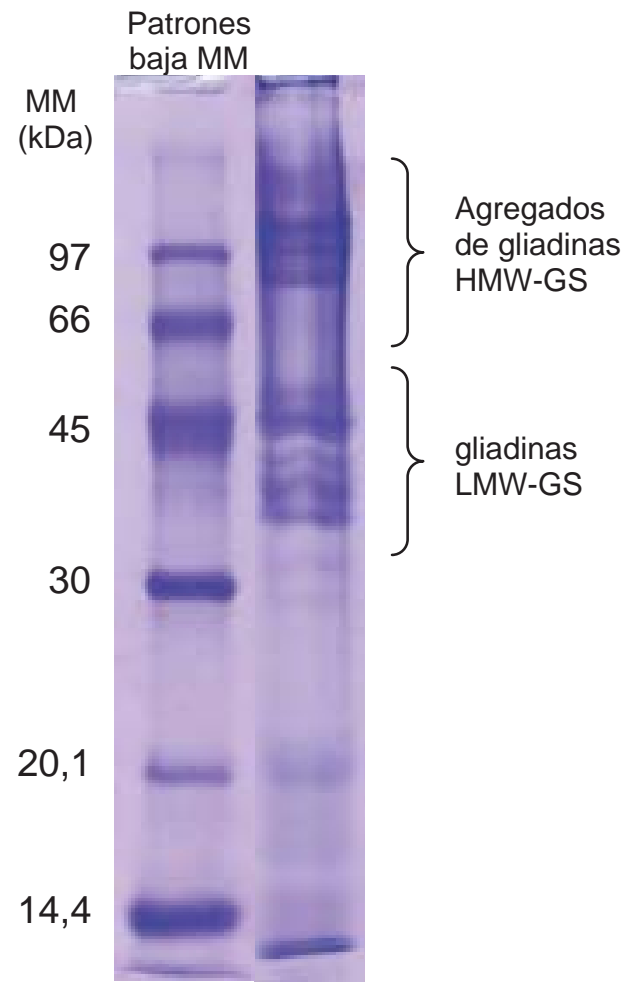

A

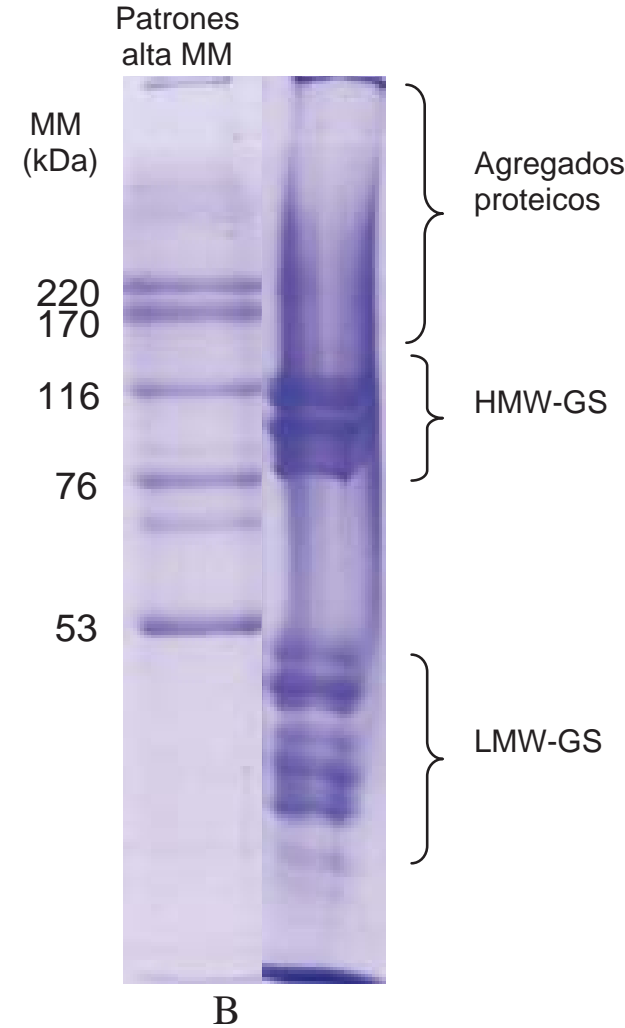

B

Figura 3.2. Electroforesis SDS-PAGE de extractos proteicos de la harina: A) proteínas solubles en propanol 50\%; B) proteínas solubles en propanol $50 \%$ después de ser reducidas con DTT. 
En el gel correspondiente a las fracciones solubles en propanol $50 \%$, donde se espera encontrar fundamentalmente gliadinas, se observaron al menos 5 bandas intensas entre 30 y $66 \mathrm{kDa}$, que pueden corresponder a $\omega$-gliadinas (53 y $48 \mathrm{kDa}$ ), y tres bandas de menor masa molecular $(43,41$ y $37 \mathrm{kDa})$ correspondientes probablemente a $\alpha$-, $\beta$ - y $\gamma$-gliadinas. En la parte superior del gel se observan 3 bandas nítidas a cercanas a $97 \mathrm{kDa}$ y algunas más difusas a mayores masas moleculares, que podrían corresponder a agregados de gliadinas. Aunque las gliadinas son consideradas monoméricas existen trabajos de diversos autores que han informado sobre la presencia de polímeros de gliadinas de masas moleculares elevadas (100 - 500 kDa), que pueden aparecer como oligómeros solubles en alcohol o junto con los polímeros de gluteninas insolubles en alcohol. A esta fracción se la ha llamado HMW-gliadinas, agregados de gliadinas o gluteninas solubles en alcohol (Shewry y col., 2003; Hubner y Bietz, 1993). Las tres bandas muy débiles observables a 20, 18 y 15 kDa corresponderían a albúminas y globulinas contaminantes.

En la Figura 3.2 B se muestra la electroforesis SDS-PAGE de los extractos obtenidos a partir del residuo insoluble en propanol $50 \%$, al que se le agregó DTT y se extrajo con propanol $50 \%+$ Tris $\mathrm{HCl} 0,08 \mathrm{M}(\mathrm{pH} 8,0)$. En la parte superior del gel se observan agregados proteicos de alta masa molecular (superior a $220 \mathrm{kDa}$ ). Además se observan bandas de masa molecular entre 111 y $103 \mathrm{kDa}$, que corresponderían a agregados de HMW-GS; y bandas a 96; 82; 78 y 74 kDa las cuales corresponderían a HMW-GS. Se observan 8 bandas con masas moleculares inferiores a $53 \mathrm{kDa}$ que corresponderían a subunidades LMW-GS, aunque no puede descartarse la presencia de $\omega$-gliadinas.

\subsection{Caracterización de los hidrocoloides utilizados}

\subsubsection{Determinación de la pureza y grado de esterificación de las pectinas y del grado de amidación de la pectina de bajo metoxilo}

Debido a que los fabricantes suelen agregar a las pectinas comerciales azúcares como dextrosa o sacarosa para estandarizar su comportamiento, asegurando de este modo la obtención de geles de igual dureza siempre que sean empleadas en iguales condiciones, y a que también se les pueden agregar buffers para controlar el $\mathrm{pH}$, las pectinas comerciales no poseen $100 \%$ de polisacárido. 
La pureza de las pectinas empleadas se determinó según se describió en el ítem 2.2.3.1. (Capítulo II) y se expresó como gramos de ácido galacturónico cada $100 \mathrm{~g}$ de pectina. En ambos casos la pureza fue del 57\%, por este motivo se ensayó un nivel adicional de pectina, más elevado que el máximo usado para las celulosas modificadas. Además se determinó el contenido de cenizas para ambas pectinas que arrojó valores de 2,0\% y 2,1\% para PAM y PBM, respectivamente. Para la humedad se hallaron valores de $7,3 \%$ para PAM y de $8,0 \%$ para PBM.

El grado de esterificación de la pectina de alto metoxilo fue del $67 \%$ mientras que para la pectina de bajo metoxilo fue del $43 \%$ y su grado de amidación del $16 \%$. La determinación del grado de esterificación y amidación es de importancia para establecer que tipo de interacciones podrían establecer cada una de las pectinas. Debido a que la función ester es menos hidrofílica que la función carboxilo, cuanto mayor sea el grado de esterificación que presenta la molécula mayor hidrofobicidad relativa presentará. Por otro lado, la introducción de la función amida en la pectina de bajo metoxilo disminuye su hidrofilicidad con respecto a una pectina de igual grado de esterificación pero sin amidación.

\subsubsection{Determinación del PM de las pectinas por viscosimetría capilar}

En la Tabla 3.5 se informa el peso molecular promedio para ambas pectinas, los cuales se obtuvieron con el empleo de la ecuación de Mark - Houwink (Ec. 2.18) y la utilización los coeficientes determinados por Anger y Berth (1986). La viscosidad intrínseca $[\eta]$, necesaria para determinar el peso molecular, se obtuvo a partir del empleo de los criterios de Huggins y Kraemer.

Tabla 3.5. Peso molecular promedio obtenido por viscosimetría capilar

\begin{tabular}{ccccc}
\hline $\begin{array}{c}\text { Criterio utilizado } \\
\text { para determinar }[\eta]\end{array}$ & {$[\eta]_{\text {PBM }}(\mathrm{ml} / \mathrm{g})$} & $<\mathrm{PM}>_{\text {PBM }}$ & {$[\eta]_{\text {PAM }}(\mathrm{ml} / \mathrm{g})$} & $<$ <M $>_{\text {PAM }}$ \\
\hline Huggins & 261,3 & $5,1 \times 10^{4}$ & 247,5 & $4,7 \times 10^{4}$ \\
\hline Kraemer & 263,2 & $5,2 \times 10^{4}$ & 256,6 & $5,0 \times 10^{4}$ \\
\hline
\end{tabular}


El peso molecular promedio para PBM se encuentra entre $5,1 \times 10^{4}-5,2 \times 10^{4}$ y para PAM entre $4,7 \times 10^{4}$ y $5,0 \times 10^{4}$; no habiéndose hallado diferencias significativas $(p<0,05)$ entre el peso molecular promedio de ambas pectinas.

\subsubsection{Determinación del peso molecular promedio de las celulosas por HPLC}

Se determinó el peso molecular promedio de las HPMCs con la finalidad de establecer otra característica, además del grado de sustitución, que pudiera diferenciarlas estructuralmente. En la Figura 3.2 se muestra la curva de calibración utilizada para el cálculo del peso molecular promedio $(<\mathrm{PM}>)$ ) de las HPMCs. A partir de un análisis de regresión por cuadrados mínimos se obtuvo la ecuación de la recta que describe a la curva de calibración. La ecuación obtenida fue:

$$
\log P M=-0,8134 t_{r}+13,216
$$

donde $t_{r}$, es el tiempo de retención en la columna. El coeficiente de determinación $\left(r^{2}\right)$ fue 0,9577 .

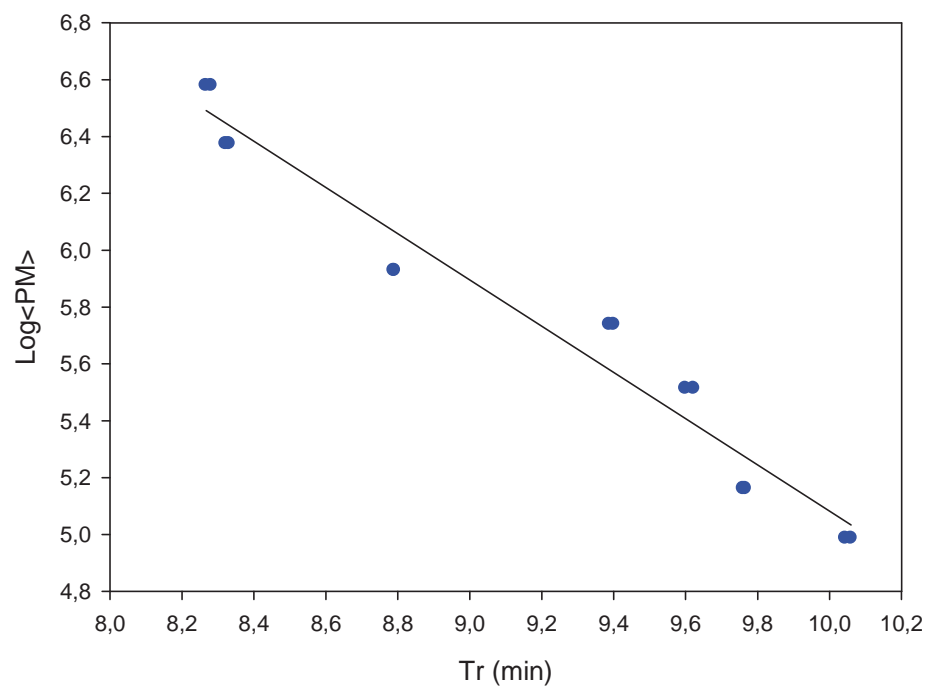

Figura 3.2. Curva de calibración obtenida con los patrones de peso molecular entre $9,7 \times 10^{4}$ y $3,8 \times 10^{6}$

El $<$ PM> obtenido para HPMC F 4M fue de 4,94 $10^{4}$ Da mientras que el $<P M>$ para HPMC F 50 fue de 2,99 104. Esta diferencia en el peso molecular, HPMC F 4M es 1,65 veces más pesada que HPMC F 50, era esperable dado que el proveedor informa que 
una suspensión 2\% de HPMC F 4M presenta una viscosidad de 4477 cP mientras que una de igual concentración de HPMC F 50 tiene una viscosidad de 46 cP.

No se pudo determinar el peso molecular de CMC con esta técnica por dificultades en hallar condiciones de corrida adecuadas. El peso molecular informado para CMC es 2,5 a $2,710^{5}$ (Du y col., 2009). 


\section{Capítulo IV}

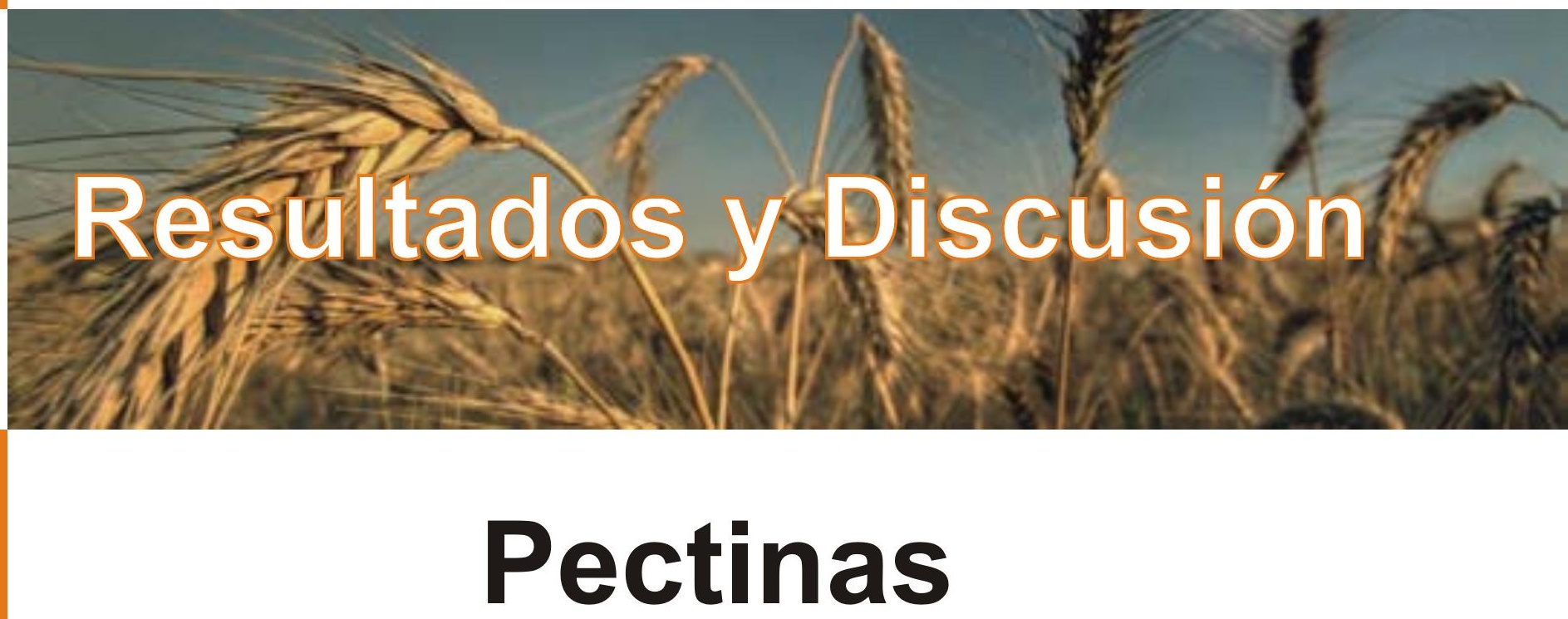




\subsection{Caracterización fisicoquímica y reológica de las masas}

El efecto producido por pectinas de alto metoxilo (PAM) ha sido evaluado en diversos trabajos encontrándose que pueden afectar la calidad del gluten obtenido (Bárcenas y col., 2009) y modificar las características reológicas de la masa (Collar y Bollaín, 2005) conduciendo, en algunos casos, a masas de mayor tenacidad y panes con mayor volumen específico (Ribotta y col., 2005). También se ha evaluado su empleo en mezclas con otros hidrocoloides, por ejemplo HPMC, mostrando un efecto antagónico sobre la tenacidad y extensibilidad de la masa (Bollaín y Collar, 2004; Rosell y col., 2007a). Por otro lado las PAM, se han empleado en la producción de bizcochuelos (Gómez y col., 2007) y de panificados libres de gluten (Lazaridou y col., 2007; Demirkesen y col., 2011).

Sin embargo, el empleo de pectinas de bajo metoxilo (PBM) en productos panificados se encuentra menos difundido, por lo que resulta interesante evaluar su empleo en masa panaria y comparar su efecto con el producido por pectinas de alto grado de esterificación.

En este capítulo se estudia el efecto producido por dos tipos de pectinas, una de alto grado de esterificación y otra de bajo grado de esterificación y amidada, sobre las características reológicas de la masa panaria sin y con $\mathrm{NaCl}$. La reología de la masa se evaluó a través de ensayos empíricos y fundamentales (farinograma, análisis de perfil de textura de la masa, ensayos dinámicos oscilatorios). Se determinaron distintas variables del proceso de panificación como absorción de agua, tiempo de amasado y de fermentación. Finalmente, se evaluó la calidad del producto y su estabilidad durante el almacenamiento.

\subsubsection{Absorción de agua de las mezclas harina - pectina}

En los ensayos farinográficos, en general, se observó una relación lineal entre la absorción de agua (A) y la concentración de pectinas en la formulación, salvo en el caso de la mezcla sin $\mathrm{NaCl}$ y con PAM con la cual sólo para las concentraciones intermedias se calculó la regresión lineal. En el caso de éstas mezclas, la variación porcentual de la absorción en función de la cantidad de pectina no fue la misma en todo el rango. Al incrementar la concentración de pectina se obtuvieron mayores valores de $A$ tanto en las mezclas $\sin \mathrm{NaCl}(58,6$ - 62,5 $\mathrm{ml} \%$ ) como en las mezclas con $\mathrm{NaCl}(56,0-60,3 \mathrm{ml} \%)$. En las Figuras 4.1 y 4.2 se muestra el incremento porcentual de la absorción farinográfica de agua respecto a la harina para las mezclas harina - 
pectina en ausencia y presencia de $\mathrm{NaCl}$ respectivamente, calculado según la Ec. 2.19.

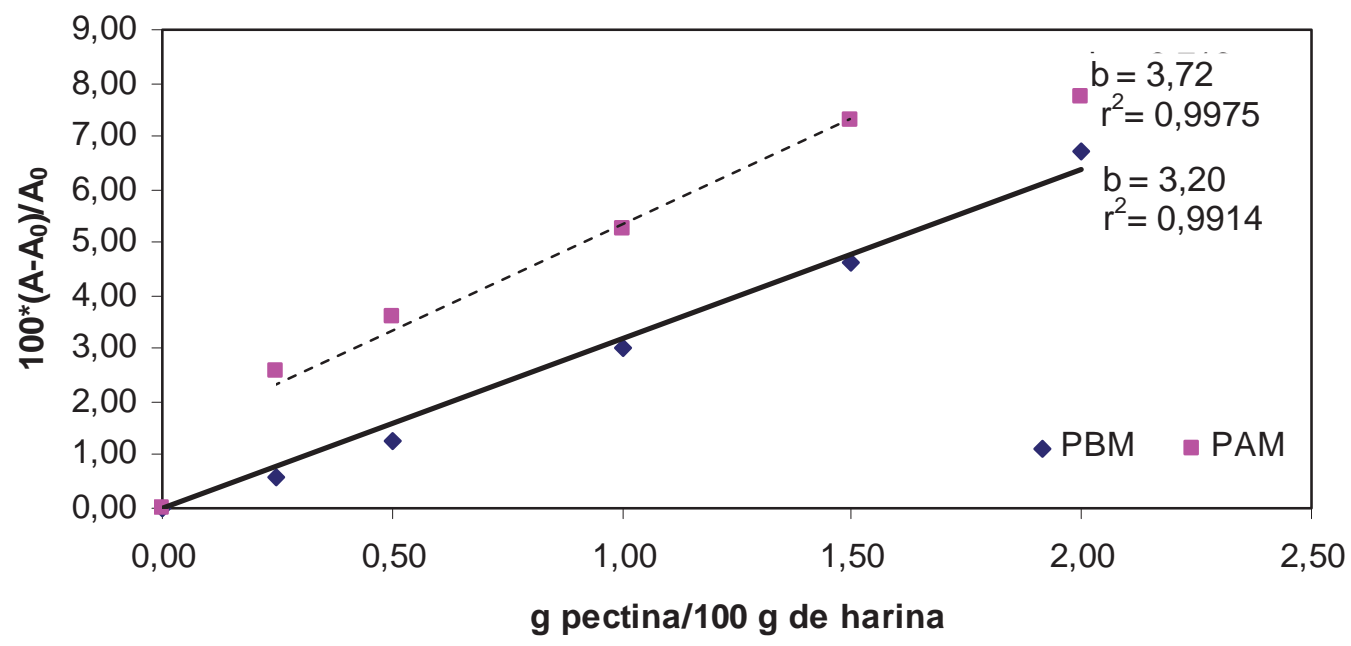

Figura 4.1. Incremento de la absorción farinográfica (\%) en función de la concentración de pectina en mezclas $\sin \mathrm{NaCl}$. $b=$ pendiente de la recta; $r^{2}$ coeficiente de determinación. Error relativo promedio: 2,3\%.

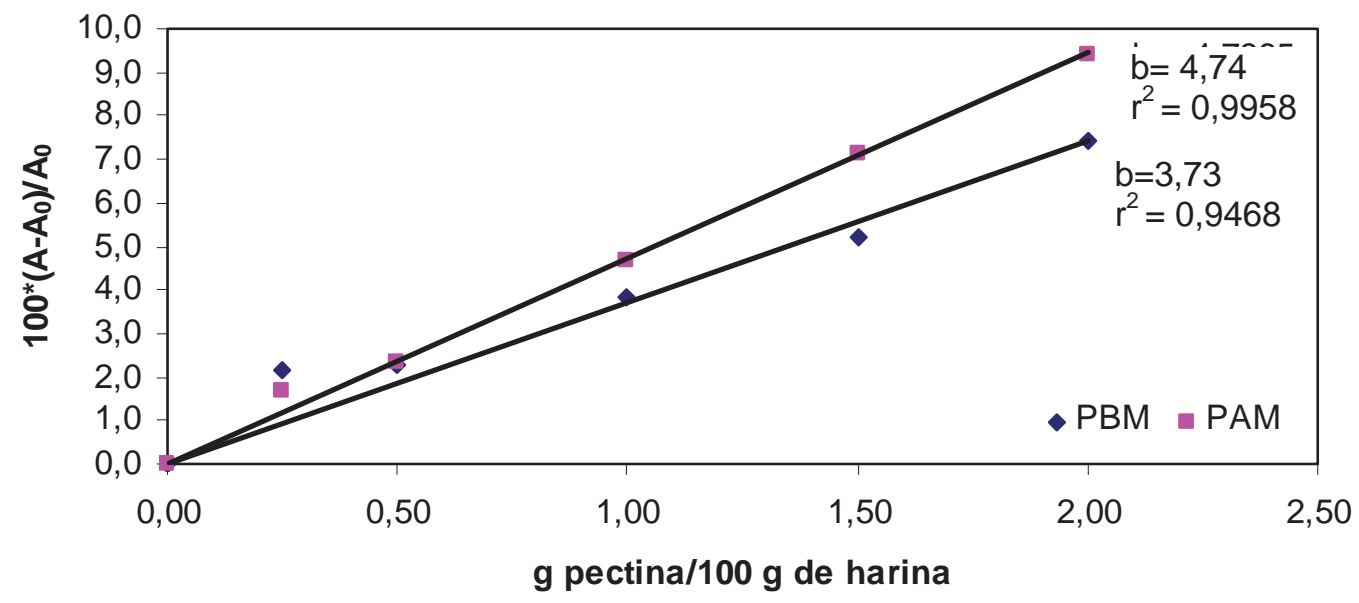

Figura 4.2. Incremento de la absorción farinográfica de agua al aumentar la concentración de PBM y PAM en las mezclas con $\mathrm{NaCl}(2 \%)$. b=pendiente de la recta; $r^{2}$ coeficiente de determinación. Error relativo promedio: 0,4\%. 
Los valores de $A$ fueron mayores en ausencia de $\mathrm{NaCl}$ para una determinada concentración de pectina.

La absorción de agua farinográfica va a depender principalmente del desarrollo de la red de gluten, a través de la entrega de energía mecánica durante el amasado. Ukai y col., (2008) han propuesto que el $\mathrm{NaCl}$ promueve un mayor entrecruzamiento entre cadenas de proteína y también cambios en su estructura secundaria conduciendo a un mayor desarrollo de la red de gluten. Si tenemos en cuenta que A es la cantidad de agua necesaria para alcanzar una consistencia de 500 UF, los cambios inducidos por la presencia de $\mathrm{NaCl}$ podrían permitir llegar a esa consistencia óptima con menor cantidad de agua. Asimismo, la formación de la red de gluten en presencia de hidrocoloides puede conducir a una matriz más o menos hidratada respecto al control sin hidrocoloide, de acuerdo al tipo de interacciones y cambios conformacionales que se puedan establecer. El aumento de hidratación en presencia PAM o PBM indicaría que la matriz de gluten con hidrocoloide sería capaz de ligar más agua. Esto podría deberse a cambios en la conformación de la red de gluten ocasionados por el hidrocoloide que aumentarían la hidratación de las proteínas, sumados a la capacidad intrínseca de hidratación de las propias pectinas.

Los ensayos de capacidad de imbibición de agua (WIC) permiten caracterizar la capacidad de absorción de agua de los componentes de la mezcla sin que se haya formado la red de gluten. Es decir, se evalúa la capacidad de absorber agua en forma espontánea. En la Figura 4.2. se muestra la capacidad de imbibición de agua (WIC) de la harina y de las mezclas harina - pectina (2\%). La presencia de las pectinas al $2 \%$

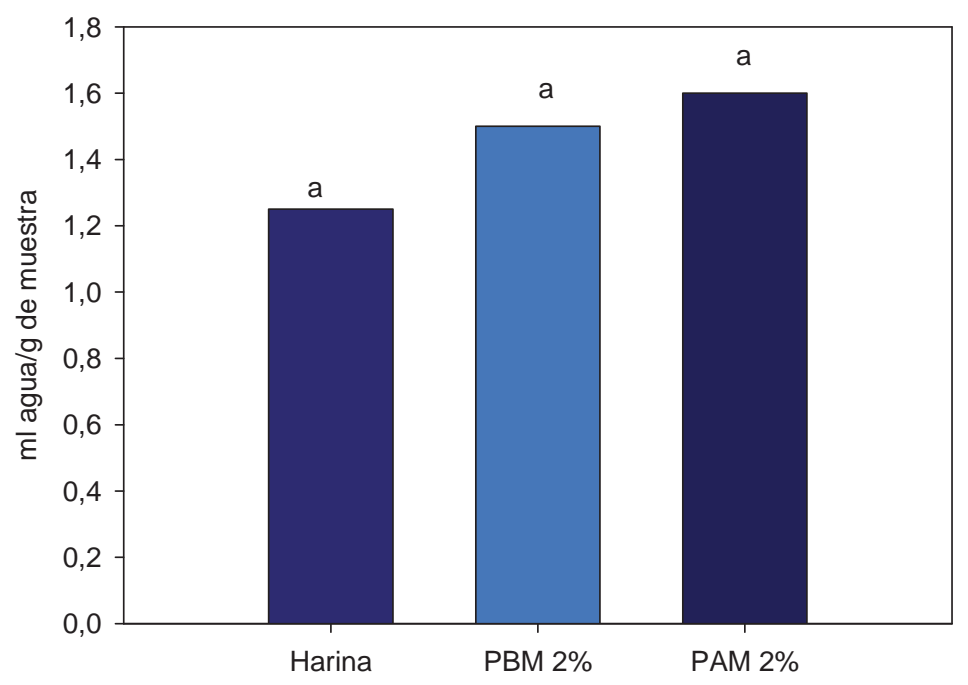

Figura 4.2. Capacidad de imbibición de agua (WIC) de harina y mezclas harinapectina. 
no modificó significativamente la capacidad de imbibición de agua de las mezclas en relación a la harina, aunque se observó una tendencia a obtener mayores valores de WIC sobre todo con PAM. Estos resultados indican que podría haber una contribución intrínseca de las pectinas a la absorción de agua.

\subsubsection{Humedad y actividad acuosa}

Las masas con pectinas presentaron mayores valores de humedad que las masas control, ya que para su preparación se utilizó la absorción farinográfica de agua y ésta resultó mayor. En la Tabla 4.1 se muestran los valores de humedad y actividad acuosa de las masas $\sin$ y con $\mathrm{NaCl}$, en presencia de pectinas (1 y $2 \%$ ). Los valores de humedad para las masas $\sin \mathrm{NaCl}$ y con pectinas se encontraron entre 45,4 \% y 45,9 $\%$ (control $=44,5 \%$ ). En las masas con $\mathrm{NaCl}$ el rango de humedad se encontró entre $42,9 \%$ y $44,9 \%$ (control= 43,2 \%). Con el mayor nivel de aditivo, las muestras con $\mathrm{NaCl}$ mostraron un aumento significativo de la humedad respecto al control.

La actividad acuosa $\left(\mathrm{a}_{\mathrm{w}}\right)$, que se relaciona con la disponibilidad de agua, no presentó diferencias significativas debidas al nivel de pectina utilizado; este comportamiento se presentó tanto en las masas $\sin \mathrm{NaCl}$ como con $\mathrm{NaCl}$. La actividad acuosa fue significativamente menor $(p<0,05)$ para las muestras con $\mathrm{NaCl}(0,969-0,973)$ que para las muestras $\sin \mathrm{NaCl}(0,987-0,988)$. Estos resultados indican que es la presencia de $\mathrm{NaCl}$ la que estaría determinando la disponibilidad del agua.

Tabla 4.1. Humedad y actividad acuosa de las masas.

\begin{tabular}{cccccc}
\hline & $\begin{array}{c}\text { Pectina } \\
(\%)\end{array}$ & \multicolumn{2}{c}{ Masas sin NaCl } & \multicolumn{2}{c}{ Masas con NaCl } \\
\cline { 2 - 6 } & Humedad \% & Aw & Humedad \% & aw \\
\hline Control & 0 & $44,5 \pm 0,4^{\mathrm{a}}$ & $0,988 \pm 0,003^{\mathrm{a}}$ & $43,2 \pm 0,5^{\mathrm{a}}$ & $0,972 \pm 0,002^{\mathrm{a}}$ \\
\hline \multirow{2}{*}{ PBM } & 1,0 & $45,0 \pm 0,2^{\mathrm{ab}}$ & $0,987 \pm 0,006^{\mathrm{a}}$ & $43,8 \pm 0,3^{\mathrm{ab}}$ & $0,969 \pm 0,003^{\mathrm{a}}$ \\
\cline { 2 - 6 } & 2,0 & $45,9 \pm 0,4^{\mathrm{b}}$ & $0,988 \pm 0,002^{\mathrm{a}}$ & $44,9 \pm 0,3^{\mathrm{b}}$ & $0,971 \pm 0,001^{\mathrm{a}}$ \\
\hline \multirow{2}{*}{ PAM } & 1,0 & $45,4 \pm 1,2^{\mathrm{ab}}$ & $0,987 \pm 0,003^{\mathrm{a}}$ & $42,9 \pm 0,3^{\mathrm{a}}$ & $0,970 \pm 0,000^{\mathrm{a}}$ \\
\cline { 2 - 6 } & 2,0 & $45,5 \pm 0,2^{\text {ab }}$ & $0,985 \pm 0,003^{\mathrm{a}}$ & $44,6 \pm 1,1^{\mathrm{b}}$ & $0,973 \pm 0,005^{\mathrm{a}}$ \\
\hline
\end{tabular}

media $\pm \mathrm{DE}$. En cada columna, letras diferentes indican diferencias significativas $(p<0,05)$. 


\subsubsection{Capacidad de hidratación de las proteínas de gluten}

Para la determinación de los valores de gluten húmedo y seco se realizó una modificación de la técnica AACC 38-12-02 según se describió en el ítem 2.2.5.2.1 de la sección Materiales y Métodos. En la Tabla 4.2 se muestran los valores obtenidos para gluten húmedo $(\mathrm{GH})$, gluten seco (GS) y el agua unida al gluten (GH-GS) a partir de masas $\sin$ y con $\mathrm{NaCl}$.

Tabla 4.2. Gluten húmedo, seco y agua unida al gluten para las masas sin y con $\mathrm{NaCl}$.

\begin{tabular}{|c|c|c|c|c|c|c|}
\hline \multirow[b]{2}{*}{ Muestra } & \multicolumn{3}{|c|}{ Masas $\sin \mathrm{NaCl}$} & \multicolumn{3}{|c|}{ Masas con $\mathrm{NaCl}$} \\
\hline & $\mathrm{GH} \%$ & GS \% & $\begin{array}{c}\text { (GH-GS) } \\
\%\end{array}$ & $\mathrm{GH} \%$ & GS\% & $\begin{array}{c}\text { (GH-GS) } \\
\%\end{array}$ \\
\hline Control & $32,0 \pm 0,3^{c}$ & $11,0 \pm 0,2^{b c}$ & $21,0 \pm 0,4^{\mathrm{d}}$ & $31,5 \pm 0,5^{\mathrm{a}}$ & $10,4 \pm 0,1^{b c}$ & $21,1 \pm 0,4^{\mathrm{a} b}$ \\
\hline PBM 1\% & $30,3 \pm 0,6^{b}$ & $10,6 \pm 0,3^{b}$ & $19,7 \pm 0,3^{\mathrm{ab}}$ & $32,3 \pm 0,6^{b}$ & $10,5 \pm 0,2^{c}$ & $21,8 \pm 0,5^{b}$ \\
\hline PBM 2\% & $32,1 \pm 0,5^{c}$ & $11,3 \pm 0,2^{c}$ & $20,8 \pm 0,5^{\mathrm{cd}}$ & $31,2 \pm 0,3^{\underline{a}}$ & $10,3 \pm 0,1^{\mathrm{abc}}$ & $20,9 \pm 0,2^{a}$ \\
\hline PAM 1\% & $30,9 \pm 0,8^{b}$ & $10,7 \pm 0,2^{b}$ & $20,2 \pm 0,6^{b c}$ & $31,7 \pm 0,4^{\mathrm{ab}}$ & $10,1 \pm 0,3^{\mathrm{ab}}$ & $21,6 \pm 0,3^{b}$ \\
\hline PAM 2\% & $29,0 \pm 0,4^{a}$ & $10,1 \pm 0,3^{\mathrm{a}}$ & $18,9 \pm 0,5^{a}$ & $31,2 \pm 0,4^{\mathrm{a}}$ & $10,1 \pm 0,1^{\mathrm{a}}$ & $21,1 \pm 0,4^{a}{ }^{a}$ \\
\hline
\end{tabular}

media \pm DE. En cada columna, letras diferentes indican diferencias significativas $(p<0,05)$. Los valores porcentuales se refieren a $100 \mathrm{~g}$ de harina.

En las masas $\sin \mathrm{NaCl}$, los mayores valores para $\mathrm{GH}$, GS y $\mathrm{GH}-\mathrm{GS}$ fueron obtenidos para el control y la masa con PBM $2 \%$, mientras que los menores valores de GH, GS y GH-GS correspondieron a las muestras con el mayor nivel de PAM (2 \%). En las masas con $\mathrm{NaCl}$ se observó una menor variación de estos parámetros. La relación GH/GS (no mostrada) no se vio afectada en ausencia de $\mathrm{NaCl}$; en presencia de $\mathrm{NaCl}$ las masas con PAM presentaron valores ligeramente mayores que el control.

Se ha visto que el efecto de las sales sobre las proteínas del gluten en la masa varía dependiendo del tipo de sal y de la concentración en la cual se encuentra (He y col., 1992). A bajas concentraciones el efecto parece deberse principalmente a interacciones iónicas atractivas o repulsivas que permiten o no la interacción entre las proteínas mientras que a mayores concentraciones $(>0,5 \mathrm{M})$ las fuerzas electrostáticas serían despreciables, debido al apantallamiento de cargas, y las interacciones hidrofóbicas serían las responsables de la agregación de las proteínas del gluten (Preston, 1989). Este efecto del $\mathrm{NaCl}$ sería extensivo a las pectinas, favoreciéndose 
las interacciones hidrofóbicas proteínas-pectina. De hecho, los menores niveles de GH y GS obtenidos con PAM $2 \%$ en ausencia de $\mathrm{NaCl}$ podrían reflejar una cierta labilidad de la red de gluten que se observa en menor grado en presencia de $\mathrm{NaCl}$.

Estos resultados no indican que haya una mayor cantidad de agua unida a la matriz de gluten por efecto del agregado de hidrocolode, como podría esperarse de los mayores niveles de absorción farinográfica observados al agregar pectina. Otros autores también han informado que PAM afecta la calidad y cantidad del gluten obteniéndose menores valores de glúten húmedo, seco y gluten index (Bárcenas y col., 2009).

\subsubsection{Ensayos reológicos empíricos y fundamentales}

\subsubsection{Farinogramas}

En la Figura 4.3 se muestran los valores de tiempo de desarrollo, estabilidad y aflojamiento farinográficos en las mezclas sin y con $\mathrm{NaCl}$. Al comparar ambos controles sin hidrocoloide, se observó que el agregado de $\mathrm{NaCl}$ ocasionó un incremento tanto del tiempo de desarrollo como de la estabilidad y una disminución del aflojamiento, esto último nos señala que la harina con $\mathrm{NaCl}$ presenta una mejor tolerancia al amasado. Dado que no se encontraron diferencias significativas entre los valores de gluten húmedo y seco de los controles, las diferencias de comportamiento farinográfico halladas indican una diferencia de calidad de la red y de las uniones entre las cadenas polipeptídicas. EI $\mathrm{NaCl}$ conduce a la obtención de una red más fuerte.

Resultados concordantes por la utilización de $\mathrm{NaCl}$ en las propiedades reológicas de la masa fueron hallados por otros autores. Galal y col. (1978) estudiaron el efecto de ácidos orgánicos y $\mathrm{NaCl}$ y a pesar de haber hallado que al agregarlos por separado inducían comportamientos opuestos (la presencia de ácidos debilitaba la red y la de $\mathrm{NaCl}$ la reforzaba) al emplearlos juntos, el $\mathrm{NaCl}$ pudo revertir la acción de los ácidos obteniéndose masas más resistentes. $\mathrm{El} \mathrm{NaCl}$ apantallaría la carga neta positiva que las proteínas del gluten presentan a pH ácido, disminuyendo de este modo la repulsión electrostática y permitiendo la interacción intermolecular. Wherle y col. (1997) hallaron resultados equivalentes, masas más estables y con menor aflojamiento por la presencia de $\mathrm{NaCl}$, aun en presencia de ácido láctico y ácido acético.

Kinsella y Hale (1984) estudiaron el efecto de aniones de diferente carácter caotrópico sobre la masa y postularon que ante la presencia de $\mathrm{F}^{-}$y $\mathrm{Cl}^{-}$, se promueven 

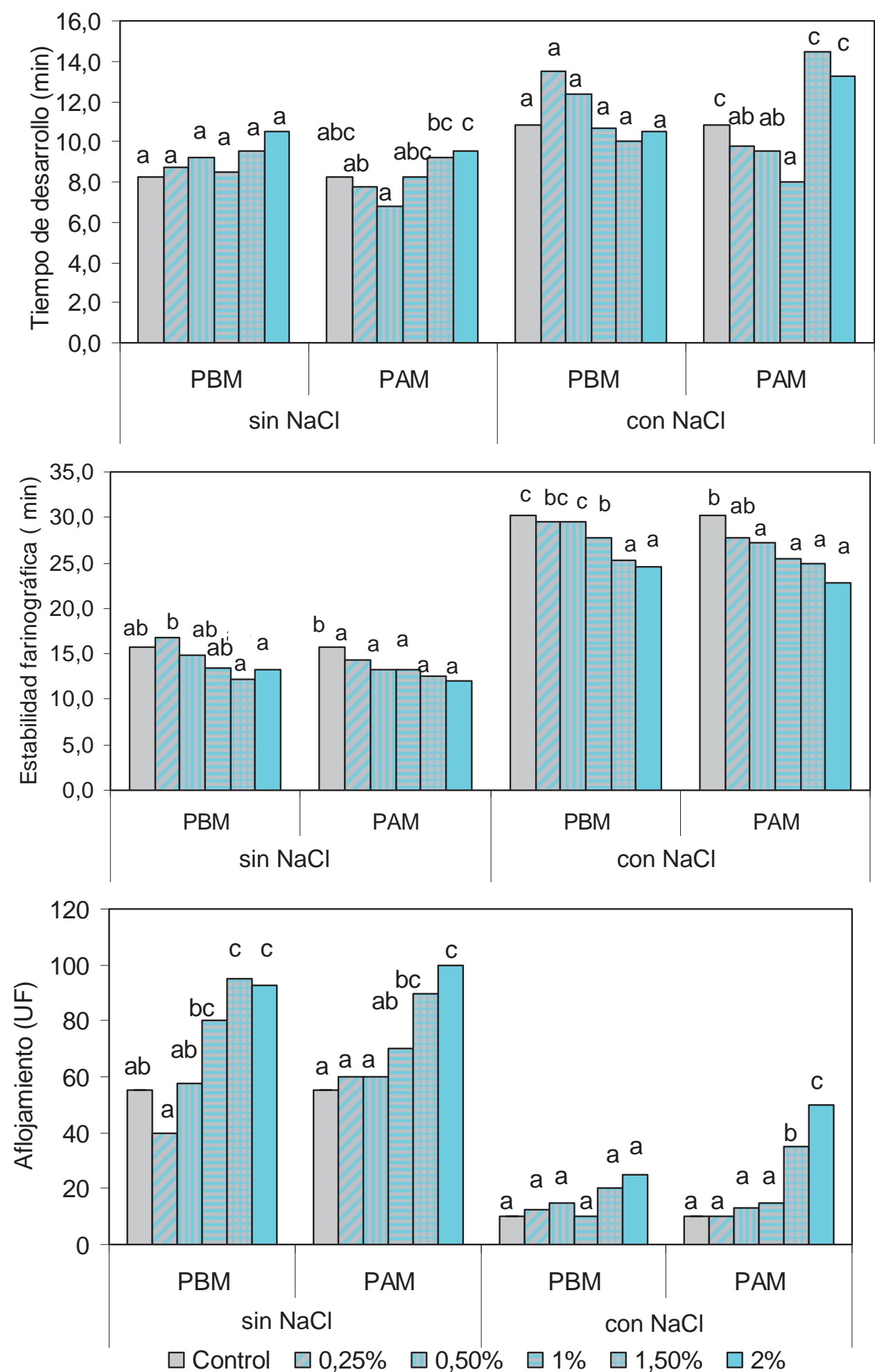

Figura 4.3. Parámetros farinográficos: tiempo de desarrollo farinográfico, estabilidad y aflojamiento de las masas $\sin$ y con $\mathrm{NaCl}$. Dentro de cada grupo de barras, letras diferentes indican diferencias significativas respecto al control y entre los diferentes niveles empleados $(p<0,05)$ 
interacciones hidrofóbicas entre las proteínas del gluten, permaneciendo más agregadas y resistentes a la hidratación por lo que se necesitan mayores tiempos de amasado. Sin embargo, la red resultante es mucho más estable en presencia de $\mathrm{NaCl}$. En el mismo sentido, a través de estudios electroforéticos y de FT-IR, Ukai y col. (2008) encontraron que el $\mathrm{NaCl}$ promueve el reforzamiento de la masa a través de cambios estructurales (disminución de estructura giro $\beta$ y aumento de hoja plegada $\beta$ ) y mayor entrecruzamiento. Preston (1989) estudió el efecto de sales de sodio con aniones de la serie liotrópica $\left(\mathrm{Cl}^{-}, \mathrm{Br}^{-}, \mathrm{ClO}_{4}^{-}, \mathrm{I}^{-}, \mathrm{SCN}^{-}\right)$sobre los parámetros farinográficos, alevográficos y extensográficos. A bajas concentraciones salinas $(0,05-$ 0,1 M) observó un reforzamiento de la red independientemente del tipo de anión, lo cual se debería a que las sales apantallarían las cargas de los aminoácidos permitiendo un aumento de las interacciones proteína-proteína, mientras que a concentraciones salinas mayores (0,5-1,0 M) sólo los iones no caotrópicos como el $\mathrm{Cl}^{-}$, que inducen las interacciones hidrofóbicas, reforzaron la red, observándose además un aumento de la extensibilidad de la masa.

Con respecto a las muestras con pectinas y $\mathrm{NaCl}$, en general, presentaron mayor tiempo de desarrollo y estabilidad y menor aflojamiento que las respectivas $\sin \mathrm{NaCl}$.

El tiempo de desarrollo no fue modificado respecto al control por PBM ni en ausencia ni en presencia de $\mathrm{NaCl}$ mientras que PAM sólo lo hizo en los mayores niveles y en presencia de $\mathrm{NaCl}$. En las masas sin $\mathrm{NaCl}$, PBM no afectó significativamente la estabilidad (respecto al control) en ninguno de los niveles ensayados mientras que el agregado de PAM disminuyó la estabilidad aunque no se hallaron diferencias significativas entre los niveles empleados. En cambio, en las masas con $\mathrm{NaCl}$, se observó una disminución de la estabilidad al agregar pectinas en niveles crecientes; esta disminución fue más pronunciada con la utilización de PAM, llegando hasta un $25 \%$ de disminución respecto al control. El aflojamiento varía en sentido inverso a la estabilidad; en las mezclas $\sin \mathrm{NaCl}$ se ve un aumento significativo del aflojamiento respecto al control con los mayores niveles de ambas pectinas (1,5 y $2 \%$ ) y en las masas con $\mathrm{NaCl}$ este efecto sólo fue significativo con el agregado de PAM en los mayores niveles (1,5 y $2 \%$ ). En general se ven efectos adversos sobre la masa más pronunciados con PAM (en los mayores niveles) y en presencia de $\mathrm{NaCl}$.

La disminución de la estabilidad estaría sugiriendo que las interacciones que se establecen entre las pectinas y las proteínas de la red afectarían negativamente la calidad de la matriz de gluten. Respecto al carácter de estas interacciones, en ausencia de $\mathrm{NaCl}$ podrían primar las fuerzas de carácter electrostático mientras que en presencia de $\mathrm{NaCl}$ se vería promovida la interacción proteínas-pectina a través de 
uniones de tipo hidrofóbico, favorecidas además por el apantallamiento de las cargas de los grupos carboxilo no metilados ni amidados; efecto que ya fue descripto para la interacción proteína-proteína (Kinsella y col., 1984; Preston, 1989; Melnik y col., 2011). Por otro lado, si bien ambas pectinas afectan la estabilidad, el hecho de que PAM lo haga en mayor grado en presencia de $\mathrm{NaCl}$ evidenciaría el carácter hidrofóbico de la interacción, ya que las características estructurales de PAM mencionadas (mayor grado de esterificación que PBM) se asocian con una mayor hidrofobicidad.

Siendo similares los pesos moleculares, otra característica estructural que podría contribuir a los diferentes efectos producidos por las pectinas es la distribución de los grupos carboxilo no sustituidos a lo largo de la cadena (Voragen y col., 2009). En las pectinas de bajo metoxilo los grupos carboxilo se encuentran agrupados en zonas con al menos 10 grupos contiguos; esta característica estructural es lo que les otorga la propiedad de gelificar a través de puentes salinos (modelo tipo "caja de huevo") (Daas y col., 2001).

\subsubsection{Ensayos dinámicos oscilatorios}

Se determinó el rango de viscoelasticidad lineal a una frecuencia de $1 \mathrm{~Hz}$ para las masas sin y con $\mathrm{NaCl}$ con el objeto de fijar las condiciones para la obtención de los espectros mecánicos. Los ensayos dinámicos fueron realizados con masas preparadas con los valores de absorción y tiempo de desarrollo farinográficos.

El rango de viscoelasticidad lineal queda definido por los valores de esfuerzo $(\tau)$ en los cuales los módulos elástico $\left(G^{\prime}\right)$ y viscoso $\left(G^{\prime \prime}\right)$ permanecen constantes lo cual indica que no ocurrió un colapso de la estructura de la muestra. En la Figura 4.4 se muestran las curvas obtenidas al realizar un barrido de esfuerzo para las masas control, con PBM y con PAM al 2\%, con $\mathrm{NaCl}$. En las masas sin $\mathrm{NaCl}$ el límite superior del rango de viscoelasticidad lineal $\left(\tau_{\text {lim }}\right)$ se encontró aproximadamente en $10 \mathrm{~Pa}$, no habiéndose hallado variaciones debido a la presencia de las pectinas (datos no mostrados). Para el control con $\mathrm{NaCl}$ el $\tau_{\text {lim }}$ fue mayor que en ausencia de $\mathrm{NaCl}(15 \mathrm{~Pa}$ ) lo que muestra su efecto reforzador sobre la red de gluten. Para las masas con $\mathrm{NaCl}$ y pectinas se obtuvieron valores menores al control, entre 8,5-10 Pa. En base a estos resultados se eligió un esfuerzo de $5 \mathrm{~Pa}$ para realizar los barridos de frecuencia.

En la Figura 4.5 se muestra el comportamiento de los módulos elástico y viscoso en función de la frecuencia para las masas sin y con $\mathrm{NaCl}$ utilizando el mayor nivel de pectina. Puede observarse que en todo el rango de frecuencia estudiado el módulo 
elástico presentó valores superiores que los del módulo viscoso, característica del comportamiento de un sólido viscoelástico.

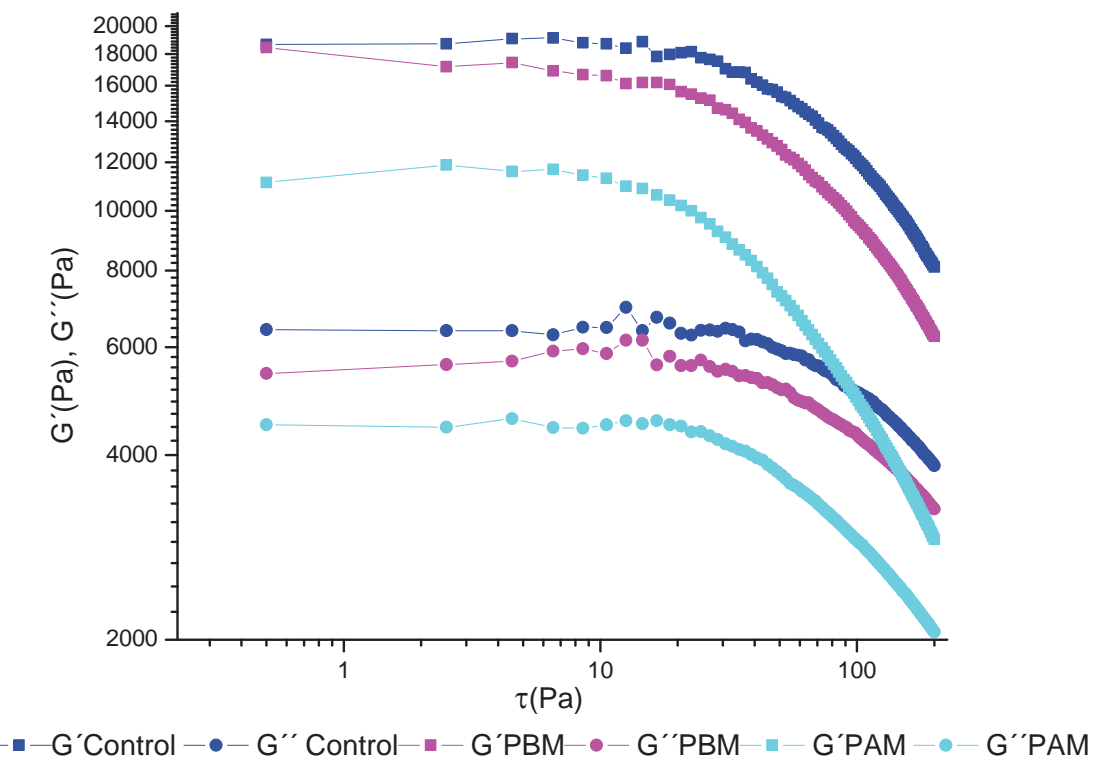

Figura 4.4. Barridos de esfuerzo a frecuencia constante $(1 \mathrm{~Hz})$ para las masas control, con PBM y PAM $2 \%$, con $\mathrm{NaCl}$.

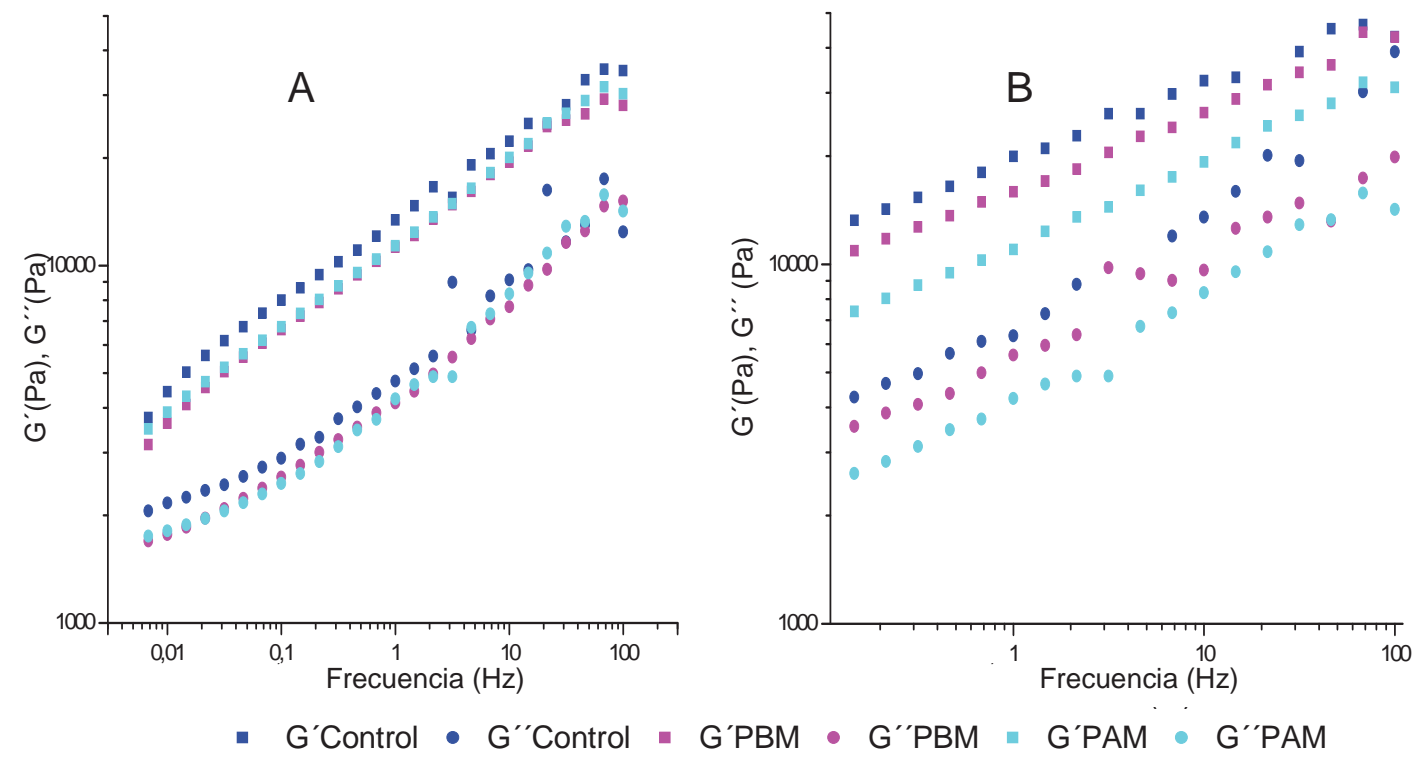

Figura.4.5. Espectro mecánicos para las masas control y con pectinas A) $\sin \mathrm{NaCl}, \mathrm{B}$ ) con $\mathrm{NaCl}$. 
En la Figura 4.6 se muestran los valores de los módulos G', G", la tangente del ángulo de desfasaje $(\tan (\delta))$ y la viscosidad compleja $\left(\eta^{*}\right)$ para las masas $\sin$ y con $\mathrm{NaCl}$ correspondientes a una frecuencia de $1 \mathrm{~Hz}$. Comparando los controles sin y con $\mathrm{NaCl}$ se observó que las masas con $\mathrm{NaCl}$ tenían mayores valores de G', G” y $\eta^{*}$ y menor valor de $\tan (\delta)$ indicando que se trata de masas más consistentes y con una mayor contribución elástica que las masas $\sin \mathrm{NaCl}$. Esos resultados concuerdan con el reforzamiento que el agregado de $\mathrm{NaCl}$ produciría sobre la red proteica y que fue discutido previamente. Larsson (2002) encontró también un aumento en G' al incrementar el contenido de $\mathrm{NaCl}$ pero otros autores (Lynch y col., 2009) han encontrado el efecto inverso. Esta es una cuestión controversial que los propios autores atribuyen a otros factores que difieren de un trabajo a otro como son la harina utilizada, la formulación empleada y las condiciones de amasado (Wherle y col., 1997; Larsson, 2002; Salvador y col., 2006; Lynch y col., 2009).

Las masas con PAM y $\mathrm{NaCl}$ exhibieron valores significativamente menores de ambos módulos (G', G") y de $\eta^{*}$ y valores significativamente mayores de la $\tan (\delta)$ (comportamiento más viscoso y menos elástico) comparadas con el control. No se encontraron diferencias significativas entre los distintos niveles de PAM utilizados. En las masas $\sin \mathrm{NaCl}$ con PAM al $2 \%$ no se observaron diferencias significativas respecto al control, mientras que al 1\% se observó una disminución significativa en G', G" y $\eta^{*}$ y un aumento en $\tan (\delta)$.

Las masas obtenidas con el agregado de PBM independientemente de la presencia o no de $\mathrm{NaCl}$, no presentaron diferencias significativas respecto a sus correspondientes controles ni tampoco diferencias entre los niveles. Si bien no se observa efecto en todos los casos, el hecho de que el agregado de PAM produzca una masa más viscosa en presencia de $\mathrm{NaCl}$ está de acuerdo con la menor estabilidad farinográfica encontrada para este sistema (Fig. 4.3) que indica una red más débil. En ausencia de $\mathrm{NaCl}$ este efecto de debilitamiento de la masa con PAM también se pudo observar aunque no llegó a ser significativo en ambos niveles. 

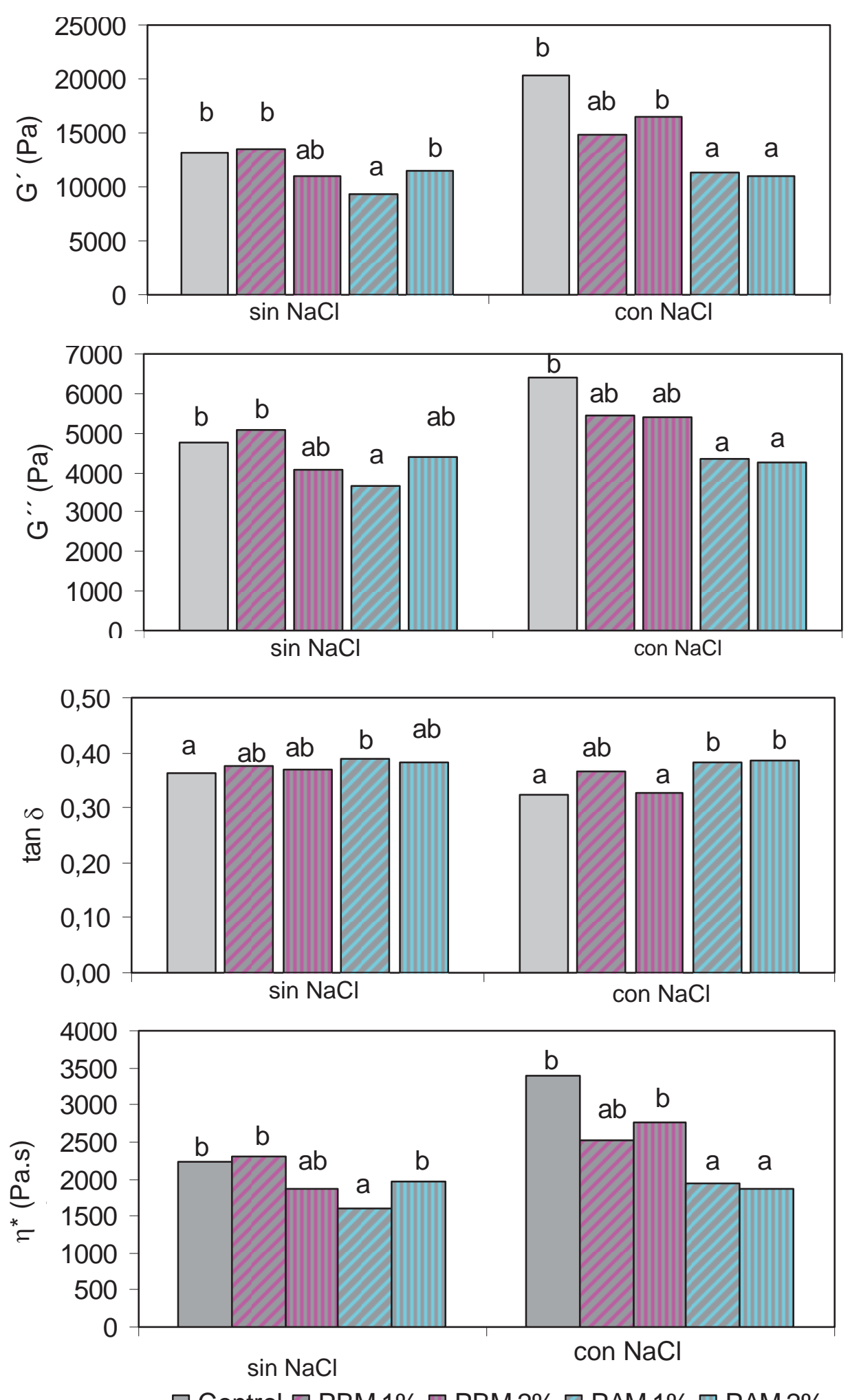

Figura 4.6. Parámetros dinámicos de las masas: módulos elástico, viscoso, tangente del ángulo de desfasaje, viscosidad compleja, a $1 \mathrm{~Hz}$. Dentro de cada grupo (sin o con $\mathrm{NaCl})$ letras diferentes indican diferencias significativas $(p<0,05)$. 


\subsubsection{Análisis de perfil de textura de las masas}

En la Figura 4.7 se muestra un perfil de textura típico de masa, el cálculo de los parámetros texturales: dureza, cohesividad, consistencia, resiliencia, elasticidad y adhesividad, se realizó tal como se describe en el Capítulo II (ítem 2.2.4.2.2.).

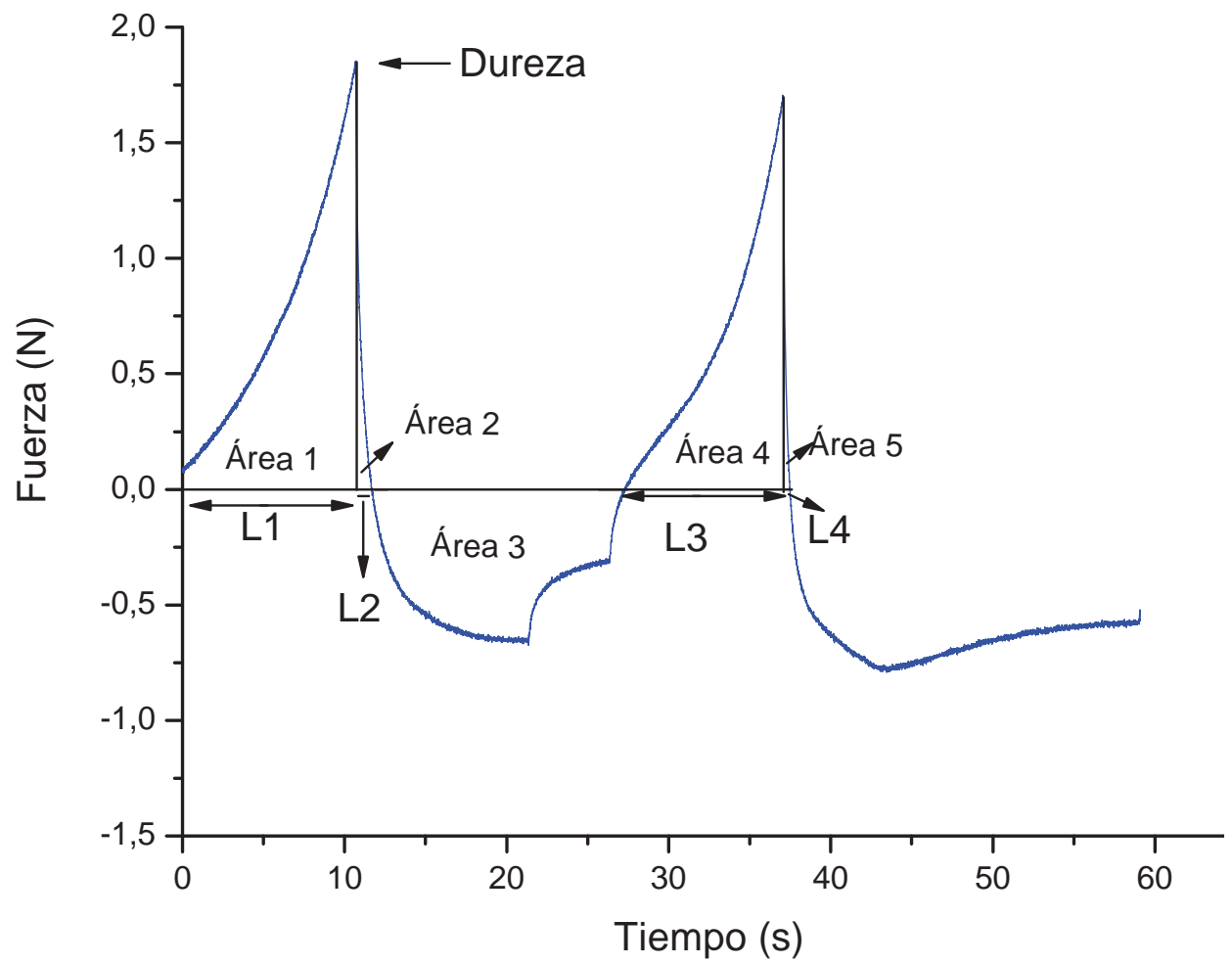

Figura 4.7. Perfil de textura de masa. Se señalan las áreas y distancias utilizadas para el cálculo de los parámetros texturales los códigos son los mismos que los detallados en el ítem 2.2.4.2.2.

En las Figuras 4.8 y 4.9 se muestran los resultados obtenidos en el análisis de perfil de textura para las masas sin y con $\mathrm{NaCl}$, obtenidas con los valores de absorción y tiempo de desarrollo farinográficos, de igual modo que para los ensayos dinámicos.

De la comparación de la dureza y la consistencia de los controles con y $\sin \mathrm{NaCl}$, surge que se obtienen masas más blandas en ausencia de $\mathrm{NaCl}$.

Al agregar pectinas, la dureza y la consistencia disminuyeron en comparación con los controles respectivos pero el efecto fue más pronunciado en presencia de $\mathrm{NaCl}$. No hay una tendencia clara respecto al efecto del nivel de pectina: en presencia de $\mathrm{NaCl}$ 
PAM tuvo el mismo efecto en ambos niveles pero PBM disminuyó menos la dureza en el nivel más alto. En ausencia de $\mathrm{NaCl}$ se observa un mantenimiento o disminución de la dureza al aumentar el nivel de hidrocoloide.

La cohesividad es un parámetro textural que se vincula con la integración de los componentes de una muestra cuando ésta es sometida a una deformación. En este caso, el efecto de las pectinas fue diferente dependiendo de la presencia o ausencia de $\mathrm{NaCl}$. Ambas pectinas en el mayor nivel disminuyeron drásticamente la cohesividad de las muestras $\sin \mathrm{NaCl}$ mientras que no la modificaron respecto al control al emplearlas al $1 \%$, lo que indica un efecto negativo sobre la integración de los componentes. En las masas con $\mathrm{NaCl}$, se observa un pequeño incremento de la cohesividad con el mayor nivel de hidrocoloide, lo cual nos estaría indicando que se obtiene un efecto positivo sobre este atributo.

Elasticidad y resiliencia están relacionadas con la recuperación de la muestra después de una deformación. La elasticidad refleja la recuperación después de un período de reposo entre ciclos y es afectada por las características viscosas de la muestra que son las que originan el retardo en la recuperación de la altura original. En cambio la resiliencia describe la recuperación inmediata o instantánea en el primer ciclo, no interviniendo en este caso la viscosidad por lo que se puede evaluar así la componente elástica de la muestra (Fiszman y col., 1998). En todos los casos, se observó una tendencia a disminuir la elasticidad de las masas por la utilización de las pectinas. En las masas $\sin \mathrm{NaCl}$ no se observaron diferencias significativas debidas al tipo de pectina ni al nivel utilizado, mientras que en las masas con $\mathrm{NaCl}$ la disminución de la elasticidad fue menos marcada con el empleo de las pectinas al $2 \%$. La resiliencia de las masas $\sin \mathrm{NaCl}$ tendió a aumentar y en las masas con $\mathrm{NaCl}$ disminuyó, no habiendo marcadas diferencias entre niveles y tipo de pectina empleados.

En cuanto a la adhesividad, en ausencia y presencia de $\mathrm{NaCl}$, se observa una disminución de la misma debido a la presencia de las pectinas y diferencias de acuerdo al nivel en que se la utiliza (disminución con el aumento del nivel de hidrocoloide en ausencia de $\mathrm{NaCl}$ y menor influencia del nivel de hidrocoloide en presencia de $\mathrm{NaCl}$ ).

Observando las tendencias generales se puede concluir que las pectinas conducen a a masas más blandas, menos elásticas, menos adhesivas y en algunos casos menos cohesivas lo que indicaría una marcada interacción con la red de gluten que dependerá tanto de la presencia de $\mathrm{NaCl}$ como del tipo y nivel de pectina. 

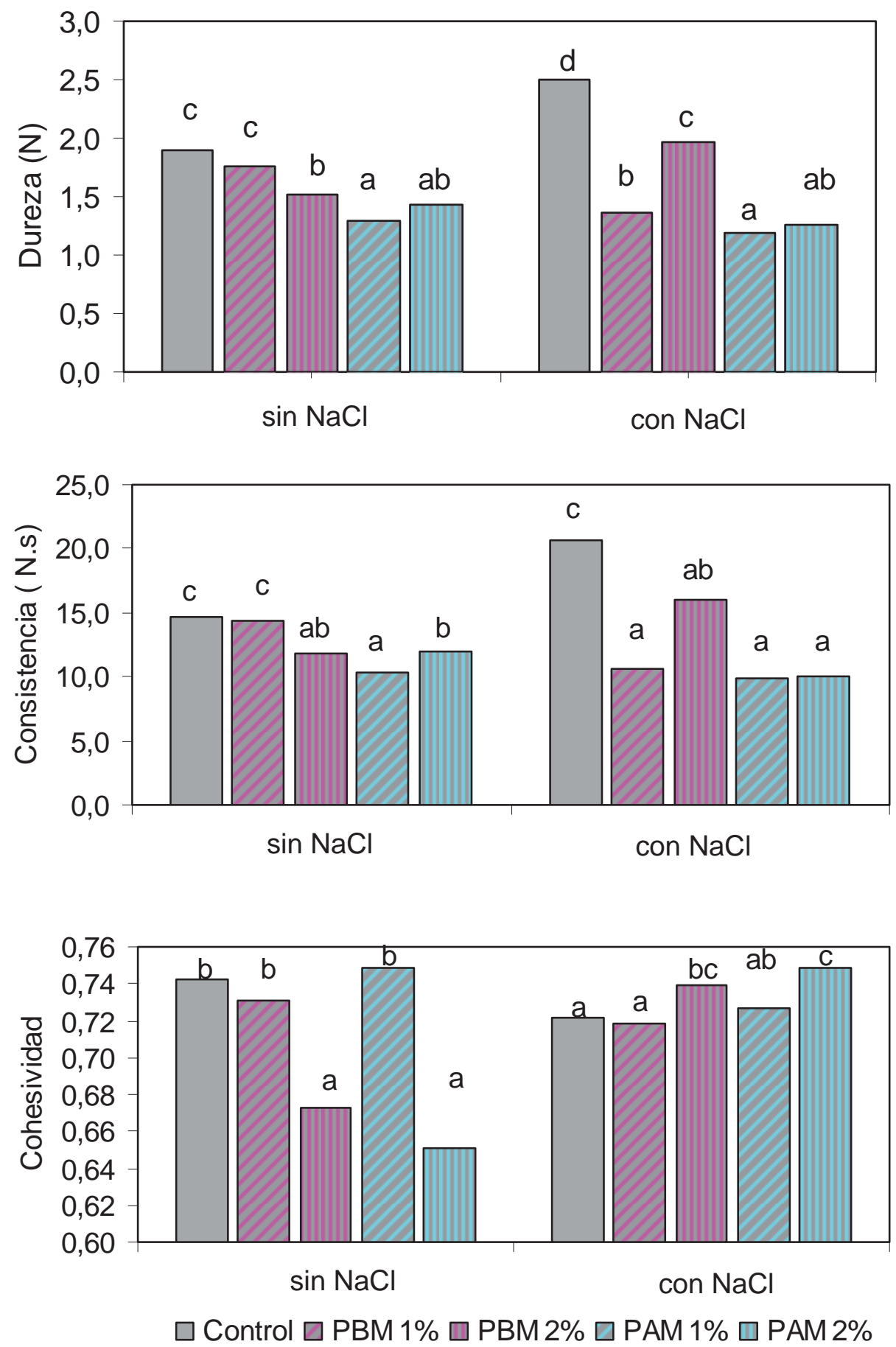

Figura 4.8. Parámetros texturales de las masas: dureza, consistencia, cohesividad. Dentro de cada grupo ( $\sin 0$ con $\mathrm{NaCl}$ ) letras diferentes indican diferencias significativas $(p<0,05)$. 

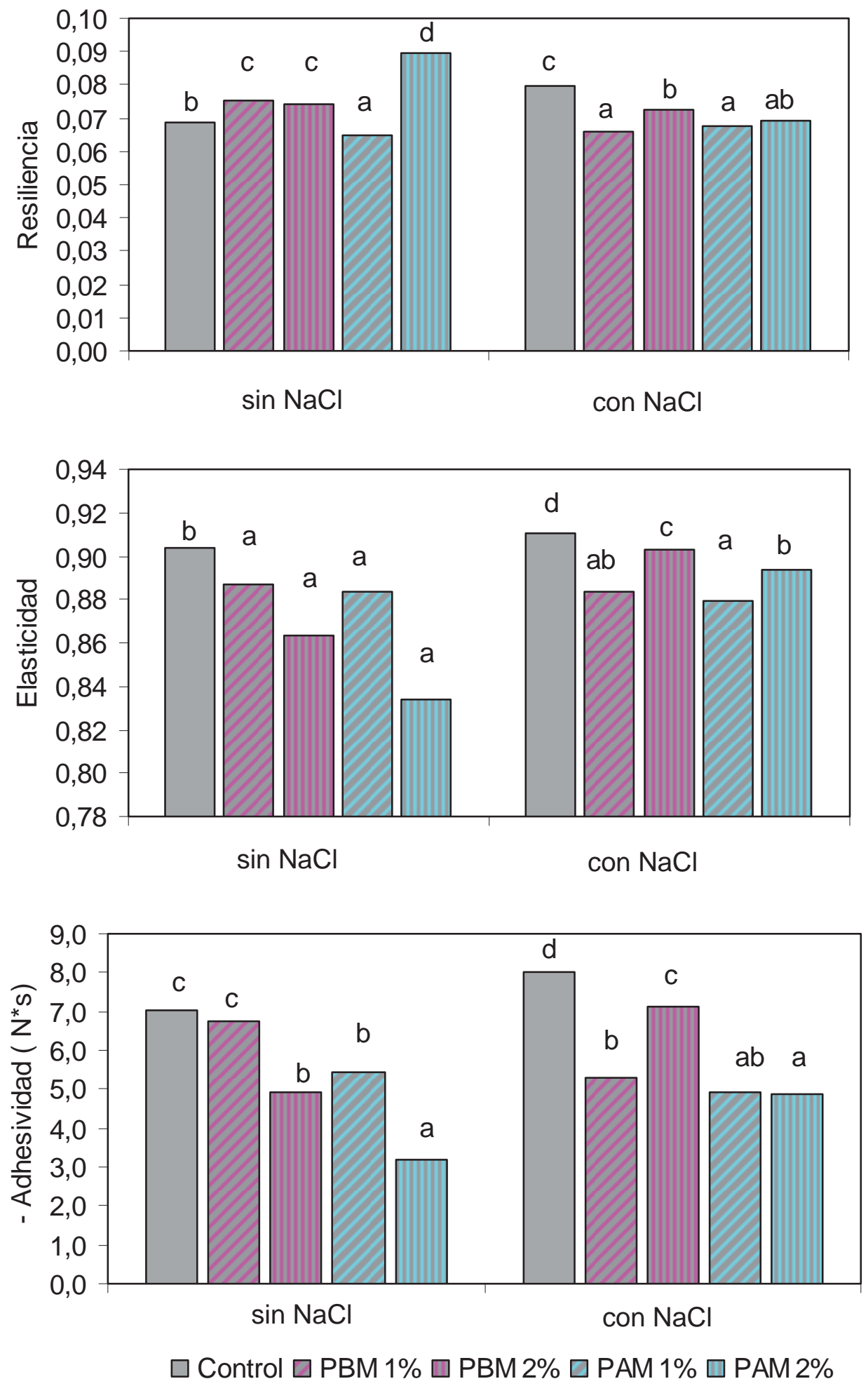

Figura 4.9. Parámetros texturales de las masas sin y con $\mathrm{NaCl}$ : resiliencia, elasticidad y adhesividad. Para un tipo de pectina letras diferentes indican diferencias significativas entre sus niveles o con respecto al control $(p>0,05)$. 


\subsubsection{Punción}

En la Figura 4.10 se muestra a modo de ejemplo el tipo de curva obtenida en los ensayos de punción de la masa, en la que pueden distinguirse diferentes regiones. Al comenzar el ensayo ocurre un aumento rápido de la fuerza debido a la deformación de la masa por la sonda, cuando la sonda penetra la masa ocurre una rotura irreversible de la misma que se evidencia por un cambio de pendiente. La siguiente zona de la curva registra la magnitud de la fuerza necesaria para que la sonda continúe penetrando en la matriz; en el caso de la masa, la fuerza continua aumentando luego de la penetración. En esta zona se determinó la firmeza de la masa como la máxima fuerza registrada durante la penetración. Luego de este punto, la sonda se retira de la masa produciéndose una disminución de la fuerza y evidenciándose la adhesividad de la masa.

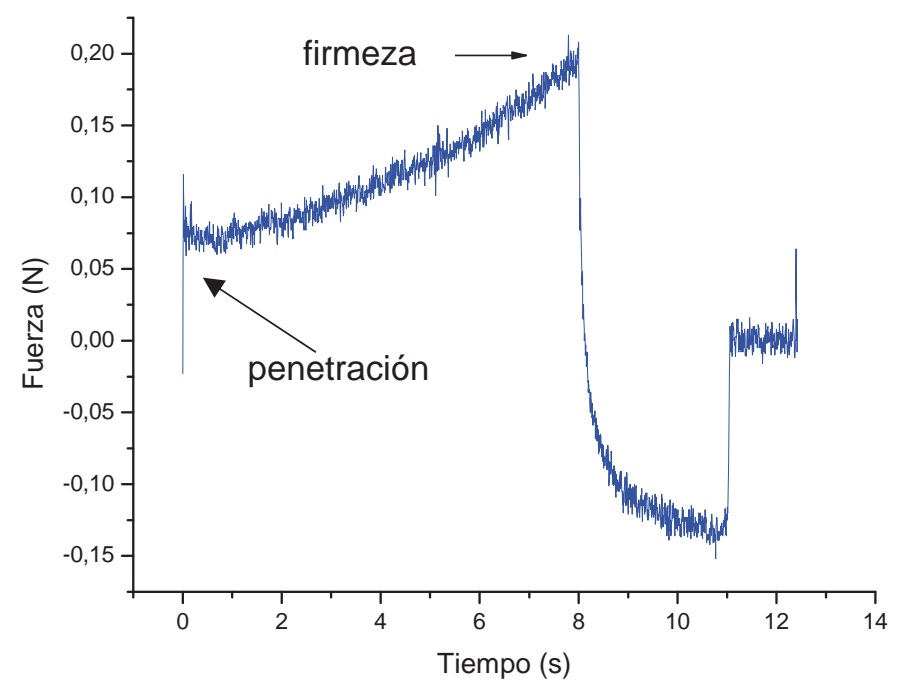

Figura 4.10. Ensayo de punción de la masa

En la Tabla 4.3 se muestran los valores de fuerza de penetración de las masas sin y con $\mathrm{NaCl}$. La presencia de $\mathrm{NaCl}$ en la masa control llevó a la obtención de mayores valores para la fuerza de penetración, lo que se relaciona con una mayor firmeza y cohesión del producto. Este comportamiento presentado por los controles es similar al obtenido para la dureza de la masa en el TPA. La presencia de ambas pectinas dio lugar a masas con menor firmeza. La disminución de la fuerza de penetración fue más marcada respecto al control en presencia de $\mathrm{NaCl}$ (Tabla 4.3). 
Tabla 4.3. Fuerza de penetración (N) en el ensayo de punción

\begin{tabular}{ccc}
\hline \multirow{2}{*}{ Muestra } & \multicolumn{2}{c}{ Fuerza de penetración (N) } \\
\cline { 2 - 3 } & Masas sin NaCl & Masas con NaCl \\
\hline Control & $0,26 \pm 0,03^{\mathrm{b}}$ & $0,33 \pm 0,03^{\mathrm{c}}$ \\
\hline PBM 1\% & $0,23 \pm 0,03^{\mathrm{a}}$ & $0,20 \pm 0,02^{\mathrm{a}}$ \\
\hline PBM 2 \% & $0,23 \pm 0,04^{\mathrm{a}}$ & $0,25 \pm 0,03^{\mathrm{b}}$ \\
\hline PAM 1\% & $0,22 \pm 0,02^{\mathrm{a}}$ & $0,22 \pm 0,02^{\mathrm{a}}$ \\
\hline PAM 2 \% & $0,23 \pm 0,02^{\mathrm{a}}$ & $0,21 \pm 0,03^{\mathrm{a}}$ \\
\hline media \pm DE. Letras diferentes indican diferencias \\
significativas & dentro de una & misma columna \\
(p<0,05).
\end{tabular}

\subsubsection{Ensayos de relajación}

Después de ser sometida a una deformación, los segmentos de cadena poliméricos de las macromoléculas presentes en la masa se reacomodan y toman la posición energéticamente más favorable que es la de menor energía libre, liberándose así los esfuerzos internos del material.

Peleg y Normand (1983) observaron dos limitaciones importantes de los ensayos de estrés-relajación en alimentos: 1) cuando son sometidos a grandes deformaciones generalmente exhiben un comportamiento viscoelástico no lineal por lo que las constantes de las ecuaciones que describen la relajación dependen tanto de la deformación como de la historia previa de la muestra; 2) la mayoría de los alimentos son inestables o biológicamente activos por lo que se dificulta la determinación de parámetros de equilibrio.

En los ensayos de relajación realizados se registró la fuerza en función del tiempo, obteniéndose curvas como la mostrada en la Figura 4.11. 


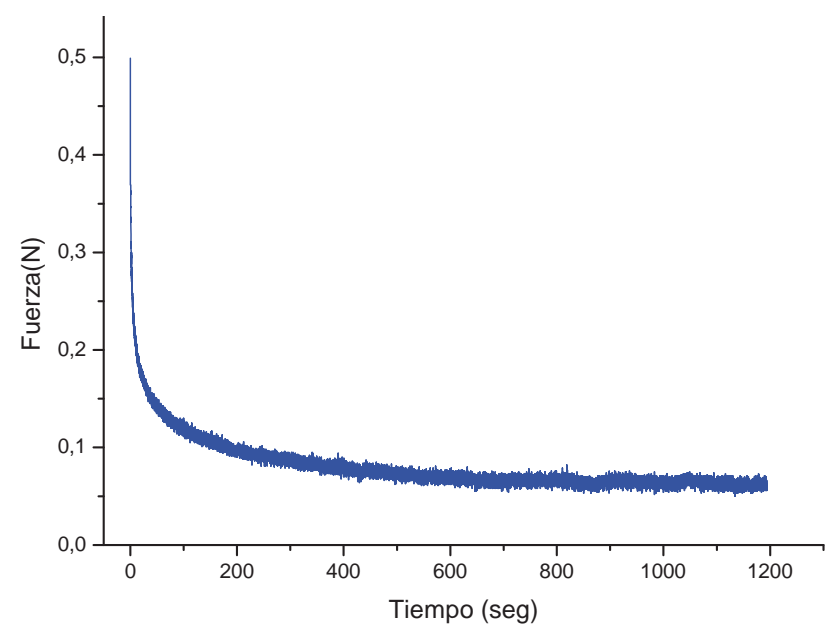

Figura 4.11. Curva típica de relajación de masa

Los datos se ajustaron con un ecuación exponencial de segundo grado (Ec. 4.1). Esta ecuación correspondería a dos elementos de Maxwell en paralelo y un resorte también en paralelo (ítem 2.2.4.2.4- Capítulo II).

$$
\sigma=A_{1} \exp \left(-\frac{t}{\lambda_{1}}\right)+A_{2} \exp \left(-\frac{t}{\lambda_{2}}\right)+\sigma_{e}
$$

donde $\sigma$ es el esfuerzo (fuerza / área), $\sigma_{e}$ es el esfuerzo de equilibrio, $\lambda_{1}$ y $\lambda_{2}$ son los tiempos de relajación y $A_{1}$ y $A_{2}$ son factores preexponenciales.

Al ser la masa un sistema complejo con biopolímeros de diferente naturaleza es esperable encontrar distintos tiempos de relajación. En este caso, las masas mostraron una distribución bimodal de tiempos de relajación, resultado que está en acuerdo con el comportamiento observado por otros autores (Bohlin y Carlson., 1980; Rao y col., 2001). La obtención de distintos tiempos de relajación refleja la existencia de una distribución de pesos moleculares en el gluten. Un mayor tiempo de relajación $(\lambda)$ se relaciona con un decaimiento del esfuerzo más lento en función del tiempo, o sea, una relajación más lenta (Steffe, 1996). Los menores tiempos de relajación obtenidos en la masa se vinculan con polímeros pequeños (relajan rápido) mientras que tiempos de relajación mayores se asocian con polímeros de alto peso molecular por lo que en la masa se encuentran directamente relacionados con la fracción insoluble de HMW-gluteninas (Li y col., 2003; Dobraszczyk y Morgenstern, 2003). 
A partir del ajuste de la Ec. 4.1 se obtuvieron el esfuerzo de equilibrio, $\sigma_{\mathrm{e}} \mathrm{y}$ los tiempos de relajación, $\lambda_{1}$ y $\lambda_{2}$ para las masas $\sin$ y con $\mathrm{NaCl}$ y pectinas, los que se muestran en la Tabla 4.4.

Al comparar los controles entre sí, se observó que la presencia de $\mathrm{NaCl}$ llevó a un marcado aumento de $\lambda_{1}$ en relación al control sin $\mathrm{NaCl}$ (293 min y 233 min respectivamente) o sea un comportamiento más tendiente al de un sólido (Steffe, 1996).

El efecto de las pectinas varió de acuerdo a la presencia o no de $\mathrm{NaCl}$. En las masas $\sin \mathrm{NaCl}$ se obtuvieron, con ambas pectinas, tiempos de relajación significativamente mayores que para el control; el esfuerzo de equilibrio no varió significativamente en este caso. Este relajamiento más lento está relacionado probablemente a la asociación proteína- hidrocoloide que genera matrices que tardan más en llegar a un estado de equilibrio. En las masas con $\mathrm{NaCl}$ sólo se observaron disminuciones significativas respecto al control en el caso de PAM ( 1 y $2 \%$ ) y no con PBM. Eso significaría que el agregado de PAM incrementó la contribución viscosa en el sistema, lo cual también se vio reflejado en los menores valores de esfuerzo de equilibrio. PBM no alteró el tiempo de relajación pero sí los valores de esfuerzo de equilibrio. Este comportamiento de PAM en las matrices concuerda con el aumento de $\tan (\delta)$ en los ensayos dinámicos, la que refleja la contribución relativa de las respuesta elástica y viscosa en un sistema.

Tabla 4.4. Tiempos de relajación $\left(\lambda_{1}, \lambda_{2}\right)$ para las masas sin y con $\mathrm{NaCl}$.

\begin{tabular}{ccccccc}
\hline \multirow{2}{*}{ Muestra } & \multicolumn{3}{c}{ Sin NaCl } & \multicolumn{3}{c}{ Con NaCl } \\
\cline { 2 - 6 } & $\sigma_{\mathrm{e}}\left(\mathrm{N} / \mathrm{m}^{2}\right)$ & $\lambda_{1}(\mathrm{~s})$ & $\lambda_{2}(\mathrm{~s})$ & $\sigma_{\mathrm{e}}\left(\mathrm{N} / \mathrm{m}^{2}\right)$ & $\lambda_{1}(\mathrm{~s})$ & $\lambda_{2}(\mathrm{~s})$ \\
\hline Control & $25,8 \pm 3,0^{\mathrm{a}}$ & $233 \pm 7,0^{\mathrm{a}}$ & $6,3 \pm 0,3^{\mathrm{a}}$ & $55,5 \pm 8,3^{\mathrm{c}}$ & $293 \pm 7^{\mathrm{b}}$ & $7,9 \pm 0,3^{\mathrm{a}}$ \\
\hline PBM 1\% & $27,4 \pm 8,0^{\mathrm{a}}$ & $275 \pm 11^{\mathrm{b}}$ & $7,2 \pm 0,1^{\mathrm{b}}$ & $23,5 \pm 2,9^{\mathrm{ab}}$ & $289 \pm 18^{\mathrm{ab}}$ & $8,2 \pm 0,7^{\mathrm{a}}$ \\
\hline PBM 2\% & $25,6 \pm 11,3^{\mathrm{a}}$ & $290 \pm 17^{\mathrm{b}}$ & $7,8 \pm 0,6^{\mathrm{b}}$ & $40,0 \pm 6,5^{\mathrm{bc}}$ & $296 \pm 9^{\mathrm{b}}$ & $7,8 \pm 0,6^{\mathrm{a}}$ \\
\hline PAM 1\% & $19,5 \pm 3,9^{\mathrm{a}}$ & $274 \pm 16^{\mathrm{b}}$ & $7,4 \pm 0,2^{\mathrm{b}}$ & $15,8 \pm 3,2^{\mathrm{a}}$ & $269 \pm 12^{\mathrm{a}}$ & $7,6 \pm 0,9^{\mathrm{a}}$ \\
\hline PAM 2\% & $25,8 \pm 9,6^{\mathrm{a}}$ & $289 \pm 13^{\mathrm{b}}$ & $7,2 \pm 0,6^{\mathrm{b}}$ & $23,2 \pm 8,5^{\mathrm{a}}$ & $275 \pm 11^{\mathrm{a}}$ & $7,5 \pm 0,3^{\mathrm{a}}$ \\
\hline
\end{tabular}

media $\pm D E$. Letras diferentes indican diferencias significativas $(p<0,05)$ dentro de una misma columna. 


\subsubsection{Análisis de componentes principales de los principales parámetros reológicos de la masa}

El análisis por componentes principales (ACP) permite simplificar el estudio cuando se tiene un gran número de variables, ya que se realiza una combinación de las mismas y de este modo se obtiene un menor número de parámetros, facilitando el análisis e interpretación de los resultados. Asimismo, el agrupamiento de variables permite determinar cuáles de ellas están relacionadas entre sí al quedar asociadas a un mismo factor.

Para poder determinar tendencias generales, se seleccionaron algunos parámetros reométricos y texturales de las masas con pectinas al 1,0\% y 2,0 \% para ser analizados por este método. Para la selección se tomó como criterio que los parámetros permitieran distinguir el comportamiento de las distintas muestras por lo que, por ejemplo los módulos dinámicos G' y G" no fueron incorporados pero si la relación entre ellos que está dada por la tangente del ángulo de desfasaje (tan( $(\delta))$. La elasticidad y el tiempo de relajación $\left(\lambda_{1}\right)$ fueron en principio incluidos pero no quedaron agrupados junto con las otras variables obligando a considerar nuevos factores. Por una cuestión de simplificación se optó por las variables de dureza, consistencia, adhesividad, resiliencia y cohesividad (TPA) y tangente del ángulo de desfasaje (ensayos dinámicos) que pudieron ser agrupadas en dos componentes explicando la mayor parte $(94,1 \%)$ de la varianza observada. El componente 1 (CP1) explicó el $61,1 \%$ de la varianza mientras que el componente 2 (CP2) el 33,0\%.

Las cargas de ambos componentes y la comunalidad se muestran en la Tabla 4.5. La carga indica la correlación que existe entre la variable original y el componente, mientras que la comunalidad expresa la proporción de varianza de la variable extraída o explicada con $\mathrm{m}$ componentes. Si $\mathrm{m}$ es igual al número total de variables la comunalidad será igual a 1.

El CP1 quedó integrado principalmente por la dureza, la consistencia, la adhesividad (con correlación positiva) y la $\tan (\delta)$ (con correlación negativa) mientras que el CP2, fundamentalmente por la cohesividad (con correlación positiva) y la resiliencia (con correlación negativa). La correlación negativa nos esta indicando que una masa más cohesiva presenta menor capacidad de recuperación luego de ser sometida a una deformación. 
Tabla 4.5. Cargas de los componentes y comunalidades

\begin{tabular}{cccc}
\hline Variable & CP1 & CP2 & Comunalidad \\
\hline Dureza & 0,988 & $-0,093$ & 0,985 \\
\hline Cohesividad & 0,186 & 0,941 & 0,919 \\
\hline Resiliencia & 0,260 & $-0,925$ & 0,923 \\
\hline Adhesividad & 0,873 & 0,460 & 0,973 \\
\hline Consistencia & 0,984 & $-0,140$ & 0,988 \\
\hline Tan $\delta$ & $-0,925$ & 0,030 & 0,857 \\
\hline Varianza & 3,6638 & 1,9808 & 5,6446 \\
\hline$\%$ Varianza & 0,611 & 0,330 & 0,941 \\
\hline
\end{tabular}

En la Figura 4.12 se muestra el gráfico de doble proyección donde se observa la puntuación para las variables texturales y reométricas analizadas en función de ambos componentes y la carga de cada variable. El control con $\mathrm{NaCl}$ muestra un comportamiento marcadamente diferente al del control $\sin \mathrm{NaCl}$ y al de las muestras con hidrocoloides, lo que se evidencia al haber quedado aislado en el cuadrante inferior derecho. Esta zona del gráfico corresponde a masas de mayor dureza, consistencia y menor carácter viscoso. El control sin $\mathrm{NaCl}$, además de presentar un comportamiento más viscoso, presentó un mayor valor de CP2 por lo que presenta mayor cohesividad, adhesividad y menor resiliencia que el control con $\mathrm{NaCl}$.

Como tendencias generales, se observa que todas las masas con $\mathrm{NaCl}$ y pectinas son más blandas y cohesivas que el control. Las muestras $\sin \mathrm{NaCl}$ presentan una mayor variabilidad aunque todas son menos duras y consistentes que el control y la mayoría menos cohesivas y más resilientes.

Resulta interesante que para PBM con $\mathrm{NaCl}$ el aumento de nivel de pectina implicó un endurecimiento de la muestra pero sin cambios en la cohesividad/resiliencia. En cambio, PBM sin $\mathrm{NaCl}$ mostró la tendencia opuesta, la muestra fue más blanda y menos cohesiva al incrementar el nivel de hidrocoloide. La masa con PAM y $\sin \mathrm{NaCl}$ perdió drásticamente su cohesividad al pasar de 1 a $2 \%$ de hidrocoloide pero no se modificó sustancialmente su dureza. El aumento de nivel de PAM en presencia de $\mathrm{NaCl}$ prácticamente no alteró las características de la masa.

Se podría decir en general que la presencia de $\mathrm{NaCl}$ ayudó a conservar la cohesividad en las muestras con pectina, y que la dureza de la masa se afectó por el tipo y nivel de 
pectina utilizado. En ausencia de $\mathrm{NaCl}$ las variaciones texturales fueron mayores incidiendo en mayor grado el tipo y concentración de hidrocoloide.

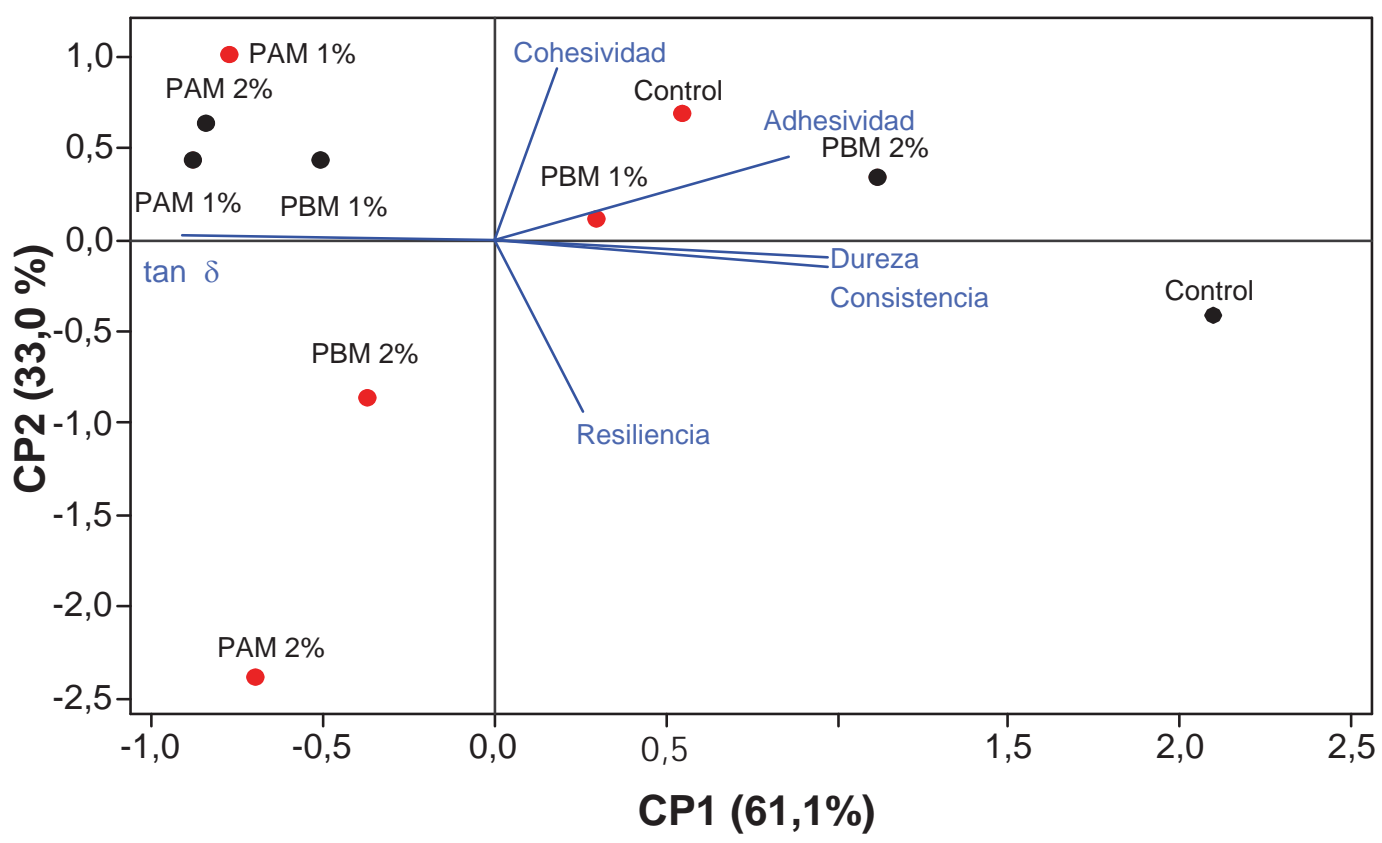

Figura 4.12. Análisis por componentes principales (rotación Varimax) de los parámetros dinámicos (tangente del ángulo de desfasaje) y texturales( adhesividad, dureza, resiliencia, consistencia y cohesividad) de las masas sin y con $\mathrm{NaCl}$. Círculos rojos: masas sin $\mathrm{NaCl}$, círculos negros: masas con $\mathrm{NaCl}$. Los números indican la concentración de hidrocoloide empleada (\% p/p base harina). 


\subsection{Panificación}

\subsubsection{Curvas de fermentación}

Se obtuvieron las curvas de fermentación con todos niveles de pectinas entre $0 \%$ y $2 \%$ en masas con $\mathrm{NaCl}$, con el fin de estudiar si se encontraban variaciones en el comportamiento de las masas durante la fermentación debido a la concentración de pectina utilizada. Además, las curvas permitieron la obtención del tiempo de fermentación óptimo como se verá más adelante. En la Figura 4.13 se muestran, a modo de ejemplo, los datos experimentales que describen el aumento del volumen en función del tiempo para la masa control y las masas con $2 \%$ de PBM y PAM.

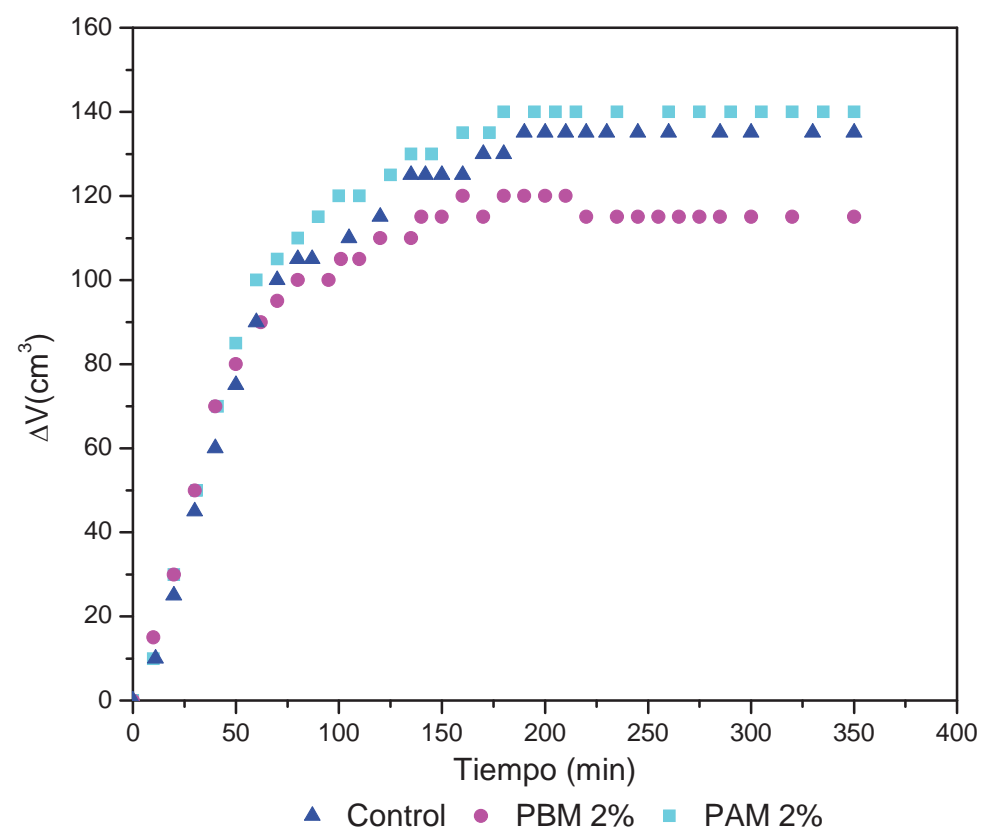

Figura 4.13. Curvas típicas de fermentación de la masa control y de las masas con pectinas al $2 \%$.

Los datos se modelaron con una ecuación sigmoidea (Ec. 4.2), la cual se seleccionó empíricamente, en base al ajuste logrado, entre otras ecuaciones.

$$
\Delta \mathrm{V}=\mathrm{af}^{*}\left(1-\exp \left(-\mathrm{b}_{\mathrm{f}}{ }^{*} \mathrm{tf}\right)\right)^{\mathrm{c}} \quad \text { Ec. } 4.2
$$

donde $\Delta \mathrm{V}$ es el incremento del volumen, $t_{f}$ es el tiempo (min) y $a_{f}, b_{f}$ y $c_{f}$ son constantes. 
El parámetro $a_{f}$ corresponde al máximo volumen alcanzado $(\Delta \mathrm{V})_{\max }$ por la masa durante la fermentación. El tiempo de fermentación óptimo se estableció como el tiempo requerido para alcanzar tres cuartos del volumen máximo y se obtuvo a partir de la ecuación específica para cada masa. Es necesario no haber alcanzado el volumen máximo antes de introducir las piezas en el horno para así evitar el colapso de la masa durante la cocción.

Los parámetros obtenidos al realizar las regresiones de las curvas de fermentación, el coeficiente de determinación de cada curva y el tiempo de fermentación calculado para cada masa se muestran en la Tabla 4.5. Como puede observarse la correlación lograda en todos los casos fue muy buena, ya que los valores de $r^{2}$ se encontraron entre 0,9983 y 0,9996 .

Tabla 4.5. Parámetros a, b y c de las curvas de fermentación, coeficiente de determinación $\left(\mathrm{r}^{2}\right)$ y tiempo de fermentación $\left(\mathrm{t}_{\mathrm{f}}\right)$ de las masas.

\begin{tabular}{cccccc}
\hline Muestra & $\mathrm{a}_{\mathrm{f}}\left(\mathrm{cm}^{3}\right)$ & $\mathrm{b}_{\mathrm{f}}(\mathrm{min})$ & $\mathrm{c}_{\mathrm{f}}$ & $\mathrm{R}^{2}$ & $\mathrm{t}_{\mathrm{f}}(\mathrm{min})$ \\
\hline Control & $134,3 \pm 1,3$ & $0,0230 \pm 0,0016$ & $1,57 \pm 0,13$ & 0,9992 & 78 \\
\hline PBM 0,25 \% & $140,6 \pm 0,9$ & $0,0266 \pm 0,0017$ & $1,34 \pm 0,11$ & 0,9993 & 62 \\
\hline PBM 0,5\% & $132,1 \pm 1,3$ & $0,0296 \pm 0,0027$ & $1,42 \pm 0,17$ & 0,9987 & 57 \\
\hline PBM 1,0\% & $124,9 \pm 0,8$ & $0,0314 \pm 0,0024$ & $1,5018 \pm 0,16$ & 0,9990 & 56 \\
\hline PBM 1,5\% & $126,5 \pm 0,7$ & $0,0347 \pm 0,0021$ & $1,5976 \pm 0,14$ & 0,9994 & 52 \\
\hline PBM 2,0 \% & $119,0 \pm 0,8$ & $0.0304 \pm 0,0021$ & $1,6172 \pm 0,16$ & 0,9991 & 60 \\
\hline PAM 0,25\% & $135,8 \pm 1,2$ & $0,0260 \pm 0.0025$ & $1,33 \pm 0,16$ & 0,9983 & 63 \\
\hline PAM 0,5\% & $138,0 \pm 1,0$ & $0,0256 \pm 0,0017$ & $1,3511 \pm 0,11$ & 0,9992 & 65 \\
\hline PAM 1,0\% & $142,9 \pm 0,8$ & $0,0274 \pm 0,0013$ & $1,9177 \pm 0,13$ & 0,9995 & 72 \\
\hline PAM 1,5\% & $145,6 \pm 0,8$ & $0,00258 \pm 0,0011$ & $1,83 \pm 0,11$ & 0,9996 & 75 \\
\hline PAM 2,0\% & $143,5 \pm 1,3$ & $0,0244 \pm 0,0020$ & $1,50 \pm 0,16$ & 0,9987 & 72 \\
\hline
\end{tabular}

media $\pm \mathrm{DE}$.

Los mayores incrementos del volumen fueron obtenidos por las masas que se prepararon con la pectina de alto metoxilo. Al utilizar la pectina de bajo metoxilo en concentraciones entre 1 y $2 \%$, los volúmenes finales fueron menores que los 
obtenidos por la masa control. Al incrementar el nivel de PAM se observa una tendencia a aumentar del volumen mientras que el efecto contrario se observa con PBM. Las masas con PAM alcanzaron mayores volúmenes que las masas con PBM, pero necesitaron mayores tiempos de fermentación. Esto se corresponde con el hecho de que las masas con PAM $2 \%$ y NaCl fueron más blandas que las masas con PBM 2 $\%$ y $\mathrm{NaCl}$ (Figura 4.8).

Se calcularon las velocidades iniciales de fermentación, para lo cual se tomaron las mediciones realizadas dentro de la primera hora del ensayo ya que durante este período se observó una relación lineal entre el incremento del volumen y el tiempo de medida. En general, los valores fueron más altos con pectinas $\left(1,6-2,0 \mathrm{~cm}^{3} / \mathrm{min}\right)$ que para el control ( $\left.1,5 \mathrm{~cm}^{3} / \mathrm{min}\right)$. Esto podría estar vinculado con la existencia de sustrato extra para la levadura debido a los azúcares que acompañan a las pectinas. Por otro lado, no se observaron diferencias en las velocidades iniciales entre las masas con PAM y PBM.

\subsubsection{Evaluación de la calidad de los panes}

\subsubsection{Volumen específico}

Entre los parámetros que determinan la calidad del pan se encuentra el volumen específico, que depende de la capacidad del gluten para retener el gas producido durante la fermentación lo cual se encuentra determinado por el adecuado desarrollo de la red de gluten durante el amasado. El volumen específico de los panes se muestra en la Figura 4.14. Los panes con PBM al $1 \%$ y $2 \%$ presentaron volúmenes específicos de 3,8 y $3,3 \mathrm{~cm}^{3} / \mathrm{g}$, respectivamente y no presentaron diferencias significativas respecto al control $\left(3,3 \mathrm{~cm}^{3} / \mathrm{g}\right)$. Sin embargo, cuando se utilizó PAM el volumen específico de los panes se incrementó significativamente alcanzándose valores de 4,0 y $4,2 \mathrm{~cm}^{3} / \mathrm{g}$ para $1 \%$ y $2 \%$ respectivamente, lo cual indica una buena performance para ambos niveles de PAM. Este mayor volumen específico obtenido con PAM no se puede inferir a partir de los datos farinográficos ya que se observó una disminución de la estabilidad al aumentar el nivel de pectina.

Las masas con PAM resultaron más blandas, según el ensayo de TPA, datos coincidentes con los mayores valores de $\tan (\delta)$ y los menores valores de $\lambda_{1}$ de los ensayos de relajación. Mayores valores de tan $(\delta)$ revelan una mayor contribución de la componente viscosa en la masa respecto a la elástica; una mayor viscosidad o extensibilidad de la masa influye favorablemente sobre el volumen de pan. Una masa 
más extensible se expande mejor, lo que se evidencia también en los mayores volúmenes alcanzados en la fermentación.

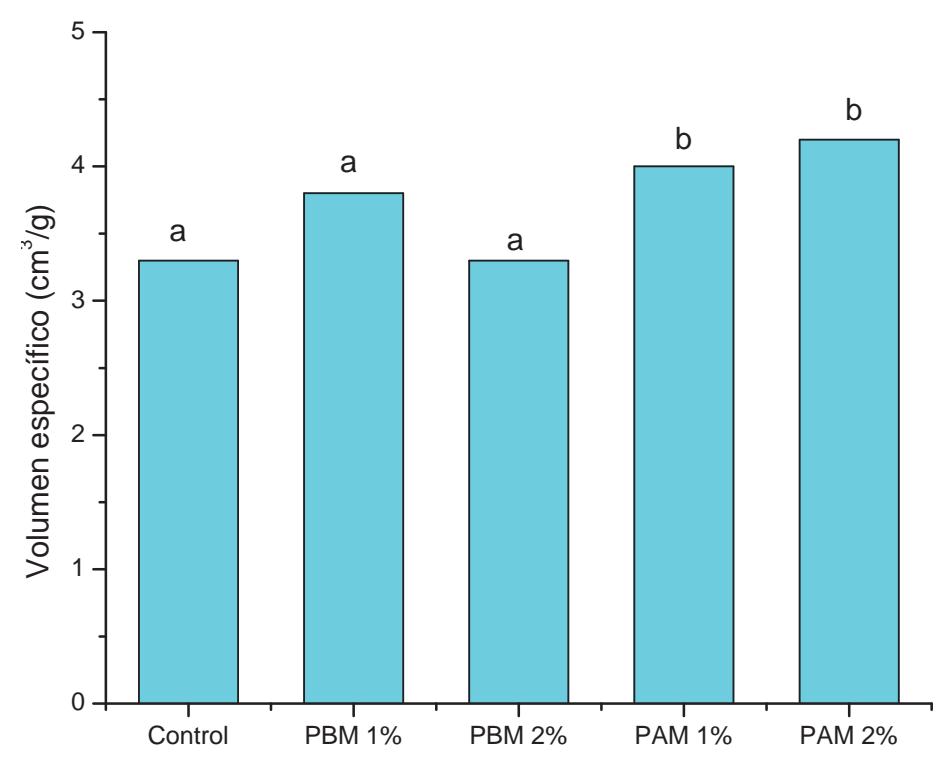

Figura 4.14. Volumen específico de los panes $\left(\mathrm{cm}^{3} / \mathrm{g}\right) \sin$ y con pectinas. Letras diferentes indican diferencias significativas $(p<0,05)$.

\subsubsection{Color de la corteza}

La medición del color de la corteza es un parámetro de calidad útil para evaluar cambios de formulación y del proceso de elaboración en productos panificados (Shittu y col., 2007). El color junto con la textura y el flavor pueden determinar la elección o no del producto por parte del consumidor.

La evaluación del color de la corteza (Tabla 4.7) muestra que la utilización de las pectinas no ocasionó cambios importantes en el color de los panes, ya que en la mayoría de los casos no se observaron diferencias significativas entre las diferentes muestras. El parámetro a tomó valores entre 9,8 y 10,8; $\boldsymbol{b}$ entre 34,2 y 35,7 y $\boldsymbol{L}$ entre 59,9 y 62,6. Estos valores corresponden al color tostado característico de la corteza del pan debido a la reacción de Maillard.

El BI (Browning index) es un parámetro cuyo cálculo engloba a $L$, a y b y presenta importancia en los procesos que ocurren reacciones de pardeamiento (no enzimático o enzimático) ya que se lo relaciona con la pureza del color marrón (Buera y col.,1985). 
En el valor del $\mathrm{Bl}$ se observó una disminución significativa respecto al control al emplear las pectinas en el mayor nivel lo que podría deberse a un parcial impedimento de la difusión de los sustratos dada la presencia de los hidrocoloides.

Tabla 4.7. Parámetros de color $\boldsymbol{L}, \boldsymbol{a}, \boldsymbol{b}$ y $\mathrm{BI}$ de la corteza de los panes.

\begin{tabular}{ccccc}
\hline muestra & $\boldsymbol{L}$ & $\boldsymbol{a}$ & $\boldsymbol{b}$ & $\mathrm{BI}$ \\
\hline Control & $59,3 \pm 3,3^{\mathrm{a}}$ & $11,1 \pm 1,6^{\mathrm{bcd}}$ & $35,9 \pm 1,1^{\mathrm{de}}$ & $103,0 \pm 12,0^{\mathrm{b}}$ \\
\hline PBM 1 \% & $60,1 \pm 3,9^{\mathrm{a}}$ & $10,7 \pm 1,9^{\mathrm{a}}$ & $35,5 \pm 1,9^{\mathrm{b}}$ & $98,9 \pm 10,5^{\mathrm{ab}}$ \\
\hline PBM 2 \% & $61,1 \pm 3,4^{\mathrm{ab}}$ & $10,4 \pm 1,7^{\mathrm{a}}$ & $34,2 \pm 1,9^{\mathrm{a}}$ & $91,9 \pm 12,2^{\mathrm{a}}$ \\
\hline PAM 1 \% & $61,1 \pm 3,5^{\mathrm{ab}}$ & $10,3 \pm 1,9^{\mathrm{a}}$ & $35,5 \pm 1,1^{\mathrm{b}}$ & $96,1 \pm 11,4^{\mathrm{b}}$ \\
\hline PAM 2 \% & $62,6 \pm 3,3^{\mathrm{b}}$ & $9,8 \pm 1,8^{\mathrm{a}}$ & $35,5 \pm 1,4^{\mathrm{b}}$ & $92,5 \pm 11,5^{\mathrm{a}}$ \\
\hline
\end{tabular}

media \pm DE. En una misma columna, letras diferentes indican diferencias significativas $(p<0,05)$

Hay que señalar, que aunque en algunos casos se hallaron diferencias significativas en los parámetros, éstas pequeñas variaciones, detectables con el colorímetro, podrían tal vez no serlo por el ojo humano. Además, para todos los productos existe un rango de color en el que la aceptabilidad del producto no se ve modificada, el cual depende de la variabilidad en la preferencia entre los consumidores, la edad y el origen étnico, entre otros, (Mac Dougall, 2002) por lo que las diferencias encontradas en el color de la corteza podrían no afectar la elección del consumidor.

\subsubsection{Alveolado de la miga}

Las características de la miga dependen en gran medida del número de alvéolos y de su tamaño. En un pan de buena calidad se espera obtener gran cantidad de alvéolos, de tamaño y distribución uniforme.

En la Tabla 4.9 se muestran las propiedades estructurales de la miga del pan obtenidas por análisis de imagen de la miga. En general, no se observaron diferencias significativas en los parámetros determinados entre el control y los panes con pectinas. Dado que la estabilización de los alvéolos depende primariamente de la matriz gluten-almidón y en segundo lugar del líquido lamelar que rodea al alvéolo (Gan y col., 1995), se pensó que la presencia de las pectinas podría ocasionar un aumento de la viscosidad del líquido de la lamella lo que podría dificultar la expansión de los 
alvéolos. Sin embargo, esto no ocurrió dado que no se hallaron diferencias significativas en el tamaño promedio de los alvéolos, así como tampoco en la moda del área alveolar (el valor más frecuente) que fue en todos los casos de 0,003 $\mathrm{cm}^{2}$.

En la fracción de aire, la cual mide la fracción de área de la sección transversal de los alvéolos respecto al área total (Zghal y col., 1999) tampoco se observaron diferencias significativas. El perímetro se relaciona con la regularidad del contorno alveolar: menores perímetros se asocian a mayor regularidad para una misma área. Por otro lado, la circularidad es un indicador de la simetría del alvéolo. Ninguno de estos descriptores se vio modificado por la utilización de las pectinas.

Tabla 4.9. Análisis del alveolado de la miga.

\begin{tabular}{lcccc}
\hline Muestra & $\begin{array}{c}\text { Área alveolar } \\
\text { promedio } \\
\left(\mathrm{cm}^{2}\right)\end{array}$ & $\%$ aire & $\begin{array}{c}\text { Perímetro } \\
(\mathrm{cm})\end{array}$ & Circularidad \\
\hline Control & $0,013 \pm 0,003^{\mathrm{ab}}$ & $43,4 \pm 3,2^{\mathrm{a}}$ & $0,67 \pm 0,06^{\mathrm{a}}$ & $0,40 \pm 0,04^{\mathrm{a}}$ \\
\hline PBM 1\% & $0,011 \pm 0,000^{\mathrm{a}}$ & $42,6 \pm 3,0^{\mathrm{a}}$ & $0,62 \pm 0,02^{\mathrm{a}}$ & $0,42 \pm 0,03^{\mathrm{a}}$ \\
\hline PBM 2\% & $0,012 \pm 0,001^{\mathrm{ab}}$ & $43,1 \pm 2,5^{\mathrm{a}}$ & $0,65 \pm 0,05^{\mathrm{a}}$ & $0,41 \pm 0,03^{\mathrm{a}}$ \\
\hline PAM 1\% & $0,014 \pm 0,002^{\mathrm{b}}$ & $46,5 \pm 5,3^{\mathrm{a}}$ & $0,66 \pm 0,05^{\mathrm{a}}$ & $0,43 \pm 0,03^{\mathrm{a}}$ \\
\hline PAM 2\% & $0,014 \pm 0,001^{\mathrm{b}}$ & $43,2 \pm 2,5^{\mathrm{a}}$ & $0,68 \pm 0,05^{\mathrm{a}}$ & $0,43 \pm 0,04^{\mathrm{a}}$ \\
\hline media \pm DE. Letras diferentes indican diferencias significativas $(\mathrm{p}<0,05)$
\end{tabular}

Se observa que a pesar de que se detectaron diferencias en el volumen específico, no se encontraron diferencias significativas en la estructura alveolar que permitan explicar las mismas. Esto puede deberse a que en general todos los panes presentaron una miga aireada lo que responde a que se usó una harina normal para los estándares del molino, de adecuada calidad panadera y por lo que pequeñas diferencias no serían detectables por esta metodología. Otra causa a tener en cuenta es la posible falta de uniformidad del alveolado en toda la superficie de la rodaja (por ejemplo, mayor compactación en la base o periferia) que no se detectó en estos ensayos ya que se realizaron únicamente con la parte central de la misma 


\subsubsection{Humedad de la miga}

En la Tabla 4.8 se muestran los valores obtenidos para la humedad de la miga de los panes en el día de elaboración y luego de un almacenamiento a $20^{\circ} \mathrm{C}$ durante 1 y 3 días. Se muestra, además, la pérdida porcentual de humedad respecto al día de elaboración (Ec. 2.41).

Durante el almacenamiento en todos los casos se observó una pérdida gradual de la humedad de la miga. Los panes control almacenados durante 3 días a $20^{\circ} \mathrm{C}$ disminuyeron su humedad hasta un $14,5 \%$ respecto al valor inicial. Aunque para igual día de almacenamiento no se observaron diferencias significativas entre los panes con pectinas y el pan control, con el empleo de PAM se obtuvieron menores porcentajes de pérdida de humedad que para el control al cabo del almacenamiento, lo cual sería un aporte beneficioso ya que permitiría conservar mejor la textura de la miga.

Tabla 4.8. Humedad de la miga del pan fresco y almacenado

\begin{tabular}{ccccc}
\hline Muestra & día 0 & día 1 & día 3 & \% pérdida \\
\hline Control & $44,2 \pm 0,5^{\mathrm{ab}}$ & $42,4 \pm 0,5^{\mathrm{a}}$ & $37,8 \pm 0,5^{\mathrm{a}}$ & 14,5 \\
PBM 1\% & $43,9 \pm 0,1^{\mathrm{a}}$ & $42,3 \pm 0,2^{\mathrm{a}}$ & $38,4 \pm 1,1^{\mathrm{a}}$ & 12,5 \\
PBM 2\% & $44,9 \pm 0,3^{\mathrm{b}}$ & $43,1 \pm 1,2^{\mathrm{a}}$ & $38,5 \pm 0,8^{\mathrm{a}}$ & 14,3 \\
PAM1\% & $44,4 \pm 0,2^{\mathrm{ab}}$ & $42,0 \pm 1,7^{\mathrm{a}}$ & $38,9 \pm 1,4^{\mathrm{a}}$ & 12,4 \\
PAM 2\% & $44,9 \pm 0,3^{\mathrm{b}}$ & $43,5 \pm 0,7^{\mathrm{a}}$ & $40,0 \pm 2,3^{\mathrm{a}}$ & 10,9 \\
\hline media \pm DE. Dentro de una misma columna, letras diferentes indican \\
diferencias significativas ( $\mathrm{p}<0,05)$.
\end{tabular}

\subsubsection{Análisis de perfil de textura de panes frescos y almacenados}

En la miga de pan valores bajos de dureza se relacionan con migas blandas lo cual constituye un atributo deseado en la misma. Por otro lado, al comer pan se espera que la miga forme un bolo rápidamente en la boca y que sea necesaria la realización de cierto esfuerzo al masticar. Esto es controlado en parte por la humedad del producto y en parte por la resistencia que ofrezcan las paredes de los alvéolos de la miga, lo cual se encuentra relacionado con la integración alcanzada por los componentes de la misma y por ende con la cohesividad. Por lo tanto, la cohesividad es un atributo buscado en los productos de panadería pero deben evitarse valores elevados de la 
masticabilidad lo cual se relaciona con la realización de un gran esfuerzo al masticar. Así mismo, en un pan fresco se espera tener una miga elástica lo cual implica que luego se ser sometida a una compresión la misma retorne a su posición original. La elasticidad de la miga también se relaciona con la resistencia de las paredes alveolares. La textura de la miga se encuentra relacionada directamente con otras características del producto como son la humedad, la densidad y la porosidad. En general, la dureza presentada por un producto panificado será menor a mayores valores de humedad y volumen del mismo. Además, el tamaño y distribución de los alvéolos también influyen en la textura de la miga (Cauvain, 2004).

En la Figura 4.15 se observa un perfil de textura típico para miga de pan donde se destaca la ausencia de adhesividad.

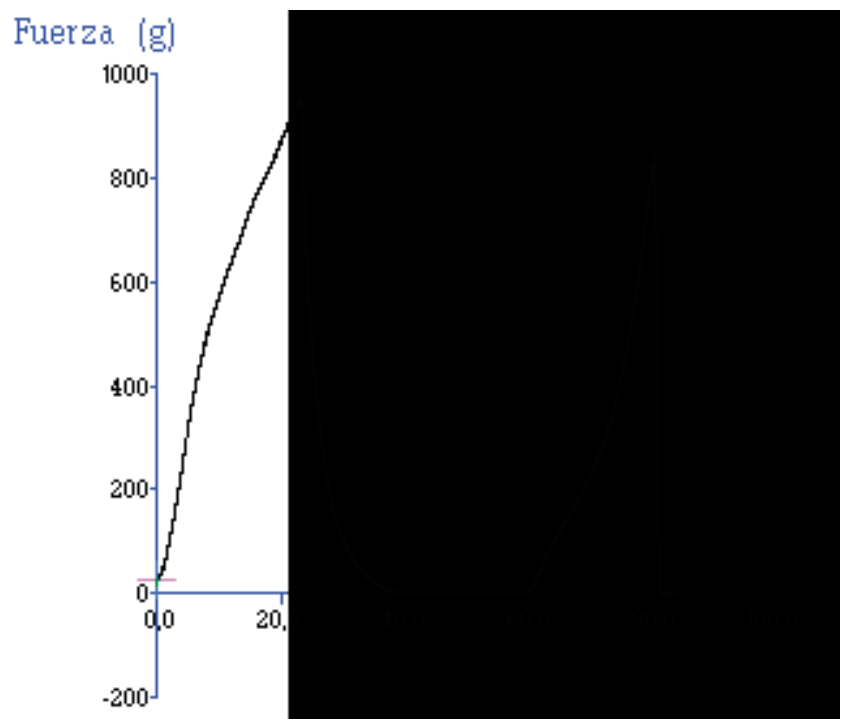

Figura 4.15. Perfil de textura de la miga de pan.

En las Figuras 4.16. y 4.17 se muestran los atributos texturales de la miga de panes frescos y almacenados durante 1 y 3 días, sin y con pectinas.

Comparando los atributos de los panes frescos (día 0) se observa que la dureza de las formulaciones con pectinas fue significativamente menor que para el control. La consistencia siguió la misma tendencia que la dureza. Para una misma pectina no se encontraron diferencias entre los niveles utilizados.

Las migas con pectinas fueron significativamente más cohesivas que la del control, lo que sugiere que se favorece la integración de los componentes en la matriz. A pesar de que se observó una cierta tendencia a valores mayores, no se hallaron diferencias significativas en la elasticidad con el agregado de hidrocoloide. 
La resiliencia fue significativamente mayor para las migas de los panes adicionados con gomas, lo cual indicaría un efecto positivo de éstas al incrementarse la capacidad de la miga para recuperar en forma instantánea sus dimensiones originales. La elasticidad solo fue significativamente mayor con PAM en ambos niveles.

La masticabilidad es el parámetro que se obtiene del producto de la elasticidad por la cohesividad y la dureza; aunque la cohesividad y la elasticidad aumentaron, la disminución de la dureza fue mayor, por lo que la masticabilidad fue significativamente menor para los panes con pectinas, en particular en los preparados con PAM. Otros autores han encontrado un efecto favorable de las pectinas sobre la miga. Ribotta y col. (2005) al estudiar el efecto de hidrocoloides comerciales (pectinas, $\lambda$ carragenanos y alginatos) sobre las propiedades reológicas y la calidad del pan obtenido, hallaron que las masas con PAM presentaban mayor tenacidad y daban lugar a panes de mayor volumen. Además, demostraron la existencia de complejos hidrofílicos entre los grupos carboxilo de las pectinas y las proteínas del gluten. Por otro lado, Gómez y col. (2007b) emplearon PAM en bizcochuelos y obtuvieron un producto más duro, menos cohesivo y de mayor volumen que sin agregado de goma.

La miga de pan puede considerarse una espuma sólida; en este tipo de estructuras el módulo de Young (E) es función del módulo de Young de las paredes de los alvéolos que lo constituyen (Es) y de la densidad relativa de la espuma, definida como la relación entre la densidad global $(\rho)$ y la densidad de la pared alveolar $(\rho s)$, de acuerdo a la expresión: $\mathrm{E} \propto \mathrm{Es}[\rho / \rho s]^{2}$ (Attenborow y col., 1989). Los resultados del análisis mecánico de la miga también se ven influidos por características geométricas de la estructura alveolar tales como tamaño, forma, interconexión entre alvéolos, espesor de la pared (Chen y col, 1994).

Se observa que el hecho de obtener migas más blandas con PAM, en ambos niveles, está en acuerdo con el mayor volumen específico (y por lo tanto menor densidad global) obtenido por estos panes. Sin embargo el agregado de PBM no condujo a diferencias significativas en el volumen específico y sí en la dureza de la miga. No habiendo diferencias significativas en las características geométricas de los alvéolos, se podría concluir que hay diferencias importantes en las características de la pared alveolar (densidad, módulo de Young) que podrían estar determinadas por la formulación empleada en cada caso. 

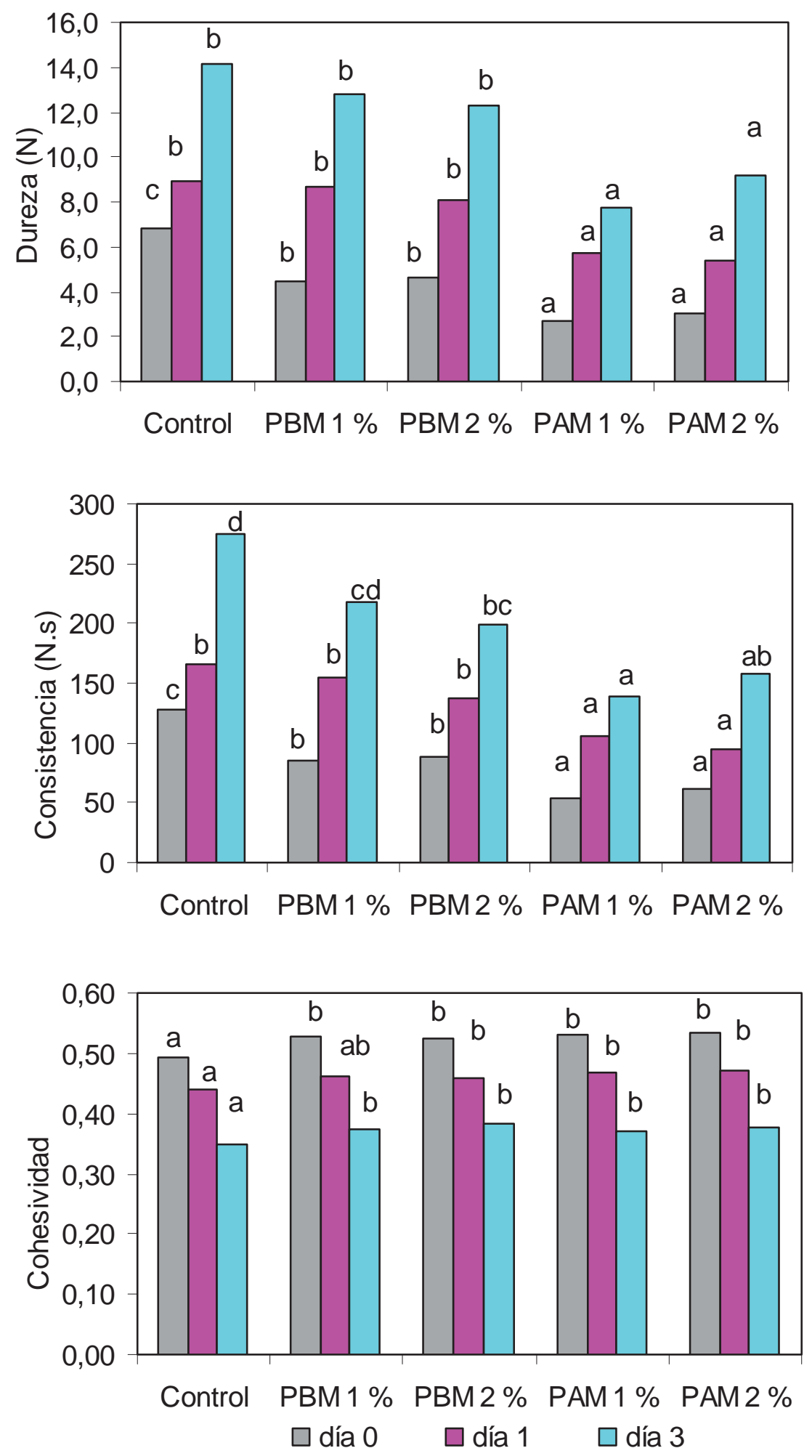

Figura 4.16.Parámetros texturales de la miga de los panes frescos y almacenados: dureza, consistencia, cohesividad. Para igual día de almacenamiento letras diferentes indican diferencias significativas $(p<0,05)$. 

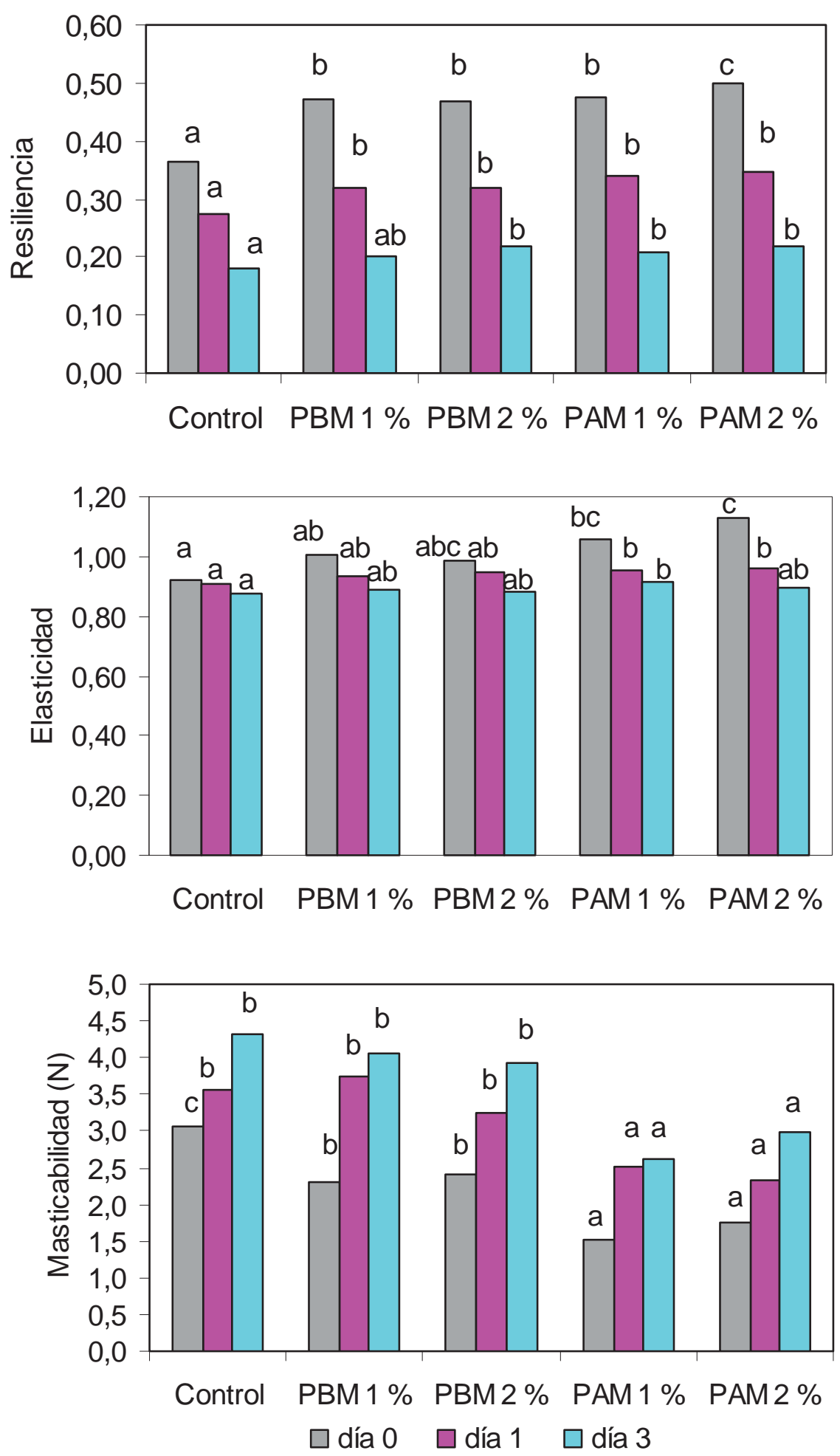

Figura 4.17.Parámetros texturales de la miga de los panes frescos y almacenados: resiliencia, elasticidad, masticabilidad. Para igual día de almacenamiento letras diferentes indican diferencias significativas $(p<0,05)$. 
Dado que la calidad del pan y su vida útil se relacionan con la textura de la miga es de importancia estudiar como se modifica con el almacenamiento. En particular, el incremento de la dureza y pérdida de elasticidad son los cambios más característicos en relación a la textura de la miga que se informan en la literatura. El endurecimiento de la miga se debe principalmente a dos motivos, la pérdida de humedad y la retrogradación del almidón (Pateras, 1998).

El envejecimiento del pan se evaluó a través de los cambios observados en los parámetros texturales a lo largo del período de almacenamiento, así como también, por la pérdida de humedad durante el mismo (Tabla 4.8). En todos los casos, los panes almacenados aumentaron su dureza pero después de 3 días de almacenamiento, los panes con PAM mantuvieron una miga significativamente más blanda que el control almacenado igual período. Mientras que la resiliencia y la cohesividad disminuyeron con el tiempo de almacenamiento. Por otro lado, la masticabilidad aumentó con el tiempo de almacenamiento, aunque en los panes con PAM este incremento fue menor. Los valores de la masticabilidad para los panes con PAM luego de tres días de almacenamiento fueron similares a los obtenidos por el pan control fresco, lo cual indica un efecto positivo contra el envejecimiento del pan por parte de este hidrocoloide. En las Tablas 4.9 y 4.10 se muestran los cambios porcentuales para los atributos texturales durante el almacenamiento. Es remarcable que las variaciones porcentuales son mayores en los sistemas con hidrocoloides que en el control. Esto podría sugerir una aceleración de los cambios en presencia de los hidrocoloides.

Tabla 4.9. Variación porcentual de la dureza, consistencia y cohesividad con el almacenamiento

\begin{tabular}{ccccccc}
\hline \multirow{2}{*}{ Muestra } & $\begin{array}{c}\text { Incremento de la } \\
\text { dureza }(\%)^{*}\end{array}$ & \multicolumn{2}{c}{$\begin{array}{c}\text { Incremento de la } \\
\text { consistencia (\%) }\end{array}$} & \multicolumn{2}{c}{$\begin{array}{c}\text { Disminución de la } \\
\text { cohesividad(\%) }\end{array}$} \\
\cline { 2 - 7 } & día 1 & día 3 & día 1 & día 3 & día 1 & día 3 \\
\hline Control & 29,9 & 81,5 & 26,9 & 90,2 & $-11,2$ & $-29,0$ \\
\hline PBM 1 \% & 93,4 & 184,7 & 80,5 & 154,5 & $-12,2$ & $-29,2$ \\
\hline PBM 2 \% & 74,6 & 166,3 & 56,9 & 125,8 & $-12,3$ & $-26,8$ \\
\hline PAM 1 \% & 113,1 & 189,2 & 95,7 & 157,1 & $-11,9$ & $-30,1$ \\
\hline PAM 2 \% & 77,7 & 201,5 & 55,6 & 156,9 & $-12,1$ & $-29,5$ \\
\hline
\end{tabular}

${ }^{*}$ ) los valores se calcularon como diferencias de las medias 
Tabla 4.10. Variación porcentual de la resiliencia, elasticidad y masticabilidad con el almacenamiento

\begin{tabular}{ccccccc}
\hline \multirow{2}{*}{ Muestra } & \multicolumn{2}{c}{$\begin{array}{c}\text { Disminución de la } \\
\text { resiliencia }(\%)^{*}\end{array}$} & \multicolumn{2}{c}{$\begin{array}{c}\text { Disminución de la } \\
\text { elasticidad }(\%)^{*}\end{array}$} & \multicolumn{2}{c}{$\begin{array}{c}\text { Incremento de la } \\
\text { masticabilidad }(\%)^{*}\end{array}$} \\
\cline { 2 - 7 } & día 1 & día 3 & día 1 & día 3 & día 1 & día 3 \\
\hline Control & $-24,1$ & $-50,5$ & $-1,2$ & $-4,0$ & 14,7 & 24,7 \\
\hline PBM 1 \% & $-32,4$ & $-57,8$ & $-7,1$ & $-11,8$ & 62,0 & 75,8 \\
\hline PBM 2 \% & $-32,0$ & $-53,4$ & $-4,3$ & $-10,5$ & 35,2 & 63,4 \\
\hline PAM 1 \% & $-28,6$ & $-55,9$ & $-10,3$ & $-13,9$ & 64,6 & 72,0 \\
\hline PAM 2 \% & $-30,5$ & $-56,3$ & $-14,9$ & $-20,4$ & 32,7 & 70,2 \\
\hline
\end{tabular}

$\left({ }^{*}\right)$ los valores se calcularon como diferencias de las medias

\subsubsection{Evaluación sensorial : Ensayo de discriminación}

Se realizó un ensayo triángular en el cual se compararon el pan control con el pan obtenido con agregado de pectina de alto metoxilo al $2 \%$, ambos preparados en el día. Dicha elección se basó en los resultados obtenidos por PAM en las pruebas de evaluación de la calidad panadera. Se realizó el ensayo con las condiciones descriptas en 2.2.8.1. Se obtuvieron en total 60 respuestas, de las cuales 26 fueron correctas. De la tabla que indica el número de respuestas necesarias para rechazar la hipótesis nula (Roessler y col.,1948) surge que para rechazarla con un $1 \%$ de confianza se necesitan 30 respuestas correctas por lo tanto se concluyé que no se encontraron diferencias significativas entre los panes control y con agregado de PAM $2 \%$ por lo que se rechaza la hipótesis alternativa con un $99 \%$ de confianza. El nivel exacto de significancia fue del $6,8 \%$ por lo tanto si dijera que las muestras son diferentes existiría una probabilidad del 6,8\% de cometer un error.

Aunque la utilización de PAM ocasionó cambios en la textura de la miga, los cuales fueron cuantificables con el empleo del texturómetro estas modificaciones en la textura no estarían brindando al producto fresco características fácilmente distinguibles por evaluadores no entrenados. Dado que luego del almacenamiento, el pan con PAM mantiene mejor las características iniciales que el pan control es probable que en estas condiciones la diferenciación entre ambos hubiera sido más sencilla para un panel no entrenado. 


\subsection{Conclusiones parciales}

La utilización de pectinas comerciales de diferente grado de esterificación en panificación permite obtener resultados satisfactorios, modificando las características de las masas y la calidad del pan obtenido. A pesar de comercializarse para otros fines, es posible utilizar las pectinas en su presentación comercial, que incluye otros hidratos de carbono de bajo peso molecular.

La adición de pectinas en la formulación condujo a cambios en el comportamiento farinográfico, lo que también dependió de la ausencia o presencia de $\mathrm{NaCl}$. En todos los casos aumentaron la absorción farinográfica, particularmente la pectina de alto metoxilo. La estabilidad fue marcadamente afectada, principalmente en presencia de $\mathrm{NaCl}$ y PAM. Según el análisis de perfil de textura, la adición de PAM en ausencia de $\mathrm{NaCl}$ llevó a la obtención de masas más blandas, más cohesivas y menos elásticas que las obtenidas por la masa control. PBM mostró un comportamiento diferencial de acuerdo al nivel utilizado, en el menor nivel y con $\mathrm{NaCl}$ siguió la tendencia de PAM. En ausencia de $\mathrm{NaCl}$ si bien las masas fueron más blandas que el control, el comportamiento de ambas pectinas varió más según el nivel utilizado. Los tiempos de relajación fueron menores para masas con PAM y $\mathrm{NaCl}$ respecto al control (masas más viscosas). A pesar de que los ensayos dinámicos reflejan el comportamiento de la masa cuando es sometida a pequeñas deformaciones y no hay ruptura estructural, se obtuvieron resultados concordantes con lo anterior: las masas con $\mathrm{PAM}$ y $\mathrm{NaCl}$ presentaron mayores valores de la tangente del ángulo de desfasaje, indicando mayor viscosidad de las masas.

El volumen específico de los panes fue mejorado significativamente por la utilización de PAM, además en este caso se obtuvieron migas más blandas, cohesivas y resilientes con una estructura alveolar similar a la del pan control. En general, ambas pectinas ejercieron una acción protectora respecto al envejecimiento del pan (medido a través de cambios en la textura) pero PAM fue más efectiva.

El efecto desigual presentado por PBM y PAM puede atribuirse al tipo de interacciones que cada una de las pectinas puede establecer con las proteínas del gluten. Aunque ambas pectinas pueden establecer interacciones iónicas a través de los grupos carboxílicos, debido a su grado de esterificación (GE=67\%) PAM presenta mayor capacidad que $\mathrm{PBM}(\mathrm{GE}=43 \%)$ para establecer interacciones hidrofóbicas con las proteínas, un tipo de interacción que se ve favorecida en presencia de $\mathrm{NaCl}$. Estas interacciones conducirían a matrices proteicas diferentes que explicarían los cambios, particularmente reológicos, observados en masa y pan. 


\section{Capítulo V}

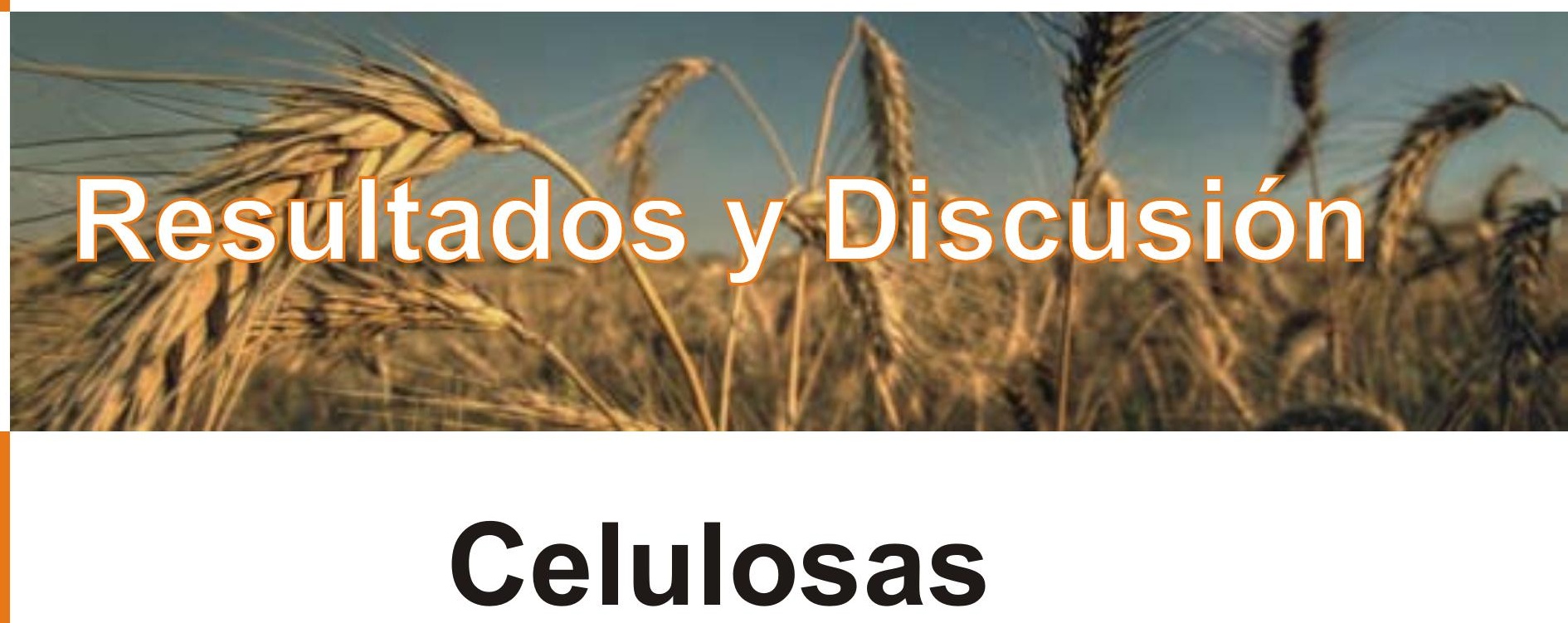




\subsection{Caracterización fisicoquímica y reológica de las masas}

Diversos autores han investigado la adición de celulosas modificadas en productos panificados, comparando su efecto con el de otros aditivos (Armero y Collar, 1996; Rosell y col.,2001; Guarda y col., 2004; Gómez y col., 2007b). Las celulosas también se han utilizado en productos panificados precocidos congelados (Bárcenas y col., 2004) y en productos libres de gluten (Lazaridou y col., 2007). Por otro lado, han demostrado ser de utilidad para mejorar las características de productos obtenidos por mezclas de harina de trigo con otras harinas (Angioloni y Collar, 2011) y para incrementar el contenido de fibra de distintos productos (Angioloni y Collar, 2009). En general, se ha encontrado que las celulosas modifican las características reológicas de la masa, los atributos texturales y el volumen específico de bizcochuelos y panes así como también se ha visto que modifican su vida útil y la aceptabilidad por parte del consumidor; cabe destacar que su efecto depende del tipo particular de celulosa empleada y de las características del sistema en estudio.

Ya que, dada la diversidad de las modificaciones químicas que es posible efectuar sobre la molécula de celulosa, los derivados obtenidos presentan distintas características estructurales y fisicoquímicas (ítem 1.10.1 - Capítulo I) resulta interesante comparar el efecto de distintas celulosas sobre una misma formulación panaria base. En el presente capítulo se estudió el efecto producido por la adición de celulosas modificadas de diferente estructura química: MCC, CMC y dos tipos de HPMC (con diferente grado de sustitución) sobre las características reológicas de la masa y sobre los atributos que determinan la aceptabilidad del pan recién horneado o almacenado obtenido a partir de la misma. Se determinaron también distintas variables del proceso de panificación en masas con celulosa: absorción de agua farinográfica, tiempo de desarrollo de la masa y tiempo de fermentación.

\subsubsection{Absorción de agua de las mezclas harina - celulosas modificadas}

En los ensayos farinográficos se observó una relación lineal $\left(r^{2}>0,93\right.$ en todos los casos) entre la absorción de agua (A) y la concentración de las celulosas modificadas en la mezcla. Al incrementar la concentración de hidrocoloide se obtuvieron mayores valores de A, los cuales se vieron modificados por la presencia o ausencia de $\mathrm{NaCl}$. Se calculó el incremento porcentual de la absorción de agua respecto al control según la ecuación 2.41 (Capítulo II). En las Figuras 5.1 y 5.2 se muestra el porcentaje de variación de la absorción de agua en función de la concentración de celulosas 
modificadas, en ausencia o presencia de $\mathrm{NaCl}$ respectivamente. Para la mayoría de las mezclas, excepto las que contenían HPMC F 50, se observó que en presencia de $\mathrm{NaCl}$ el incremento porcentual en la absorción de agua fue menor que para las mezclas $\sin \mathrm{NaCl}$, lo cual se vio reflejado en una menor pendiente. Así, para el mayor nivel de celulosa (1,5\%) el rango de $\mathrm{A}$ en ausencia de $\mathrm{NaCl}$ fue de 59 a 66,7 y en presencia $\mathrm{NaCl}$ fue de 55,4 a $62,5 \mathrm{ml} \%$.

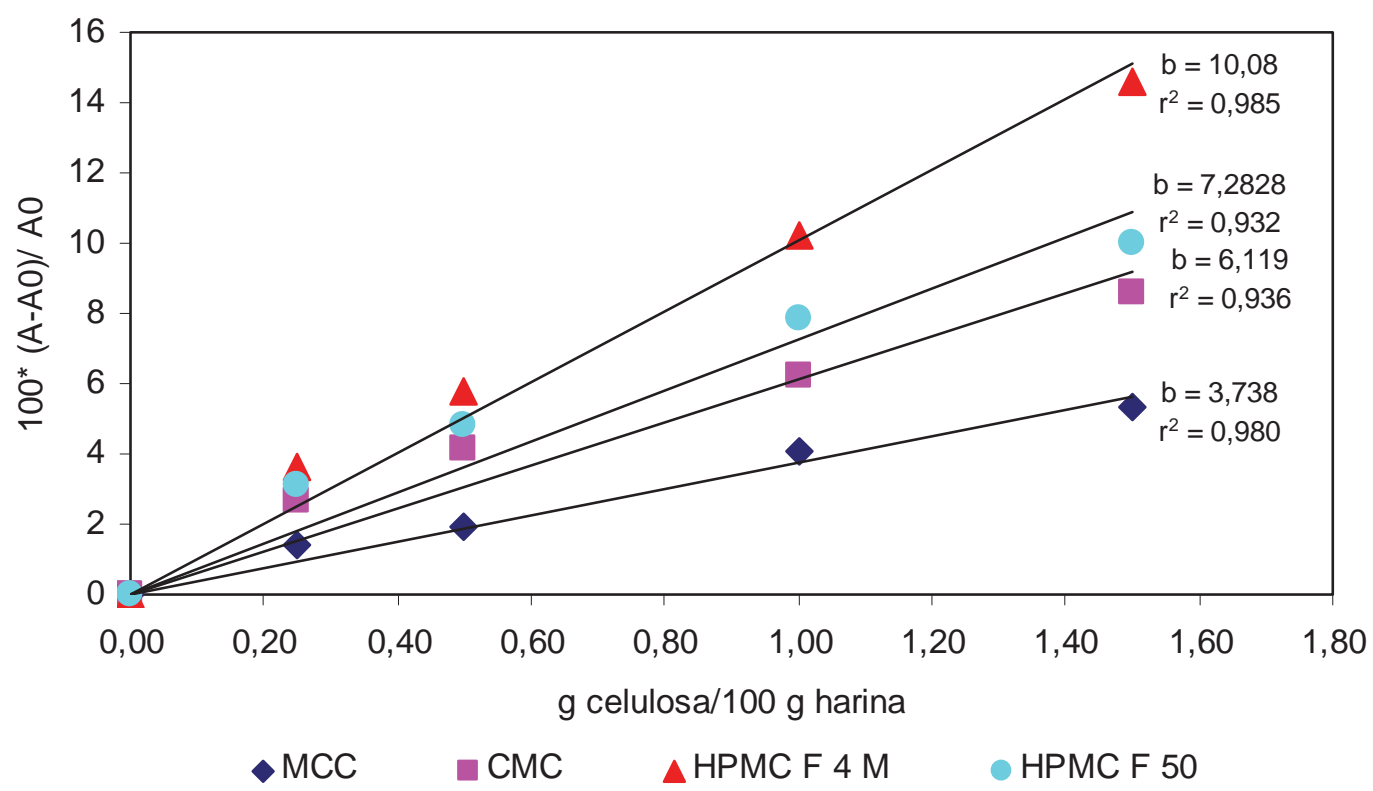

Figura 5.1. Incremento de la absorción farinográfica (\%) en función de la concentración de celulosas modifcadas en mezclas $\sin \mathrm{NaCl} . \mathrm{b}=$ pendiente de la recta. $r^{2}=$ coeficiente de determinación.

Como ya se mencionó en el capítulo anterior, el efecto de los electrolitos sobre las propiedades de la masa se basa principalmente en la disociación o asociación (agregación) de las proteínas del gluten dependiendo del tipo de ion (caotrópico o no caotrópico) (Salovaara, 1982). Los iones no caotrópicos como el $\mathrm{Cl}^{-}$promueven la estructuración del agua favoreciéndose la exposición de grupos no polares de las proteínas lo que permite aumentar la interacción proteína-proteína a través de interacciones hidrofóbicas (He y col.,1992). De este modo, ésta mayor interacción proteína-proteína dejaría menos zonas expuestas a la hidratación, conduciendo a una 
menor capacidad de ligar agua. Otros autores han informado un aumento del entrecruzamiento proteico en presencia de $\mathrm{NaCl}$, lo que generaría redes más fuertes (Ukai y col., 2008). Esto último permitiría alcanzar la consistencia de 500 UF en el farinograma con menores valores de agua.

En particular las HPMCs son, de las celulosas utilizadas, las más hidrofóbicas debido a su estructura (ítem 1.10.1.3. -Capítulo I); el hecho de que las mezclas que las contienen sean las de mayor absorción farinográfica indicaría una posible interacción con las proteínas de gluten que conduce a matrices más hidratatables.

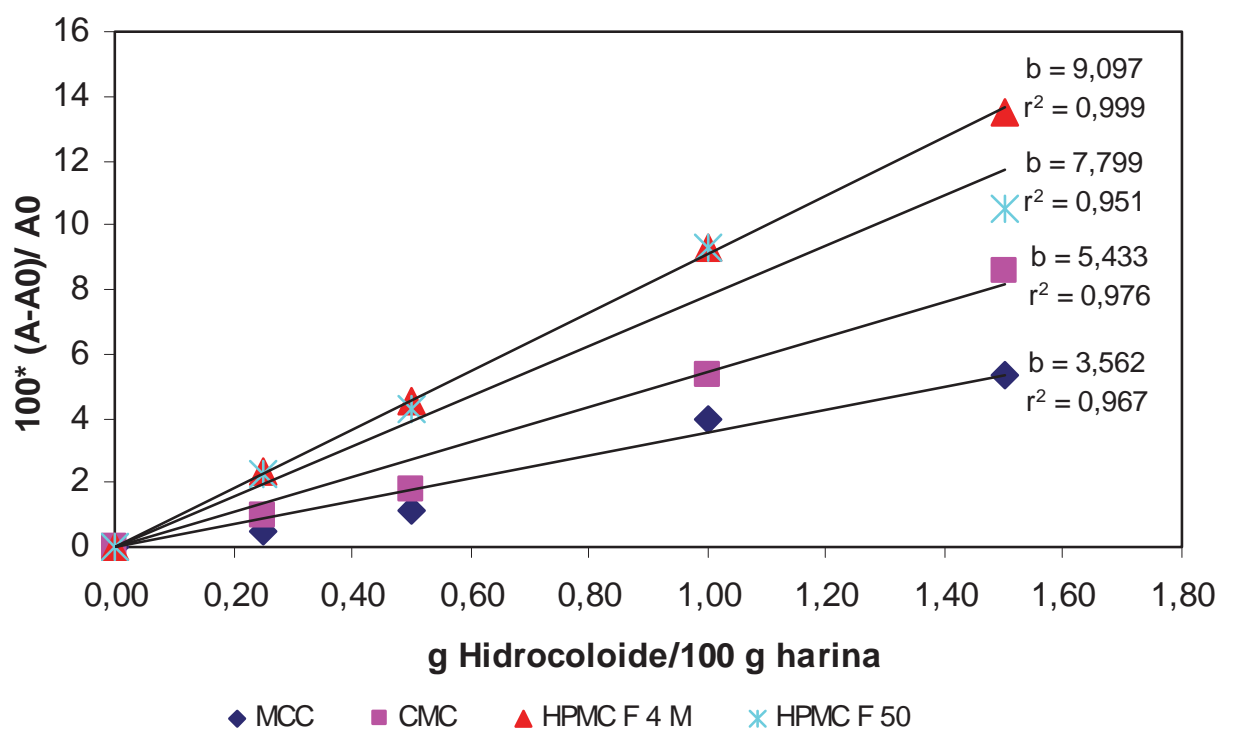

Figura 5.2. Incremento de la absorción farinográfica (\%) en función de la concentración de celulosas modifcadas en mezclas con $\mathrm{NaCl}$. $\mathrm{b}=$ pendiente de la recta. $\mathrm{r}^{2}=$ coeficiente de determinación.

En la Figura 5.3 se muestran los valores obtenidos para la capacidad de imbibición de agua (WIC) de las mezclas harina - celulosas modificadas (sin $\mathrm{NaCl}$ ). La mezcla con HPMC F 4M presentó un valor de WIC significativamente mayor que la harina sin aditivo, lo que coincide con la mayor absorción de agua farinográfica. Aunque las otras mezclas no fueron significativamente diferentes al control, se observó una tendencia a mayores valores de WIC en las harinas con MCC y CMC. Dado que en este ensayo no se desarrolla la red de gluten estos resultados indican que podría existir una influencia intrínseca de los hidrocoloides en los valores de A obtenidos. No obstante, las 
diferencias en la absorción farinográfica probablemente se deban a una combinación tanto de la mayor o menor absorción del hidrocoloide como de la matriz glutenhidrocoloide formada.

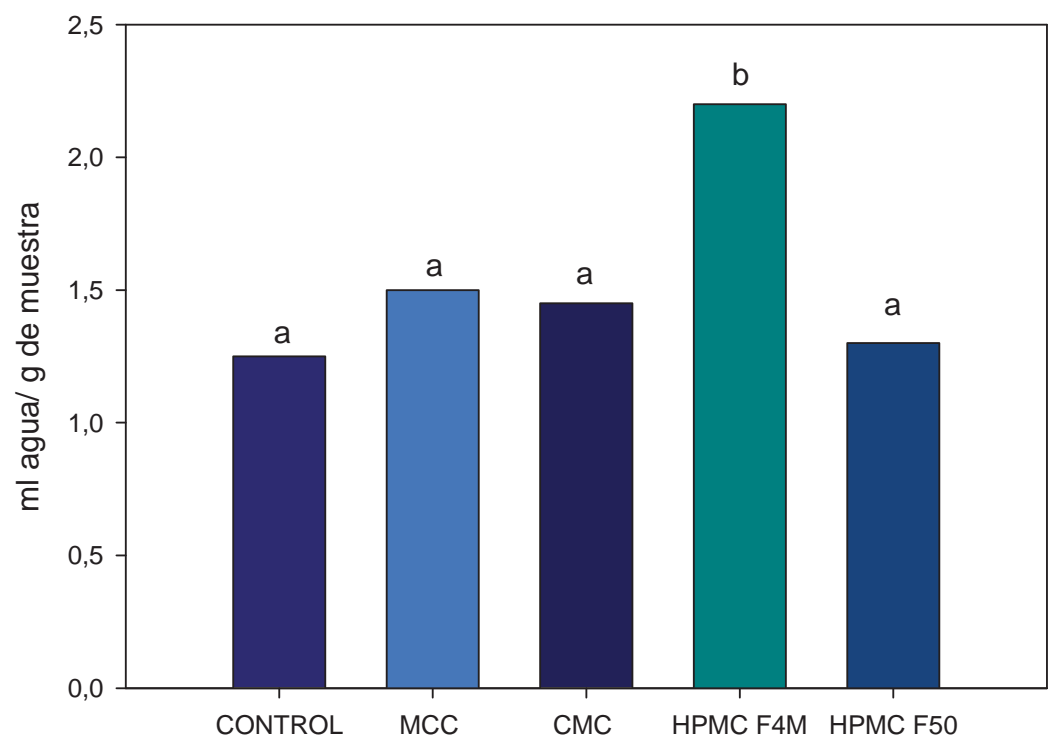

Figura 5.3. Capacidad de imbibición de agua (WIC) de las mezclas harina- celulosas modificadas. Nivel de celulosa: 1,5\% (base harina).

\subsubsection{Actividad acuosa y humedad}

Se determinaron la humedad y la actividad acuosa $\left(a_{w}\right)$ de las masas $\sin$ y con $\mathrm{NaCl}$ preparadas según se describió en el ítem 2.2.5.1.2.1 (Capítulo II). Los valores de humedad y $a_{w}$ hallados se muestran en la Tabla 5.1. En la humedad de las masas se encontraron diferencias significativas respecto al control, dado que en la preparación de las mismas el agua empleada estuvo determinada por la absorción farinográfica de cada una. Los valores de humedad se encontraron entre $42,7 \%$ para la masa control con $\mathrm{NaCl}$ y para $\mathrm{MCC} 0,5 \% \sin \mathrm{NaCl}$ y $45,7 \%$ para la masa con HPMC F 4M 1,5\% con $\mathrm{NaCl}$. Sin embargo, en ambos tipos de masas pudo observarse que la actividad acuosa no presentó diferencias significativas respecto al control por el agregado de celulosas modificadas.

En todos los casos, las masas $\sin \mathrm{NaCl}$ presentaron valores significativamente mayores de $\mathrm{a}_{\mathrm{w}}$ que las masas con $\mathrm{NaCl}$ mientras que en general no se observó una variación de $a_{w}$ por la presencia de los hidrocoloides. Esto estaría indicando, como se 
observó ya en las masas con pectina, que sería el $\mathrm{NaCl}$ y no los hidrocoloides el factor que más afecta a la disponibilidad de agua de las masas.

Tabla 5.1. Humedad y actividad acuosa de las masas $\sin$ y con $\mathrm{NaCl}$

\begin{tabular}{ccccc}
\hline \multirow{2}{*}{ Muestras } & \multicolumn{2}{c}{ Masas sin NaCl } & \multicolumn{2}{c}{ Masas con NaCl } \\
\cline { 2 - 5 } & Humedad & $a_{w}$ & Humedad & $a_{w}$ \\
\hline Control & $44,5 \pm 0,4^{c}$ & $0,986 \pm 0,002^{a b}$ & $42,7 \pm 0,3^{a}$ & $0,971 \pm 0,002^{c}$ \\
\hline MCC 0,5\% & $42,7 \pm 0,1^{a}$ & $0,987 \pm 0,001^{\text {ab }}$ & $42,9 \pm 0,1^{a}$ & $0,966 \pm 0,003^{a b}$ \\
\hline MCC 1,5\% & $45,6 \pm 0,1^{\mathrm{d}}$ & $0,987 \pm 0,002^{\mathrm{b}}$ & $43,7 \pm 0,2^{\mathrm{ab}}$ & $0,968 \pm 0,001^{\mathrm{abc}}$ \\
\hline CMC 0,5\% & $44,6 \pm 0,3^{\mathrm{c}}$ & $0,987 \pm 0,001^{\mathrm{b}}$ & $43,0 \pm 0,3^{\mathrm{a}}$ & $0,968 \pm 0,001^{\mathrm{abc}}$ \\
\hline CMC 1,5\% & $45,5 \pm 0,4^{\mathrm{d}}$ & $0,980 \pm 0,001^{\mathrm{a}}$ & $44,6 \pm 0,1^{\mathrm{bc}}$ & $0,971 \pm 0,002^{\mathrm{c}}$ \\
\hline HPMC F 4M 0,5\% & $44,4 \pm 0,4^{\mathrm{bc}}$ & $0,987 \pm 0,002^{\mathrm{b}}$ & $43,3 \pm 0,5^{\mathrm{a}}$ & $0,971 \pm 0,002^{\mathrm{c}}$ \\
\hline HPMC F 4M 1,5\% & $45,3 \pm 0,7^{\mathrm{cd}}$ & $0,990 \pm 0,002^{\mathrm{b}}$ & $45,7 \pm 0,2^{\mathrm{d}}$ & $0,967 \pm 0,001^{\mathrm{abc}}$ \\
\hline HPMC F 50 0,5\% & $43,6 \pm 0,0^{\mathrm{ab}}$ & $0,987 \pm 0,004^{\mathrm{b}}$ & $43,7 \pm 0,5^{\mathrm{ab}}$ & $0,970 \pm 0,001^{\mathrm{bc}}$ \\
\hline
\end{tabular}

media \pm DE. Letras diferentes, dentro de una misma columna, indican diferencias significativas $(p<0,05)$

\subsubsection{Capacidad de hidratación de las proteínas de gluten}

La determinación de los valores de gluten húmedo (GH), gluten seco (GS) y agua unida al gluten (GH-GS), al igual que en el caso de las pectinas se realizó mediante una modificación de la técnica AACC 38-12-02, habiéndose preparado la masa como se describe en el ítem 2.2.4.2.1.(Capítulo II). En la Tabla 5.2 se muestran los resultados obtenidos.

En el caso de las masas $\sin \mathrm{NaCl}$, los valores de $\mathrm{GH}$ se encontraron entre $24,4 \%$ y $32,1 \%$ y los de GS entre $8,6 \%$ y $11,3 \%$, mientras que los valores de GH-GS se encontraron en el rango 15,8\% - 21,1\%. La relación GH/GS en ningún caso arrojó diferencias significativas respecto al control cuyo valor fue de 2,9 (resultados no mostrados). En las muestras $\sin \mathrm{NaCl}$, se encontró una disminución significativa en los valores de gluten húmedo al emplear los máximos niveles de CMC y MCC (24\% y 19\% menos que el GH control, respectivamente). También fueron inferiores en estos casos los valores de GS: para la muestra con CMC fue un $22 \%$ inferior al control y para la 
muestra con MCC, un 15,5\% menos que para el control. Consecuentemente los valores de GH-GS fueron también significativamente inferiores en estos casos.

Tabla.5.2. Gluten húmedo, gluten seco y agua unida al gluten de las masas sin y con $\mathrm{NaCl}$.

\begin{tabular}{|c|c|c|c|c|c|c|c|}
\hline \multirow{2}{*}{\multicolumn{2}{|c|}{ Muestra }} & \multicolumn{3}{|c|}{ Masas sin $\mathrm{NaCl}$} & \multicolumn{3}{|c|}{ Masas con $\mathrm{NaCl}$} \\
\hline & & $\mathrm{GH} \%$ & GS\% & $\begin{array}{c}\text { GH-GS } \\
\%\end{array}$ & $\mathrm{GH} \%$ & GS\% & $\begin{array}{c}\text { GH-GS } \\
\%\end{array}$ \\
\hline \multicolumn{2}{|c|}{ Control } & $32,0 \pm 0,3^{d}$ & $11,0 \pm 0,1^{\mathrm{de}}$ & $21,1^{\mathrm{C}}$ & $31,5 \pm 0,6^{\text {cde }}$ & $10,4 \pm 0,1^{b c}$ & $21,1^{\mathrm{cd}}$ \\
\hline \multirow{2}{*}{ MCC } & $0,5 \%$ & $31,1 \pm 0,1^{\mathrm{cd}}$ & $11,0 \pm 0,0^{\text {de }}$ & $20,1^{b c}$ & $31,8 \pm 0,3^{\mathrm{de}}$ & $10,6 \pm 0,3^{c}$ & $21,2^{\text {cd }}$ \\
\hline & $1,5 \%$ & $26,1 \pm 0,6^{b}$ & $9,3 \pm 0,3^{b}$ & $16,8^{a}$ & $30,8 \pm 0,2^{\mathrm{bcd}}$ & $10,3 \pm 0,1^{b c}$ & $20,5^{b c}$ \\
\hline \multirow{2}{*}{ CMC } & $0,5 \%$ & $30,0 \pm 0,6^{c}$ & $10,2 \pm 0,1^{c}$ & $19,8^{b}$ & $31,0 \pm 1,0^{b c}$ & $10,4 \pm 0,1^{b c}$ & $20,6^{a b c}$ \\
\hline & $1,5 \%$ & $24,4 \pm 0,3^{\text {a }}$ & $8,6 \pm 0,1^{a}$ & $15,8^{\mathrm{a}}$ & $29,9 \pm 0,6^{\mathrm{ab}}$ & $10,4 \pm 0,2^{b c}$ & $19,5^{\mathrm{ab}}$ \\
\hline \multirow{2}{*}{$\begin{array}{c}\text { HPMC F } \\
4 M\end{array}$} & $0,5 \%$ & $31,4 \pm 0,3^{d}$ & $10,6 \pm 0,3^{\mathrm{cd}}$ & $20,8^{b c}$ & $30,7 \pm 0,4^{\mathrm{bcd}}$ & $10,3 \pm 0,3^{b c}$ & $20,4^{b c}$ \\
\hline & $1,5 \%$ & $31,1 \pm 0,2^{\text {cd }}$ & $10,7 \pm 0,2^{\mathrm{cd}}$ & $20,4^{b c}$ & $29,0 \pm 0,2 \stackrel{a}{ }$ & $9,9 \pm 0,2^{a}$ & $19,1^{\mathrm{a}}$ \\
\hline \multirow{2}{*}{$\begin{array}{c}\text { HPMC F } \\
50\end{array}$} & $0,5 \%$ & $32,0 \pm 0,4^{d}$ & $11,3 \pm 0,1^{d}$ & $20,7^{b c}$ & $32,1 \pm 0,5^{\mathrm{e}}$ & $10,4 \pm 0,1^{c}$ & $21,7^{d}$ \\
\hline & $1,5 \%$ & $32,0 \pm 0,2^{d}$ & $11,1 \pm 0,0^{\mathrm{de}}$ & $20,9^{b c}$ & $30,3 \pm 0,3^{b}$ & $10,1 \pm 0,1^{\mathrm{ab}}$ & $20,2^{a b c}$ \\
\hline
\end{tabular}

media $\pm D E$. Letras diferentes indican diferencias significativas $(p<0,05)$, dentro de una misma columna.

Esta disminución observada en GH y GS indica un efecto negativo de CMC y MCC en la formación de la red proteica. El efecto producido por MCC podría estar relacionado a la presencia de CMC ya que MCC se comercializa copolimerizada con 12 \% CMC. No se observó efecto significativo de las HPMCs sobre GH, GS y GH-GS. Bárcenas y col. (2009) analizando el efecto del agregado de 1\% HPMC (con 22\% de sustitución de grupos metilo y $8 \%$ de hidroxipropilo) en sistemas gluten-hidrocoloide $\sin \mathrm{NaCl}$ observaron que este hidrocoloide no afectaba significativamente los valores de gluten húmedo y seco, mientras que otras gomas (goma arábiga y pectina) si lo hacían por lo que propusieron que éstas últimas debilitaban la estructura del gluten.

Para las masas con $\mathrm{NaCl}$, los valores de $\mathrm{GH}$ se encontraron entre 29,0\% y $32,1 \%$, mientras que los de GS variaron entre 9,9\% y 11,3\%. GH-GS tomó valores entre $19,1 \%$ y $21,2 \%$. En las masas con $\mathrm{NaCl}$, al agregar hidrocoloide en el mayor nivel se 
observó una disminución significativa del GH respecto al control (excepto con MCC), aunque en ningún caso fue superior al $8 \%$. Los valores de GS no presentaron diferencias significativas respecto al control salvo en el nivel más alto de HPMC F 4M. GH-GS fue ligeramente inferior con CMC y HPMC F 4M 1,5\%. Los valores de GH/GS variaron entre 2,9 y 3,1, sin diferencias significativas entre las muestras (resultados no mostrados). Como ya se vio en el caso de las mezclas con pectina, la cantidad de agua unida al gluten no varió en forma concordante con la absorción farinográfica.

Estos resultados muestran que el mayor efecto negativo sobre la formación del gluten se encontró con MCC y CMC en los niveles más elevados en ausencia de $\mathrm{NaCl}$ y con HPMC F 4M y CMC en el nivel más elevado en presencia de $\mathrm{NaCl}$ aunque en menor grado que las masas $\sin \mathrm{NaCl}$. Los resultados obtenidos con $\mathrm{CMC}$ muestran que es capaz de interaccionar negativamente con la red de gluten pero que el apantallamiento de cargas en la molécula en presencia de $\mathrm{NaCl}$ podría dificultar esa interacción. Otros autores han sugerido esta interacción gluten-CMC. Collar y col. (1998) encontraron que el agregado de $\mathrm{CMC}$ en masas con $\mathrm{NaCl}$ podía desplazar los lípidos unidos a la proteína hacia la fracción almidonosa, deduciendo así que CMC podía interaccionar con el gluten.

\subsubsection{Ensayos reológicos empíricos y fundamentales}

\subsubsection{Farinogramas}

La realización de los farinogramas permitió evaluar el comportamiento de las mezclas de harina-celulosa durante el amasado. El tiempo de desarrollo, la estabilidad y el aflojamiento de las mezclas $\sin$ y con $\mathrm{NaCl}$ se muestran en las Figuras 5.4, 5.5 y 5.6 respectivamente. El efecto producido por el agregado de $\mathrm{NaCl}$ se describió en el Capítulo correspondiente a pectinas .

El agregado de hidrocoloides afectó el comportamiento farinográfico, tanto en ausencia como en presencia de $\mathrm{NaCl}$ pero en forma diferenciada según el tipo de celulosa. Los resultados obtenidos para el tiempo de desarrollo se muestran en la Figura 5.4. En ausencia de $\mathrm{NaCl}$ (Figura 5.4 A) CMC fue la celulosa que más afectó al tiempo de desarrollo; ambas HPMCs y MCC también modificaron el tiempo de desarrollo pero en menor medida. En todos los casos, el efecto sólo fue significativo en los mayores niveles. Dado que el tiempo de desarrollo es el tiempo necesario para la desnaturalización e hidratación de las proteínas del gluten y la obtención de la red, el incremento del mismo puede estar indicando diferencias en la matriz formada en 
presencia de hidrocoloides. Las celulosas modificadas pueden afectar la disponibilidad de agua para el desarrollo de la red y además pueden estar interaccionando específicamente con las proteínas. En presencia de $\mathrm{NaCl}$ (Figura 5.4 B) se observó la misma tendencia, con un aumento significativo del tiempo de desarrollo sólo en los mayores niveles de goma para las masas con MCC y HPMCs. En cambio, el agregado de CMC incrementó significativamente este parámetro en todos los niveles.

La estabilidad de las mezclas $\sin \mathrm{NaCl}$ (Figura $5.5 \mathrm{~A}$ ) no se vio modificada respecto a la del control con la utilización de MCC o las HPMCs mientras que CMC en los mayores niveles la redujo drásticamente. Inversamente a lo observado en las mezclas $\sin \mathrm{NaCl}$, en las mezclas con $\mathrm{NaCl}$ (Figura $5.5 \mathrm{~B}$ ) la estabilidad no se vio modificada por el agregado CMC, pero si por el empleo de HPMC a niveles iguales o mayores a 0,25\% (dependiendo del tipo de HPMC). El agregado de HPMCs afectó drástica y negativamente la estabilidad. La incorporación de MCC no afectó este parámetro en presencia de $\mathrm{NaCl}$.

La estabilidad y el aflojamiento son parámetros vinculados con la tolerancia al amasado y que se encuentran inversamente relacionados ya que una masa más estable suele tener un menor aflojamiento. En la Figura 5.6 se muestran los resultados de aflojamiento, observándose que los valores en las masas $\sin \mathrm{NaCl}$ fueron mucho mayores que los obtenidos para las masas con $\mathrm{NaCl}$, lo cual está de acuerdo con el fortalecimiento de la red de gluten por efecto del $\mathrm{NaCl}$. Como se vio en los casos anteriores, el efecto de las celulosas modificadas varió de acuerdo a la ausencia o presencia de $\mathrm{NaCl}$. En las mezclas sin $\mathrm{NaCl}$ (Figura 5.6 A) el aflojamiento sólo se vio incrementado al utilizar CMC en los mayores niveles, las otras celulosas modificadas no ocasionaron variaciones. En las mezclas con $\mathrm{NaCl}$ (Figura 5.6 B) aunque todas las celulosas en su mayor nivel provocaron un aumento de este parámetro, con HPMC F $4 \mathrm{M}$ al $1,5 \%$ se observó el máximo aflojamiento (60 UF), el cual es cercano al que presenta la harina $\sin \mathrm{NaCl}, 55 \mathrm{UF}$. Esta celulosa fue la que produjo el mayor decrecimiento en la estabilidad en presencia de $\mathrm{NaCl}$. 

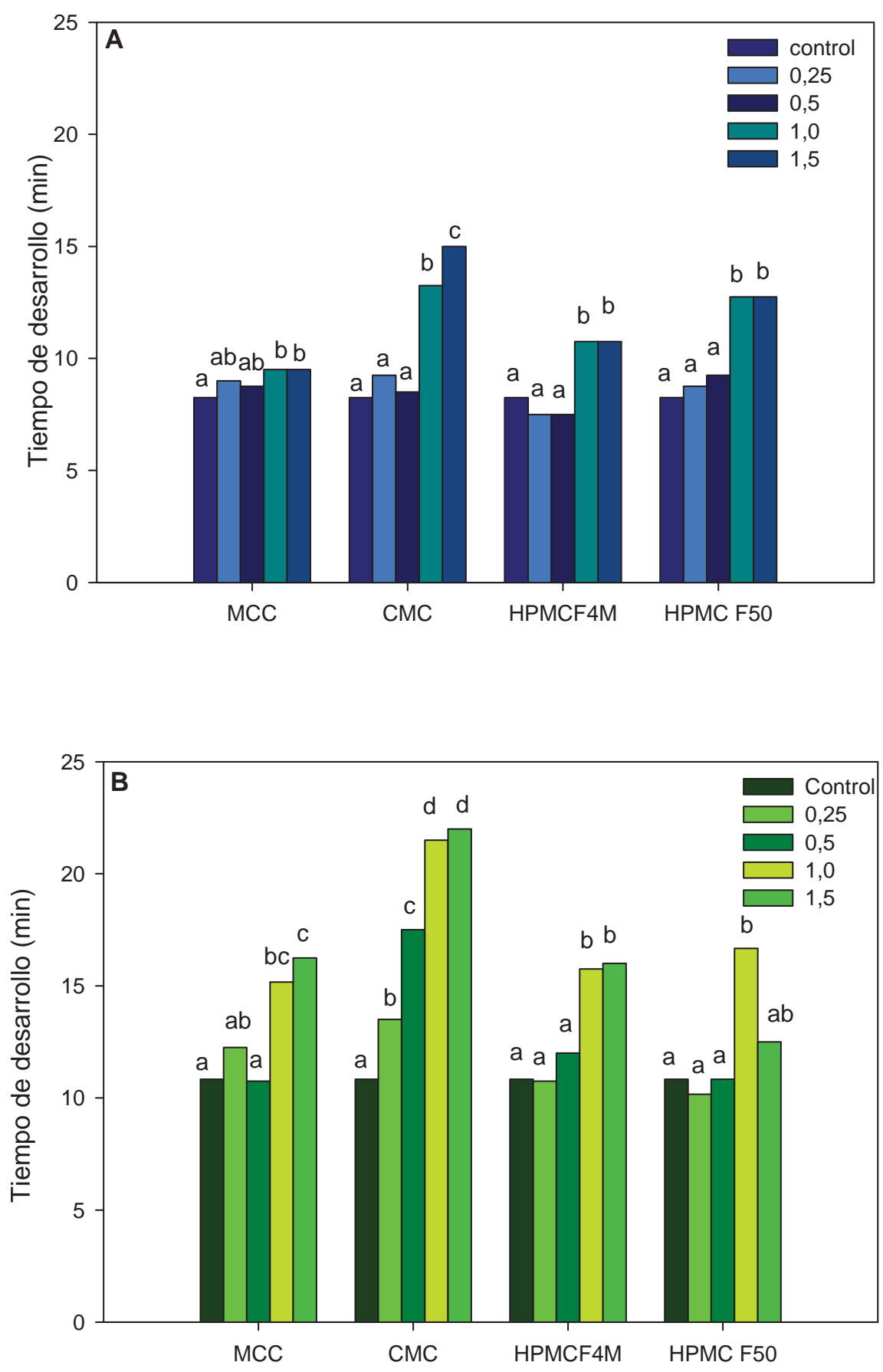

Figura. 5.4. Tiempo de desarrollo de las mezclas harina - hidrocoloide. A) $\sin \mathrm{NaCl}$. B) con $\mathrm{NaCl}$. Para cada hidrocoloide, letras diferentes indican diferencias significativas $(p<0,05)$ 

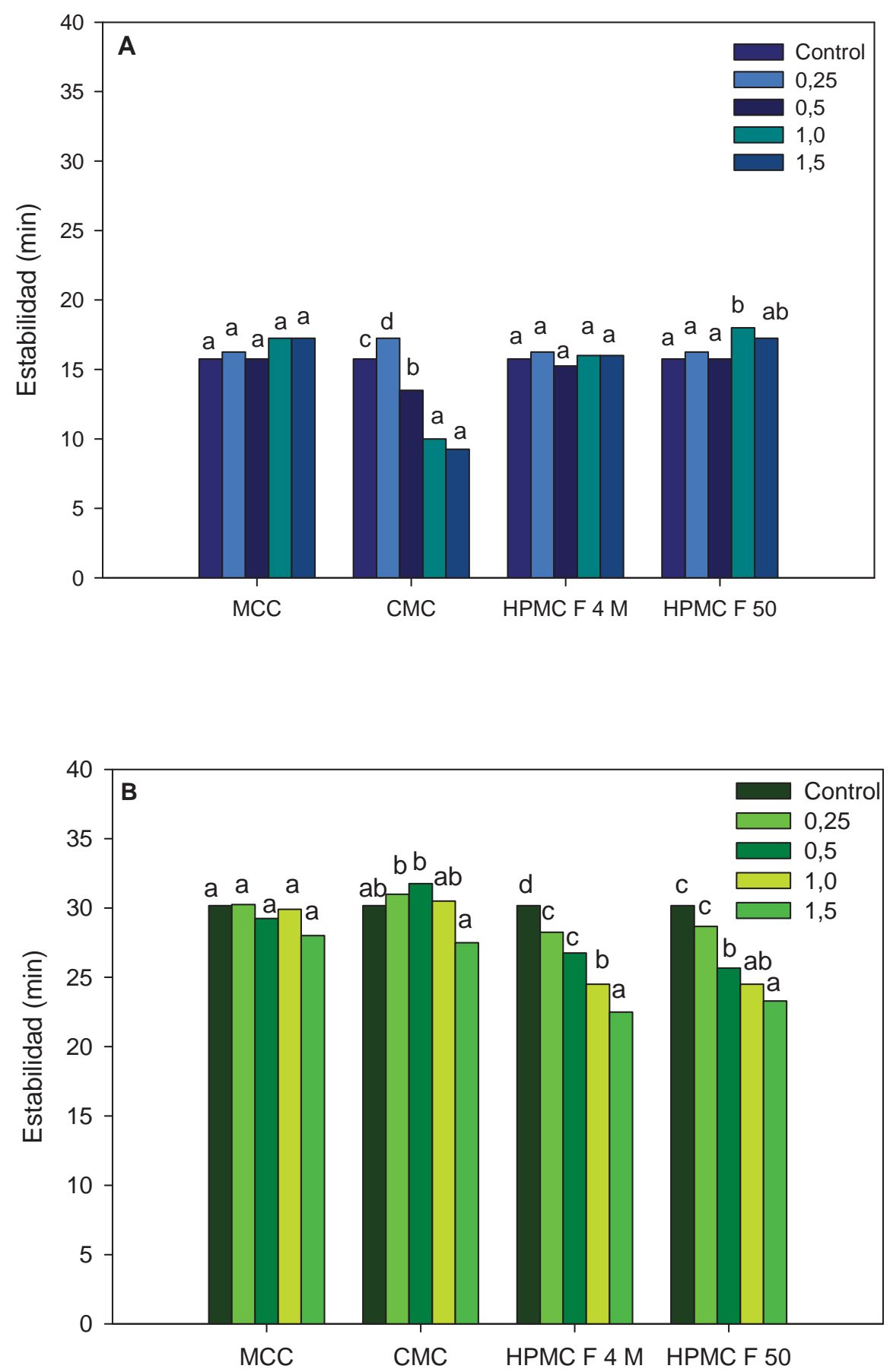

Figura 5.5. Estabilidad farinográfica de las mezclas harina - hidrocoloide. A) $\sin \mathrm{NaCl}$. B) con $\mathrm{NaCl}$. Para cada hidrocoloide, letras diferentes indican diferencias significativas $(p<0,05)$ entre sus niveles. 

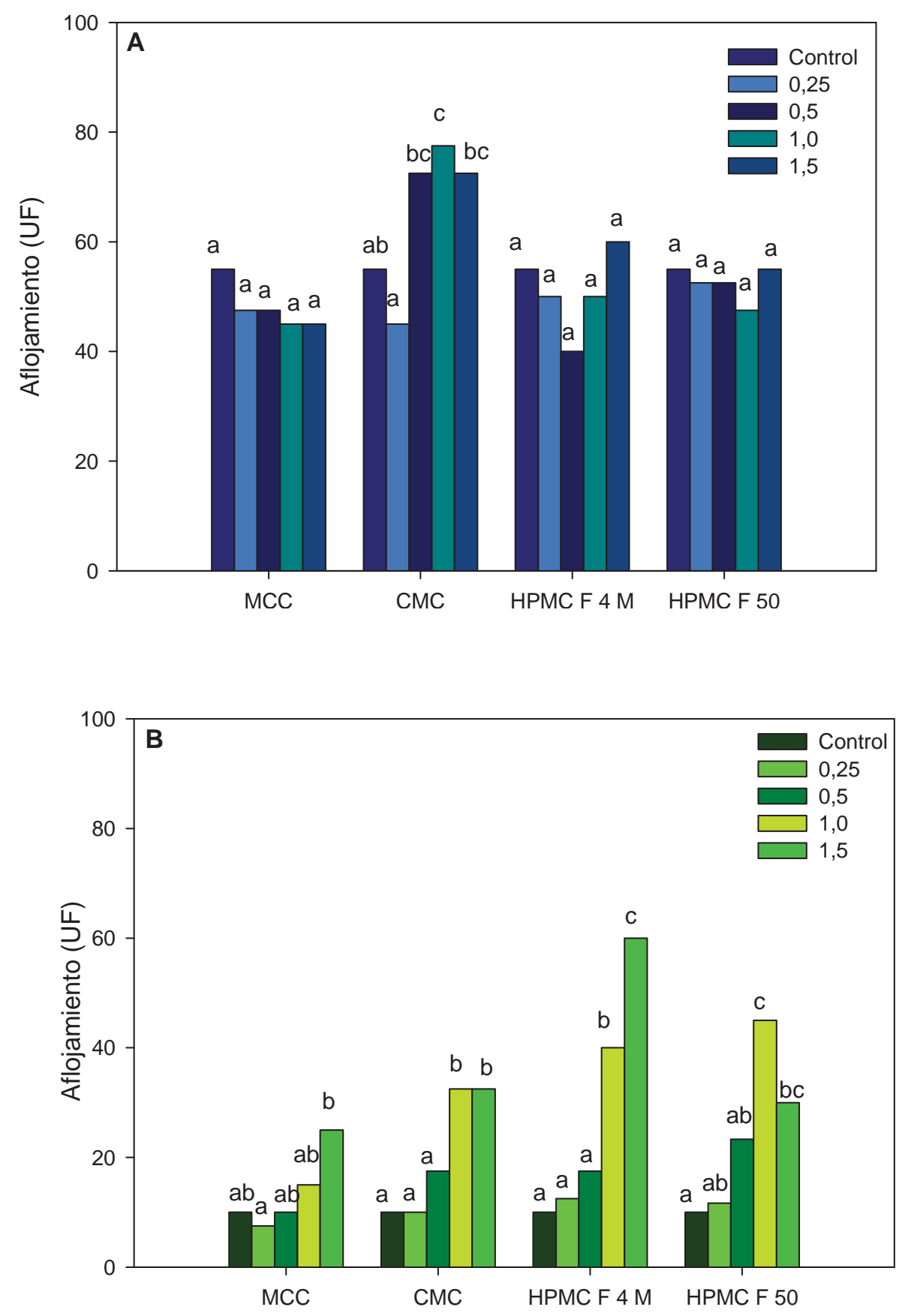

Figura 5.6. Grado de aflojamiento de las mezclas A) $\sin \mathrm{NaCl}, \mathrm{B}$ ) con $\mathrm{NaCl}$. Para cada hidrocoloide, letras diferentes indican diferencias significativas $(p<0,05)$ entre sus niveles. 
Los menores valores de $\mathrm{GH}$ y GS encontrados para $\mathrm{CMC}$ en la masa sin $\mathrm{NaCl}$ (Tabla 5.2) concuerdan con la menor estabilidad de la masa observada en el farinograma. Sin embargo, en otros casos no se pudo hallar una correlación entre el contenido de gluten húmedo y seco y los resultados de estabilidad farinográfica. El agregado de MCC 1,5\% lleva a una disminución de la formación de gluten pero no a una menor estabilidad. Por otro lado, los valores de gluten para ambas HPMCs en las masas con $\mathrm{NaCl}$ fueron similares a los del control, sin embargo, la estabilidad farinográfica disminuyó respecto al control al incrementar el nivel de hidrocoloide (Figura 6.4.B).

Esto puede explicarse porque la calidad de la red de gluten no depende sólo de la cantidad de proteína sino que también de las interacciones establecidas; una red más débil podría constituirse sin una disminución en la cantidad de gluten formado. Este comportamiento diferencial de las celulosas modificadas se puede vincular con su diferente estructura química, en particular con su carga y grado de hidrofobicidad. Mientras que MCC y las HPMCs son moléculas neutras, CMC es una molécula aniónica. Por otro lado, la presencia de $\mathrm{NaCl}$ induce la reestructuración de las moléculas de agua promoviendo las interacciones hidrofóbicas (Kinsella y Hale, 1984). Dado que las HPMC son polímeros más hidrofóbicos comparadas con las otras celulosas, el efecto observado podría deberse al establecimiento de interacciones hidrofóbicas con las proteínas de la red de gluten, dando lugar a una red más débil y menos estable. Por otro lado, cuando el sistema no contiene $\mathrm{NaCl}$, no se encuentra favorecido el establecimiento de interacciones hidrofóbicas por lo que las HPMC no interaccionarían en el mismo grado con las proteínas del gluten y por este motivo no se modificaría la estabilidad. En el caso de CMC, el $\mathrm{NaCl}$ podría apantallar las cargas de CMC impidiendo la interacción con las proteínas de la red que se producía en ausencia de $\mathrm{NaCl}$ por lo cual no se modificaría la estabilidad de la masa. Se ha informado que otras moléculas cargadas como las pectinas o los carragenatos en ausencia de $\mathrm{NaCl}$ interaccionan con las proteínas del gluten a través de complejos electrostáticos (León y col., 2000 y Ribotta y col., 2005).

\subsubsection{Ensayos oscilatorios dinámicos}

Con la finalidad de obtener el rango de viscoelasticidad lineal para las masas con celulosas $(0,5$ y $1,5 \%)$ en ausencia y presencia de $\mathrm{NaCl}$ se realizaron los barridos de esfuerzo a una frecuencia de $1 \mathrm{~Hz}$. En la Figura 5.7 se muestran las curvas obtenidas para las masas $\sin \mathrm{NaCl}$ y con $\mathrm{NaCl}$ y con el máximo nivel de hidrocoloide. 

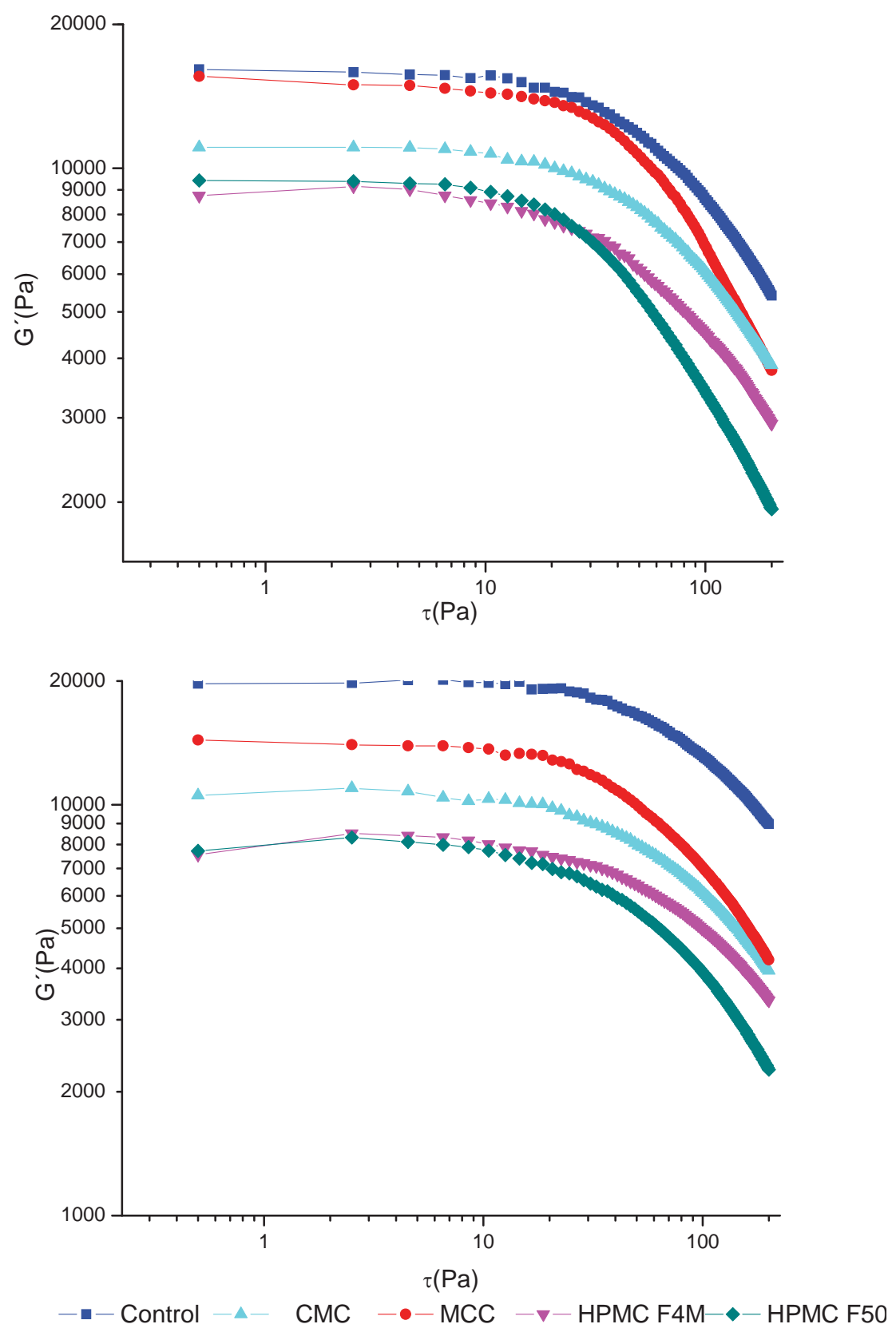

Figura 5.7. Barrido de esfuerzo para la determinación del rango de viscoelasticidad lineal. A) Masas $\sin \mathrm{NaCl}$, B) Masas con $\mathrm{NaCl}$. Nivel de celulosas modificadas utilizado: $1,5 \%$.

El límite superior del rango de viscoelasticidad lineal se encontró entre 7 y 11 Pa para las masas $\sin \mathrm{NaCl}$. El menor valor de $\tau_{\text {lim }}$ hallado correspondió a las masas con HPMC F 4M y F 50 (7 Pa), seguido por CMC (10 Pa) y masas control y MCC (11 Pa). 
Se observó que en presencia de $\mathrm{NaCl}$ el rango de viscoelasticidad lineal fue mayor que en ausencia de $\mathrm{NaCl}$ para el control (15 Pa) pero resultan similares a los de las masas $\sin \mathrm{NaCl}$ en los otros casos (entre $7 \mathrm{~Pa}$ para las HPMCs y $12 \mathrm{~Pa}$ para CMC y MCC). La reducción que se verifica en general sobre el rango de viscoelasticidad lineal al agregar celulosas indica que la matriz comienza a colapsar a esfuerzos menores siendo por lo tanto más débil.

De acuerdo a los resultados obtenidos, se eligió una deformación de 5 Pa para la realización de todos los barridos de frecuencia.

Al realizar los barridos de frecuencia (espectros mecánicos), todas las masas presentaron un comportamiento de sólido viscoelástico dado que el módulo elástico fue superior al viscoso ( $G^{\prime}>G^{\prime \prime}$ ) en todo el rango, con una dependencia de ambos módulos respecto a la frecuencia. En la Figura 5.8 se ejemplifica este comportamiento con los espectros mecánicos de las masas control, con CMC y con HPMC F 4M en el mayor nivel y en ausencia y presencia de $\mathrm{NaCl}$.
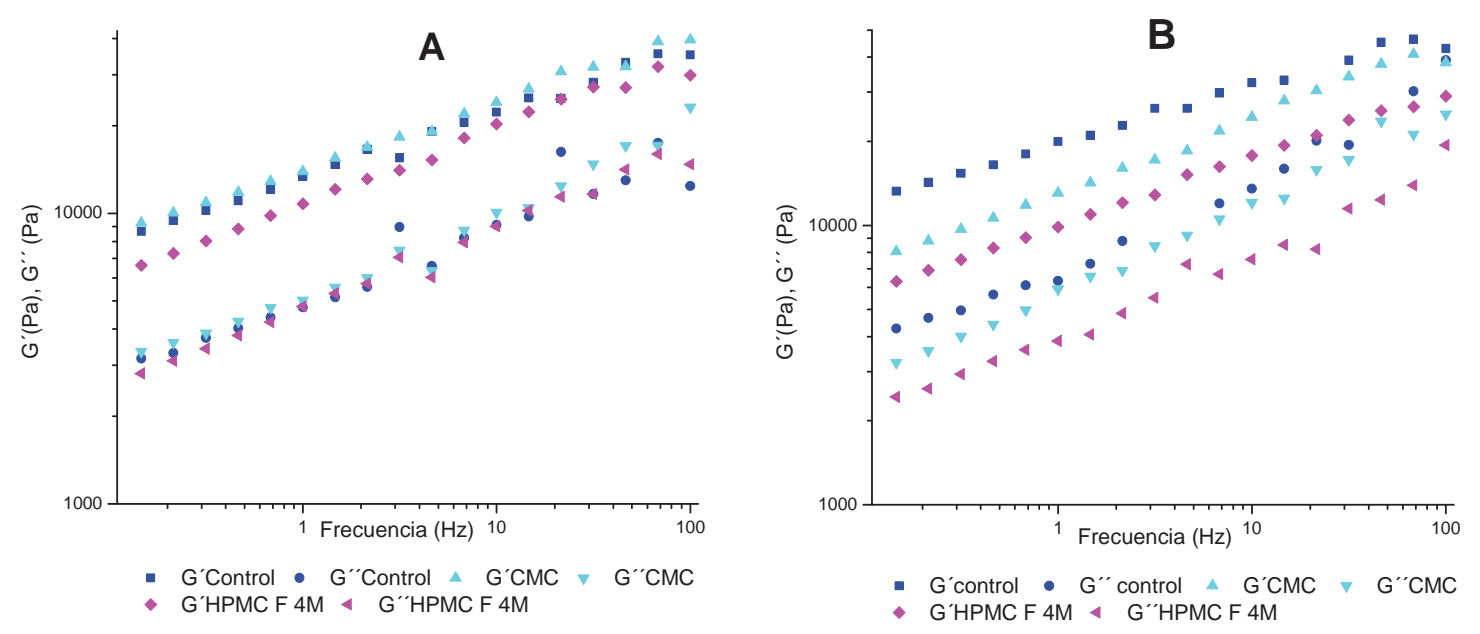

Figura 5.8. Espectros mecánicos de masas control con CMC y HPMC F 4M en ausencia y presencia de $\mathrm{NaCl}$.

En la Figura 5.9 se muestran los valores de los módulos elástico y viscoso, de la tangente del ángulo de desfasaje y de la viscosidad compleja obtenidos por las masas sin y con $\mathrm{NaCl}$. En las masas sin $\mathrm{NaCl}$ preparadas con $\mathrm{MCC}$ los parámetros reológicos dinámicos no presentaron diferencias significativas respecto al control. En el caso de la masa con CMC no se observó una tendencia clara: en el mayor nivel no se 
observaron diferencias significativas respecto al control en ningún parámetro y en el menor nivel disminuyeron la viscosidad compleja y $\mathrm{G}^{\prime}$. Aunque las diferencias no fueron significativas, en las masas con HPMCs se observó una tendencia decreciente en los módulos elástico, viscoso y la viscosidad compleja. La $\tan (\delta)$ aumentó significativamente al agregar hidrocoloide lo que significa que las masas tuvieron un comportamiento más viscoso.

Las masas con $\mathrm{NaCl}$ presentaron, en general, un aumento de los módulos y de la viscosidad compleja respecto a las masas $\sin \mathrm{NaCl}$. El agregado de hidrocoloide no alteró los parámetros en el caso de MCC o disminuyó el módulo elástico y la viscosidad compleja en el caso de las masas con CMC o HPMCs. En éstas se observaron mayores valores de la $\tan (\delta)$, lo cual indica que estas masas presentan un comportamiento más viscoso que la masa control. En las masas con HPMCs además se observó una disminución del módulo viscoso. No se encontró un efecto significativo del nivel de hidrocoloide empleado.

Rosell y Foegeding (2007) estudiaron el efecto de HPMC sobre las propiedades viscoelásticas del gluten en ausencia de $\mathrm{NaCl}$ y encontraron una disminución de los módulos elástico y viscoso aunque no encontraron diferencias en $\tan (\delta)$. En nuestro caso, observamos un efecto similar de las HPMCs sobre estos módulos pero un aumento de $\tan (\delta)$, lo cual indica que ha ocurrido un cambio en la contribución relativa de los módulos elástico y viscoso al comportamiento viscoelástico de la masa, debido probablemente a cambios estructurales ocasionados por el agregado del hidrocoloide. En el caso de las masas con pectinas se observaron tendencias similares a las descriptas: disminución de los módulos indicando masas menos consistentes en presencia de hidrocoloide y un aumento de $\tan (\delta)$ que se relaciona con el incremento de la respuesta viscosa en el sistema 

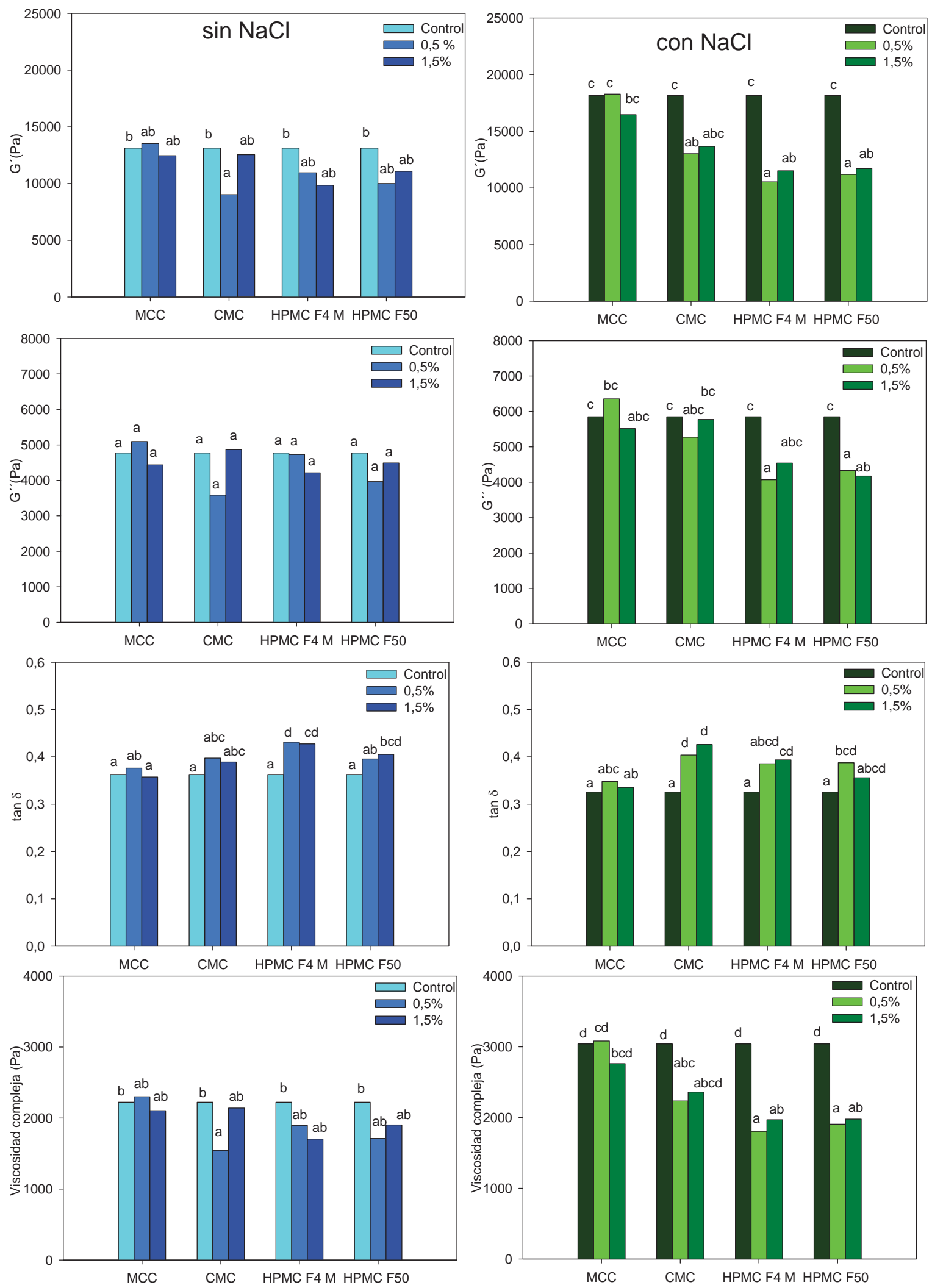

Figura. 5.9. Módulo elástico, módulo viscoso, tangente del ángulo de desfasaje y viscosidad compleja de las masas $\sin \mathrm{NaCl}$ (izquierda) y con $\mathrm{NaCl}$ (derecha) evaluados a $1 \mathrm{~Hz}$. Letras diferentes indican diferencias significativas $(p<0,05)$. 


\subsubsection{Análisis de perfil de textura}

En las Figuras 5.10 y 5.11 se observan los principales atributos texturales (dureza, consistencia, cohesividad, elasticidad, resiliencia y adhesividad) de las masas $\sin \mathrm{NaCl}$ y con $\mathrm{NaCl}$ para dos niveles de hidrocoloide, 0,5 y $1,5 \%$. El efecto del $\mathrm{NaCl}$ en la masa sin hidrocoloide fue comentado en el Capítulo anterior.

En las masas $\sin \mathrm{NaCl}$ (Figura 5.10) se observa que tanto la dureza como la consistencia disminuyeron debido al empleo de los hidrocoloides en la formulación. Con el máximo nivel de hidrocoloide se verificó una disminución significativa tanto de la dureza como de la consistencia en todos los casos. Con el menor nivel de hidrocoloide $(0,5 \%)$ se obtuvieron disminuciones significativas de estos dos atributos en todos los casos menos con MCC. Con CMC y HPMC F 4M se observó que la consistencia disminuía en menor grado cuando se agregaba el mayor nivel de hidrocoloide.

La cohesividad se relaciona con el grado de integración de los componentes de las muestras, en el caso de las masas con CMC y MCC al 1,5\% $\sin \mathrm{NaCl}$, la menor cohesividad se vio reflejada también en los valores de gluten obtenidos, los cuales fueron marcadamente menores a los del control (Tabla 5.2). La cohesividad no mostró en general grandes variaciones al incorporarse los hidrocoloides, indicando que éstos no afectan mayormente la integración de los componentes.

De acuerdo a la Figura 5.11, se observa que la elasticidad, relacionada con la recuperación retardada, sólo disminuyó significativamente respecto al control con MCC y CMC mientras que la resiliencia o elasticidad instantánea aumentó con los mayores niveles de estas dos gomas. Las muestras con HPMC F 50 mostraron igual disminución de la resiliencia con ambos niveles de este hidrocoloide mientras que las muestras con HPMC F 4M no mostraron disminución de la resiliencia respecto al control. Ninguna de las HPMC mostraron cambios en la elasticidad.

En general, todas las celulosas modificadas utilizadas tendieron a disminuir la adhesividad, siendo esta disminución significativa con el máximo nivel de hidrocoloide en todos los casos. Esta propiedad de superficie probablemente se ve afectada por una mayor retención de agua en el sistema derivada de la presencia de las celulosas. En las masas con $\mathrm{NaCl}$, se observó una disminución significativa de la dureza y de la consistencia respecto al control en todos los casos y para todos los niveles de hidrocoloide (Figura 5.10). En el caso de MCC no se observó diferencia en estos atributos con el aumento del nivel de hidrocoloide. Con CMC se halló una disminución de la dureza y de la consistencia al aumentar la concentración de hidrocoloide. El 
efecto opuesto se obtuvo con las HPMCs: al aumentar la concentración de goma aumentaron tanto la dureza como la consistencia, aunque siguen siendo significativamente menores al control.

Respecto a la cohesividad, se observó en todos los casos un incremento respecto al control al utilizar el mayor nivel de hidrocoloide.

La resiliencia (Figura 5.11) disminuyó al agregar celulosas y fue mayor la disminución con el aumento de la concentración en casi todos los casos. El efecto sobre la elasticidad resultó mucho menos marcado, obteniéndose menores valores con el nivel más bajo de hidrocoloide.

La adhesividad disminuyó en todos los casos, con ambos niveles de celulosa. Con el nivel menor se obtuvieron en general menores adhesividades que con el nivel más alto.

Las HPMCs generaron en presencia de $\mathrm{NaCl}$ matrices más blandas, más cohesivas, menos resilientes y menos adhesivas que en ausencia de $\mathrm{NaCl}$. Estas moléculas relativamente, más hidrofóbicas, pueden interactuar mejor con las proteínas de gluten al favorecerse las interacciones hidrofóbicas en presencia de $\mathrm{NaCl}$ como se vio en los ensayos farinográficos (ítem 5.1.2.1). En los ensayos farinográficos estos hidrocoloides generaron matrices menos resistentes al amasado (menos estables y con mayor aflojamiento).

Los resultados con CMC y MCC son de interpretación más compleja. En principio lo observado para MCC puede estar relacionado, como se vio anteriormente, con el porcentaje de CMC que tiene esta celulosa copolimerizada. Como caso a destacar, la CMC condujo a muestras menos cohesivas y menos elásticas, aunque más resilientes, en ausencia de $\mathrm{NaCl}$, lo que se revirtió en las muestras con $\mathrm{NaCl}$. En ausencia de $\mathrm{NaCl}$ se vio que este hidrocoloide afectaba negativamente los parámetros farinográficos de estabilidad y aflojamiento probablemente por interacciones de tipo electrostático con las proteínas del gluten. El agregado de $\mathrm{NaCl}$ permitía el apantallamiento de estas cargas y de este modo mejoraba la resistencia de la masa.

Se puede remarcar además que los resultados de TPA aunque en un rango de deformaciones muy diferente al de los ensayos dinámicos oscilatorios mostraron tendencias similares: el ablandamiento de la masa observado en TPA coincide con la obtención en general de menores valores de módulo elástico dinámico habiéndose hallado un coeficiente de correlación igual a 0,7698 que indica una relación moderadamente fuerte entre ambas variables. 

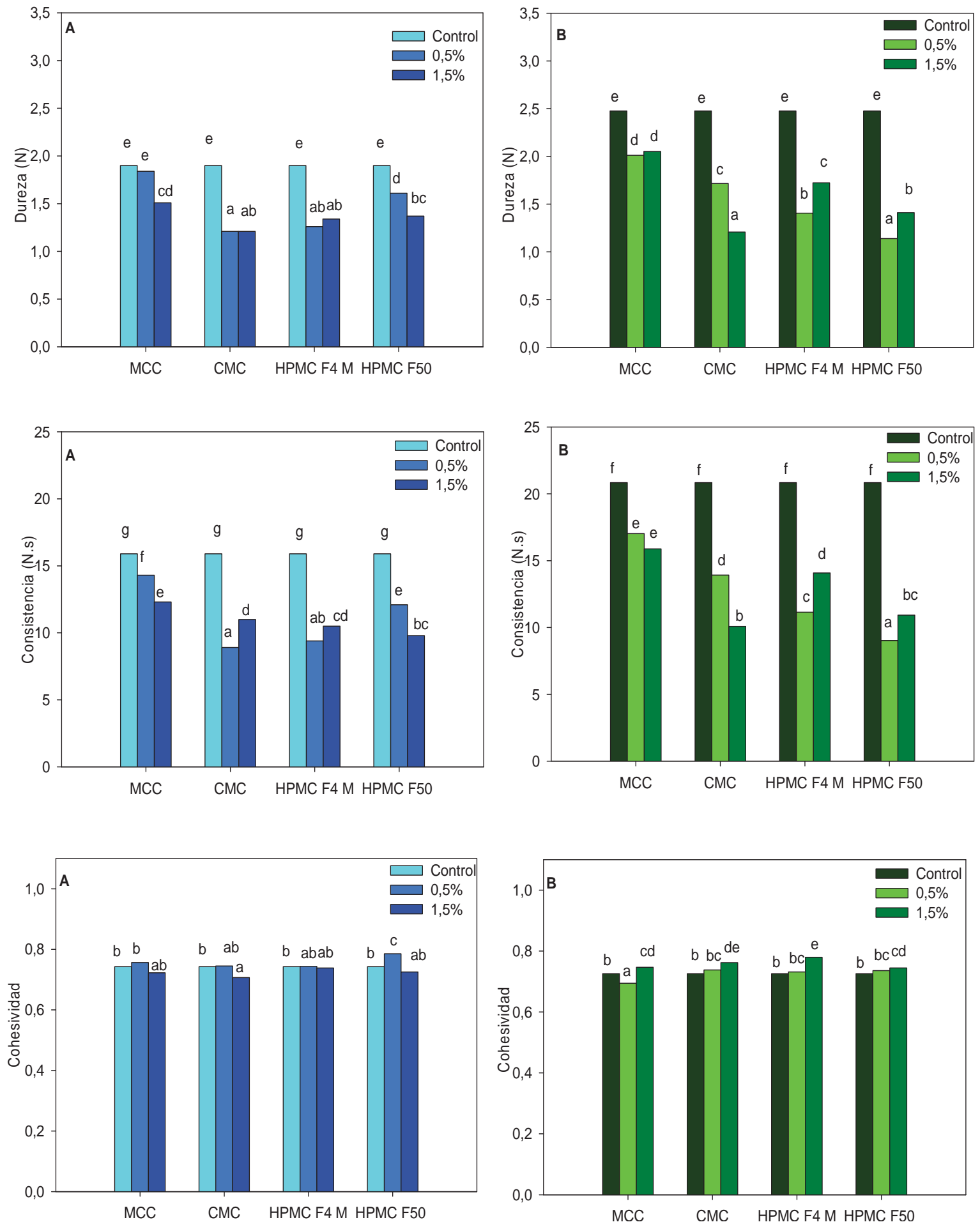

Figura 5.10. Dureza, consistencia y cohesividad de las masas $\sin (A)$ y con $\mathrm{NaCl}(B)$. Letras diferentes indican diferencias significativas $(p<0,05)$. 

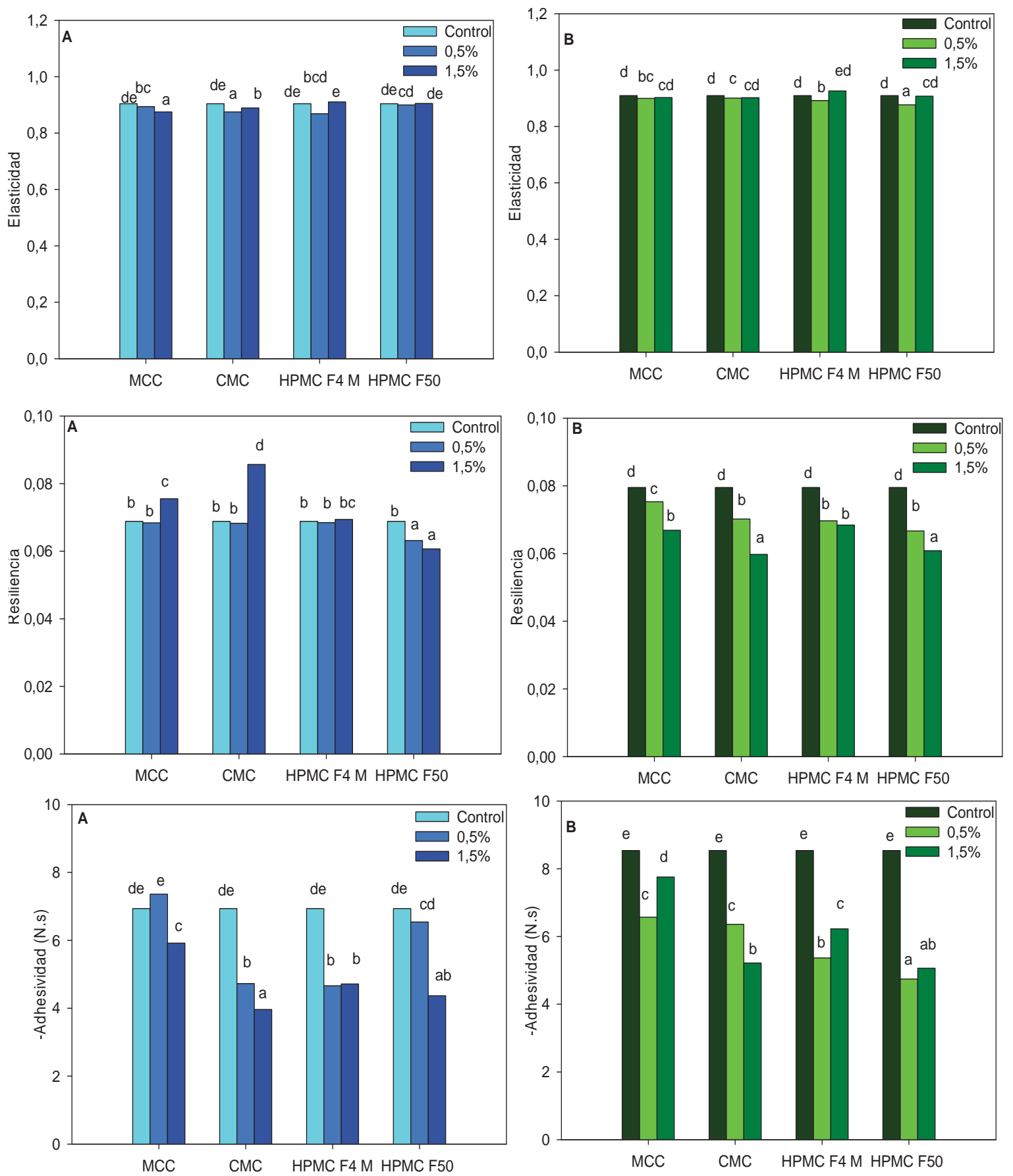

Figura 5.11. Elasticidad, resiliencia y adhesividad de las masas $\sin (\mathrm{A})$ y con $\mathrm{NaCl}(\mathrm{B})$. Letras diferentes indican diferencias significativas $(p<0,05)$. 


\subsubsection{Ensayos de punción}

En la Tabla 5.3 se muestran los resultados obtenidos para las masas $\sin$ y con $\mathrm{NaCl}$ en los ensayos de punción. La adición de celulosas modificadas produjo la disminución de la resistencia a la penetración particularmente en el caso de las masas con $\mathrm{NaCl}$, donde esta reducción llegó a un 45\% respecto al control con CMC. Aunque significativa en la mayoría de los casos, la disminución en la fuerza de penetración fue mucho menos marcada en las masas $\sin \mathrm{NaCl}$, no superando el $27 \%$ respecto al control. Si bien las masas sin hidrocoloide dieron valores muy diferentes entre sí, se observó que al agregar hidrocoloide los valores de la fuerza de penetración sin y con $\mathrm{NaCl}$ son similares.

Tabla 5.3. Fuerza de penetración (N) en el ensayo de punción

\begin{tabular}{ccc}
\hline \multirow{2}{*}{ Muestra } & Masas sin NaCl & Masas con NaCl \\
\cline { 2 - 3 } & Fuerza de penetración (N) & Fuerza de penetración (N) \\
\hline Control & $0,26 \pm 0,03^{\mathrm{e}}$ & $0,33 \pm 0,03^{f}$ \\
\hline MCC 0,5\% & $0,24 \pm 0,02^{\mathrm{cd}}$ & $0,23 \pm 0,02^{\mathrm{cde}}$ \\
\hline MCC 1,5\% & $0,22 \pm 0,2^{\mathrm{bc}}$ & $0,25 \pm 0,03^{\mathrm{de}}$ \\
\hline CMC 0,5\% & $0,22 \pm 0,02^{\mathrm{bc}}$ & $0,25 \pm 0,02^{\mathrm{e}}$ \\
\hline CMC 1,5\% & $0,25 \pm 0,03^{\mathrm{e}}$ & $0,18 \pm 0,02^{\mathrm{a}}$ \\
\hline HPMC F 4M 0,5\% & $0,19 \pm 0,01^{\mathrm{a}}$ & $0,21 \pm 0,02^{\mathrm{bcd}}$ \\
\hline HPMC F 4M 1,5\% & $0,21 \pm 0,02^{\mathrm{ab}}$ & $0,22 \pm 0,02^{\mathrm{bc}}$ \\
\hline HPMC F 50 0,5\% & $0,24 \pm 0,02^{\mathrm{cd}}$ & $0,21 \pm 0,02^{\mathrm{b}}$ \\
\hline HPMC F 501,5\% & $0,22 \pm 0,03^{\mathrm{bc}}$ & $0,21 \pm 0,03^{\mathrm{bc}}$
\end{tabular}

media $\pm \mathrm{DE}$. En una columna, letras diferentes indican diferencias significativas $(p<0,05)$.

\subsubsection{Ensayos de relajación}

Al igual que para las masas con pectinas, el comportamiento seguido por las masas en los ensayos de relajación se modeló con una ecuación de segundo grado (Ec. 4.1), habiéndose obtenido en todos los casos un coeficiente de determinación $\left(r^{2}\right)$ mayor a 0,966. Los resultados para ambos tiempos de relajación $\left(\lambda_{1}, \lambda_{2}\right)$ y el esfuerzo de equilibrio $\left(\sigma_{\mathrm{e}}\right)$ para las masas $\sin$ y con $\mathrm{NaCl}$ se muestran en la Tabla 5.4. 
En la Tabla 5.4 se observa que existe una diferencia de magnitud notable entre los tiempos de relajación $\lambda_{1}$ y $\lambda_{2}$ y que la mayor variación entre muestras se obtuvo en $\lambda_{1}$, como ya se había observado en las masas con pectinas. En ausencia de $\mathrm{NaCl}$, los tiempos de relajación no fueron significativamente diferentes al control, excepto para las muestras con CMC (0,5 y 1,5\%) cuyos $\lambda_{1}$ y $\lambda_{2}$ significativamente mayores que el control. Esto significa que las muestras con CMC relajan más lentamente, respuesta característica de sistemas más sólidos. Esta conducta de las muestras con CMC va en el mismo sentido que el incremento de la resiliencia en el máximo nivel en las masas $\sin \mathrm{NaCl}$ pero no se reflejó en la tan( $\delta$ ) de los ensayos dinámicos. En todos los casos se observó un valor de $\sigma_{\mathrm{e}}$ remanente lo que demuestra el comportamiento de sólido viscoelástico de las masas aunque no se observó una tendencia clara en la variación con respecto al control.

Tabla 5.4. Tiempos de relajación $\left(\lambda_{1}, \lambda_{2}\right)$ para las masas con y $\sin \mathrm{NaCl}$.

\begin{tabular}{ccccccc}
\hline \multirow{2}{*}{ Muestra } & \multicolumn{3}{c}{ Sin NaCl } & \multicolumn{3}{c}{ Con NaCl } \\
\cline { 2 - 7 } & $\sigma_{\mathrm{e}}\left(\mathrm{N} / \mathrm{m}^{2}\right)$ & $\lambda_{1}(\mathrm{~s})$ & $\lambda_{2}(\mathrm{~s})$ & $\sigma_{\mathrm{e}}\left(\mathrm{N} / \mathrm{m}^{2}\right)$ & $\lambda_{1}(\mathrm{~s})$ & $\lambda_{2}(\mathrm{~s})$ \\
\hline Control & $25,8 \pm 3,0^{\text {cd }}$ & $233 \pm 7^{\mathrm{a}}$ & $6,3 \pm 0,3^{\mathrm{a}}$ & $55,5 \pm 8,3^{\mathrm{e}}$ & $293 \pm 7^{\dagger}$ & $7,9 \pm 0,3^{\mathrm{d}}$ \\
\hline MCC 0,5\% & $23,0 \pm 4,1^{\text {cd }}$ & $248 \pm 12^{\mathrm{ab}}$ & $7,2 \pm 0,8^{\mathrm{abc}}$ & $52,5 \pm 9,6^{\mathrm{e}}$ & $279 \pm 6^{\mathrm{def}}$ & $8,2 \pm 0,7^{\mathrm{d}}$ \\
\hline MCC 1,5\% & $18,0 \pm 2,0^{\mathrm{bc}}$ & $241 \pm 11^{\mathrm{ab}}$ & $7,5 \pm 0,9^{\mathrm{bc}}$ & $42,9 \pm 7,4^{\mathrm{de}}$ & $292 \pm 13^{\text {ef }}$ & $7,7 \pm 0,3^{\mathrm{cd}}$ \\
\hline CMC 0,5\% & $11,5, \pm 2,6^{\mathrm{a}}$ & $266 \pm 7^{\mathrm{b}}$ & $8,2 \pm 0,8^{\mathrm{c}}$ & $16,6 \pm 3,1^{\mathrm{ab}}$ & $250 \pm 10^{\mathrm{bc}}$ & $7,1 \pm 0,5^{\mathrm{bc}}$ \\
\hline CMC 1,5\% & $35,6 \pm 4,4^{\mathrm{d}}$ & $262 \pm 13^{\mathrm{b}}$ & $8,3 \pm 0,7^{\mathrm{bc}}$ & $29,1 \pm 3,5^{\mathrm{cd}}$ & $248 \pm 10^{\mathrm{b}}$ & $6,6 \pm 0,2^{\mathrm{b}}$ \\
\hline HPMC F 4M 0,5\% & $10,5 \pm 2,3^{\mathrm{a}}$ & $220 \pm 14^{\mathrm{a}}$ & $6,8 \pm 0,7^{\mathrm{abc}}$ & $11,4 \pm 3,8^{\mathrm{a}}$ & $250 \pm 12^{\mathrm{bc}}$ & $6,9 \pm 0,3^{\mathrm{b}}$ \\
\hline HPMC F 4M 1,5\% & $24,2 \pm 6,0^{\mathrm{c}}$ & $235 \pm 19^{\mathrm{a}}$ & $6,6 \pm 0,7^{\mathrm{ab}}$ & $25,8 \pm 7,2^{\mathrm{bc}}$ & $211 \pm 7^{\mathrm{a}}$ & $5,3 \pm 0,1^{\mathrm{a}}$ \\
\hline HPMC F 50 0,5\% & $11,2 \pm 1,7^{\mathrm{a}}$ & $240 \pm 15^{\mathrm{a}}$ & $7,1 \pm 0,6^{\mathrm{abc}}$ & $12,4 \pm 2,9^{\mathrm{a}}$ & $270 \pm 10^{\mathrm{cd}}$ & $7,5 \pm 0,3^{\mathrm{bcd}}$ \\
\hline HPMC F 50 1,5\% & $11,3 \pm 1,2^{\mathrm{ab}}$ & $231 \pm 6^{\mathrm{a}}$ & $6,8 \pm 0,6^{\mathrm{abc}}$ & $21,9 \pm 5,1^{\mathrm{bc}}$ & $272 \pm 19^{\text {de }}$ & $7,1 \pm 0,6^{\mathrm{bcd}}$ \\
\hline
\end{tabular}

media $\pm \mathrm{DE}$. En una columna, letras diferentes indican diferencias significativas $(p<0,05)$.

En presencia de $\mathrm{NaCl}$, todas las muestras con gomas (excepto $\mathrm{MCC}$ ) exhibieron tiempos de relajación $\left(\lambda_{1}\right)$ menores que el control, es decir, relajan más rápidamente lo cual indica que presentan un comportamiento más viscoso. El valor del esfuerzo de equilibrio resultó significativamente menor al control en todos los casos, excepto en las masas con MCC. Estos resultados se encuentran en acuerdo con el efecto de 
ablandamiento observado en el ensayo de TPA (Figura 5.10) y con el incremento en la tangente del ángulo de desfasaje (Figura 5.8).

En el valor del esfuerzo de equilibrio no se encontró una tendencia clara, lo que podría relacionarse con las limitaciones inherentes del ensayo que ya fueron comentadas en el capítulo de pectinas o también a que este parámetro podría ser más sensible a dichas limitaciones.

\subsubsection{Análisis de componentes principales de los parámetros reométricos y texturales}

El análisis de componentes principales de las masas con celulosas modificadas al 0,5 \% y $1,5 \%$ se realizó empleando los mismos parámetros reométricos y texturales que en el caso de las masas con pectinas: dureza, consistencia, adhesividad, resiliencia y cohesividad y tangente del ángulo de desfasaje. Aunque se evaluó la incorporación de otras variables como por ejemplo la elasticidad y el tiempo de relajación se encontró la misma dificultad que en las masas con pectinas, éstas variables quedaban agrupadas en un tercer o cuarto componente y no se aumentaba en gran medida la explicación de la varianza. Los dos componentes principales explicaron el $87,8 \%$ de la varianza y quedaron integrados de igual modo que en las masas con pectinas. El CP1 explicó el $58,4 \%$ de la varianza y se integró principalmente por la dureza, consistencia, adhesividad (con correlación positiva) y la tan $\delta$ (con correlación negativa) mientras que el CP2 explicó el 29,4\% de la varianza y estuvo integrado fundamentalmente por la cohesividad (con correlación positiva) y la resiliencia (con correlación negativa).

En la Tabla 5.5 se muestran las cargas de ambos componentes y las comunalidades.

En la Figura 5.12 se muestra el gráfico de doble proyección que muestra la puntuación para las variables texturales y reométricas analizadas en función de ambos componentes y la carga de cada variable.

Las masas con $\mathrm{NaCl}$ (excepto $\mathrm{MCC}$ al 0,5\%) quedaron ubicadas en la parte superior del gráfico y por arriba del control mostrando así que son más cohesivas y menos resilientes. Por otro lado, un comportamiento menos definido en relación al control respectivo fue observado en relación a CP2 en las masas $\sin \mathrm{NaCl}$.

Se observa con facilidad en el gráfico que el agregado de $\mathrm{NaCl}$ en las masas con $\mathrm{CMC}$ al 1,5\% provocó un cambio drástico en la cohesividad y la resiliencia (CP2). La masa con $\mathrm{CMC}$ y $\mathrm{NaCl}$ fue más cohesiva y menos resiliente que la masa $\sin \mathrm{NaCl}$. Este resultado se encuentra en acuerdo con el comportamiento observado en la estabilidad farinográfica, cuando la masa no contiene $\mathrm{NaCl}$ la estabilidad farinográfica disminuye. 
Tabla 5.5. Cargas de los componentes y comunalidades

\begin{tabular}{cccc}
\hline Variable & CP1 & CP2 & Comunalidad \\
\hline Dureza & 0,979 & $-0,084$ & 0,966 \\
\hline Cohesividad & 0,038 & 0,931 & 0,867 \\
\hline Resiliencia & 0,236 & $-0,846$ & 0,771 \\
\hline Adhesividad & 0,974 & 0,134 & 0,967 \\
\hline Consistencia & 0,958 & $-0,203$ & 0,959 \\
\hline Tan $\delta$ & $-0,789$ & 0,342 & 0,739 \\
\hline Varianza & 3,5047 & 1,7651 & 5,2698 \\
\hline$\%$ Varianza & 0,584 & 0,294 & 0,878 \\
\hline
\end{tabular}

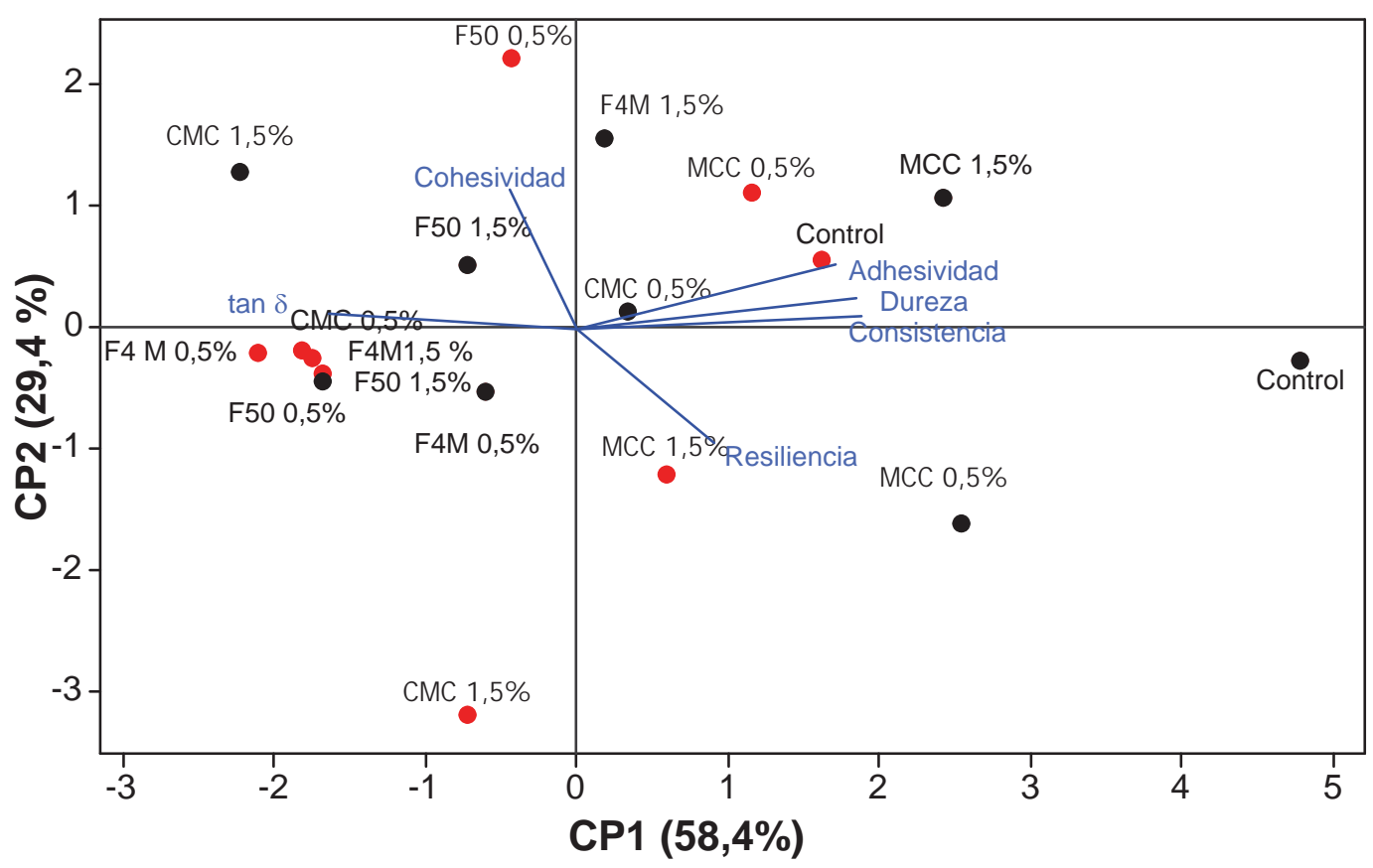

Figura.5.12. Análisis por componentes principales (rotación Varimax) de los parámetros dinámicos (tangente del ángulo de desfasaje) y texturales(adhesividad, dureza, resiliencia, consistencia y cohesividad) de las masas sin y con $\mathrm{NaCl}$.

Círculos de color rojo corresponden a las masas $\sin \mathrm{NaCl}$ y los de color negro a las masas con $\mathrm{NaCl}$. Los números indican la concentración de hidrocoloide empleada (\% $\mathrm{p} / \mathrm{p}$ harina). 
La mayoría de las muestras con HPMC independientemente de la concentración de goma y el agregado o no de $\mathrm{NaCl}$, aparecen agrupadas en una región más o menos delimitada del gráfico (zona superior izquierda), la cual corresponde a masas más blandas, más cohesivas, menos adhesivas y resilientes. En cambio las muestras con CMC aparecen mucha más dispersas, en diferentes zonas del gráfico y las masas con MCC son las que aparecen más cercanas a los respectivos controles.

\subsection{Panificación}

\subsubsection{Curvas de fermentación}

El incremento del volumen de la masa panaria durante el leudado, al igual que en el caso de las masas con pectinas, se describió por medio de la ecuación de Chapman, una ecuación exponencial de 3 parámetros (Ec. 4.2).

En la Figura 5.13 se muestran los datos experimentales de fermentación de la masa control y las masas con celulosas al 1,5\%; observándose que las masas con CMC y HPMC F 4M alcanzaron los mayores volúmenes finales.

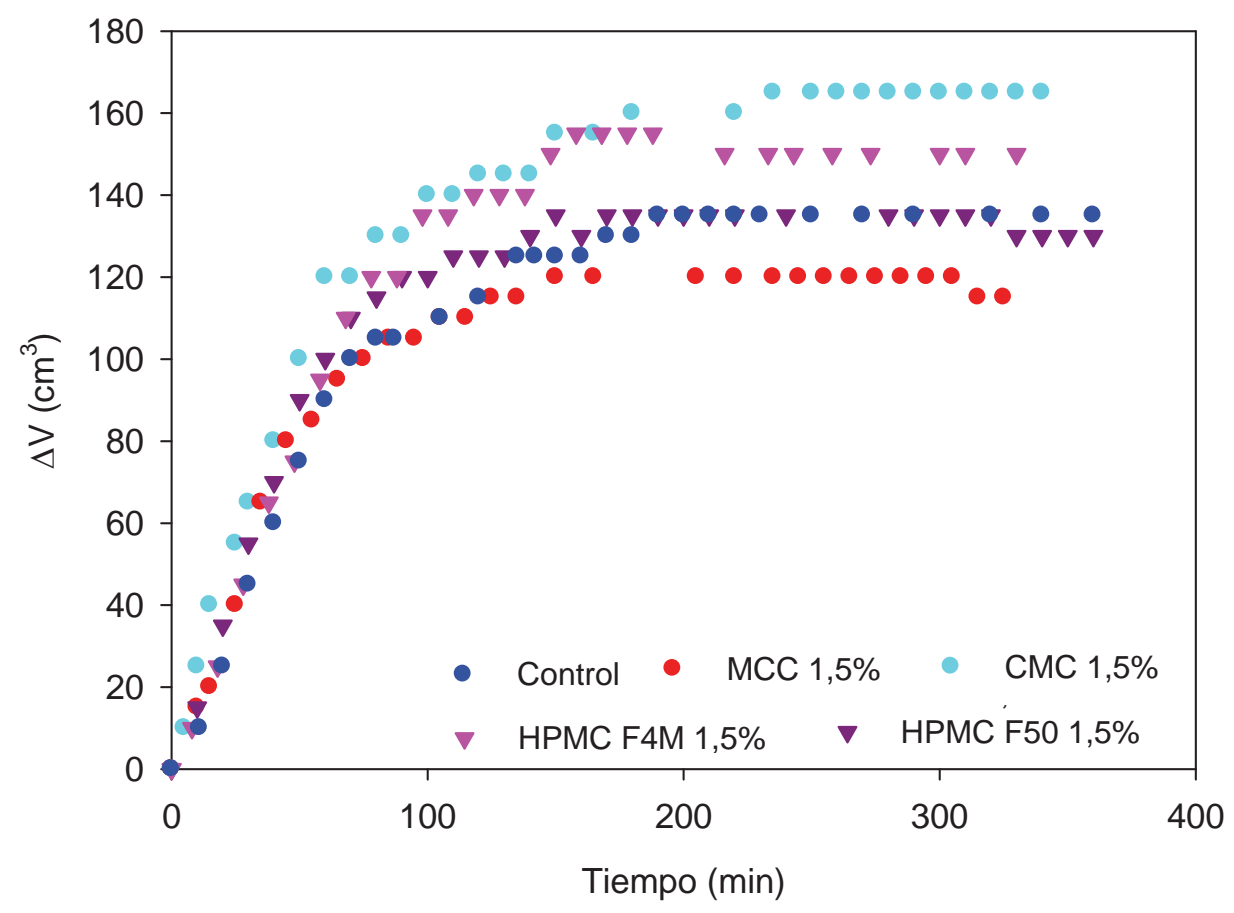

Figura 5.13. Curvas de fermentación de las masas control y con celulosas modificadas al $1,5 \%$. 
En la Tabla 5.6 se muestran los parámetros obtenidos a partir de las regresiones de las curvas de fermentación, el coeficiente de determinación y el tiempo de fermentación calculado a partir de las regresiones para cada masa. El máximo incremento del volumen alcanzado durante la fermentación por las masas se corresponde con el parámetro $a_{f}$ de la regresión. El tiempo de fermentación se definió como el tiempo necesario para alcanzar tres cuartos del volumen máximo.

Tabla 5.6. Parámetros $a_{f}, b_{f}$ y $c_{f}$ de las curvas de fermentación, coeficiente de determinación $\left(\mathrm{r}^{2}\right)$ y tiempo de fermentación $\left(\mathrm{t}_{\mathrm{f}}\right)$ de las masas.

\begin{tabular}{cccccc}
\hline Muestra & $a_{f}\left(\mathrm{~cm}^{3}\right)$ & $b_{f}(\min )$ & $c_{f}$ & $r^{2}$ & $t_{f}(\min )$ \\
\hline Control & $134,3 \pm 1,3$ & $0,023 \pm 0,002$ & $1,57 \pm 0,13$ & 0,9992 & 77,8 \\
\hline MCC 0,25\% & $117,1 \pm 1,0$ & $0,027 \pm 0,002$ & $1,27 \pm 0,12$ & 0,9991 & 60,1 \\
\hline MCC 0,5\% & $125,24 \pm 0,8$ & $0,024 \pm 0,001$ & $1,36 \pm 0,09$ & 0,9995 & 69,5 \\
\hline MCC 1,5\% & $118,5 \pm 0,7$ & $0,030 \pm 0,002$ & $1,39 \pm 0,11$ & 0,9994 & 55,5 \\
\hline CMC 0,25\% & $114,7 \pm 1,1$ & $0,032 \pm 0,003$ & $1,65 \pm 0,20$ & 0,9984 & 56,7 \\
\hline CMC 0,5\% & $141,6 \pm 0,9$ & $0,026 \pm 0,002$ & $1,40 \pm 0,11$ & 0,9993 & 64,4 \\
\hline CMC 1\% & $139,9 \pm 1,4$ & $0,028 \pm 0,002$ & $1,69 \pm 0,18$ & 0,9989 & 66,3 \\
\hline CMC 1,5\% & $162,9 \pm 1,2$ & $0,019 \pm 0,001$ & $1,08 \pm 0,07$ & 0,9992 & 75,9 \\
\hline HPMC F 4M 0,25\% & $139,8 \pm 1,3$ & $0,025 \pm 0,002$ & $1,47 \pm 0,14$ & 0,999 & 68,7 \\
\hline HPMC F 4M 0,5\% & $141,7 \pm 1,1$ & $0,025 \pm 0,002$ & $1,63 \pm 0,13$ & 0,9993 & 71,7 \\
\hline HPMC F 4M 1\% & $129,4 \pm 0,8$ & $0,034 \pm 0,002$ & $1,97 \pm 0,14$ & 0,9994 & 59,3 \\
\hline HPMC F 4M 1,5\% & $147,0 \pm 1,9$ & $0,028 \pm 0,003$ & $1,98 \pm 0,27$ & 0,9982 & 71,0 \\
\hline HPMC F 50 0,25\% & $133,7 \pm 1,2$ & $0,023 \pm 0,002$ & $1,38 \pm 0,13$ & 0,999 & 72,9 \\
\hline HPMC F 50 0,5\% & $140,5 \pm 0,8$ & $0,063 \pm 0,001$ & $1,84 \pm 0,12$ & 0,9995 & 73,4 \\
\hline HPMC F 50 1\% & $140,7 \pm 0,9$ & $0,028 \pm 0,001$ & $1,77 \pm 0,13$ & 0,9995 & 67,7 \\
\hline HPMC F 50 1,5\% & $132,2 \pm 0,7$ & $0,031 \pm 0,002$ & $1,66 \pm 0,13$ & 0,9994 & 59,5 \\
\hline media \pm DE & & & & & \\
\hline
\end{tabular}

media $\pm \mathrm{DE}$.

En todas las concentraciones ensayadas las masas con MCC presentaron un menor incremento del volumen que el control. Este comportamiento nos daría un indicio de lo que sucederá en la panificación por lo que esperaríamos obtener panes con menor volumen que el control. Por otro lado, todas las masas obtenidas con CMC superaron 
el máximo volumen alcanzado por el control. Habiéndose obtenido con CMC al 1,5\% el máximo incremento del volumen entre todas las masas estudiadas. Con HPMC F 50 se obtuvieron también mayores valores de $\Delta \mathrm{V}_{\max }$ respecto al control, salvo en la mayor concentración. El comportamiento de HPMC F 4M resultó menos claro probablemente por el error experimental, sin embargo en la mayor dosis se encontró un leve incremento del volumen respecto a la masa control. Rosell y col. (2001) encontraron que la estabilidad de las masas durante la fermentación era mejorada por el empleo de HPMC, además, se lograba una mejor retención de gas durante la misma, lo que explicaría los mayores volúmenes alcanzados.

De lo expuesto surge que CMC en todos los niveles ensayados fue el hidrocoloide que más favoreció al comportamiento de la masa durante la fermentación ya que permitió incrementar los máximos volúmenes alcanzados en la misma.

A partir de las mediciones realizadas durante la primera hora de fermentación se calcularon las velocidades iniciales con la finalidad de evaluar si las celulosas la modificaban. Los valores de las velocidades iniciales para el incremento de volumen no mostró grandes variaciones respecto al control, habiéndose encontrado en todos los casos entre 1,5 y $1,9 \mathrm{~cm}^{3} / \mathrm{min}$.

\subsubsection{Evaluación de la calidad de los panes}

\subsubsection{Volumen específico}

En la Figura 5.14 se muestran los resultados obtenidos para el volumen específico de pan. La utilización de CMC y ambas HPMC permitió incrementar significativamente el volumen específico respecto al control. Por otro lado, no se encontraron diferencias significativas respecto al control en los panes que contenían MCC, 0,5 y 1,5\% o HPMC F 50 1,5\%. Con CMC y HPMC F 4M se observó una tendencia al incremento del volumen con el incremento de la concentración pero no se hallaron diferencias significativas entre los niveles 0,5 y 1,5\%. Rosell y col. (2001) al estudiar el efecto de HPMC $0,5 \%$ sobre las características reológicas y calidad del pan obtenido obtuvieron también un incremento del volumen específico respecto al control, lo que relacionaron con una mayor retención de gas durante la fermentación. Resultados similares fueron encontrados por Guarda y col. (2004) y por Bárcenas y Rosell (2005) con el empleo de HPMC. Por otro lado, Dodić y col. (2007) no encontraron diferencias significativas en el volumen específico de pan al emplear CMC en concentraciones 0,2-1,0\% 


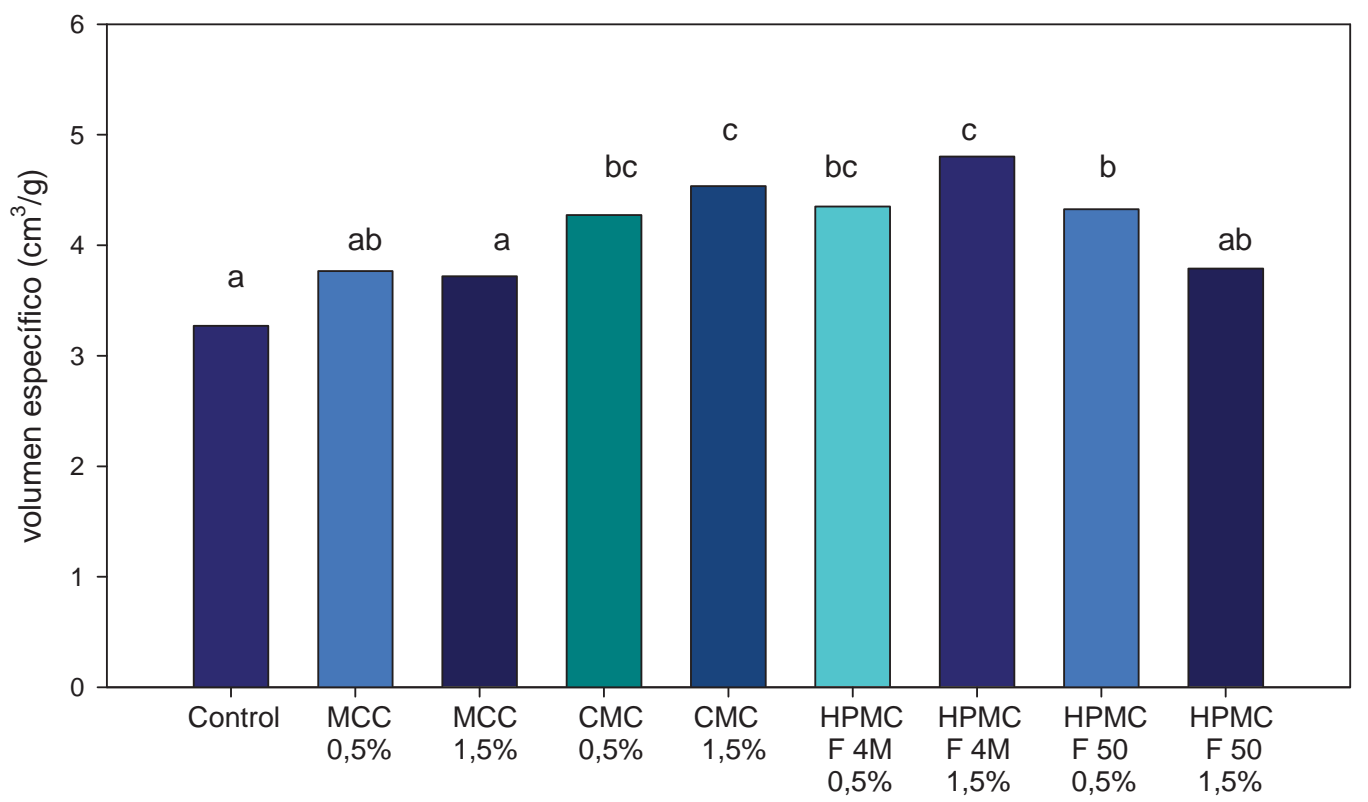

Figura 5.14. Volumen específico de pan. Letras diferentes indican diferencias significativas. $(p<0,05)$.

\subsubsection{Color de corteza}

Al evaluar el color de la corteza de los panes no se encontraron grandes diferencias en el mismo debido al agregado de las celulosas modificadas (Tabla 5.7).

Se observó escasa variación en los parámetros determinados $L$, $\boldsymbol{a}$ y $\boldsymbol{b}$ al agregar las celulosas modificadas. Con HPMC F 50 1,5\% se obtuvo el mayor valor de $\boldsymbol{L}$ y el menor valor de a respecto al control. Con la utilización de CMC 1,5\% se obtienen panes con una corteza más tostada, más rojiza y amarillenta que el control.

Los panes con MCC y HPMC F 50 en el mayor nivel mostraron una disminución significativa del $\mathrm{BI}$ respecto al control mientras que al emplear CMC 1,5\% se observó un aumento significativo del mismo. 
Tabla 5.7. Color de la corteza. Parámetros de color $L, \boldsymbol{a}, \boldsymbol{b}$ y BI.

\begin{tabular}{ccccc}
\hline Muestra & $\boldsymbol{L}$ & $\boldsymbol{a}$ & $\boldsymbol{b}$ & $\mathrm{BI}$ \\
\hline Control & $59,3 \pm 3,3^{\mathrm{abc}}$ & $11,1 \pm 1,6^{\mathrm{bcd}}$ & $35,9 \pm 1,1^{\mathrm{de}}$ & $103,0 \pm 12,0^{\mathrm{c}}$ \\
\hline MCC 0.5\% & $60,2 \pm 3,1^{\mathrm{bc}}$ & $11,2 \pm 1,4^{\mathrm{bcd}}$ & $34,6 \pm 1,2^{\mathrm{bc}}$ & $96,1 \pm 10,6^{\mathrm{bc}}$ \\
\hline MCC 1.5\% & $61,5 \pm 3,8^{\mathrm{cd}}$ & $10,7 \pm 1,7^{\mathrm{b}}$ & $34,7 \pm 1,3^{\mathrm{bc}}$ & $93,1 \pm 11,4^{\mathrm{b}}$ \\
\hline CMC 0.5\% & $61,3 \pm 2,9^{\mathrm{cd}}$ & $10,8 \pm 1,2^{\mathrm{bc}}$ & $36,2 \pm 1,3^{\mathrm{de}}$ & $96,1 \pm 10,6^{\mathrm{bc}}$ \\
\hline CMC 1.5\% & $57,1 \pm 3,0^{\mathrm{a}}$ & $12,9 \pm 1,5^{\mathrm{e}}$ & $36,8 \pm 1,4^{\mathrm{e}}$ & $114,1 \pm 9,1^{\mathrm{d}}$ \\
\hline HPMC F 4M 0.5\% & $60,8 \pm 2,6^{\mathrm{cd}}$ & $10,9 \pm 1,2^{\mathrm{bcd}}$ & $35,3 \pm 1,1^{\mathrm{cd}}$ & $96,6 \pm 8,2^{\mathrm{bc}}$ \\
\hline HPMC F 4M 1.5\% & $58,1 \pm 3,6^{\mathrm{ab}}$ & $12,0 \pm 1,3^{\mathrm{de}}$ & $34,3 \pm 1,3^{\mathrm{b}}$ & $100,8 \pm 9,7^{\mathrm{c}}$ \\
\hline HPMC F 50 0.5\% & $58,1 \pm 3,6^{\mathrm{ab}}$ & $11,7 \pm 1,2^{\mathrm{cd}}$ & $34,2 \pm 1,8^{\mathrm{b}}$ & $100,1 \pm 8,6^{\mathrm{c}}$ \\
\hline HPMC F 50 1.5\% & $63,1 \pm 3,7^{\mathrm{d}}$ & $9,8 \pm 1,6^{\mathrm{a}}$ & $32,8 \pm 1,4^{\mathrm{a}}$ & $83,2 \pm 11,2^{\mathrm{a}}$
\end{tabular}

media \pm DE. Dentro de cada columna, letras diferentes indican diferencias significativas $(p<0,05)$.

\subsubsection{Alveolado de la miga}

En la Tabla 5.8 se muestran los parámetros estructurales de la miga del pan control y de los panes con celulosas modificadas.

Tabla 5.8. Parámetros estructurales de la miga

\begin{tabular}{ccccc}
\hline Muestra & $\begin{array}{c}\text { Área alveolar } \\
\text { media }\left(\mathrm{cm}^{2}\right)\end{array}$ & $\%$ Aire & $\begin{array}{c}\text { Perímetro } \\
(\mathrm{cm})\end{array}$ & $\begin{array}{c}\text { Circularidad } \\
(\text { adim })\end{array}$ \\
\hline Control & $0,013 \pm 0,003^{\mathrm{ab}}$ & $43,4 \pm 3,2^{\mathrm{ab}}$ & $0,67 \pm 0,06^{\mathrm{b}}$ & $0,40 \pm 0,04^{\mathrm{a}}$ \\
\hline MCC 0,5\% & $0,014 \pm 0,003^{\mathrm{ab}}$ & $40,9 \pm 1,1^{\mathrm{a}}$ & $0,67 \pm 0,06^{\mathrm{b}}$ & $0,42 \pm 0,01^{\mathrm{a}}$ \\
\hline MCC 1,5\% & $0,012 \pm 0,001^{\mathrm{ab}}$ & $42,6 \pm 3,3^{\mathrm{ab}}$ & $0,64 \pm 0,03^{\mathrm{ab}}$ & $0,41 \pm 0,05^{\mathrm{a}}$ \\
\hline CMC0,5\% & $0,011 \pm 0,001^{\mathrm{a}}$ & $42,8 \pm 2,5^{\mathrm{ab}}$ & $0,57 \pm 0,05^{\mathrm{a}}$ & $0,45 \pm 0,03^{\mathrm{a}}$ \\
\hline CMC 1,5\% & $0,014 \pm 0,001^{\mathrm{ab}}$ & $45,8 \pm 2,7^{\mathrm{b}}$ & $0,68 \pm 0,04^{\mathrm{b}}$ & $0,42 \pm 0,02^{\mathrm{a}}$ \\
\hline HPMC F 4M 0,5\% & $0,013 \pm 0,001^{\mathrm{ab}}$ & $42,1 \pm 2,1^{\mathrm{ab}}$ & $0,67 \pm 0,05^{\mathrm{b}}$ & $0,41 \pm 0,03^{\mathrm{a}}$ \\
\hline HPMC F 4M 1,5\% & $0,014 \pm 0,002^{\mathrm{b}}$ & $43,1 \pm 1,1^{\mathrm{ab}}$ & $0,67 \pm 0,07^{\mathrm{b}}$ & $0,43 \pm 0,02^{\mathrm{a}}$ \\
\hline HPMC F 50 0,5\% & $0,015 \pm 0,002^{\mathrm{b}}$ & $42,7 \pm 1,5^{\mathrm{ab}}$ & $0,67 \pm 0,03^{\mathrm{b}}$ & $0,43 \pm 0,02^{\mathrm{a}}$ \\
\hline HPMC F 50 1,5\% & $0,012 \pm 0,002^{\mathrm{ab}}$ & $41,2 \pm 2,3^{\mathrm{a}}$ & $0,64 \pm 0,05^{\mathrm{ab}}$ & $0,43 \pm 0,02^{\mathrm{a}}$ \\
\hline media \pm DE. Dentro de cada columna, letras diferentes indican diferencias \\
significativas (p<0,05).
\end{tabular}


Al igual que en el caso de las pectinas y probablemente por los motivos detallados en el capítulo anterior, no se encontraron diferencias significativas en las características alveolares de la miga entre las diferentes muestras.

Bárcenas y Rosell (2005) habiendo hallado diferencias significativas en el volumen específico de pan tampoco hallaron diferencias significativas en las características estructurales de la miga.

\subsubsection{Humedad de panes frescos y almacenados}

En la Tabla 5.9 se muestran los resultados hallados para la humedad de la miga de los panes frescos y almacenados durante 1 y 3 días a $20^{\circ} \mathrm{C}$. La pérdida de humedad fue calculada como la diferencia entre la humedad de los días 3 y 0 respecto a la humedad para el día 0 . A pesar de que, en general, en los días 0 y 1 no se encontraron diferencias significativas en la humedad de los panes con adición de celulosas respecto al control, puede observarse que la pérdida global fue menor para los panes con celulosas modificadas que para el control, lo cual indicaría que el agregado de las gomas aumenta la retención de agua. Esto sería un aporte favorable por parte de las gomas dado que la menor pérdida de agua, ayudaría a obtener una mayor constancia en la textura a lo largo del tiempo de almacenamiento.

Tabla 5.9. Humedad de la miga del pan fresco y luego de 1 y 3 días de almacenamiento

\begin{tabular}{|c|c|c|}
\hline & día 3 & \% pérdida \\
\hline Control & $44,3 \pm 0,5^{\mathrm{bcd}} 42,4 \pm 0,5^{\mathrm{a}} 37,8 \pm 0,6^{\mathrm{a}}$ & 14,6 \\
\hline MCC $0,5 \%$ & $43,0 \pm 0,2^{\mathrm{a}} \quad 42,7 \pm 1,1^{\mathrm{ab}} 38,3 \pm 1,0^{\mathrm{ab}}$ & 10,9 \\
\hline MCC $1,5 \%$ & $43,6 \pm 0,3^{a b} \quad 42,6 \pm 0,5^{a} \quad 40,7 \pm 0,5^{c d}$ & 6,8 \\
\hline CMC $0,5 \%$ & $44,6 \pm 0,1^{d} 43,2 \pm 0,5^{a b c} 40,6 \pm 0,5^{c d}$ & 9,0 \\
\hline CMC $1,5 \%$ & $44,3 \pm 0,3^{c d} 43,7 \pm 0,8^{a b c} 42,1 \pm 0,5^{d}$ & 5,0 \\
\hline HPMC F 4M 0,5\% & $44,7 \pm 0,5^{d} \quad 44,5 \pm 0,1^{b c} 40,2 \pm 0,8^{c d}$ & 10,0 \\
\hline HPMC F 4M 1,5\% & $44,6 \pm 0,3^{d} \quad 44,5 \pm 0,3^{c} 39,9 \pm 1,0^{b c}$ & 10,6 \\
\hline HPMC F 50 0,5\% & $43,6 \pm 0,5^{\mathrm{abc}} 43,5 \pm 0,9^{\mathrm{abc}} 40,9 \pm 0,2^{\mathrm{cd}}$ & 6,1 \\
\hline HPMC F 50 1,5\% & $44,3 \pm 0,8^{d} \quad 44,0 \pm 1,2^{c} \quad 40,9 \pm 1,0^{c d}$ & 7,7 \\
\hline
\end{tabular}




\subsubsection{Análisis de perfil de textura de panes frescos y almacenados}

En general, con el agregado de celulosas modificadas se obtuvieron migas con menores valores de dureza que el control, correspondiendo la miga más blanda a los panes con CMC 1,5\% (Figura 5.15). El efecto de la concentración dependió del tipo de celulosa modificada utilizada. Un aumento del nivel de CMC ó HPMC F 4M condujo a una disminución de la dureza de la miga mientras que con un aumento en el nivel de MCC o HPMC F 50 se obtuvieron migas de mayor dureza.

Con el almacenamiento la dureza de miga se vio incrementada en todos los casos lo cual está indicando que los hidrocoloides no llegan a inhibir los fenómenos asociados al envejecimiento del pan. Sin embargo, con la excepción de MCC, todas las gomas llevaron a una menor dureza de miga respecto al control. Se destacan los resultados obtenidos con los panes con CMC 1,5\% ya que al tercer día de almacenamiento presentaron valores de dureza de miga similares a los del control el día de elaboración.

El coeficiente de determinación $\left(r^{2}\right)$ entre volumen específico y dureza de la miga fue de 0,7. Sin embargo, muestras con volúmenes específicos estadísticamente equivalentes como CMC, en ambos niveles, HPMC F 4M, en ambos niveles, y HPMC F 50 0,5\% mostraron diferencias significativas en la dureza de la miga, presentando los panes con CMC y HPMC F 4M 1,5\% los menores valores de dureza. Dado que en este caso el valor de $\rho$ es el mismo, las diferencias observadas en la dureza podrían atribuirse a diferencias en la densidad y/o en el módulo de Young de las paredes alveolares, como ya se discutió para el caso de las pectinas.

En la Tabla 5.10 se muestra el incremento porcentual en la dureza de la miga para los días 1 y 3 con respecto al día 0 . Al día 1 el menor incremento en la dureza se obtiene para el control, en los panes con agregado de gomas se duplica o triplica este valor. Al tercer día de almacenamiento, el pan control y el pan con agregado de HPMC al 1,5\% son los que presentaron menor incremento de la dureza mientras que en los otros casos se observa la misma tendencia que el día 1. Esto estaría indicando que aunque con los hidrocoloides se obtienen migas más blandas, la velocidad de endurecimiento es mayor.

Con la excepción de HPMC F 50 1,5\%, el agregado de todos los hidrocoloides permite obtener migas más cohesivas que para el control (Figura 5.15), esta característica es favorable dado que estaría indicando que se obtiene una miga menos desgranable. Con el almacenamiento la cohesividad disminuye, lo cual se ve reflejado en la mayor 

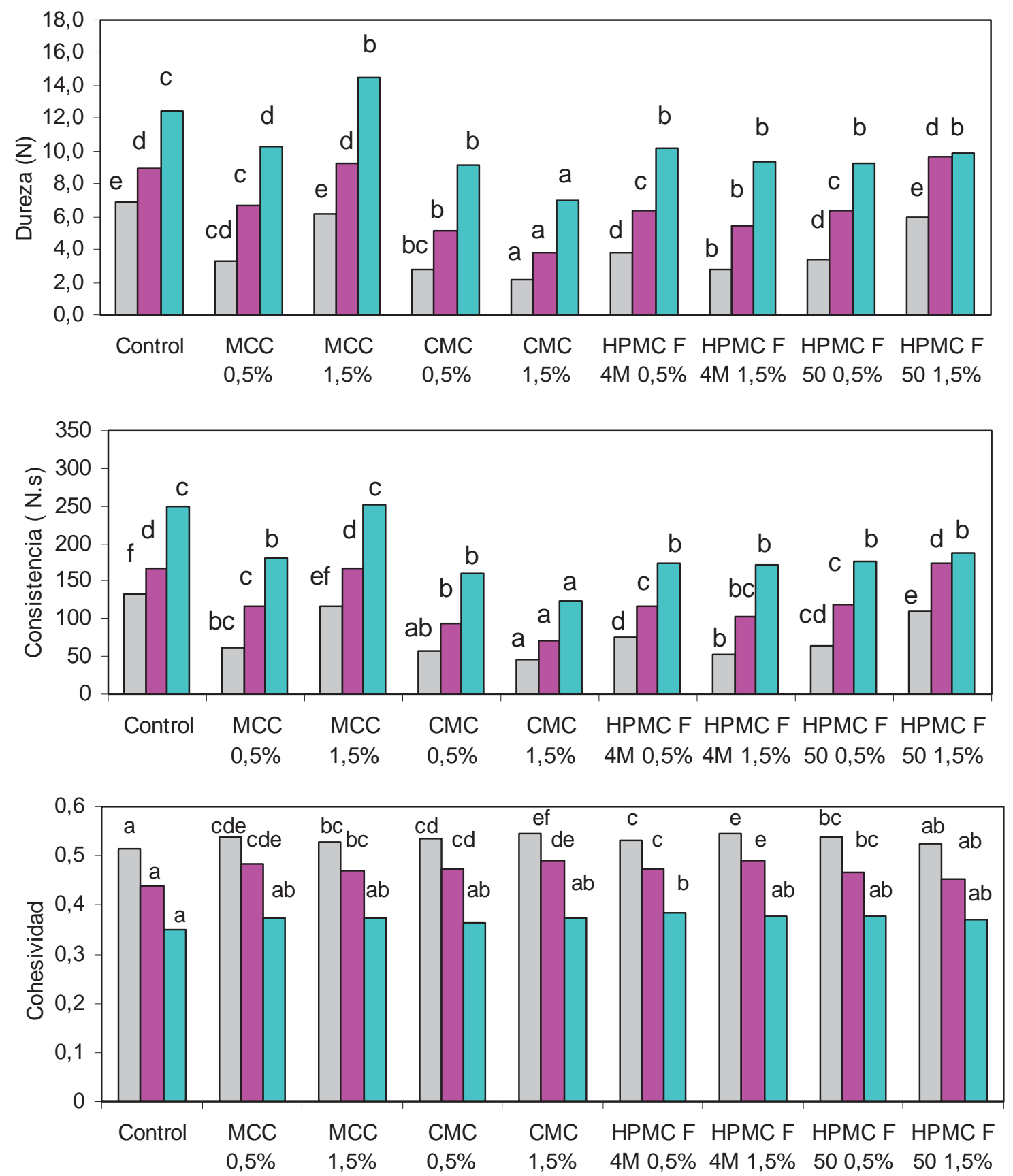

$\square$ día 0 día 1 día 3

Figura 5.15. Evolución de la dureza, consistencia y cohesividad de la miga con el almacenamiento. Letras diferentes indican diferencias significativas entre las muestras para igual tiempo de almacenamiento $(p<0,05)$. 

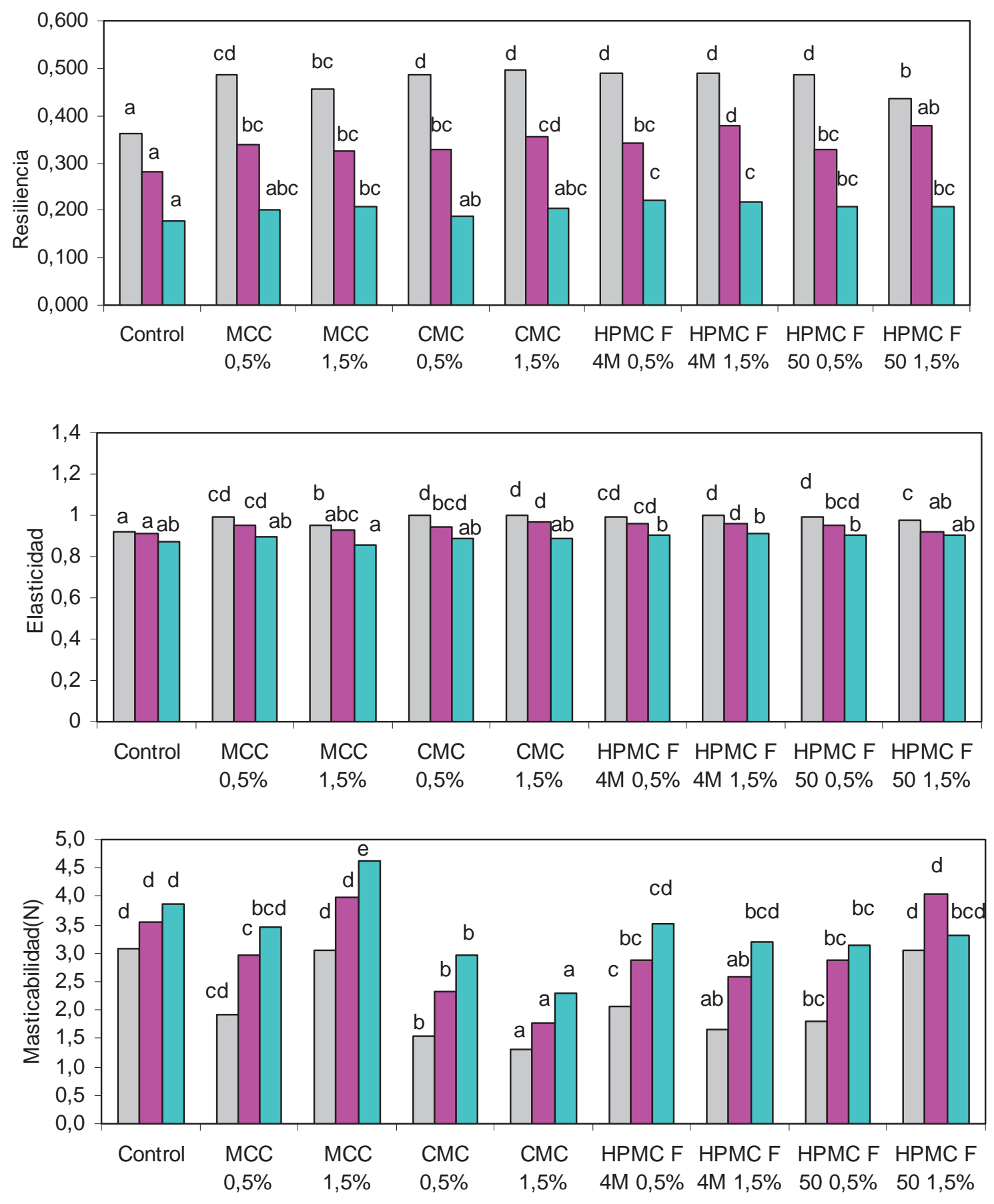

$\square$ día 0 ๑ día 1 ๑ día 3

Figura 5.16. Evolución de la resiliencia, elasticidad y masticabilidad de la miga con el almacenamiento. Letras diferentes indican diferencias significativas entre las muestras para igual tiempo de almacenamiento $(p<0,05)$. 
facilidad de la misma para desgranarse. En el día 1 de almacenamiento los panes con agregado de celulosas modificadas presentaron mayor cohesividad que el control mientras que al día 3 salvo para HPMC F 4M 1,5\% no se observaron diferencias significativas respecto al mismo. En la Tabla 5.10 puede observarse que la disminución de la cohesividad en el control y las muestras con celulosas fue similar variando entre 9,6 y $13,9 \%$ en el día 1 , respecto al pan fresco, y entre 27,9 y $32,1 \%$ para el día 3.

Tabla 5.10. Variación porcentual de la dureza, consistencia y cohesividad con el almacenamiento

\begin{tabular}{ccccccc}
\hline \multirow{2}{*}{ Muestra } & \multicolumn{2}{c}{$\begin{array}{c}\text { Incremento de la } \\
\text { dureza }(\%)^{*}\end{array}$} & \multicolumn{2}{c}{$\begin{array}{c}\text { Incremento de la } \\
\text { consistencia }(\%)^{*}\end{array}$} & \multicolumn{2}{c}{$\begin{array}{l}\text { Disminución de la } \\
\text { cohesividad (\%) }\end{array}$} \\
\cline { 2 - 7 } & día 1 & día 3 & día 1 & día 3 & día 1 & día 3 \\
\hline Control & 29,9 & 81,5 & 26,9 & 90,2 & $-11,2$ & $-29,0$ \\
\hline MCC 0,5\% & 96,7 & 210,2 & 89,5 & 193,4 & $-10,6$ & $-30,8$ \\
\hline MCC 1,5\% & 50,6 & 135,4 & 42,7 & 116,0 & $-10,7$ & $-28,5$ \\
\hline CMC 0,5\% & 88,0 & 223,9 & 69,9 & 186,3 & $-11,8$ & $-32,1$ \\
\hline CMC 1,5\% & 75,5 & 221,9 & 57,8 & 173,3 & $-9,6$ & $-31,4$ \\
\hline HPMC F 4M 0,5\% & 68,4 & 166,2 & 57,1 & 132,5 & $-11,1$ & $-27,9$ \\
\hline HPMC F 4 M 1,5\% & 99,5 & 241,2 & 96,4 & 224,6 & $-10,4$ & $-31,2$ \\
\hline HPMC F 50 0,5\% & 90,3 & 175,6 & 86,3 & 176,8 & $-12,7$ & $-29,7$ \\
\hline HPMC F 50 1,5\% & 62,1 & 65,5 & 57,9 & 69,4 & $-13,9$ & $-29,3$ \\
\hline
\end{tabular}

* valores obtenidos a partir de la diferencia de las medias de cada atributo

El pan fresco con aditivos presenta mayor resiliencia que el pan control, lo cual significa que ante una deformación externa se recupera mejor. Con el tiempo la resiliencia disminuye en todos los casos, pero el pan control es el más afectado presentando tanto el día 1 como el día 3 el valor más bajo. Ambas HPMC mostraron un efecto positivo al permitir obtener migas más resilientes al tercer día de almacenamiento. Al comparar la disminución porcentual de la resiliencia con respecto al día 0 (Tabla 5.11), el control es la muestra que presenta menor disminución. Al día 1, el pan con HPMC F 4M 1,5\% presentó un comportamiento muy parecido al del control. En el día 3, la disminución de la resiliencia duplica a los valores del día 1. No obstante, se obtuvieron con ambas HPMCs los mayores valores de resiliencia al final del almacenamiento. 
Tabla 5.11. Variación porcentual de la resiliencia, elasticidad y masticabilidad con el almacenamiento

\begin{tabular}{ccccccc}
\hline \multirow{2}{*}{ Muestra } & \multicolumn{2}{c}{$\begin{array}{c}\text { Disminución de la } \\
\text { resiliencia }(\%)^{*}\end{array}$} & \multicolumn{2}{c}{$\begin{array}{c}\text { Disminución de la } \\
\text { elasticidad }(\%)^{*}\end{array}$} & \multicolumn{2}{c}{$\begin{array}{c}\text { Incremento de la } \\
\text { masticabilidad (\%) }\end{array}$} \\
\cline { 2 - 7 } & día 1 & día 3 & día 1 & día 3 & día 1 & día 3 \\
\hline Control & $-24,1$ & $-50,5$ & $-1,2$ & $-4,0$ & 14,7 & 24,7 \\
\hline MCC 0,5\% & $-30,0$ & $-58,6$ & $-11,5$ & $-16,9$ & 54,8 & 79,7 \\
\hline MCC 1,5\% & $-30,6$ & $-54,7$ & $-2,1$ & $-10,0$ & 30,3 & 51,7 \\
\hline CMC 0,5\% & $-32,7$ & $-61,7$ & $-7,1$ & $-12,9$ & 54,6 & 96,5 \\
\hline CMC 1,5\% & $-28,1$ & $-57,7$ & $-12,5$ & $-19,6$ & 36,7 & 76,1 \\
\hline HPMC F 4M 0,5\% & $-30,5$ & $-54,9$ & $-6,3$ & $-11,6$ & 39,4 & 69,5 \\
\hline HPMC F 4 M 1,5\% & $-21,5$ & $-55,0$ & $-12,6$ & $-17,4$ & 56,3 & 94,0 \\
\hline HPMC F 50 0,5\% & $-32,1$ & $-57,2$ & $-4,5$ & $-11,1$ & 59,0 & 73,0 \\
\hline HPMC F 50 1,5\% & $-27,1$ & $-52,2$ & $-5,5$ & $-7,3$ & 32,8 & 8,7 \\
\hline Valores 0bidos a pariryyyyyyyyyyyyyy
\end{tabular}

${ }^{*}$ valores obtenidos a partir de la diferencia de las medias de cada atributo

Todas las gomas permitieron aumentar la elasticidad de la miga del pan fresco (Figura 5.16), dado que la elasticidad es un atributo positivo y buscado en miga de pan, esta modificación respecto al control introducida por la presencia de las celulosas es favorable. En el pan almacenado durante 1 día la miga presentó una elasticidad similar a la del control cuando se agregó MCC 1,5\% y HPMC F 50 1,5\%, en los otros casos la miga presentó mejores características que el control. Luego de 3 días todas las muestras presentaron elasticidad igual a la del control. A pesar de esto, la disminución porcentual de la elasticidad (Tabla 5.11) fue mayor que para el control en todos los casos. La mayor pérdida de elasticidad se encontró con MCC 0,5\%, CMC 1,5\% y HPMC F 4M 1,5\%.

En el pan fresco los menores valores de masticabilidad (dureza $\mathrm{x}$ cohesividad $\mathrm{x}$ elasticidad) correspondieron a CMC y HPMC F 4M. Además, con estas gomas un incremento en su concentración ocasionó una disminución de la masticabilidad. Mientras que con MCC y HPMC F 50 el incremento en la concentración de goma llevó a mayores valores de masticabilidad. Durante el almacenamiento se observó un incremento de la masticabilidad de la miga en todos los casos. Sin embargo, con la utilización de alguna de las celulosas se obtuvieron menores valores que para el control, en particular los panes con CMC presentaron menores valores de 
masticabilidad durante los 3 días de almacenamiento. Al comparar el incremento porcentual respecto al día 0 (Tabla 5.11), las migas de los panes control y con HPMC F 50 1,5\% son las que presentan los menores incrementos.

Si bien las celulosas permitieron obtener mejores atributos texturales que el pan control, el almacenamiento condujo a un aumento de la dureza y pérdida de elasticidad, resiliencia y cohesividad, que son cambios desfavorables. Como la mejora en la textura es grande muchas veces se llega después del almacenamiento a resultados similares al control o superiores.

El hidrocoloide favorece la retención de humedad, esto que es un hecho favorable puede sin embargo estar incidiendo en la promoción de la retrogradación por tratarse de un proceso difusional.

\subsection{Evaluación Sensorial}

Para la realización del ensayo de discriminación triangular se decidió comparar el pan control con el pan con CMC 1,5\%, esta elección se fundamentó en el comportamiento mostrado por los panes con CMC en las pruebas de calidad panadera. El diseño de la prueba se realizó de igual modo que para las pectinas, se evaluaron 30 personas que efectuaron el ensayo por duplicado. Al comparar el control con el pan obtenido con CMC 1,5\% 25 de las 60 respuestas fueron correctas, es decir, lograron identificar la muestra diferente del trío. Dado que son necesarias 30 respuestas correctas para rechazar la hipótesis nula con un $1 \%$ de confianza (Roessler y col.,1948) se concluyó que no habían diferencias significativas entre los panes control y con agregado de CMC $1,5 \%$ ya que para la mayoría de los evaluadores no fue posible distinguir la muestra del trío. Además, se calculó el nivel de significancia exacto del ensayo el cual fue 11,00 . Por lo tanto, si se dijera que las muestras son diferentes, la probabilidad de cometer un error sería del $11 \%$.

En este caso, se realizó además un ensayo de aceptabilidad sensorial a través del método de la escala hedónica. Se evaluaron la apariencia, el sabor, la textura y la aceptabilidad global del pan. En la Figura 5.17 se muestran los resultados obtenidos. 


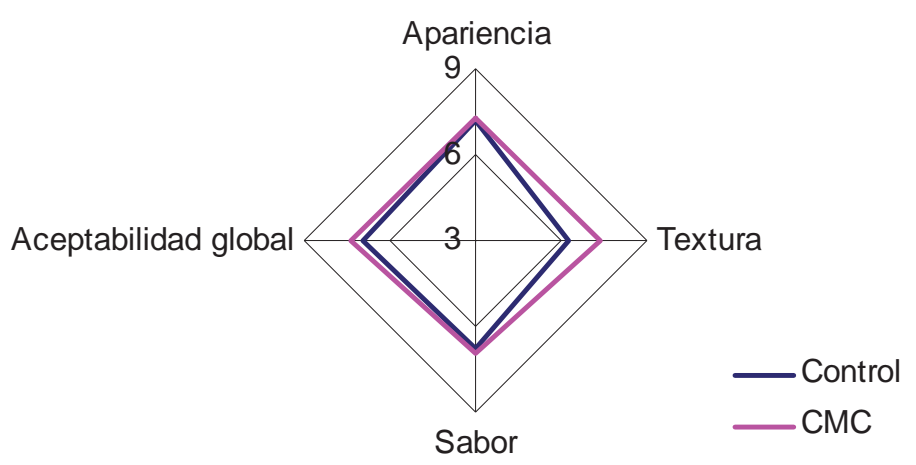

Figura 5.17. Puntaje promedio obtenido por cada atributo en el ensayo de aceptabilidad sensorial

Tanto el pan control como el pan con agregado de CMC presentaron buena puntuación en los atributos evaluados. No habiéndose hallado diferencias significativas en la apariencia, sabor y aceptabilidad global. Sin embargo, en la textura la muestra con $\mathrm{CMC}$ recibió un puntaje significativamente mayor que el control.

\subsection{Conclusiones parciales}

Las celulosas modificadas pueden cambiar las características de la masa dependiendo de su estructura química, concentración y presencia o no de $\mathrm{NaCl}$.

Con una molécula cargada como $\mathrm{CMC}$ en ausencia de $\mathrm{NaCl}$ se obtuvo una red de gluten menos estable lo que se evidenció por los parámetros farinográficos. Este efecto no se observó al agregar $\mathrm{NaCl}$, que puede apantallar las cargas de la molécula inhibiendo las interacciones electrostáticas que pudiera establecer con las proteínas del gluten. En particular el efecto de la $\mathrm{CMC}$ en ausencia de $\mathrm{NaCl}$ sobre las proteínas del gluten se reflejó en la determinación de gluten húmedo y de gluten seco, obteniéndose valores muy inferiores al del control. Por otro lado, las celulosas más hidrofóbicas como ambas HPMCs dan lugar a una red menos estable en presencia de $\mathrm{NaCl}$, ya que el $\mathrm{NaCl}$ promueve las interacciones hidrofóbicas.

El agregado de goma disminuyó los atributos texturales como dureza, consistencia y adhesividad con respecto al control tanto en las masas sin como con $\mathrm{NaCl}$. En general, las masas con $\mathrm{NaCl}$ mostraron mayor cohesividad y menor resiliencia que el control. En la mayor parte de las masas con $\mathrm{NaCl}$ y adición de hidrocoloide se obtuvieron menores tiempos de relajación que para el control, indicando un 
comportamiento más viscoso. En cambio, en las masas sin $\mathrm{NaCl}$ los tiempos de relajación no fueron significativamente diferentes al control, excepto para las muestras con CMC en donde los valores superiores obtenidos corresponden a una masa menos viscosa. En los ensayos en reómetro oscilatorio, se observó un aumento de la respuesta viscosa del sistema en relación a la respuesta elástica de las masas debido al agregado de las celulosas modificadas -tanto en sistemas sin como con $\mathrm{NaCl}$ - y un aumento de los módulos cuando en las masas se agregó $\mathrm{NaCl}$, lo cual está de acuerdo con la mayor consistencia observada en los ensayos de textura.

Respecto a la panificación, algunas gomas como CMC y HPMC F 4M mostraron un marcado efecto mejorador sobre las características de volumen y textura de miga de los panes (mayor volumen específico, migas más blandas y cohesivas y con mayor capacidad de recuperación instantánea o resiliencia). Otras en cambio, como MCC y HPMC F 50 no mejoraron las características de los panes comparando con el control. Respecto al efecto durante el almacenamiento, los panes con HPMC F 50 mostraron el menor incremento de dureza al 3er día, siendo mejor este resultado que con las otras gomas.

Estos resultados indican que la reología de la masa puede verse modificada por el agregado de celulosas modificadas de diferente estructura química y además por la presencia o no de $\mathrm{NaCl}$ en la masa. La presencia de $\mathrm{NaCl}$ apantalla las cargas como se vio en el caso de pectinas impidiendo la interacción electrostática negativa con las proteínas en el caso de CMC así, la CMC debilita las masas en ausencia de $\mathrm{NaCl}$ pero tiene efecto mejorador en combinación con $\mathrm{NaCl}$. Las más hidrofóbicas de las celulosas utilizadas, HPMCs ven favorecida su acción en presencia de $\mathrm{NaCl}$. 


\section{Capítulo VI}

Resiultados y Discusión

\section{Microestructura e \\ interacción entre \\ los componentes}




\subsection{Microscopía de la masa}

Se caracterizó la estructura de las masas sin y con $\mathrm{NaCl}$ a través de distintas técnicas microscópicas, electrónica de barrido (SEM) y láser confocal de barrido (CSLM) .

\subsubsection{Microscopía electrónica de barrido (SEM)}

Se realizaron micrografías de las masas con tres niveles de magnificación: 500X, $3000 \mathrm{X}$ y $5000 \mathrm{X}$, que permiten visualizar con distinto grado de detalle la estructura de la matriz de gluten. Como ejemplo, en la Figura 6.1, se muestran las micrografías de la masa control con $\mathrm{NaCl}$ y la masa con $\mathrm{CMC}$ y con $\mathrm{NaCl}$ con los 3 aumentos utilizados. En particular, la micrografía de menor aumento, permite apreciar la integridad de la red de gluten.
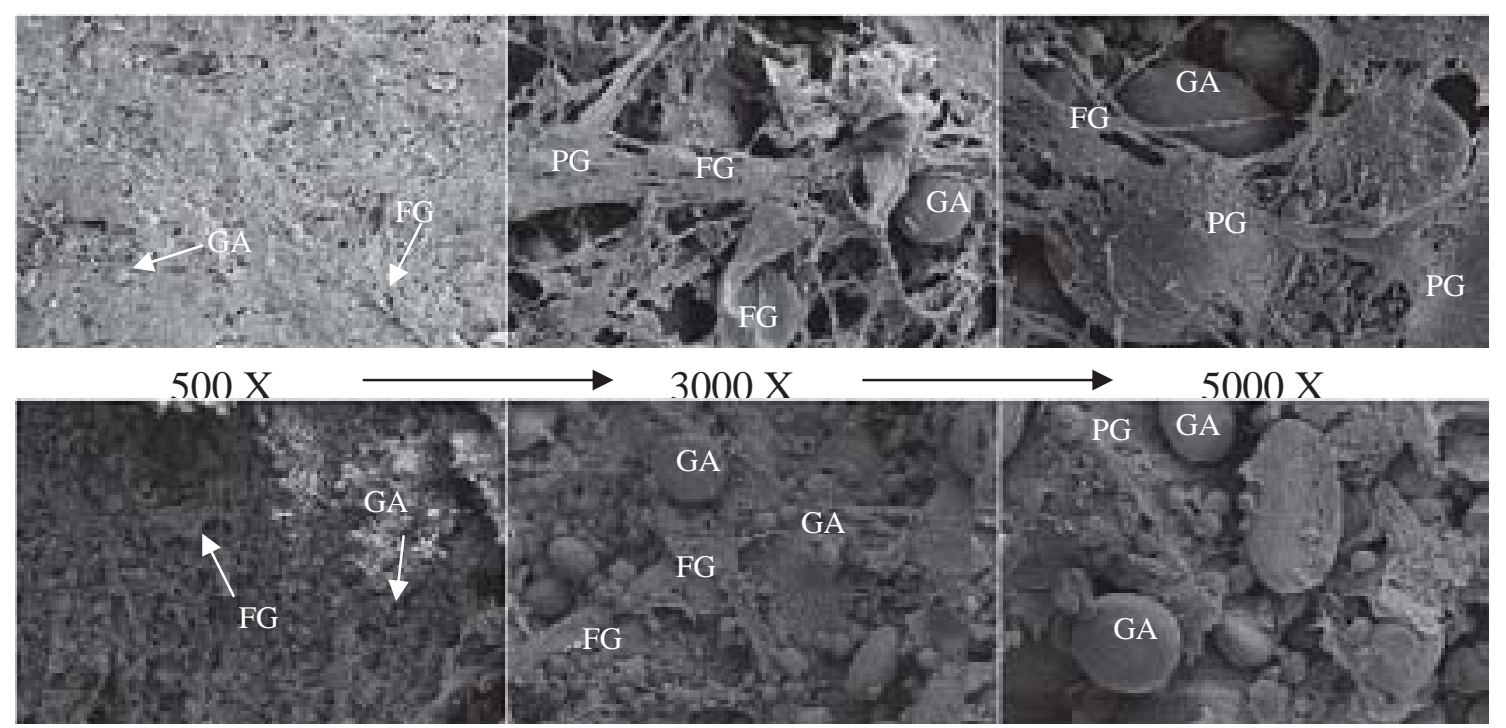

Figura 6.1: Micrografías de la masa control con $\mathrm{NaCl}$ (arriba) y la masa con CMC con $\mathrm{NaCl}$ (abajo). PG: película de gluten, FG: filamento de gluten, GA: gránulo de almidón.

En la Figura 6.2 se muestran micrografías electrónicas representativas de la masa control y de las masas con ambas pectinas al $2 \%$ en ausencia y presencia de $\mathrm{NaCl}$. 

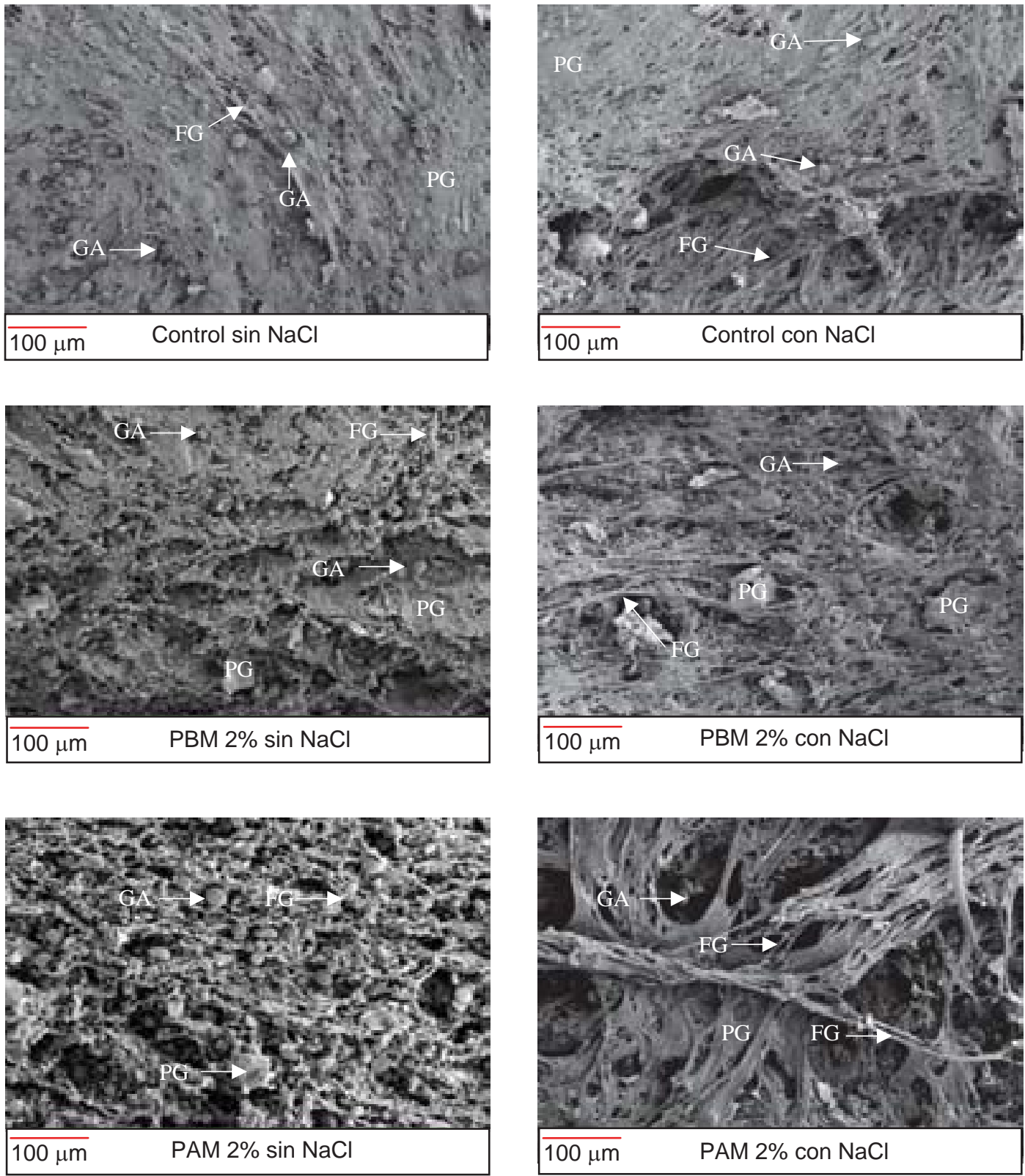

Figura 6.2. Micrografías electrónicas de la masa control y de las masas con pectinas al $2 \%$ en ausencia de $\mathrm{NaCl}$ (izquierda) y presencia de $\mathrm{NaCl}$ (derecha). PG: película de gluten, FG: filamento de gluten, GA: gránulo de almidón. Magnificación: 500X. La barra roja corresponde a $100 \mu \mathrm{m}$.

En ambos controles se observaron películas de gluten y zonas con filamentos aunque con diferentes características. En ambas masas se visualizaron gránulos de almidón 
cubiertos y sin cubrir por la red. En el control sin $\mathrm{NaCl}$ se observan filamentos más gruesos solapados con películas de gluten mientras que en el control con $\mathrm{NaCl}$ se observó una estructura más filamentosa y entrecruzada. En los ensayos farinográficos, este tipo de estructura más entrecruzada de la masa control con $\mathrm{NaCl}$ demostró tolerar mejor el sobreamasado presentando mayor estabilidad y un menor aflojamiento. En los ensayos reométricos este tipo de estructura condujo a un comportamiento menos fluido (menor $\tan (\delta)$ ).

Al adicionar pectinas en las masas sin $\mathrm{NaCl}$, se observó una menor proporción de las zonas de películas de gluten y un aspecto más filamentoso respecto a la masa control. Estos cambios fueron menos marcados en la masa con PBM, mientras que las características de la masa con PAM fueron muy diferentes a las del control, observándose una estructura mucho más disgregada. Esta masa evidenció una menor estabilidad farinográfica respecto al control.

En presencia de $\mathrm{NaCl}$, las masas con pectinas mostraron una estructura más filamentosa que el control, lo que fue particularmente evidente al emplear PAM. En este caso, se observó una red de filamentos gruesos y abierta. Las masas con PAM presentaron una disminución de la estabilidad farinográfica y de la dureza, así como también con un carácter más viscoso en los ensayos oscilatorios dinámicos, lo que podría relacionarse con éstas características microscópicas de la matriz. En general, el empleo de ambas pectinas aumentó la proporción de filamentos de gluten respecto a los presentes en los controles; la utilización de PAM ocasionó los mayores cambios en la constitución de la red.

En las Figuras 6.3 y 6.4 se muestran micrografías electrónicas representativas de las masas control y de las masas obtenidas con el agregado de celulosas modificadas al $1,5 \%$ en ausencia y presencia de $\mathrm{NaCl}$. En la Figura 6.3 se puede observar el efecto del agregado de MCC y CMC sobre la estructura. Al igual que en la Figura 6.2, en la muestra control (campo diferente al de la Fig. 6.2) pudo observarse que el gluten forma películas (PG) alrededor de algunos de los gránulos de almidón. Además es posible ver algunos filamentos. Las muestras con el agregado de MCC mostraron una estructura aparentemente más disgregada, en particular cuando no se agregó $\mathrm{NaCl}$. Ambas muestras con CMC exhiben una estructura compacta similar a la del control pero no se observaron películas de gluten recubriendo los gránulos de almidón y la estructura resulta menos filamentosa que la del control. No se observaron diferencias estructurales importantes entre las muestras con $\mathrm{CMC} \sin$ y con $\mathrm{NaCl}$ a través de esta técnica. 

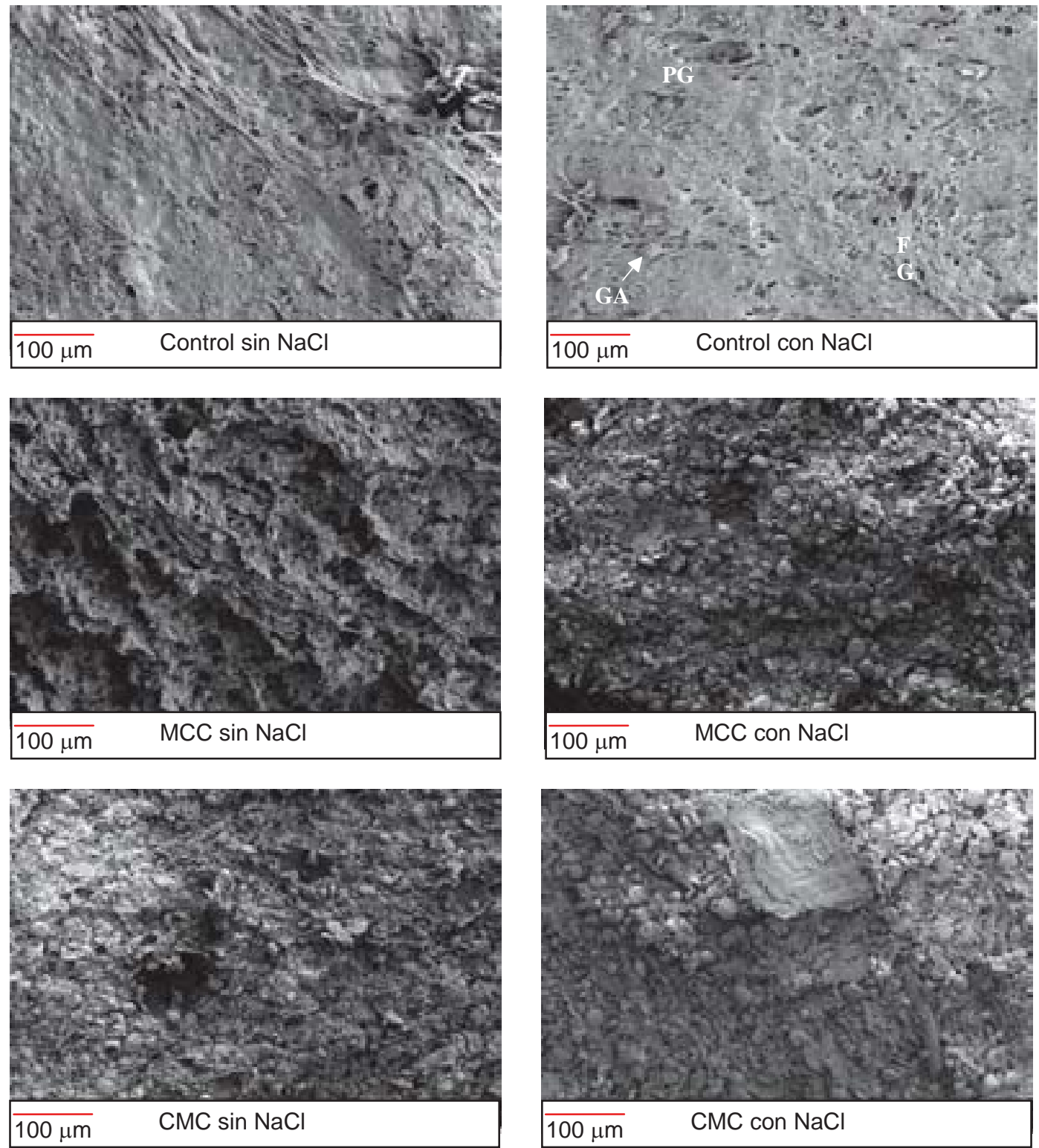

Figura. 6.3. Micrografías electrónicas de la masa control y de las masas con MCC y CMC (1,5\%). PG: película de gluten, FG: filamento de gluten, GA: gránulo de almidón. Magnificación: 500X. La barra roja corresponde a $100 \mu \mathrm{m}$. 
En la Figura 6.4 se muestran las micrografías de masas con HPMC, que mostraron en general una estructura más filamentosa que MCC y CMC. La muestra con HPMC F 4M con $\mathrm{NaCl}$ mostró una matriz marcadamente filamentosa con hebras más gruesas y aunque es posible observar también algunas pequeñas porciones de películas de gluten, hay menor proporción que en el control. La masa con esta celulosa, en ausencia de $\mathrm{NaCl}$ exhibió un aspecto menos filamentoso y una mayor proporción de películas de gluten. Desde el punto de vista reológico, las masas obtenidas con HPMC F 4M $\sin \mathrm{NaCl}$ mostraron una estabilidad similar a la del control, lo cual estaría indicando una contribución positiva de este tipo de estructura de la red de gluten. La masa $\sin \mathrm{NaCl}$ y con HPMC F 50 exhibió una matriz más filamentosa y abierta que el control y que la muestra con HPMC F 50 con $\mathrm{NaCl}$. Comparando las muestras con HPMC y $\mathrm{NaCl}$, la matriz de la masa con HPMC F 4M resultó mucho más abierta y filamentosa que la masa con F 50 y también fue la estructura que presentó menor estabilidad farinográfica.
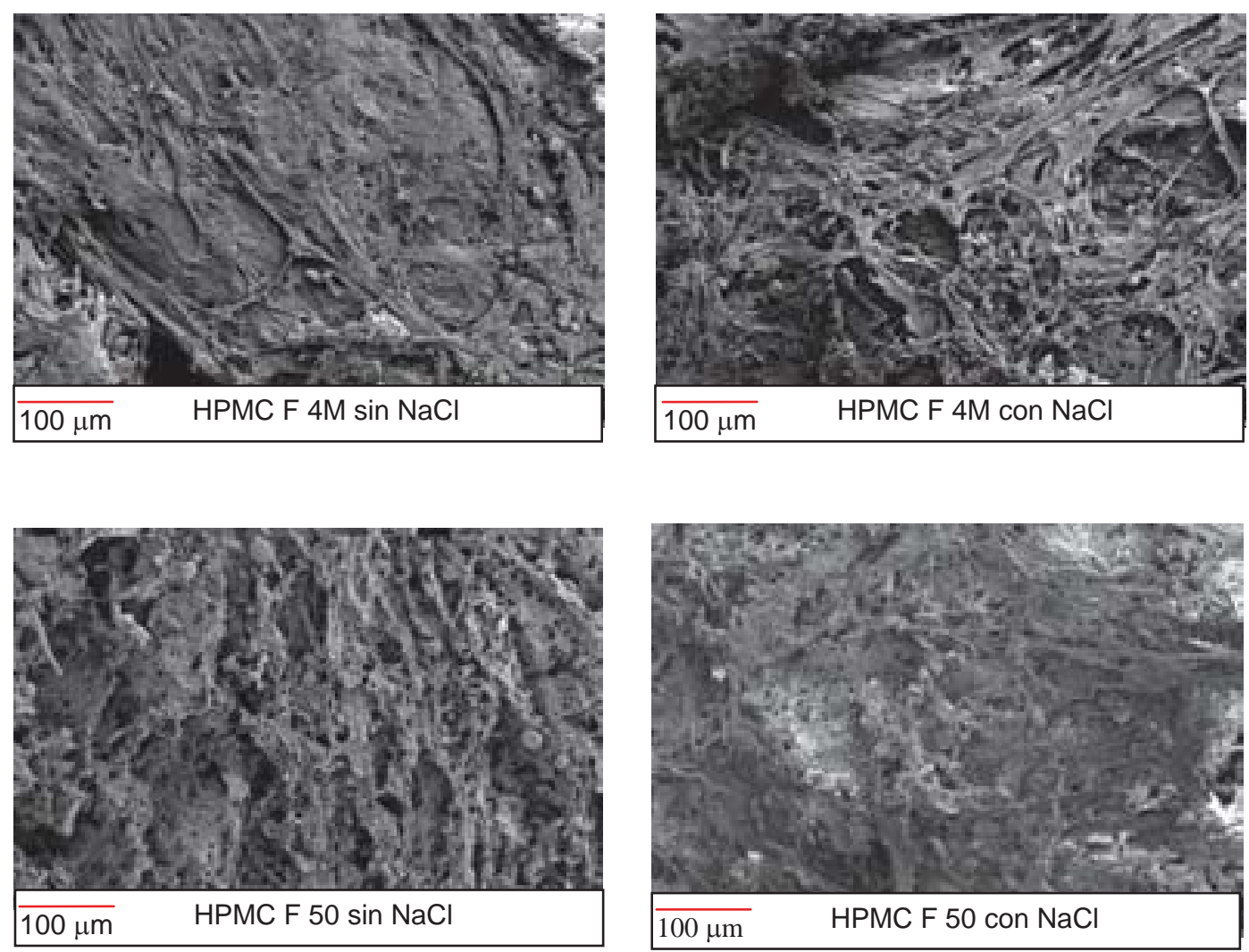

Figura. 6.4. Micrografías electrónicas de las masas con HPMC F 4M y HPMC F 50 $(1,5 \%)$ en ausencia de $\mathrm{NaCl}$ (izquierda) y presencia de $\mathrm{NaCl}$ (derecha). PG: película de gluten, FG: filamento de gluten, GA: gránulo de almidón. Magnificación: 500X. La barra roja corresponde a $100 \mu \mathrm{m}$. 


\subsubsection{Microscopía láser confocal de barrido (CSLM)}

La microscopía confocal láser de barrido presenta como ventaja frente a otros tipos de microscopía que es una técnica no invasiva por lo que permite la visualización de la microestructura con menores alteraciones. Se minimiza así el riesgo de observar artefactos debidos a modificaciones en la muestra durante su preparación ya que no necesita ser fijada o deshidratada (Newberry y col., 2003). Por este motivo es una técnica cuyo uso para el estudio de la microestructura de diferentes sistemas se encuentra en ascenso, habiéndose empleado con éxito para la evaluación de la microestructura de masa de harina de trigo destinada a panificación (Dürrenberger y col., 2001; Li, y col., 2004; Baier-Schenk y col., 2005; Peighmbardoust y col., 2006; Jekle y Becker, 2011) y producción de pasta (Huang y col., 2010; Sissons y col., 2010; Aravind, 2012), miga de pan (Primo -Martín y col., 2006 y 2007, Dürrenberger y col., 2001); y sistemas formados por mezclas de diferentes biopolímeros (Hans Tromp y col., 2001, van de Velde y col., 2003; Schober y col., 2008; Parada y Aguilera, 2011).

Con la finalidad de encontrar las condiciones óptimas para la visualización de la estructura de la masa se ensayaron diferentes condiciones: 1) se probaron dos solventes como medio para la aplicación de los fluoróforos a la masa: N, Ndimetilformamida (DMF) y agua; 2) se evaluó la utilización de diferentes aumentos: 20X, 63X y 63X+2,1 zoom óptico; 3) se realizaron observaciones en el plano xy y tomas transversales en el plano xz a partir de las que se realizó una reconstrucción de la imagen y se la proyectó en el plano.

\subsubsection{Elección del solvente}

\section{a) Fluoróforos disueltos en N,N-dimetilformamida}

La utilización de varios marcadores fluorescentes permite observar simultáneamente múltiples estructuras donde cada fluoróforo marca una en particular, por lo que se pueden emplear para estudiar la microestructura de sistemas complejos formados por polisacáridos y proteínas permitiendo determinar su ubicación. Cuando se emplean fluoróforos que se unen en forma no covalente, el contraste obtenido con las sondas fluorescentes depende del balance entre la hidrofobicidad de las fases a distinguir y de la estructura de la matriz que rodea al compuesto que se desea teñir (van Velde y col., 2003). En este caso, se realizó un teñido no covalente con isotiocianato de fluoresceína (FITC) y rodamina B disueltos en DMF, los cuales se han empleado para 
el estudio de la microestructura de masas de harina de trigo (Peighambardoust y col., 2006) y en masas formadas por gluten y almidón de papa (Parada y Aguilera, 2011). En la masa, la rodamina $B$ se une a la proteína porque tiene mayor afinidad por ella mientras que el FITC se puede unir tanto a la proteína como al almidón.

En la Figura 6.5.A se observan las fotografías obtenidas para la masa control con $\mathrm{NaCl}$ cuando ambos fluoróforos (FITC 1\% + Rodamina B 0,1\%) se prepararon en DMF. En la parte superior de la Figura se muestran las imágenes obtenidas por la marcación de cada fluoróforo por separado. Con rodamina B se tiñe sólo la proteína lo que permite visualizar la red de gluten en color rojo quedando los gránulos de almidón sin teñir (zonas oscuras). Por otro lado, con FITC se tiñen la proteína y el almidón, ambos en color verde. Al realizar la superposición de las imágenes tomadas por ambos canales de adquisición del microscopio se obtiene la foto que se encuentra en la parte inferior de la Figura 6.5 A, en la cual la proteína se observa de color anaranjado y los gránulos de almidón de color verde intenso (zonas oscuras en la Figura). De este modo se confirma que los gránulos de almidón correspondían a las zonas oscuras en la imagen adquirida con rodamina B. A pesar de que el empleo de los fluoróforos en DMF permite visualizar tanto a las proteínas de la masa como al almidón se pierde la apreciación de la estructura de la red de gluten, ya que se observa una estructura continua debido probablemente a la desnaturalización proteica por el solvente empleado.

\section{B) Fluoróforos disueltos en agua}

Al aplicar a la masa la solución conteniendo los colorantes en agua (FITC 0,01\% + rodamina $\mathrm{B} 0,001 \%$ ) se obtuvieron imágenes como las de la Figura $6.5 \mathrm{~B}$. En la parte superior de la Figura se muestran las imágenes obtenidas por la tinción de cada fluoróforo por separado y abajo la obtenida por superposición de ambos canales de adquisición. Al igual que cuando los fluoróforos se disolvieron en DMF, con el empleo de rodamina $B$ se tiñe de color rojo sólo la proteína mientras que al utilizar FITC se tiñen tanto la proteína como el almidón, visualizándose ambos en color verde. En este caso es posible observar con mayor nitidez la estructura proteica. A partir de estos resultados se decidió emplear agua como solvente para la preparación de la solución colorante ya que ésta permite observar la estructura de la red de gluten en condiciones más cercanas a las que presenta en la masa que la utilización de DMF. 


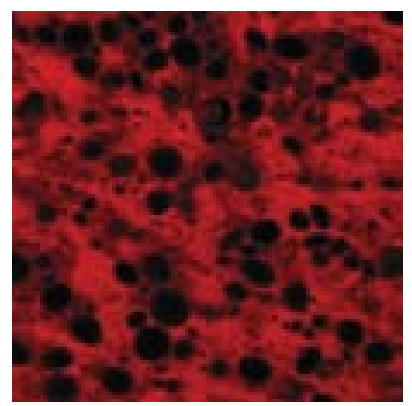

Rodamina B

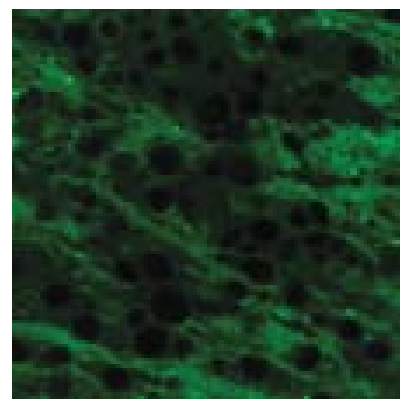

FITC

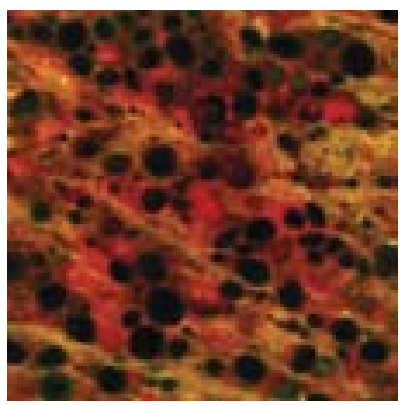

Superposición de los dos canales
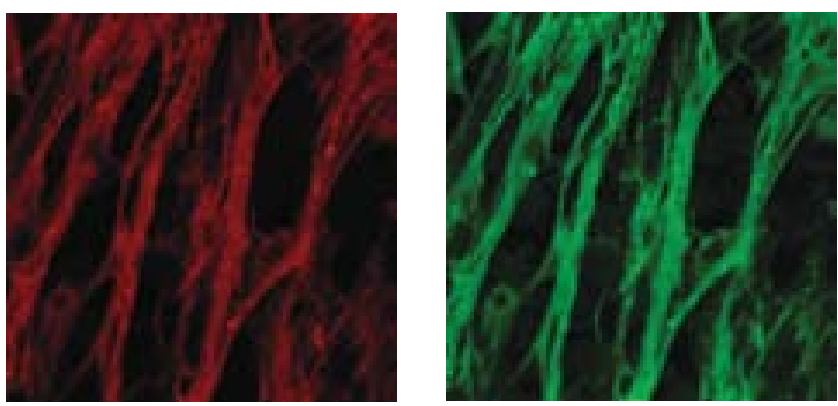

B

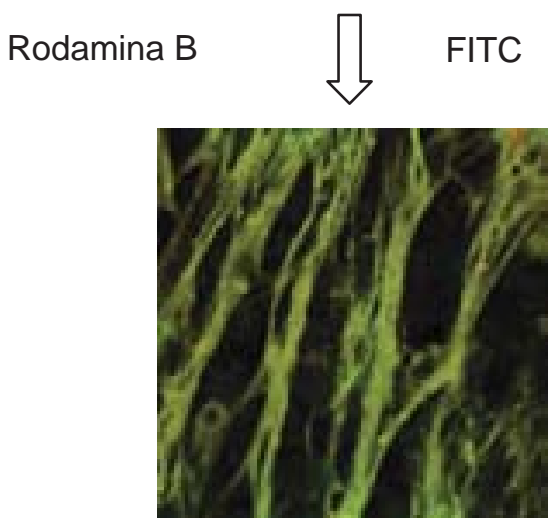

Superposición de los dos canales

Figura 6.5. Imágenes de la masa control con $\mathrm{NaCl}$ obtenidas por microscopía confocal con un aumento de $63 \mathrm{X}$ por superposición de los canales rodamina B y FITC utilizando distintos disolventes para los fluoróforos: A) con DMF B) con agua. 


\subsubsection{Elección del aumento}

En la Figura 6.6 se muestran las imágenes obtenidas para la masa control con $\mathrm{NaCl}$ utilizando dos magnificaciones: A) 20X, B) 63X. Mientras que la imagen obtenida con un aumento de $20 \mathrm{X}$ permite tener una perspectiva global de la estructura de la masa con la imagen obtenida a $63 \mathrm{X}$ se obtiene un mayor detalle de la microestructura. Por ejemplo, con el mayor aumento es posible visualizar mejor los gránulos de almidón. Se priorizó la evaluación de la microestructura en forma global para poder comparar la matriz de gluten de las distintas formulaciones por lo que se empleó el aumento de $20 X$.

A

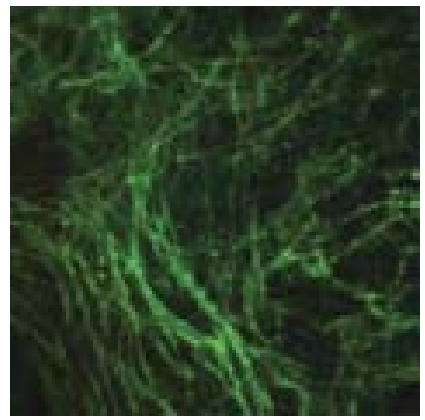

B

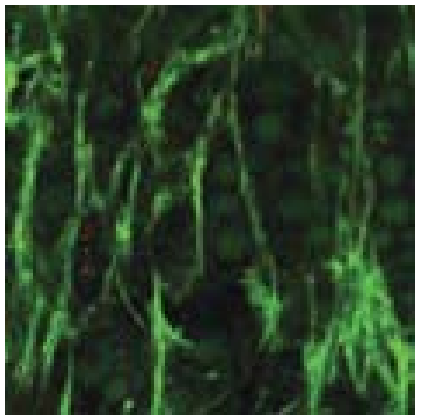

Figura 6.6. Evaluación del poder de magnificación sobre la imagen obtenida. A) 20X, B) 63X. Imágenes obtenidas por superposición de los canales de ambos fluoróforos, rodamina $B$ y FITC.

\subsubsection{Tipo de secciones ópticas}

El microscopio confocal ofrece la posibilidad de analizar secciones ópticas transversales permitiéndonos observar la estructura interna de la muestra sin necesidad de ningún tipo de preparación especial, lográndolo a través del desplazamiento del plano focal a través de la muestra. Esta posibilidad representa una gran ventaja frente a la microscopía óptica con la cual sólo es posible observar la muestra en el plano xy. En la Figura 6.7 se muestran las secciones ópticas transversales obtenidas para el control y la proyección obtenida a partir de las mismas. Se decidió hacer las comparaciones en base a fotografías tomadas en el plano xy y no 
en la proyección en z ya que no se obtenía una mayor ventaja en la utilización de esta última y eran en cambio muy largos los tiempos de obtención de cada micrografía.

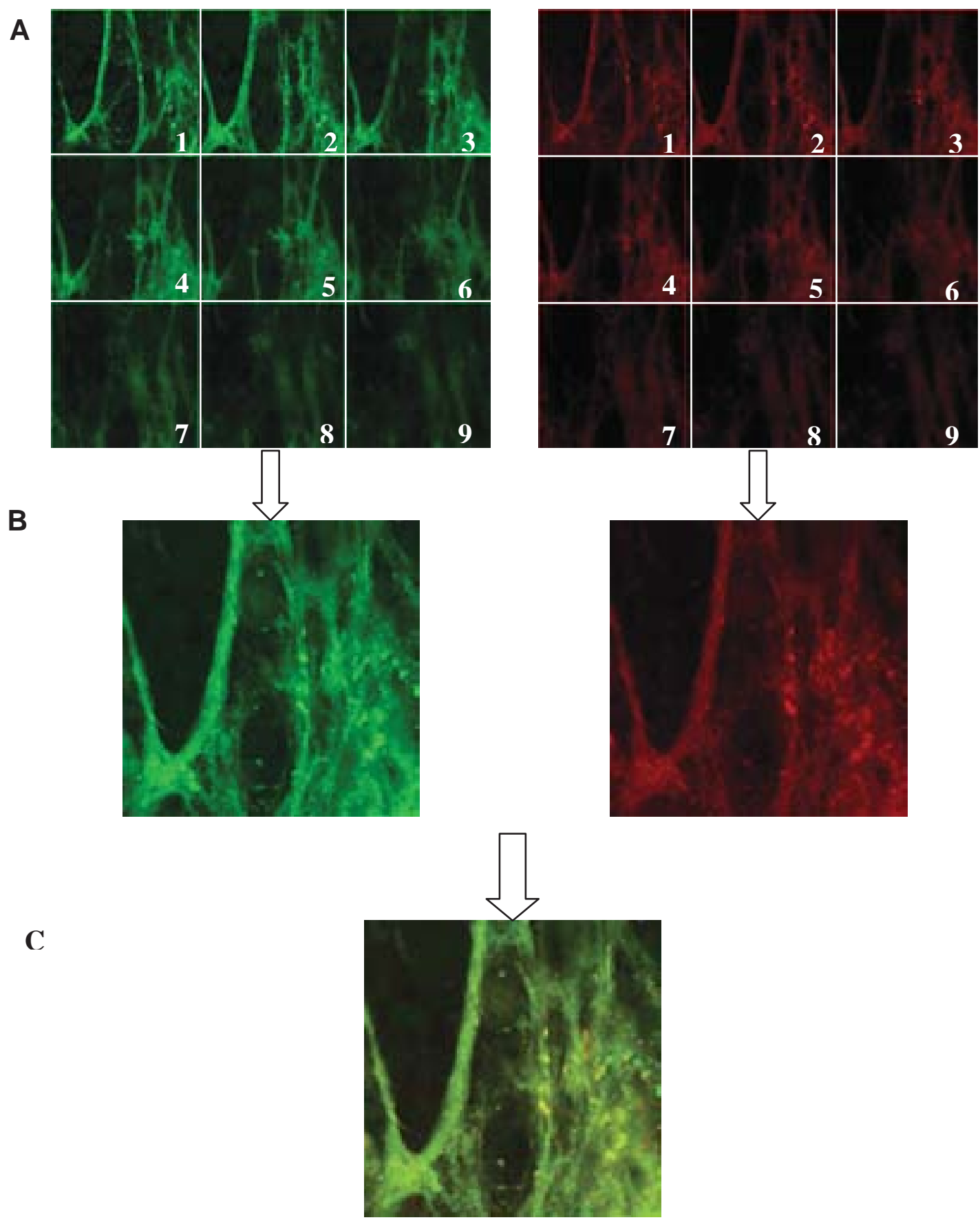

Figura 6.7. A) Secciones transversales (9 en total) obtenidas con cada fluoróforo, B) proyección en z para cada fluoróforo, C) imagen obtenida por superposición de ambos canales. 


\subsubsection{Efecto de los hidrocoloides sobre la microestructura de la masa}

A partir de los resultados obtenidos en los ensayos previos se tomaron imágenes de la masa con una magnificación de 20X, empleando agua como disolvente para los fluoróforos. Antes de realizar la observación de las muestras marcadas se verificó que la masa no presentara autofluorescencia en las condiciones del ensayo. Se tomaron por muestra no menos de 10 micrografías. Las que se muestran a continuación son representativas de la estructura característica de cada masa.

En la Figura 6.8 se muestran las imágenes para las masas control y con pectinas en ausencia y presencia de $\mathrm{NaCl}$. La masa control sin $\mathrm{NaCl}$ presenta una estructura de la red de gluten mucho más abierta que la masa con $\mathrm{NaCl}$, presentando ésta última los filamentos de la red de gluten más entrecruzados y con mayor orientación, lo que da como resultado una red más cerrada. Las manchas rojas que se observan se deben a depósitos cristalinos de rodamina B que no fueron arrastrados con el lavado. Estas características de la red más entrecruzada en la masa control con $\mathrm{NaCl}$ ya habían sido observadas con SEM.

En las masas $\sin \mathrm{NaCl}$ y con PBM se observa una estructura con características similares a las del control, mientras que con PAM se obtiene una red con hebras más entrecruzadas y marcadamente orientadas. En este caso se puede apreciar mucho mejor la orientación de la red proteica que en la fotos obtenidas por SEM.

Al agregar $\mathrm{NaCl}$, en todas las masas se observó un aumento de la orientación de los filamentos de la red de gluten. Aunque esta mayor orientación se observó en las masas con ambas pectinas, el cambio fue más evidente en el caso de la masa con PBM que presentó una red más orientada y entrecruzada que en ausencia de $\mathrm{NaCl}$. En la masa con PAM, que ya presentaba orientación, al agregar $\mathrm{NaCl}$ los cambios fueron menos pronunciados. En comparación con el control con $\mathrm{NaCl}$, las masas con ambas pectinas mostraron una estructura más abierta, particularmente con PAM. Similares resultados se pudieron observar con SEM.

En la Figura 6.9 se muestran las imágenes de las masas con MCC y CMC sin y con $\mathrm{NaCl}$. En general, las masas con MCC presentaron características similares a los controles respectivos. En ausencia de $\mathrm{NaCl}$, la red es entrecruzada y abierta mientras que la masa con $\mathrm{NaCl}$ es más orientada y entrecruzada, dando lugar a una estructura más cerrada. En este caso se pudieron apreciar mejor las estructuras que con el uso de SEM. 

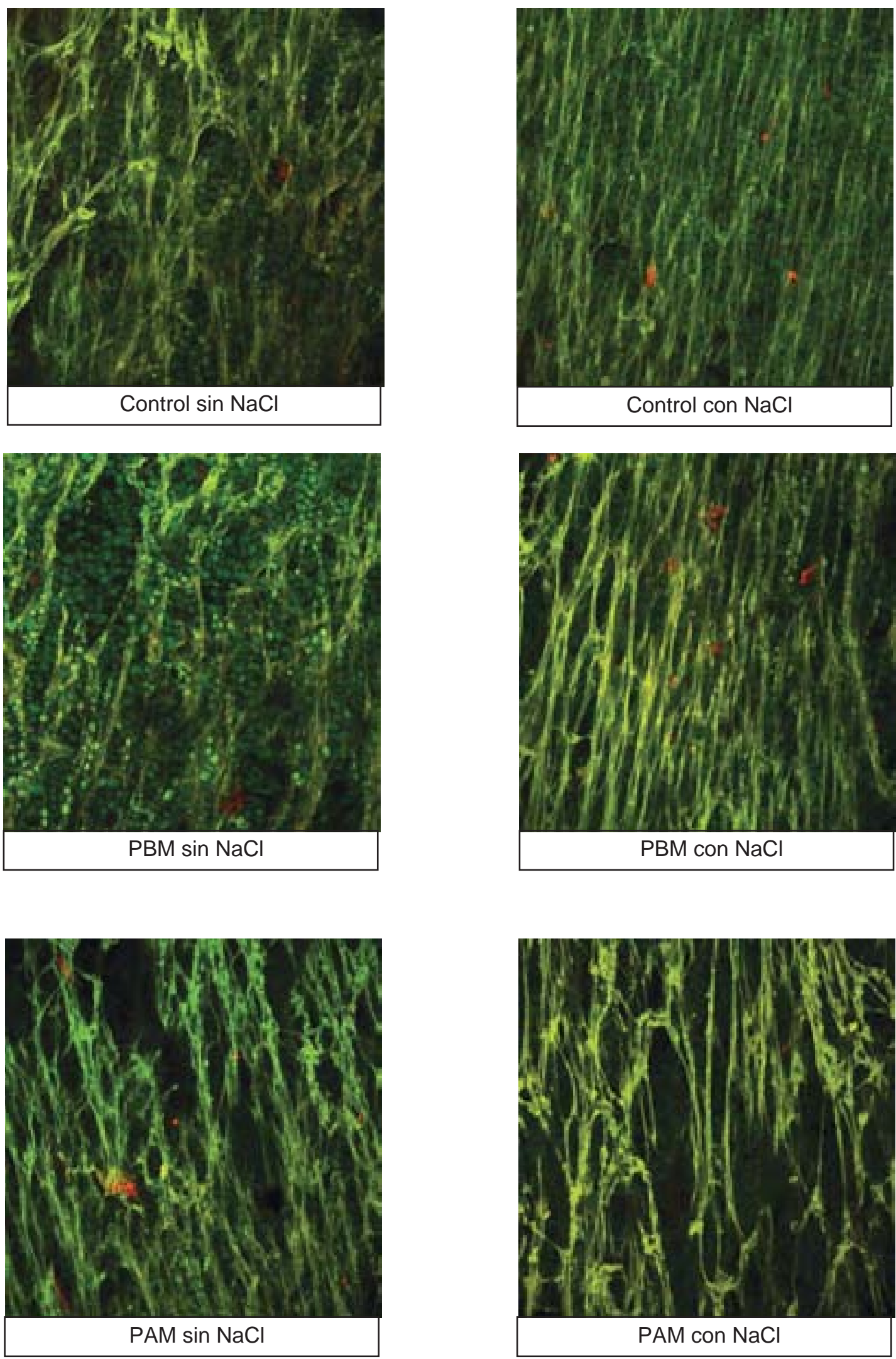

Figura 6.8. Masas con pectina de bajo y alto metoxilo en ausencia y presencia de $\mathrm{NaCl}$ (Magnificación 20X). Tamaño de la imagen $775 \mu \mathrm{m}$ x $775 \mu \mathrm{m}$. 
Estas características de la red de gluten pueden relacionarse con el hecho de que las masas con MCC no hayan presentado diferencias significativas con respecto al control en la estabilidad y aflojamiento farinográficos, así como tampoco en los ensayos oscilatorios dinámicos.

Como en el caso anterior, esta técnica permitió apreciar mejor que con SEM las diferencias microestructurales en las muestras con CMC. La masa con $\mathrm{CMC} \sin \mathrm{NaCl}$ presentó una estructura filamentosa y orientada pero con muy pocos entrecruzamientos entre las hebras. Por el contrario, la masa con $\mathrm{NaCl}$ presentó una estructura también filamentosa y orientada pero con mayor entrecruzamiento, con características parecidas a las del control con $\mathrm{NaCl}$ aunque aparentemente más abierta. Al comparar la masa con $\mathrm{CMC} \sin \mathrm{NaCl}$ respecto al control, se observa que ante el agregado de CMC la red de gluten se orientó y disminuyó el número de entrecruzamientos. Estas diferencias observadas en la red de gluten en las masas con CMC ante la ausencia o agregado de $\mathrm{NaCl}$ podrían explicar el diferente comportamiento reológico presentado por ambas. La masa con CMC $\sin \mathrm{NaCl}$ tuvo una baja estabilidad farinográfica y bajo contenido de $\mathrm{GH}$, indicativos de una red débil mientras que la masa con $\mathrm{CMC}$ con $\mathrm{NaCl}$ daba lugar a una red más fuerte, de igual estabilidad farinográfica y contenido de GH que el control, probablemente en relación con la similitud microestructural de ambas.

En la Figura 6.10 se muestran las masas con ambas HPMCs sin y con $\mathrm{NaCl}$ observándose marcadas diferencias en las mismas por efecto del $\mathrm{NaCl}$. Las masas con HPMC F 4M sin $\mathrm{NaCl}$ muestran una red de gluten formada por filamentos orientados y agrupados dando lugar a una estructura algo abierta pero mucho más orientada que el respectivo control. Por otro lado, la masa con HPMC F $50 \sin \mathrm{NaCl}$ da lugar a una red muy abierta de características muy diferentes a las del control. A pesar de las diferencias estructurales encontradas respecto al control $\sin \mathrm{NaCl}$, estas muestras no presentaron diferencias en la estabilidad farinográfica. En presencia de $\mathrm{NaCl}$, las masas con ambas HPMCs presentaron una estructura formada por finos filamentos entrecruzados. La estructura de la red proteica en la masa con HPMC F 4M con $\mathrm{NaCl}$ fue más abierta que la mostrada por la muestra con HPMC F 50 con $\mathrm{NaCl}$, lo cual puede vincularse como se dijo anteriormente, con la menor estabilidad farinográfica mostrada por la primera. En general estos resultados son concordantes con los obtenidos por SEM. 

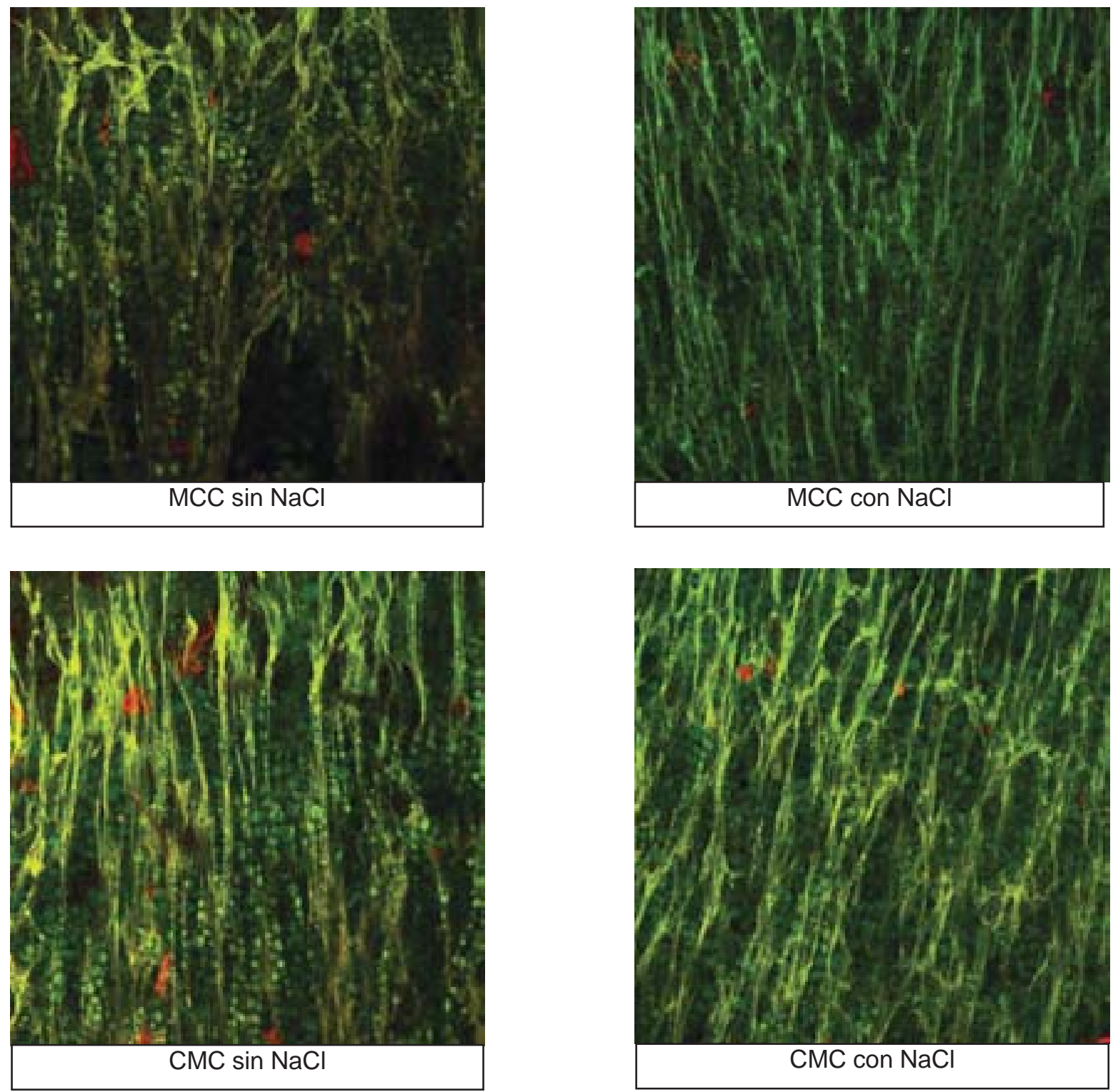

Figura 6.9.Microestructura de la masas control, con MCC y CMC en ausencia y presencia de $\mathrm{NaCl}$ (Magnificación 20X). Tamaño de la imagen $775 \mu \mathrm{m} \times 775 \mu \mathrm{m}$. 

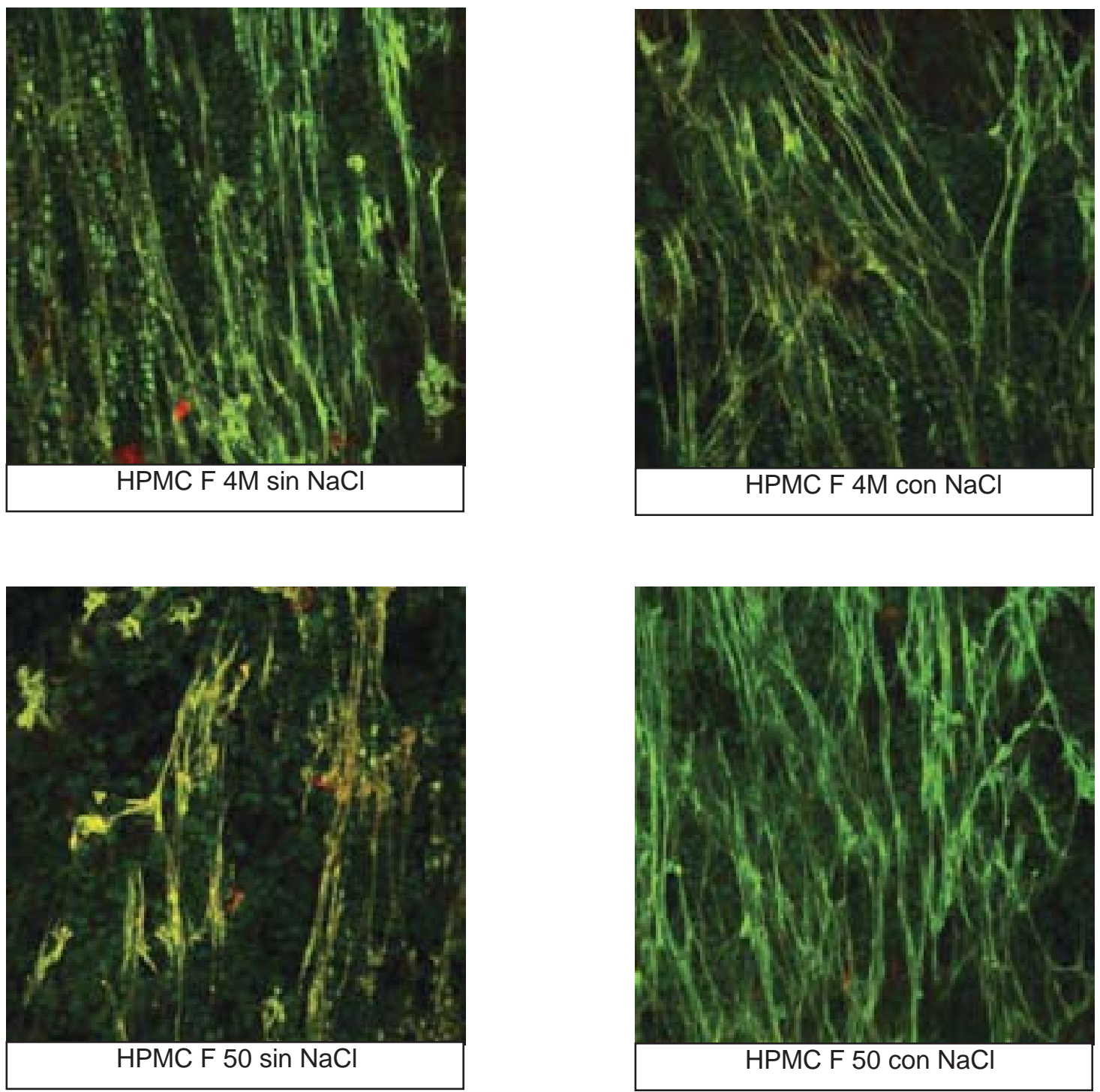

Figura 6.10. Masas con HPMC F 4M y HPMC F50 en ausencia y presencia de $\mathrm{NaCl}$ (Magnificación 20X). Tamaño de la imagen $775 \mu \mathrm{m}$ x $775 \mu \mathrm{m}$.

En general se puede concluir que un mayor grado de orientación y entrecruzamiento inducido por el $\mathrm{NaCl}$ se puede relacionar con una mejora en la estabilidad farinográfica y una menor viscosidad de la masa. El agregado de hidrocoloides conduce a redes más abiertas, lo que estaría vinculado con la menor dureza y en general, mayor viscosidad, de las masas que los contienen. Estas características de orientación y entrecruzamiento relacionadas con una red de gluten más fuerte pueden apreciarse mejor con la microscopía confocal que con SEM. 


\subsection{Movilidad molecular en la matriz panaria}

El término "movilidad molecular" involucra varios conceptos relacionados con la estabilidad de un producto, inherentes a su procesamiento o almacenamiento. Lo que se denomina "movilidad" abarca diferentes tipos de movimientos: desplazamientos moleculares, deformación, migración de solvente o soluto debido a gradientes de potenciales químicos o campos eléctricos, difusión molecular, rotación de grupos de átomos o segmentos poliméricos, alrededor de enlaces covalentes. Normalmente la movilidad es influida por la temperatura, hidratación del sistema y cambios de estado físico (transición vítrea, fusión, entre otros) (Roudaut y col., 2004). Se estudió la movilidad molecular en masa y miga panarias a través de dos técnicas diferentes, con el objeto de evaluar el efecto de los hidrocoloides sobre la matriz.

\subsubsection{Ensayos de relajación $\mathrm{T}_{2}$ por ${ }^{1} \mathrm{H}-\mathrm{RMN}$ en masa}

Se analizó la movilidad molecular de las matrices de las diferentes masas mediante ensayos de relajación ${ }^{1} \mathrm{H}$ spin-spin $\left(\mathrm{T}_{2}\right)$ utilizando la secuencia de Carr-PurcellMeiboom-Gill.

En la Figura 6.11 se muestran a modo de ejemplo, las curvas de relajación de los controles y las masas con HPMC F $501,5 \%$ sin y con $\mathrm{NaCl}$.

Las curvas de relajación obtenidas se modelaron con una ecuación exponencial de primer orden (Ec. 6.1) a partir de la cual se obtuvieron los tiempos de relajación característicos de cada masa.

$$
I=A_{1} \exp \left(\frac{-t}{T_{2}}\right)
$$

donde I es la intensidad de la señal del protón en función del tiempo, $A_{1}$ es la intensidad inicial, la cual es proporcional a la cantidad de núcleos de hidrógeno en la muestra y $T_{2}$ es el tiempo de relajación spin-spin. 


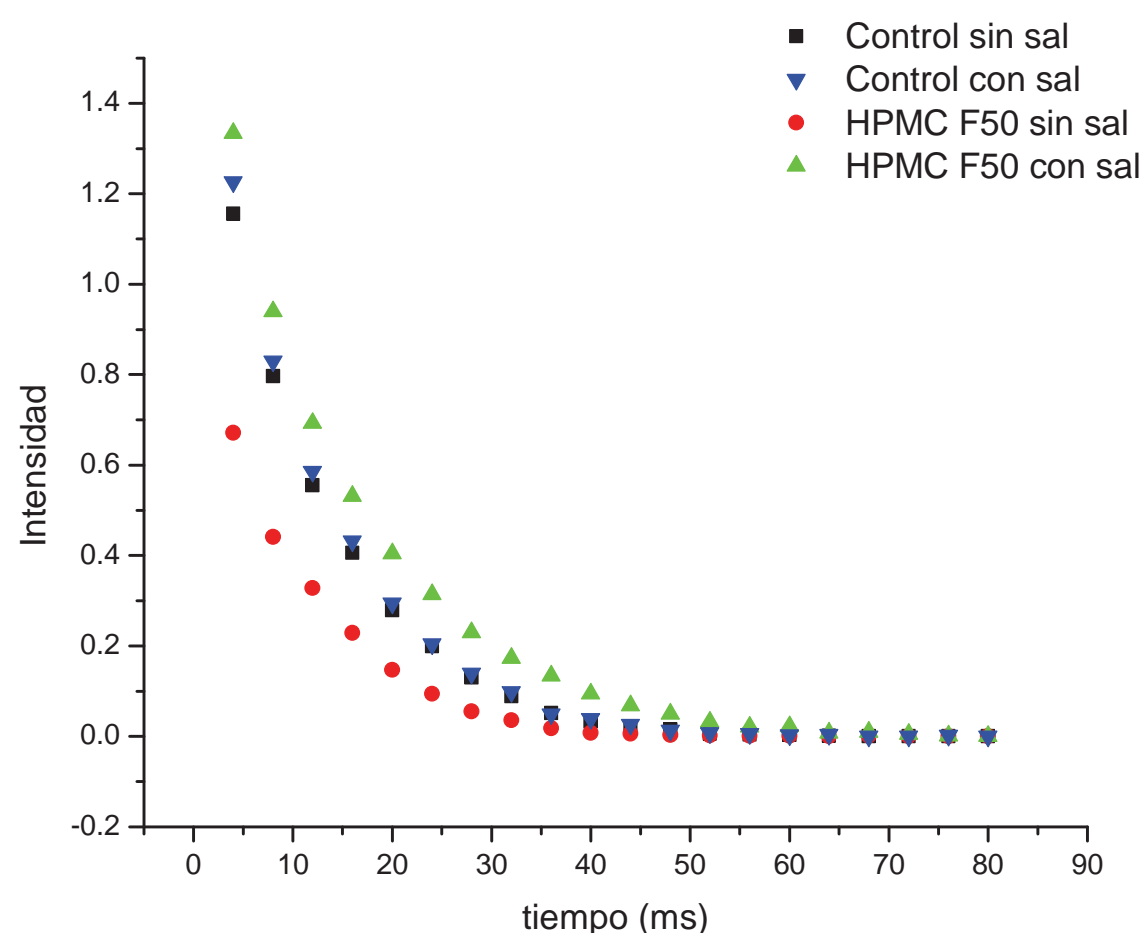

Figura 6.11. Relajación de las masas control y con HPMC F 50 sin y con $\mathrm{NaCl}$.

La señal obtenida es una combinación de las señales de los diferentes tipos de protones: los del agua, los del almidón, las proteínas e hidrocoloides presentes, por lo que el tiempo de relajación observado es un promedio pesado de los tiempos de relajación de estos. La incidencia en la señal de cada tipo de protón dependerá de su proporción y de la velocidad de intercambio con el medio (Zimmerman y col., 1957). Si bien se intentó ajustar los resultados experimentales con expresiones exponenciales de más de un término no se obtuvieron resultados satisfactorios. El hecho de que el mejor ajuste se haya obtenido con una ecuación monoexponencial indica que las poblaciones son indiferenciables en las condiciones de medición utilizadas. Al respecto, la información disponible en literatura es controversial: algunos autores (Leung y col., 1979) han informado sobre la existencia de dos poblaciones de protones en la masa de harina de trigo correspondientes a dos fracciones de movilidad diferentes pero otros autores (López Da Silva y col., 2007) han supuesto una sola. Las causas de un decaimiento de tipo monoexponencial pueden ser diversas: intercambio muy rápido de protones entre fases comparado con el lapso de relajación, pequeña proporción de una población de protones respecto a la otra, excesiva diferencia o 
similitud entre los tiempos de relajación característicos de cada población que no puedan ser detectados por el equipo (Leung y col., 1976).

En la Tabla 6.1 se muestran los parámetros obtenidos $\left(A_{1}\right.$ y $\left.T_{2}\right)$ en las regresiones de las curvas de relajación para las muestras $\sin$ y con $\mathrm{NaCl}$, en todos los casos el coeficiente de determinación $\left(r^{2}\right)$ fue superior a 0,999. Mayores tiempos de relajación $\left(\mathrm{T}_{2}\right)$ están relacionados con una mayor movilidad molecular en la matriz.

Se encontraron efectos significativos tanto del agregado de sal como del tipo de hidrocoloide $(p<0,05)$. En general se observa, salvo en el caso de PAM y HPMC F 50 sin sal, mayores tiempos de relajación (comparando con el control respectivo) cuando se agregan hidrocoloides a la matriz, tanto en ausencia como en presencia de $\mathrm{NaCl}$, lo que está indicando mayor movilidad molecular.

Tabla 6.1. Tiempos de relajación $\mathrm{T}_{2}$ de las masas sin y con $\mathrm{NaCl}$ y con hidrocoloides

\begin{tabular}{ccccc}
\hline \multirow{2}{*}{ Muestra } & \multicolumn{2}{c}{ Sin $\mathrm{NaCl}$} & \multicolumn{2}{c}{ Con NaCl } \\
\cline { 2 - 5 } & $\mathrm{A}_{1}$ (Volt) & $\mathrm{T}_{2}(\mathrm{~ms})$ & $\mathrm{A}_{1}$ (Volt) & $\mathrm{T}_{2}(\mathrm{~ms})$ \\
\hline Control & $1,70 \pm 0,05^{\mathrm{b}}$ & $11,7 \pm 0,3^{\mathrm{b}}$ & $1,76 \pm 0,02^{\mathrm{ab}}$ & $11,2 \pm 0,2^{\mathrm{a}}$ \\
\hline MCC 1,5\% & $1,67 \pm 0,09^{\mathrm{b}}$ & $12,2 \pm 0,5^{\mathrm{b}}$ & $1,82 \pm 0,02^{\mathrm{b}}$ & $12,6 \pm 0,1^{\mathrm{c}}$ \\
\hline CMC 1,5\% & $1,67 \pm 0,07^{\mathrm{b}}$ & $12,2 \pm 0,1^{\mathrm{bc}}$ & $1,71 \pm 0,08^{\mathrm{a}}$ & $11,9 \pm 0,3^{\mathrm{b}}$ \\
\hline HPMC F 4M 1,5\% & $1,64 \pm 0,08^{\mathrm{b}}$ & $12,7 \pm 0,4^{\mathrm{c}}$ & $1,80 \pm 0,03^{\mathrm{ab}}$ & $13,1 \pm 0,1^{\mathrm{cd}}$ \\
\hline HPMC F 50 1,5\% & $1,02 \pm 0,05^{\mathrm{a}}$ & $10,9 \pm 0,2^{\mathrm{a}}$ & $1,79 \pm 0,03^{\mathrm{ab}}$ & $13,3 \pm 0,2^{\mathrm{d}}$ \\
\hline Control & $1,70 \pm 0,05^{\mathrm{a}}$ & $11,7 \pm 0,3^{\mathrm{b}}$ & $1,76 \pm 0,02^{\mathrm{a}}$ & $11,2 \pm 0,2^{\mathrm{b}}$ \\
\hline PBM 2\% & $1,81 \pm 0,04^{\mathrm{b}}$ & $11,5 \pm 0,2^{\mathrm{b}}$ & $1,87 \pm 0,03^{\mathrm{b}}$ & $11,3 \pm 0,2^{\mathrm{b}}$ \\
\hline PAM 2\% & $1,77 \pm 0,02^{\mathrm{b}}$ & $10,3 \pm 0,1^{\mathrm{a}}$ & $1,89 \pm 0,02^{\mathrm{b}}$ & $10,6 \pm 0,1^{\mathrm{a}}$
\end{tabular}

media \pm DE. En una columna, para cada tipo de hidrocoloide (celulosas 0 pectinas) letras diferentes indican diferencias significativas $(p<0,05)$.

Lusse y Arnold (1998) estudiaron el fenómeno de relajación en soluciones de polisacáridos y encontraron diferentes tiempos de relajación, atribuyendo las diferencias entre distintos polímeros a procesos de reorientación del agua ligada respecto al sitio de unión y a la movilidad de la cadena principal del polímero. Las macromoléculas de cadena más rígida presentaron menores tiempos de relajación (menor movilidad) mientras que las cadenas de polímeros más flexibles daban tiempos de relajación mayores (mayor movilidad). En el caso del presente trabajo, la movilidad que se está observando corresponde a un promedio de toda la matriz, por las causas 
explicadas anteriormente (limitaciones experimentales para distinguir las diferentes poblaciones de protones) por lo que los tiempos obtenidos reflejarían la movilidad de la matriz gluten-hidrocoloide-agua en conjunto. Los valores más altos obtenidos, en general, con las celulosas indican una mayor flexibilidad de la matriz cuando se agregan hidrocoloides, tanto en ausencia como en presencia de sal. PAM daría matrices más rígidas, en coincidencia con lo informado por Linlaud y col., (2011) en masa panaria.

Por otro lado, Esselink y col. (2003) estudiaron el efecto del tiempo de amasado en la estructura de la red de gluten y hallaron que redes más filamentosas (obtenidas con mayores tiempos de amasado) arrojaban valores más altos de tiempos de relajación. Los autores atribuyeron lo observado a la liberación de agua ocasionada por la disrupción de la red de gluten en la masa sobreamasada. En este trabajo se ha visto, en los estudios microscópicos (ítem 6.1) que el agregado de hidrocoloides incrementaba las características filamentosas en la red, disminuyendo la proporción de láminas o películas de gluten y coincidiendo con mayores tiempos de relajación (salvo en el caso de PAM y HPMC F 50 sin $\mathrm{NaCl}$ ).

\subsubsection{Ensayos de análisis mecánico diferencial (DMA) en miga}

Este tipo de análisis permite el estudio de los fenómenos de movilidad molecular en las proximidades de la transición vítrea del sistema, en la que un material sólido amorfo pasa a un estado gomoso o viscoso. La localización de la temperatura de transición vítrea depende de la cantidad de agua del sistema (Orford y col., 1989) y del peso molecular medio de los componentes (Orford y col., 1990).

El estudio de esta transición es importante tanto para la caracterización de un material como para evaluar su estabilidad frente al almacenamiento. Por arriba de la temperatura de transición vítrea $\left(\mathrm{T}_{\mathrm{g}}\right)$ la movilidad molecular es suficiente como para permitir que ocurran cambios dependientes de la difusión molecular. Por debajo de esta temperatura el material posee una viscosidad extremadamente alta ( $>10^{12} \mathrm{~Pa} . \mathrm{s}$ ) y los movimientos moleculares se encuentran restringidos a modos vibracionales y rotacionales de corto alcance. En estas condiciones los cambios que pueden ocurrir son muy lentos y se puede considerar que existe estabilidad frente a una gran parte de procesos de deterioro (Roos, 1995). No obstante, hoy se reconoce que $T_{g}$ no puede considerarse un umbral absoluto para la determinación de la estabilidad del sistema ya que ciertos cambios estarían relacionados con reordenamientos o la posibilidad de 
movilidad molecular en el estado vítreo (por ejemplo perdida de crocancia o ciertas reacciones químicas) (Schebor y col., 1999; Champion y col., 2000). Los principales métodos que se utilizan para la determinación de $T_{g}$ son calorimetría diferencial de barrido (DSC), análisis termomecánico dinámico (DMA) y espectroscopía dieléctrica.

La temperatura de transición vítrea determinada por análisis mecánico dinámico (DMA) suele denominarse $T_{\alpha}$ para diferenciarla de la determinada por DSC $\left(T_{g}\right)$ ya que no son completamente equivalentes debido a que los principios por los cuales se determinan son diferentes. En DSC la muestra es sometida a un cambio de temperatura y en DMA la muestra es sometida, además, a un esfuerzo mecánico.

Se obtuvieron los espectros dinámicos mecánicos de la miga de los panes control, y con el máximo nivel de cada aditivo: celulosas modificadas al $1,5 \%$ y pectinas al $2 \%$ y se evaluaron los módulos elástico o de almacenamiento $\left(E^{\prime}\right)$, viscoso $\left(E^{\prime \prime}\right)$ y la tangente del ángulo de desfasaje $(\tan (\delta))$. En la Figuras $6.12,6.13$ y 6.14 se muestran los espectros típicos obtenidos en miga de pan control y en muestras con hidrocoloide. Se observa en todos los casos una caída del módulo elástico o de almacenamiento $\left(E^{\prime}\right)$ y un aumento progresivo de la $\tan (\delta)$ a medida que se incrementa la temperatura lo cual muestra que aumenta el comportamiento viscoso de la muestra. $\mathrm{T}_{\alpha}$ suele identificarse como un pico de $\tan (\delta)$, como una caída en $E^{\prime}$ o como un pico en $E^{\prime \prime}$. Aunque el pico en $\tan (\delta)$ es la forma más común de determinar $\mathrm{T}_{\alpha}$, normalmente esta temperatura es mayor que la que se obtiene con el punto medio de la caída de $E^{\prime}$ (Kalichevsky y col., 1992). Probablemente, el uso extendido de la $\tan (\delta)$ para determinar $T_{\alpha}$ se deba a que en los biopolímeros, la caída en $E^{\prime}$ en $T_{\alpha}$ es menos abrupta que en los polímeros sintéticos debido a la presencia parcial de cristalinidad y algún grado de interacción, por ejemplo por puente de hidrógeno (Choi y col., 2010). Desde un punto de vista físico es más correcto determinar $\mathrm{T}_{\alpha}$ a partir del máximo observado en $E^{\prime \prime} y$, por otro lado, en sistemas de bajo peso molecular el pico en la $\tan (\delta)$ puede no ser observable (Champion y col., 2000).

En la curva correspondiente al módulo viscoso o de pérdida ( $\left.E^{\prime \prime}\right)$ se observaron 2 ó 3 picos dependiendo de la muestra, en algunos casos estos picos también se pueden observar aunque desplazados y con menor magnitud en los otros módulos. El pico observado en $\mathrm{E}^{\prime \prime}$ cercano a $0^{\circ} \mathrm{C}$ se atribuye a la fusión del hielo $\left(T_{\mathrm{m}}\right)$, el pico cercano a $-30^{\circ} \mathrm{C}$ se ha atribuido a una relajación $\alpha$ la que se asocia a la transición vítrea $\left(T_{\alpha}\right)$ 

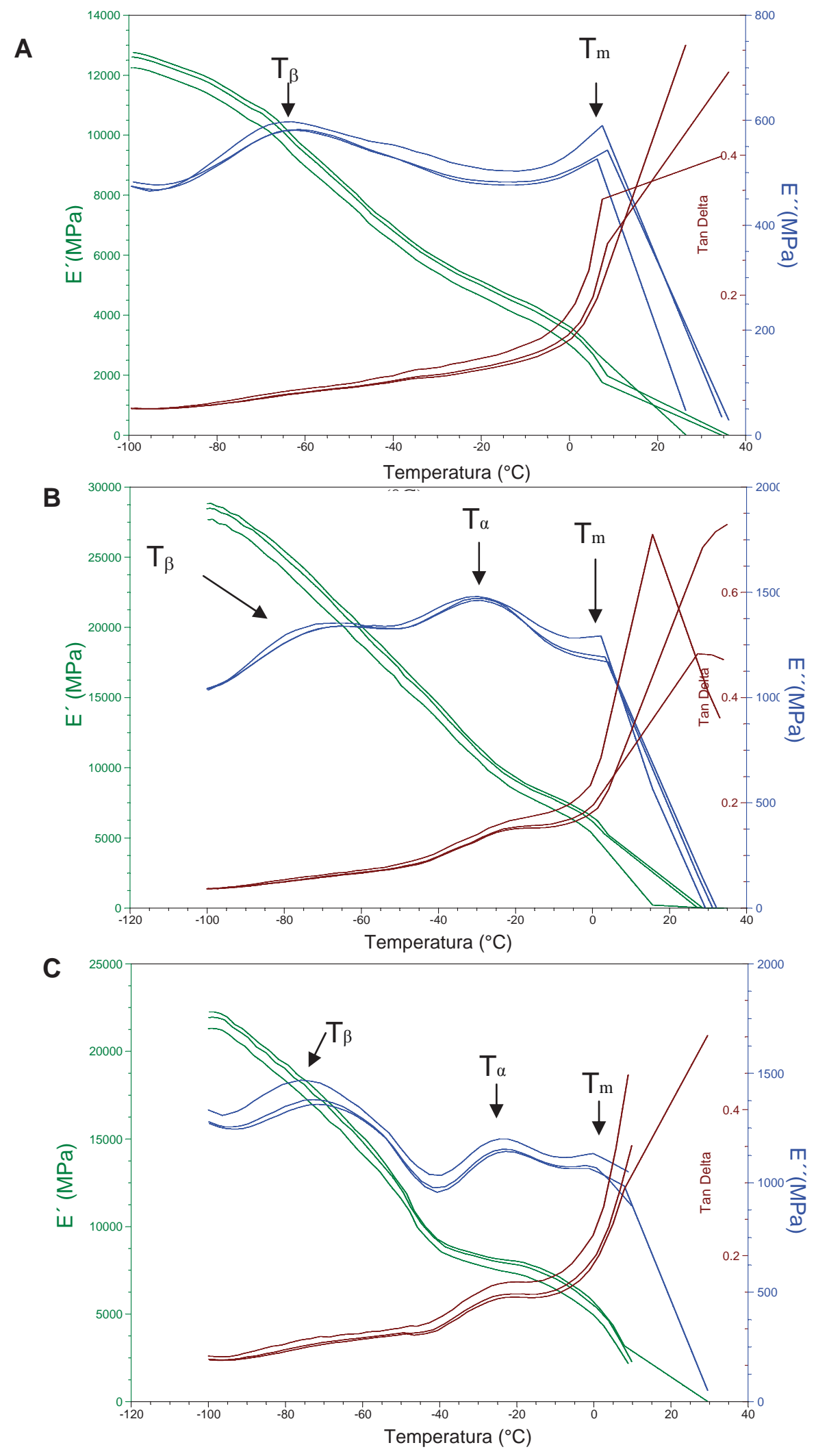

Figura 6.12. Espectros dinámicos mecánicos de la miga de pan a $1 \mathrm{~Hz}, 5 \mathrm{~Hz}$ y $10 \mathrm{~Hz}$. A) control, B) con MCC y C) con CMC. 
A

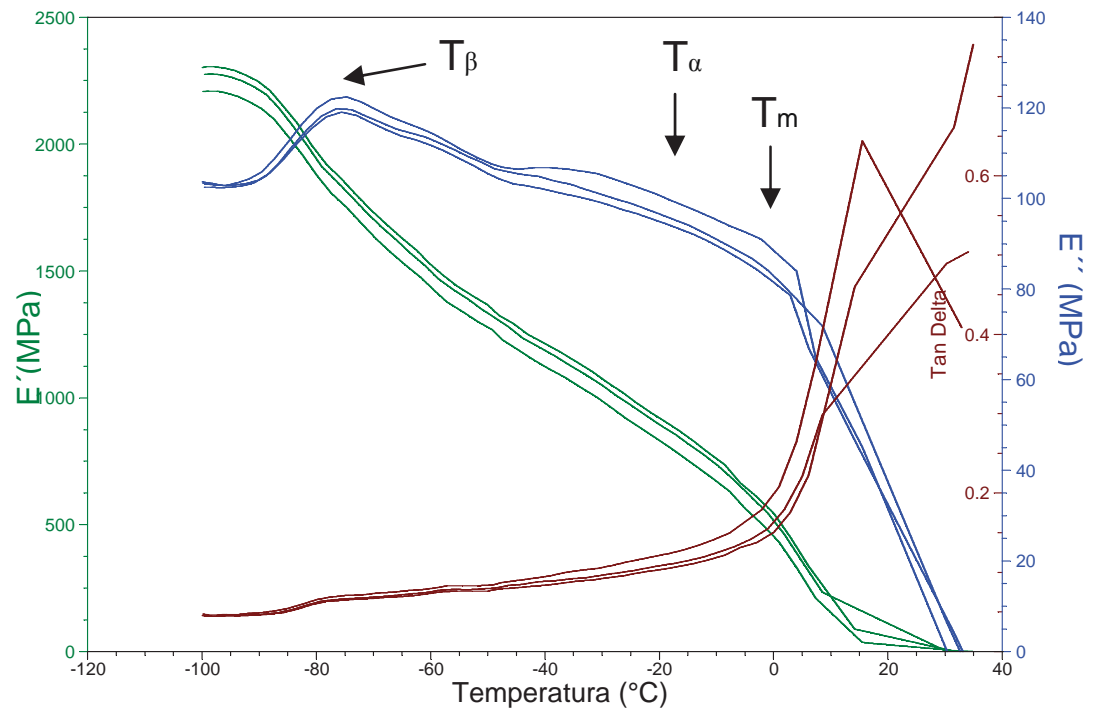

B

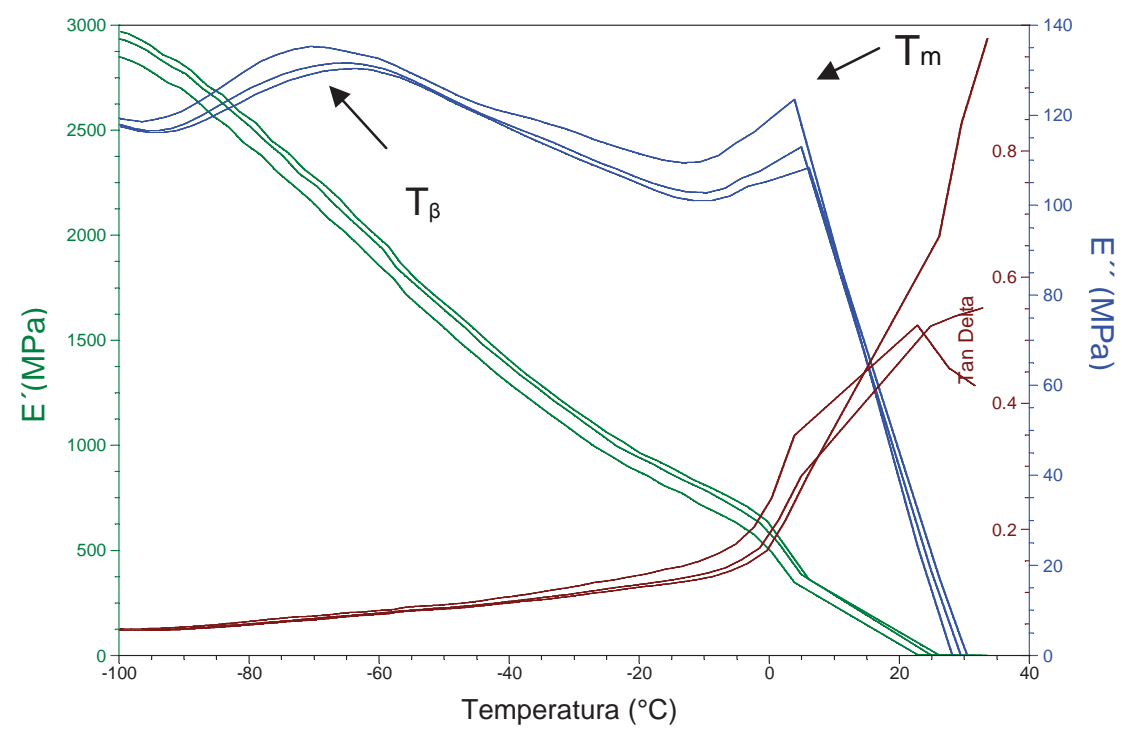

Figura 6.13. Espectros dinámicos mecánicos de la miga de pan a $1 \mathrm{~Hz}, 5 \mathrm{~Hz}$ y $10 \mathrm{~Hz}$. A) con HPMC F 4M; B) con HPMC F 50.

mientras que el pico cercano a $-70^{\circ} \mathrm{C}\left(\mathrm{T}_{\beta}\right)$ que fue observado en todas muestras se ha atribuido a una relajación $\beta$, por debajo de $T_{\alpha}$ (Champion y col., 2000) la cual correspondería a movimientos moleculares más localizados que persisten en el estado vítreo (Johary y col., 1976). La fusión del hielo también se reflejó en los otros módulos: en la $\tan (\delta)$ como un incremento que da lugar a un pico y en $E^{\prime}$ como una inflexión en la curva. 
A

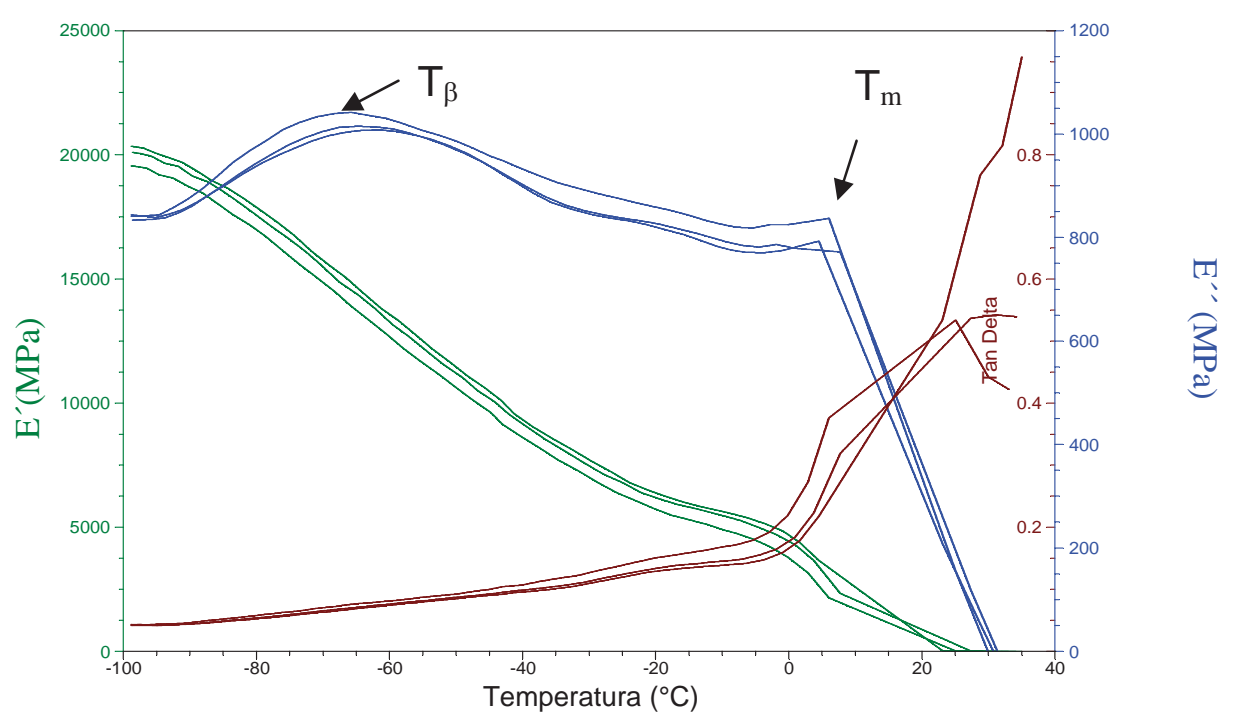

B

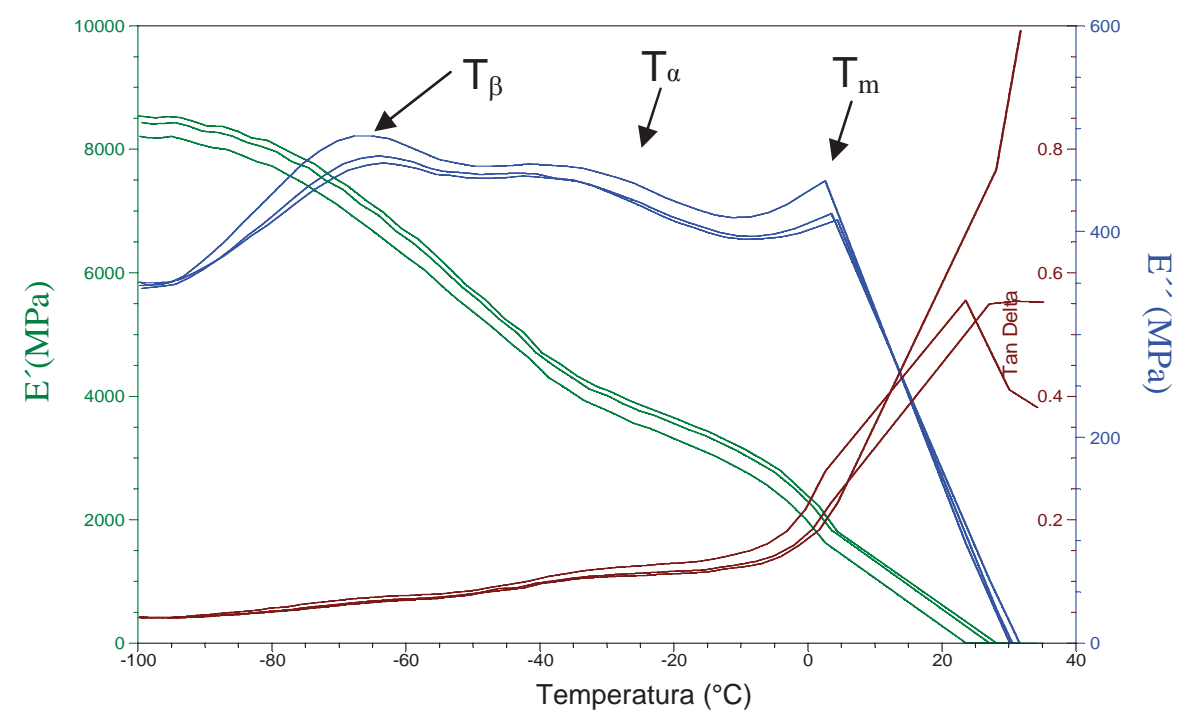

Figura 6.14. Espectros dinámicos mecánicos de la miga de pan a $1 \mathrm{~Hz}, 5 \mathrm{~Hz}$ y $10 \mathrm{~Hz}$. A) con PBM; B) con PAM.

Los espectros mecánicos de las muestras con distintos hidrocoloides fueron diferentes en cuanto a los picos observables. En el caso de las muestras con CMC y MCC (que tiene un cierto porcentaje de $\mathrm{CMC}$ ) se observa, más pronunciado que en las otras muestras, el pico relacionado con la transición vítrea, pudiéndose determinar $\mathrm{T}_{\alpha}$ (Fig. 6.12). Esta transición no es distinguible en las muestras con HPMC F 50 (Fig. 6.13) ni tampoco en el control y aparece esbozada en las muestras con pectinas, particularmente con PAM, y con HPMC F 4M (Fig. 6.14). Por otro lado, la relajación asociada a $T_{\beta}$ (observada en todas las muestras) está indicando que la matriz tiene 
movilidad rotacional en mayor o menor grado en el estado vítreo. Aunque todavía hay controversia respecto al origen de las relajaciones $\beta$, en polisacáridos este evento ha sido relacionado con la rotación de grupos laterales o con cambios conformacionales de la cadena principal (Scandola y col., 1991).

En la Tabla 6.2 se muestran las temperaturas $T_{\alpha}$ y $T_{\beta}$ determinadas a partir de las curvas del módulo de pérdida a las tres frecuencias estudiadas: 1, 5 y $10 \mathrm{~Hz}$. En las tres frecuencias estudiadas el comportamiento fue similar.

Tabla 6.2. Temperaturas de pico correspondientes a las relajaciones $\beta$ y $\alpha$ obtenidas a partir del módulo de pérdida en los espectros mecánicos

\begin{tabular}{cccc}
\hline & \multicolumn{3}{c}{$\mathrm{T}_{\beta}\left({ }^{\circ} \mathrm{C}\right)$} \\
\cline { 2 - 4 } & $1 \mathrm{~Hz}$ & $5 \mathrm{~Hz}$ & $10 \mathrm{~Hz}$ \\
\hline Control & $-72,8 \pm 10,3$ & $-70,7 \pm 12,1$ & $-70,3 \pm 11,5$ \\
\hline MCC & $-72,5 \pm 1,1$ & $-68,6 \pm 5,7$ & $-68,6 \pm 5,7$ \\
\hline CMC & $-73,1 \pm 3,8$ & $-69,5 \pm 3,7$ & $-68,9 \pm 3,9$ \\
\hline HPMC F 4M & $-74,7 \pm 0,1$ & $-72,3 \pm 5,3$ & $-71,7 \pm 5,6$ \\
\hline PBM 50 & $-69,7 \pm 1,2$ & $-66,3 \pm 1,0$ & $-65,5 \pm 1,0$ \\
\hline PAM & $-70,2 \pm 2,9$ & $-69,4 \pm 2,9$ & $-69,2 \pm 2,4$ \\
\hline Control & $-67,4 \pm 0,6$ & $-65,2 \pm 1,4$ & $-64,8 \pm 2,0$ \\
\hline MCC & $-29,3 \pm 0,7$ & $-28,3 \pm 0,8$ & $-28,3 \pm 0,8$ \\
\hline CMC & $-34,7 \pm 8,8$ & $-32,7 \pm 9,3$ & $-31,1 \pm 9,1$ \\
\hline HPMC F 4M & - & - & - \\
\hline HPMC F 50 & - & $5 \mathrm{~Hz}$ & - \\
\hline PBM & - & - & - \\
\hline PAM & - & - & - \\
\hline media \pm DE & & & - \\
\hline
\end{tabular}

A través de análisis de varianza, se compararon las temperaturas de pico de las celulosas entre sí y respecto al control y de las pectinas entre si y respecto al control, 
no hallándose diferencias significativas, probablemente por las altas desviaciones estándar obtenidas en algunos casos.

En la muestra control, en los panes obtenidos con ambas HPMC y con las pectinas no fue posible determinar $T_{\alpha}$ con las condiciones empleadas en este ensayo. Ribotta y Le Bail (2007) se encontraron con una dificultad similar para determinar $T_{\alpha}$ en panes precocidos congelados y almacenados debido a un ensanchamiento en el pico correspondiente a la transición vítrea y una reducción de su intensidad.

Los resultados obtenidos con DMA sugieren que existe un efecto de los hidrocoloides sobre los procesos de relajación de la miga asociados a $T_{\alpha}$ y $T_{\beta}$. Sahagian y Goff (1995) estudiaron las relajaciones moleculares en sistemas sacarosa-hidrocoloide a través de análisis termomecánico (TMA) y encontraron que las diferentes macromoléculas utilizadas (xántica, guar, gelatina) afectaban el proceso de relajación por debajo de la temperatura de transición vítrea. En todos los casos obtenían tiempos de relajación mayores en presencia de los hidrocoloides. Estos autores concluyeron que un mayor enredamiento de los polímeros y el solapamiento de cadenas laterales dificultaban la reorientación molecular inherente a la relajación. Los resultados obtenidos indicarían que las celulosas y pectinas utilizadas inciden de manera diferente en la reorientación de los polímeros de la matriz panaria. Si bien hay diferencias de escala entre los registros, la matriz gluten-almidón-CMC es la que presenta los picos más pronunciados, sugiriendo un mayor grado de relajación del sistema, lo que se relacionaría con menores impedimentos en los movimientos de corto alcance (rotacionales) relacionados con $\mathrm{T}_{\beta}$ y en los de mayor alcance (difusionales) relacionados con $\mathrm{T}_{\alpha}$.

\subsection{Interacción entre los principales componentes de la masa y los aditivos}

\subsubsection{Interacción almidón-aditivo}

\subsubsection{Interacción almidón-aditivo en sistemas modelo}

\subsection{Viscoamilogramas rápidos}

En el viscoamilógrafo una suspensión de almidón o harina en agua es sometida a un programa de calentamiento y enfriamiento mientras se ejerce un esfuerzo mecánico. A lo largo del ensayo se registran los cambios de viscosidad que se pueden relacionar con el grado de disrupción del gránulo de almidón y la interacción con otros componentes presentes. Al comenzar el calentamiento, el gránulo de almidón 
comienza a hidratarse, aumenta de tamaño y se registra un aumento de la viscosidad, posteriormente el gránulo comienza a abrirse y la amilosa sale hacia el medio circundante por lo que la viscosidad continua aumentando. En el pico de máxima viscosidad coexisten gránulos hidratados cuyo tamaño se ha incrementado y amilosa liberada por lo que la resistencia al flujo es máxima. Luego, debido al efecto de cizalla producido por la paleta del amilógrafo y al mantenimiento del sistema a una alta temperatura $\left(95^{\circ} \mathrm{C}\right)$ ocurre una mayor ruptura de los gránulos de almidón por lo cual la viscosidad decrece y se obtiene lo que se conoce como pasta caliente. Al enfriar esta pasta se verifica un aumento de la viscosidad debido a la formación de un gel por alineamiento de las moléculas de amilosa; en ese gel se hallan embebidos restos de gránulos de almidón. Esta región de la curva se conoce como zona de asentamiento (setback). La concentración de almidón o harina usada en este ensayo no supera los $12 \mathrm{~g} / 100 \mathrm{~g}$ pasta por lo que estos sistemas se encuentran muy alejados de la relación sólidos/agua característica de la masa. Sin embargo las variaciones obtenidas en el comportamiento amilográfico pueden arrojar evidencias sobre capacidad de interaccionar entre los componentes, particularmente entre el almidón y los hidrocoloides.

En la Figura 6.15 se muestran los perfiles viscoamilográficos obtenidos para las mezclas de harina-hidrocoloide en ausencia y presencia de $\mathrm{NaCl}$, utilizando la máxima concentración de hidrocoloide (2\% para pectinas, 1,5\% para celulosas modificadas). En general, se puede observar que con la utilización de la CMC en ausencia de $\mathrm{NaCl}$, y con MCC, CMC y HPMC F 4M en presencia de $\mathrm{NaCl}$ se obtuvieron las mayores variaciones en los perfiles respecto al control.

Doublier y col. (1987) establecieron que las pastas de almidón pueden ser descriptas como suspensiones de gránulos de almidón hidratados dispersos en un medio macromolecular continuo, en donde los gránulos hidratados se encuentran formados principalmente por amilopectina mientras que la amilosa ha sido liberada al medio. Basándose en este modelo, Alloncle y col. (1989) postularon que los hidrocoloides se encuentran sólo en la fase continua por lo cual a medida que los gránulos se hidratan la concentración de los hidrocoloides en esta fase aumenta lo cual da lugar a un incremento sustancial de la viscosidad. Por este motivo, las mayores diferencias se observan poco antes y después del pico de viscosidad máxima, etapa del ensayo en que ya ha habido una hidratación sustancial de los gránulos. Las diferencias observadas entre los sistemas $\sin \mathrm{NaCl}$ y con $\mathrm{NaCl}$, podrían relacionarse con las interacciones posibles entre moléculas de hidrocoloides en cada caso. 

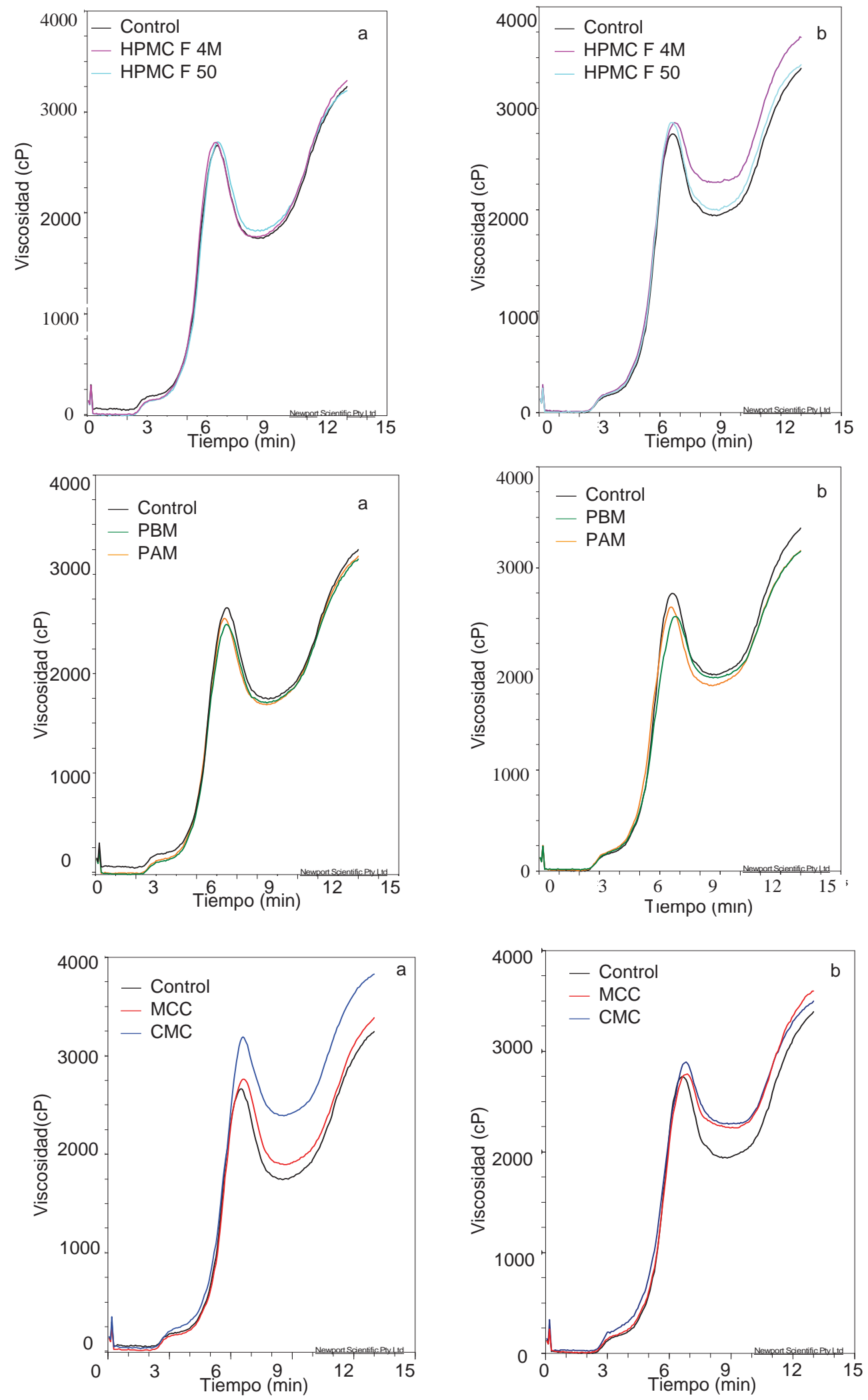

Figura 6.15. Perfil viscoamilográfico de la harina y las mezclas harina hidrocoloide en a) ausencia y b) presencia de $\mathrm{NaCl}(2 \%)$. 
Así en ausencia de $\mathrm{NaCl}$, se observan perfiles muy parecidos al control con la MCC, las HPMC y las pectinas mientras que la CMC da un perfil muy diferente que indicaría por las mayores viscosidades una fuerte hidratación e interacción con otros componentes como amilosa liberada del granulo y proteína. La presencia de $\mathrm{NaCl}$ en la fase continua podría promover las interacciones hidrofóbicas que pueden establecerse entre HPMCs y así ocasionar una mayor viscosidad tanto en el máximo como en el mínimo. Esto se verifica solamente en el caso de HPMC F 4M (Fig. 6.15).

En presencia de $\mathrm{NaCl}$ existe además la posibilidad de un apantallamiento de las cargas que favorecería interacciones antes impedidas por estas. El apantallamiento de cargas podría explicar la mayor viscosidad obtenida en el caso de CMC y MCC, en este último sistema por tener la MCC comercial una cierta cantidad de CMC en su composición. No obstante es mucho mayor la diferencia observada en el perfil amilográfico de los sistemas con $\mathrm{CMC}$ en ausencia de $\mathrm{NaCl}$ (Figura 6.15), cuya causa estaría dada por interacciones de tipo electroestático entre la CMC y otros componentes.

La temperatura de empaste $\left(T_{e}\right)$, es la temperatura en la cual el gránulo de almidón comienza a hincharse lo que se evidencia a través del incremento de la viscosidad. Si bien la temperatura de empaste se ha tratado de utilizar para estimar la temperatura de gelatinización, se ha observado que $T_{p}$ es siempre superior a la temperatura de gelatinización obtenida por DSC (Bao, 2008).

El ANOVA bifactorial arrojó un efecto significativo del $\mathrm{NaCl}$ pero no de los hidrocoloides en la temperatura de empaste. En los sistemas formados por harinahidrocoloide en ausencia de $\mathrm{NaCl}, \mathrm{T}_{\mathrm{e}}$ tomó valores entre 66,2 y $66,9^{\circ} \mathrm{C}$ y entre 67,4 y $69,3^{\circ} \mathrm{C}$ en presencia de $\mathrm{NaCl}$. Sobre el efecto producido por los hidrocoloides en la temperatura de empaste hay resultados contradictorios. Rojas y col. (1999) estudiaron el efecto de PBM y HPMC K 4M al 0,5 y 1,0\% sobre las propiedades de empaste de una harina de trigo comercial y observaron que ambos hidrocoloides aumentaban levemente dicha temperatura. Bárcenas y col. (2009) estudiaron el efecto de PAM y HPMC en concentraciones entre 0 y 1,3\% (base almidón) sobre el comportamiento viscoamilográfico de almidón de trigo, no encontrando diferencias significativas respecto al control. Estas discrepancias pueden radicar en las diferencias estructurales entre los hidrocoloides empleados en estos estudios y también en ligeras diferencias en las condiciones de ensayo.

Se realizó un ANOVA bifactorial para evaluar el efecto de la $\mathrm{NaCl}$ y del agregado de los distintos tipos de celulosa modificada sobre los parámetros amilográficos. Se encontró efecto significativo del $\mathrm{NaCl}$, del tipo de hidrocoloide e interacción 
significativa de $\mathrm{NaCl} \times$ hidrocoloide $(p<0,05)$. En el caso de las mezclas con pectina se observó efecto significativo del $\mathrm{NaCl}$ en todos los parámetros menos en el asentamiento 1, del hidrocoloide en todos los parámetros e interacción significativa en todos los casos menos en la inestabilidad $(p<0,05)$.

En la Figura 6.16 se muestran algunos de los parámetros amilográficos obtenidos para la harina y las mezclas harina-hidrocoloide en ausencia de $\mathrm{NaCl}$.

La viscosidad de pico $\eta_{p}$, parámetro relacionado con la capacidad de absorción de agua del almidón y con la facilidad con que se rompe el gránulo (Copeland y col., 2009), mostró un comportamiento diferencial dependiendo del tipo de hidrocoloide utilizado. Entre las celulosas, el agregado de MCC y CMC ocasionó un incremento significativo de la viscosidad de pico con respecto al control, no así las HPMCs. Las pectinas dieron valores de viscosidad similares entre sí aunque la mezcla con PBM fue significativamente menor que el control.

Christianson (1982) planteó que el efecto producido por los hidrocoloides sobre la viscosidad máxima era debido por un lado a las interacciones establecidas entre las gomas y la amilosa y moléculas de amilopectina de bajo peso molecular solubilizadas y por otro lado a que por el efecto espesante de los hidrocoloides las fuerzas ejercidas sobre los gránulos se incrementan, con respecto a suspensiones acuosas y como consecuencia de estos efectos la ruptura de los gránulos y el exudado de los gránulos se modifican. La reducción en la viscosidad de pico puede atribuirse a un cierto grado de impedimento en la hidratación de los gránulos de almidón o la salida de amilosa.

La inestabilidad definida como $\left(\eta_{\mathrm{p}}-\eta_{\min }\right)$ se relaciona con la resistencia de las suspensiones gelatinizadas al calentamiento sostenido a alta temperatura y al cizallado. Este parámetro fue mínimo para la mezcla harina-CMC, no encontrándose diferencias significativas respecto al control con el empleo de los otros hidrocoloides. Este hecho es positivo ya que indica una mayor estabilidad de las pastas con CMC.

Durante el enfriamiento de la pasta y posterior mantenimiento de la temperatura en $50^{\circ} \mathrm{C}$ el comportamiento del sistema esta gobernado por la amilosa: las moléculas de alinean y forman una red que retiene agua y a los gránulos de almidón fragmentados determinando de este modo la viscosidad final que alcanza el sistema. El asentamiento 1 , diferencia entre esta viscosidad y la mínima alcanzada $\left(\eta_{f}-\eta_{\min }\right)$, y el asentamiento 2, diferencia entre esta viscosidad y la viscosidad de pico: $\left(\eta_{f}-\eta_{p}\right)$, permite evaluar la propensión a la retrogradación del sistema.

Comparando las pastas con celulosas modificadas entre sí y respecto al control no se observaron diferencias en el asentamiento 1 mientras que en el asentamiento 2, CMC lo incrementa y HPMC F 50 lo disminuye. Se ha postulado que CMC se asociaría con 
la amilosa en la pasta caliente ocasionando un incremento de la viscosidad pero esta asociación no sería estable al enfriar (Christianson y col., 1981). Por lo tanto, CMC no inhibiría la retrogradación de la amilosa, lo que podría explicar el incremento observado en el asentamiento 2 en la mezcla harina-CMC.

Analizando las pectinas no hubo diferencias respecto al control en el caso del asentamiento 1 y la mezcla con PBM aumentó significativamente el valor del asentamiento 2 respecto al control.

En la Figura 6.17 se muestran algunos de los parámetros amilográficos obtenidos para la harina y las mezclas harina-hidrocoloide en presencia de $\mathrm{NaCl}$.
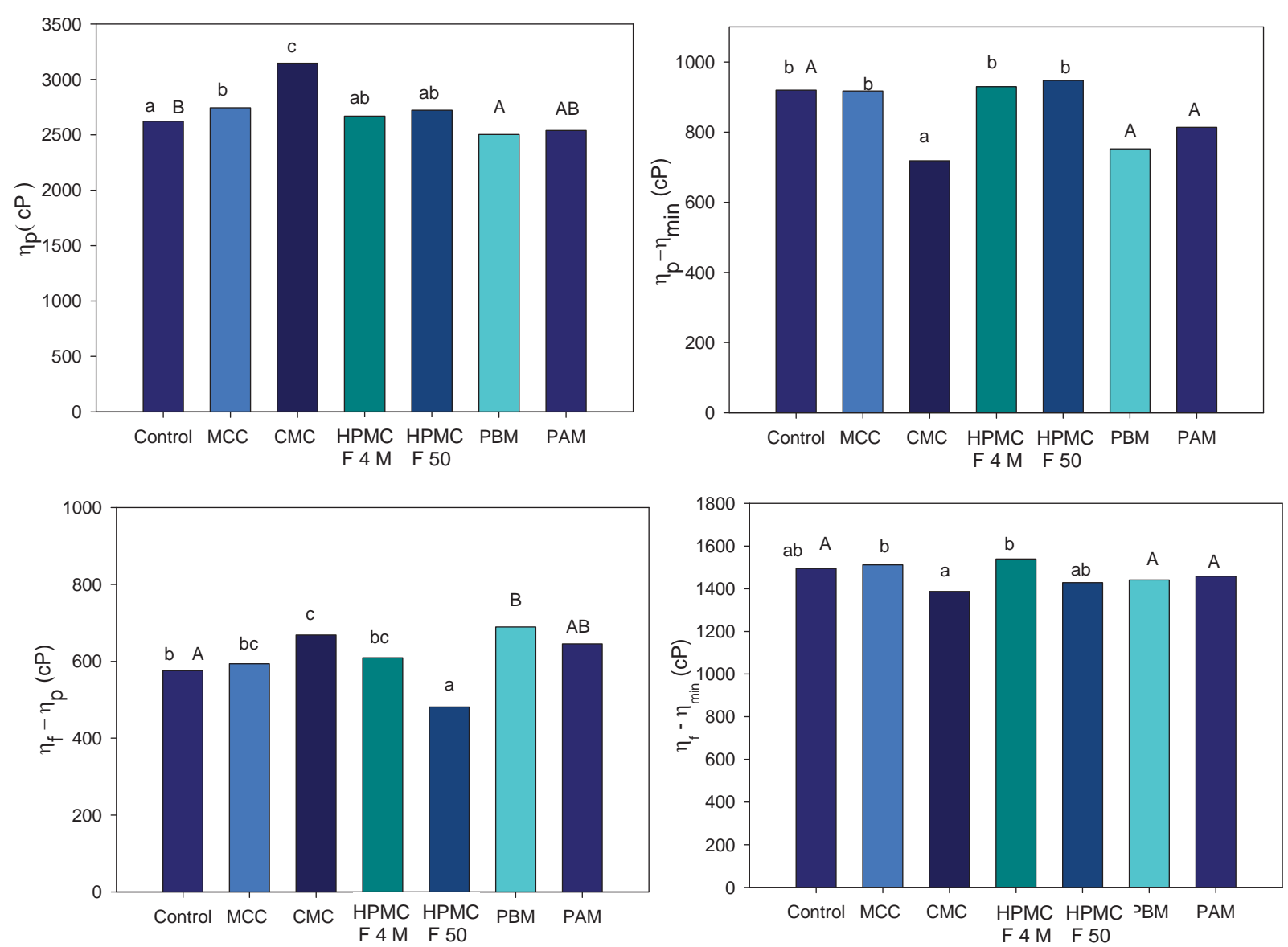

Figura 6.16. Parámetros viscoamilográficos obtenidos para las mezclas harina de trigo -hidrocoloide en ausencia de $\mathrm{NaCl}$. Letras minúsculas diferentes indican diferencias significativas entre celulosas y con el control; letras mayúsculas diferentes indican diferencias significativas entre pectinas y con el control $(p<0,05)$. 
En las mezclas con celulosas en presencia de $\mathrm{NaCl}$ la viscosidad de pico observada fue mayor que en ausencia de $\mathrm{NaCl}$ en todos los casos. Comparando las mezclas con las distintas celulosas en presencia de $\mathrm{NaCl}$ entre sí y respecto al control con $\mathrm{NaCl}$ se observó, como ya se había encontrado en las mezclas sin $\mathrm{NaCl}$, un incremento significativo con el agregado de MCC y CMC. El agregado de pectinas disminuyo la viscosidad de pico respecto al control.

La inestabilidad de las pastas calientes $\left(\eta_{p}-\eta_{\min }\right)$ disminuyó respecto al control en las mezclas con MCC, CMC y HPMC F 4M pero se mantuvo igual al control con HPMC F 50. Esto indica que en general las celulosas modificadas tendieron a estabilizar la pasta en presencia de $\mathrm{NaCl}$ frente al tratamiento térmico y el esfuerzo mecánico. Respecto a las pectinas, PBM tuvo también un efecto estabilizador.
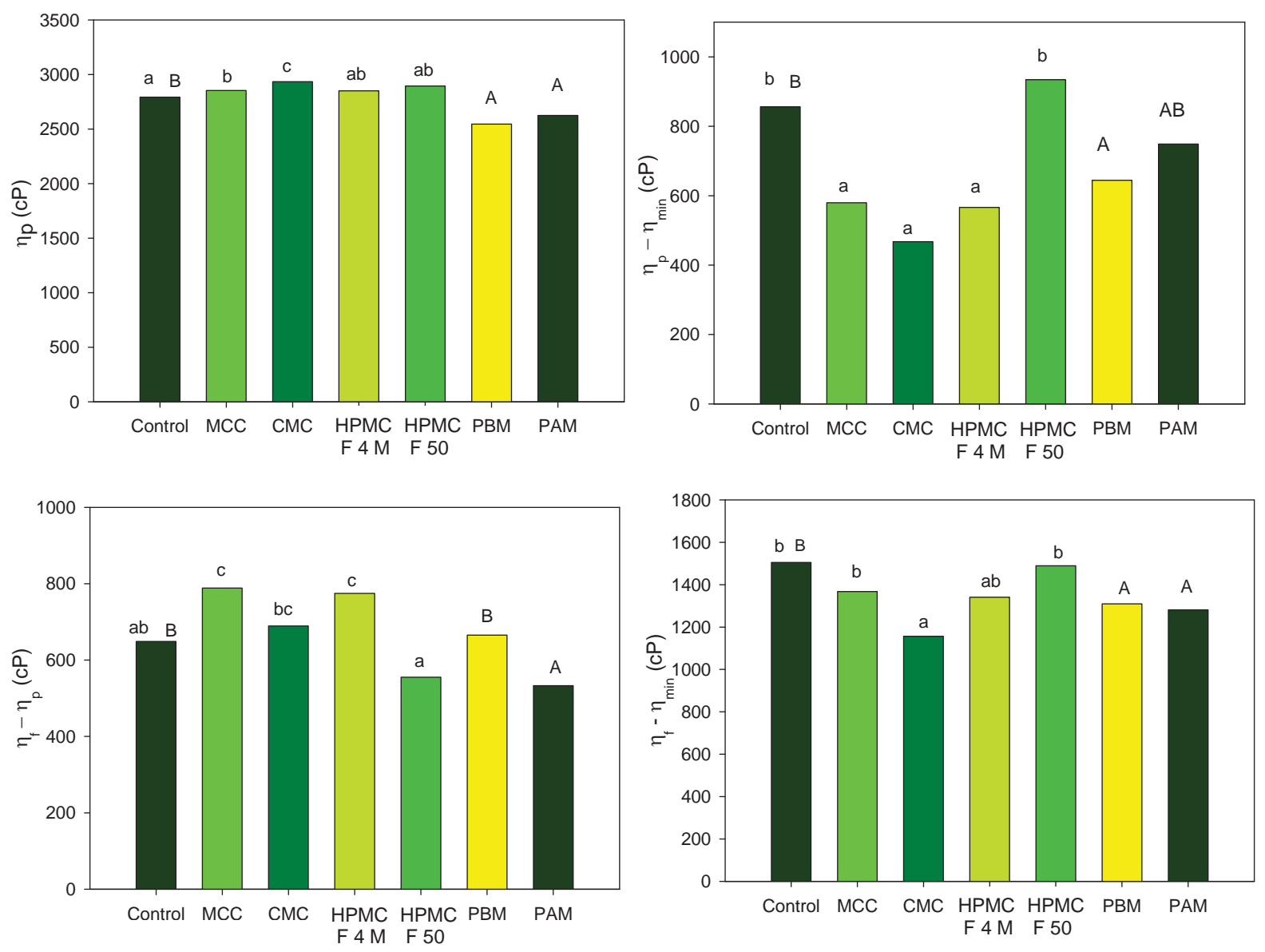

Figura 6.17. Parámetros viscoamilográficos obtenidos para las mezclas harina de trigo -hidrocoloide- $\mathrm{NaCl}$. Letras minúsculas diferentes indican diferencias significativas entre celulosas y con el control; letras mayúsculas diferentes indican diferencias significativas entre pectinas y con el control $(p<0,05)$. 
Respecto al asentamiento 1, solo fue disminuido con CMC y con ambas pectinas. El asentamiento 2 se incrementó en forma equivalente respecto al control con MCC y HPMC F 4M y disminuyó con PAM.

De acuerdo a estos resultados, se observan más cambios en los perfiles viscoamilográficos en presencia de $\mathrm{NaCl}$ que en ausencia de $\mathrm{NaCl}$. Parte de los efectos observados estará probablemente vinculado a las proteínas de gluten, que se han podido hidratar y desplegar por la energía mecánica y el calor entregados a lo que se suma en algunos de los ensayos la presencia de $\mathrm{NaCl}$. Las proteínas dispersas estarían por la tanto más disponibles para interactuar con los hidrocoloides y de acuerdo a la naturaleza de los mismos se darán diferentes efectos en la viscosidad de pico y en la estabilidad del sistema.

Si tomamos como referencia para evaluar la potencialidad de retrogradación al asentamiento 1 ya que refleja el cambio de viscosidad entre el final del calentamiento y el final del ensayo, se observa un escaso efecto de las HPMCs y un efecto protector de las CMC y pectinas. Como el aumento de viscosidad que refleja el asentamiento se debe a la interacción entre cadenas de amilosa, una posible explicación es que con las HPMCs, por impedimento estérico y una mayor hidrofobicidad no se vería tan favorecida la interacción amilosa-HPMCs como la amilosa-amilosa.

\subsection{Gelatinización de almidón}

La gelatinización es una transición endotérmica en donde el gránulo nativo de almidón, en presencia de suficiente cantidad de agua se hidrata y pierde su organización y cristalinidad. Como se dijo anteriormente, esta transición es importante en el proceso de panificación durante la etapa de horneado porque contribuye a las características finales de la miga y además es esencial para hacer digerible al almidón.

Por otro lado es reconocida la influencia del fenómeno de cristalización de amilosa y amilopectina (retrogradación) en los cambios detectados en la textura de la miga de pan durante su almacenamiento. En particular la calorimetría diferencial de barrido ha sido una herramienta útil para la evaluación de este fenómeno (Slade y Levine, 1987). En el presente trabajo ha sido de interés analizar el efecto de los hidrocoloides tanto sobre la gelatinización como sobre la retrogradación, teniendo en cuenta que al ser moléculas hidrofílicas podrían afectar la disponibilidad de agua necesaria para ambos procesos. En primer término se analizó su influencia en la gelatinización en sistemas modelo y luego en la masa.

A partir de almidón extraído de la harina 000 según se describe en el ítem 2.2.5.3.1.1 se prepararon mezclas de almidón-hidrocoloide en ausencia y presencia de $\mathrm{NaCl}$ las 
cuales se sometieron a un calentamiento desde $5^{\circ} \mathrm{C}$ hasta $140^{\circ} \mathrm{C}$ en el calorímetro diferencial de barrido.

En la Figura 6.18 se muestran a modo de ejemplo los termogramas típicos para el sistema almidón sin hidrocoloide (control) sin y con $\mathrm{NaCl}$ y para la mezcla almidón$\mathrm{CMC}$ sin y con $\mathrm{NaCl}$. Se puede apreciar que el pico correspondiente a la gelatinización del almidón se desdobló en dos endotermas debido a que la gelatinización ocurrió bajo condiciones de restricción de agua (37,4 g agua/100 g mezcla). El tercer pico observable corresponde a la disociación del complejo amilosa-lípido. En presencia de $\mathrm{NaCl}$ se observa un corrimiento de las temperaturas características de la segunda endoterma a valores más altos. El agregado de hidrocoloide no modificó sustancialmente el tipo de perfil del termograma.

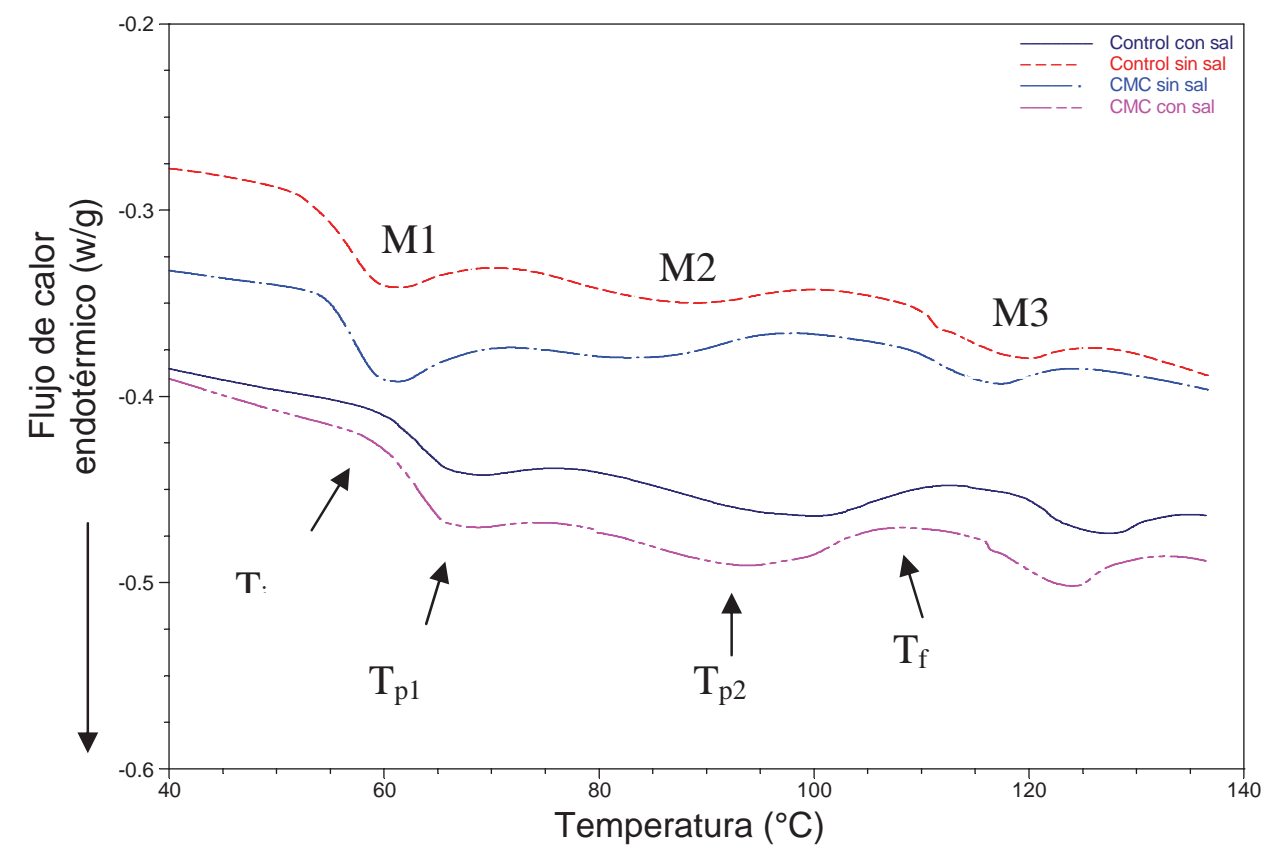

Figura 6.18. Termogramas de almidón y de los sistemas almidón-CMC, ambos en ausencia y presencia de $\mathrm{NaCl}$. M1 y M2 endotermas de gelatinización, M3 endoterma de disociación del complejo amilosa-lípido. $\mathrm{T}_{\mathrm{i}}$ : temperatura de inicio de gelatinización, $T_{p 1}$ y $T_{p 2}$ temperaturas de pico, $T_{f}$ : temperatura final

Diversos autores han estudiado esta transición a través de calorimetría diferencial de barrido utilizando diversas condiciones de disponibilidad de agua (Donovan, 1979; Biliaderis, 1983, 1992). Dependiendo de la relación almidón/agua el proceso endotérmico puede transcurrir en una o dos etapas. En los sistemas en donde se tiene 
agua en exceso se observa una única endoterma mientras que en sistemas donde la relación almidón/agua es alta aparece una segunda endoterma a mayores temperaturas, la cual se convierte en predominante a bajos contenidos de agua. Mientras la primera transición ocurre prácticamente a temperatura constante, la segunda endoterma se desplaza a temperaturas mayores a medida que el contenido de agua disminuye (Biliaderis, 1983, 1986). La aparición de múltiples endotermas ha sido objeto de diversas explicaciones. Una de las hipótesis es que los cristales menos estables funden primero dando lugar a la primera endoterma y dejando así menos agua disponible para los cristales más estables, cuya fusión daría lugar a la segunda endoterma, a mayores temperaturas (Evans y Haisman, 1982; Zobel, 1984) Según otros autores (Biliaderis, 1992) el perfil de endotermas múltiples simplemente refleja procesos de fusión y reorganización granular que ocurren simultáneamente durante la gelatinización. Se puede generalizar que para contenidos de agua altos, superiores a $60-70 \%(\mathrm{p} / \mathrm{p})$ se observa una sola endoterma, para contenidos inferiores a $30-40 \%$ $(\mathrm{p} / \mathrm{p})$ aparece también una única endoterma a altas temperaturas y para contenidos intermedios aparecen dos endotermas o desdoblamiento (Roos, 1995).

En la Tabla 6.3 se muestran los valores hallados para la entalpía $(\Delta H)$ y las temperaturas de inicio $\left(T_{i}\right)$, de ambos picos $\left(T_{p 1}, T_{p 2}\right)$ y de finalización $\left(T_{f}\right)$ de gelatinización en sistemas almidón-celulosa en ausencia y en presencia de $\mathrm{NaCl}$. A través de un análisis de varianza bifactorial se analizó el efecto tanto de $\mathrm{NaCl}$ como de la presencia de los distintos hidrocoloides y la posible interacción. El $\mathrm{NaCl}$ tuvo un efecto significativo $(p<0,05)$ sobre todas las temperaturas pero no en la entalpía de gelatinización. Se encontró un efecto significativo de la presencia de hidrocoloides en $\mathrm{T}_{\mathrm{p} 2}, \mathrm{~T}_{\mathrm{f}} \mathrm{y} \Delta \mathrm{H}$. Se detectó interacción significativa $\mathrm{NaCl}$ x hidrocoloide sobre la entalpía y $\mathrm{T}_{\mathrm{p} 2}$

En ausencia de $\mathrm{NaCl}$ se observa que los hidrocoloides no afectan las temperatura final pero en presencia de $\mathrm{NaCl}$ se observa una tendencia a valores más bajos respecto al control con $\mathrm{NaCl}$, que llega a ser significativa en el caso de HPMC F 50. Respecto a la entalpía en general no se ve modificada pero si se observa un valor más alto para $\mathrm{CMC}$ en ausencia de $\mathrm{NaCl}$.

Los resultados correspondientes a los sistemas con pectina se muestran en la Tabla 6.4. Se encontró efecto significativo $(p<0,05)$ del $\mathrm{NaCl}$ en todas las temperaturas y del hidrocoloide sobre $T_{i}, T_{p 1}$ y $T_{p 2}$. Sobre $\Delta H$ no se observó efecto ni del $\mathrm{NaCl}$ ni del hidrocoloide. 
Tabla 6.3. Gelatinización del almidón en mezclas almidón-celulosas modificadas

\begin{tabular}{|c|c|c|c|c|c|c|}
\hline & sistema & $\mathrm{T}_{\mathrm{i}}\left({ }^{\circ} \mathrm{C}\right)$ & $\mathrm{T}_{\mathrm{p} 1}\left({ }^{\circ} \mathrm{C}\right)$ & $\mathrm{T}_{\mathrm{p} 2}\left({ }^{\circ} \mathrm{C}\right)$ & $\mathrm{T}_{\mathrm{f}}\left({ }^{\circ} \mathrm{C}\right)$ & $\begin{array}{c}\Delta \mathrm{H}(\mathrm{J} / \mathrm{g} \\
\text { almidón) }\end{array}$ \\
\hline \multirow{5}{*}{$\begin{array}{c}\sin \\
\mathrm{NaCl}\end{array}$} & Control & $52,2 \pm 1,02^{a}$ & $59,9 \pm 0,0^{a}$ & $88,1 \pm 0,0^{a}$ & $99,5 \pm 0,2^{a}$ & $10,3 \pm 0,2^{a}$ \\
\hline & $\overline{M C C}$ & $52,9 \pm 0,8^{a}$ & $60,2 \pm 0,1^{a}$ & $88,3 \pm 0,2^{a}$ & $99,0 \pm 1,4^{a}$ & $11,2 \pm 0,6^{a b}$ \\
\hline & CMC & $53,1 \pm 0,8^{a}$ & $60,6 \pm 0,6^{a}$ & $86,3 \pm 0,3^{a}$ & $96,8 \pm 1,4^{a}$ & $14,0 \pm 0,6^{b}$ \\
\hline & HPMC F 4M & $53,1 \pm 0,2^{a}$ & $60,3 \pm 0,5^{a}$ & $88,1 \pm 0,5^{a}$ & $98,4 \pm 0,5^{a}$ & $11,9 \pm 0,6^{a b}$ \\
\hline & HPMC F 50 & $53,3 \pm 0,3^{a}$ & $60,5 \pm 0,0^{a}$ & $87,6 \pm 1,4^{a}$ & $97,9 \pm 0,2^{a}$ & $11,7 \pm 0,2^{a b}$ \\
\hline \multirow{5}{*}{$\begin{array}{c}\mathrm{con} \\
\mathrm{NaCl}\end{array}$} & Control & $58,1 \pm 0,1^{\mathrm{a}}$ & $67,5 \pm 0,4^{a}$ & $100,0 \pm 0,9^{b}$ & $112,5 \pm 0,5^{b}$ & $10,8 \pm 0,2^{a}$ \\
\hline & MCC & $57,6 \pm 0,5^{a}$ & $66,7 \pm 0,9^{a}$ & $100,2 \pm 0,5^{b}$ & $111,1 \pm 1,6^{a b}$ & $10,7 \pm 0,6^{a}$ \\
\hline & $\mathrm{CMC}$ & $57,7 \pm 0,0^{a}$ & $67,0 \pm 0,8^{a}$ & $95,4 \pm 0,3^{a}$ & $108,7 \pm 0,7^{a b}$ & $11,9 \pm 0,4^{a}$ \\
\hline & HPMC F 4M & $58,4 \pm 0,6^{a}$ & $67,5 \pm 1,7^{\mathrm{a}}$ & $92,75 \pm 0,9^{a}$ & $108,2 \pm 0,9^{a b}$ & $10,3 \pm 0,0^{a}$ \\
\hline & HPMC F 50 & $58,5 \pm 0,2^{a}$ & $65,8 \pm 0,2^{a}$ & $93,2 \pm 0,7^{a}$ & $107,5 \pm 1,1^{a}$ & $12,1 \pm 0,6^{a}$ \\
\hline
\end{tabular}

media $\pm \mathrm{DE}$. En de la misma columna y dentro de cada grupo $(\sin \mathrm{NaCl}, \operatorname{con} \mathrm{NaCl})$, letras diferentes indican diferencias significativas $(p<0,05)$.

Tabla 6.4. Gelatinización del almidón en mezclas almidón- pectinas

\begin{tabular}{ccccccc}
\hline & sistema & $\mathrm{T}_{\mathrm{i}}\left({ }^{\circ} \mathrm{C}\right)$ & $\mathrm{T}_{\mathrm{p} 1}\left({ }^{\circ} \mathrm{C}\right)$ & $\mathrm{T}_{\mathrm{p} 2}\left({ }^{\circ} \mathrm{C}\right)$ & $\mathrm{T}_{\mathrm{f}}\left({ }^{\circ} \mathrm{C}\right)$ & $\begin{array}{c}\Delta \mathrm{H}(\mathrm{J} / \mathrm{g} \\
\text { almidón })\end{array}$ \\
\hline \multirow{2}{*}{$\sin$} & Control & $52,2 \pm 1,02^{\mathrm{a}}$ & $59,9 \pm 0,0^{\mathrm{a}}$ & $88,1 \pm 0,0^{\mathrm{a}}$ & $99,5 \pm 0,2^{\mathrm{ab}}$ & $10,3 \pm 0,2^{\mathrm{a}}$ \\
\cline { 2 - 7 } $\mathrm{NaCl}$ & $\mathrm{PBM}$ & $54,5 \pm 0,5^{\mathrm{a}}$ & $61,5 \pm 0,9^{\mathrm{a}}$ & $87,9 \pm 2,0^{\mathrm{a}}$ & $97,3 \pm 0,2^{\mathrm{a}}$ & $11,7 \pm 1,7^{\mathrm{a}}$ \\
\cline { 2 - 7 } & $\mathrm{PAM}$ & $54,1 \pm 0,1^{\mathrm{a}}$ & $61,0 \pm 0,3^{\mathrm{a}}$ & $89,7 \pm 0,1^{\mathrm{a}}$ & $101,8 \pm 1,9^{\mathrm{b}}$ & $10,6 \pm 0,5^{\mathrm{a}}$ \\
\hline \multirow{2}{*}{$\mathrm{con}$} & Control & $58,1 \pm 0,1^{\mathrm{a}}$ & $67,5 \pm 0,4^{\mathrm{a}}$ & $100,0 \pm 0,9^{\mathrm{b}}$ & $112,5 \pm 0,5^{\mathrm{a}}$ & $10,8 \pm 0,2^{\mathrm{a}}$ \\
\cline { 2 - 7 } $\mathrm{NaCl}$ & PBM & $58,0 \pm 0,5^{\mathrm{a}}$ & $66,7 \pm 0,0^{\mathrm{a}}$ & $95,1 \pm 0,0^{\mathrm{a}}$ & $109,8 \pm 0,7^{\mathrm{a}}$ & $12,1 \pm 0,1^{\mathrm{b}}$ \\
\cline { 2 - 7 } & PAM & $58,2 \pm 0,9^{\mathrm{a}}$ & $66,2 \pm 0,5^{\mathrm{a}}$ & $93,2 \pm 0,6^{\mathrm{a}}$ & $108 \pm 1,9^{\mathrm{a}}$ & $12,6 \pm 0,1^{\mathrm{b}}$ \\
\hline
\end{tabular}

Los valores se expresan como: media $\pm \mathrm{DE}$. Dentro de la misma columna y en cada grupo ( $\sin \mathrm{NaCl}$, con $\mathrm{NaCl}$ ), letras diferentes indican diferencias significativas $(p<0,05)$.

Analizando las diferencias dentro de cada grupo $\sin$ y con $\mathrm{NaCl}$, se observó que en las masas con pectinas en presencia de $\mathrm{NaCl}$ hay una disminución significativa de la temperatura de pico de la segunda endoterma y un aumento de la entalpía de gelatinización del almidón. 
La endoterma correspondiente al complejo amilosa lípido también se vio significativamente afectada por la presencia de $\mathrm{NaCl}$ corriéndose las temperaturas inicial $\left(108,3^{\circ} \mathrm{C}\right)$, de pico $\left(120,1^{\circ} \mathrm{C}\right)$ y final $\left(127,4^{\circ} \mathrm{C}\right)$ a valores más altos $\left(118,3^{\circ} \mathrm{C}\right.$, $126,6^{\circ} \mathrm{C}$ y $134,8^{\circ} \mathrm{C}$ respectivamente). Los resultados completos se muestran en el Anexo. No hubo un efecto significativo de los hidrocoloides en los niveles empleados. La movilidad del agua y su capacidad de actuar en la gelatinización se ha visto que decrece en presencia de sacarosa y de cloruro de sodio (Chinachoti 1991 a, b) causando un corrimiento a temperaturas más altas. Esto explica los valores obtenidos al agregar $\mathrm{NaCl}$ al sistema modelo. Como se muestra en la Tabla 6.3, los hidrocoloides no han afectado mayormente los parámetros de gelatinización, probablemente porque los niveles de agua utilizados aun son suficientes para que haya disponibilidad de la misma en el proceso. Ferrero y col. (1996) informaron que el efecto de algunas gomas (guar, xantica, alginato) sobre la temperatura final de gelatinización era significativo por debajo de ciertos niveles de humedad en sistemas modelo almidón-hidrocoloide. Este hecho también dependerá de la capacidad de ligar agua de cada polisacárido. Es interesante destacar lo que se observa al combinar $\mathrm{NaCl}$ e hidrocoloide. Si se comparan los valores de corrimientos de las temperaturas finales de los sistemas con $\mathrm{NaCl}+$ hidrocoloide respecto del control $\sin \mathrm{NaCl}$, se observa que tienen una tendencia a ser menores que el corrimiento producido cuando sólo se agrega $\mathrm{NaCl}$. Esto está indicando probablemente una interacción $\mathrm{NaCl}$ hidrocoloide que favorece la disponibilidad de agua para la gelatinización respecto a la $\mathrm{NaCl}$ sola. Chaplin (2011) ha propuesto que los hidrocoloides cargados (como pectinas y $\mathrm{CMC}$ en el caso del presente trabajo) generan una capa de agua de alta densidad en torno a las moléculas de carbohidrato, la que ha su vez genera una capa contigua de baja densidad. Por otro lado superficies moleculares hidrofóbicas favorecen una zona de baja densidad de agua en torno a la molécula. Los iones caotrópicos, que ligan agua más débilmente tienden a ubicarse en las zonas de menor densidad donde es más fácil su hidratación. Los iones cosmotrópicos que tienen alta densidad de carga y ligan agua más fuertemente se ubican preferencialmente en las zonas de agua de alta densidad. Por sus características, los iones constituyentes del cloruro de sodio podrían ver favorecida su presencia en zonas cercanas a las macromoléculas. Esta formación de gradientes inducida por los hidrocoloides podría generar tal vez una mayor disponibilidad de agua para procesos como el de gelatinización. 
Así, aunque el corrimiento a mayores temperaturas por efecto de la $\mathrm{NaCl}$ se verifica aun en las muestras con hidrocoloides, existe una atenuación del mismo debido a la presencia de estos.

\subsubsection{Interacción almidón-aditivo en masa}

\subsection{Gelatinización del almidón}

Una vez evaluadas las transiciones en los sistemas modelo se ensayaron las masas sin y con $\mathrm{NaCl}$ y el efecto de los hidrocoloides. Los perfiles de los termogramas obtenidos fueron similares a los de los sistemas modelo, observándose también un desdoblamiento en dos picos de la endoterma que se puede atribuir a lo explicado anteriormente.

Los parámetros de gelatinización de sistemas con celulosas modificadas y pectinas se muestran en las Tablas 6.5 y 6.6, respectivamente. En el caso de las masas con celulosas se observó un efecto significativo del $\mathrm{NaCl}(p<0,05)$ sobre todas las temperaturas pero no sobre la entalpía. Hubo un efecto significativo del tipo hidrocoloide (sobre $\mathrm{T}_{\mathrm{i}}, \mathrm{T}_{\mathrm{p} 2}, \mathrm{~T}_{\mathrm{f}}$ ) e interacción $\mathrm{NaCl} \times$ hidrocoloide significativa en algunos parámetros $\left(\mathrm{T}_{\mathrm{i}}, \mathrm{T}_{\mathrm{p} 1}\right.$ y $\left.\mathrm{T}_{\mathrm{f}}\right)$.

Analizando el efecto del agregado de celulosas sobre las temperaturas dentro de cada grupo de masas ( $\sin$ y con $\mathrm{NaCl}$ ), se destaca el efecto significativo sobre la temperatura final con todos los hidrocoloides en las masas con $\mathrm{NaCl}$. En las masas sin $\mathrm{NaCl}, \mathrm{T}_{\mathrm{f}}$ fue solo afectada significativamente por agregado de HPMC F 4M. Si bien se observaron en las otras temperaturas unos pocos casos de corrimientos significativos no se verificó un tendencia general de disminución por agregado de hidrocoloide. La entalpía de gelatinización tampoco varió dentro de cada grupo por agregado de hidrocoloide.

En el caso de las pectinas se encontró efecto significativo del $\mathrm{NaCl}(\mathrm{p}<0,05)$ sobre todas las temperaturas pero no sobre la entalpía. Aunque no hubo efecto significativo del hidrocoloide sobre ningún parámetro, si se verificó efecto significativo $\mathrm{NaCl} x$ hidrocoloide (en $\mathrm{T}_{\mathrm{i}}, \mathrm{T}_{\mathrm{p} 1} \mathrm{~T}_{\mathrm{f}} \mathrm{y} \Delta \mathrm{H}$ ). Como en los casos anteriores, se observó una disminución de $\mathrm{T}_{\mathrm{f}}$ en las muestras con $\mathrm{NaCl}$ por agregado de pectinas. 
Tabla 6.5. Gelatinización del almidón en masas con celulosas modificadas

\begin{tabular}{|c|c|c|c|c|c|c|}
\hline & Muestra & $\mathrm{T}_{\mathrm{i}}\left({ }^{\circ} \mathrm{C}\right)$ & $\mathrm{T}_{\mathrm{p} 1}\left({ }^{\circ} \mathrm{C}\right)$ & $\mathrm{T}_{\mathrm{p} 2}\left({ }^{\circ} \mathrm{C}\right)$ & $\mathrm{T}_{\mathrm{f}}\left({ }^{\circ} \mathrm{C}\right)$ & $\begin{array}{c}\Delta \mathrm{H}(\mathrm{J} / \mathrm{g} \\
\text { almidón) }\end{array}$ \\
\hline & Control & $57,7 \pm 0,5^{\mathrm{ab}}$ & $66,2 \pm 0,0^{a b}$ & $86,6 \pm 0,8^{a}$ & $95,3 \pm 1,2^{b}$ & $7,8 \pm 0,6^{a}$ \\
\hline & MCC & $57,5 \pm 0,2^{a b}$ & $66,6 \pm 0,1^{a b}$ & $84,8 \pm 0,3^{a}$ & $94,4 \pm 0,0^{b}$ & $8,3 \pm 0,1^{a}$ \\
\hline $\sin$ & $\mathrm{CMC}$ & $58,2 \pm 0,6^{a b}$ & $67,3 \pm 0,9^{a b}$ & $86,1 \pm 0,8^{a}$ & $94,7 \pm 0,5^{b}$ & $7,5 \pm 0,6^{a}$ \\
\hline \multirow[t]{4}{*}{$\mathrm{NaCl}$} & HPMC F 4M & $56,6 \pm 0,5^{a}$ & $65,1 \pm 0,0^{a}$ & $84,0 \pm 1,1^{a}$ & $91,5 \pm 0,2^{a}$ & $8,7 \pm 0,3^{a}$ \\
\hline & HPMC F 50 & $58,7 \pm 0,3^{b}$ & $67,8 \pm 0,6^{b}$ & $85,7 \pm 0,2^{a}$ & $94,9 \pm 0,4^{b}$ & $7,7 \pm 0,5^{a}$ \\
\hline & Control & $62,3 \pm 0,7^{b}$ & $72,7 \pm 1,2^{a}$ & $92,4 \pm 0,5^{b}$ & $102,9 \pm 0,8^{c}$ & $6,9 \pm 0,8^{a}$ \\
\hline & $\mathrm{MCC}$ & $61,0 \pm 0,7^{\mathrm{ab}}$ & $71,2 \pm 0,2^{a}$ & $90,5 \pm 0,4^{a b}$ & $98,2 \pm 0,3^{a b}$ & $8,2 \pm 0,6^{a}$ \\
\hline con & CMC & $59,8 \pm 0,5^{a}$ & $72,4 \pm 0,8^{a}$ & $92,4 \pm 0,3^{b}$ & $100,1 \pm 0,8^{b}$ & $8,6 \pm 0,4^{a}$ \\
\hline \multirow[t]{2}{*}{$\mathrm{NaCl}^{-}$} & HPMC F 4M & $60,8 \pm 0,7^{a b}$ & $71,1 \pm 1,2^{a}$ & $89,6 \pm 0,9^{a}$ & $98,0 \pm 0,6^{a}$ & $8,5 \pm 0,8^{a}$ \\
\hline & HPMC F 50 & $62,3 \pm 1,2^{a b}$ & $71,9 \pm 0,6^{a}$ & $90,8 \pm 0,9^{a b}$ & $99,9 \pm 1,0^{a b}$ & $7,8 \pm 0,3^{a}$ \\
\hline
\end{tabular}

media $\pm \mathrm{DE}$. Dentro de la misma columna y en cada grupo ( $\sin \mathrm{NaCl}$, con $\mathrm{NaCl}$ ), letras diferentes indican diferencias significativas $(p<0,05)$.

En general, no se observó efecto de los hidrocoloides sobre las temperaturas características del complejo amilosa-lípido pero sí un corrimiento a valores más altos por presencia de $\mathrm{NaCl}$ (anexo 4). Por otro lado, se observó un aumento en la entalpía de disociación debido al agregado de CMC, HPMC F 4M, PBM Y PAM.

Tabla 6.6. Gelatinización del almidón en masas con pectinas

\begin{tabular}{ccccccc}
\hline \multicolumn{2}{c}{ Muestra } & $\mathrm{T}_{i}\left({ }^{\circ} \mathrm{C}\right)$ & $\mathrm{T}_{\mathrm{p} 1}\left({ }^{\circ} \mathrm{C}\right)$ & $\mathrm{T}_{\mathrm{p} 2}\left({ }^{\circ} \mathrm{C}\right)$ & $\mathrm{T}_{\mathrm{f}}\left({ }^{\circ} \mathrm{C}\right)$ & $\Delta \mathrm{H}(\mathrm{J} / \mathrm{g}$ almidón $)$ \\
\hline \multirow{3}{*}{ Sin NaCl } & Control & $57,7 \pm 0,5^{\mathrm{a}}$ & $66,2 \pm 0,0^{\mathrm{a}}$ & $86,6 \pm 0,8^{\mathrm{a}}$ & $95,3 \pm 1,2^{\mathrm{a}}$ & $7,8 \pm 0,6^{\mathrm{a}}$ \\
\cline { 2 - 6 } & PBM & $59,7 \pm 0,2^{\mathrm{a}}$ & $68,1 \pm 0,6^{\mathrm{b}}$ & $87,5 \pm 0,3^{\mathrm{a}}$ & $96,5 \pm 1,9^{\mathrm{a}}$ & $7,3 \pm 0,5^{\mathrm{a}}$ \\
\cline { 2 - 6 } & PAM & $58,9 \pm 0,6^{\mathrm{a}}$ & $67,9 \pm 0,4^{\mathrm{ab}}$ & $87,6 \pm 0,4^{\mathrm{a}}$ & $96,5 \pm 0,3^{\mathrm{a}}$ & $8,0 \pm 0,9^{\mathrm{a}}$ \\
\hline \multirow{3}{*}{ Con $\mathrm{NaCl}$} & Control & $62,3 \pm 0,7^{\mathrm{a}}$ & $72,7 \pm 1,2^{\mathrm{a}}$ & $92,4 \pm 0,5^{\mathrm{a}}$ & $102,9 \pm 0,8^{\mathrm{b}}$ & $6,9 \pm 0,8^{\mathrm{a}}$ \\
\cline { 2 - 6 } & PBM & $61,0 \pm 0,7^{\mathrm{a}}$ & $72,4 \pm 0,5^{\mathrm{a}}$ & $90,6 \pm 1,6^{\mathrm{a}}$ & $98,9 \pm 0,5^{\mathrm{a}}$ & $8,9 \pm 0,6^{\mathrm{b}}$ \\
\cline { 2 - 6 } & PAM & $61,8 \pm 0,8^{\mathrm{a}}$ & $71,9 \pm 0,4^{\mathrm{a}}$ & $90,8 \pm 0,8^{\mathrm{a}}$ & $98,7 \pm 0,4^{\mathrm{a}}$ & $7,5 \pm 0,5^{\mathrm{ab}}$ \\
\hline
\end{tabular}

media \pm DE. Dentro de la misma columna y en cada grupo (sin $\mathrm{NaCl}$, con $\mathrm{NaCl})$, letras diferentes indican diferencias significativas $(p<0,05)$. 
Comparando con los resultados obtenidos para el sistema modelo almidónhidrocoloide se observa en general la misma tendencia, la presencia de hidrocoloides compensa parcialmente el efecto de corrimiento a mayores temperaturas observado al agregar $\mathrm{NaCl}$.

\subsection{Retrogradación del almidón en presencia de hidrocoloides}

Debido a que la retrogradación de amilopectina es reversible por debajo de los $100^{\circ} \mathrm{C}$, (Miles y col., 1985) es posible su estudio por calorimetría diferencial de barrido. Se realiza un registro del calor necesario para volver a fundir los cristales de amilopectina que han cristalizado, por lo que el valor de entalpía obtenido es de igual magnitud pero signo contrario al de retrogradación. Con la finalidad de evaluar la retrogradación del almidón se simuló la cocción de la masa en un calorímetro diferencial de barrido (DSC) y las cápsulas fueron almacenadas durante 3 y 7 días a $20^{\circ} \mathrm{C}$. En estos ensayos se utilizaron únicamente masas con $\mathrm{NaCl}$, en los mismos niveles que se emplearon en la panificación. En la Tabla 6.7 se muestran los resultados obtenidos para los sistemas con celulosas modificadas.

Se registraron algunas diferencias respecto al control en las temperaturas de inicio, de pico y final de acuerdo al tipo de hidrocoloide utilizado. Luego de 3 días de almacenamiento, los sistemas con HPMC F 4M y F 50 mostraron una temperatura de inicio de retrogradación significativamente inferior a las otras masas y al control. La temperatura final fue significativamente superior con MCC y CMC. Respecto a la entalpía, solamente el sistema con HPMC F 4M fue significativamente superior al control.

En líneas generales al pasar de 3 a 7 días de almacenamiento se observa poco cambio en las temperaturas características y si una tendencia a aumentar la entalpía, como es esperable dado que aumenta la cantidad de amilopectina retrogradada. Se debe tener en cuenta que la retrogradación de amilopectina es un proceso a largo plazo que se desarrolla en el termino de días (Miles y col., 1985) y que el período de almacenamiento en el presente trabajo se limitó a una semana. 
Tabla 6.7. Parámetros de las endotermas de retrogradación luego de 3 y 7 días de almacenamiento.

\begin{tabular}{ccccc}
\hline \multirow{2}{*}{ Muestra } & \multicolumn{4}{c}{ día 3} \\
\cline { 2 - 5 } Control & $44,1 \pm 0,3^{\mathrm{c}}$ & $55,2 \pm 0,1^{\mathrm{a}}$ & $69,4 \pm 0,1^{\mathrm{a}}$ & $2,1 \pm 0,3^{\mathrm{a}}$ \\
\hline MCC & $44,9 \pm 0,0^{\text {cd }}$ & $59,3 \pm 0,2^{\mathrm{c}}$ & $71,2 \pm 0,8^{\mathrm{bc}}$ & $2,3 \pm 0,1^{\mathrm{a}}$ \\
\hline CMC & $45,5 \pm 0,2^{\mathrm{d}}$ & $58,4 \pm 0,4^{\mathrm{bc}}$ & $72,0 \pm 0,1^{\mathrm{c}}$ & $2,1 \pm 0,2^{\mathrm{a}}$ \\
\hline HPMC F 4 M & $35,4 \pm 0,5^{\mathrm{a}}$ & $53,9 \pm 0,6^{\mathrm{a}}$ & $68,8 \pm 0,0^{\mathrm{a}}$ & $4,4 \pm 0,2^{\mathrm{b}}$ \\
\hline HPMC F 50 & $39,3 \pm 1,6^{\mathrm{b}}$ & $56,3 \pm 1,0^{\mathrm{ab}}$ & $69,7 \pm 0,3^{\mathrm{ab}}$ & $2,3 \pm 0,3^{\mathrm{a}}$ \\
\hline Control & $42,9 \pm 0,7^{\mathrm{bc}}$ & $56,1 \pm 0,3^{\mathrm{a}}$ & $69,7 \pm 1,1^{\mathrm{a}}$ & $3,2 \pm 0,4^{\mathrm{a}}$ \\
\hline MCC & $44,1 \pm 1,1^{\mathrm{c}}$ & $55,9 \pm 0,6^{\mathrm{a}}$ & $70,0 \pm 0,8^{\mathrm{a}}$ & $2,7 \pm 0,3^{\mathrm{a}}$ \\
\hline CMC & $41,2 \pm 0,4^{\mathrm{ab}}$ & $55,4 \pm 0,1^{\mathrm{a}}$ & $70,4 \pm 1,4^{\mathrm{a}}$ & $2,7 \pm 0,5^{\mathrm{a}}$ \\
\hline HPMC F 4 M & $41,7 \pm 1,0^{\text {abc }}$ & $53,5 \pm 2,1^{\mathrm{a}}$ & $68,0 \pm 0,6^{\mathrm{a}}$ & $4,3 \pm 0,9^{\mathrm{a}}$ \\
\hline HPMC F 50 & $40,0 \pm 1,3^{\mathrm{a}}$ & $54,7 \pm 1,2^{\mathrm{a}}$ & $70,0 \pm 1,3^{\mathrm{a}}$ & $3,8 \pm 0,6^{\mathrm{a}}$ \\
\hline media \pm DE. En una columna, letras $^{\text {diferentes }}$ indican & diferencias \\
significativas (p<0,05). & & &
\end{tabular}

En la Tabla 6.8 se observan los valores obtenidos para los parámetros determinados en los sistemas con pectinas. En general, a cada tiempo de almacenamiento no se observaron grandes diferencias ni en las temperaturas ni en las entalpías respecto al control. Aunque al día 3 de almacenamiento la entalpía de la muestra con PAM fue significativamente mayor que la del control. En todos los casos, como era de esperar, en el día 7 de almacenamiento se obtuvieron mayores entalpías respecto al día 3.

Para evaluar el proceso de retrogradación puede calcularse también el índice de retrogradación (IR) (León y col., 1997; Bárcenas y Rosell, 2005) que se define como el cociente entre la entalpía de retrogradación y la entalpía de gelatinización (Ec. 6.2).

$$
\% \mathrm{IR}=\frac{\Delta \mathrm{H}_{\text {después del almacenamiento }}}{\Delta \mathrm{H}_{\text {gelatinización }}} * 100
$$

Los valores hallados para el índice de retrogradación se muestran en la Tabla 6.9. 
Tabla 6.8. Parámetros de las endotermas de retrogradación de sistemas con pectina luego de 3 y 7 días de almacenamiento.

\begin{tabular}{ccccc}
\hline \multirow{2}{*}{ Muestra } & \multicolumn{4}{c}{ día 3 } \\
\cline { 2 - 5 } & $\mathrm{T}_{\mathrm{i}}$ & $\mathrm{T}_{\mathrm{p}}$ & $\mathrm{T}_{\mathrm{f}}$ & $\Delta \mathrm{H}(\mathrm{J} / \mathrm{g}$ almidón $)$ \\
\hline Control & $44,1 \pm 0,3^{\mathrm{a}}$ & $55,2 \pm 0,1^{\mathrm{a}}$ & $69,4 \pm 0,1^{\mathrm{a}}$ & $2,1 \pm 0,3^{\mathrm{a}}$ \\
\hline PBM & $44,1 \pm 0,9^{\mathrm{a}}$ & $56,0 \pm 1,0^{\mathrm{a}}$ & $67,6 \pm 1,3^{\mathrm{a}}$ & $1,9 \pm 0,0^{\mathrm{a}}$ \\
\hline PAM & $41,5 \pm 0,5^{\mathrm{a}}$ & $54,6 \pm 1,2^{\mathrm{a}}$ & $69,1 \pm 0,4^{\mathrm{a}}$ & $2,8 \pm 0,0^{\mathrm{b}}$ \\
\hline & & & día 7 & \\
\hline Control & $42,9 \pm 0,7^{\mathrm{a}}$ & $56,1 \pm 0,3^{\mathrm{b}}$ & $69,7 \pm 1,1^{\mathrm{a}}$ & $3,2 \pm 0,4^{\mathrm{a}}$ \\
\hline PBM & $42,20,7^{\mathrm{a}}$ & $55,6 \pm 0,5^{\mathrm{b}}$ & $69,0 \pm 0,7^{\mathrm{a}}$ & $2,5 \pm 0,1^{\mathrm{a}}$ \\
\hline PAM & $43,1 \pm 0,1^{\mathrm{a}}$ & $53,2 \pm 1,0^{\mathrm{a}}$ & $68,1 \pm 1,4^{\mathrm{a}}$ & $3,2 \pm 0,1^{\mathrm{a}}$ \\
\hline
\end{tabular}

media $\pm \mathrm{DE}$. En una columna, letras diferentes indican diferencias significativas $(p<0,05)$.

Tabla 6.9. Índice de retrogradación en sistemas con hidrocoloide

\begin{tabular}{ccc} 
Muestra & día 3 & día 7 \\
\hline Control & $31,4 \pm 0,6^{\mathrm{a}}$ & $37,2 \pm 1,5^{\mathrm{ab}}$ \\
\hline MCC & $27,8 \pm 0,1^{\mathrm{a}}$ & $37,8 \pm 6,1^{\mathrm{ab}}$ \\
\hline CMC & $39,0 \pm 5,1^{\mathrm{a}}$ & $34,4 \pm 5,7^{\mathrm{a}}$ \\
\hline HPMC F 4M & $57,2 \pm 4,7^{\mathrm{b}}$ & $59,3 \pm 9,9^{\mathrm{b}}$ \\
\hline HPMC F 50 & $25,8 \pm 2,0^{\mathrm{a}}$ & $40,9 \pm 5,6^{\mathrm{ab}}$ \\
\hline Control & $31,4 \pm 0,6^{\mathrm{b}}$ & $37,2 \pm 1,5^{\mathrm{a}}$ \\
\hline PBM & $23,0 \pm 0,9^{\mathrm{a}}$ & $38,4 \pm 0,7^{\mathrm{a}}$ \\
\hline PAM & $33,9 \pm 1,3^{\mathrm{b}}$ & $38,4 \pm 0,0^{\mathrm{a}}$ \\
\hline
\end{tabular}

media \pm DE. En una columna para cada tipo de hidrocoloide

(celulosas o pectinas), letras diferentes indican diferencias significativas $(p<0,05)$.

Los valores hallados para el IR muestran que en general no hay diferencias significativas en el porcentaje de almidón retrogradado entre las muestras con los diferentes hidrocoloides y el control, salvo para la masa con HPMC F 4M que presentó un valor significativamente mayor de \%IR. La tendencia a una mayor retrogradación observada en el caso de las HPMCs, y particularmente en el caso de HPMC F 4M 
podría relacionarse con el mayor contenido de agua de estas muestras (Tabla 5.1) y la mayor movilidad molecular del sistema (Tabla 6.1).

Al comparar el IR de los días 3 y 7 se observó un aumento significativo de la retrogradación con el almacenamiento para el control y las muestras con HPMC F 50 y las pectinas.

\subsubsection{Interacción proteína-aditivo}

\subsubsection{Electroforesis de los extractos proteicos de las masas}

Se empleó la técnica SDS-PAGE para el análisis cualitativo de las fracciones proteicas (gliadinas y gluteninas) que fueron extraídas de masa liofilizada sin y con $\mathrm{NaCl}$. Esta técnica es ampliamente utilizada en el estudio de las proteínas del gluten para comparar las proteínas extraídas por diferentes métodos, evaluar los cambios que ocurren en las proteínas durante el amasado, horneado o durante el almacenamiento y en programas de mejoramiento genético para determinar la composición de HMW-GS y LMW-GS (Khan y col., 2003). Por otro lado, este tipo de análisis también es empleado para determinar el perfil proteico de las harinas y poder relacionarlo con su calidad panadera a partir de la presencia o ausencia de ciertas subunidades, particularmente de gluteninas (Orth y Bushuk, 1973; Payne y col., 1979; MacRitchie y col., 1991; Ponzio y col., 2008).

En el presente trabajo la base proteica es la misma en todas las muestras ya que se usó un solo tipo de harina por lo que el objetivo fue tratar de inferir, a través de las diferencias detectadas en los perfiles electroforéticos (por ejemplo, atenuación o desaparición de bandas) la mayor o menor labilidad de las subunidades en la matriz gluten-hidrocoloide que pudiera atribuirse a interacciones específicas entre las proteínas y los polisacáridos.

\subsection{Extractos en propanol $50 \%$}

En la Figuras 6.19 y 6.20 se muestran los perfiles electroforéticos típicos obtenidos por SDS-PAGE de extractos en propanol $50 \%$ obtenidos a partir de masa lifiolizada sin y con $\mathrm{NaCl}$ respectivamente. Si bien el empleo de este solvente tiene como objetivo extraer principalmente gliadinas, se observaron bandas correspondientes a otras fracciones, particularmente gluteninas. Respecto a esto, Shewry y col. (2003) han remarcado que en los distintos solventes (soluciones salinas, alcohólicas) es posible 
hallar remanentes de otras fracciones. Esto hace que no sean esperables, para una fracción determinada, eficiencias de extracción superiores al $80 \%$. Por otro lado, tampoco es posible obtener extractos que contengan todas las proteínas, gliadinas o gluteninas, presentes en la matriz.

La extracción se realizó en condiciones no reductoras ya que la mayoría de las gliadinas no forman puentes disulfuro intercatenarios por lo que no es necesario el uso de agentes específicos para separar las distintas subunidades. Tanaka y col. (1973, a) realizaron electroforesis SDS-PAGE de las proteínas solubles extraíbles en alcohol de masas, empleando condiciones reductoras y no reductoras, mostrando sus resultados mínimas diferencias cualitativas y cuantitativas entre ambas condiciones. En los últimos años se ha informado que las gliadinas pueden formar agregados que aparecen como oligómeros solubles en alcohol o junto con los polímeros de gluteninas insolubles en alcohol (Shewry y col., 2003; Hubner y Bietz, 1993) por lo que las pequeñas diferencias observadas por Tanaka y col. podrían atribuirse a la presencia de este tipo de agregados. Al no haberse realizado como paso previo la extracción de albúminas y globulinas (ítem 2.2.5.2.2.2-Capítulo II) se visualizaron bandas correspondientes a estas fracciones en la parte inferior del gel. Por otro lado, debido a que las fracciones proteicas de albúminas y globulinas no se ven modificadas por el amasado y no determinan el comportamiento de la harina durante el mismo (Tanaka y Bushuk, 1973b) no se realizó una caracterización exhaustiva de éstas.

Los extractos de las masas liofilizadas $\sin \mathrm{NaCl}$ presentaron igual número de bandas y en similar posición (Fig. 6.19), habiéndose observado bandas con masas moleculares entre 68 y 15 kDa.

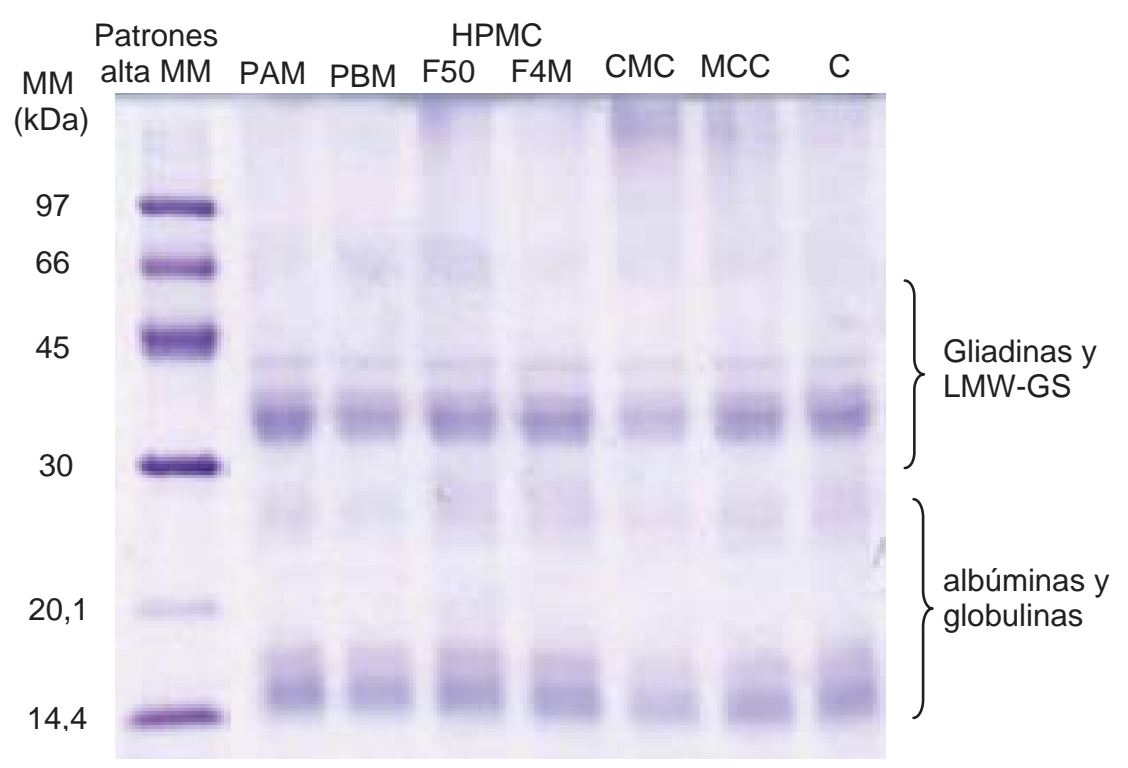

Figura 6.19. Extractos en propanol $50 \%$ de masa liofilizada $\sin \mathrm{NaCl} . \mathrm{C}=$ control. 
Las bandas muy tenues correspondientes a mayores masas moleculares $(68,61,56$ y $48,8 \mathrm{kDa}$ ) corresponderían a $\omega$-gliadinas, las de masa molecular intermedia $(41 ; 37$; 35; 32) podrían ser asignadas a $\alpha$-, $\beta$ - y $\gamma$-gliadinas o LMW-GS y las bandas correspondientes a menores masas moleculares (26; 17 y $15 \mathrm{kDa}$ ) a albúminas y globulinas. En algunos casos (HPMC F 50, CMC y MCC) en la parte superior del gel, se observaron en forma difusa, agregados de alta masa molecular que podrían corresponder a asociaciones de gliadinas.

Teniendo en cuenta que la extracción se realizó en idénticas condiciones en todas las masas liofilizadas, la menor intensidad de bandas en la calle correspondiente a masa con CMC (particularmente en la zona de 41 a $32 \mathrm{kDa}$ ) indicaría que en este caso la extracción se vio dificultada si se compara con el control y las otras masas.

En las masas con $\mathrm{NaCl}$ (Figura 6.20), al igual que en el caso de las masas $\operatorname{sin~} \mathrm{NaCl}$, todas las muestras presentaron similar perfil electroforético. Se individualizaron bandas de masas moleculares entre 106 y $15 \mathrm{kDa}$. En la parte superior del gel se observaron al menos 4 bandas con masa molecular cercana a $97 \mathrm{kDa}$ que podrían corresponder a HMW-GS o a agregados de gliadinas (106, 98; 93 y 88 kDa); seguidas por cinco bandas que de a acuerdo a sus masas moleculares podrían corresponder a $\omega$-gliadinas $(52,47$ y $42 \mathrm{kDa})$. Las bandas entre 40 y 37 kDa son también asignables a gliadinas y/o subunidades de LMW-GS que se pudieran haber coextraído. Por último, las bandas con masas entre 21 y 15 kDa corresponderían a albúminas y globulinas también coextraídas.

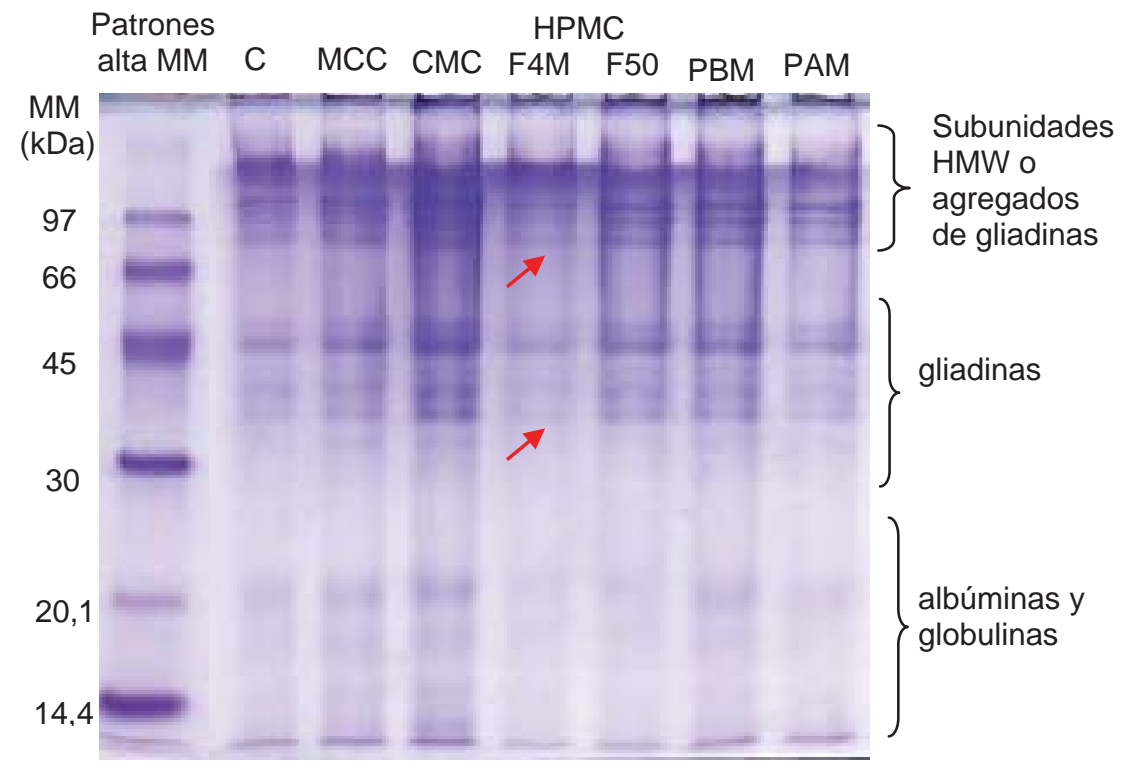

Figura 6.20. Extractos con propanol 50\% a partir de masa liofilizada con $\mathrm{NaCl}$. 
En la calle correspondiente a extracto de la masa con CMC (Fig. 6.20) se observan bandas más intensas que para el control y las otras muestras. En cambio, en la calle correspondiente a la masa con HPMC F 4M se observa una menor intensidad de las bandas (resaltado con las flechas rojas) respecto al control por lo que habría menor proteína extraída en este caso. Esto permitiría suponer que las características de la red de gluten formada en presencia de ambos hidrocoloides conduce a una diferente labilidad de las subunidades proteicas frente al solvente de extracción empleado: en la masa con $\mathrm{CMC}$ en presencia de $\mathrm{NaCl}$ la extracción se vería facilitada (al contrario de lo observado en el caso de las masas $\sin \mathrm{NaCl}$ ) y parece ocurrir lo contrario en presencia de HPMC F4 M.

Estos resultados contribuirían a la hipótesis de que las interacciones establecidas en la estructura de la red proteica de las masas no fueron las mismas en ausencia o presencia de $\mathrm{NaCl}$, lo que conduciría a que, aun en iguales condiciones de extracción, no se solubilicen las mismas subunidades. En las masas $\sin \mathrm{NaCl}$ se extrajeron mayor proporción de las fracciones más livianas mientras que en las masas con $\mathrm{NaCl}$ aparecieron más intensificadas bandas de alta masa molecular y agregados proteicos.

\subsection{Extractos en ácido acético en condiciones no reductoras}

Las gluteninas son proteínas que se encuentran polimerizadas a través de enlaces disulfuro formando agregados de alto peso molecular. Por este motivo, se realizó una extracción en condiciones no reductoras (ácido acético $0,1 \mathrm{M}$ ) para su análisis. Previamente y según se indica en el ítem 2.2.5.2.2.1 del Capítulo II, se hicieron extracciones con 1) agua, 2) buffer Tris- $\mathrm{HCl} 50 \mathrm{mM} \mathrm{pH} \mathrm{7,8} \mathrm{con} \mathrm{KCl} 100$ mM + EDTA 5 $\mathrm{mM}$ y 3) propanol $50 \%$.

En la Figura 6.21 se muestra la electroforesis SDS-PAGE correspondiente a la fracción proteica soluble en ácido acético $0,1 \mathrm{M}$ obtenida a partir de masa liofilizada sin $\mathrm{NaCl}$.

En todas las muestras se observaron agregados proteicos de masa molecular superior a 97 kDa y proteínas con masas moleculares que corresponderían a gliadinas (56-33 kDa), y a albúminas y globulinas (masas inferiores a 25 kDa). Burnouf y Bietz (1989) observaron que con el empleo de soluciones diluidas de ácido acético junto con HMWGS y LMW-GS se coextraen albúminas, globulinas y gliadinas.

La presencia de los hidrocoloides ocasionó cambios en el perfil electroforético. Las masa control y con MCC mostraron la mayor intensidad de bandas lo que estaría indicando una mayor extracción mientras que las masas con CMC y PAM presentaron 


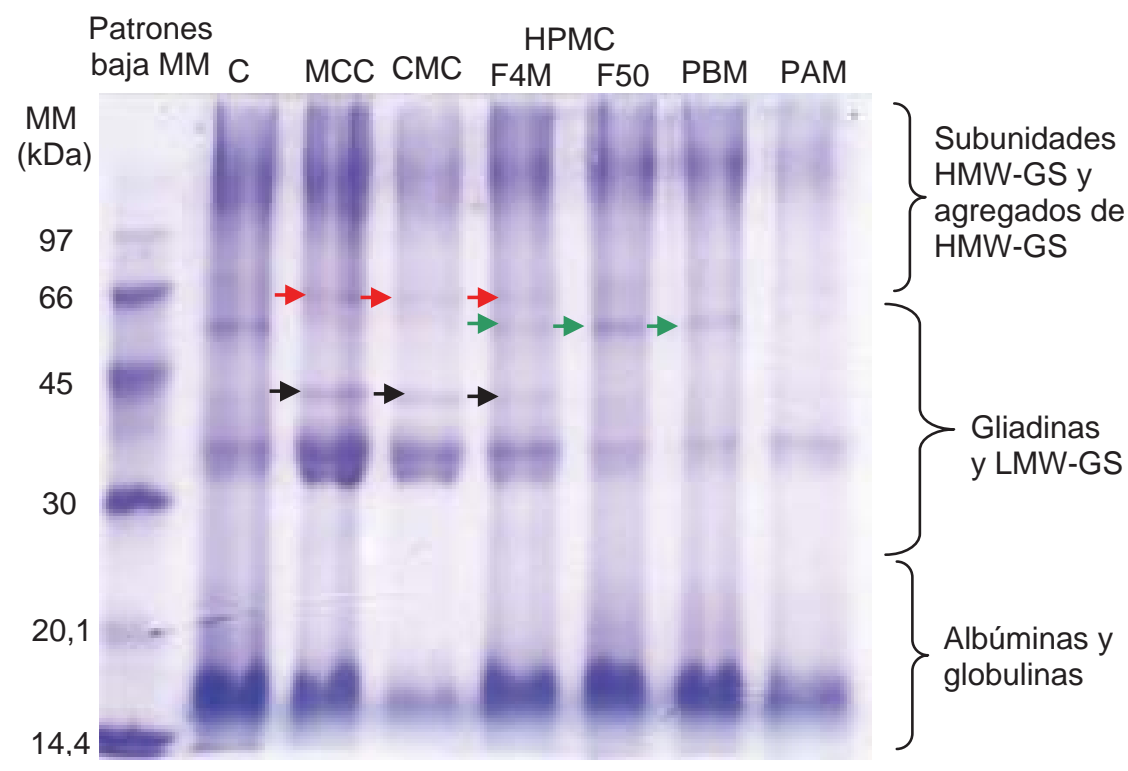

Figura 6.21. Gluteninas extraídas con ácido acético $0,1 \mathrm{M}$ a partir de masa liofilizada $\sin \mathrm{NaCl}$.

menores intensidades de banda en la zona de altas masas moleculares (subunidades HMW-GS y agregados de HMW-GS), y la muestra con PAM también presentó bandas muy tenues en la zona de gliadinas y LMW.

Se observa además diferencias cualitativas entre las calles. Los extractos de masas con HPMC F 4M, HPMC F 50 y PBM presentaron la misma banda (muy débil en el caso de HPMC F 4M) que el control, a 56 kDa (flechas verdes en Fig. 6.21), no así MCC, CMC y PAM. Por otro lado, en las calles correspondientes a masas con MCC, HPMC F 4M y CMC se pudieron observar (aunque muy débilmente con CMC) bandas a $65 \mathrm{kDa}$ (indicadas con flechas rojas) y a $41 \mathrm{kDa}$ (flechas negras) que están prácticamente ausentes en las otras calles.

Estos resultados estarían sugiriendo diferentes labilidades de las subunidades frente la extracción en presencia de estos hidrocoloides. Los casos más destacados son los de las muestras con CMC y PAM. Justamente, las masas con CMC y PAM eran las que presentaban menor estabilidad farinográfica que el control, indicando una interacción negativa con la red de gluten. Estos resultados confirmarían la existencia de una interacción.

La presencia de los hidrocoloides en la matriz no aumentó la intensidad de las bandas correspondientes a la zona de HMW-GS o agregados de HMW-GS respecto al control 
(salvo en las calles de las muestras con CMC y PAM donde disminuyó); esto indicaría que no hubo despolimerización del gluten que condujera a una mayor cantidad de agregados solubles.

En la Figura 6.22 se muestra la electroforesis SDS-PAGE de los extractos con ácido acético $0,1 \mathrm{M}$ a partir de las masas con $\mathrm{NaCl}$. Se observan bandas mucho más débiles que en el caso de las muestras $\sin \mathrm{NaCl}$ lo que era esperable dado que el paso previo a esta extracción fue con propanol 50\%. Como se vio en el inciso anterior, en estas condiciones, se ve favorecida la extracción a partir de masas con $\mathrm{NaCl}$, por lo que quedarían menos proteínas disponibles para el paso con ácido acético.

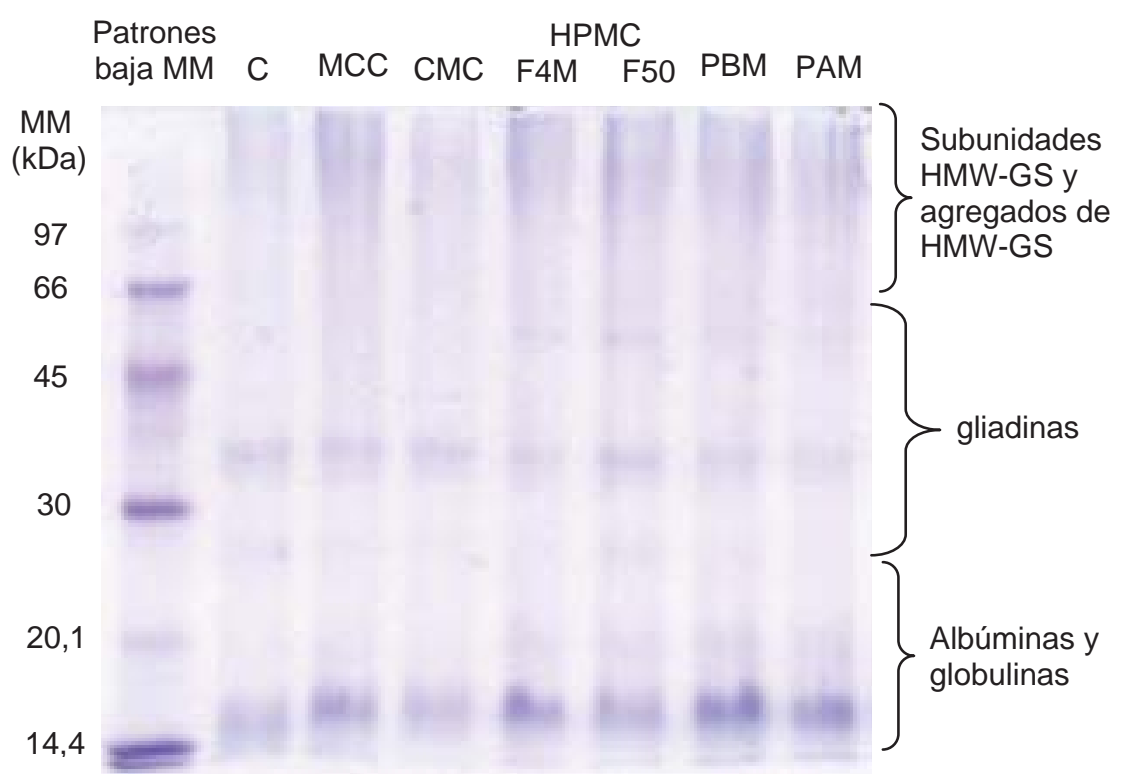

Figura 6.22. Extractos con ácido acético $0,1 \mathrm{M}$ a partir de masa liofilizada con $\mathrm{NaCl}$.

\subsection{Extractos con propanol $50 \%$ en condiciones reductoras}

En la Figura 6.23 se muestra la electroforesis SDS- PAGE de los extractos obtenidos a partir de las masas sin $\mathrm{NaCl}$ en condiciones reductoras (con DTT). Estos extractos se obtuvieron a partir del residuo proveniente de la extracción con propanol $50 \%$ cuyos resultados se discutieron en 6.2.2.1.1. Las bandas obtenidas en el control correspondieron a agregados de HMW (134, 122 y 108 kDa), subunidades HMW (99, $93 \mathrm{kDa}$ ) y además se obtuvieron bandas con masas moleculares inferiores a $53 \mathrm{kDa}$ (al menos 8 bandas) las cuales podrían corresponder a gliadinas de mayor masa (probablemente $\omega$-gliadinas) y subunidades LMW-GS $(52,47$ y $44 \mathrm{kDa})$ y las restantes 


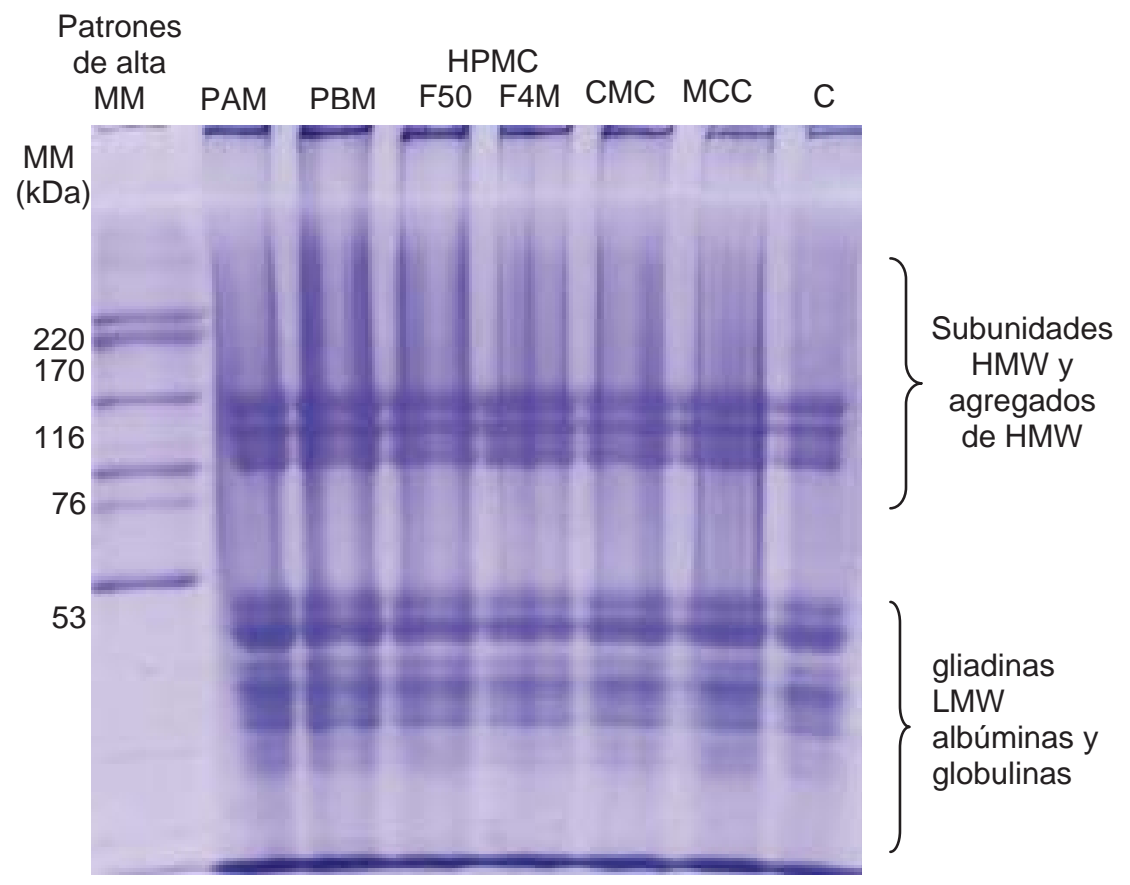

Figura 6.23. Gluteninas extraídas en condiciones reductoras (con DTT) a partir de masa liofilizada $\sin \mathrm{NaCl}$

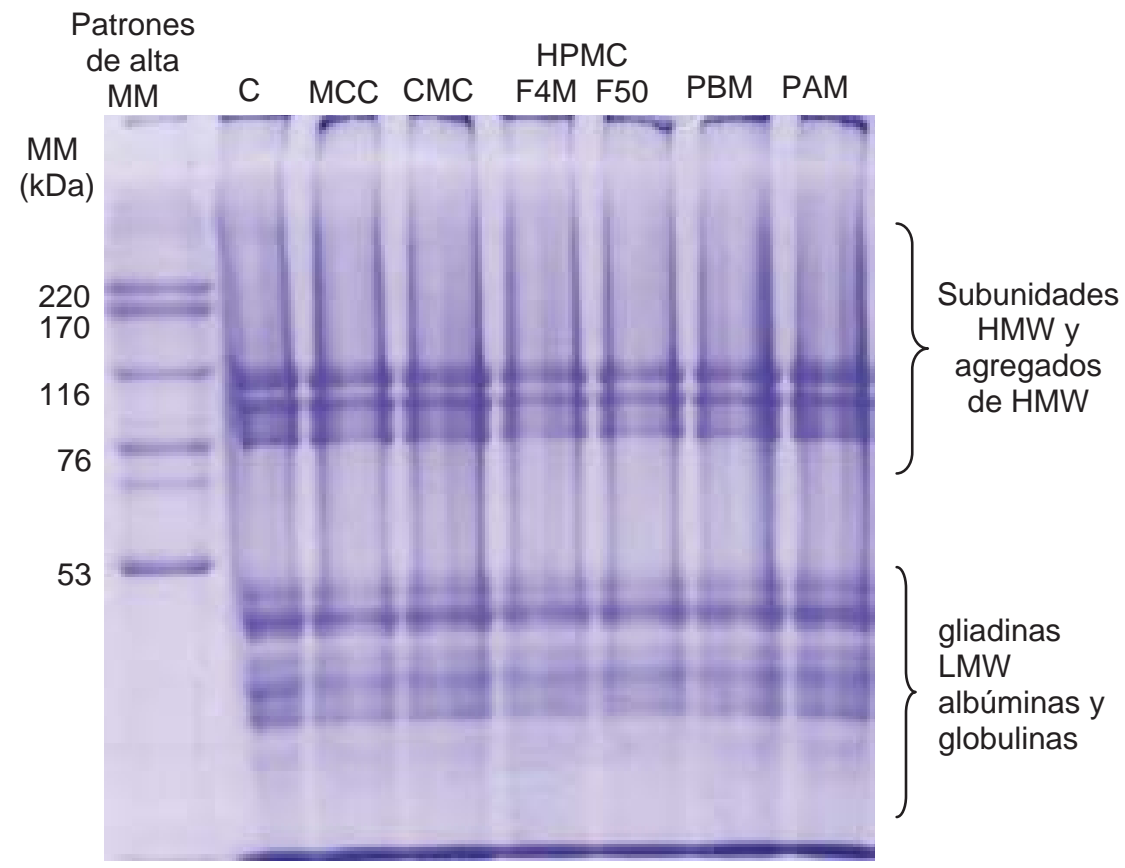

Figura 6.24. Gluteninas extraídas en condiciones reductoras (con DTT) a partir de masa liofilizada con $\mathrm{NaCl}$ 
a gliadinas de menor masa (39; 35 kDa); y albúminas y globulinas (25, 20 y 18 kDa). En todas las muestras se observaron bandas similares y agregados proteicos con masa molecular superior a $220 \mathrm{kDa}$ que no entraron en el gel separador.

En la Figura 6.24 se muestra la electroforesis SDS-PAGE de los extractos obtenidos a partir de las masas con $\mathrm{NaCl}$ en condiciones reductoras. El perfil de bandas obtenido fue similar al encontrado en las masas $\sin \mathrm{NaCl}$, con bandas entre 116 y $22 \mathrm{kDa}$ y presencia de agregados proteicos de peso molecular superior a $220 \mathrm{kDa}$ en la parte superior del gel. Las intensidades de las bandas también fueron similares entre las masas sin y con $\mathrm{NaCl}$ por lo que no existiría gran diferencia en el grado de extracción de las proteínas en estas condiciones. Este resultado es esperable ya que al ser el DTT un agente reductor permite la disociación de las gluteninas por ruptura de los enlaces disulfuro entre subunidades. De este modo es posible extraer las subunidades LMW-GS y HMW-GS que en la masa se encontraban polimerizadas y por lo tanto no eran extraíbles.

\subsubsection{Espectroscopía FT-Raman}

A través de esta técnica se obtuvieron los espectros de masa cruda, en los cuales se analizó la zona correspondiente a la banda Amida I (Figura 6.25). Esta banda suele utilizarse juntamente con la de Amida III para caracterizar la conformación de las cadenas polipeptídicas. Si bien en gran parte del espectro las bandas correspondientes a almidón se superponen con las de proteína, en la zona correspondiente a Amida I (1650-1660 cm $\left.\mathrm{cm}^{-1}\right)$, el almidón no interfiere por lo que resulta una región adecuada para analizar los cambios conformacionales resultantes del agregado de hidrocoloides.

Dentro de la banda mediante un procedimiento de deconvolución, fiteo y ajuste de las mismas se pueden encontrar los picos correspondientes a la contribución de las distintas conformaciones como: hoja plegada $\beta$ antiparalela $\left(1675-1695 \mathrm{~cm}^{-1}\right)$, giro $\beta$

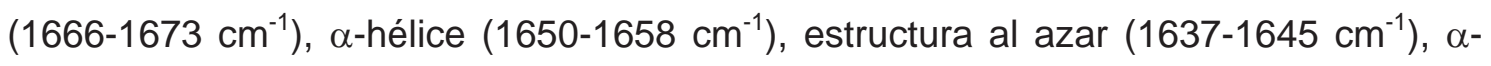
hélice solvatada $\left(1625-1637 \mathrm{~cm}^{-1}\right)$ y hoja plegada $\beta$ paralela $\left(1613-1625 \mathrm{~cm}^{-1}\right)(\mathrm{Tu}$, 1982; Ngarize, 2004; Herrero, 2008). Cada una de estas conformaciones corresponde a un mayor o menor grado de plegamiento de la proteína, siendo las estructuras más compactas la de $\alpha$-hélice y $\alpha$-hélice solvatada y la menos compacta 0 más desordenada la estructura al azar.

La incidencia de los hidrocoloides en la estructura proteica puede entonces inferirse de los cambios producidos en la proporción relativa de cada conformación respecto a la 


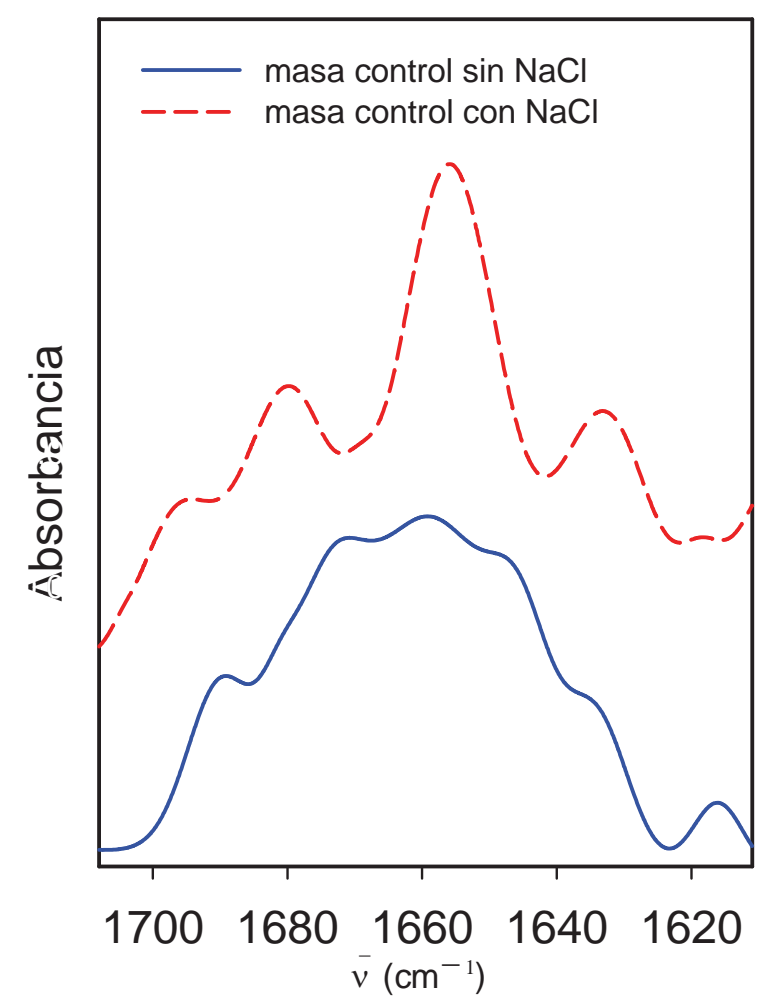

Figura 6.25. Banda amida I para los controles $\sin$ y con $\mathrm{NaCl}$. Las bandas se superpusieron a modo ilustrativo por lo que no están en la misma escala.

masa control. Por otro lado, se pudo analizar también a través de estos ensayos el efecto del agregado de $\mathrm{NaCl}$. En la Tabla 6.10 se muestra la proporción relativa de las diferentes conformaciones observadas en las masas $\sin \mathrm{NaCl}$.

Se ha visto que estructuras proteicas más ordenadas se relacionan con una mayor proporción de la conformación $\alpha$-hélice (Ferrer y col., 2008; Ferrer y col., 2011). En base al porcentaje de esta conformación podríamos establecer que las masas control y con MCC, fueron las de estructura más compacta, menos desplegada, seguidas por: masa con PAM, masas con HPMCs (que tienen una proporción similar de conformación $\alpha$-hélice y distinta proporción de $\alpha$-hélice solvatada), masa con PBM y masa con CMC.

Comparando la masa control con la masa obtenida con MCC, se observa que aunque presentan proporciones comparables (61,43 y 55,09 \% respectivamente) de conformación a-hélice (no solvatada + solvatada) la distribución de las conformaciones en la masa con MCC prácticamente no presenta giros $\beta(0,88 \%)$ y sí una contribución importante de hoja plegada $\beta$ antiparalela ( $26,35 \%$ de la conformación total). 
Tabla. 6.10. Estructura secundaria: porcentajes de las diferentes conformaciones en las masas $\sin \mathrm{NaCl}$.

\begin{tabular}{ccccccc}
\hline \multirow{2}{*}{$\begin{array}{c}\text { Masas sin } \\
\text { NaCl }\end{array}$} & $\begin{array}{c}\text { hoja } \beta \text { - } \\
\text { antiparalela }\end{array}$ & giro $\beta$ & a-helice & al azar & $\begin{array}{c}\text { a-helice } \\
\text { solvatada }\end{array}$ & $\begin{array}{c}\text { hoja } \beta- \\
\text { paralela }\end{array}$ \\
\cline { 2 - 7 } Control & 14,19 & 13,25 & 52,61 & 7,65 & 8,82 & 3,52 \\
\hline MCC & 26,35 & 0,88 & 48,09 & 11,16 & 7,00 & 6,39 \\
\hline CMC & 6,84 & 40,65 & 10,69 & 36,20 & 1,69 & 3,79 \\
\hline HPMC F 4M & 19,64 & 12,19 & 24,94 & 13,10 & 6,70 & 23,42 \\
\hline HPMC F 50 & 26,66 & 11,64 & 22,78 & 5,87 & 23,24 & 9,76 \\
\hline PAM & 22,62 & 14,50 & 35,66 & 9,38 & 13,62 & 4,20 \\
\hline PBM & 24,99 & 12,98 & 18,26 & 17,91 & 4,44 & 21,45 \\
\hline
\end{tabular}

$(\mathrm{DE}=0,6-0,7)$

La masa preparada con CMC presenta el mínimo porcentaje $(12,38 \%)$ de estructura a-hélice (no solvatada + solvatada) por lo cual las cadenas polipeptídicas se encontrarían más desplegadas, lo que se ve reflejado en un aumento del porcentaje de estructura al azar (36,20\%) y de giros $\beta(40,65 \%)$.

En general, las masas obtenidas con HPMC F 4M y PBM presentan una distribución de conformaciones similar, encontrándose alrededor de un $40-45 \%$ de estructura de hoja plegada $\beta$ (paralela y antiparalela) y $12 \%$ de giros $\beta$. Sin embargo HPMC F 4M presentó contribuciones algo mayores $(31,6 \%)$ de conformación $\alpha$-hélice (no solvatada + solvatada) respecto a la PBM $(22,7 \%)$.

En las masas con HPMC F 50 o PAM se obtuvieron porcentajes de estructura a-hélice (no solvatada + solvatada) de $46,02 \%$ y $49,3 \%$ respectivamente, que resultaron mayores que para las masas con HPMC F 4 M y PBM. A su vez, esos porcentajes fueron menores que para las masas control y con MCC. Esto es indicativo de que tanto la masa con PAM como con HPMC F 50 presentan un menor desplegamiento de la red proteica. En los ensayos de ${ }^{1} \mathrm{H}-\mathrm{RMN}$ se había observado, en ausencia de sal, que las masas con PAM y con HPMC F 50 tenían una movilidad significativamente 
menor que la masa sin hidrocoloide lo que se podía atribuir a una estructura menos flexible.

Al agregar $\mathrm{NaCl}$ se observó en la masa control (Tabla 6.11) una disminución de la proporción de la conformación a-hélice y un aumento de la conformación hoja plegada $\beta$ antiparalela y paralela respecto al control $\sin \mathrm{NaCl}$, lo que estaría indicando un mayor desplegamiento de la estructura cuando se agrega la sal. El aumento de conformación hoja plegada $\beta$ se vio acompañado de la disminución de giros $\beta$. Observaciones similares fueron informadas por Ukai y col. (2008) en proteínas de gluten utilizando FT-IR. Estos autores hallaron que el aumento en la concentración de $\mathrm{NaCl}$ producía una disminución de la estructura giro $\beta$ y un aumento en la estructura de hoja plegada $\beta$.

Tabla 6.11. Estructura secundaria: porcentajes de las diferentes conformaciones en las con $\mathrm{NaCl}$.

\begin{tabular}{|c|c|c|c|c|c|c|}
\hline \multirow{2}{*}{$\begin{array}{c}\text { Masas } \\
\text { con } \\
\mathrm{NaCl}\end{array}$} & \multicolumn{6}{|c|}{ proporción relativa (\%) } \\
\hline & $\begin{array}{c}\text { Hoja } \beta- \\
\text { antiparalela }\end{array}$ & $\begin{array}{c}\text { Giro } \\
\beta\end{array}$ & a-hélice & al azar & $\begin{array}{c}\text { a-hélice } \\
\text { solvatada }\end{array}$ & $\begin{array}{l}\text { Hoja } \beta \text { - } \\
\text { paralela }\end{array}$ \\
\hline Control & 28,4 & 1,20 & 39,25 & - & 18,37 & 13,18 \\
\hline MCC & 16,18 & 17,51 & 15,29 & 15,46 & 2,26 & 33,26 \\
\hline CMC & 14,66 & 34,03 & 3,95 & 27,58 & 4,67 & 15,09 \\
\hline $\begin{array}{l}\text { HPMC } \\
\text { F 4M }\end{array}$ & 11,99 & 11,19 & 16,94 & 27,10 & 3,92 & 28,87 \\
\hline $\begin{array}{l}\text { HPMC } \\
\text { F } 50 \\
\end{array}$ & 14,91 & 37,80 & 16,47 & - & 15,22 & 15,61 \\
\hline PAM & 21,91 & 4,15 & 46,37 & 5,27 & 8,27 & 14,06 \\
\hline PBM & 14,82 & 10,00 & 46,94 & 6,75 & 11,07 & 10,29 \\
\hline
\end{tabular}

En las masas con celulosas modificadas en presencia de $\mathrm{NaCl}$ se observa una disminución del porcentaje de la conformación a-hélice con respecto a la masa control. La contribución de a-hélice solvatada también disminuyó marcadamente salvo en el 
caso de HPMC F 50. En general, las contribuciones de $\alpha$-hélice y $\alpha$-hélice solvatada fueron menores en presencia de $\mathrm{NaCl}$ respecto a las masas $\sin \mathrm{NaCl}$. Esto indica una mayor contribución de estructuras menos ordenadas en presencia de sal. En particular la muestra con HPMC F 4M presentó un importante aumento de la estructura al azar (27,1\%). Las masas con HPMCs y $\mathrm{NaCl}$ fueron las que dieron los valores de mayor movilidad en los ensayos de ${ }^{1} \mathrm{H}-\mathrm{RMN}$.

Por otro lado, en las masas preparadas con ambas pectinas se observan mayores porcentajes $(54,64 \%$ con PAM y 58,01 \% con PBM) de estructura $\alpha$-hélice (no solvatada + solvatada) que los obtenidos en las masas con pectinas $\sin \mathrm{NaCl}$. Estos valores son similares a los del control con sal $(57,62 \%)$. Ambas pectinas presentaban los menores valores de movilidad en masas con sal respecto a los otros hidrocoloides en los ensayos de ${ }^{1} \mathrm{H}-\mathrm{RMN}$.

La masa con $\mathrm{CMC}$ y $\mathrm{NaCl}$ presentó la estructura más desordenada dado que las conformaciones presentes en mayor proporción fueron la estructura al azar y los giros $\beta$, las cuales representaron el $61,61 \%$ de contribución. Esta masa presentó el menor porcentaje de estructura a-hélice (3,95\%) y de a-hélice solvatada (4,67\%). Si comparamos la masa con $\mathrm{CMC}$ y $\mathrm{NaCl}$ respecto a $\mathrm{CMC} \sin \mathrm{NaCl}$ observamos que se desfavorece aún más la formación de a-hélice pero se favorece la formación de estructuras $\beta$ plegada paralela y antiparalela y hay una menor contribución de estructuras al azar y giros $\beta$ que en ausencia de $\mathrm{NaCl}$.

\subsection{Conclusiones parciales}

A través del análisis microscópico se observaron importantes cambios en la red por agregado de hidrocoloides y/o NaCl. Ambas técnicas, SEM y CSLM permitieron visualizar las mismas tendencias pero resultó más adecuada la microscopía láser confocal para apreciar algunos rasgos particulares de la red, como la orientación.

El agregado de $\mathrm{NaCl}$ condujo a una red de gluten más entrecruzada y orientada que en la masa sin sal. Con algunos hidrocoloides se logró una apreciable orientación y entrecruzamiento en presencia de $\mathrm{NaCl}$ (CMC, MCC, PBM). Otros condujeron a redes mas abiertas (PAM $+\mathrm{NaCl}$, HPMCs sin o con $\mathrm{NaCl}$ ) con mayor o menor grado de orientación. En general, relacionando estos resultados con los farinográficos se pudo concluir que un mayor entrecruzamiento y orientación, correspondía en general a masas con una mayor estabilidad farinográfica. El ejemplo más marcado de esta relación se observó con CMC. Como se explicó, al ser CMC una molécula cargada podría interactuar negativamente con la red de gluten dando lugar a una estructura 
más débil tal como se refleja en los ensayos reológicos y que corresponde a una red menos entrecruzada y más abierta como se observó por microscopía. El agregado de $\mathrm{NaCl}$ evitaría esta interacción negativa entre gluten y CMC y la red que se obtiene es diferente, visualizándose más entrecruzada y orientada.

Existe una diferencia de conformación proteica inducida por los distintos hidrocoloides que varía en presencia o ausencia de sal y que se relaciona con lo observado a nivel microscópico. Los ensayos FT- Raman indicaron una disminución de la estructura de $\alpha$-hélice de las proteínas con aumento de estructuras menos ordenadas en todos los casos excepto cuando se agregaron pectinas en presencia de $\mathrm{NaCl}$. En la masa con CMC y $\sin \mathrm{NaCl}$, las conformaciones predominantes fueron al azar y giros $\beta$, lo que indica un mayor desplegamiento proteico. Esto permitiría una mayor interacción, en este caso negativa desde el punto de vista de la estabilidad. En presencia de $\mathrm{NaCl}$, las masas con CMC también presentaron un mayor desplegamiento pero con un aumento de la contribución de hojas plegadas $\beta$; estas masas presentaron mayor estabilidad farinográfica. Un aumento de estructura hojas plegadas $\beta$ también se observó en el control al agregar sal por lo que se podría inferir que esta relacionada con matrices más estables, que son las que se observan como más orientadas y entrecruzadas en el microscopio. En otros casos como el de las HPMCs y las pectinas no fue posible relacionar los cambios en la estabilidad de la masa con algún cambio particular de la estructura secundaria que fuera inducido por el hidrocoloide. Los resultados de electroforesis SDS-PAGE confirmaron que existe un efecto diferencial de los hidrocoloides sobre la masa, dependiente de la presencia o no de $\mathrm{NaCl}$. Al incorporar CMC a la masa con $\mathrm{NaCl}$ se observó un incremento en la capacidad de extracción de subunidades proteicas con propanol $50 \%$ lo que estaría indicando una mayor labilidad respecto a la red de gluten. Las proteínas en las masas con HPMC F 4M y sal fueron menos lábiles. En las masas $\sin \mathrm{NaCl}$ y con $\mathrm{CMC}$ se observó una atenuación de las bandas lo que sugiere una menor extracción, probablemente porque las proteínas están más fuertemente asociadas a la red.

Los ensayos de DMA y RMN también indicaron un efecto diferencial de los hidrocoloides sobre la movilidad molecular de la matriz tanto de masa cruda como de miga. En masas sin sal la mayor movilidad se obtuvo en presencia de MCC, CMC y HPMC F 4M. En masas con sal todas las celulosas aumentaron la movilidad respecto al control. Si bien no se pudieron cuantificar diferencias en los ensayos de DMA de miga, los sistemas con CMC presentaron transiciones más marcadas sugiriendo mayores movilidades. Respecto a la interacción de los hidrocoloides con el almidón, los ensayos viscoamilográficos en sistemas harina-agua indicaron un potencial efecto 
inhibitorio sobre la retogradación (de amilosa) por parte de CMC y pectinas; en la masa no se vieron mayores efectos sobre la gelatinización ni sobre la retrogradación de amilopectina. 


\section{Capítulo VII}

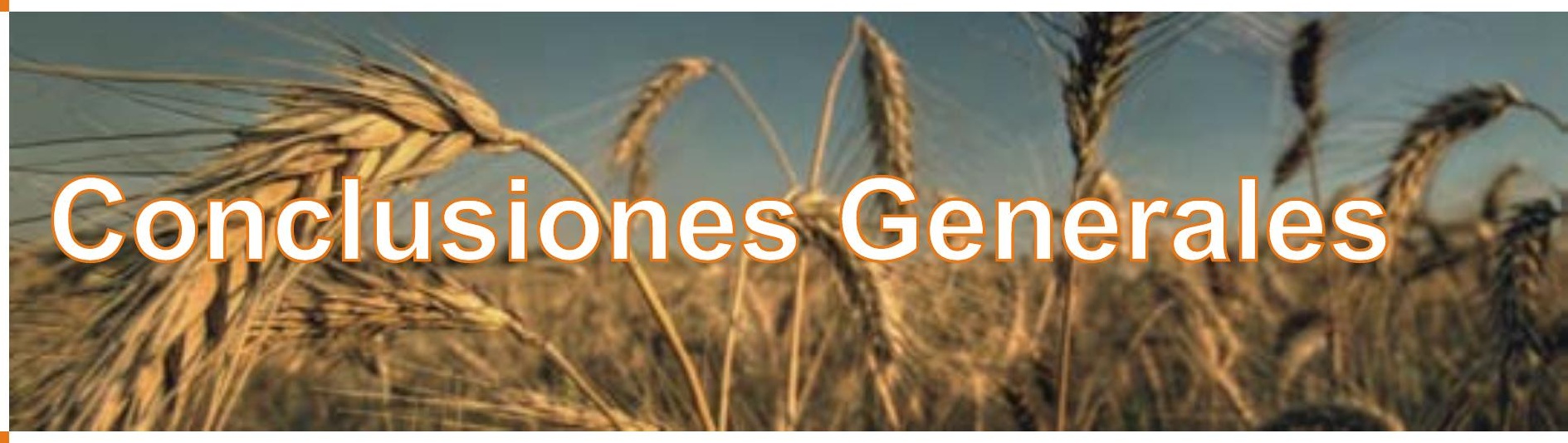




\subsection{Conclusiones}

Efecto sobre la masa y variables de proceso

- El efecto provocado por los hidrocoloides en el comportamiento reológico de la masa depende tanto de la estructura química del hidrocoloide como de la presencia de otros componentes, debido a que esto determina el tipo de interacciones que pueden establecerse en la masa. Se pudo demostrar que la presencia de $\mathrm{NaCl}$ provoca un comportamiento diferencial de la estabilidad de la masa ante el agregado de CMC y HPMC debido a que su presencia modifica las interacciones que se establecen entre estos hidrocoloides y las proteínas del gluten.

- El $\mathrm{NaCl}$ tuvo un efecto importante sobre las características de la masa: aumento del tiempo de desarrollo, de estabilidad farinográfica, de la dureza y consistencia de la masa, aumento de la elasticidad y resiliencia, disminución de la cohesividad, aumento de la adhesividad, de los módulos dinámicos y la viscosidad compleja. Incrementó significativamente los tiempos de relajación.

- De las pectinas fue PAM la que modificó más las características de las masas mientras que entre las celulosas se destacaron CMC y HPMC dependiendo su efecto de la presencia o ausencia de $\mathrm{NaCl}$. MCC fue la celulosa que menos incidencia tuvo, en general, sobre las características de la masa.

- La presencia de los hidrocoloides modificó variables del proceso de panificación: en todos los casos su incorporación aumentó marcadamente la absorción de agua y en general se necesitaron modificar los tiempos de desarrollo y fermentación.

- Los ensayos de relajación en texturómetro mostraron diferencias de acuerdo a la presencia o no de $\mathrm{NaCl}$ y el aditivo utilizado: en ausencia de sal ambas pectinas y CMC aumentaron los tiempos de relajación respecto al control (el sistema tiende a un comportamiento de sólido viscoelástico) mientras que en presencia de sal PAM, CMC y HPMCs lo disminuyen; el material relaja más rápidamente (se acerca más a un liquido viscoelástico). Estos cambios son de importancia en el proceso de panificación ya que durante el mismo la masa se deja reposar.

- Las masas obtenidas con hidrocoloides resultaron en general más blandas, menos consistentes y menos adhesivas tanto en ausencia como en presencia de $\mathrm{NaCl}$. La resiliencia (elasticidad instantánea) y cohesividad (relacionada con 
la integración de los componentes del sistema) variaron en forma opuesta una respecto de la otra y las variaciones dependieron del hidrocoloide, la concentración utilizada y la presencia o no de $\mathrm{NaCl}$.

- La masa es un sistema viscoelástico y el tipo de comportamiento, en general, no fue modificado por la presencia de hidrocoloides. A través de los ensayos dinámicos, que permiten discriminar las respuestas elástica y viscosa de un material, se verificó que el agregado de hidrocoloides da lugar a masas más viscosas

Efecto sobre el pan y su conservación

- Se obtuvieron mayores volúmenes específicos que para el control (pan sin el agregado de aditivos) con PAM, CMC y HPMC particularmente con HPMC F 4M. Sin embargo, en ningún caso se encontró un efecto negativo de los hidrocoloides sobre el volumen específico.

- El alveolado de la miga de los panes con hidrocoloides presentó características similares a las del control y el color de la corteza se modificó muy poco no viéndose alterada la aceptabilidad.

- Con todos los hidrocoloides se obtuvieron panes con migas más blandas, de mayor cohesividad, resiliencia y elasticidad, todas características buscadas en un producto panificado. Además, con todos los hidrocoloides se obtuvieron migas con menores valores de masticabilidad que el control, característica también buscada. Por lo tanto, todas estas variaciones dan lugar a un producto panificado con mejores atributos texturales que el control.

- Los hidrocoloides permitieron en general una mejor retención de la humedad lo que junto con las variaciones ocasionadas en los parámetros texturales de la miga permitieron una mejor conservación del pan. Aunque no evitan el aumento de la firmeza, así como tampoco, la pérdida de elasticidad durante el almacenamiento, la dureza final es menor que la lograda sin el uso de hidrocoloides por lo que su utilización es ventajosa.

Efecto sobre la microestructura

- Los hidrocoloides interaccionan con la red de gluten según su carga y la presencia o no de $\mathrm{NaCl}$. En ausencia de $\mathrm{NaCl}, \mathrm{CMC}$ y PAM al ser moléculas cargadas pueden, probablemente, establecer interacciones electrostáticas. 
CMC conduce a redes mas débiles mientras que la influencia de las pectinas es menor.

- En presencia de $\mathrm{NaCl}$ hay apantallamiento de cargas y se promoverían las interacciones hidrofóbicas proteína-hidrocoloide en aquellos casos en que la estructura del hidrocoloide lo permita. En estas condiciones, las HPMCs y PAM dieron redes menos estables. MCC es la celulosa que menos influye, tanto en presencia como en ausencia de $\mathrm{NaCl}$.

- El $\mathrm{NaCl}$ promueve la orientación y el entrecruzamiento en la matriz de gluten y los hidrocoloides parecen reforzar este efecto en algunos casos generando matrices más orientadas y entrecruzadas.

- Las matrices con hidrocoloide serían más móviles (movimientos rotacionales, de corto alcance) en algunos casos (celulosas) y más rígidas en otros (pectinas)

- Los hidrocoloides pueden inducir cambios conformacionales, que dependerán de la presencia o ausencia de sal en el sistema. Las celulosas en ausencia y presencia de $\mathrm{NaCl}$ promueven el desplegamiento de las proteínas (desordenamiento) (menor estructura de $\alpha$ hélice y aparición de hoja $\beta$ plegada paralela y antiparalela).

- La labilidad de las proteínas de la red de gluten se ve afectada por las características de las matrices obtenidas.

- El agregado de celulosas modificadas o pectinas en masa no afectaría sustancialmente la gelatinización de almidón ni la retrogradación de amilopectina, fenómenos involucrados en la panificación y conservación del pan.

El principal efecto de los hidrocoloides estudiados se observó sobre las proteínas del gluten, debido a que conducen a cambios conformacionales que modifican las características de la red. Estos cambios dependen de las interacciones químicas que cada polisacárido puede establecer y de las condiciones del medio y explicarían, a nivel macroscópico, las diferencias observadas en el comportamiento reológico de la masa y en los atributos de calidad del pan. 


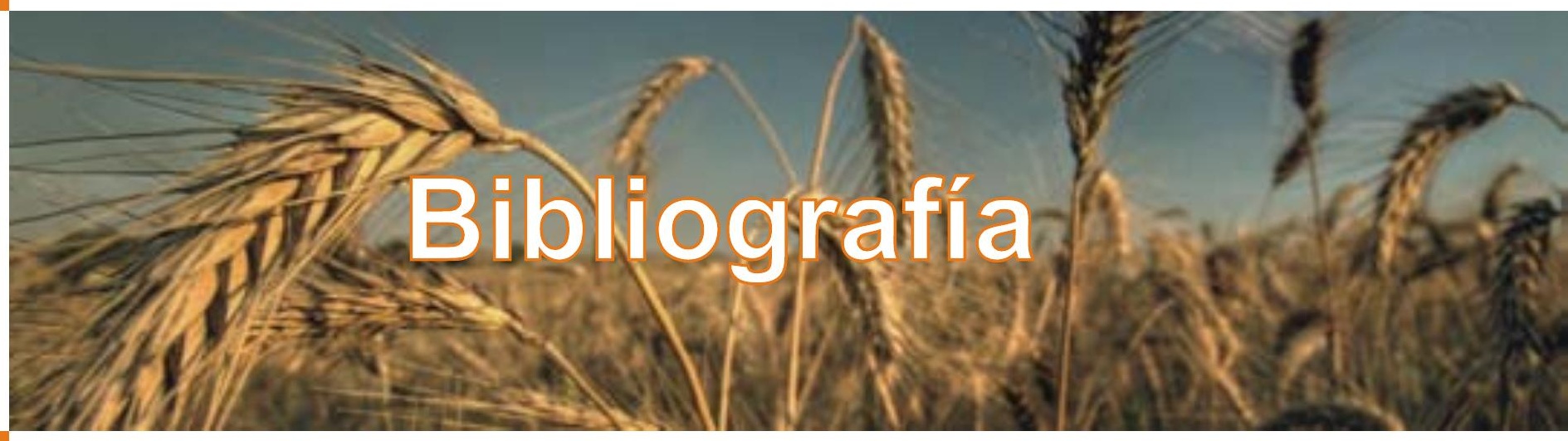


AACC International (2000). Métodos: 08-01; 30-25.01; 54.30.02, 22-08.01; 38-12, 4419; 76-21; 56.81. Approved Methods of the American Association of Cereal Chemists, 10th Ed. St. Paul, MN: The American Association of Cereal Chemist, Inc.

Alloncle, M., Lefebvre, J., Llamas, G., Doublier, J.L. (1989). A rheological characterization of cereal starch-galactomannan mixtures. Cereal Chemistry 66 (2): 90 93.

Anger, H., Berth, G. (1986) Gel permeation chromatography and the Mark Houwink relation for pectins with different degrees of esterification. Carbohydrate Polymers 6: 193-202.

Angioloni, A., Collar,C. (2009). Gel, dough and fibre enriched fresh breads: Relationships between quality features and staling kinetics. Journal of Food Engineering 91: 526-532.

Angioloni, A., Collar,C. (2011). High legume-wheat matrices: an alternative to promote bread nutritional value meeting dough viscoelastic restrictions. European Food Research and Technology 234 (2): 273-284.

Añon, M.C., Jovanovich, G. (2000). Calorimetría diferencial de barrido (Capítulo 5) en Caracterización funcional y estructural de proteínas (pp 97-126). Pilosof, A. Editorial Universitaria de Buenos Aires.

Aravind, N., Sissons, M., Fellows, C.M. (2012). Effect of soluble fibre (guar gum and carboxymethylcellulose) addition on technological, sensory and structural properties of durum wheat spaghetti. Food Chemistry 131 (3): 893-900.

Armero, E., Collar, C. (1996). Anstistaling additives, flour type and sourdough process effects on functionality of wheat doughs. Journal of Food Science, 61: 299-303.

Attenburrow, G.E., Goodband, R.M., Taylor, L.J., Lillford, P.J. (1989). Structure, mechanics and texture of a food sponge. Journal of Cereal Science 9: 61-70.

Baier-Schenk, A., Handschin,S., von Schönau, M., Bittermann, A.G., Bächi, T., CondePetit, B. (2005). In situ observation of the freezing process in wheat dpough by 
confocal laser scanning microscopy (CLSM): Formation of ice and changes in the gluten network. Journal of Cereal Science 42: 255-260.

Bao, J. (2008). Accurate measurement of pasting temperature by the rapid viscoanalyser: a case study using rice flour. Rice Science 15 (1): 69-72.

Bárcenas, M.E., Benedito,C., Rosell, C.M. (2004). Use of hydrocolloids as bread improvers in interrupted baking process with frozen storage. Food Hydrocolloids 18: 769-774.

Bárcenas, M.E., Rosell, C.M. (2005). Effect of HPMC addition on the microstructure, quality and aging of wheat bread. Food Hydrocolloids 19: 1037-1043

Bárcenas, M.E., De la O-Keller, J., Rosell, C.M. (2009) Influence of different hydrocolloids on major wheat dough components (gluten and starch). Journal of Food Engineering 6 (3-4): 241-247.

Blazek, J., Copeland, L. (2008). Pasting and swelling properties of wheat flour and starch in relation to amylose content. Carbohydrate polymers 71: 380-387.

Belton, P. S. (1999). On the elasticity of wheat gluten. Journal of Cereal Science 29: 103-107.

Belton, P.S. (2003). The molecular basis of dough rheology. Capítulo 13 en Bread making Improving Quality. Editado por Stanley P. Cauvain. Publicado por Woodhead Publishing Limited, Cambridge-Inglaterra

BeMiller, J.N. (2001). Classification, structure, and chemistry of polysaccharides of foods. Capítulo 31 en Handbook of dietary fiber. New York: Marcel Dekker, Inc.

Beta, T., Corke, H., Rooney, L.W., Taylor, J. (2000). Starch properties as affected by sorghum grain chemistry. Journal of the Science of Food and Agriculture 81 (2): 245251.

Bettge, A.D., Morris, C.F. (2000) Relationships among grain hardness, pentosan fractions and end-use quality of wheat. Cereal Chemistry 77 (2): 241-247. 
Biliaderis, C.G. (1983). Differential scanning calorimetry in food reserch- A review. Food Chemistry 10: 239-265.

Biliaderis, C.G. (1992). Structures and phase transitions of starch in food systems. Food Technology 6: 98-109.

Bohlin, L., Carlson, T.L.G., (1980). Dynamic viscoelastic properties of wheat flour doughs: dependence on mixing time. Cereal Chemistry 57: 175-181.

Bollaín, C., Collar, C. (2004). Dough viscoelastic response of hydrocolloid/ enzyme/ surfactant blends assessed by uni- and bi-axial extension measurements. Food Hydrocolloids 18 (3): 499-507.

Bourne, Malcom (2002). Principles of objective texture measurement (Capítulos 3, 4, pp 107-187) en Food Texture and Viscosity: Concept and Measurement. Academic Press, California, USA.

Buera, M.P., Retriella, C., Lozano, R.D. (1985). Definition of colour in the nonenzymatic browning. Die Farbe 33: 316-326.

Burnouf, T.,Bietz,J.A. (1989). Rapid purification of wheat glutenin for reversed-phase high-performance liquid chromatography: Comparison of dimethyl sulfoxide with traditional solvents. Cereal Chemistry 66 (2): 121-127.

Campbell, G.M. (2003). Bread aeration. Capítulo 17 en Breadmaking Improving Quality. Editato por Stanley P. Cauvain. Woodhead Publishing Limited. Cambridge England.

Carr, N.O., Daniels, N.W.R., Frazier, P.J. (1992). Lipid interactions in breadmaking. Critical Reviews in Food Science and Nutrition 31: 237-258.

Catterall, P. (1998). La molienda - Capítulo 12- (pp 349-390) en Fabricación de pan. Editado por Cauvain, S.P; Young, L.S. Editorial Acribia, S.A. Zaragosa, España. 
Cauvain, S.P. (2002), Pan: el producto (Capítulo1); Procesos de panificación (Capítulo 2). En: Fabricación de pan editado por Cauvain, S.P. y Young, L.S. Editorial Acribia S.A, Zaragoza, España.

Cauvain S.P. (2004) Improving the texture of bread (Capítulo 18) en Food Texture Vol 2: Solid foods.Editado por David Kilcast. Woodhead Publishing Limited, Cambridge, Inglaterra.

Champion, D., Le Meste, M., Simatos, D. (2000). Towards an improved understanding of glass transition and relaxations in foods:molecular mobility in the glass transition range. Trends in Food Science and Technology 11: 41-55.

Chaplin, M.F. (2001). Water; its importance to life. Biochemical and Molecular Biology Education 29: 54-59 (http://www.Isbu.ac.uk/water/).

Chidichimo, H.O., Sempé, M.E., Aulicino ,.M.B, Almaráz ,.L.B. Informe sobre la calidad comercial e industrial de trigo. Campañas 1994/95 - 2005/06. Realizado por la Universidad Nacional de La Plata. Disponible en http:/www.minagri.gob.ar/new/00/programas/dma/dma/lo_nuevo.php.

Chinachoti, P., White, V.A. ., Lo, L., Stengle, T.R. (1991). Application of high resolution carbon-13, oxygen-17, and sodium-23 NMR to study the influences of water, sucrose and $\mathrm{NaCl}$ on starch gelatinization. Cereal Chemistry 68: 238-244.

Chinachoti, P., Kim-Shin,M.-S., Mari, F., Lo, L. (1991). Gelatinization of wheat starch in the presence of sucrose and $\mathrm{NaCl}$ : the correlation between $\mathrm{Tp}$ and water mobility as determined by ${ }^{17} \mathrm{O}$ nuclear magnetic resonance. Cereal Chemistry 68: 245-248.

Chinachoti, P., Vittadini, E., Chatakanonda, P., Vodovotz, Y. (2008). Characterization of molecular mobility in carbohydrate food Systems by NMR. Modern Magnetic Resonance (1703-1712).

Choi, Y.J, Kim, B.Y, Baik,M.Y (2010). Analytical methodology for bread staling. Journal of the Korean Society for Applied Biological Chemistry 53 (4): 389-400. 
Christensen, S. H, Pectins (1982). En M. Glicksman (Ed) Food Hydrocolloids. Vol 3 (pp. 205-230) Boca Raton: CRC Press, Inc.

Christianson, D.D. (1982) Hydrocolloid interactions with starches. En . Lineback, D.R., Inglett, G.E. (Eds). Food carbohydrates (pp 399-419). IFT Basic symposium series Wesport, Connecticut: AVI Publishing Company, Inc.

Christianson, D. D., Hodge, j. E. , Osborne, D., Detroy, R. W. (1981). Gelatinization of wheat starch as modified by xanthan gum, guar gum, and cellulose gum. Cereal Chemistry 58 (6): 513-517

Chung, OK., Pomeranz, Y., Finney, K.F. (1978). Wheat flour lipids in breadmaking. Cereal Chemistry 55 (5): 598-618.

Chung,O.K. (2003) Improving wheat quality- Capítulo 16- en Breadmaking Improving Quality. Editado por Stanley P. Cauvain, Woodhead Publishing Limited y CRC press LLC. Cambridge, England.

Cleemput,G., Roels,S.P., Van Oort,M., Grobet,P.J., Delcour,J.A. (1993). Heterogeneity in the structure of water-soluble arabinoxylans in European wheat flours of variable bread-making quality. Cereal Chemistry 70: 324-329.

Código Alimentario Argentino (2011). www. anmat.gov.ar. Capítulo XVIII-Aditivos alimentarios (Art. 1398).

Collar, C., Armero, E., Martínez, J. (1998). Lipid binding of formula bread doughs Relationships with dough and bread technological performance Relationships with dough and bread technological performance European Food Research and Technology 207 (2): 110-121.

Collar, C. (2003). Significance of viscosity profile of pasted and gelled formulated wheat doughs on bread staling. European Food Research and Technology 216: 505513. 
Collar, C., Bollaín, C. (2005). Relationships between dough functional indicators during breadmaking steps in formulated samples. European Food Research and Technology 220 (3-4): 372-379.

Copeland, L., Blazek,J., Salman, H., Chiming Tang, M. (2009). Form and functionality of starch. Food Hydrocolloids 23:1527-1534.

Courtin, C.M, Delcour, J.A. (2002). Arabinoxylans and endoxylanases in wheat flour breadmaking. Journal of Cereal Science 35, 225-243.

Cuniberti M., Mir,L., Berra,O., Macagno,S. (2008). Reporte de cosecha caliad del trigo de la región central del país. Camapaña 2007-2008. www.inta.gob.ar

Cuniberti M., Mir,L., Berra,O., Macagno,S. (2012). Reporte de cosecha caliad del trigo de la región central del país. Camapaña 2011-2012. www.inta.gob.ar

Curic, D., Karlovic, D., Tusac, D., Petrovic, D., Dugum, J. (2001). Gluten as a standard of wheat flour quality. Food Technology and Biotechnology 39 (4): 353-361.

Czerniejewski, C.P., Shank, C.W., Bechtel, W.G., Bradley, W.B. (1964). The mineral of wheat flour and bread. Cereal Chemistry 41: 65-72.

Daas, P.J.H, Boxma, B., Hopman, A.M.C.P, Voragen, A.G.J., Schols, H.A. (2001) Nonesterified galacturonic acid sequence homology of pectins. Biopolymers 58 (1): 18.

Demirkesen, I., Mert, B., Summu, G., Sahin, S. (2011). Rheological properties of gluten-free bread formulations. Journal of Food Engineering 96 (2): 295-303.

Dengate, H.N. (1984). Swelling, pasting and gelling of wheat starch. Advances in Cereal Science and Technology 6: 49-82.

Dewettinck, K., Van Bockstaele, F., Kühne,B., Van de Walle, D., Courtens, T.M., Gellynck, X. (2008) Nutritional value of bread: Influence of processing, food interaction and consumer perception. Journal of Cereal Science 48: 243-257. 
Dirección de Coordinación de delegaciones - Estimaciones Agrícolas- SAGPYA- CNA http://www.minagri.gob.ar/SAGPyA/agricultura/cultivos_en_la_argentina/01mapa_principales_cultivos/index.php

Dobraszczyk, B.J. (2003, a). Measuring the rheological properties of dough. Capítulo 18 en Breadmaking improving quality. Editado por Stanley P. Cauvain, Woodhead Publishing Limited y CRC press LLC. Cambridge, Inglaterra.

Dobraszczyk, B.J., Morgenstern, M. P. (2003, b). Rheology and the breadmaking process. Journal of Cereal Science 38: 229-245.

Dodic'J., Pejin, S., Dodic'S., Popov, S., Mastilovic'J., Popov-Raljic'J., Zivanovic, S. (2007). Effects of hydrophilic hydrocolloids on dough and bread performance of samples made from frozen doughs. Journal of Food Science 72 (4): 235-241.

Dow Chemical company (1997). Methocel Cellulose ethers -Technical Handbook.

Du, B., Li, J., Zhang, H., Huang, L., Chen, P., Zhou, J. (2009). Influence of molecular weight and degree of sustitution of carboxymethylcellulose on the stability of acidified milk drinks. Food Hydrocolloids 23: 1420-1426.

Dupont, F.M., Altenbach, S.B. (2003). Molecular and biochemical impacts of environmental factors on wheat grain development and protein synthesis. Journal of Cereal Science 38: 133-146.

Doublier, J.L. Llamas, G., Le Meur, M. (1987) A rheological investigation of cereal Starch pastes and gels. Effect of pasting procedures. Carbohydrate Polymers 7: 251275.

Dürrenberger, M.B, Handschin, S., Conde-Petit,B., Escher, F. (2001). Visualization of food structure by confocal laser scanning microscopy (CLSM). LebensmittelWissenschaft und Technologie 34: 11-17.

Eliasson, A.C. (2003). Starch structure and bread quality. Capítulo7 en Breadmaking Improving Quality. Editato por Stanley P. Cauvain. Woodhead Publishing Limited. Cambridge, Inglaterra. 
Esselink, E., van Aalst, H., Maliepaard, M., Henderson, T.M.H., Hoekstra, N.L.L., van Duynhoven, J. Impact of industrial dough processing on structure: A rheology, nuclear magnetic resonance, and electron microscopy study. Cereal Chemistry 80 (4): 419423.

Evans, I.D., Haisman, D.R. (1982). The effect of solutes on the gelatinization temperature range of potato starch. Starch/Stärke 34: 224.

Faivre, J.; Bonithon-Kopp, C. (1999). Diets, fibres and colon cancer. Advances in experimental Medicine and Biology 472: 199-206.

FAO. / JECFA. (2001) FNP52 add 9. Pectins. Disponible en la pagina web de la FAO: http://www.fao.org/ag/agn/jecfa-additives/specs/Monograph1/Additive-306.pdf

FAOSTAT, sitio web: http://faostat.fao.org/

Feldheim, W., Wisker, E. (2000). Studies on the improvement of dietary fibre intake. Deutsche Lebensmittel Rundschau 96: 327-330.

Fernandez, M. L. (2001). Pectin. In Sungsoo Cho S. , Dreher M.L. Handbook of dietary fiber. Capítulo 30. New York: Marcel Dekker, Inc.

Ferrer, E.G., Bosch, A., Yantorno, O., Baran, E.J. (2008) A spectroscopy approach for the study of the interactions of bioactive vanadium species with bovine serum albumin. Bioorganic and Medicinal Chemistry 16: 3878-3886.

Ferrer, E.G., Gómez, A.V., Añón, M.C., Puppo, M.C.(2011). Structural changes in gluten protein structure after addition of emulsifier. A Raman spectroscopy study. Spectrochimica Acta Part A 79: 278-281.

Ferrero, C., Martino, M.N., Zaritzky, N.E. (1996). Effect of hydrocolloids on starch thermal transitions, as measured by DSC. Journal of Thermal Analisys 47: 1247-1266.

Fido, R.J., Bekes, F., Gras, P.W., Tatham, A.S.(1997). Effects of $\alpha^{-}, \beta^{-}, \gamma^{-}$and $\omega^{-}$ gliadins on the dough mixing properties of wheat flour. Journal of Cereal Science 26: 271-277. 
Friedman, H.H., Whitney, J.E., Szczesniak, A.S. (1963). The texturometer- A new instrument for objective texture measurement. Journal of Food Science 28 (4): 390396.

Fiszman, S.M., Pons, M., Damásio, M.H. (1998). New parameters for instrumental texture profile analysis: instantaneous and retarded recoverable springiness Journal of Texture Studies 29: 499-508

Galal, A. M., Varriano-Marston, E., Jhonson, J. A. (1978). Rheological dough properties as affected by organic acids and salt. Cereal Chemistry 55: 683-691.

Gan, Z., Ellist, P.R., Schofield, J.D. (1995). Gas Cell Satbilization and Gas Retention in wheat Bread Dough. Journal of Cereal Science 21:215-230.

Ghiasi, K., Hoseney, R.C., Varriano, E. (1982) Effects of flour components and dough ingredients on starch gelatinization. Cereal Chemistry 60 (1): 58-61.

Glicksman, M (1982). En M. Glicksman (Ed) Food Hydrocolloids. Vol I Boca Raton: CRC Press, Inc.

Goesaert, H., Brijs, K, Veraverbeke, W.S, Courtin, C.M, Gebruers, K., Delcour, J.A. (2005). Wheat flour constituents: How they impact bread quality, and how to impact their functionality. Trends in Food Science and Technology 16: 12-30.

Gómez Pallarés, M., León A. E., Rosell, C.M., (2007, a) Trigo en "De tales panes tales Harinas" (Capítulo 1). (pp. 17-72). Editado por León, A.E y Rosell, C.M., Báez ediciones.

Gómez, M, Ronda F, Caballero, P.A, Blanco, C.A, Rosell, C.M.(2007, b). Functionality of different hydrocolloids on the quality and shelf-life of yellow layer cakes. Food Hydrocolloids 2: 167-173.

Grover, J. (1982). Methylcellulose (MC) and Hydroxypropylmethylcellulose (HPMC). Capítulo 4 en Food Hydrocolloids Vol III editado por Gliksman,M.Boca Raton: CRC Press, Inc. 
Guarda, A., Rosell, C.M., Benedito, C., Galotto, M.J.(2004). Different hydrocolloids as bread improvers and antistaling agents. Food hydrocolloids 18: 241-247.

Hans Tromp, R., van de Velde, F., van Riel, J., Paques, M. (2001). Confocal scanning ligh microscopy (CSLM) on mixtures of gelatine and polysaccharides. Food Research International 34: 931-938.

Hajsělová, M. Analysing wheat and flour. Capítulo 9 en Bread making Improving Quality Editado por Stanley P. Cauvain. Publicado por Woodhead Publishing Limited, Cambridge, Inglaterra.

Harding, Stephen E. (1997) The intrinsic viscosity of biological macromolecules. Progress in measurement, interpretation and application to structure in dilute solution. Progress in Biophysics Molecular Biology 68 (23): 207-262.

He, H., Roach, R.R., Hoseney, R.C. (1992). Effect of non chaotropic salts on flour bread-making properties. Cereal Chemistry 69 (4): 366-371.

Herrero, A.M. (2008). Raman spectroscopy a promising technique for quality assessment of meat and fish: A review. Food Chemistry 107: 1642-1651.

Hizukuri, S., Takeda, Y., Yasuda, M. (1981). Multi-branched nature of amylose and the action of debranching enzymes. Carbohydrate Research 94: 205-213.

Hoseney, R.C, Rogers, D.E. (1990) The formation and properties of wheat flour doughs. Food Science and Nutrition 29 (2): 73-93.

Hoseney, R.C, (1994) Principles of cereal science and technology $\left(2^{\text {nd }} e d\right) . S t$. Paul, MN: Association of Cereal Chemist, Inc. (pp 81-101, 229-273).

Howitt, C:A., Tamás, L., Solomon, R. G., Gras, P.W., Morell, M. K., Békés, F., Appels, R. (2003). Modifying flour to improve functionality. Capítulo 11 en Breadmaking Improving Quality Editado por Stanley P. Cauvain. Publicado por Woodhead Publishing Limited, Cambridge, Inglaterra. 
Huang, Y.C., Li, H.M. (2010). Noodle quality affected by different cereal starches. Journal of Food Engineering 97 (2):135-143.

Huebner, F.R., Bietz, J.A. (1993). Improved chomatographic separation and characterization of etanol-soluble wheat proteins. Cereal Chemistry 70: 506-511.

Instituto Argentino de Racionalización de Materiales. (2000). Método 15855.

Instituto Argentino de Racionalización de Materiales.(1995). Método 15864

Internacional Standard Organization. (2006). Method 20483 (E) Cereals and pulsesDetermination of the nitrogen content and calculation of the crude protein contentKjeldhal method.

Internacional Standard Organization. (2006) Method 21415-2: 2006 (E) Wheat and wheat flour- Gluten content-

Jane, J. (2004). Starch: Structure and Properties. Capítulo 7 en Chemical and functional properties of food saccharides. Editado por Piotr Tomasik. CRC PRESS LLC. Boca Raton -Washington, D.C. Estados Unidos.

Janhøj, T., Frøst, M.B, Ipsen, R. (2008). Sensory and rheological characterization of acidified milk drinks. Food Hydrocolloids 22: 798-806.

Jekle, M., Becker,T. (2011). Dough microstructure: Novel analysis by quantification using confocal laser scanning microscopy. Food Research International 44: 984-991.

Johari, G.P. (1976) Glass transition and secondary relaxations in molecular liquids and crystals. Annals of the New York Academy of Sciences 2: 117-140.

Juan, Néstor Antonio (2003). Clasificación de trigo por aptitud de uso industrial. http://www.inta.gov.ar/anguil/info/pdfs/boletines/bol76/cap10.pdf

Kalichevsky, M.T., Blanshard, J.M.V. (1992). A study of effect of water on the glass transition of 1:1 mixtures of amylopectin, casein and gluten using DSC and DMTA. Carbohydrate Polymers 19: 271-278. 
Khan,K, Zhu, J., Huang, D.Y., Borneo, R. (2002). Glutenin size distribution, determinated by multi-stacking SDS-PAGE: Relationship to Breadmaking Quality. Capítulo 5 en Cereal Chemists, Minnesota, Estados Unidos.

Khan, K., Nygard, G., Pogna, N.E., Redaelli, R., Ng, P.K.W., Fido, R.J., Shewry, P.R. (2003). Electrophoresis of wheat gluten proteins. Capítulo 3 en Wheat gluten protein analysis. Editado por Shewry, P., Lookhart, G.L. American Association of Cereal Chemists, Inc. St. Paul, Minnesota, Estados Unidos.

Karlsson, R., Olered, R., Eliasson, A.C. (1983). Changes in starch granule size distribution and starch gelatinization properties during development and maturation of wheat, barley and rye. Starch/Stärke 35: 335-340.

Keller, J.D (1982) Sodium carboxymethylcellulose (CMC). Capítulo 2 en Food Hydrocolloids Vol 3 (pp 43-111), editador por Gliksman, M. Boca Raton: CRC Press, Inc.

Kim, S.K., D' Appolonia, B.L. (1977, a) Effect of pentosans on retrogradation of wheat starch gels. Cereal Chemistry 54: 150- 160.

Kim, S.K., D’ Appolonia, B.L. (1977, b) bread staling studies III. Effect of pentosans on dough, bread and brad staling rate. Cereal Chemistry 54: 225- 229.

Kinsella, J. E., Hale, M. L. (1984). Hydrophobic associations and gluten consistency: Effects of specific anions. Journal of Agriculture and Food Chemistry 32: 1054-1056.

Komlenić, D.K., Ugarčić-Hardi, Z., Jukić, M., Planinić, M., Bucić-Kojić, A., Strelec, S. (2010). Wheat dough rheology and bread quality effected by Lactobacillus brevis preferment, dry sourdough and lactic acid addition. International Journal of Food Science and Technology 45 (7): 1417-1425.

Kruger, J.E., Marchylo, B.A., Hatcher, D. (1988). Preliminary assessment of a sequential extraction scheme for evaluating quality by reversed-phase highperformance liquid chromatography and electrophoretic analysis of gliadins and glutenins. Cereal Chemistry 65: 208-214. 
Laemmli, U.K. (1970). Cleavage of structural proteins during the assembly of the head of Bacteriophage T4. Nature 227: 680-685.

Larsson, K. (1986). Functionality of wheat lipids in relation to gluten gel formation (pp 62-74) en Chemistry and Phisics of Baking. Editado por Blanshard, J.M.V., Frazier, P.J., Galliard, T. Royal Society of Chemistry, Londres, Inglaterra.

Larsson, H. (2002). Effect of $\mathrm{pH}$ and sodium chloride on wheat flour dough properties: Ultracentrifugation and rheological measurements. Cereal Chemistry 79: 544-545.

Lazaridou, A., Duta, D., Papageorgiou, M., Belc, N., Biliaderis, C.G. (2007). Effects of hydrocolloids on dough rheology and bread quality parameters in gluten-free formulations. Journal of Food Engineering 79 (3): 1033-1047.

Lee, M.R., Swanson, B.G, Baik, B.K. (2001). Influence of amylose content on properties of wheat starch and breadmaking quality of starch and gluten blends. Cereal Chemistry 78 (6):701-706.

León, A., Durán, E., Benedito de Barber, C. (1997). A new approach to study starch changes occurring in the dough-baking process and during bread storage. Zeitschrift für Lebensmittel Untersuchung und Forschung 204: 116-120.

Leon, A., Ribotta, P., Ausar, S., Fernandez, C., Landa, C., Beltramo, D. (2000). Interactions of different carrageenan isoforms and flour components in breadmaking. Journal of Agriculture and Food Chemistry 48: 2634-2638.

Leung, H.K., Steinberg, M.P., Wei, L.S., Nelson, A.I. (1976). Water of macromolecules determined by pulsed NMR. Journal of Food Science 41 (2): 297-300.

Li, W., Dobraszczyk, B.J., Schofield, J.D. (2003). Stress relaxation behaviour of wheat dough and gluten protein fractions. Cereal Chemistry 80: 333-338.

Li, W., Dobraszczyk, B.J., Wilde, P.J. (2004). Surface properties and locations of gluten proteins and lipids revealed using confocal scanning laser microscopy in bread dough. Journal of Cereal Science 39: 403-411. 
Lindsay, M.P., Skerritt, J.H. (1999) The glutenin macropolymer of wheat flour doughs: structure-function perspectives. Trend in Food Science and Technology 10: 247-253.

Linlaud, N., Ferrer, E., Puppo, M.C., Ferrero, C. (2011). Hydrocolloid Interaction with Water, Protein, and Starch in Wheat Dough. Journal of Agricultural and Food Chemistry 59: 713-719.

Lodish, H., Berk,A., Matsudaira, P., Kaiser, C.A., Krieger, M., Scott, M.P., Zipursky, S.L., Darnell, J. (2005). Capítulo 5: Visualización de la arquitectura celular en Biología Celular y Molecular. Editorial Panamericana.

Long, D.A. (1977). Raman Spectroscopy. Mc. Graw Hill:London.

Lopes-Da Silva, J.A., Santos, D.M., Freitas, A., Brites, C., Gil,M. (2007). Rheological and nuclear magnetic resonante $(\mathrm{RMN})$ studt of the hydration and heating of undeveloped wheat doughs. Journal of Agricultural and Food Chemistry 55: 56365644 .

Lusse, S.; Arnold, K. (1998). Water binding of polysaccharides-NMR and ESR studies. Macromolecules 31: 6891-6897.

Lynch, E.J., Dal Bello, F., Sheehan, E.M., Cashman, K.D., Arendt, E.K. (2009). Fundamental studies on the reduction of salt on dough and bread characteristics. Food Research International 42: 885-891.

Ma, C.Y, Phillips, D.L. (2002). FT-Raman Spectroscopy and its applications in cereal science. Cereal Chemistry 79 (2) 171-177.

Mac Dougall, D.B. (2002). Colour measurement of food: principles and practice. Capítulo 3 en Color in Food. Improving Quality. Editado por Mac Dougall, D.B. CRC Press LLC, Boca Raton FL, Estados Unidos.

Mac Masters, M., Hinton, J.J.C., Bradbury. D. (1978). Microscopic strucutre and composition of the wheat kernel (pp 51-113). Capítulo 3 en Wheat: Chemistry and Technology, editado por Pomeranz, Y. AACC St. Paul, Minnesota. 
Macritchie, F., Kasarda, D.D., Kuzmicky, D.D. (1991). Characterization of wheat protein fractions differing in contributions to breadmaking quality. Cereal Chemistry 68 (2): 122- 130.

Maloney, D.H., Foy, J.J. (2003). Yeast Fermentations. Capítulo 3 en Handbook of Dough Fermentations editado por Kulp, K. y Lorenz, K. Marcel dekker, inc. Nueva York, Estados Unidos.

Martin, M.L, Hoseney, R.C. (1991). A mechanism of bread firming I. Role of starch swelling. Cereal Chemistry 68: 498-503.

Martínez Nistal, A. Microscopía confocal. Servicio de proceso de imágenes. Universidad de Oviedo, España.

Mattisek, R., Schnepel, F.M, Steiner, G.(1998). Análisis de los alimentos: Fundamentos-métodos- aplicaciones. Ed. Acribia. S.A. Zaragoza, España.

May, C.D. (2000). Pectins. Capítulo 10 en Handbook of Hydrocolloids. Editado por Phillips G.O., Williams, P.A. Woodhead Publishing Limited and CRC Press LLC.

Melnyk, J.P., Dreisoerner, J., Bonomi, F., Marcone, M.F., Seetharaman,K. (2011). Effect of the Hofmeister series on gluten aggregation measured using a high shearbased technique. Food Research International 44: 893-896.

Miles, M.J., Morris, V.J., Orford, P.D., Ring, S.G. (1985). The roles of amylose and amylopectin in the gelation and retrogradation of starch. Carbohydrate Research 135 (2): 271-281.

Moon, M., Giddings, J. (1993). Rapid separation and measurements of particle size distribution of starch granules by sedimentation /steric field-flow fractionation. Journal of Food Science 58:1166-1171.

Murray, J.C.F. (2000). Cellulosics. Capítulo 12 en Handbook of Food Hydrocolloids. Woodhead Publishing Limited and CRC Press LLC. 
Newberry, M.P, Simmons, L.D., Morgenstern, M.P. (2003). Confocal visualisation of MDD dough development (263-266) - Capítulo:Gluten rheology and Functionality en The Gluten proteins:Lafiandra, D., Mascis, D’Ovidio R, Royal Society of Chemistry (Great Britan). Proceedings of the 8th Gluten workshop (Viterbo, Italia, 8-10 September, 2003)

NG, P.K.W., Bushuk, W. (1988). Statistical relationships between high molecular weight subunits of glutenin and breadmaking quality of Canadian-grown wheats. Cereal Chemistry 65:408-412.

Ngarize, S., Herman, H., Adams, A., Howell, N. (2004). Journal of Agricultural and Food Chemistry 52: 6470-6477.

Nieto-Taladriz, M. T.; Ruiz, M.; Martinez, M. C.; Vazquez, J. F.; Carrillo, J. M. (1997). Variation and classification of B low-molecular-weight glutenin subunit alleles in durum wheat Theorical and Applied Genetics 95: 1155- 1160.

Ohm, J.B, Chung, O.K (1999). Gluten, pasting, and mixograph parameters of hard winter wheat flours in relation to breadmaking. Cereal Chemistry 76: 606-613.

Orford, P.D., Parker, R., Ring, S.G., Smith, A.C. (1989). Effect of water as a diluent on the glass transition behavior of malto-oligosaccharides, amylose and amylopectin. International Journal of Biological Macromolecules 11:91-96.

Orford, P.D., Parker, R., Ring, S. G. (1990). Aspects of the glass transition behaviour of mixtures of carbohydrates of low molecular weight. Carbohydrate Research 196: 1118.

Orth, R.A., Bushuk, W. (1973). Studies of glutenin III. Identification of subunits coded by the D-genome and their relation to breadmaking quality. Cereal Chemistry 50: 680 687.

Pantanelli, A. (2003). "Parámetros Industriales de la Calidad del Trigo". Asociación Argentina de productores de Trigo. www.aaprotrigo.org. 
Parada, J., Aguilera, J.M. (2011). Microstructure, mechanical properties and starch digestibility of a cooked dough made with potato starch and wheat gluten. LWT-Food Science and Technology 44: 1739-1744.

Pateras, I. (1998). Bread spoilage and staling (pp 240-261). En Technology of Breadmaking. Eds S P Cauvain y L S Young, London, Blackie Academic \& Professional.

Payne, P.I., Corfield, K.G., Blackman, J.A. (1979). Identification of a high-molecularweight subunit of glutenin whose presence correlates with bread-making quality in wheats of related pedigree. Theoretical And Applied Genetics 55 (3-4): 153-155.

Peighambardoust, S.H., van der Goot, A.J., van Vliet, T., Hamer, R.J., Boom, R.M. (2006). Microstructure formation and rheological behaviour of dough under simple shear flow. Journal of Cereal Science 43: 183-197.

Peleg, M., Normand, M.D. (1983). Comparison of two methods for stress relaxation data presentation of solid foods. Rheological Acta 22: 108-113.

Piermaria, J.A., de la Canal, M.L., Abraham, A.G. (2008). Gelling properties of kefiran, a food grade polysaccharide obtained from kefir grain. Food Hydrocolloids 22, 1520 1527.

Pomeranz, Y.(1987) Modern cereal science and technology. Capítulo 3 "Microscopic structure and composition of the wheat kernel" (pp51-113), y Capítulo 7 "Grain quality" (pp 72-150) VCH New York.

Ponzio, N.R., Puppo, M.C., Ferrero, C. (2008). Mixtures of two Argentinean wheat cultivars of different quality: A study on breadmaking performance. Cereal Chemistry 85 (5): 579-585.

Preston, K.R. (1989). Effects of neutral salts of the lyotropic series on the physical dough properties of a Canadian red spring wheat flour. Cereal Chemistry 66(3):144148. 
Primo-Martin, C.; Van de Pijpenkamp, A.; Van Vliet, T.; De Jongh, H.J.; Plijter, J.J., Hamer, R.J. (2006). The role of the gluten network in the crispness of bread crust. Journal of Cereal Science 43: $342-352$.

Primo-Martin, C., van Nieuwenhuijzena, N.H. (2007). Crystallinity changes in wheat starch during the bread-making process: Starch crystallinity in the bread crust. Journal of Cereal Science 45 (2): 219 -226.

Prosky, L. (1999). What is fibre? Current controversies. Trends in Food Science and Technology 10: 271-275.

Rao, V.K., Mulvaney, S.J., Dexter, J.E., Edwards, N.M., Peressini, D. (2001). Stressrelaxation properties of mixograph semolina-water doughs from durum wheat cultivars of variable strength in relation to mixing characteristics, bread-and pasta- making performance. Journal of Cereal Science 34: 215-232.

Ribotta, P.D., Ausar, S.F., Beltramo, D.M., Leon, A.E. (2005). Interactions of hydrocolloids and sonicated-gluten proteins. Food Hydrocolloids 19: 93-99.

Ribotta, P.D., Le Bail, A. (2007). Themo-physical and themo-mechanical assessment of partially baked bread during chilling and freezing process. Impact of selected enzymes on crumb contraction to prevent crust flaking. Journal of Food Engineering 78: 913-921.

Roudaut, G., Simatos, D., Champion, D., Contreras-Lopez, E., Le Meste, M. (2004). Molecular mobility around the glass transition temperature: a mini review. Innovative Food Science and Emerging Technologies 5:127-134.

Roessler, E.B., Warren, J., Guymon, J.F. (1948). Significance in triangular taste tests. Journal of Food Science 13 (6).

Rojas, J.A., Rosell, C.M., Benedito de Barber, C. (1999). Pasting properties of diferent wheat flour-hydrocolloid systems. Food Hydrocolloids 13: 27-33.

Roos, Y.H. (1995). Phase transition in foods. San Diego: Academic Press. 
Rosell, C:M, Rojas, J.A, Benedito de Barber C. (2001). Influence of hydrocolloids on dough rheology and bread quality. Food Hydrocolloids 15: 75-81.

Rosell, C:M, Collar,C., Haros, M. (2007). Assessment of hydrocolloid effects on the thermo-mechanical properties of wheat using the Mixolab. Food Hydrocolloids 21 (3): 452-462.

Rosell, C. M., Foegeding, A. (2007). Interaction of hydroxypropylmethylcellulose with gluten proteins: Small deformations properties during thermal treatment. Food Hydrocolloids 21: 1092-1100.

Sahagian, M.E., Goff, H.D. (1995). Influence of stabilizers and freezing rate on the stress relaxation behaviour of freeze-concentrated sucrose solutions at different temperaturas. Food Hydrocolloids 9 (3):181-188.

Salovaara, H. (1982). Effect of partial sodium chloride replacement by other salts on wheat dough rheology and bread making. Cereal Chemistry 59: 422-426.

Salvador, A., Sanz, T.; Fiszman S. M. (2006). Dynamic rheological characteristics of wheat flour-water doughs. Effect of adding $\mathrm{NaCl}$, sucrose and yeast. Food Hydrocolloids 20: 780-786.

SENASA. Sitio web www.senasa.gov.ar

Scandola, M., Ceccorulli, G., Pizzoli, M. (1991). Molecular motions of polysaccharides in the solid state: dextran, pullulan and amylose. International Journal of Biological Macromolecules 13 (4): 254-260.

Schebor, C., Buera, M.P., Karel, M., Chirife, J. (1999). Color formation due to non enzymatic browning in amorphous, glassy, anhydrous, model systems. Food Chemistry 65 (4): 427-432.

Schober, T.J., Bean, S.R., Boyle, D.L., Park, S.H. (2008). Improved viscoelastic zein-starch doughs for leavened gluten - free breads: Their rheology and microstructure. Journal of Cereal Science 48: 755-767. 
Shewry, P.R., Popineau, Y., Lafiandra, D., Belton, P. (2001). Wheat glutenin subunits and dough elasticity: findings of the EUROWHEAT project. Trend in Food Science and Technology 11: 433-441.

Shewry, R.(2003). Wheat gluten proteins (pp1-13). En Wheat gluten protein analysis editado por Shewry, R. y Lookhart, G. L. American Association of Cereal Chemist, St. Paul, Minnesota, Estados Unidos.

Shibanuma, K., Takeda, Y., Hizukuri, S., Shibata, S. (1994). Molecular-structures of some wheat starches. Carbohydrate Polymers 25: 111-116.

Shittu, T.A., Raji, A.O., Sanni, L.O. (2007). Bread from composite cassava-wheat flour I. Effect of baking time and temperature in some physical properties of bread loaf. Food Research International 40: 280-290.

Shittu, T.A., Raji, A.O., Sanni, L.O. (2008). Bread from composite cassava- heat flour. II: Effect of cassava genotype and nitrogen fertilizer on bread quality Food Research International 41: 569-578.

Singh, N.K., Donovan, G.R., Batey, I.L., MacRitchie, F. (1990). Use of sonication and size-exclusion High-Performance Liquid Chromatography in the study of wheat flour proteins. I. Distribution of total proteins in the absence of reducing agents. Cereal Chemistry 67 (2): 150-161.

Sing, N.K, Sheperd, K.W y Cornish G.B. (1991). A simplified SDS-PAGE procedure for separating the LMW subunit of glutenin. Journal of Cereal Science 14: 203-208.

Singh, H., MacRitchie, F. (2001). Application of Polymer Science to Properties of Gluten. Journal of Cereal Science 33: 231-243

Sistema Nacional de Vigilancia y Monitoreo de Plagas - SENASA. http://www.sinavimo.gov.ar/cultivo/trigo

Sissons, M., Aravind, N., Fellows, C.M. (2010). Quality of fiber-enriched spaghetti containing microbial transglutaminase. Cereal Chemistry 87: 57-64. 
Slade, L. and Levine, H. (1987). Recent Advances in Starch Retrogradation (pp 387430). En Industrial Polysaccharides - The Impact of Biotechnology and Advanced Methodologies editado por Stivala, S.S., Crescenzi, V. y Dea, I.C.M. Gordon and Breach Science Publishers, New York.

Sroan, B.S, Bean, S.R., MacRitchie, F. (2009). Mechanism of gas cell stabilization in bread making. I. The primary gluten-starch matrix. Journal of Cereal Science 49: 3240.

Šramková, Z., Gregová, E., Šturdík, E. (2009). Chemical composition and nutricional quality of wheat grain. Acta Chimica Slovaca $2(1): 115-138$.

Stauffer, C.E. (1990). Functional Additives for Bakery Foods. Van Nostrand ReinholdNew York, Estados Unidos.

Stauffer,C. (1998). Fundamentos de formación de la masa (pp. 309-347). En: Fabricación de pan editado por Cauvain, S. y Young,L. Acribia, Zaragoza.

Steffe, J. F. (1996). Rheological methods in food process engineering (Segunda edición.). East Lansing, Michigan: Freeman Press.

Szczesniak, A.S. (1962) Clasification of textural characteristics. Journal of Food Science 28 (4): 385-389.

Tanaka, K., Bushuk, W. (1973, a). Changes in four proteins during dough-mixing.ll. filtration and electrophoresis results. Cereal Chemistry 50: 597-605.

Tanaka, K., Bushuk, W. (1973, b). Changes in flour proteins during dough-mixing.l. solubility results. Cereal Chemistry 50: 590-596.

Tatham, A. S., Shewry, P. R. (1995). The S-poor prolamins of wheat, barley and rye. Journal of Cereal Science 22:1-16.

Thomas, W.R. (1982). Microcrystalline cellulose (MCC or cellulose gel). Capítulo 1 en Food Hydrocolloids, vol III, editado por Glicksman, M. M. Boca Raton: CRC Press, Inc. 
Tolstoguzov, V. (1997). Thermodinamic aspects of dough formation and functionality. Food Hydrocolloids 11(2): 193-197.

Tu, A.T. (1982). Raman Spectroscopy en Biology: Principles and Applications, John Wiley and Sons Inc., New York.

Tudorica, C.M, Kuri, V., Brennan, C.S. (2002) Nutritional and physicochemical characteristics of dietary fiber enriched pasta. Journal of Agricultural and Food Chemistry 50: 347-356.

Ukai, T., Matsumura, Y., Urade, R. (2008). Disaggregation and reaggregation of gluten proteins by sodium chloride. Journal of Agricultural and Food Chemistry 56: 11221130.

Van de Velde, F., Weinbreck, F., Edelman, M.W., van der Linden, E., Hans Tromp, R. (2003). Visualisation of biopolymer mixtures using confocal scanning laser microscopy (CSLM) and covalent labelling techniques. Colloids and Surfaces B: Biointerfases 31: 159-168.

Voragen, A.G.J., Coenen, G.J., Verhoef, R. P., Schols, H.A. (2009). Pectin, a versatile polysaccharide present in plant cell walls. Journal of Structural Chemistry 20: 263-275.

Watts, B.M., Ylimaki, G.L., Jeffery, L..E., Elías, L.G. Métodos sensoriales básicos para la evaluación de alimentos (1992). Ottawa, Ont., CIID.

Webb, C., Owens, G.W. (2003). Milling and flour quality. Capítulo 10 en Breadmaking improving Quality. Editado por Stanley P. Cauvain. Ed. Woodhead Publishing Limited. Cambridge, Inglaterra.

Weegels, P.L., de Groot, A.M.G., Verhoek, J.A., Hamer, R.J.(1994) Effects on Gluten of Heating at Different Moisture Contents. II. Changes in Physico-Chemical Properties and Secondary Structure. Journal fo Cereal Science 19(1): 39-47.

Wheat Marketing Center, wheat and flour testing methods: A guide to understanding wheat and flour quality, Version 2, Kansas State University (2008). 
Wherle, K., Grau, H., Arendt, E. K. (1997). Effects of lactic acid, acetic acid, and table salt on fundamental rheological properties of wheat dough. Cereal Chemistry 74: 739744.

Wieser, H. Bushuk, W., Mac Ritchie, F. (2006) The polymeric glutenins (pp 213-240). En Gliadin and Glutenin: The unique balance of wheat quality editado por Wringley, C., Bekes, F.,Bushuk, W. St. Paul American Association of Cereal Chemistry.

Wieser, H. (2007). Chemistry of gluten proteins. Food microbiology 24: 115-119.

Williams, P.A., Phillips, G. O. (2000). Introduction to food hydrocolloids (pp.1-19). Capítulo 1 en Handbook of Hydrocolloids editado por Phillips, G.O., y Williams, P.A. Woodhead Publishing Limited and CRC Press LLC.

Wrigley, C.W., Du Cros, D.L., Fullington, J.G., Kasarda, D.D. (1984). Changes in polypeptide composition and grain quality due to sulfur deficiency in wheat. Journal of Cereal Science 2: 15-24.

Wrigley, C., Batey, I. (2003). Assessing grain quality. Capítulo 4 en Breadmaking Improving Quality Editado por Stanley P. Cauvain. Publicado por Woodhead Publishing Limited, Cambridge, Inglaterra.

Yalungo, Y. (2007). Evolución de la tendencia en el uso de variedades de trigo pan campañas: 2003/04, 2004/05, 2005/06 y 2006/07. Informe de la Secretaría de Agricultura, Ganadería, Pesca y Alimentos- Subsecretaría de Agricultura, Ganadería y Forestación-Dirección Nacional de Producción Agropecuaria y Forestal-DIRECCION DE AGRICULTURA.

Zhao, F.J., Salmon, S.E., Withers, P.J.A., Monaghan, J.M., Evans, E.J., Shewry, P.R., McGrath, S.P. (1999). Variation in the breadmaking quality and rheological properties of wheat in relation to sulphur nutrition under field conditions. Journal of Cereal Science 30 (1): 19-31.

Zimmerman, J.R., Britton, W.E. (1957). Nuclear magnetic resonance studies in multiple phase systems: lifetime of water molecule in an adsobing phase on a silica gel. Journal of Physical Chemistry 61: 1328-1333. 
Zobel, H.F., (1984). Gelatinization of starch and mechanical properties of starch pastes (285-309). Capítulo IX en Starch Chemistry and Technology (Segunda edición). Editado por Whistler, R.L., BeMiller, J.N., Paschall, E. Academic Press Inc. Florida, Estados Unidos. 


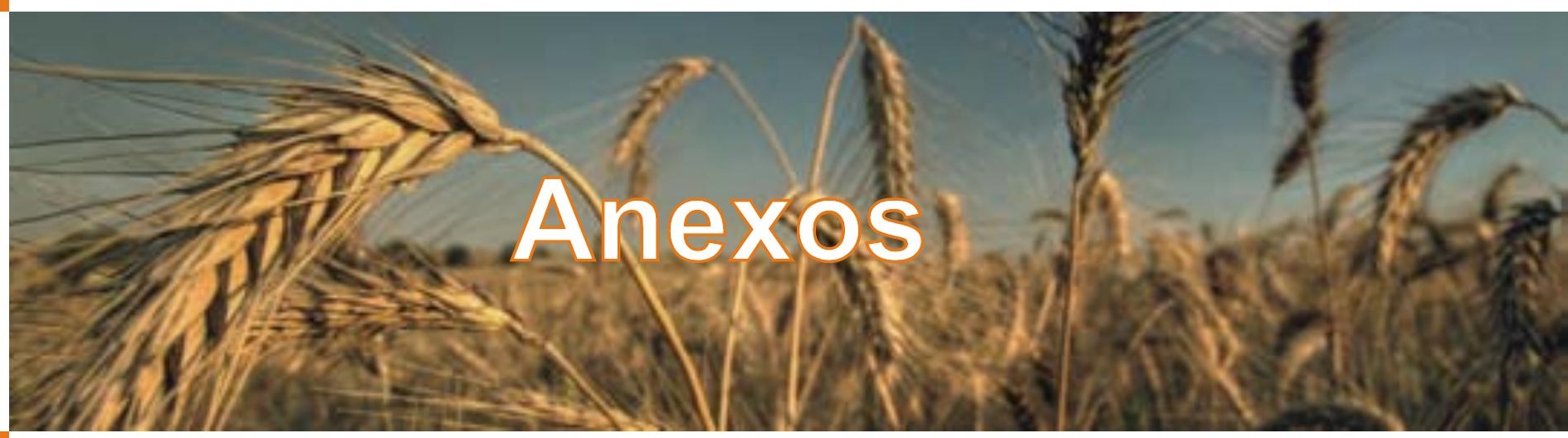




\section{Anexo 1}

Planilla en la cual se indica que muestra recibió cada evaluador

\begin{tabular}{|c|c|c|c|c|c|c|c|}
\hline Evaluador & M358 & M135 & M886 & & M687 & M500 & M104 \\
\hline 1 & C & $\mathrm{H}$ & C & 1 & $\mathrm{H}$ & C & C \\
\hline 2 & C & $\mathrm{H}$ & $\mathrm{H}$ & 2 & C & $\mathrm{H}$ & C \\
\hline 3 & C & $\mathrm{H}$ & C & 3 & $\mathrm{H}$ & C & C \\
\hline 4 & $C$ & $\mathrm{H}$ & $C$ & 4 & $\mathrm{H}$ & C & $\mathrm{H}$ \\
\hline 5 & C & C & $\mathrm{H}$ & 5 & C & $\mathrm{H}$ & C \\
\hline 6 & $C$ & $C$ & $\mathrm{H}$ & 6 & $\mathrm{C}$ & $\mathrm{H}$ & $\mathrm{H}$ \\
\hline 7 & $\mathrm{H}$ & C & $\mathrm{H}$ & 7 & C & $\mathrm{H}$ & C \\
\hline 8 & C & $\mathrm{H}$ & $\mathrm{H}$ & 8 & $\mathrm{H}$ & C & $\mathrm{H}$ \\
\hline 9 & $\mathrm{H}$ & $\mathrm{H}$ & C & 9 & $\mathrm{H}$ & C & C \\
\hline 10 & $C$ & $\mathrm{H}$ & $\mathrm{H}$ & 10 & $\mathrm{H}$ & $C$ & $C$ \\
\hline 11 & C & $\mathrm{H}$ & $\mathrm{H}$ & 11 & C & $\mathrm{H}$ & C \\
\hline 12 & $\mathrm{H}$ & $C$ & $\mathrm{H}$ & 12 & $\mathrm{H}$ & $C$ & $\mathrm{H}$ \\
\hline 13 & C & C & $\mathrm{H}$ & 13 & C & $\mathrm{H}$ & C \\
\hline 14 & $\mathrm{C}$ & $\mathrm{H}$ & $\mathrm{C}$ & 14 & $\mathrm{H}$ & $\mathrm{C}$ & $\mathrm{H}$ \\
\hline 15 & $\mathrm{H}$ & $C$ & $\mathrm{H}$ & 15 & $\mathrm{H}$ & C & $\mathrm{H}$ \\
\hline 16 & $\mathrm{H}$ & $\mathrm{H}$ & $\mathrm{C}$ & 16 & $C$ & $\mathrm{H}$ & $\mathrm{H}$ \\
\hline 17 & C & C & $\mathrm{H}$ & 17 & $\mathrm{H}$ & C & C \\
\hline 18 & $\mathrm{H}$ & $\mathrm{C}$ & C & 18 & $\mathrm{H}$ & $\mathrm{C}$ & $\mathrm{H}$ \\
\hline 19 & $C$ & $C$ & $\mathrm{H}$ & 19 & $\mathrm{H}$ & C & $\mathrm{H}$ \\
\hline 20 & $C$ & $\mathrm{H}$ & $\mathrm{C}$ & 20 & $C$ & $\mathrm{H}$ & $\mathrm{H}$ \\
\hline 21 & $\mathrm{H}$ & $C$ & $\mathrm{H}$ & 21 & $C$ & $\mathrm{H}$ & $\mathrm{H}$ \\
\hline 22 & $\mathrm{H}$ & $\mathrm{H}$ & C & 22 & $C$ & $\mathrm{H}$ & C \\
\hline 23 & $C$ & $\mathrm{H}$ & $\mathrm{H}$ & 23 & $C$ & $\mathrm{H}$ & C \\
\hline 24 & $\mathrm{H}$ & C & C & 24 & $\mathrm{H}$ & $C$ & $\mathrm{H}$ \\
\hline 25 & $\mathrm{H}$ & $C$ & $\mathrm{H}$ & 25 & C & $\mathrm{H}$ & C \\
\hline 26 & $\mathrm{H}$ & $C$ & $C$ & 26 & $C$ & $\mathrm{H}$ & C \\
\hline 27 & $\mathrm{H}$ & $C$ & C & 27 & $C$ & $\mathrm{H}$ & $\mathrm{H}$ \\
\hline 28 & $\mathrm{H}$ & $\mathrm{H}$ & $C$ & 28 & $\mathrm{H}$ & $C$ & $\mathrm{H}$ \\
\hline 29 & $\mathrm{H}$ & $\mathrm{H}$ & C & 29 & $\mathrm{H}$ & $C$ & $\mathrm{H}$ \\
\hline 30 & $\mathrm{H}$ & C & C & 30 & C & $\mathrm{H}$ & C \\
\hline
\end{tabular}




\section{Anexo 2}

Planilla de evaluación prueba del triángulo

\begin{tabular}{|c|c|c|}
\hline \multicolumn{3}{|c|}{ PRUEBA DEL TRIANGULO } \\
\hline \multicolumn{3}{|c|}{ 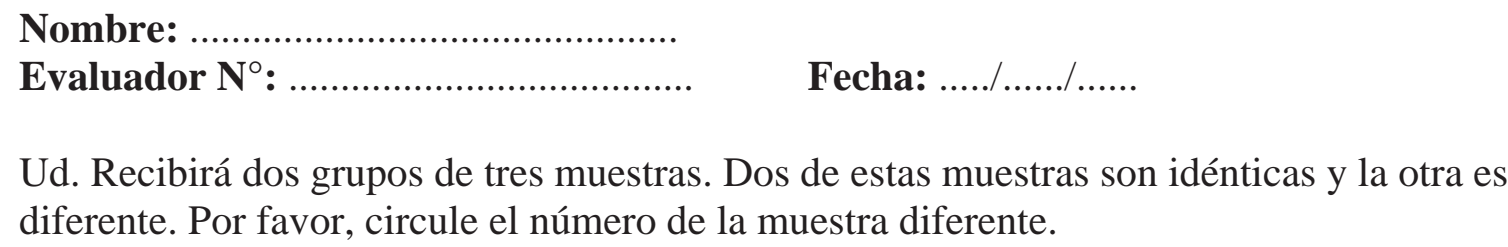 } \\
\hline 358 & 135 & 886 \\
\hline 687 & 500 & 104 \\
\hline
\end{tabular}




\section{Anexo 3}

Planilla de evaluación utilizada en el ensayo de escala hedónica

\section{ACEPTABILIDAD DE PAN POR ATRIBUTOS}

Nombre:

Consumidor $\mathrm{N}^{\circ}$

Utilizando la siguiente escala, por favor evalúe la aceptabilidad de cada atributo.

Primero evalúe todos los atributos de la muestra 616 y luego recién la 534.

MUESTRA N 616

Disgusta Gusta

Apariencia

Textura

Sabor

Aceptabilidad global
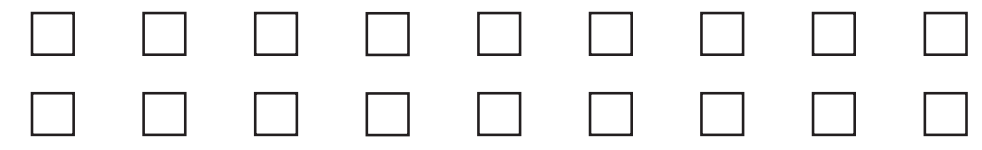

$\square$
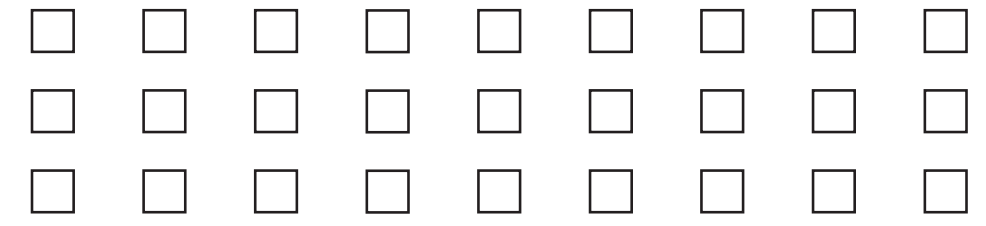

\section{MUESTRA N 534}

Disgusta

Gusta

Apariencia

Textura

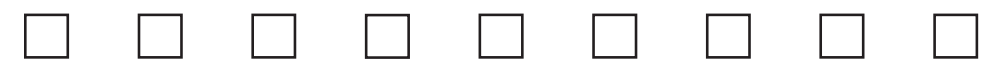

Sabor

Aceptabilidad global
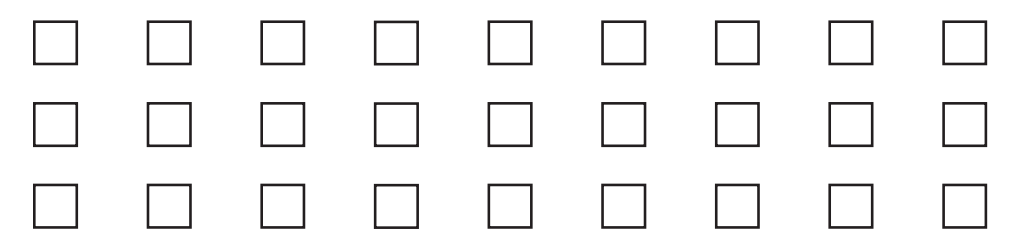


\section{Anexo 4}

\section{Datos calorimétricos complejo amilosa-lípido en sistemas modelo}

Disociación del complejo amilosa -lípido en sistemas modelo con celulosas modificadas

\begin{tabular}{|c|c|c|c|c|c|}
\hline & Muestra & $\mathrm{T}_{\mathrm{i}}\left({ }^{\circ} \mathrm{C}\right)$ & $\mathrm{T}_{\mathrm{p}(\mathrm{a}-\mathrm{lip})}\left({ }^{\circ} \mathrm{C}\right)$ & $\mathrm{T}_{\mathrm{f}}\left({ }^{\circ} \mathrm{C}\right)$ & $\begin{array}{c}\Delta \mathrm{H}(\mathrm{J} / \mathrm{g} \\
\text { masa seca) }\end{array}$ \\
\hline \multirow{5}{*}{$\begin{array}{l}\text { Sin } \\
\text { sal }\end{array}$} & Control & $107,8 \pm 2,8^{a}$ & $119,5 \pm 0,4^{b}$ & $126,7 \pm 0,6^{\text {ab }}$ & $1,7 \pm 3,2^{a}$ \\
\hline & MCC $1,5 \%$ & $111,1 \pm 0,1^{\mathrm{a}}$ & $119,2 \pm 0,4^{a b}$ & $128,9 \pm 1,1^{b}$ & $1,6 \pm 0,1^{a}$ \\
\hline & CMC $1,5 \%$ & $108,7 \pm 0,2^{a}$ & $117,1 \pm 0,3^{a}$ & $123,6 \pm 1,8^{a}$ & $1,4 \pm 0,2^{a}$ \\
\hline & HPMC F 4M 1,5 \% & $109,1 \pm 1,2^{a}$ & $118,1 \pm 1,2^{a b}$ & $125,8 \pm 0,4^{a b}$ & $1,3 \pm 0,3^{a}$ \\
\hline & HPMC F 50 1,5\% & $109,1 \pm 1,1^{\mathrm{a}}$ & $118,2 \pm 0,3^{a b}$ & $126,5 \pm 0,6^{a b}$ & $1,5 \pm 0,2^{a}$ \\
\hline \multirow{5}{*}{$\begin{array}{l}\text { Con } \\
\text { sal }\end{array}$} & Control & $118,3 \pm 0,4^{a}$ & $126,6 \pm 0,6^{b}$ & $134,8 \pm 0,4^{a}$ & $1,4 \pm 0,0^{a}$ \\
\hline & MCC 1,5\% & $118,3 \pm 0,2^{a}$ & $126,6 \pm 0,7^{b}$ & $132,5 \pm 1,1^{a}$ & $1,3 \pm 0,0^{a}$ \\
\hline & CMC $1,5 \%$ & $113,0 \pm 0,9^{a}$ & $124,0 \pm 0,6^{a}$ & $132,3 \pm 0,0^{a}$ & $1,8 \pm 0,4^{a}$ \\
\hline & HPMC F 4M 1,5\% & $114,3 \pm 2,4^{a}$ & $124 \pm 0,1^{a}$ & $132,6 \pm 1,4^{a}$ & $1,3 \pm 0,3^{a}$ \\
\hline & HPMC F 50 1,5\% & $112,9 \pm 2,1^{a}$ & $122,7 \pm 0,2^{a}$ & $131,0 \pm 1,2^{a}$ & $1,7 \pm 0,5^{a}$ \\
\hline
\end{tabular}

media \pm DE.En cada columna y en cada grupo ( $\sin \mathrm{NaCl}$, con $\mathrm{NaCl})$ letras diferentes indican diferencias significativas $(p<0,05)$.

Disociación del complejo amilosa -lípido en sistemas modelo con pectinas

\begin{tabular}{cccccc}
\hline \multicolumn{2}{c}{ Muestra } & $\left.\mathrm{T}_{\mathrm{i}}\left({ }^{\circ} \mathrm{C}\right)\right)$ & $\mathrm{T}_{\mathrm{p}(\mathrm{a}-\mathrm{lip})}\left({ }^{\circ} \mathrm{C}\right)$ & $\mathrm{T}_{\mathrm{f}}\left({ }^{\circ} \mathrm{C}\right)$ & $\begin{array}{c}\Delta \mathrm{H}(\mathrm{J} / \mathrm{g} \\
\text { masa seca })\end{array}$ \\
\hline \multirow{2}{*}{ Sin sal } & Control & $107,8 \pm 2,8^{\mathrm{a}}$ & $119,5 \pm 0,4^{\mathrm{b}}$ & $126,7 \pm 0,6^{\mathrm{a}}$ & $1,7 \pm 3,2^{\mathrm{a}}$ \\
\cline { 2 - 6 } & PBM 2\% & $110,1 \pm 1,3^{\mathrm{a}}$ & $117,8 \pm 0,7^{\mathrm{a}}$ & $125,8 \pm 1,1^{\mathrm{a}}$ & $1,2 \pm 0,5^{\mathrm{a}}$ \\
\cline { 2 - 6 } & PAM 2\% & $111,2 \pm 0,6^{\mathrm{a}}$ & $120,6 \pm 0,0^{\mathrm{b}}$ & $128,3 \pm 0,3^{\mathrm{a}}$ & $1,6 \pm 0,0^{\mathrm{a}}$ \\
\hline \multirow{3}{*}{ Con sal } & Control & $118,3 \pm 0,4^{\mathrm{c}}$ & $126,6 \pm 0,6^{\mathrm{b}}$ & $134,8 \pm 0,4^{\mathrm{b}}$ & $1,4 \pm 0,0^{\mathrm{a}}$ \\
\cline { 2 - 6 } & PBM 2\% & $113,9 \pm 0,0^{\mathrm{b}}$ & $123,8 \pm 0,4^{\mathrm{a}}$ & $132,8 \pm 0,5^{\mathrm{a}}$ & $1,5 \pm 0,0^{\mathrm{a}}$ \\
\cline { 2 - 6 } & PAM 2\% & $111,6 \pm 0,1^{\mathrm{a}}$ & $122,6 \pm 0,5^{\mathrm{a}}$ & $131,5 \pm 0,3^{\mathrm{a}}$ & $1,9 \pm 0,1^{\mathrm{b}}$
\end{tabular}

media $\pm \mathrm{DE}$. En cada columna y en cada grupo $(\sin \mathrm{NaCl}$, con $\mathrm{NaCl})$ letras diferentes indican diferencias significativas $(p<0,05)$. 


\section{Anexo 5}

Disociación del complejo amilosa lípido en masas sin sal y con celulosas modificadas

\begin{tabular}{|c|c|c|c|c|c|}
\hline & Muestra & $\mathrm{T}_{\mathrm{i}}\left({ }^{\circ} \mathrm{C}\right)$ & $\mathrm{T}_{\mathrm{p}(\mathrm{a}-\mathrm{lip})}\left({ }^{\circ} \mathrm{C}\right)$ & $\mathrm{T}_{\mathrm{f}}\left({ }^{\circ} \mathrm{C}\right)$ & $\begin{array}{c}\Delta \mathrm{H}(\mathrm{J} / \mathrm{g} \text { masa } \\
\text { seca })\end{array}$ \\
\hline \multirow{5}{*}{$\begin{array}{l}\text { Sin } \\
\text { sal }\end{array}$} & Control & $99,4 \pm 1,6^{a}$ & $112,4 \pm 0,3^{a}$ & $119,5 \pm 0,6^{a}$ & $1,5 \pm 0,1^{a}$ \\
\hline & MCC $1.5 \%$ & $98,4 \pm 1,8^{a}$ & $112,6 \pm 0,2^{a}$ & $119,4 \pm 0,3^{a}$ & $1,6 \pm 0,3^{a}$ \\
\hline & CMC $1.5 \%$ & $99,3 \pm 2,8^{a}$ & $112,4 \pm 0,7^{\mathrm{a}}$ & $119,4 \pm 1,6^{a}$ & $1,7 \pm 0,3^{a}$ \\
\hline & HPMC F 4M 1.5\% & $98,4 \pm 2,3^{a}$ & $110,8 \pm 0,5^{a}$ & $118,3 \pm 0,7^{a}$ & $1,6 \pm 0,3^{a}$ \\
\hline & HPMC F 50 1.5\% & $96,5 \pm 0,7^{a}$ & $110,9 \pm 0,7^{a}$ & $118,6 \pm 0,6^{a}$ & $1,5 \pm 0,0^{a}$ \\
\hline \multirow{5}{*}{$\begin{array}{l}\text { Con } \\
\text { sal }\end{array}$} & Control & $117,0 \pm 0,3^{b}$ & $124,6 \pm 0,8^{c}$ & $0,5 \pm 0,0^{a}$ & $107,4 \pm 1,3^{a}$ \\
\hline & MCC $1.5 \%$ & $116,0 \pm 0,6^{a b}$ & $122,4 \pm 0,3^{a b}$ & $1,1 \pm 0,2^{a b}$ & $105,9 \pm 0,9^{a}$ \\
\hline & CMC $1.5 \%$ & $117,1 \pm 0,4^{b}$ & $124,2 \pm 0,1^{b c}$ & $1,3 \pm 0,2^{b}$ & $105,8 \pm 1,7^{a}$ \\
\hline & HPMC F 4M 1.5\% & $115,2 \pm 0,7^{a}$ & $121,9 \pm 0,9^{a}$ & $1,3 \pm 0,3^{b}$ & $104,9 \pm 1,0^{a}$ \\
\hline & HPM & $116,6 \pm$ & $124,0 \pm 0,2^{b c}$ & $1,1 \pm 0,0^{a b}$ & $105,3 \pm 0,7^{a}$ \\
\hline
\end{tabular}

media $\pm \mathrm{DE}$. En cada columna y en cada grupo $(\sin \mathrm{NaCl}$, con $\mathrm{NaCl})$ letras diferentes indican diferencias significativas $(p<0,05)$.

Disociación del complejo amilosa lípido en las masas con sal y pectinas

$\begin{array}{lllll}\text { Muestra } & \left.\mathrm{T}_{\mathrm{i}}\left({ }^{\circ} \mathrm{C}\right)\right) & \mathrm{T}_{\mathrm{p}(\text { a-lip })}\left({ }^{\circ} \mathrm{C}\right) & \mathrm{T}_{\mathrm{f}}\left({ }^{\circ} \mathrm{C}\right) & \begin{array}{c}\Delta \mathrm{H}(\mathrm{J} / \mathrm{g} \\ \text { masa seca })\end{array}\end{array}$

\begin{tabular}{cccccc}
\hline \multirow{3}{*}{ Sin sal } & Control & $99,4 \pm 1,6^{\mathrm{a}}$ & $112,4 \pm 0,3^{\mathrm{a}}$ & $119,5 \pm 0,6^{\mathrm{a}}$ & $1,5 \pm 0,1^{\mathrm{a}}$ \\
\cline { 2 - 5 } & PBM 2\% & $100,4 \pm 1,7^{\mathrm{a}}$ & $113,4 \pm 1,6^{\mathrm{a}}$ & $119,4 \pm 0,9^{\mathrm{a}}$ & $1,4 \pm 0,2^{\mathrm{a}}$ \\
\cline { 2 - 5 } & PAM 2\% & $100,8 \pm 0,6^{\mathrm{a}}$ & $113,6 \pm 0,3^{\mathrm{a}}$ & $120,9 \pm 0,2^{\mathrm{a}}$ & $1,4 \pm 0,0^{\mathrm{a}}$ \\
\hline \multirow{2}{*}{ Con sal } & Control & $107,4 \pm 1,3^{\mathrm{b}}$ & $117,0 \pm 0,3^{\mathrm{a}}$ & $124,6 \pm 0,8^{\mathrm{a}}$ & $0,5 \pm 0,0^{\mathrm{a}}$ \\
\cline { 2 - 5 } & PBM 2\% & $105 \pm 1,0^{\mathrm{a}}$ & $115,9 \pm 0,6^{\mathrm{a}}$ & $122,4 \pm 0,4^{\mathrm{a}}$ & $1,3 \pm 0,2^{\mathrm{b}}$ \\
\cline { 2 - 5 } & PAM 2\% & $105,5 \pm 0,3^{\mathrm{ab}}$ & $116,3 \pm 0,4^{\mathrm{a}}$ & $122,7 \pm 1,3^{\mathrm{a}}$ & $1,2 \pm 0,2^{\mathrm{b}}$
\end{tabular}

media $\pm \mathrm{DE}$. En cada columna y en cada grupo (sin $\mathrm{NaCl}$, con $\mathrm{NaCl})$ letras diferentes indican diferencias significativas $(p<0,05)$.. 


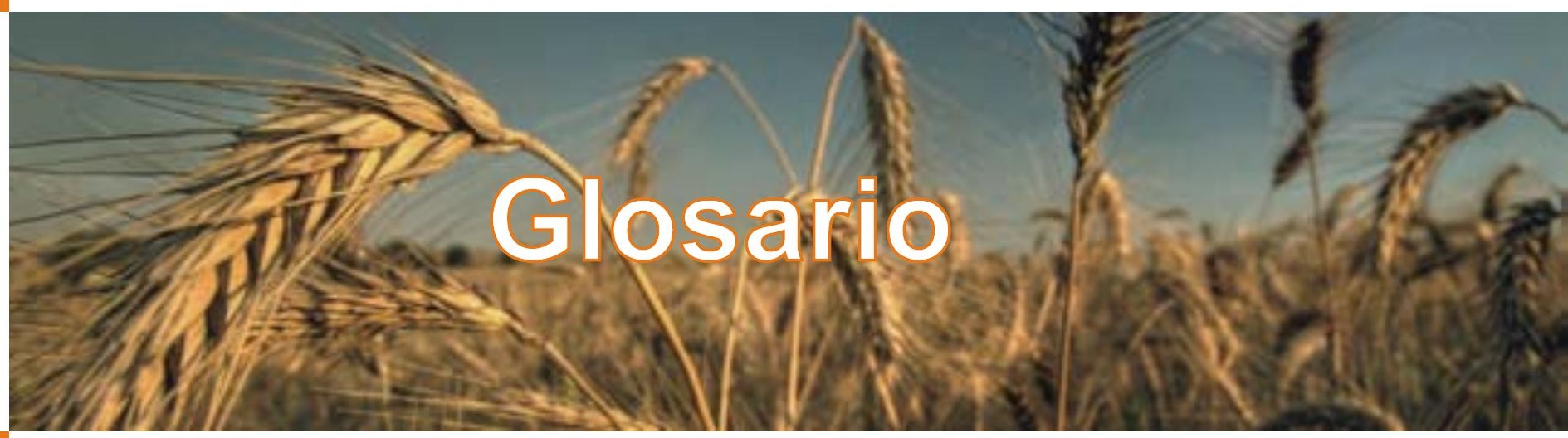




\section{Glosario}

\section{A}

$\AA ̊ \AA$ : angstrom

A: Absorción farinográfica de agua

$A_{1}$ :

a: exponente a de Mark - Houwink

AACC: Approved Methods of the American Association of Cereal Chemists

ADI: acceptable daily intake (ingesta diaria aceptable)

af: máximo volumen alcanzado durante la fermentación

ANOVA: análisis de varianza

Art: artículo

$a_{w}$ : actividad acuosa

B

BI: browning index (índice de pardeamiento)

$b_{f}$ : coeficiente $b$ de la curva de fermentación

C

C: control

${ }^{\circ} \mathrm{C}$ : grados centígrados

$\mathrm{C}^{*}$ : concentración crítica

$\mathrm{cm}^{3}$ : centímetro cúbico

CAA: código Alimentario Argentino

$\mathrm{C}_{\mathrm{f}}$ :Coeficiente $\mathrm{c}$ de la curva de fermentación

CMC: Carboximetil celulosa sódica

Cm: centímetro

$\mathrm{CP}$ : centipoise

CSLM: confocal scanning laser microscopy (Microscopía láser confocal de barrido)

CV: Coeficiente de variación 
D

Da: Dalton

DATEM: ésteres de mono y diglicéridos del ácido diacetiltartárico

DE: desvío estándar

Dec.: decreto

DMA: análisis mecánico diferencial

DMF: N,N-dimetilformamida

DSC: calorimetría diferencial de barrido.

DTT: ditiotreitol

E

$E^{\prime}$ : módulo elástico o de almacenamiento

$E^{\prime \prime}$ : módulo viscoso o de pérdida

$E^{*}$ : módulo dinámico

Ec: ecuación

EDTA: ácido etilendiamino tetracético

$\mathbf{F}$

FAO: Food and Agriculture Organization of the United Nations (Organización de las Naciones Unidas para la Alimentación y la Agricultura)

FG: filamento de gluten

FG: filamento de gluten

Fig: figura

FITC: isotiocianato de fluoresceína

FN: falling number (índice de caída de Hagberg)

FT-Raman: espectroscopía raman por transformada de Fourier

G

g: gramo

G: módulo elástico.

G’: módulo de almacenamiento 
G": módulo de pérdida

G*: módulo complejo

GA: gránulos de almidón

GE: grado de esterificación

GH: gluten húmedo

Gl: gluten index

GRAS: generalmente reconocido como seguro

Gs: grado de sustitución

GS: gluten seco

\section{H}

$\mathrm{H}$ : humedad de la harina

$\mathrm{H}_{0}$ : humedad de la miga del pan fresco

$\mathrm{H}_{3}$ :humedad de la miga luego de 3 días de almacenamiento

ha: hectárea

$\mathrm{HDC}_{\mathrm{t}}$ : hidratos de carbono totales

HMW-GS: high molecular weight glutenin subunit (subunidad de glutenina de alto peso molecular)

HPMC: hidroxipropilmetilcelulosa

$\mathrm{Hz}$ : hertz

${ }^{1} \mathrm{H}-\mathrm{RMN}$ : resonancia magnética nuclear de protón

I

I: intensidad de la señal del protón (RMN)

INTA: Instituto Nacional de Tecnología Agropecuaria

J

J: joule (julio)

JECFA: Joint FAO/WHO Expert Committee on Food Additives (Comité Mixto FAO /OMS de Expertos en Aditivos Alimentarios) 


\section{K}

$\mathrm{K}$ : constante de Mark - Houwink

kDa: kilodaltons

$\mathrm{K}_{\mathrm{H}}$ : constante adimensional de Huggins

$\mathrm{K}_{\mathrm{k}}$ : constante de Kramer

$\mathbf{L}$

I: litro

L: extensibilidad

LDL: low density lipoprotein (lipoproteína de baja densidad)

LMW-GS: low molecular weight glutenin subunit (subunidad de glutenina de bajo peso molécular).

M

m: masa de harina

M: molar

M1: primera endoterma de gelatinización

M2: segunda endoterma de gelatinización

M3: endoterma de disociación del complejo amilosa-lípido

MAGyP: Ministerio de Agrícultura, Ganadería y Pesca

max: máximo

MCC: celulosa microcristalina

mg: miligramo

mín: mínimo

min: minuto

mm: milímetro

MM: masa molecular

$\mathbf{N}$

$\mathrm{N}$ : Normalidad

$\% \mathrm{~N}$ : cantidad de nitrógeno cada $100 \mathrm{~g}$ de harina (en base seca) 
NOA: Noroeste Argentino

NEA: Noreste Argentino

$\mathbf{0}$

OMS: Organización Mundial para la Salud

$\mathbf{P}$

$P$ : tenacidad

Pa: pascal

PAM: pectina de alto metoxilo o alto grado de sustitución

PBM: pectina de bajo metoxilo o bajo grado de sustitución

PCA: análisis de componentes pricipales

PG: película de gluten

PG: película de gluten

$<$ PM $>$ : peso molecular promedio

$P_{\text {meq: }}$ peso del miliequivalente

psi: pounds per square inch (libra por pulgada cuadrada)

$\mathbf{R}$

$r^{2}$ : coeficiente de determinación

rpm: revoluciones por minuto

RVA: viscoamilógrafo rápido

RVU: unidades del viscoamilógrafo rápido

S

s: segundos

SCF: Scientific Committee for Food (Comité Científico de la Alimentación Humana)

SDS: dodecil sulfato de sodio

SDS-PAGE: electroforesis desnaturalizante - disociante

SEM: scanning electron microscope (microscopía electrónica de barrido)

SENASA: Servicio Nacional de Sanidad y Calidad Agroalimentaria 
Sm: grado de sustitución molar.

SN: stirring number (número de agitación).

SSL: estearoil lactilato de sodio

\section{$\mathbf{T}$}

t: tiempo

$t_{0}$ : tiempo de elusión del solvente

$\mathrm{T}_{2}$ : tiempo de relajación spin-spin

$\mathrm{T}_{\mathrm{a}:}$ temperatura de transición vítrea determinada por DMA

$\mathrm{T}_{\beta}$ : temperatura de la relajación $\beta$

$\tan (\delta)$ : tangente del ángulo de desfasaje

td: tiempo de desarrollo farinográfico

$\mathrm{T}_{\mathrm{e}}$ : temperatura de empaste

Temed: $\mathrm{N}, \mathrm{N}, \mathrm{N}^{\prime}, \mathrm{N}^{\prime}$, -tetrametiletilendiamina

$t_{\mathrm{f}}$ : tiempo de fermentación

$\mathrm{T}_{\mathrm{g}}$ : temperatura de transición vítrea

$\mathrm{T}_{\mathrm{i}}$ : temperatura de inicio (DSC)

$\mathrm{T}_{\mathrm{p} 1}$ : temperatura del pico 1 (DSC)

$\mathrm{T}_{\mathrm{p} 2}$ :temperatura del pico 2 (DSC)

$\mathrm{T}_{\mathrm{m}}$ : temperatura de fusión del hielo

tn: toneladas

TPA: texture profile analysis (ensayo de perfil de textura)

$t_{r}$ : tiempo de retención en la columna

\section{$\mathbf{U}$}

UF: unidades farinográficas

USP: United States Pharmacopeia (Farmacopea de los Estados Unidos)

\section{V}

$\mathrm{V}_{\mathrm{m}}$ : volumen de $\mathrm{HCl}$, en $\mathrm{ml}$, requeridos para titular la muestra

$\mathrm{V}_{0}$ : volumen de $\mathrm{HCl}$, en $\mathrm{ml}$, requeridos para titular el blanco 


\section{W}

W: trabajo de deformación

WIC: water imbibing capacity (capacidad de imbibición de agua)

\section{Alfabeto griego}

$\alpha$

$\alpha$ : nivel de significancia

$\gamma$

$\gamma:$ gradiente de velocidad

$\gamma$ : deformación relativa del material

$\gamma_{0}:$ amplitud de la deformación

$\delta$

$\delta$ : ángulo de desfasaje

$\Delta \mathrm{H}$ : entalpía

$\Delta \mathrm{V}$ : variación de volumen

$\Delta \mathrm{V}_{\max }$ : máximo incremento del volumen alcanzado en la fermentación

$\varepsilon$

$\varepsilon_{0}:$ máxima deformación

$\varepsilon(\mathrm{t})$ : deformación sinusoidal perpendicular a la muestra (DMA)

$\eta$

$\eta^{*}$ : viscosidad compleja 
[ๆ]: viscosidad intrínseca

$\eta_{\text {red: }}$ viscosidad reducida

$\eta_{f}$ : viscosidad final en el viscoamilograma

$\eta_{\min }$ : viscosidad mínima en el viscoamilograma

$\eta_{\mathrm{p}}$ : viscosidad de pico en el viscoamilograma

$\eta_{\text {rel: }}$ viscosidad relativa

$\lambda$

$\lambda_{\mathrm{i}}$ : tiempo de relajación

$\mu$

$\mu$ : coeficiente de viscosidad

$\mu \mathrm{l}$ : microlitro

$\mu \mathrm{m}:$ micrómetros

$\rho$

$\rho:$ densidad de la muestra

$\rho_{0}$ : densidad del solvente

$\sigma$

$\sigma:$ esfuerzo

$\sigma_{0}:$ amplitud del esfuerzo

$\sigma_{\mathrm{e}}$ : valor del esfuerzo una vez alcanzado el equilibrio

$\tau$

$\tau$ : esfuerzo (reometría) 
$\tau_{\text {lim: }}$ límite superior del rango de viscoelasticidad lineal

U

$\bar{V}:$ número de onda $\left(\mathrm{cm}^{-1}\right)$

$\Delta v$ : desplazamiento del número de onda

$\omega$

$\omega$ : frecuencia

\section{Símbolos}

$\approx$ :aproximadamente

$<$ : menor

$<$ : mayor 